
Califormia Scademy of Siences

RECEIVED GY OIFT FROM

Pacific Coast Entomological Society October 19, 1951 
Publuation date Qct 19, 1951 



\title{
THE SUCKING LICE
}

\author{
G. F. FERRIS \\ Prolessor of Entomology \\ Stontord University. Colitormio \\ With the Colloboration of \\ Chester J. Stojonovich \\ Communicoble Disuose Center \\ United Stotes Public Heolth Service \\ Aflonto, Georgio
}


Published and for sale by

THE PACIFIC COAST ENTOMOLOGICAL SOCIETY

Cal ifornla dcalemy of Sclences, Coliten Gate Park, San Francisco 18, Cal ifornd a

Printed by

New York I,t thogruphing Corporation, New York 
"In the progress of this work, however, the author has hat to contend with repeated rebukes from his friends for enterine uDon ihe illustration of a tribe of insects whose ver"ll name was sufficient to create feelings of discust." -Henry Venny, 1842. 



\section{PREFACE}

This volume represents an attempt to summize existing hinowled ge on the systematics of the sucking lice, which are here considered to be the Order Anoplula of the lnsecta. Since sound lixomong should rest npon morpholom and inatomy, an extended considelution vill he riven to these sulijects. Included also will he a review of the historical development of our knowledpe of the group; a consideration of the clissiticition here adopted; keys to the lanilies, subfamilies, genera, and species and a levien of' al 1 these categories; illustrations of all the avisilable types of genera and of the species occurrinir on domestic animals; an extended discussion of the species occurring on man and other P'rimates; is list of the mamalian hosts; and finally, a consideration of the problems of geographical distrilution.

I wish here to express my appreciation of the assistance given me by my collahorator, Mr. Chester Stojanovich, whose unusual shill in minute dissection and in illustration has made possible the sections on the monthparts and internal anatomy. Mr. Stojanovich beran this work while he was a graduate student at Stanford University and Liter was granted leave from his duties with the Communicable Disease Center of the United States Public Health Service, which enabled him to return to my laboratory during the summer of 1950 and complete it. I wish here to express my thanhs to Dr. R. A. Yonderlehr, Medical Director in charre of the Communicable Disease Center, by whom this leave nus officially uranted and to Dr. G. H. Bradley, by whom it was recommended. My part in the preparation ol the sections in question has been that of supplyin: the textual material. Mr. Stojanovich assisted also in the preparation and lesting of various of the longer heys to species.

The purely taxonomic portion of the work, all names therein proposed, and all opinions herein expressed are to be ascribed strictly to myself'. This work has its basis in a series of studies published by me over a period of years from 1919 to 1935, in eight papers entitled "Contributions Toward a Monograph of the Sucking Lice." These appeared as Volume II of what was in part entitled Leland Stantord Junior Publications, University Series, and in part Stanford University Publications, University Series, Biolorical Sciences. In them will be found illustrations of almost all of the species known up to 1935, together with a statement of the sources of the material upon which the work was based. Owing to the cumbersome nature of the full citation, this work will herein be cited merely" as "Contributions Toward a Monogriuph of the Sucking Lice."

This volume is closed as of July 1, 1951.

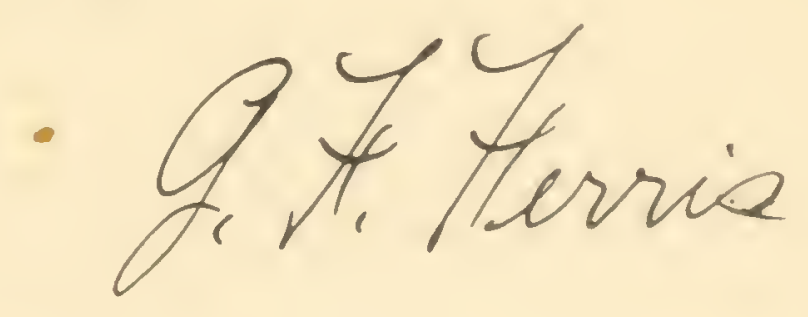

Stanford University, Calitomia 



\section{TABLE OF CONTENTS}

\section{CHAP'ILK I}

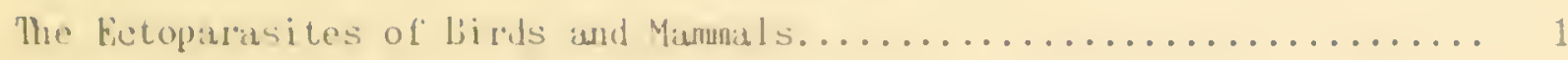

CHAPTER II

The yorpholory and Anatomy of the Anoplura..................

Cll AP'T'K'K III

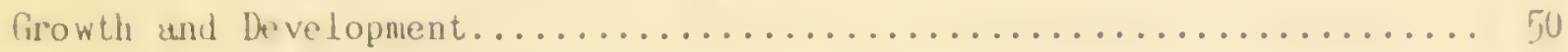

CHAPTER IV

The Taxonomic Status of the Sucking Lice.................... F

CIIAPTER V

The Classilication within the Order Anoplura................ 63

CILAPTER VI

Review of the Families, Subfamilies, Genera, and Species of the Anoplura 71

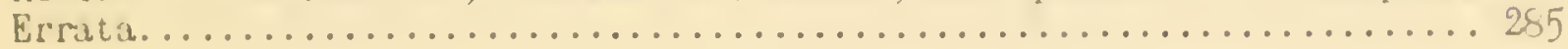

CHAPTER VII

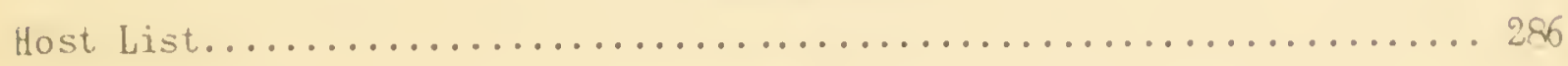

CHAPTER VTII

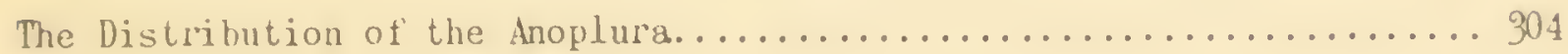

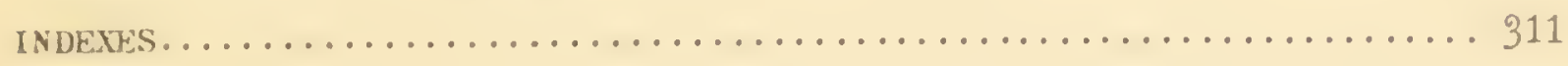





\section{CHAPTER I}

\section{The Ectoparasites of Birds and Mammals}

When in the conlese of thrig evolution the lalds achieved teathers and the manmials achieved hatr, a new wolld to conquer wits oflered to the lreth-

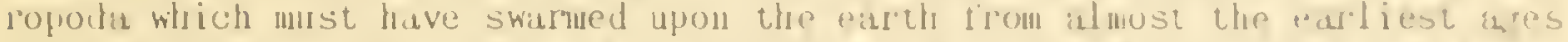
of' terrestrial lite. Sume of the arthrupeds moved imte this aren norld ard

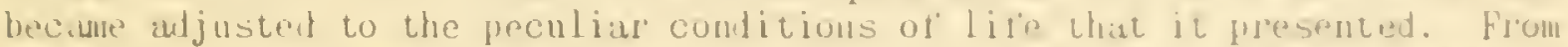
these pioneers caule the ectopalasites that tolay intest in some mensme probably every species of hild and every species of mimmis except the Cotacea and the sirenia.

These ectoparasites, as we see thom todal, have fren deloivent flom mally sonrces. One may smmise that the earliest to entel this norld uf hair and teathers nere mites, for the mites ale a very ancient ploup and they mal very well have teod upon the bleod of haildess amphifians and reptiles, even as they do todiay, before the hirds and mamials hiad evolved. Todis che mites constitute probubly the mior ectoparasitic launis of the vortelirates. They have penetrated into the luniss of theil hosts, into the ear's, into the skin, and even at times into the intestine and hladder and thry swarm in the hair and the teather's. They induce pathological conditions ot' their hosts by their own activities and they act as transmitting agents of mumerous diseases that are already known and undonbtedly maly more that are not yet known. They are the preatest of all the proups of ectoparasites and scarcely more than a beginning ol their study has bet been achieved.

It seems probuble that only after hair and leathers had become well doveloped did the insects move in. These insect ectorarasiles have come from various 0rders. There are the blood-sucking llies ot the family llippoloscidae, which occur on loth birds and mammis, and the lamilies Streblidac and Nycteribidac, wich occur only on bats. There are the "bedbuss," which are Hemiptera, ot the tamily Cimicidae, and which occur chiefly on birds and bats. There is the more or less closely related Hemipterous lamily Polyctenidae, which occurs only on bats and which numbers scarcely tro dozen known species. There is at least one species of the Order Demaptera. which occurs on an Atrican rodent. There are a few beetles, includin: that singular parasite. Platupsylla castoris Ritsema, which occurs only on beavers. There is even a moth which lives in its larval stajes in the hair of a sloth and which may justifiably be included in the list. There is the whole Order Siphonaptera, the f'leas, which in their adult stare live upon woth birds and manmals and feed upon their blood.

There are two proups of what are commonly called lice. One of these gromps comprises what are t'requently called "hird lice, "althou th a considerable number of them live upon mamals. They are more appropriately called "biting lice" and constitute what is here considered to be the Order Yallophira, which includes somethin more than 2,000 known species. And finally, there is the little rroup which is the sulject of this volume, the suckin? Lice, comprising what is here called the Order Anoplura. At present scarcely more than 225 species of Anoplura are hnown. They live exclusively upon mammals and reed upon the blood ol their hosts.

The ectoparasites of hirds and mammals present many leatures of seneral biolotical interest. Some of them are zoological curiosities hecause of their unusnal moditications of stmeture or habit. Thus, the parasitic bat flies of the tamilies Streblidae and Nicteribiidae are strunge torms because of their structural modilications alone. But comlined with this strangeness of form, the members of these two tamilies and of the more or 
less related family Hippoboscidae have the habit, rare among insects, of retaining the Larva within the body of the female where it is nourished by glandular secretions until it is ready to pupate. The members of the little family Polyctenidae likewise retain the immature insect within the body of the female until it is partly grown, but in this case it is nourished through what is functionally a placenta that is developed from the body of the young itself. The extraordinary developments of both structure and habit which occur among the mites offer an endless variety, the exploration of which has scarcely more than begun.

Throughout the entire series of these ectoparasites there are phenomena of special interest from the point of view of evolution. There are beautiful examples of what appears to be convergent evolution which has resulted in the development of similar habits and similar structures in quite unrelated forms. There is the problem of perennial interest which has to do with the occurrence of related parasites upon related hosts and the consequent suggestion that the relationships of the parasites may perhaps throw some light upon the phylogeny of the hosts and, conversely, that the relationships of the hosts may throw some light on those of the lice. This will be discussed in detail in a section of this work.

Above all there is the circumstance that certain of these ectoparasites are concerned with the transmission of disease. Most of what is known concerning this has to do with the transmission of disease in man, but it seems clear that the same thing must occur in the case of many other animals. Since numerous diseases of man have unquestionably come over to him from other animals the whole picture of the epidemiology of these diseases cannot be grasped until the background in the animals from which a particular disease has come is understood. In many instances the occurrence of a particular disease in man is to be regarded as purely an accident. This, for example, seems to be true of "murine typhus," which arises each time independently from the backyround formed by certain rodents and their parasites. One of the most illuminating instances of this sort is the recognition-as late as 1947-of the disease called "rickettsial pox," a disease that was previously unknown and was shown to have been transmitted to man through the agency of mites from the ordinary house mouse, an animal that had previously not been known to be connected with any disease of man.

We are not here attempting to recite the story of the relation of ectoparasitic insects to the transmission of disease. The intention is merely to emphasize the principle that no blood-sucking arthropod, even if it occurs only on a bat on some remote island, may be eliminated entirely from the range of our interest. The time is at hand for the building up of greater knowledge of blood-sucking ectoparasitic insects in all groups. Almost none of these groups, except perhaps the fleas, has received the attention which it deserves. And, as will appear in subsequent sections of this volume, our knowledge of the little Order of the sucking lice is still barely past its earliest stages. 


\section{CHAPTER ॥}

\section{The Morphology and Anatomy of the Anoplura}

As hus ul ready been noted, the sucking lice are very peculiar forms. 'They ure commonly described as degenerute, but this is a word which has no proper place in a biological vocabulary, since it carries with il certain purely authropomorphic comotations that involve a llavor of reproach. It would be better to say merely that they are hi ghly specialized for lite in the peculiar enviroment which they occupy. The evolutioniry processes which have been at work upon them have produced a large imount of specialization by loss and reduction of purts. There is not the slightest vestige of wings. The eyes have been very greatly reduced, being scarcely or not at all recomitable in the majority of species and consisting of a single liacet even when best developed. The tarsi have been reduced tron tive to one or at the most two segnents. The antemale have been reduced to at the most tive sements. In many species the sclerotization of the aldomen has been almost completely lost. There has been a reduction of the number of spiricles, no known species having more than one pair ou the thorax and six pairs on the abdomen. The structures which comprise the ovipositor of the more general ized insects are reduced to mere vestiges.

Along with these reductions and losses there have gone some specializations of a quite different type. Thus, the mouthparts of the sucking lice are perhaps as highly specialized as are to be found anywere among the insects and the claws have become highly developed in correlation with the habit of clinging to hair.

The great degree of reduction and modification found in these insects has led to much misunderstanding concerning their morphology and this misunderstanding has centered especially about the mouthparts. Here, even yet, we cannot give a final answer to all the questions involved although we are undoubtedly somewhere near that answer.

In the preparation of the following section on morphology and anatomy, Mr. Stojanovich has done all the laborious work of dissection and of preparing the illustrations. Parts of this material have already been published by him in a paper entitled "The Head and Mouthparts of the Suching Lice, "which appeared in "Microentomology, "Volume 10, Part 1 (1945).

There are certain minor points concerning the anatomy of the lice which have not yet been adequately explored, but the following account will cover the major features, especially those which may at some time have a bearing upon problems of taxonomy.

\section{The Head \\ Preliminary Statement}

The most difficult problems connected with the morphology of the sucking lice are those which concern the mouthparts. The head itself is not difficult to understand, but betore entering into a discussion of its morpholog it may be well to review certain developments which have occurred within recent years in the study of the comparative morphology of the insects. These developments have resulted chiefly from a series of papers wich have appeared in the journal "Microentomolos, " which is published from the iatural II istory Museum of Stanford University. A brief summary of the conclusions which have been derived from this work and wich are pertinent to an understandin: of the Anopluran head follows. 
There has lon: been difference of opinion amon' morphologists as to the sementation of the insect head, opinion as to the number of sements involved havin ${ }_{\dot{b}}$ varied from as low as four sements to as many as nine. Furthennore, there has been much disagreement as to the arrangement of these segments and certain concepts that we believe to be based upon grievous errors have become deeply imbedded in the literature of the comparative morphology of the insects. Not until those errors have been removed is it possible to arrive at any understanding of the morphology of a specialized head such as that of the Anoplura.

The work that has been done in this laboratory has involved studies of external structure, of musculature, and of the semental distribution of nerves. The study of the nervous system of the head region has been carried through a long series of forms ranging from the Oligochaete and Polychaete worms to the insects and has demonstrated that a unified system of segmentation of this region exists throughout the Annulata. The followini conclusions have been derived from these studies.

1. The head of insects involves a total of six segments, these-in morphological order-being the Labral, clypeal, ocular-antennal, mandibular, maxillary, and labial se ments.

2. The labral segment is segment one of the body and the anterior portion of the alimentary cand, which is called the stomodaeum, is an invarination of this segment. The ventral portions of this segment are much reduced and seem to involve only the "hypopharynireal suspensor plates, "upon which the mouth angle retractor muscles insert.

3. The clypeus is the dorsal element of sement two and the hypopharynx is basically the ventral portion of this segment.

4. The hypopharynx is primarilya ventral lobe of segment two, but it is possible that in some insects elements derived from the mandibular segment may be involved in it.

5. The ocular-antennal segment bears the antennae, the ocelli, and the compound eyes. It is commonly divided transversely by a suture, usually called the epicranial suture, which usually torms a V-shaped line across the head, with the lateral arms terminating on each side between the compound eye and the corresponding antenna. This suture is definitely intrasegmental and is something more than a mere line of weakness along which the dern splits at the times of ecdysis. It is a line of very ancient origin, the antecedents of which can be seen even in the Polychacte worms. The area anterior to this suture and posterior to the clypeofrontal suture may properly be called the frons.

No ventral element ascribable to the ocular-antennal segment can be identified in any insect thus far examined, although morpholorically some such element, however much reduced, should theoretically be present. No muscles ascribable to this segment, other than those of the antennae and certain evanescent muscles of the ptilinum in flies, are known to exist. The anterior tentorial pits apparently belonig to this segment.

6. In cases where the mandibles have been lost the mandibular segment may entirely disappear, at least as far as any muscles and any sclerotized elements are concerned.

7. The maxillary se fment is usually much reduced and in many insects is entirely membranous. In many insects it forms no part of the sclerotized head capsule. The posterior tentorial pits seem to belon to this sement.

8. The liabial sement is always much reduced dorsally and no insect is known in which the dorsal wall of this serment is sclerotized and enters into the composition of the sclerotized heid capsule. The area called the submerutum, however, is conunonly selerotized and torms a portion of the ventral-or posterior-wall of the head capsule, althouith at times this area may he entirely membranous. The sumentum is merely a portion of the ventral wall of' segment six. The salivary grlands belong to segment six 


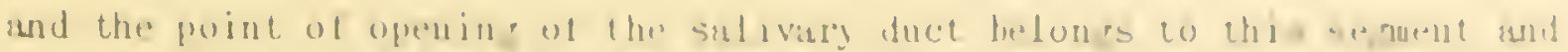

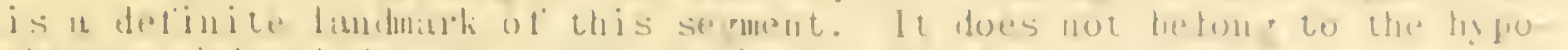
pharyux althomph it mity hecome involved nith this structure.

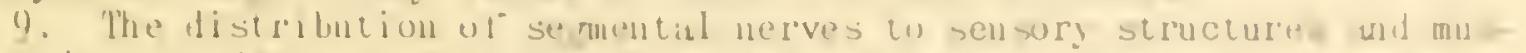
cles is a prositive indiciation of sernentil homologies when all nerves are present. At times nerves mity he lust, il the structures which they servet ale lost, and at times the clarity of smpmental relations mat he disturbed by the tusion ot herves.

10. The insertions of muscles are constant, but the origums my shith, even lirom one serment to another, if the ectodermal areas ngun which they prialitively originated are lost or displaced.

With these general conclusions in mind it is possible to proceed to the problem of the or ganization of the Anoplurim head.

of all the species of Anoplura now hinown, those of the getnus periculus seen to present the least modification of the head. Therefore it is appropriate to beirin with the head ot Periculus.

The Head Capsule of Pediculus humams fii rures 1,2

In this head the anterior apex is more or less membranous and torms a slightly eversible protuberance, commonty called the haustellum, which surrounds the apparent month opening and is beset with sinall hooks. In this membrane, on the dorsal side, there is a small, sclerotized plate which is by all criteria the Labmm. Posterior to the Labrum is a large plate which extends across the head in t'ront ot the antennae and is continued somewhat

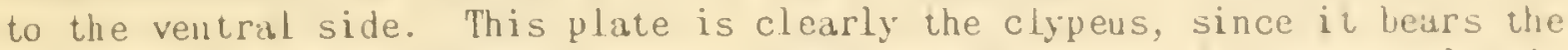
origins of the cibarial muscles and the place of origin of these muscles is constant in all insects that have been examined. This plate is separated by a broad suture f'rom the next plate, which makes up the greater part of the dorsal wall of the head. The entire posterior portion of the head capsule, dorsally, is composed of the ocular-antennal segment. The antennae are attached to the head at the anterior-lateral angles of this plate and the eyes are placed on each side at ahout the middle of the lateral lorder. The plate is divided by a V-shaped suture, the lateral terminations of which are between the eyes and the antennae. The base of the $V$ is connected with the median coronal suture. The portion of the ocular-antennal segment anterior to this $\mathrm{V}$ is the frons, wile the areas posterior to the suture constitute the ocular lobes or, as they are sometimes called, the frarietals.

The dorsal sclerotization of the ocular-antennal se ment extends around somewhat to the ventral side of the head. There are no dorsal areas that can be assi med definitely to the griathal sements.

Except for the reduction of the dorsal elements there is nothing in any nay peculiar thus far about this head capsule.

On the ventral side of the head the areas not occupied by the ventral extensions of the dorsal sclerotization are entirely membranous and show no indications of sementation.

The tentorium, as in all Anoplura, is lackinis and there are consequently no tentorial pits.

The mouthparts are entirely retracted within the head and will be considered later.

The Head Capsule of Haematopinus suis Fi rure 3

The head capsule of this species is considered because it presents certain features which would not be readily understood on the basis ot what 


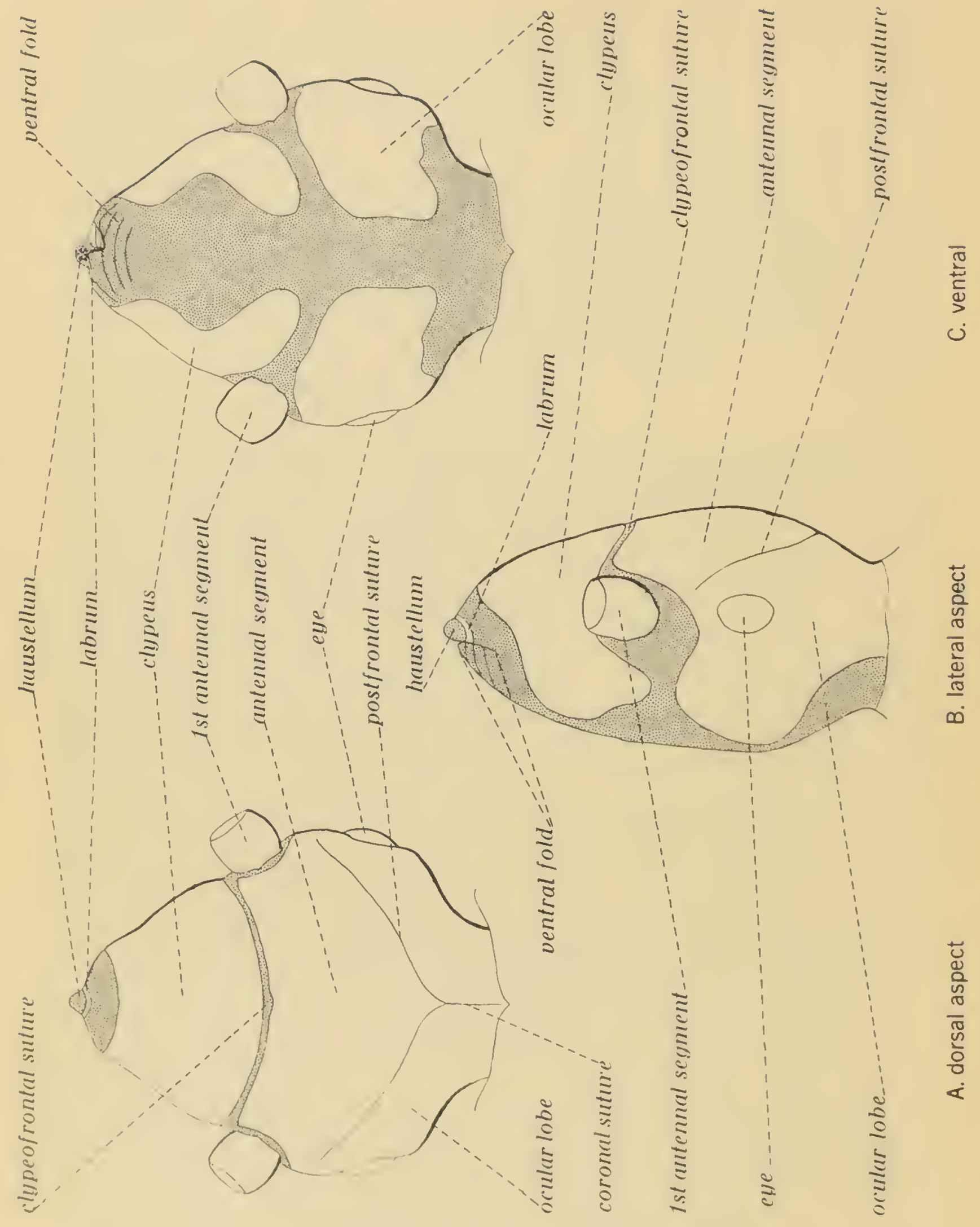

Head structures as shown in Pediculus humanus Linnaeus

Figure 1 


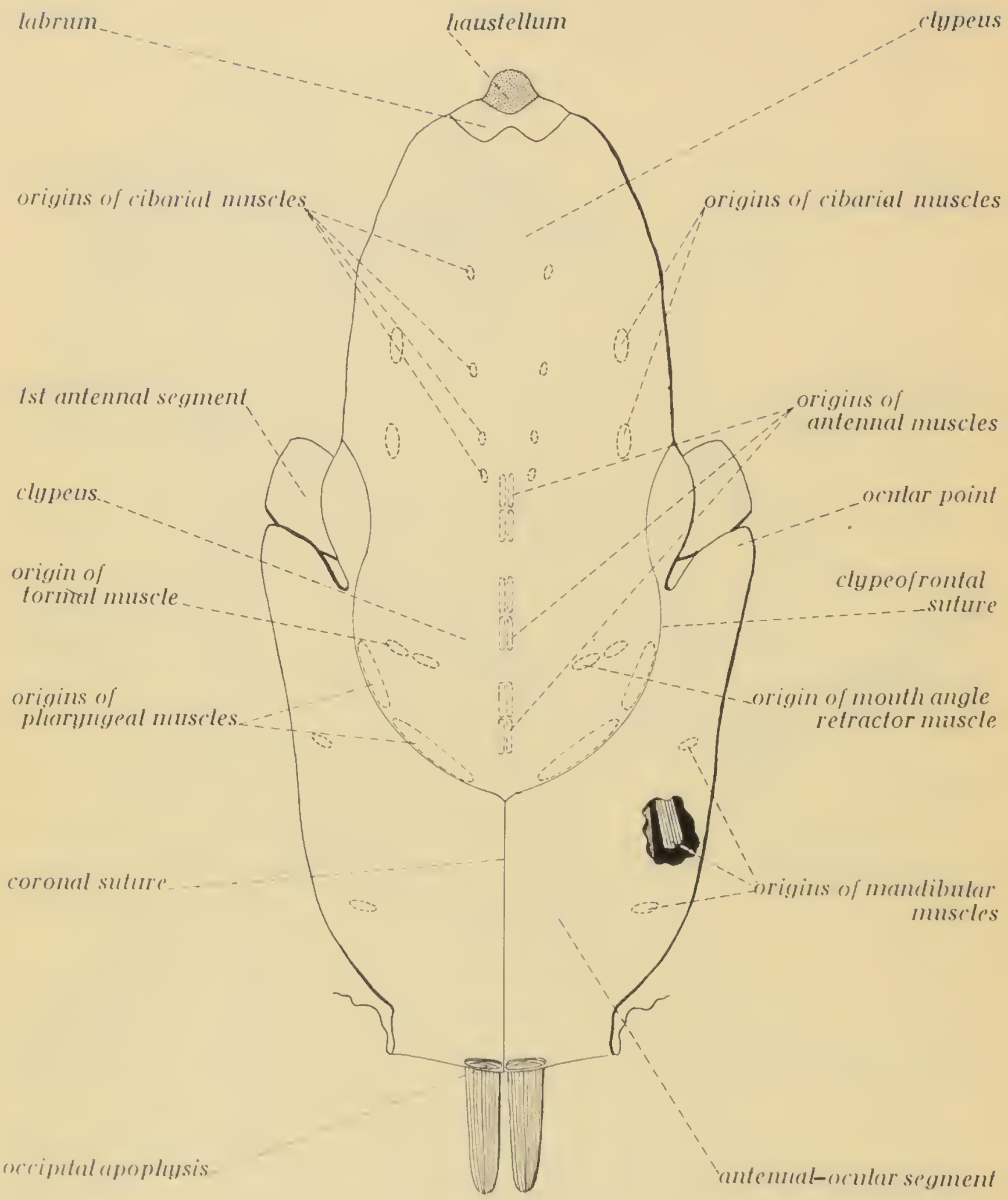

Structures and origms of muscles in head of Haematopinus suis (Linnaeus)

Figure 3 
is lonmel in ferellomlus.

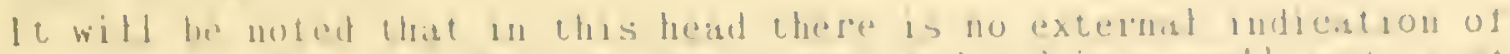

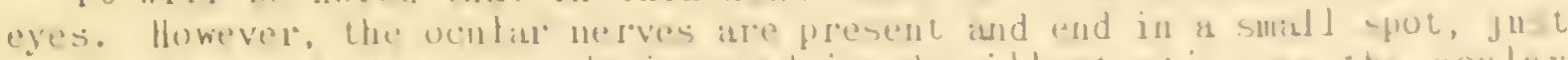
at the buse of the aleas desirnated in the illustration as the oculat poinls, which an morphoturicially the eges. heblu has demonstrated that in some specinesls, at least, definite but mall lenses can be recornized.

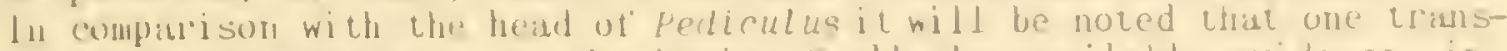
velse sutule is missing. Un the basis of all the available evidence, includin: the study of uther species not here considered, we interpret the comlitions as follows. he assume that the clypeus has been froduced fusteriorly until it has crowled ont the t'runs, and the frontuclypeal and postrontal sutures have becume contluent. Therelore nothins is lett of the frons except the snall areas at each side which hear the antennae. The chimsverse, V- or U-shaped suture is theretore morphologically the postfrontal + clypeofrontal sucure. 'This conclusion is supported ly the pusitions of the origins of the cibarial muscles.

One other leature of this head calls tor mention.

At the posterior border of the heat are tro invorinuted sclerutiations, the occipital apophyses. Tu these attach muscles which serve to retract or elevate the head. Evidence derived from the innervation of these muscles indicates that they and the structures upon which they insert belong to the head. To just what segment of the head they belong remains to be determined.

The ventral side of the head is so similar to that of Periculus that it is not here illustrited.

\section{The Head Capsule of Other Anoplura}

There are some moditications of the head capsule in other species of Anoplura, but they can all be accounted for on the basis of the two species which have been discussed. Consequently, we need belabor this subject no further.

\section{The Youthparts and Intemal Structures}

As has already been noted, the mouthparts of the sucking lice are of a very peculiar type which is not found elsewhere in the insects. Functionally they are to be described as "piercing and sucking," but their mechanism is very different from anything that is to he tound in other piercing and sucting forms such as the Hemiptera and the blood-sucking flies. They have been the subject of much controversy and there are still certain details which remain doubtul and which will require embryological work for their final elucidation.

Since, apart from the space occupied by the brain, the internal structures of the head are almost exclusively associated with the mechanism of feedin: we may consider all these structures together.

The first necessary step is that of forming a clear picture ot the relationship of the piercin structures and the food channel. It must be srasped at the very herinning that the piercing structures do not in any way form the tood channel. In order to understand this clearly, reterence may be made to Fignre 4. In Part $A$ of this ligure is shown a longitudinal section throuth a normal insectan head, with the lateral parts such as mandibles and maxillae omitted. The roof of the oral chamer or cibarium is here formed by a continuation of the ventral wall of the labrum and the floor of the chamber by the hypopharnx and the anterior wall of the labium. Leaving aside any argument as to where the true mouth opening actually is we may for the present consider it to be the opening into the pharyx. Note especially the openin: of the salivary duct between the hypopharnx 


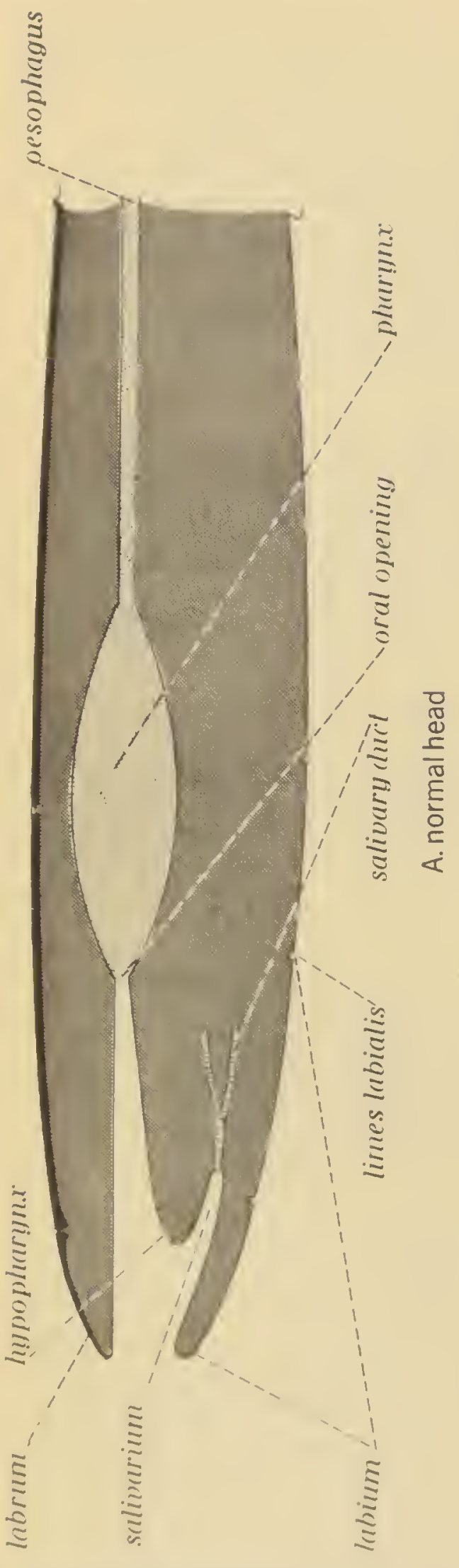

Diagram of mouthparts

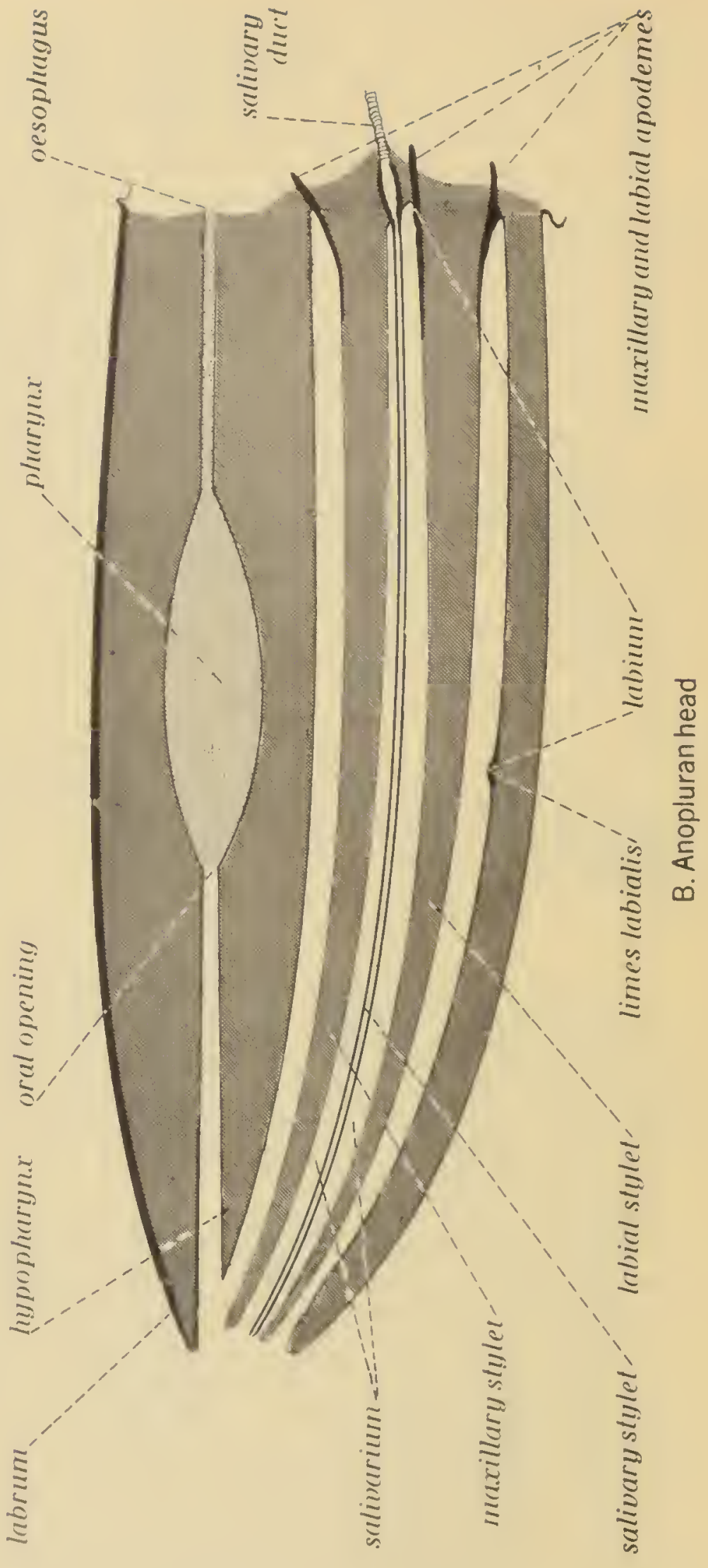

Figure 4 
and the laticum.

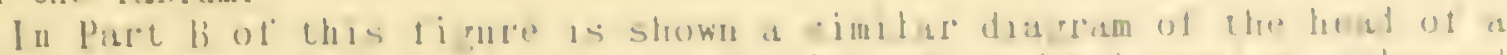
suckinis funse. Note that the upper portion of the head reman unclanes anct the moliticitions involvad are all in the luner-molpholopicall! the posterior-portion. It is evident thist the parts involved an the prercing structures have been mulled back into a sic that lies entirels beneath the month. 'lhe three needles which torm the prercing instrument ori inate from the base of this siac. When the instrument is broutht into action it is extruded through a small opening in the lloor of the oral chanber just in trom the apex of the heiul. It is very evident that the blood or the host does not pass into this sac on its wily into thr alimentary canal. The actual arian rement of the sic and its relation to other parts is shown in less diargrumatic lorm in Figure 5

The questions at issue have to do mostly with the homolories of the three stylets which comprise the piercing instrument. In the diarrammatic illustration they ire greatly exirgerated in thickress. Actually, they are exceedingly delicate and are closely appressed together. However, the questions concerning these stylets are not all there is to the problem, since there are certain other structures which do not appeal in this diasram and which have to be explained.

For our explanation it is necessary to turn to the musculature and the innervations of the muscles.

Perhaps the most favorable subject for study of these problems is the hoy louse, Haematopinus suis. This is a lather large species and it shows ail the structures. It may be noted that all the work on which the accompanying illustrations were based was done by the method of dissection employing powers up to $\mathrm{x} 115$ of the binocular dissecting microscope,

In Finure 6 are shown the structures which appear upon removal of the dorsal wall of the head. We may in passing note the muscles of the antennae, which originate upon the dorsal wall. In iusects wich possess a tentorium they would originate upon that structure, but since the tentorium is here lacking the origins must of necessity shift to another position. In some Anoplura they originate in part upon the lateral wall of the head ventrad of the antenuae.

The "brain" is relatively lare and is composed of the supraoesophageal and suboesophageal anglia which are connected by the very short circumo esophareal connectives that pass around the oesophagus (see Figure 25). One landmark to be especially noted is the trontal ganglion, which in all insects lies in front of the brain and between the cibarial and pharyngal muscle bundles. Just posterior to this frontal ganglion the alimentary canal swells into a bulb which is the pharynx and which forms the sucking pump. From the phargnx large bundles of muscles extend to the dorsal wall of the head. It is these muscles which function to dilate the pharynx and cause it to operate as a pump in sucking up the blood of the host. There is nothing in any way unusual about them or their arrangement.

Ancerior to the frontal ganglion are several muscle bundles originating upon the clypeus and inserting upon the dorsal wall of the oral chamber. These are the cibarial muscles, as is contirmed by their innervations which will be discussed later.

Anteriorly to these muscle bundles the dorsal wall of the mouth chamber is formed by a sclerotized plate. somewhat in the lorm of an inverted $Y$. From the apex of each arm a muscle extends formard to a little, external. plate which we have previously identitied as the labrum. These muscles may be regarded as the compressors of the labrum and are essentially the same as are to be found in most insects. The plate to which they insert, and wich forms the dorsal wall of the chamber, is here called the palatal plate. It is morphologically equivalent to the plates which are to be found in the dorsal wall of the oral chamber, in one form or another, in a wide 
variety of insects.

There is nothing here that is in any way unusual or markedly different from what is to be seen in any typical insect.

Disre rard for the moment the pair of structures which lie one on each side of the palatal plate. They present one of the most obscure problems involved in the mouthparts of these insects and we shall discuss them later.

Look arain at Figure 5 in which the relations of the various structures are shown and note the position of the ventral trophic sac and the point at which it joins the cibarium.

In Figure 8 the ventral wall of the head has been dissected away to reveal the trophic sac and its associated muscles. The piercins stylets are concealed within this sac and only the branching ends of the apodemes upon which the muscles of the stylets insert, and which are formed from the walls of the sac, appear at the posterior extremity.

Note that from these apodemes slender muscles extend forward to attach to a sclerotized transverse band in the ventral nall of the sac at about the midpoint of its length. Also, certain muscles extend from the apodemes and attach to the obturaculum, a structure which will be discussed later, and there is a relatively huge, transverse muscle at the base of the trophic sac, this originating at each of its ends upon the obturaculum. Along the trophic sac are inserted certain slender muscles which originate upon the outer head wall.

In Figure 9 the base of the trophic sac is shown as with the walls cut away to reveal the apodemes of the stylets which are contained within the sac. It must be emphasized that the stylets are outgrowths from the wall of the sac and so are these apodemes, the sac being closed apically. There are no muscles inside the sac. The sac is an invagination of the body wall and anything inside it is morphologically outside the body. We may note in passing that certain illustrations of these structures which have been published show the apodemes as being inside the sac and thus in effect indicate an arrangement that is a morphological impossibility.

Let us now turn our attention to the stylets themselves. There are three of them-a dorsal, a middle, and a ventral. The dorsal and ventral stylets are tlattened and relatively broad; the central stylet is cylindrical and very delicate. The three are very closely appressed together and extend forward so far that when at rest their anterior ends lie just within the mouth chamber. They enter the chamber through a slit in its floor. If they are extended to reach a blood vessel the base of the sac must be pushed far forward to lie close to the apex of the head.

The homologies of these stylets have been much disputed.

The nature of the median stylet is, however, quite clear. It carries the extension of the salivary duct and except for the lumen of the duct is solid. There is no reason whatsoever to consider it as anything more than a rreatly elongated papilla which arises from about the mouth of the salivary duct and it is here called the salivary stylet. It has been considered to be the hypopharynx, but only because of a complete misunderstanding which has been widely spread among morphologists. The salivary duct does not belon: to the hypopharynx and the opening of this duct defines a point that belongs to the labium.

Nor can there be much doubt concerning the ventral stylet. It is unquestionably derived f'rom the labium and its muscles are innervated by nerves that seem clearly to he labial. Presumably the stylet is formed from the terminal portion of the labium, the part generally called the ligula, and there are no labial palpi. To understand the structure one must vismalize the entire lahium as heing pulled back into the head, part of it forming the floor of the consequent invarination and part of it being free of the trophic sic is formed from the labium as far forward as the point 


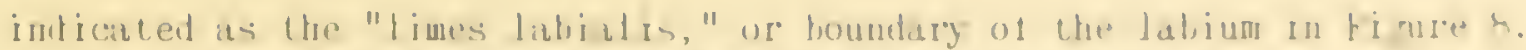

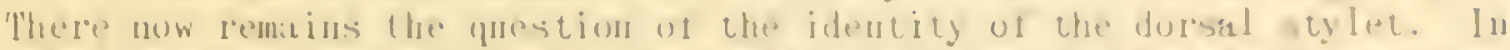

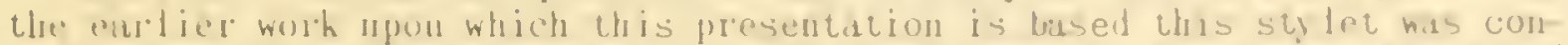

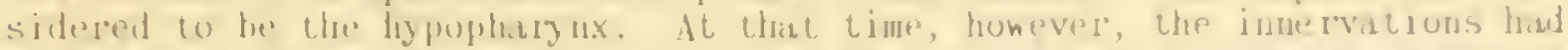
not jet heen stmlied. In the liefit of tinrther studies ne have heen lured t.o conclude that this stylet is atetually formed from the lused arexillate. The reasuns tor this decision will be discussed when we constder the nervons system ot the heidl.

The hypopharym here, on the basis ot evidence presented by the nerves, is represented hy the dorsal wall of the trophic sac and the t'luor of the oral chanter as lar posteriorly as the opening into the pharym. Yuscles insertin: npon this areat are innervated by nerves which can be nothing hut nerves of the hypophiaryux.

he are lett now with the problem of the frail ul structures ly ing inside the heal just in trom the apex, one on each side of the palatal plate and (o) which we reterred earlier.

In onl previous work we considered these structures to he vestiges of the maxillace, but in the light of the intormation now avalable this opinion can not he maintained. The maxillae trave already been acconnted for and there remin but two possibilities in regard to the structures in question. It wuld seem that they must be either completely new structures with no antecedents in other insects or that they must be derived from solue preexisting movable structure and the only such structures that exist in this part of the head of any insects are either the mandibles or certain developments trom the dorsal wall ol the cibarium to which the name "premandibles," or the better name "messoles, " have been applied. He discard recourse to the tirst sugrestion-that they are completely new structures-as a matter of principle and concentrate upon the thought that they are derived from some pre-existiry movable structure provided with muscles and nerves.

First let us describe them as they occur in Haematopinus (Figure 10). Here they cousist of a pair of somewhat wed re-shaped, sclerotized bodies, lying within the heid cavity, one on eacli side of the palatal plate. Each of them is connected hy a strong and undoubtedly chitinous ligament to the head wall just at the nargin of the labrum and each is also connected by a slighter liframent to the marion of the palatal plate. Each is provided with one very large muscle that originates far liach on the lateral wall of the ocular Lohe of the head and inserts upon the doubtul structure by way ot a long and strong apodeme. A much smaller muscle originates upon the sclerotized wall of the pharyn. Both these muscles are innervated by branches of a nerve, which is one of the first pair to arise from the suboesophareal gamplion (Figrure 25).

In the lisht of this innervation we are forced to conclude that the structures in question are actually the mandibles. They cannot have been derived from such structures as the messores, which are developed from the dorsil wall of the cibarium and whose muscles are innervated by branches trom the labral nerve.

How these mandibles have become nithdrawn into the body and how they have acquired two connections to the body wall are problems which can only be solved by careful and detailed embryological studies that are still to
be made. But that no interpretation other than that here presented is consistent with their innervations is clear.

These structures vary somewhat in form and position in ditferent groups of the lice, in some species lying close to the ventral side of the head (Figure 11) and close together, but they seem to retain the same connections to the head wall and to the palatal plate and to retain also the same musculature. It is possible that a minntely detailed study of them would offer some evidence that would have a hearing upon problems of relationships within the group but at the present time this seems impracticable. 
Structures Associated With the Mouthparts

Pawlowsky's Glands and Salivary Glands

Figures 5, 6, 7, 9, 10, 11

These are a pair of small, ylandular structures each of which opens through a short duct into the trophic sac. Their function is unknown, as are their homologies. They are innervated by branches of what we here consider to be the hypopharyngeal nerves. There exists very little information-and that mostly very varue-concerning glands of the head region other than the salivary glands and at present we can make no statement concerning Pawlowsky's glands other than to record their position and their innervation. He have suspected that they may be homologous with what have been called "pharyngeal glands" in other insects, but an extended study. would be necessary to determine whether or not this is the case.

In those lice which have been investirated in regard to the matter there are two pairs of salivary or labial glands. These lie in the thorax, dorsad of the alimentary canal. In Pediculus humanus the members of one pair are small and oval or somewhat kidney-shaped, those of the other pair are tubular and folded. From each gland a duct extends forward and unites with the duct from the other type of gland on the same side of the body. These two ducts then unite into the common duct near the point of their entry into the head. This conmon duct then discharges at the apex of the median, salivary stylet which has been described.

The Obturaculum

Figures 7, 8, 12

The mouthparts themselves are not the only peculiar feature of the head in these insects. He have referred earlier to a structure which we have called the "obturaculum," literally the plug or cork, which represents a most peculiar development that, as far as at present known, occurs only in this Order.

The extreme posterior portion of the head is filled by a mass of tissue which in histological preparations has the appearance of being minutely fibrous and which may be regarded as connective tissue. This tissue forms a plug, or a transverse diaphragm, which fills the occipital foramen and extends into the thorax. There it more or less completely envelopes the ganglia which are concentrated in that region. The anterior end of the plug is concave and cup-like. Through this plug the alimentary canal, the tracheae, the salivary duct, and the tracheae enter the head in the manner of tubes through the cork of a bottle.

The base of the trophic sac extends into the concavity of the anterior end of the obturaculum and certain of the muscles which have their insertions on the apodemes of the trophic stylets originate upon the walls of the cup. Thus, the large, transverse labial muscle, which inserts upon the ventral surface of the trophic sac, originates in this manner as do the folded maxillary retractors and the labial retractors. The importance of this will be apparent upon reference to the illustration of the head of Linosnathus vituli (Figure 12). Here it will be seen that the trophic sac extends far lack into the thorax. Upon what would its muscles ori rinate if the olturiaculum were not present? This mass of connective tissue is evidently a pirt of the solution of the problem of functioning which is presented by the peculiar trophic mechanism and its signilicance in connection with this will be liscussed later.

The orifin and homolories of' the ohturaculum are at present quite in doubt. It seems evidently to he a mas of comective tissue, but at present there is very little information concernin: the occurrence of such tissue in insects. (Other work it present in proigress has shown that a sheath 


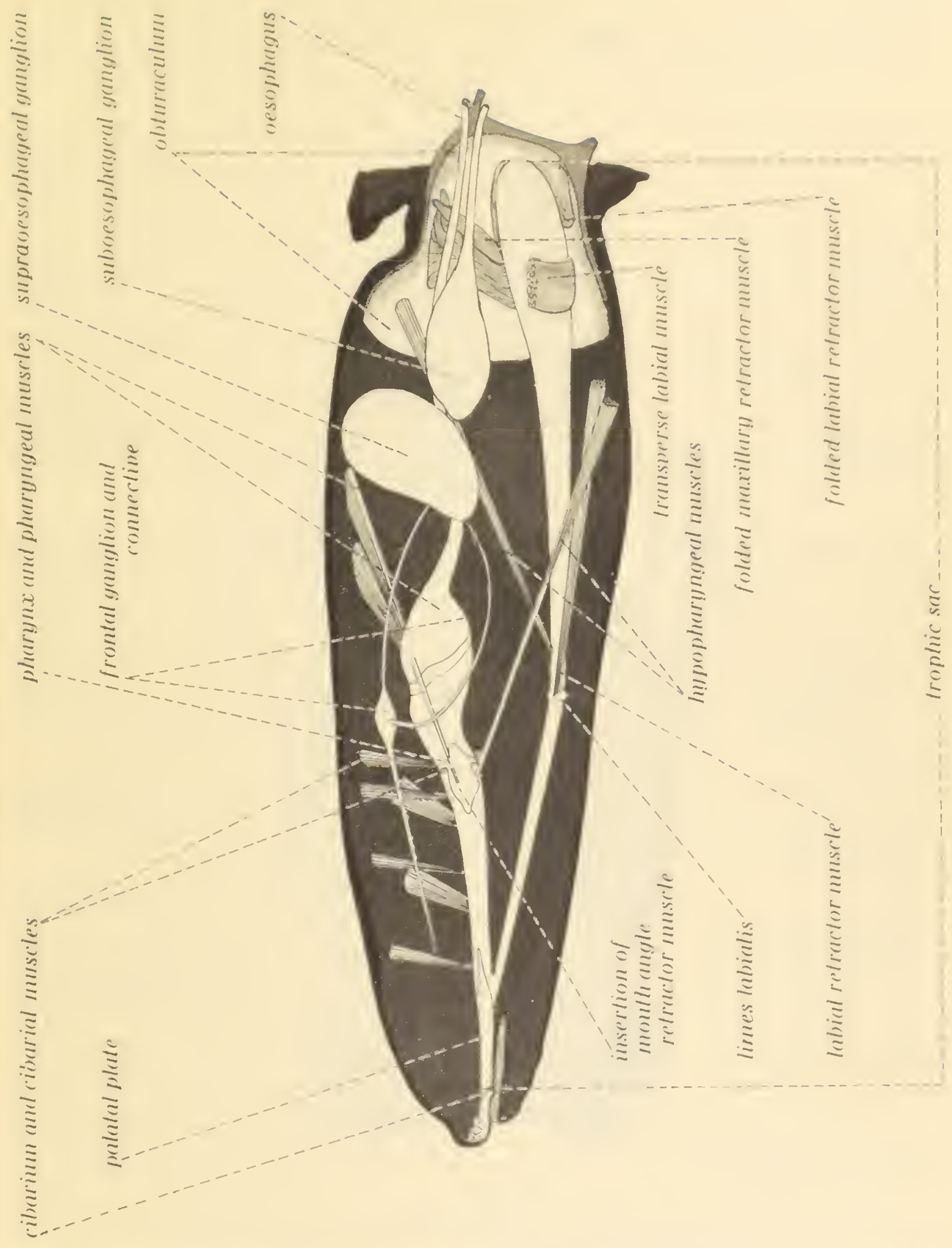

Internal structures of head in Haematopinus suis

Figure 5 


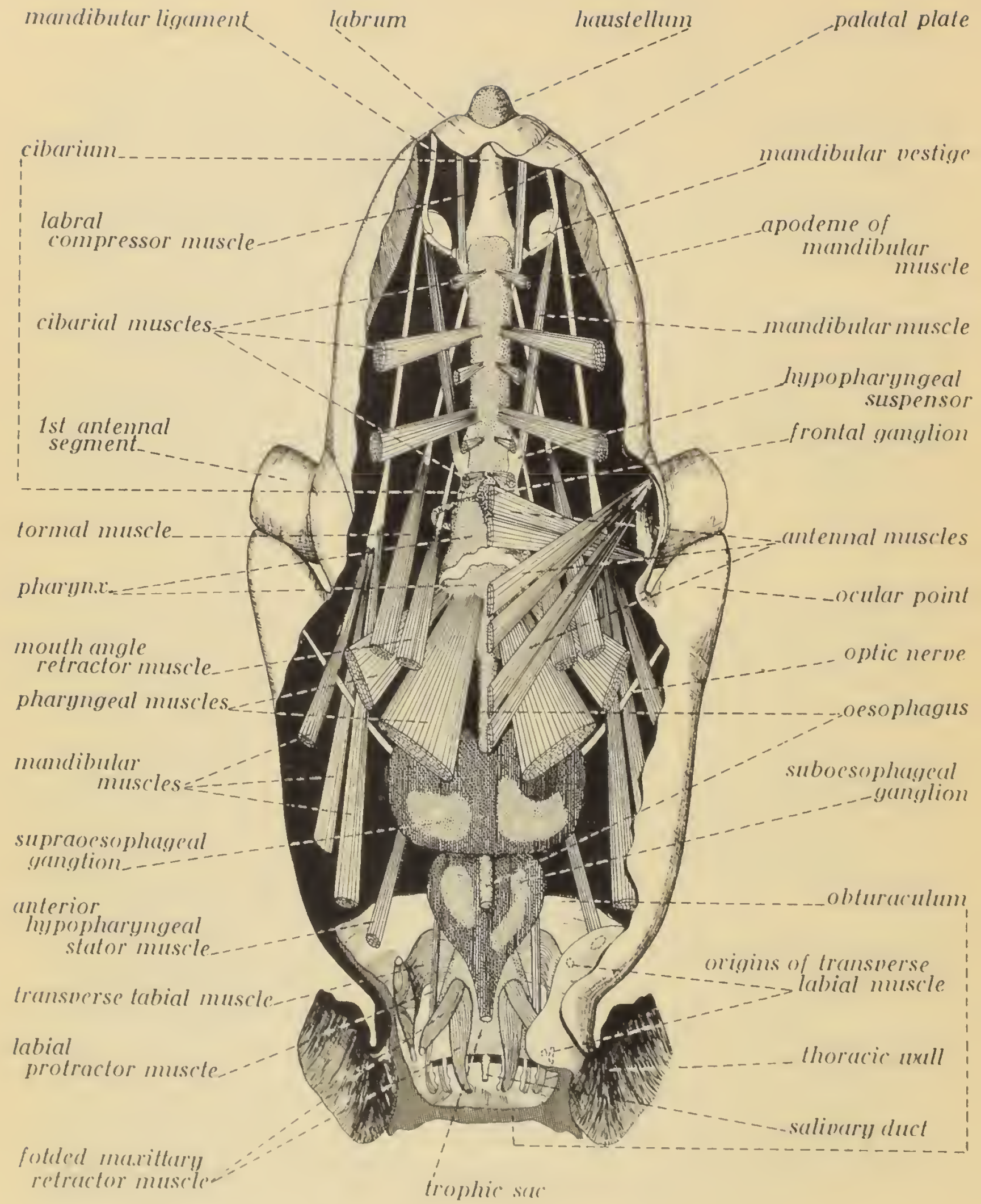

Structures in the head of Haematopinus suis, dorsal aspect

Figure 6 


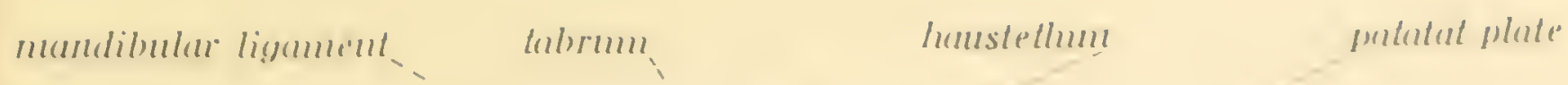

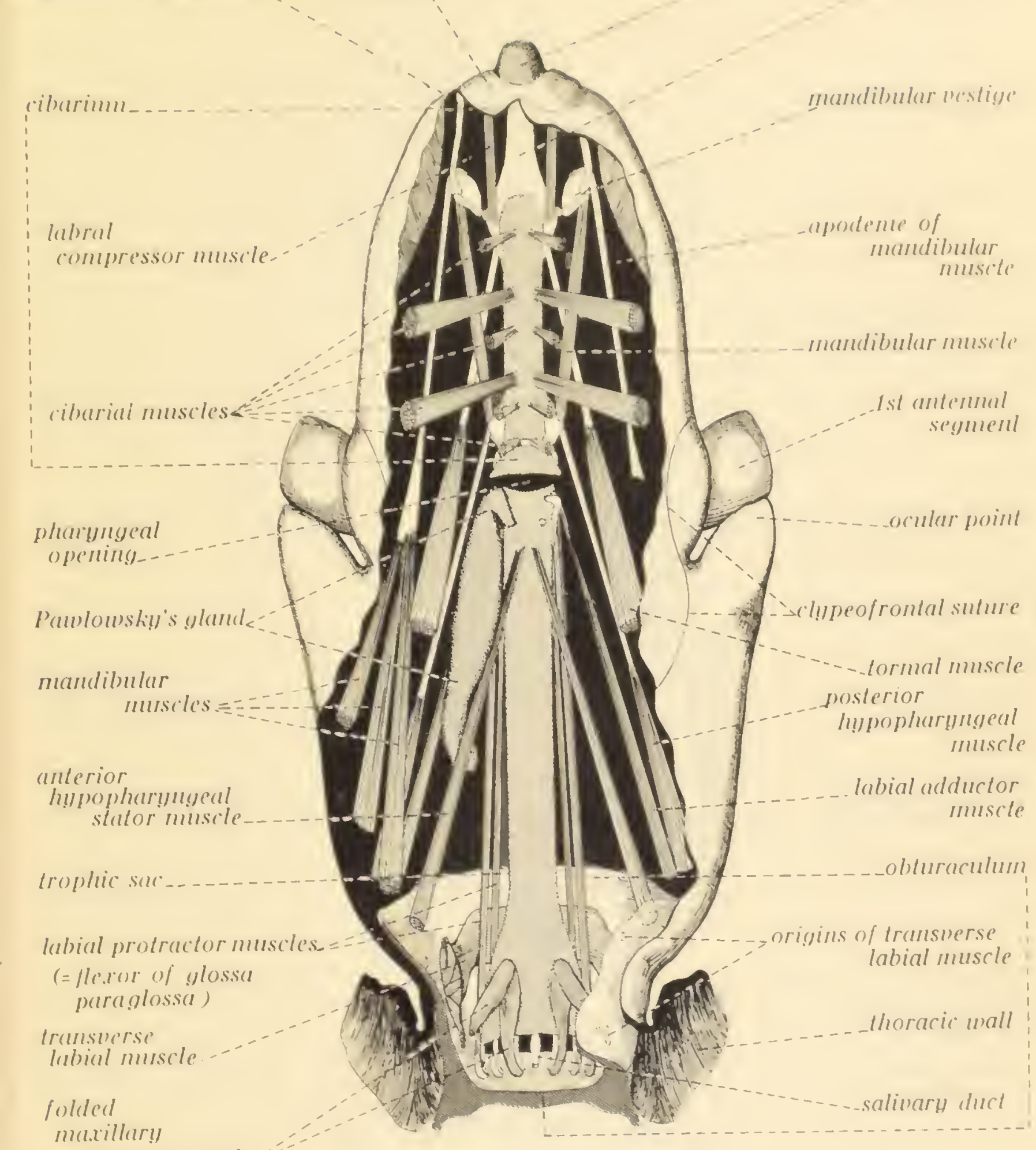

maxillary

retructor minscle- =

Structures in the head of Haematopinus suis, pharynx and brain removed

Figure 7 


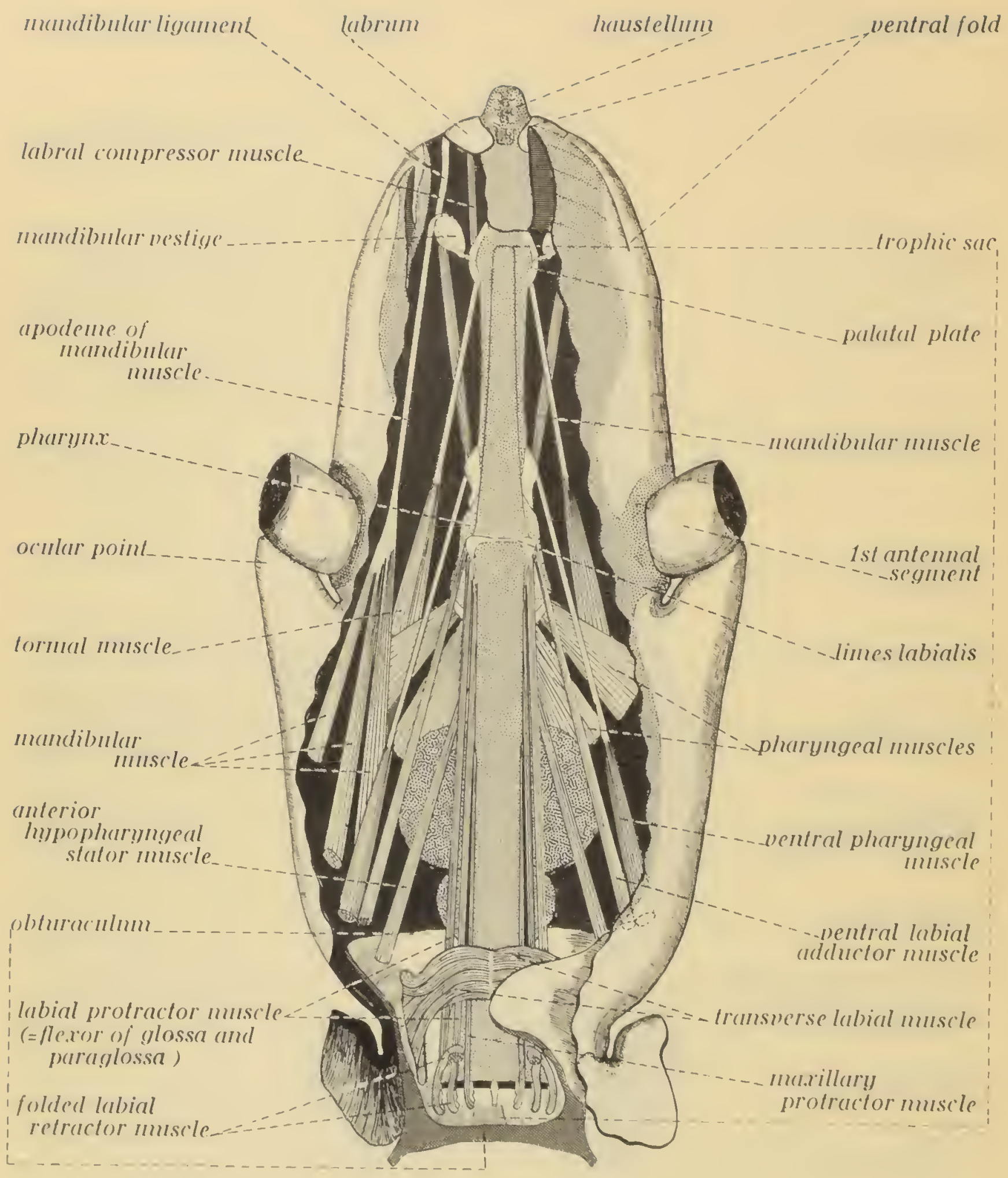

Structures in the head of Haematopinus suis, ventral aspect

Figure 8 
marillum! upulenus....

folled mullilku!!

relrutor mulsile

sulilurylull).

labial protractor muscles $r=$ lleater of glossa arul puralolossa )

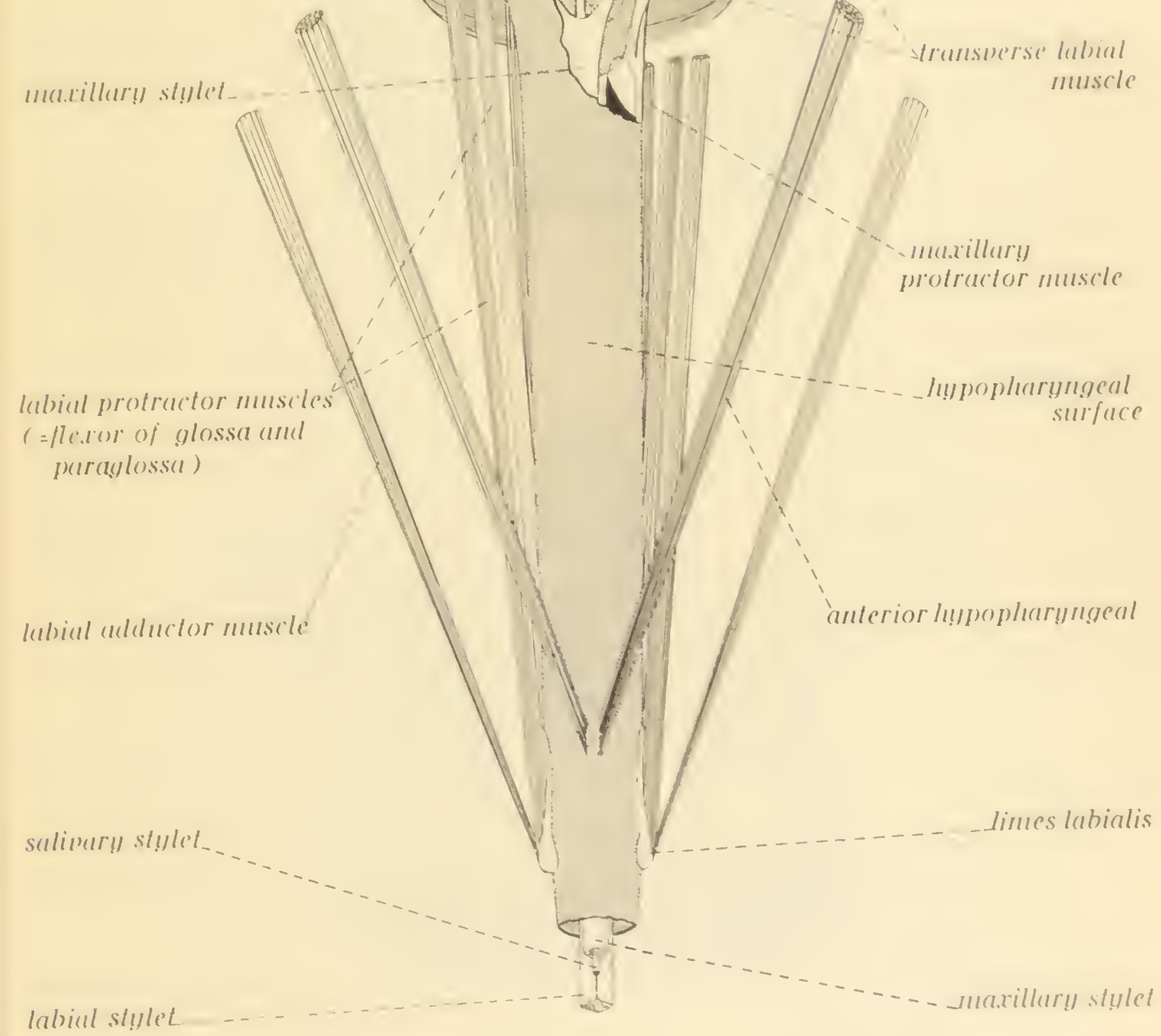

labiul style't

Base of trophic sac in Haematopinus suis

Figure 9 


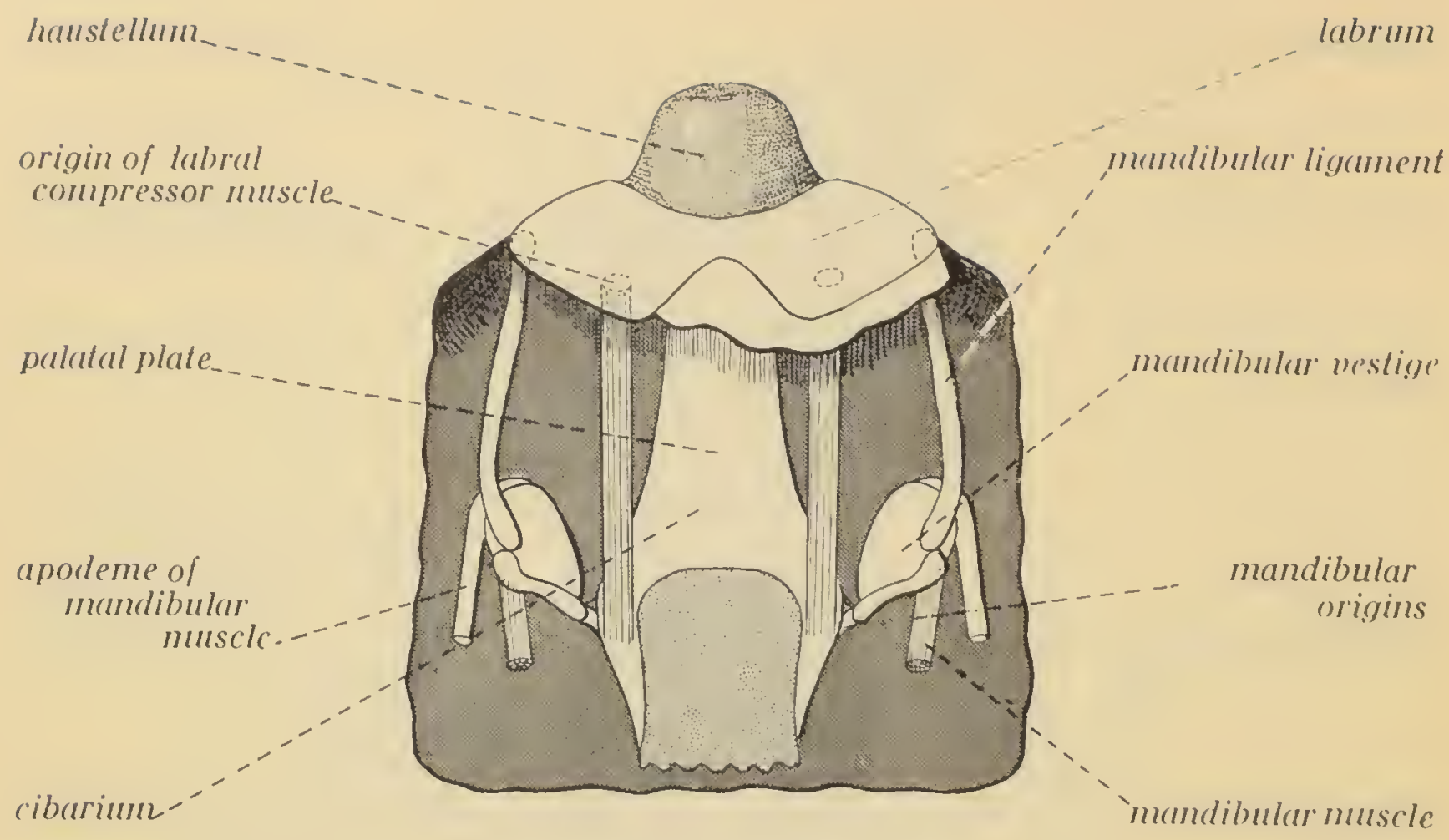

A. dorsal aspect

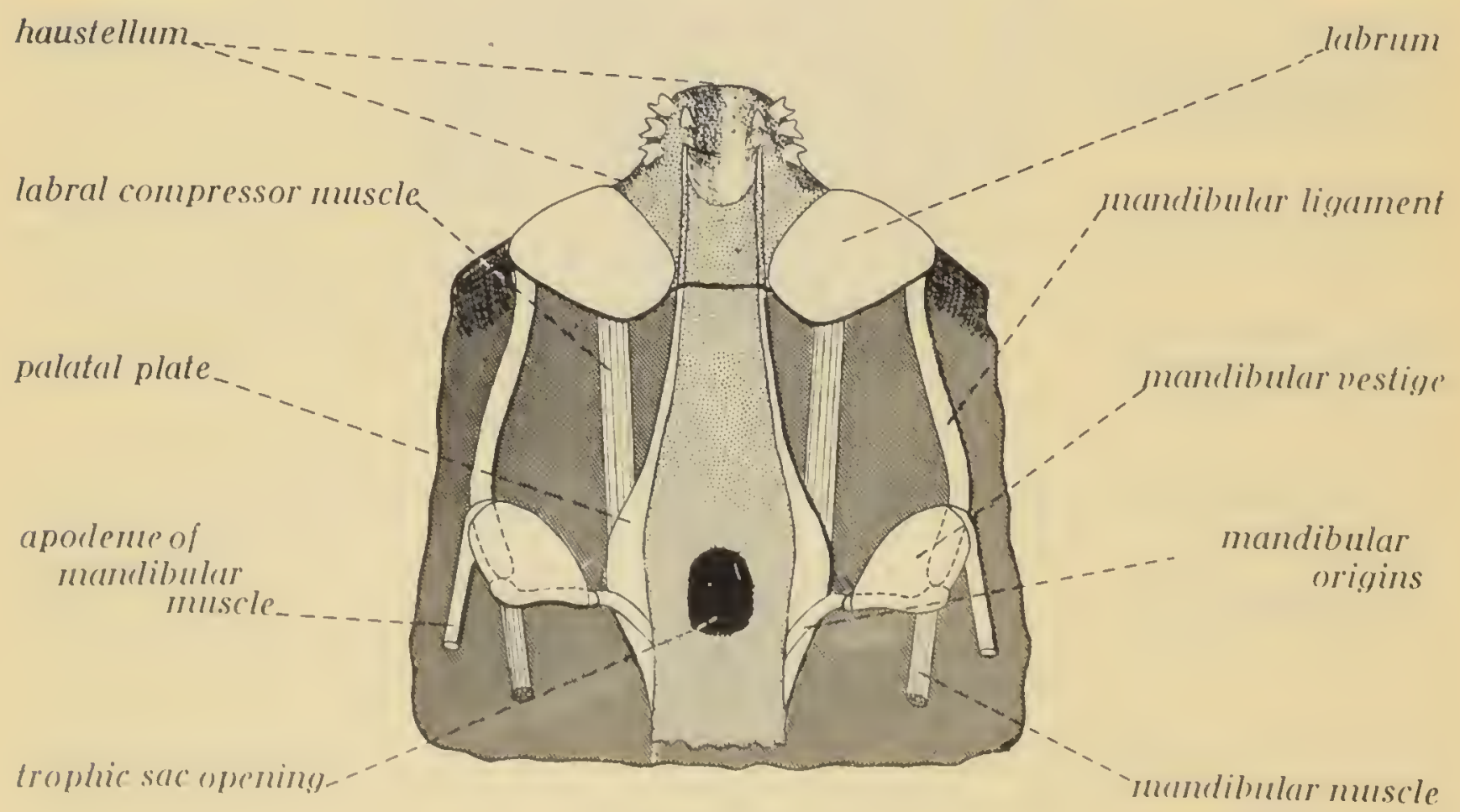

B. ventral aspect

The mandibles in Haematopinus suis

Figure 10 
lunustrlllum!

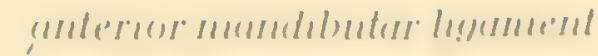

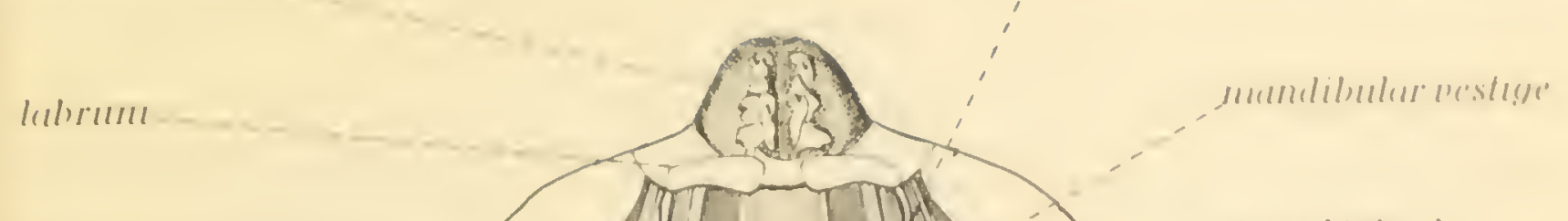

retriclormilsiste

labral (e)mupressor

mitsisles

humpopluarynumpenl
plate
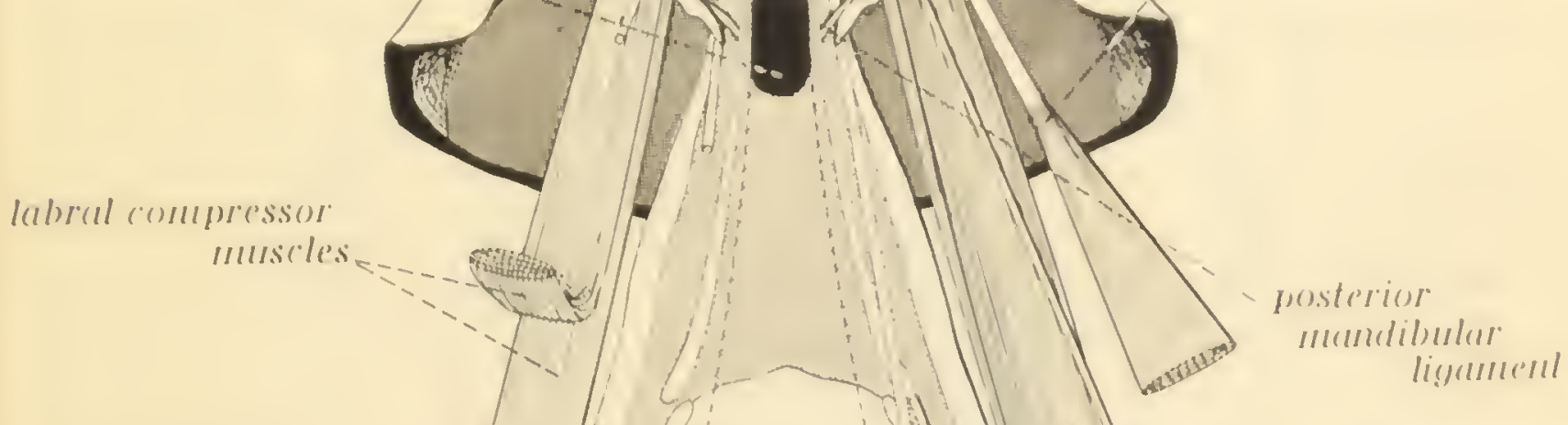

troplicic sac

\section{(inlerior) \\ lrlbiell \\ relenlor \\ miliscles}

labial prolraclor manscle

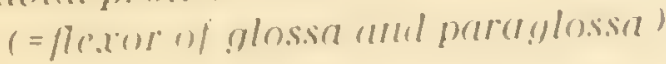

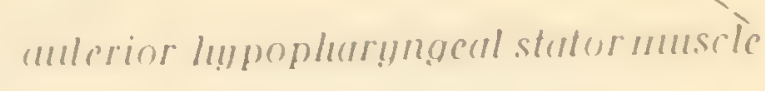

Cibarial region in Pediculus humanus, trophic sac removed

Figure 11 


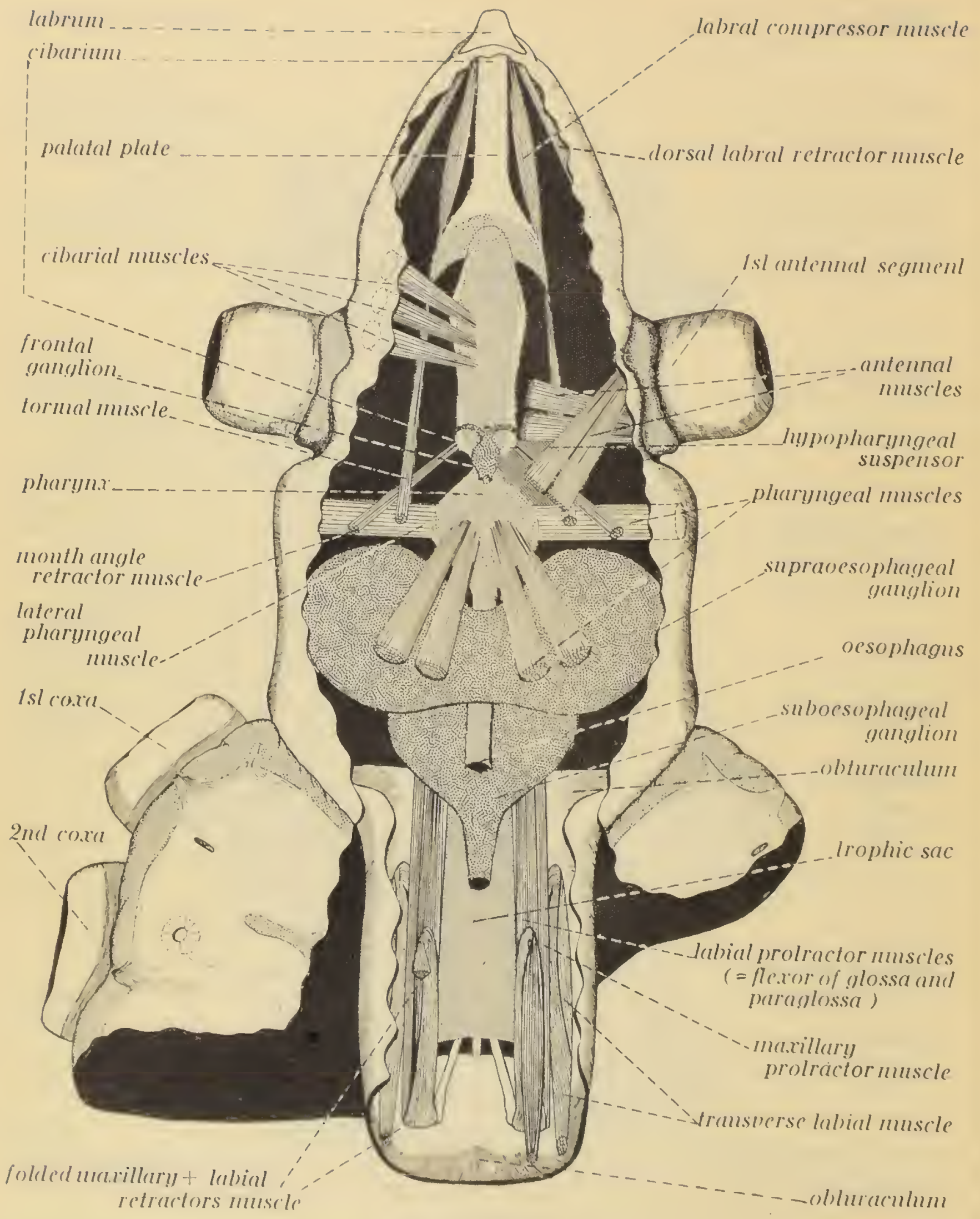

Structures in the head of Linognathus vituli (Linnaeus) Figure 12 
of connective tisiur which emplopes the thoracic ganflu and extends into

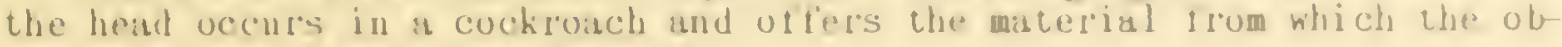
toraculum could have beren derived.

\section{'The fructioning of' the Mouthparts}

Some idea of now the trophic mechanism may function can be derived from contemplating the urrangements that have been described.

It seems probable, tron purely mechanical cunsiderations, that the slender muscles which extend furward from the branches of the maxillary and labial apodemes and attich to the walls ot the trophic sac must act to pull the stylets forward, birt it seems inprobable that they can furnish the entire drive necessary lor the complete exsertion of the suylets. He may therefore surmise that the action of these muscles is aided by bluod pressure. That pressure mirht very well be developed by the contruction of the powerful dorso-ventral muscles of the abdonen. The pressures thus developed would be transmitted through the obturaculum to the head cavity and thus brought to bear upon the trophic sac.

In any case, however the necessary tore is developed, the stylets are pushed out of the trophic sac and forced into the tissues of the host. It is evident from the structure of the stylet bundle that the blood does not pass through any channel formed by the stylets themselves. If it did so it would merely pass into the trophic sac itselt and not into the pharynx. He may assume, therefore, that the stylets merely serve to pierce a blood vessel. The membranous area at the apex of the head can be unrolled and appressed closely to the skin of the host. It seems probable that the blood is drawn up around the stylet bundle and into the mouth by the action of the pump formed by the pharyinx.

The retraction of the stylets offers some interesting mechanical problems. Presumably the muscles which accomplish this are those indicated in the illustrations as the folded retractors of the labium and maxillae. These muscles when at rest are actually folded upon themselves and raise the question of how such a lolded muscle can function. This may possibly be accounted for in the following way.

It seems probable that in forms such as Linognathus vituli, where the trophic sac extends far back into the thorax, a rather peculiar muscle would be required to permit of the extreme degree of relaxation and extension that would be necessary when the stylets are fully extended and that this muscle would have to be extremely long. He suspect that when the muscles are extended they are under little or no strain. Note that these muscles originate on the obturaculum which is composed of a tissue that seems to be extremely elastic, as can be seen in dissections of fresh material. We may suppose then that when the stylets are to be withdrawn the retractor muscles give merely an initial pull and that the completion of the retraction of the parts is accomplished by the elasticity of the obturaculum. As the retraction comes to completion the retractor muscles simply fold upon themselves. He see no other way of accounting for the mechanics of such a peculiar arrangement.

\section{The Antennae}

The antennae are normally f'ive-semgented and no species of sucking. louse is known that has more segmenis than this. In a fer species there is apparently a tusion of the two terminal segments, leading to an apparent four-semented condition. In one senus, Haematopinoides, the antennae are definitely four-se mented. In a few species the three terminal se ments are but weakly separated trom each other and the antennae have the appearance of being three-se fmented. 
Each of the two terminal segments usually bears upon its posterior border a ring-like structure that may be regarded as a sensorium, but in some forms these are lacking.

No especially peculiar developments of the antennae are known. In some forms there is a slight sexual dimorphism which involves seument three in the male. This seyment may have its apical, preaxial angle somewhat prolonged and this prolongation may terminate in a recurved spine or a short, stout seta or some other modification of setae may occur. In some cases a modified seta may here be present unaccompanied by any other modification. No instance is known where the antennae of the male are developed into such extreme clasping structures as occur at times in the Mallophaga.

\section{The Eyes}

Definitely developed and clearly recognizable eyes are present in only a few species of the sucking lice. In these species each eye possesses a single lens, beneath which is a pigment spot. The presence of such eyes has been accepted as a taxonomic character and has been much used in the definition of genera.

Webb* in a recent paper has shown definitely the existence of eye vestiges in Haematopinus suis, each eye consisting of a very small and obscure lens, "beneath which there are two or possibly four ovoid crystalline bodies surmounting a cluster of pigmented sensory cells ending in nerve fibres." He has identified-in all probability quite correctly-what he considered to be eye vestiges in a considerable number of species of Haematopinus, Linognathus, Solenopotes, Ratemia, Prolinognathus, Rybophthirus, and Antarctophthirus. They are definitely present in Pediculus, Phthirus, Pedicinus, Hicrothoracius, and Pecaroecus.

Unfortunately, the great majority of all the species of sucking lice are known only from preparations made from dried specimens and in the course of making these preparations any spots of eye pinment are destroyed and the lenses themselves at times become difficult or even impossible to recognize and to differentiate from any small, clear spot. For this reason the existence of eyes cannot at present definitely be demonstrated in many forns where they may actually exist. For this the study of properly preserved material must be awaited.

It is clear, however, that the presence of recognizable eyes cannot form a sound basis for any system of classification within the Order Anoplura, although in some instances it may offer good key characters for identification.

Webb has referred to these eyes as "ocelli," but their position indicates clearly that they are the morphological homologues of the compound eyes of other insects and not of the structures for which the term ocelli is ordinarily employed. Morphologically, they are vestigial compound eyes.

The Thorax

Figures 13, 14

In association with the absence of wings the thorax is very much reduced. While three separate segments are definitely present they are closely fused and certain marked modifications have tatien place. The metathorax is the most reduced of the three segments and may be represented only by small lateral elements. Only one pair of spiracles is present, this telonging to the mesuthorax.

An understanding of the structure of the thorax in these insects rests upon the recomition of certain landmarks. In the vast majority of insects

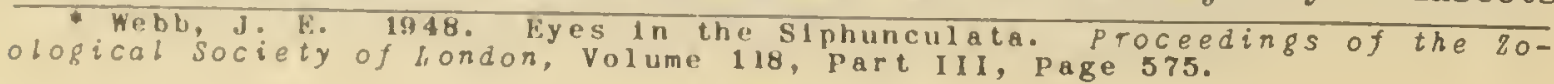



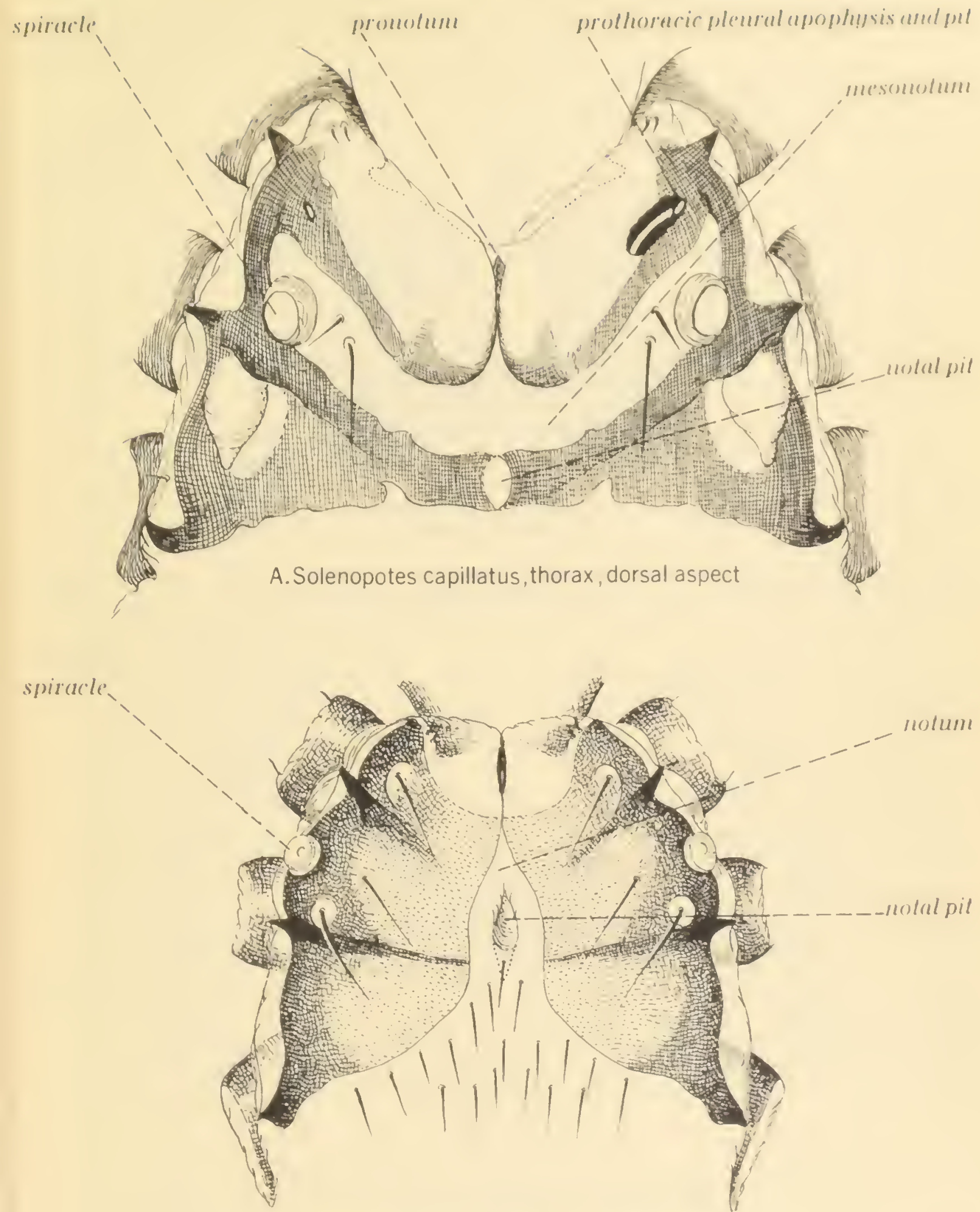

B. Pediculus humanus, thorax dorsal aspect 

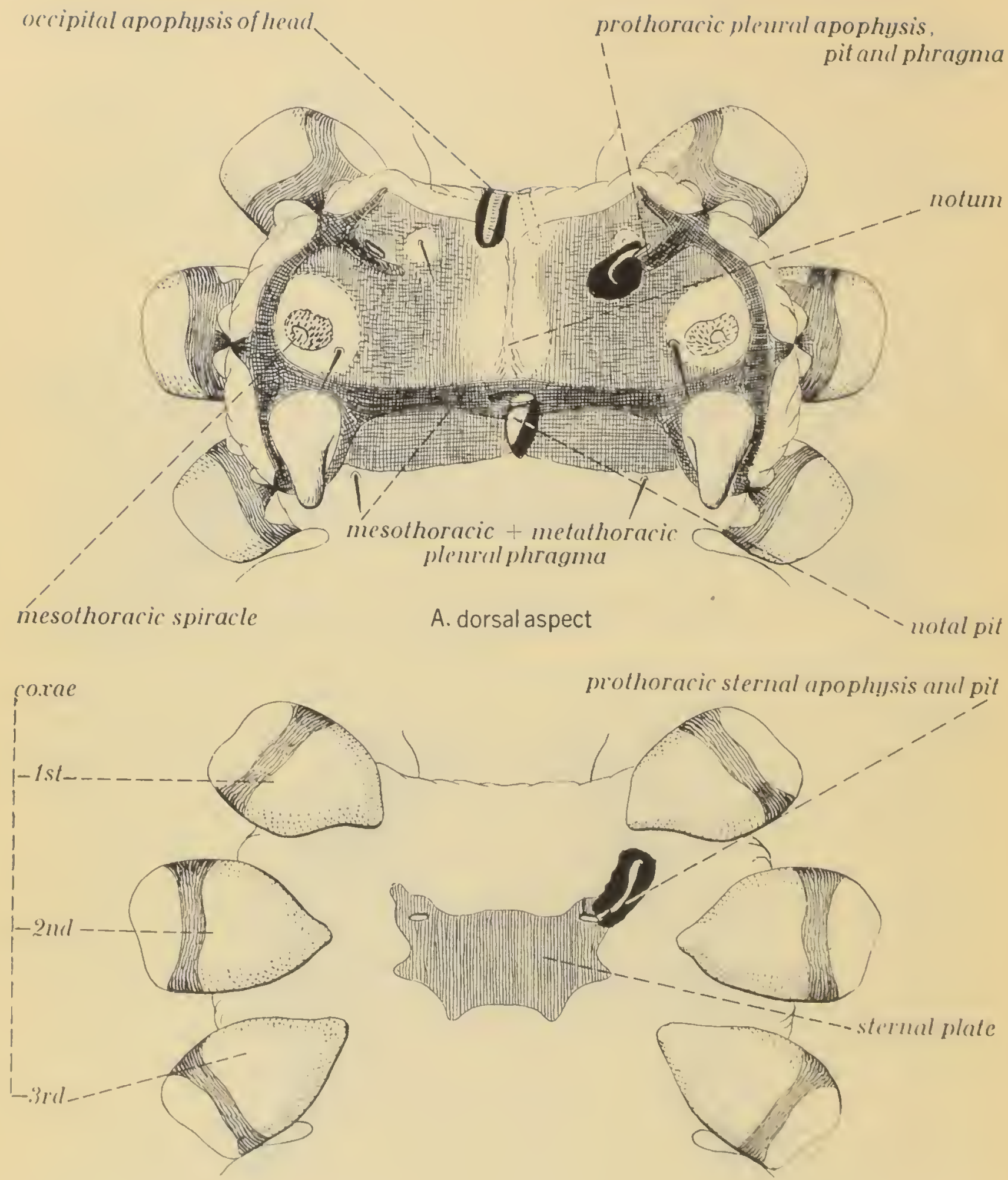

B. ventral aspect

Structures of the thorax in Haematopinus suis

Figure 14 
there oceres on each side, on the so-cialled plenlite of the protholiax, all

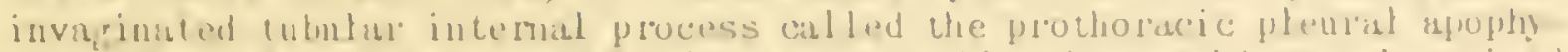
sis. The externil upening ot this apophysis lies in a told or sclorotized stitfening lib thut is known as the pleural told or pleural ridee. The latter is hest characterized as the prothoracic pleural phramito The poine of oritrin of this apophysis in the hody wall is a precise landarark which definitely det"mes the "pleurite"-morphologically the subcoxa-of this se ment. A similar phragriat, but without such a definite apophysis, occurs on ench of the other two segments. 'The principal coxal articulation in all insects is with the apex of this phrargua.

On the basis of the lamdmark aftorded by the prothoracic plenral apophysis und of other minor indications it is clear that the apparent notum of the thorax in the Anoplura is composed tor the nost part of the so-called pleurites, morphologically the subcoxae. The true notun, at the very most, includes merely a nar'ow median area, usually unsclerotized, and a lateral extension of this area on each side which includes the spiracle. In some species the notnm is rednced almost completely to anedian notal pit, the subcoxae having fused with each other across the nictine of the dorsum, even to the extent of enveloping and isolating the notal element about the spiracles.

Perhaps the nearest approach to a normal thorax that is to be seen in any sucking louse is that found in the penus Solenopotes (Figure 13A). Here the pronotum is reduced merely to a median fold, but the mesonotum is of considerable extent in its anterior portion, althou its posterior portion torms merely a median pit which lies in the subcoxal phrama. In Haematopinus suis (Figure 14) the notum is reduced to a slight median line throughout, with a very large median pit which is entirely enclosed by the mesothoracic subcoxal phrama, and the spiracles seem to torm isolated islands of notal ori ${ }^{\circ}$ in. In Pediculus humanus (Figure 13B) there is a somewhat broader notal area let't, this being membranous and enclosing the notal pit, but the spiracles are even more completely isolated, being surrounded by a sclerotized area of the mesothoracic subcoxa.

Apart from the modifications of the mouthparts this reduction or almost complete obliteration of the notal areas of the thorax is perhaps the most characteristic feature in the morphology of the sucking lice.

The ventral side of the thorax is always quite simple. Nothing at all remains of the primitive ventral arcs of the subcoxae and the whole ventral area nomally is membranous except for a single, median, sternal plate, even this not being present in some species. It is not clear whether this plate belon:s to any one of the sements or is a fusion product derived from all of them. In a few species, such as in the genus Haematopinus, it is clear that the plate belongs at least in part to the prothorax, a pair of sternal apophyses being present which fuse with the prothoracic pleural apophyses in a maner like that found in many other insects. These sternal apophyses are present iu only a relatively small number of the sucking lice.

In many Anoplura the stemal plate becomes f'ree from the body around its marbius. especially at its posterior end. In some species it is lacking and in a few it is merely an irregular, sclerotized area.

\section{The Legs}

The principal modifications of the less are found in the tibiae and tarsi and are connected with the grasping of the hairs of the host. There is a single tarsal claw on each ley, except in tour species. In these foll $r$ species the anterior tarsus bears a short. somewhat hooked stmcture which arises at the side of the usual claw. This structure has the appearance of a claw but there is difticulty in being certain ahout its true nature and the opinion is here held that it is not actually movale. 
The tarsus is at the most but weakly two-segmented and even this appearance of segmentation is usually obliterated. In almost all forms the tarsus is closely joined to the tibia and is but doubtfully movable upon the tibia. The tibia is usually more or less produced at its morphologically ventral apical angle, a thumb-like process being formed that opposes the claw and thus participates in grasping the hairs of the host.

Usually the anterior legs are smaller than the others and have a slender claw. In the majority of forms the middle legs are somewhat larger than the first, with stouter claw, and in most species the posterior legs are much broadened and flattened, wi th a stout claw. There are, however, various combinations of these characters and in a few species the legs are all of essentially the same size and form.

There is never anything that can be called a pulvillus, but frequently there is a small, membranous lobe or blade-like process on the inner margin of the tarsus. In Haematopinus there is a peculiar, sclerotized plate in the "palm" at the base of the tarsus.

Certain very peculiar developments found only in the genus Euhaematopinus will be discussed in connection with that genus.

\section{The Abdomen}

The primitive number of seyments in the abdomen of insects is here considered to be eleven. The anus is borne upon the eleventh segment, the gonopore of the female upon the eighth (usually appearing as between the eighth and the ninth) and the gonopore of the male upon the tenth. If the full complement of abdominal spiracles is present there are eight pairs, borne upon segments one to eight. There is a rather general tendency for the number of abdominal segments to be reduced by the reduction or obliteration of segments either at the anterior or posterior ends of the body or at times in both. In order to determine the homolouies of segmental structures in any insect it is necessary to rely closely upon established landmarks. Of these landmarks the gonopore in either sex may be regarded as the most useful. In the Anoplura the spiracles are of but little aid since no known species has more than six pairs.

Among the Anoplura the genus Hoplopleura seems most nearly to retain evidence of the full complement of abdominal segments. Here the paratergal plates, which will be discussed later, are present on eight segments and the eighth of these segments bears the gonopore in the female and also bears a pair of gonopods. The ninth segment is well developed, but the tenth and eleventh are reduced to mere membranous areas around the anus. The first segment is evidently much reduced, but can still be distinguished. Since in this genus all the evidence is harmonious and consistant re need have no hesitation in accepting it. We may therefore take the position of the vulva in the female, which lies between the gonopods of segment eight, as the initial point for all reckonings of segmentation of the abdomen.

In some forms, such as the genus linognathus, the abdomen is membranous almost throughout except for the tergum of segment nine and certain sclerotized areas on the ventral side in association with the renitalia. In others, such as Haematopinus, the derm of the dorsum is slightly sclerotized almost throushout with small plates of denser sclerotization and with sclerotized paraterial areas along the lateral margins. But in the majority of known species, the abdominal seiments, both dorsally and ventrally, bear distinct, semmentally arranged, sclerotized plates in addition to the paratergal sclerotizations. These terisal and sternal plates are usually assuciated cach with a row of setae and the arrangement of the plates and rows of setiac is to some degree distinctive of the various grenera. Thus, in polyplax the lemile bears two plates and two rows of setae on most of the segments both dorsally and ventrally, while in Hoplopleura there are 
normally three plates and three lows of setae on most of the ermant. There are some species in which the plates are entirely lackitr, hut the rows of setac lemain. 'There is a certain measure of' sexual dimorphism in regard to the mubers of the plates and rows of setae in certain of the grenera.

In the majority of known species there is at the lateral margin of each of at least some of the abdominal segments a distinct, sclerotized plate which bear's or is at least closely associated with the spiracle, al thou th these plates may be present on segments on which the spilacles are lacking; In earlier literature these plates were characterized as "pleural plates," but since the spiracles may be regarded as belonring morpholoricaldy to the dorsum the term "paratergal plates" or the term "laterotergites" is proterable. They are here called puratergites.

The number and form ot these plates is of very great importance for the recuinition of both genera and species. In sume genera, such as Boplopleura, Schlzophthirus, and Pterophthirus, they torm an overliuping series aloug each side of the abdomen, with their posterior margins free from the body and at times extraordinarily prolonged.

\section{The External Genitalia of the Female}

As already pointed out, the gonopore of the temale belonirs to the venter of the eighth ahdominal sement. Morphologically, the gonopore and the vulva are not necessarily the same thing, since the bonopore may be retracted into the body with the consequent formation of a genital chamber or vayina into which surrounding elements may be withdrawn, even to the extent of involving the venter of one or more segments. However, in the Anoplura there seem to be no complications involved which disturb the apparently normal seumental arranuements.

The sternal plate of sement eight, lying anteriorly to the transverse fold which forms the vulva, is always or almost always in some degree sclerotized to afford support for muscle origins and this sclerotization at limes involves also the venter of segment seven. These sclerotizations, wich are usually in some degree united if more than one segment is involved, collectively form what is here called the genital plate.

The gonopods, which represent the primitive paired segmental appendages of sement eight, are practically always indicated at least by the presence of a cluster of setae on each side at the end of the vulvar fold. In the majority of species they are definitely represented by a pair of flattened, apically free lobes which at times are of considerable size. The mesal margin of each gonopod is continued into the fold that forms the lip or anterior maryin of the vulva and this lip is at times beset with a fringe of delicate processes or is at other times simple.

Just within the vulva is the varinal chamber. In some species the dorsal wall of this chamber is slirhty sclerotized. Into this dorsal wall opens the duct of the spermatheca, if the spermatheca is present. In some species the spermatheca seems not to be developed, as in Pediculus and Haematopinus. It is very strongly developed in Pthirus and in at least most of the species of Li nosnathus and occasionally in other forms. In some instances where it appears to be lacking this may be occasioned merely by its weak sclerotization or perhaps even by its destruction in the makin of the preparation. It is a structure wich calls for further investi tation.

The spermatheca itsell, at its best development, is a swollen, sclerotized structure at the inner end of the sclerotized spermathecal duct (Fi:ure 12t) and there seems never to be more than one. ¿sually, the openin? of the duct through the will of the varina is surrounded by a small area of dense sclerotization, it the dict is present. 
The venter of serment nine bcars near each lateral margin a tuft of setae, one or nore of which may be enlarged and flattened and is also at times produced at each posterior lateral anile into a distinct lobe. These structures may-and very probably do-represent vestiges of the gronopods of this segment.

The sucking lice are therefore to be characterized as possessing at least vestiges of an ovipositor.

\section{The Exterual Genitalia of the Male Figure 15}

In all insects the gonopore of the male belongs to the venter of segment nine of the abdomen. We cannot here enter into the much disputed problem of the homolories of the parts associated with these grenitalia and their morphological origins. A study of the greneral problem, made by Dr. Joel Gustafson, ${ }^{*}$ has been published and the following conclusions are derived from it.

Fundamentally, the structure of the external genitalia of the males of insects is a simple matter. There is the median gonopore itself. There is a pair of the primitive semmental appendages belonging to segment nine which form claspers, each consisting of a coxite and a one-segmented movable piece which is considered to represent the coxal style; and there is another pair of movable appendages, likewise belonging to the ninth segment, and derived morphologically from the primitive eversible sacs of this segment. These are the parameres. This simple basic set of structures may, however, be modified in fearful and wonderful ways.

First of all the gonopore may be borne at the apex of what we may regard as a papilla which may become so greatly enlarged that it forms a sac, here called the renital sac. This sac, when at rest, is usually retracted into the body. The gonopore may be surrounded by a sclerotization of the walls of the sac and a penis is thus formed. Furthermore, other sclerotizations of the walls of the sac may form as supporting structures for the penis and these structures may become extremely complicated. The entire structure included in all this is the aedeagus.

The pair of structures formed f'rom the primitive segmental appendages of segment nine may form elaborate clasping structures for holding on to the female during copulation, or they may be reduced or even lost.

The other pair of movable structures, the parameres, may become very closely associated with the base of the aedeagus or may even seem to becone a part of the aedearus itself. Or they may be lost. Only rarely do both the claspers and the parameres appear clearly developed in the same insect and consequently doubt has at times been expressed-or in fact the definite opinion has been expressed-that two pairs of movable structures do not actually exist. But the fact that both pairs were a part of the primitive genitalic complex is indisputable and there are insects in which both are retained.

Because of these factors of loss of some parts, coincidentally at times with unusual development of other parts, the homologics of the parts are at times much obscured. But if we clinir closely to principles and identify the Landmarks consistenty, genitalia of even the most complicated appearance can lie shown to consist merely of modifications of these tew basic parts.

Now to apply these ideas to the Anopluria.

The structures appear in a very simple and even somewhat reduced form in the mitle of pediculus (Firure 15) as shown in their expanded position when enigared in cupulation.

* Gustafson, Jorl f. 1050. The orlginand violution of the Gent alia of the Insecta. Nicrosntomology 15:2. 


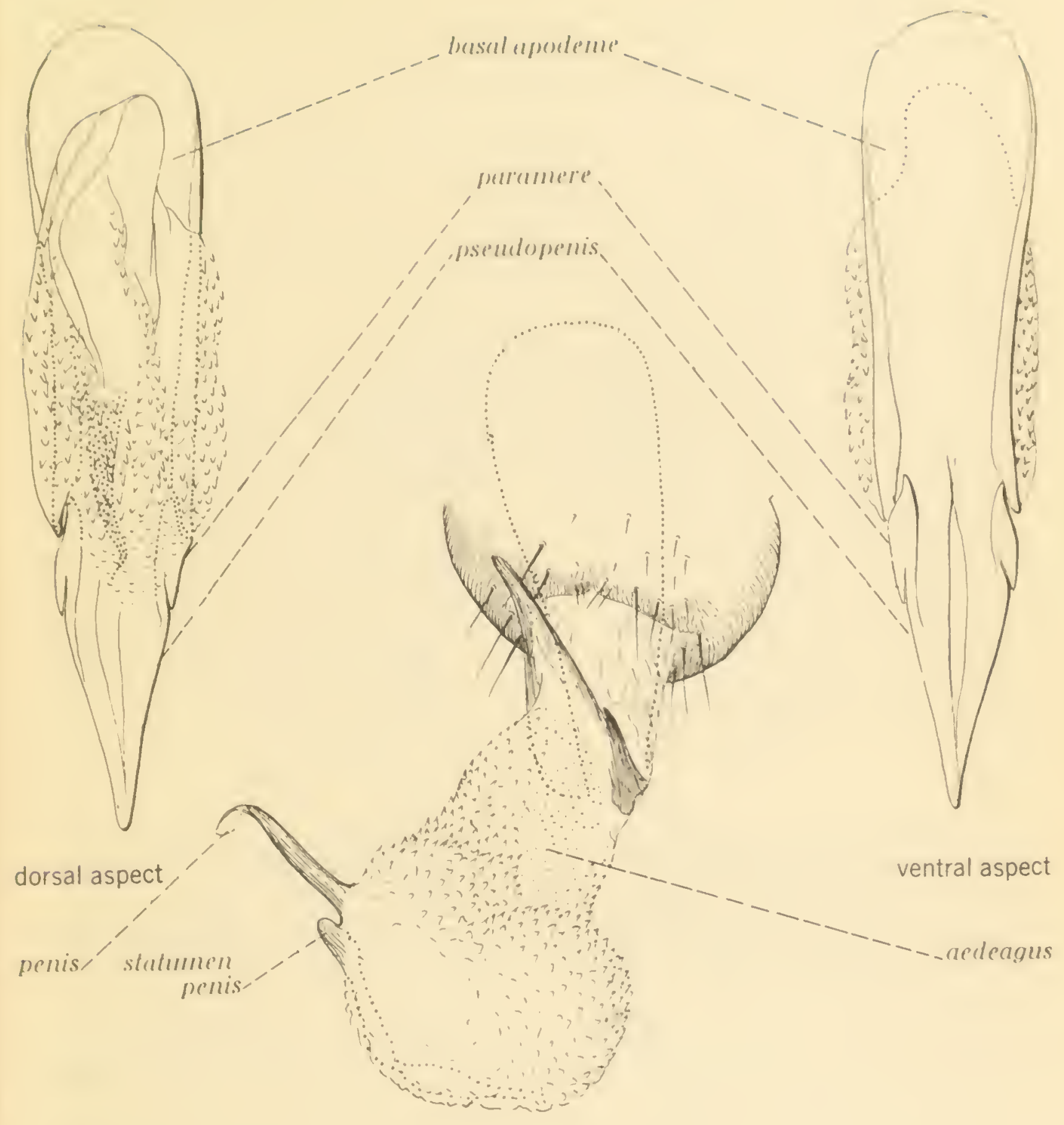

Genitalia of the male of Pediculus humanus

Figure 15 
We have here a very large genital sac. Near the apex of the sac is the gonopore, which is borne upon a sclerotized, tubular process, the penis, formed as a continuation of the walls of the sac. Close to this penis is another sclerotization of the walls of the renital sac, f'or which the term "statumen penis" was employed by Nuttall-and which presumably serves to aid in supporting the penis. Arising from the dorsal wall of the sac, toward its base, is a fold of the wall which is partially sclerotized and forms a quite large, V-shaped structure, the apex of which is free. For this, no better term than "pseudopenis," which in the past has been employed, is available. Partially fused with the base of the pseudopenis there is on each side a short, strongly sclerotized piece which is apically free. These pieces are here interpreted as the parameres, a term that has commonly been employed for similar structures throughout the group and which is in all probability morphologically correct. Articulated to the base of the sac is a lonis, flat, sclerotized apodeme which extends into the body. This piece has commonly been called the basal plate, but the term genital apodeme would be better.

When the genitalia are at rest they are retracted into the body, with no more than the apex of the pseudopenis extruded. The parts are then necessarily folded upon each other in such a manner that it is difficult to determine their exact relationships and in our systematic work, in wich the details of the genitalia of the male are of great importance for the separation of species, we can as a rule do little more than merely to recognize the sclerotized parts as seen in the retracted position.

The changes in the structure of the genitalia are very largely concerned with changes in the details of form of the various sclerotized parts, the parameres, the pseudopenis and the sclerotizations of the genital sac. In some species apparently certain additional structures are tormed from the walls of the sac which are not yet completely understood and remain to be elucidated in the future, but this happens in only a f'ew species. In general, if one will recall the simple basic plan of structure, it will not be difficult to understand the illustrations which will be presented in connection with the species which are to be treated in detail.

\section{The Tracheal System Figure 16}

As has already been pointed out the thorax always bears but a single pair of spiracles, these belonging to the mesothorax. They have at times been ascribed to the prothorax, but this is definitely in error, since no insect, with the very dubious exception of some of the Apterygota, possesses prothoracic spiracles. It has at times been claimed that a pair exists on the metathorax in some of the sucking lice, but this too is definitely in error.

No species of Anoplura possesses more than six pairs of abdominal spiracles, these being on the third to eighth sements. In many species the number is less. In one genus, Neolinognathus, there is but one pair, this being on the eighth segment.

The tracheal system itself is very simple. There is but one tracheal trunk on each side of the body and there are no tracheal sacs. The accompanyin illustration of the tracheal system of Haematopinus suis will suflice (Figure 16).

The spiracles, however, present some points of special interest. While they have in the past been illustrated for a few species, the only comprehensive studies of them are those of Welb.* Webb has studied them to some

* Webb, J. F. 194B, proceedingsof the zoological society of London 116: 49-118; 1447, proceedings of the 200logical Society of London $116: 575-578 ;$ 1948, Proceedings of the 80ological Society of London 118:582-587. 


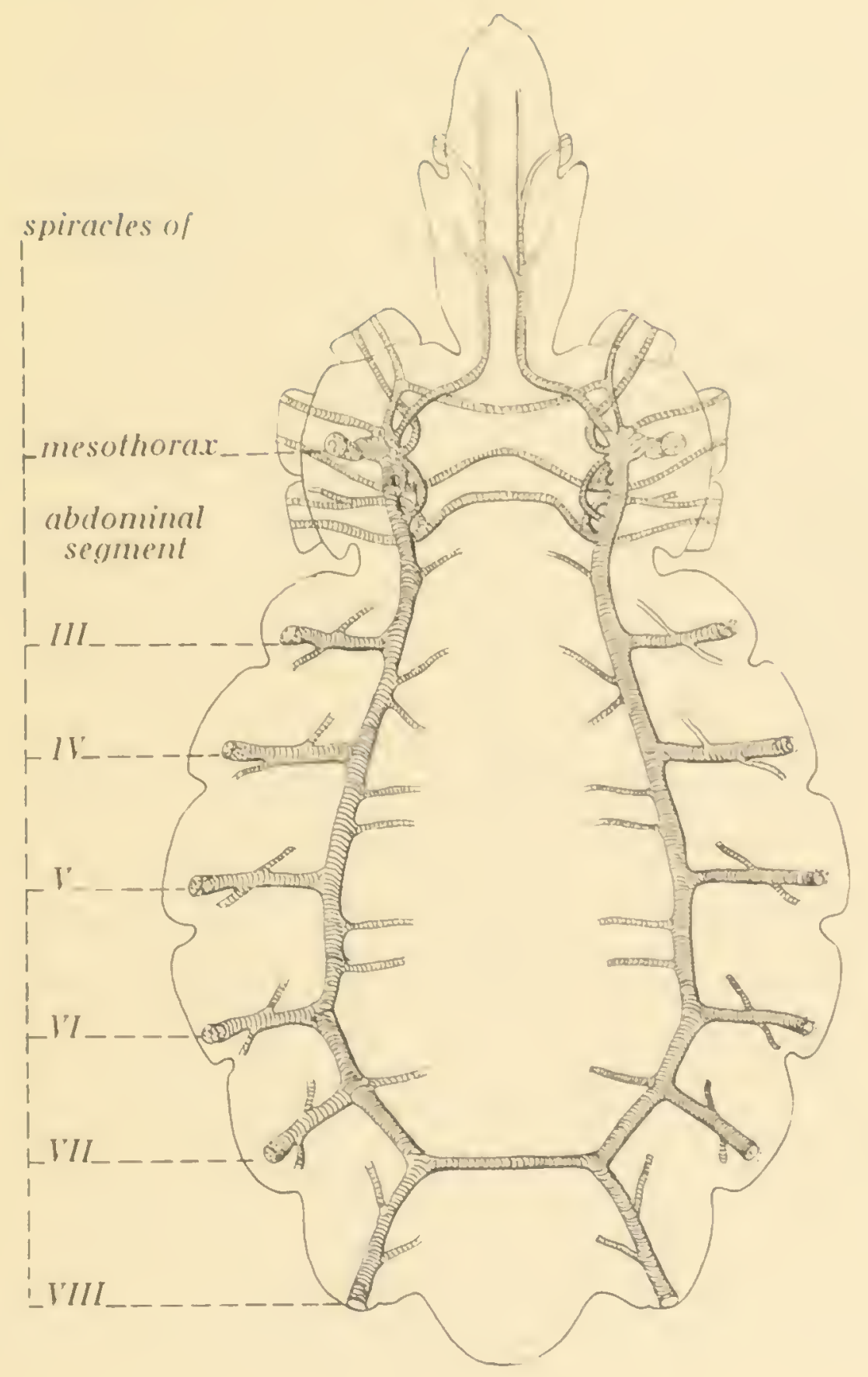

Tracheal system of Haematopinus suis

Figure 16 
extent in histolouical preparations and also has given an extensive account of them as they appear in such preparations as are used for taxonomic purposes.

It is not possible in a general work such as this to go into this subject in all its details, but since hebb has proposed a partial classification of the Anoplura on the basis of the spiracles they must be considered at some length.

It may be noted at the berinning that the thoracic spiracles usually differ somewhat from those of the abdomen, usually being definitely larger - as is common in almost all insects-and also slightly different in details, although of essentially similar character. They are ordinarily somewhat difficult to study because of the presence of other structures that somewhat obscure them and we shall here concentrate attention upon the abdominal spiracles.

In its simplest form an Anopluran spiracle consists of the following parts. There is an oval or circular opening which leads into a somewhat expanded chamber called the atrium. This chamber possesses quite strongly sclerotized walls and may be subglobular or more or less elongated. On its inner end it is constricted, usually very suddenly, and then continues into a tapering second chamber which finally becomes much attenuated. At the point of greatest attenuation there is usually attached to its wall a minute, sclerotized rod which is the apodeme of the occlusor muscle. At this point the trachea berins with its usual ctenidial threads.

The occlusor muscle originates upon the body wall and by contracting seems to bring about a pinching of the attenuated inner end of the atrium, thus closing the spiracle. In some forms the apodeme of the occlusor muscle seems to be lacking and the muscle inserts directly upon the wall of the atrium.

Hebb has described a gland which accompanies the atrium and discharges a waxy material that coats the inner walls of the chamber. This gland, however, will not appear in ordinary taxonomic preparations. Hebb has indicated that in some cases what he considers to be the duct of this gland has taken over the duty of formiu the narrowed air passage into the trachea, while a portion of the attenuated atrium has been left as a side chamber that ends blindly. This side chamber is at its greatest development quite small. On the basis of Webb's own illustrations and upon greneral morpholorical grounds, it is here maintained that Webb has misunderstood the situation. The present writer does not belicve that any such change as that indicated has occurred. It seems much more probable that the atrium at times is produced on one side somewhat past the internal opening into the spiracle and thus forms a slight diverticulum.

The walls of the atrium may be beset with little points or ledires which project into the chamber on the inner side, as Hebb has clearly shown in histolorical sections. These ledges vary greatly in their size and extent and in the degree and manner in which they may anastomose with each other. Viewing a spira le from the side they are indicated as dark lines which sometimes form rings ahout the chanber or form a network. At times they correspond with deep furrows on the wall of the chamber that may result in constrictions, which divide the atrium in rinu-like sections as shown in figure 17 .

The simplest spiracle which appears in the extensive material at hand is that ol'sctpin aulacodi (figure 17). Here we have an a lmost spherical atrium, with appiarently mo internal ledges. It constricts very abruptly into the slender protongation that Irats to the opening of the trachea. A very similar arranpement is seen in Haematopinoides squamosus (Figure 17). In fullnosnuthus aculeatus (Figure 17) the appearance is the same except that the second chamber is somewhat swollen and has thickened walls. The next step scems to lo represented in Haemoripsus ventricosus and Neohaematopinus 


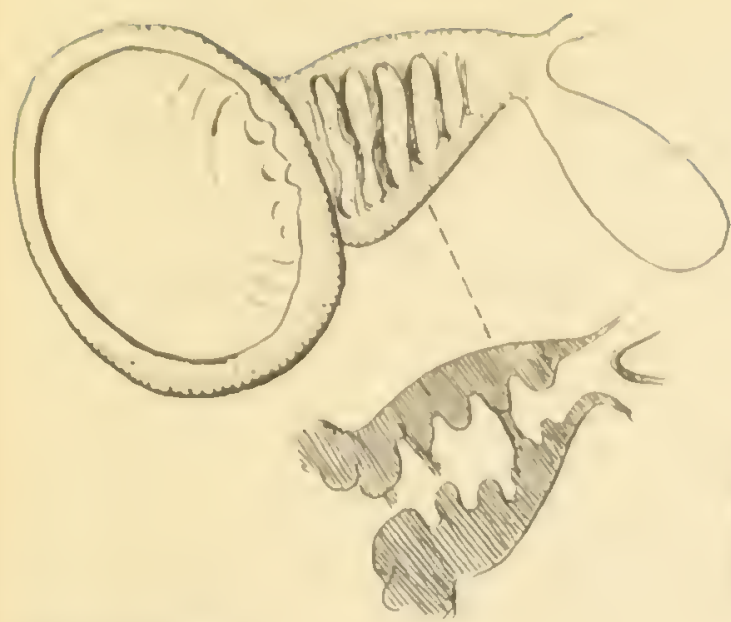

Adroctenes

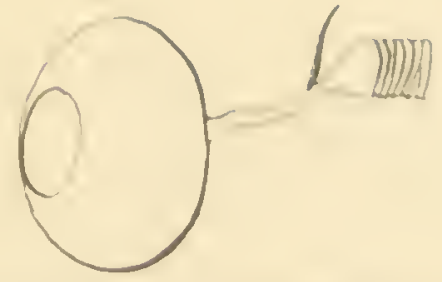

Haematopinoides squamosus

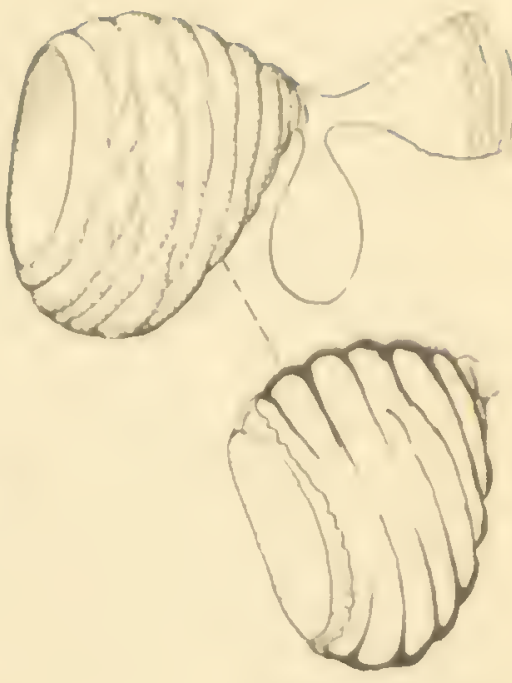

Hesperoctenes

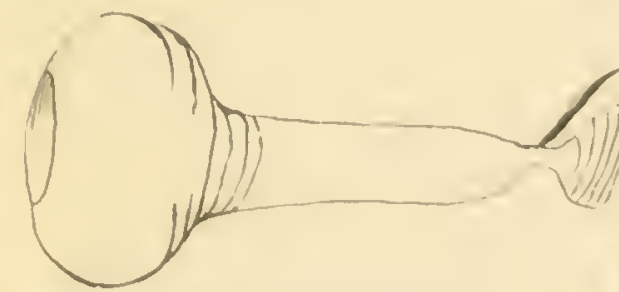

Haemodipsus ventricosus
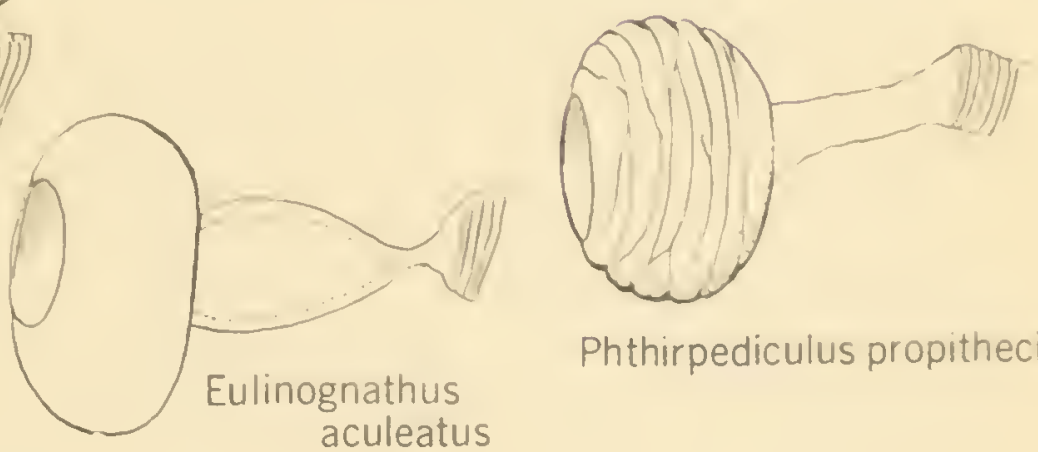

Phthirpediculus propitheci

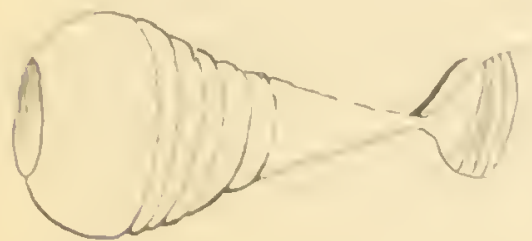

Neohaematopinus sciuropteri

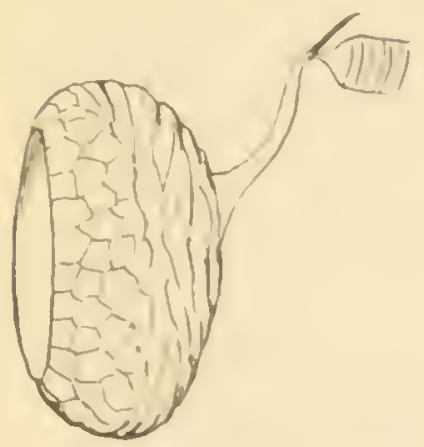

Neolinognathus praelautus

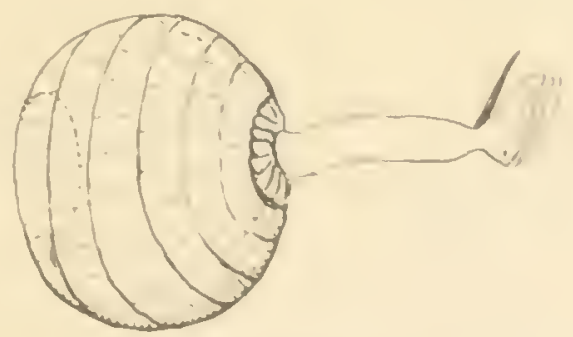

Polyplax spinulosa

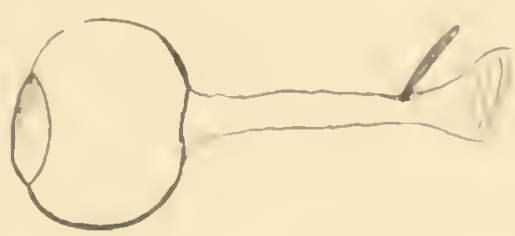

Scipio aulacodi

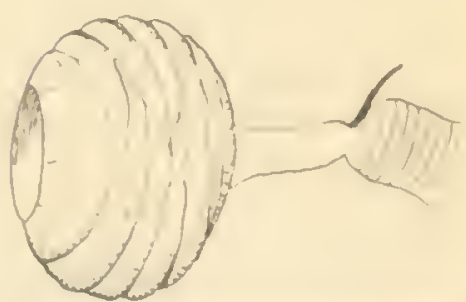

Hoplopleura acanthopus

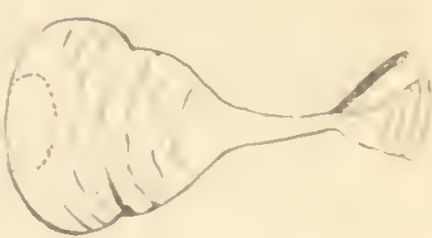

Ctenophthirus cercomydis

Figure 17 
sciuropteri (Figure 17) where the transition from the atrium to the second chamber is more gradual and shows annular constrictions which appear as slight ledges inside the chamber. In Phthirpediculus propitheci (Figure 17) and Hoplopleura acanthopus (Figure 17) the walls of the atrial chamber present a number of slight furrows marking the position of internal ledges which anastomose to some degree. In Enderleinellus longiceps (Figure 18) the chamber presents deep, annular constrictions which are widely spaced. In some species, such as Neol inognathus praelautus (Figure 17) and Enderleinellus malaysianus (Finure 18) the lines marking the internal ledges become more or less anastomosed, forming a network which marks out cell-like areas on the surface.

In Microthoracius mazzai (Figure 18) the lines mark out very distinct cells, but here we have a quite distinctive feature in the fact that at the points of intersection of the internal ledges the ledges form pointed processes projecting into the atrial chamber.

Very beautiful examples of a network and enclosed cell-like areas is furnished by Linognathus setosus (Figure 18) and Linognathus stenopsis (Figure 18). In these species, what seems to represent the diverticulum formed by the spiracular gland appears as a slight swelling at one side of the base of the second chamber. In solenpotes capillatus (Figure 18) the atrium is elongated and almost cylindrical, with the lines which mark the courses of the internal ledges forming a quite distinctive angular pattern, but in other species of this : renus the atrium is more nearly spherical although the pattern of the lines is similar. In this genus also there is a tendency for the spiracle to be borne in a slightly elevated, more or less sclerotic tubercle, but this is at times much reduced or but little evident.

In Hybophthirus notophallus (Figure 18) the atrial chamber is short and almost cylindrical, with its walls marked by very short and non-anastomosin' lines indicating the presence of short and interrupted internal lediges. The second chamber is but little narrower in diameter than the atrium.

In Pediculus humanus (Firure 18) the atrium is more or less conical with the openin at the apex and is marked by lonitudinal lines. Inside it is beset with slender points. A quite similar arrangement appears in Pthirus.

In Haematopinus suis (Figure 18), as in other species of this genus, the atrium is elongated, apparently includinir the second chamber of the area usually occupied by the second chamber, and is marked throughout by little, circular areas which correspond with multitudinous points which line its inner wall.

The most distinctive spiracles in the 0rder are those of the lice of marine carnivores. These are here illustrated (Figure 18) as they occur in Antarctophthirus callorhini, a species in which the membranous derm permits them to be clearly seen. Here the spiracle opens through a short, membranous papilla. Slightly in from the apex of the papilla is a peculiar, sclerotized collar which marks the beginning of a short, simple, sclerotized tube that constitutes the atrium. The spiracle then expands into the second chamber, which may be membranous or partially sclerotized and forms a sort of lulb. To the wall of this bulb attaches the large apodeme of the occlusor muscle and then the trachea begins. This type of spiracle is very distinctive of the little group of species considered to form the family Echinophthiriidae.

The simificance of these structures in the intra-ordinal classification of the Anoplura will be considered in the chapter on classification. As having a possible bearin: upon the question of their value for such purposes, there are here presented illustritions (Firure 17) of the spiracles in two genert of the llemipterous limily Polyctenidae, which are ectoparasites occurring on lats. It may he noted that in their general features they quite closely resemble the spiracles of some of the Anoplura. They display the sume characteristics of all atrium and a second chamber, with 

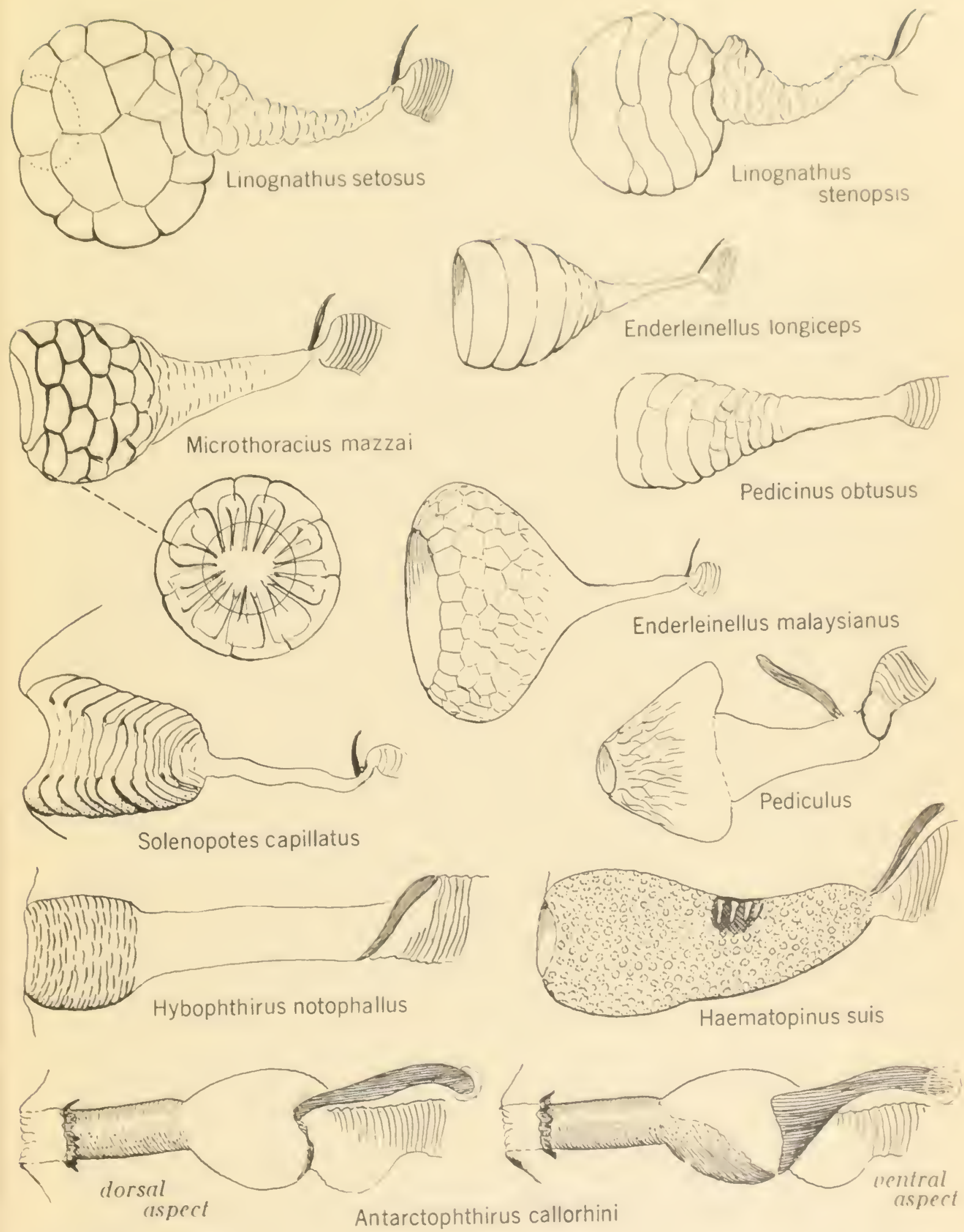

Spiracles of Anoplura

Figure 18 
the walls of the atrium beset internally with ledges. The principal difterence lies in the presence of a very well-developed diverticulum which may possibly represent the atrial gland described by Hebb for the Anoplura.

We may here call special attention to the spiracles of Enderleinellus malaysianus (Firure 18) and Enderleinellus longiceps (Figure 18). It may very well be that at some time in the future these two species will be referred to different genera, but with the utmost degree of splitting they will stand as still belonging to closely related venera. Yet the pattern of these spiracles does not sugrest any close relationship.

\section{Internal Anatomy}

There still remain numerous details of the internal anatomy of the Anoplura which have not been well investisated and which cannot here be considered. This chapter is therefore somewhat incomplete. It will be concerned only with the major features, especially as they may have a bearing upon the understandin; of external morpholony and thus aid in the problem of taxonomy.

\section{The Head}

It was necessary to consider certain aspects of the internal anatomy of the head while we were attempting to explain the homologies and functioning of the mouthparts. What remains to be reviewed consists chiefly of the nervous system.

We have briefly mentioned the musculature of the antennae. In insects which are provided with a tentorium the muscles of the antennae originate upon it. But since there is no tentorium in the Anoplura the muscles ori inate upon the head wall. There is some variation in the position of their oririns, in Haematopinus all being upon the dorsal wall, while in some other species a portion of the origins are upon the ventral side.

This is a matter ol some general interest, since the claim has been made by one morpholorist that the origins of muscles do not shift. There can be no possible question of the fact that they do so in these insects.

Pawlowsky's slands, as previously noted, are a pair of rather large, apparently glandular structures, opening separately through the dorsal wall of the trophic sac (Firure 11). They are innervated by a branch from the hypopharyngeal nerve and thus may definitely be regarded as belonging to the hypopharyix and consequently to the clypeal senment. A reneral study of the occurrence of crlands in this region in other insects will be required before their homologies can be determined.

We may here call attention once more to the peculiar mass of connective tissue which occurs in the posterior portion of the head and which we have called the obturaculum. It extends into the thorax, where it envelopes the thoracic sanglia of the nervous system. It serves as the point of oririn of various muscles and in this respect, if in no other, presents a quite unique development. Afain, no conclusions concerninir this mass of tissue can be drawn until a greneral. study of connective tissue in this rerion of the body of other insects has been made. The present knowledire of the occurrence of connective tissue in the bodies of insects is exceedingly sli rht.

The salivary gadis have alreidy been noted and described in connection with the morpholos ot the hear and monthpirts.

The muscles lound in the head liave heen considered to some extent in connection with the description of the monthparts. he shall not here describe them in detail, musele by muscte, relying rither upon the illustrations which have alrewly hen plesented, hut we shall reler to them argain in connection with the nervons system. 
It has al rewly been pointed out thist the true nutum of all of the thor acie se ments is math reduced. Apart leom the sun tia of the nervous sys cem, which will he tomsidred later, the thorax is occupied mostly by the musches connected with the lers. We shall here content ourselve with th arneral description of the disposition of these musches whith will did to some deree in muterstinding the external structures.

In figme $19 \mathrm{~A}$ the muscles are showil as they appeid nheu the dorsal derm hisi heen removed. Ln fig gure $19 \mathrm{~B}$ are shown the muscles which are leverialed ly the removil of the tir'st Layer of dor'sul muscles.

lote in Figre $14 \AA$ the prothoracic pleural ridre or phraras. Uyou this phriprat there originate on each side of the lody alitule cluster ot muscles which insert mpon the anterior margin of the sternal plate, these hein, properly desi priated as the dorsoventral prothorwac muscles. Just anteror to the phrimima little cluster ot muscles ori ginates and these muscles pass torward to insert mpon the posterior border ot the head wear i 2 lateral marin. From each of the two apophyses at the posterior border of the head nirrow muscle bands extend posteriorly to the median notal apophysisor pit.

The muscles of all the legs converge to points of origin upon the trinsverse, sclerotized band which includes the notal pit or upophysis. This biand is apparenty formed by a continuation and tiusion of the pleural ridges ol phramiati of hoth the mesothorax and metathorax.

There are three muscles inserting upon each coxa. Since the muscles of the coxac in other insects-there usually being lour of them-have lieen nincd according to their functions us promotor, remotor, levator, and depressor muscles and since these various functions seem here to be carried ont by but three muscles, it becomes a very dubious procedure to assign specit'ic names to them and no attempt will he made to do so. Thes are perhaps best called simply anterior, posterior, and dorsal muscles. The dorsal muscle ot the anterior coxae sends a small branch to the corresponding pleurosternal apophysis.

From the nutal pit bands of muscles radiate posteriorly to attach at the posterior border of the thorax (which may involve an element belonging properly to the abdomen) and presumably function to move the thorax in relation to the abdomen.

Ventrally there are very few muscles (Figure 19B). Attention may be called to a sin;le suall muscle strand extending from each coxa to the marin of the sternal plate: to a snall strand which passes across between the prothoracic plcurosternil apophyses; to another quite larre strand which extends across between the posterior coxae.

The musculature within the leigs themselves shows no especially interesting leatures and will not be discussed here.

\section{The Abdomen}

The se:mentation of the abdomen has already been discussed.

Apurt trom the muscles connected with the genital or ans the principal muscles of the abdomen are found in the relatively huge dorsoventral bundles urranged in a row on each side of the alimentary canal and extendin: from the tergite to the sternite of each sement. It may very well lie that upon these miscles depends to a large depree the compression of the abdomen which sets up internal pressures in the hody fluids by which various movements-such as perhaps the extrision of the trophic stylets-are ai least in part accomplished.

The muscles of the reproductive structures will le considered in connection with the account of these structures. 


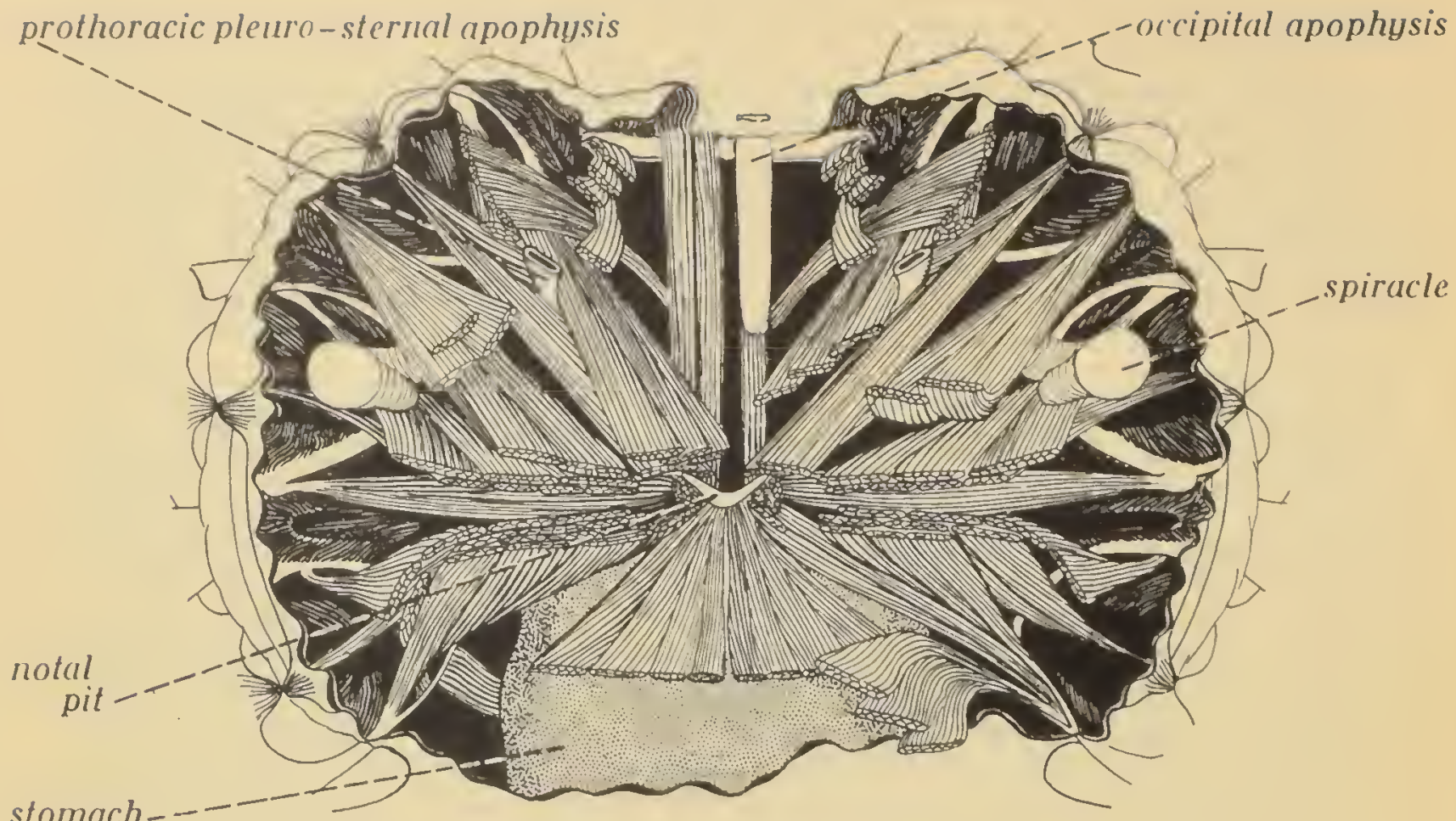

A. thoracic musculature, dorsal muscles in place

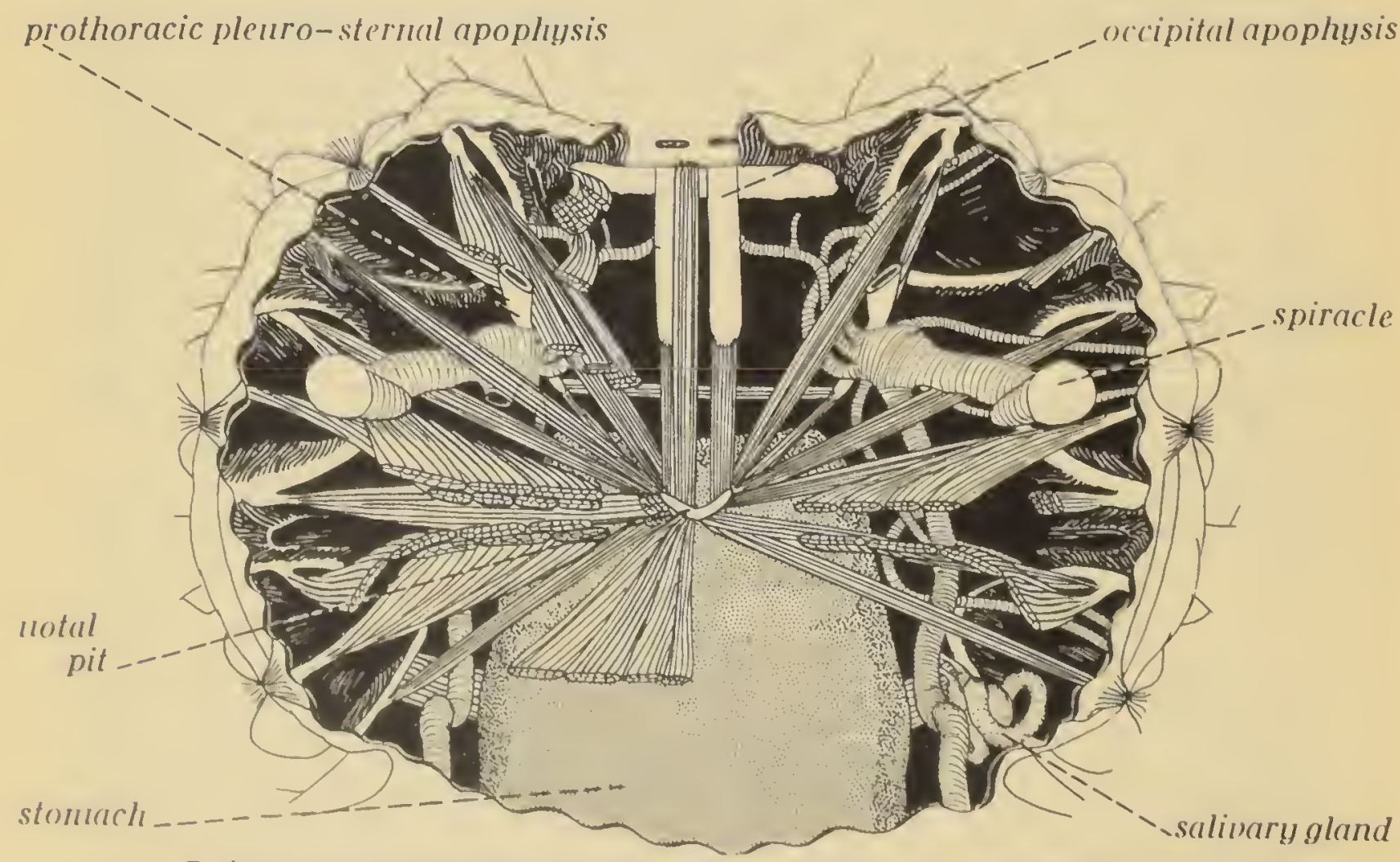

B. thoracic musculature, dorsal muscles removed, and tracheal system

Musculature of thorax of Haematopinus sıis

Figure 19 


\section{'The Al imentury Cural \\ fir ures 20,22}

'lihe very slenter orsopharus passes throurh the obturaculum ard then $6 x$ pands ubruptly into the relatively huge mid-gut. heilin and Autrall' indicate the presence of caeca at the interior end of the mid-gut, but these do nut appear in Hamatoplnus suis. This Large intestine then passes directJy thiourh the hody without any convolutions until it becomes the sandl intestine. The small intestine is somewhat convoluted and variously snollen, these swellinirs perhaps depending upon the contents. It passes 1 initll into a swollen, bulbous structure, the rectal sac, then narrows a rain to the anus. Upon the rectal sac are tour or more pad-lihe or plate-litie structures which are the rectal "rlands" or rectal pads us lound in uther insects.

\section{The Oryans of Excretion}

There appear to be but tour Malpi phian tubules in Hacmatoplnus suls and four are recorded by Keilin and Nuttall" lor Pediculus humanus. These discharge into the ulimentary canal near the anterior end of the small intestine. keilin and Nuttall have indicated that excretory products in tis be stored in certain "nephrocytes" or" cells of the tat body, bnt this is questioned by Hi:slesworth.

\section{The Heart \\ Figure 2u}

The dorsal vessel is of a peculiar form in the suckin lice. It consists mostly ot the very lon; and slender aortis which continues posteriorly almost to the end of the abdomen and then torms a bulbous swelling, from which muscles extend apparently to the body wall.

\section{The Reproductive Organs of the Female Figure 21}

Each ovary consists in Haematopinus suis of five ovarioles and the same number is recorded by hilin and Nuttall for periculus humanus. Apparently at any moment only one of these tubules will contain an err ready for deposition. The ovarioles are distributed alon an oviduct which leads to the uterus from each ovary. Openinis into each oviduct there are in Baematopinus suis apparently three quite larre accessory tands.

The common oviduct or uterus is a very large structure with apparently muscular walls. The duct from each ovary opens into the uterus far back toward the posterior end of the latter.

At $i$ ts posterior end the uterus opens into the varina and from the vagina various small muscles pass to the body wall.

The spermatheca has already been described. It apparently does not occur in all species of the Anoplura and the details of its histolopical structure remain sill to be studied.

\section{The Spermatheca}

A sinile spermitheca is present in the female of so many species of Anoplura that it seems justifiable to regard this structure as a part of the basic structure of the proup, although in some species it seems to have been lost. Thus, it appears to be laching in Pediculus, Haematoninus, and some other ienera.

* Kel11n. D., and G. H. F. Suttall. 1930. Parasitology 22: plate XI. 


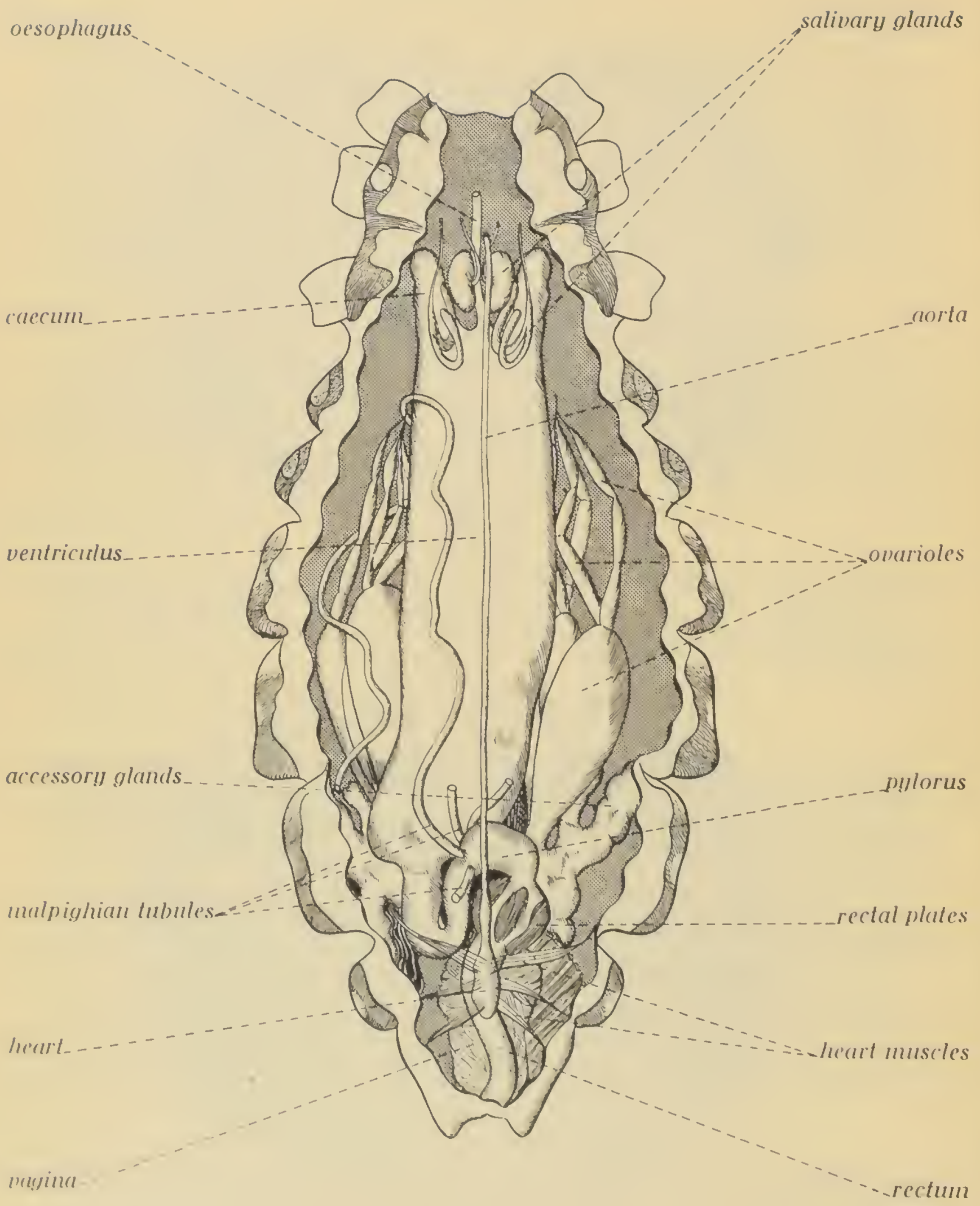

Internal abdominal structures of female of Pediculus humanus

Figure 20 


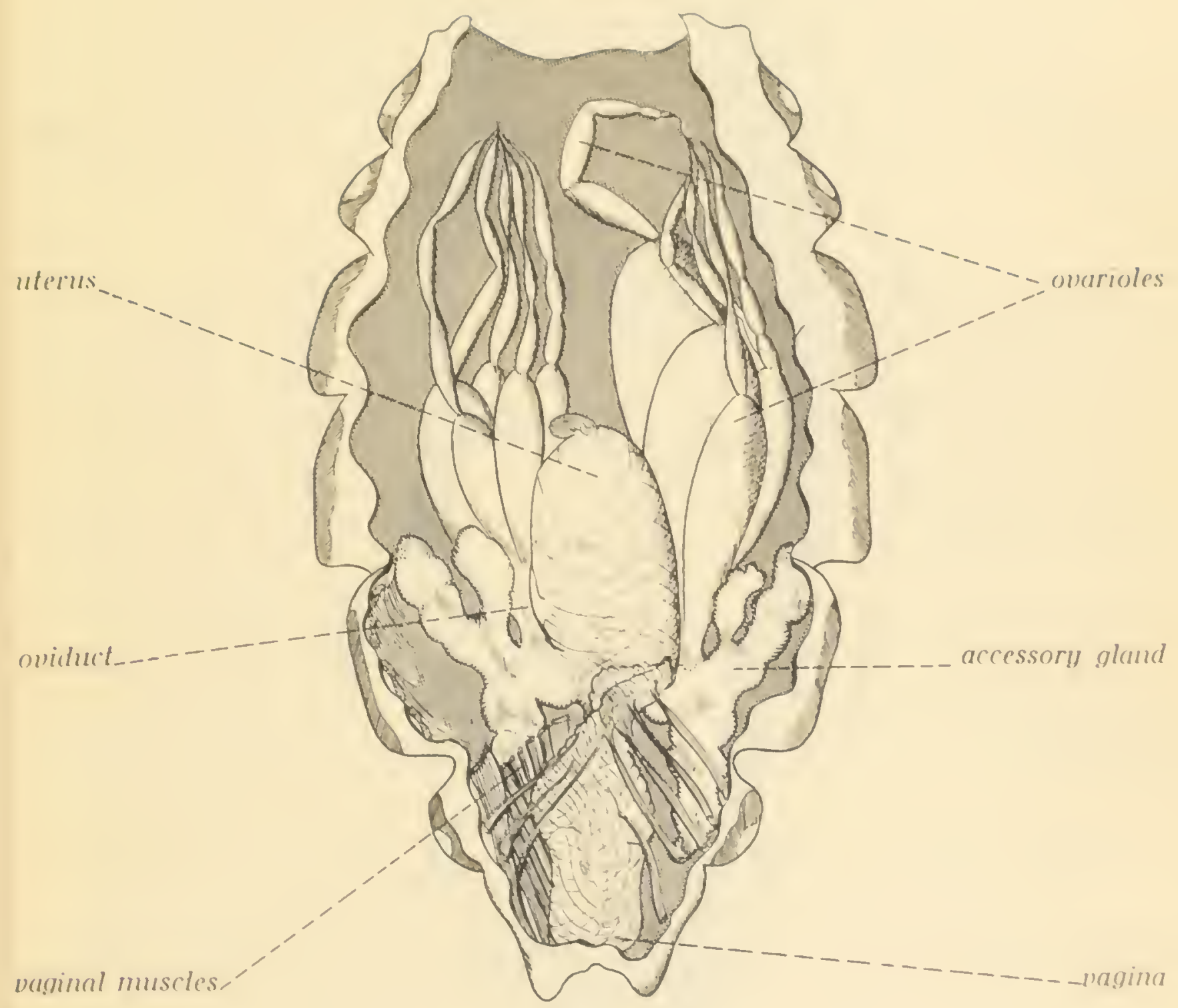

Reproductive organs of female of Pediculus humanus

Figure 21 


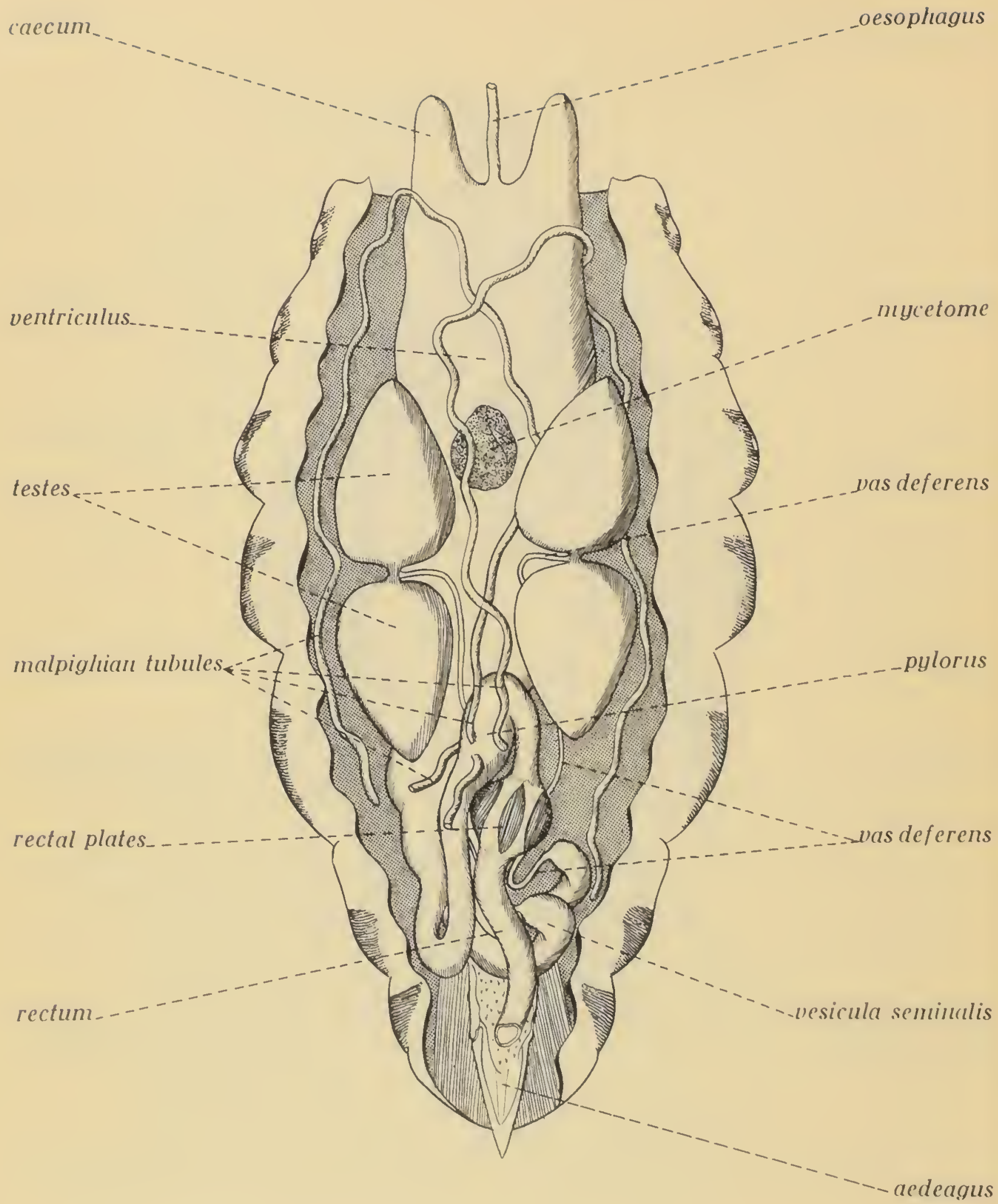

Internal abdominal structures of the male of Pediculus humanus

Figure 22 
In apperalince it consists of a delicute, weats selerotized tube moleh extends 1 rom the dorsal wall of the varing tor a short distance and termal utes in u membrimous or more or less selerorized bulb. The opentin anto the varima is commonly surrounded by a crescentic or circular ring ot strong sclerotiantion and this ring is at times almost the sole evidence of the plesence ot the spermatheca.

The lulh is comnonly extremely delicate and subject to distortion in preparations and even to loss. Becuuse of these circunstunces it is renerally of somewhat dubious taxonomic valire. In one group, hovever, that of certain species of the genus Enderleinellus, il is extremely helptul, its valiations presenting the only apparent means of separating the t'entes of certain of the species. It merits an extended study, throughout the Anopluia, which is scarcely practicable in a work of the present type.

for an example ot a well-developed spel'mitheca the reader is l'eferred to the illustration of the genitalia of the female of Pthirus pubis (Fin re 1't).

The Reproductive Orians of the Misle Fi gures 22, 23

The number of testes can be interpreted either as four with the members of each pair comected torether by a short and slender ube, from which the vas deferens issues, or as two, each ot which is much constricted to form a dumbell-shaped structure, with the vas deterens issuin: from the constipted portion. Each vas deferens proceeds for some distance as a slender tube and then expands to f'orm a thick tube which has been considered by various anthors to represent the vesicula seminalis. The two vesiculae lie close together, appressed aruinst the ventral side of the alimentary canal, and are twice convoluted, the convolutions extendin: forward almost to the anterior border of the abdomen. Posteriorly, the vesicles unite into a common tube which forms the ejaculatory duct.

The ejaculatory duct terminates at the apex of the sclerotized penis, so that when the genitalia are extruded as in copulation it must traverse the length of the aedeagus.

The musculature of the genitalic parts has been studied in connection with this work only in Baematopinus suis (Figure IA) and here only sulticiently to grive a general idea of the mode of operation. It is probable that other species will show some departure from the arrangements here illustrated.

A relatively massive muscle inserts upon the base of the basal apodeme ventrally and originates upon the terminal sternite of the abdomen. Apparently this muscle, probably with the aid of blood pressure, serves to extrude the genitalia. From the dorsal side of the basal apodeme arises a mass of muscle bundles which curve toward the mid-line where those from the two halves unite and finally insert upon the base of the senital sac. These are undoubtedly concerned with the retraction of the sac. From each side of the sac a series of muscle bundles extends to the ventral hody wall, where the bundles originate upon the senital plate. These apparently also serve as retractors. Another small muscle inserts on each side near the apex of the sclerotization of the genital sac and inserts on the terminal sternite of the aldomen close to the apex of the lody. The function of this is not entirely clear, but it is evidently concerned with the retraction of the complex.

The lervous Sirstem Figure 24

For an understanding of the elements of the nerrous system as related to 


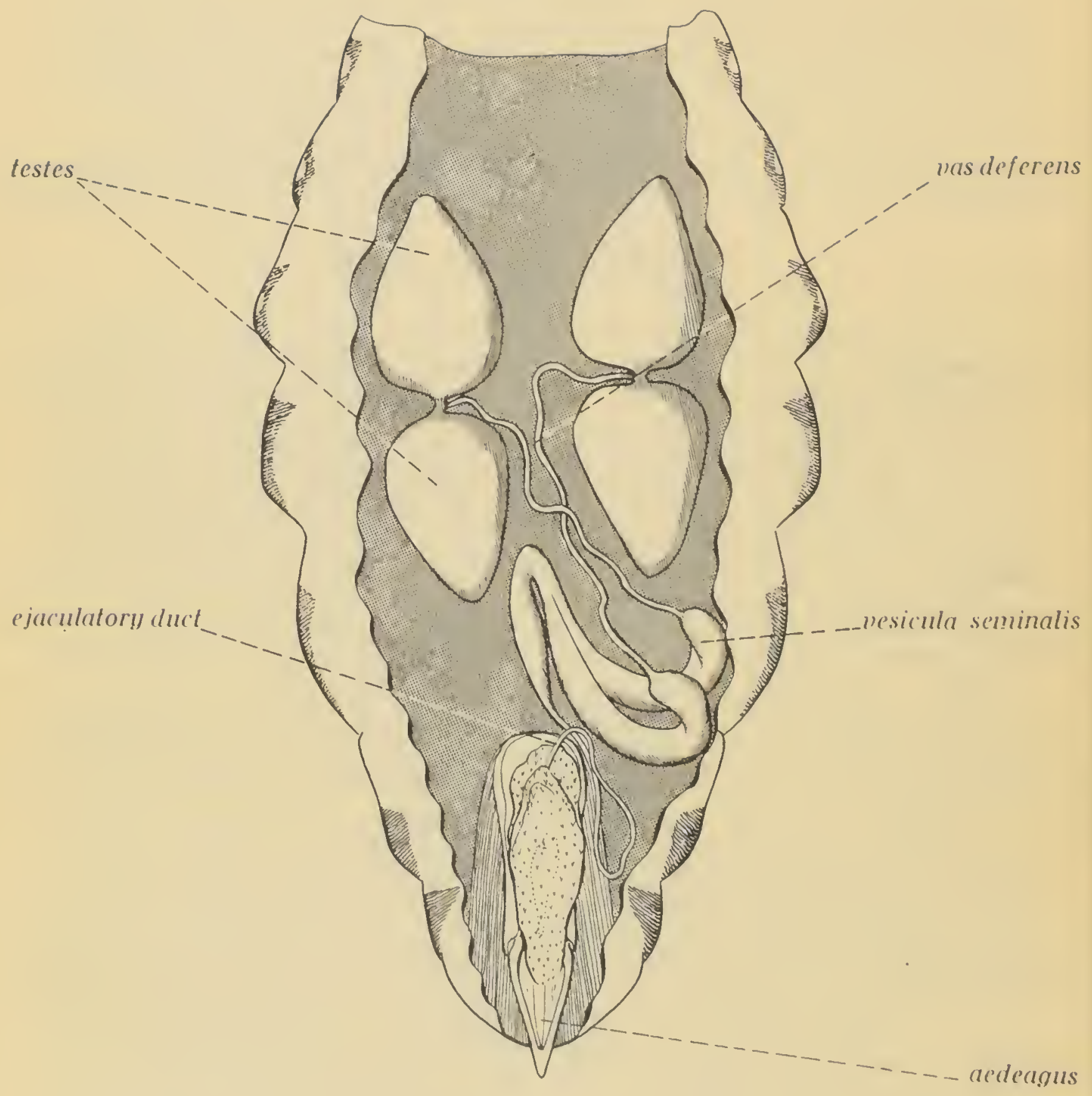

Structure of male reproductive organs of Pediculus humanus Figure 23 
merve lo lalural

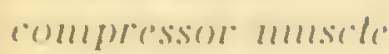

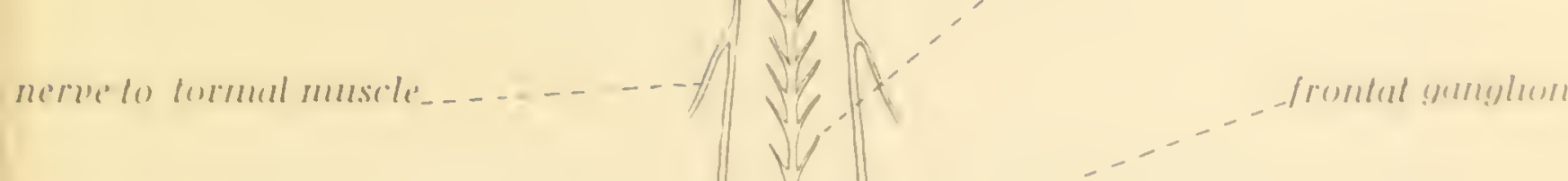

nerle lo monill anugle

retruclor milsisele

merless to minnor

mandil)ular muls(lecte-

supreatsophlangent

(y)mylion

nerless to major

mandibular muscles

amuleterminued struclute $X$

sulnoesophangem (y)!n!ylionn

sulinury nervenerve to folded micl.xillar!y relraclor mussele, nerve to tramsunersen labial mulsele

prolhoracie nervest (

Nervous system of Haematopinus suis

Figure 24 
the sementation of the head the reader is referred to a series of papers by Laura M. Henry* in which the significance of the innervations is discussed in detail. The conclusions there presented are here adopted without reservation and have been employed as the basis for an understanding of the head and mouthparts of these lice.

Some description of the arrangement of the nervous elements in the head has already been iven in connection with the consideration of the mouthparts, but we may review this again in connection with the nervous system as a whole.

From the supraoesophageal ganglion there originate three pairs of nerves. of these, one pair innervates the eyes and one the antennae. Those of the third pair are the nerves of the labrum and the stomodaeum and innervate all inuscles which insert upon these parts. All muscles which they innervate are therefore to be identified as inserting upon structures that belon: morphologically to the labral segment, which is segment one of the body. These nerves pass f'orward and branch. A mesal branch trom each leads to the frontal ganglion and close to the point of origin of this branch is a lateral branch which passes to the muscle which we identify. as the mouthan rle retractor. The main nerves continue forward and give off laterally a branch which innervates what we consider to be the tormal muscle, a muscle that inserts upon the posterior-lateral ansle of the palatal plate. Continuing, the main nerves innervate the muscle that we consider to be the compressor of the labrum.

From the frontal ganglion a single median nerve extends posteriorly, this bein the recurrent nerve which cares for the innervations of the anterior portion of the alimentary canal, that is to say of all those portions derived from the stomodaeum. We have not followed it in complete detail, but Florence** has indicated that it forms a small ganglion which may be identified as the occipital ganglion, and then branches.

The circumoesophageal connectives are very short and the opening enclosed by them for the passage of the oesophagus and other structures is extremely small.

Arising from the suboesophayeal ganglion, somewhat toward the meson, is a pair of nerves which through branches supplies the two pairs of muscles that we identify as belonging to the mandibles.

Next comes a pair of nerves which arise from near the side of the suboesophaseal ganglion and which, through branches, innervate all the structures that we identify as belonging to the hypopharynx, these including Pawlowsky's gland and certain muscles. From each of these main nerves, near its base, there arises a short stalk that terminates in a little, knob-like structure, indicated in Figure 25 as $\mathrm{X}$. We have no evidence as to what this structure is.

There follows a pair of nerves which we consider to be formed by a fusion of the maxillary and labial nerve trunks and which innervate the muscles assigned to the maxilla and labium. The last pair innervate the salivary glands and are connected by a sinall cross-nerve to the labial-maxillary trunk.

Following the suboesophageal ganglion the ventral nerve cord is very slender for a short distance and then expands into the huge mass of fused fanglia in the thorax. This ganglion mass is very evidently composed of the three thoracic ganglia and includes also all the abdominal ganglia. From its posterior-lateral angles there arise on each side four nerves which supply the structures of the atdomen. We have not traced these nerves beyond the point of determining that the last nerve of the series, which is

\footnotetext{
- Henry, Laura M. 1947, Nicroentorobogy 12:3:65-82; r1gs. 23-29; 1947, Nicroentomology 12:4: 43-116; rigs. 30-45; 1848, Nicroentorology 13: 1: 1-26; rigs. 1-9; 1949 , Nicroentomology 13: $2: 27-18 ;$ rigs. $10-16$.

* Florence, Laura. 1921. Corneli oniversity Agriculturab Bxperiant station, Ithaca, Jew York, Nenoir 51, pages 612-ri3.
} 
the largest, cares for all the reproductive system. There is revidemels is considerable derree of tusien of the nerves to the various a emente and this remitins still to les worked out.

the haver met traced the innervation ot the heart. It is therefore evi dent that there is more work still to be done bratore all the detalls of the IItrvous syste'll are linally established.

\section{The Mycelome \\ h'i fule 22}

The structure called the mycetome has keen noted by several authors in valious species of Anopluna and knowled ge concentning it has berall sumed up by Steinhaus in his bouk "Insect Microbiolog" (19.6). The entipe subject of the mycetome is a rather complicated one and will not he reviened here. It will sultice for our purposes to nute it as a visible disk ut cells lying on the mid-int in the larvate and in the adult male. In the adult lemale the enclosed symbionts leave the rerion of the stumach and mi rate into the ovaries. The mycetome has been observed in Pellculus humanus, pthirus pubis, a species ol pedicinus, Haemalopimus suis, eurysternus, and asini, Linognathus vituli and setosus, and in Polyplax spinulosa. The position of the mycetome appear's renerally to be essentially as is indicated for the male of' Peticulus humanus in Figure "2.). 


\title{
CHAPTER III
}

\section{Growth and Development}

\author{
The Eso \\ Figures 25,26
}

As far as is known the sucking lice, with one single exception, always attach their eggs to the hairs of the host. This single exception is a louse of man which will attach eggs to the clothing. Even here the method is essentially the same as in other forms, the eggs being attached to projecting fibers whenever possible. The attachment is by means of a drop of cement which surrounds a single hair, or in some instances several hairs, and encloses one end of the egg itself. Florence (1921) has indicated that the cement originates in the collaterial or accessory glands illustrated in Figure 21.

The free end of the egg is always provided with an operculum that breaks away to permit the exit of the larva and, as far as observations go, the egg is always oriented with this end away from the base of the hair upon which the eigs is attached. The egrs are always arranged singly along the hair, although at times they may be placed in a very closely spaced series.

The total amount of information concerning the egis of the Anoplura is relatively sinall. The egis of a number of species have been illustrated from time to time but these illustrations are usually but little detailed and the structures of the eg: shell have only rarely been studied in detail. Such information as there is has been derived nostly from the egg of Pediculus humanus.

In many forms, such as Pediculus humanus, the operculum is beset with small, knob-like tubercles, each of which carries a minute external opening. This pore commnicates with a somewhat expanded chamber, which in turn communicates with the interior of the egr by a pore. However, this arrangement is by no means present, at least in such form, in the egigs of all species.

Unfortunately, the total amount of material available in connection with the present work has been quite small and the eigs of only a few species can be illustrated. These are sufficient, however, to show that there is considerable variation in details and to suggest that an extended study would be worth while and might throw some lirht on the prohlems of gerieral cliassification. It may be remarked that egis call be obtained with no diff'iculty from the skins of mammals in museum collections, even if remains of' the lice themselves are not present. However, this presents difficulties, since as many as three species of lice may occur upon a single host and consequently doubt will arise in many instances as to the ascription of the egr:s to the proper species. Also, there is the difficulty that a large percentage of the ergs will have hatched and consequently the operculum will be lackinis. In such examples the most distinctive characters of the egiss will have heen lost.

On the basis of the material that is aviliable the following notes are oftered. In figure $25 \mathrm{C}$ is shown the egis of Pediculus humanus corporis as altached by in irregular drop of cement to acluster of f'ibers of the clothinf of the host. The operculnm is shown as detached and flattened. It will he noted that the re are 15-20 of the little air cells or cellulae, these being alrumged in an eccentrically placed group. In egus of what is here for the moment called Pediculus chapini (Figure 26D) the number of cells is lewer, hit material has not been available to permit the dissecting uway of an operculum in such a manner as to reveal the exact number. 


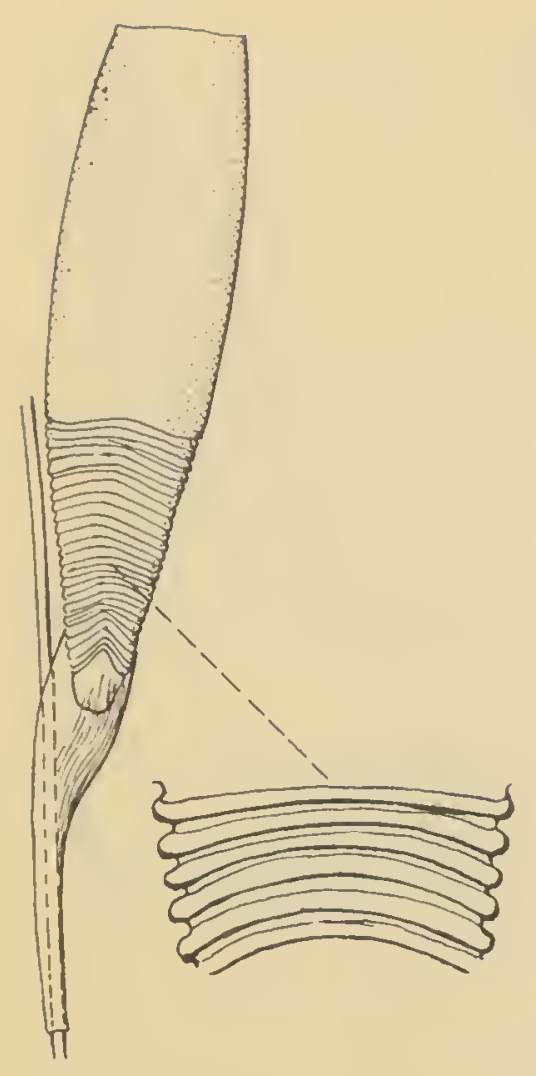

A. Neohaematopinus sciuropteri

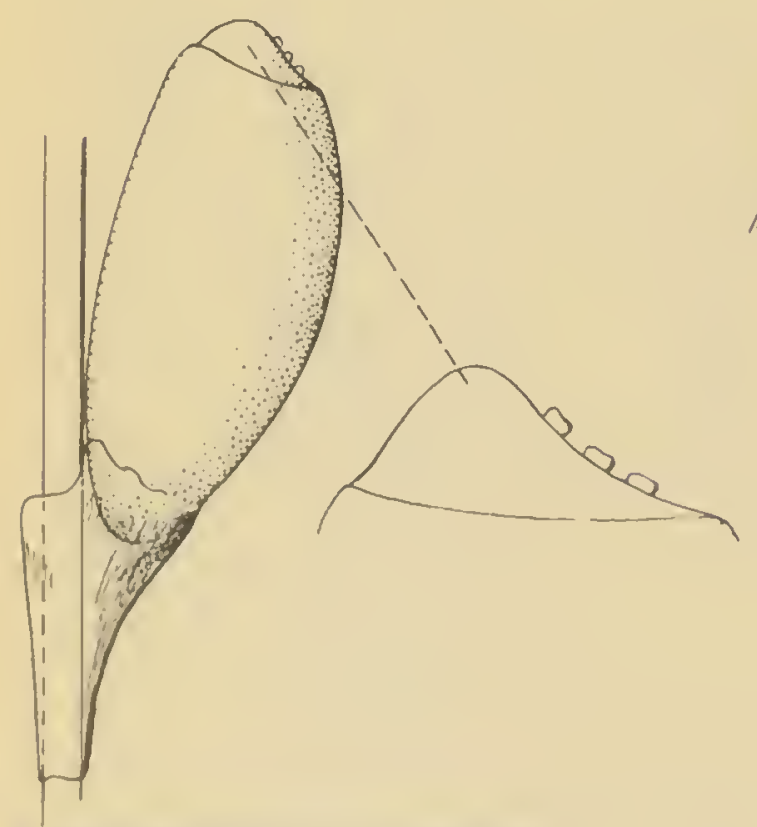

D. Fahrenholzia microcephala

Eggs of Anoplura

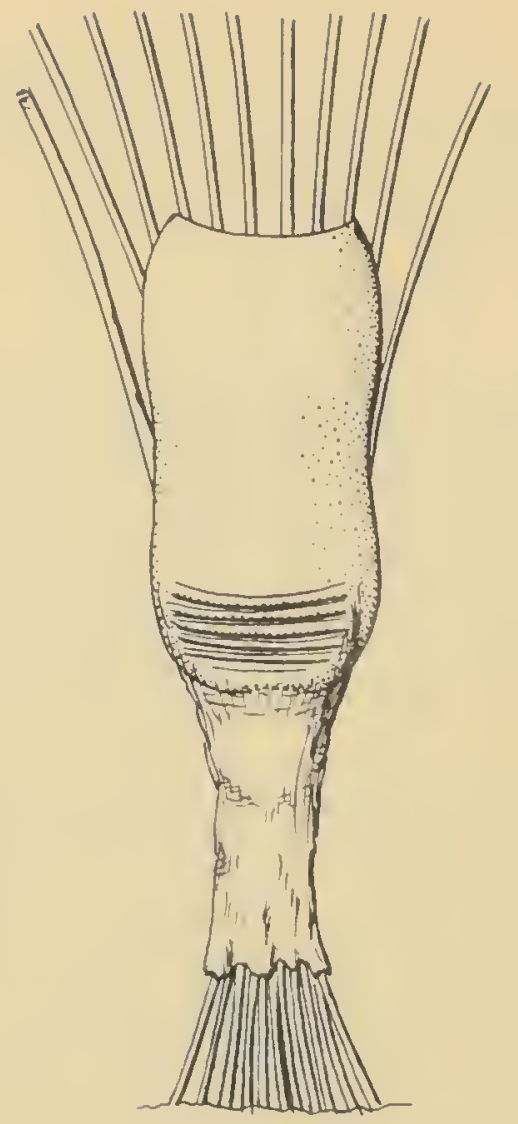

B. Haematopinoides
squamosus

C. Linognathus breviceps

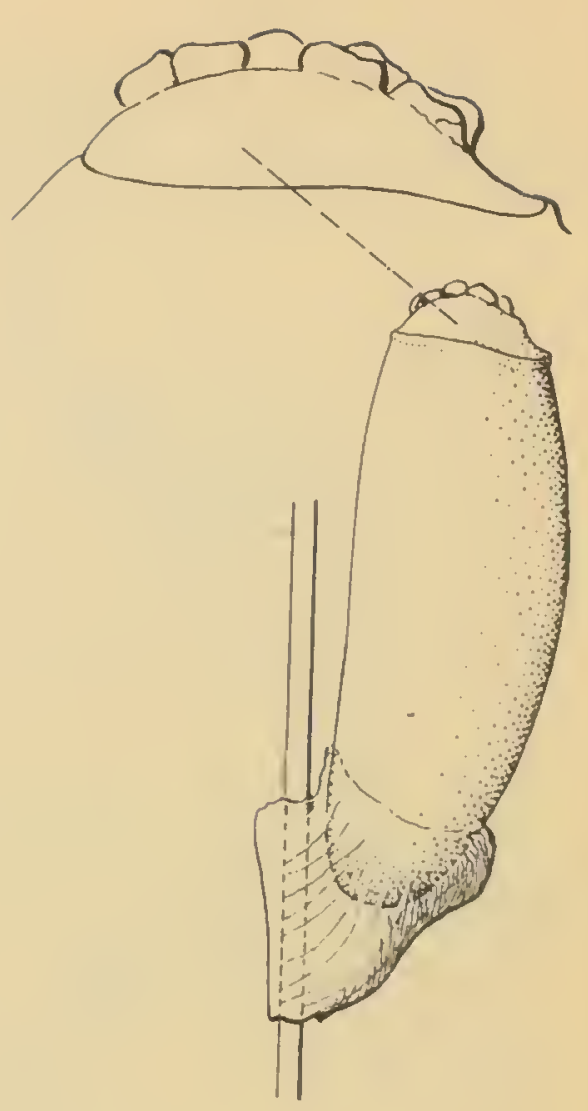

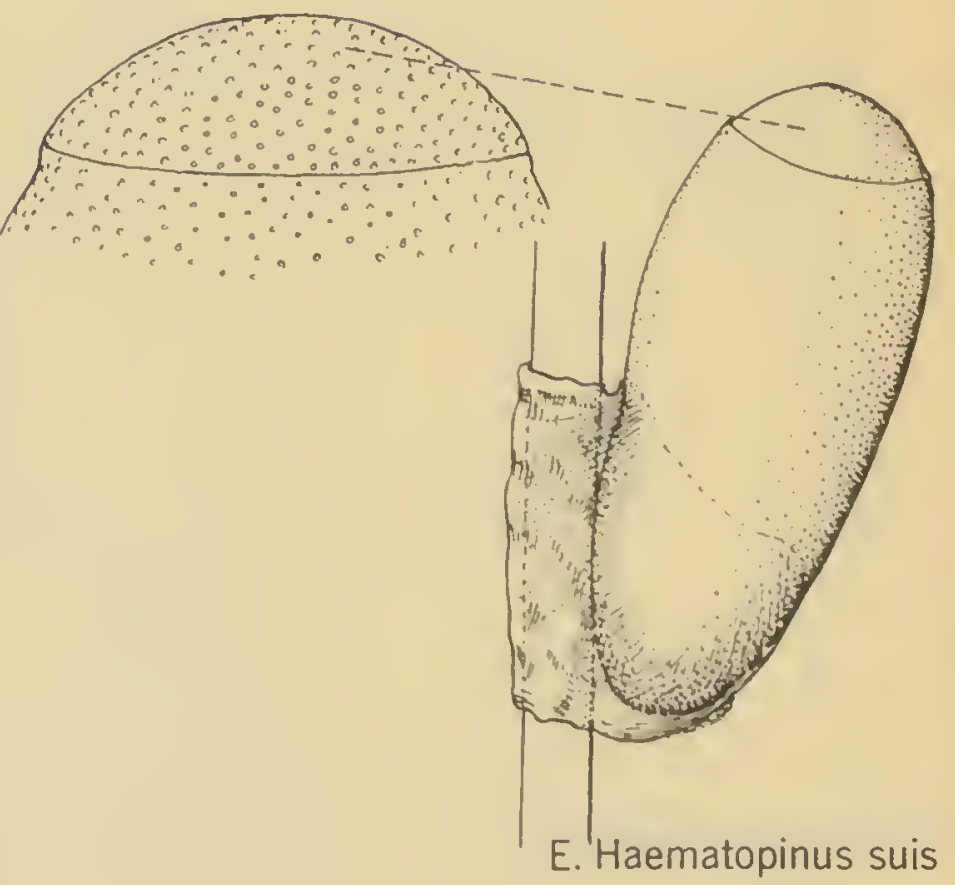

Figure 26 


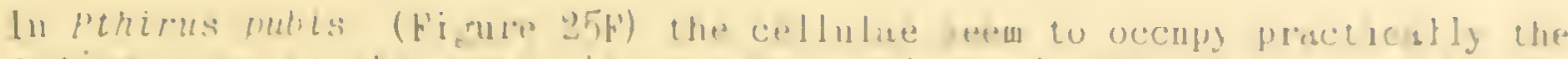
cutire area of the operoular surtace und are labe and eloneted. In

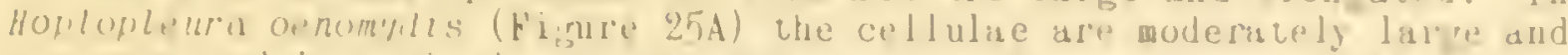
are arranged in a simple row extendin? around the operculum cluse to the marpin. In Hoplopledrra cruptira (figure 25ib) the cellulate are very sinall, heing scurcely iargen than the enclosed pore and there seem to be abour 10 ot them. In fahrenholzia microcephala (f'irgure 260 ) there serm to be only 3 or a cellulue and these are very surall and are displaced lowad one side. In I thosnathus breviceps (firure 26C) there are perhaps 10 cellular, these occupying the central area. In Enterleinellus osborni (fipure zit there

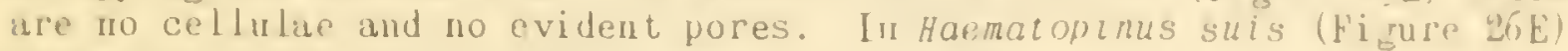
there are no evident cellulae.

The egg shell appears sculptured in some species. Thas, in the exo ot Hovlopleura oenomills (Fimme $25 \mathrm{~A}$ ) it is matked by two sets of diaronal crosstines which divide the surtace into little, lozenge-shaped areas that can be seen only in lavorable specimens and by proper ndjustment of the light in the microscope. In Haematopinus suis the entire shell, including the operculum, is marked with minure, clear, cellular areas. In Hoplopleura cryptica the shell hears somewhat irrerular, cellular areas. In other species here illustrated there seem to he no markings of any kind. In the eng ot veohaematopinus sciuropteri (Firure $26 \mathrm{~A}$ ) - or at least ou the basis of circumstantial evidence an ery presumed to belon' to that species- the available specimens have losi the operculum, unt the base of the eits is very distinctly marked by transverse tolds or ridpes.

The form of the cement pedicel varies. Its attachment to the hair may be very short or may be much extended. It may be rough and irregular or smooth. The attuchment to the esg may be strictly apical or may extend up one side of the erg. In the eir ot Haematopinoides squamosus (Figure $26 \mathrm{l}$ ), which seems usua $\mathrm{H} y$ to be attached to a cluster of hairs of the host, the cement itselt' is transversely wrinkled on the side awa from the attachnent.

The number of hairs enclosed within the cement seems frequently to be variable. In general, it appears on the basis of the small amount of available material that ordinarily a single hair is involved. There seems to he no special choice as to the size of the hairs. Thus, egrs are at hand of Fahrenholzia microcephala, taken from the same host individual, some of which are attached to small, slender hairs and others to larre, syiny hairs. In the latter case the cement is spread very thinly around the hair.

In the form ot the exs there seems in seneral to be nothing especially distinctive, although certainly in some species this is not true. The egg of Haematopinoires squamosus in the material at hand is somewhat constricted medially. The eng of periculus chapini is quite pointed basally. The eip of Neohaematopinus sciuropter $i$ is noticeably long and slender. In most of the species here illustrated the actual form of the eps is probably more slender than is indicated. since dried egs usually collapse with consequent apparent broadening.

$$
\begin{aligned}
& \text { Developmental Stages } \\
& \text { Finures } 27,29,29,30
\end{aligned}
$$

The existing knowledge of the immature stages of the Anoplura is quite scanty, there bein: probably not more than a halt-dozen species of which all the stages are known. The only species at hand of which all stages are represented are Pediculus humanus, Pediculus mjobersi (Figure 2i) and Pericinus obtusus (Figure 28 ).

There seem to be a total of four instars. It will we noted that in these species the principal chanjes which occur, apart from the development of the genitalic structires and alteration of proportions, are associated with the development of the paratergites. In Periculus mjober $i$ these are 


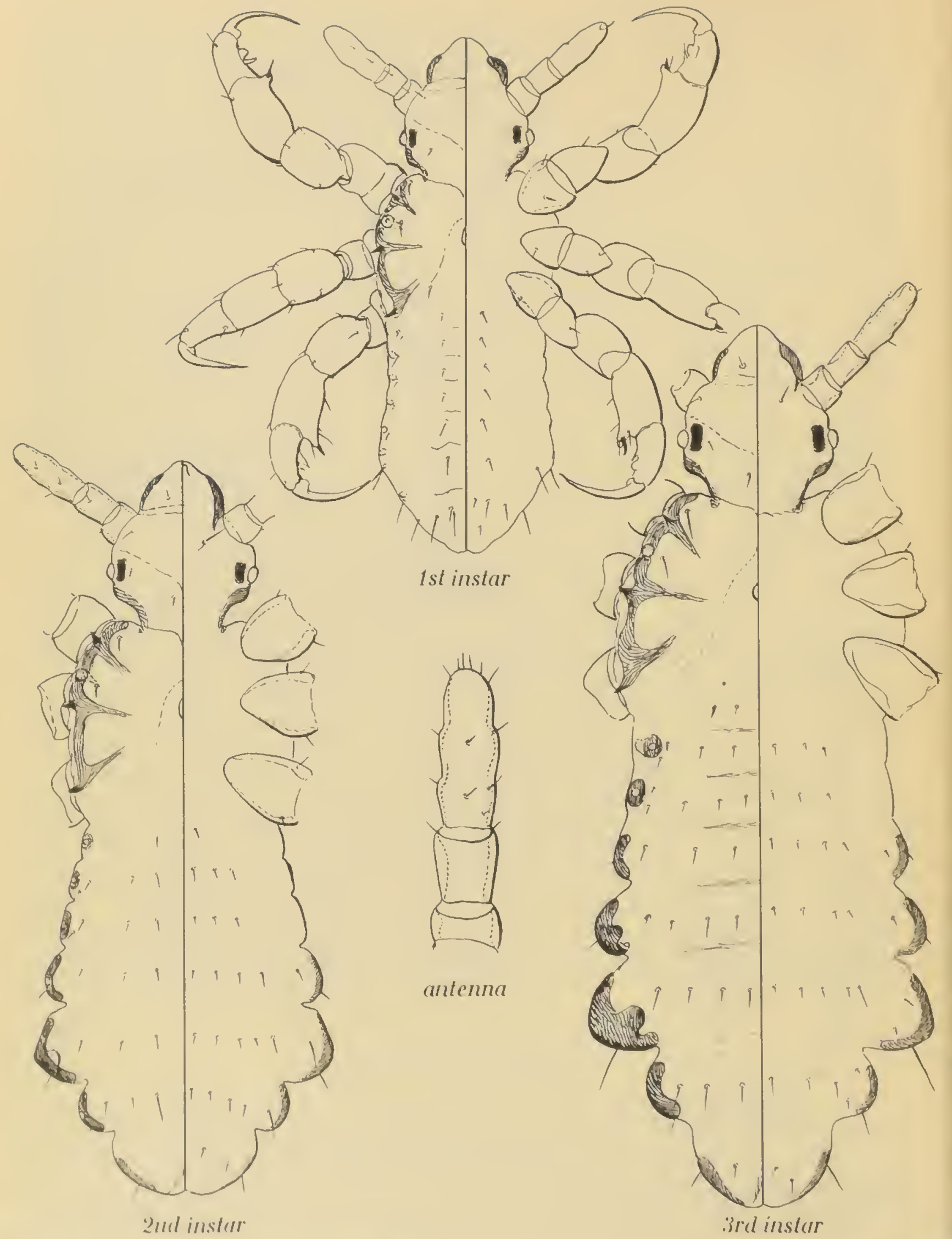

Nymphal stages of Pediculus mjobergi Ferris

Figure 27 


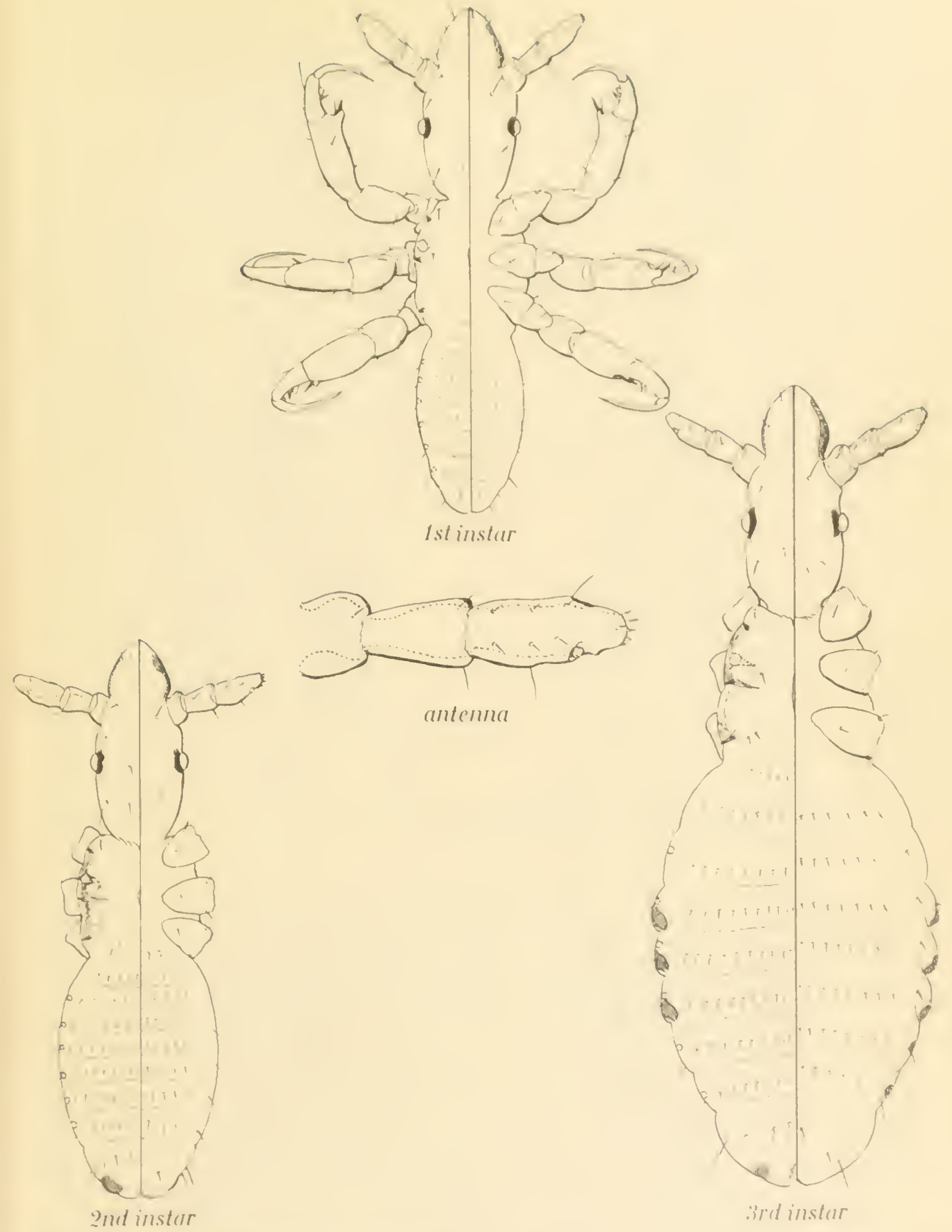

Nymphal stages of Pedicinus obtusus (Rudow)

Figure 28 


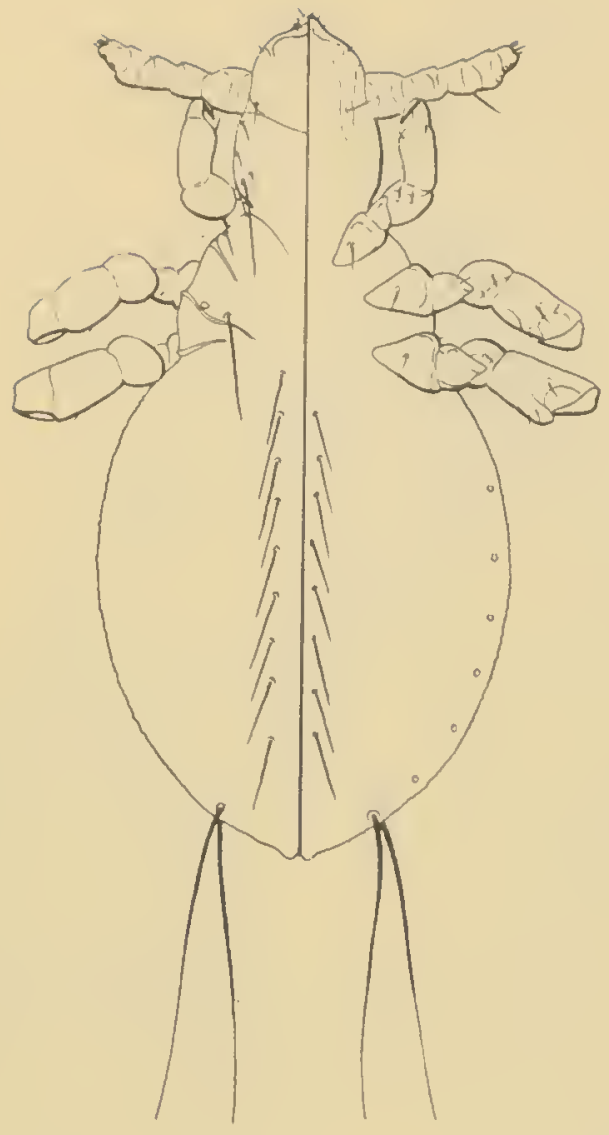

Ist instur

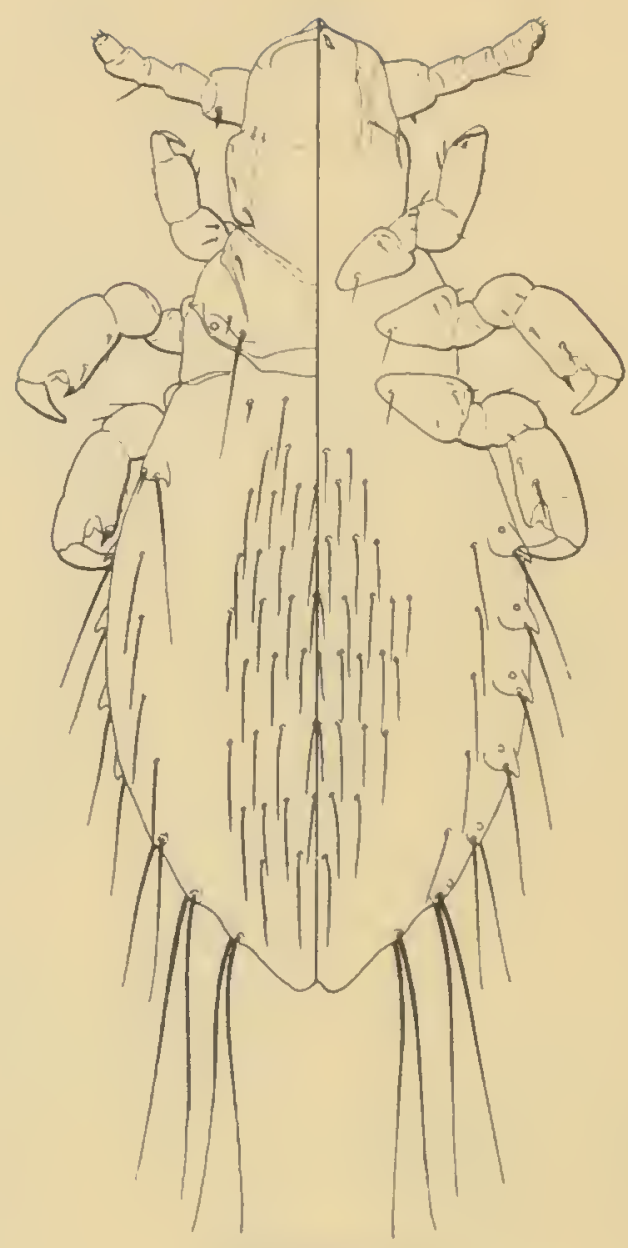

2nd instar."

Nymphal stages of Polyplax spinulosa (Burmeister)

Figure 29

recognizable in the second instar, while in Pedicinus obtusus they do not appear until the third instar. Also, in these species there are certain changes in the antennae, the last three segments being scarcely or not at all indicated in the first three instars. This is not generally true, the first stage usually having five antennal segments as does the adult.

of other species, there are at hand only a few immature individuals, no complete developmental series being represented. Consequently, it is difficult to assign these specimens to their proper instars. On the basis of present indications, however, it appears that the only species in which the immature stares present any especially peculiar developments are those of the genus Hoplopleura. In this genus there seems to be a reneral tendency toward the development of sclerotized tubercles on the antennae and on the ventrial side of the head and also of unusual setae on the abdominal maryins. It is not clear in which stage the paratergites appear in these forms.

The appearance of the immature stares in the genus Hoplopleura is such that an incuutious worker might very well be led to suspect the presence of more than one species. Illustrations of some of these stares of this renus are herewith presented. 

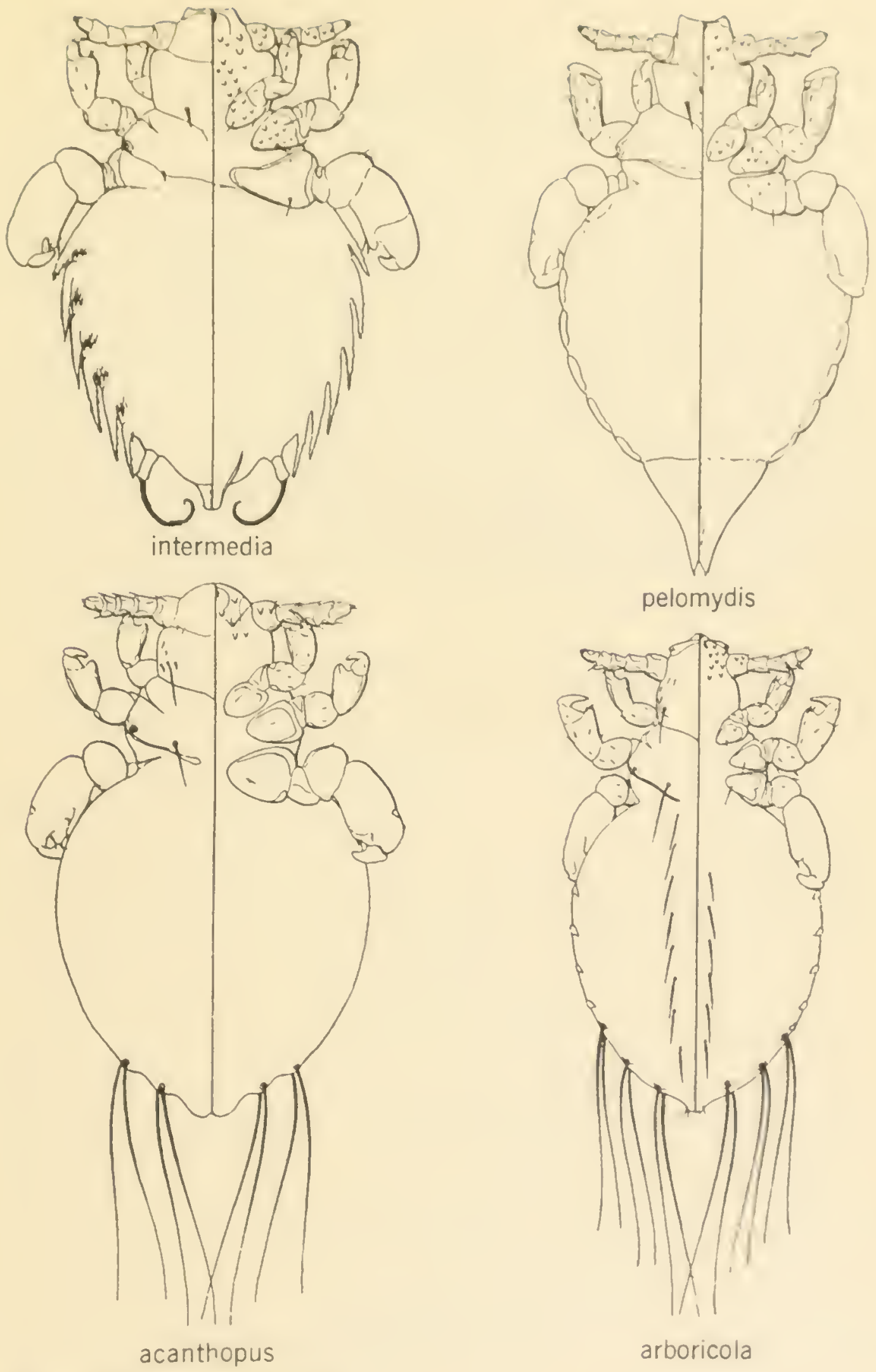

pelomydis

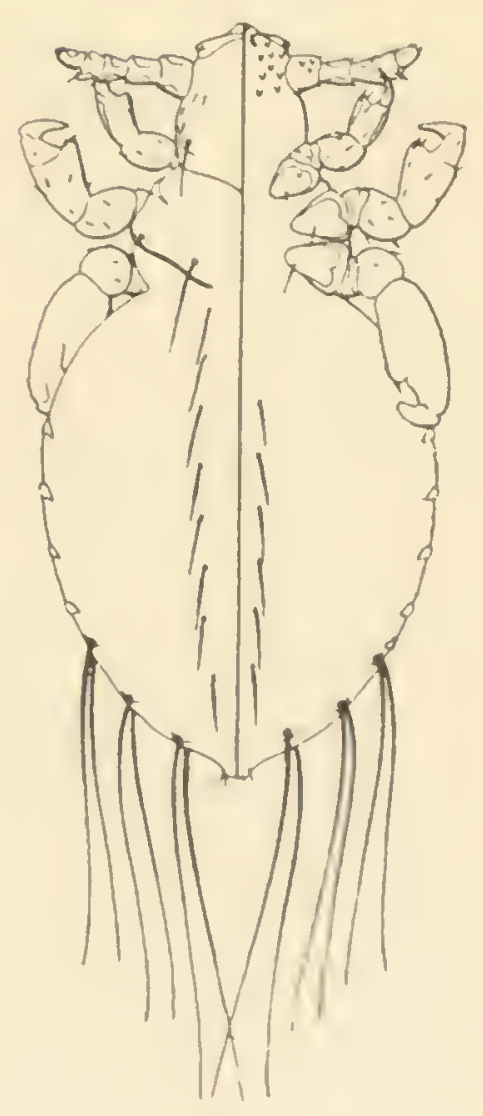

arboricola

First stage of species of Hoplopleura

Figure 30 


\title{
CHAPTER IV
}

\section{The Taxonomic Status of the Sucking Lice}

\author{
Historical Review
}

The sucking lice are for the most part very small forms and require special methods of preparation for study under the microscope. Such methods were scarcely available until comparatively recent times and in tact have reached a satisfactory degree of development only within the last thirty-five years; even yet very f'ew entomoloyists have become fully aware of them or have become proficient in their use. Moreover, the members of this group of ectoparasites were long regarded as merely "disgusting parasites" and therefore scarcely worthy of the attention of' anyone possessed of esthetic feelings. And still beyond that, it requires a special effort to secure material of any larige representation of the group, since the collector must first obtain specimens of the mamnals upon which they occur. For all of these reasons they have until relatively recent years received but little attention from entomologists. Their taxonomic history represents a series of stumbling attempts to assign them to some generally acceptable position in the scheme of classification of the insects and to devise a system of classification within the group itself. Even yet there is no absolute agreement in regard to either of these aspects of their classification.

Fahrenholz, ${ }^{*}$ in a paper published in 1936, save a detailed review of the taxonomic history of the proup, which has been utilized in preparing the following summary. This has been supplemented from other sources and brought up to date, especially with the aid of a work on the history of the development of insect classification published in 1937.**

We need not concern ourselves with anything that may have been done prior to the appearance of the tenth edition of Linnaeus" "Sy'stema Naturae" of 1758 , upon which our present system of classification and nomenclature is grounded. In this work Linnacus adopted the ancient Latin name Periculus for a genus into which he threw almost everything that could conceivaluly be called a "louse," placing this genus in the insect Order Aptera alon: with the mites, fleas, and the primitively wingless group now called the Thysanura. The genus contained a weird assortinent of forms, includins biting lice, sucking Lice, Corrodentia, a beetle triun tulinid and a Hippoboscid tly.

In 1775, Fabricius, in his "Systema Entomologiae", included the grenus with essentially the same composition in his Order Antliata, placing in itamiscellancous assortment of forms that included mites and some flies, and this sy'stem was followed in his "Systema Antliatorum" which was published in 1805.

In 1806, Latreille recogmized thic Order Parasita, which was composed of the two iroups of lice-the bitinis lice being placed in the grenus Ricinus and the sucking lice in the renus pediculus.

Also in 1806, Lamarck, in his "Histoire Naturelle des Animaux sans Vertebres," placed these senera in the Order Arachnides Antennistes, in the strinise compiny of the centipedes, the myriopods, and certain insects now isenerially referred to the Order Thysanura.

In 1815. Leach, in the "Edinbursh Encyclopacdia," placed the lice in the

- Fahrenholz, H. Zeitschrift fur parasitenkurde, Volume 8, Part 1, pages $50-57.1936$.

* Wllson, H. F., and M. H. Doner. The Bistorical Developrent of Insect classification. 1937. 


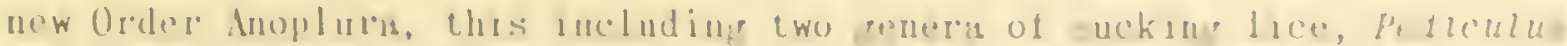

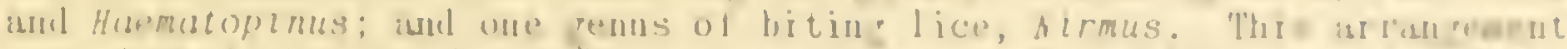

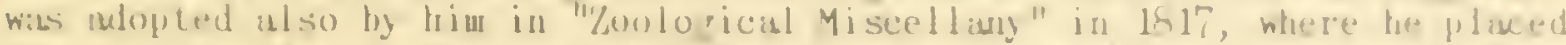

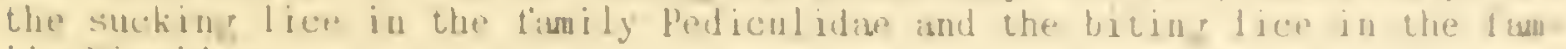
ily Nirurilite.

In 1818. Nitzsch, in a paper entitled "Darstellung der familien und frat-

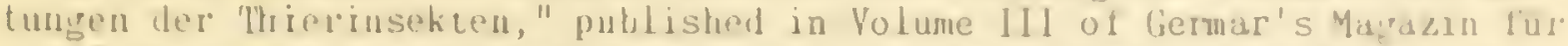
die Entonolorie. recornized these two groups bnt placed the sucking lice in the Hemiptera bizoicis and the biting lice in the Orthoptera Epizoica.

In 15.3, Duneril, in lris "Considerations grencrales sur le classe des insectes, "placed the sucking lice in the group khinaptera along with the lleas and at least some mites.

In 1825 , Latreille, in Iris "Fanilies naturelles du rome animal, "retained the Order Parasita and divided it into two groups, Siptrunculata for the suckin: lice and Yandibulatis tor the biting lice.

In 1826 , Kirby and Spence, in Volune IV ot their "Introduction to bintumolory," placed all the lice toggether in the Order Aptera, still alon? with the Thysanura, the myriopods and varions arachnids.

At some time hetween $1835 \mathrm{amd} 1840$, Burme ister, in his "llurdtuch der Entomolourie," which was published in tive volumes during these years, placed the sucking lice under the 0rder khynchota and the biting lice in the Order Mallophara, this apparently be ing the lirst use of the latter name.

In 1842, Demy, in his "Monorraphia Anoplurorum Britanniae, " restored the Order Anoplura, dividing it into two suborders. For the sucking lice he employed the subordinal names Rhynchota or Haustellata and for the biting lice the names Mallophara or Mandibulata, in each case apparently as al ternatives.

In 1874, Giebel, in his great work "Insecta Epizoa," placed the sucking lice as the lamily Pediculina in the Order Hemiptera, calling the group llemiptera Ep izon.

In 1880, Piaget, in his monumental "Les Pediculines, " very frankly avoided the use of any ordinal names, but regarded the sucking lice as constituting a single family, the Pediculidae, and the biting lice as two families, Liotheidae and Philopteridae, the three lamilies being considered as of' equal rank.

In 1896(?), Hackel referred the two gronps of lice to the Order Phthiraptera and this name has recently been taken up by Heber and by Eichler, these authors using it to include the suborders Anoplura, Mallophaga and Rhynchophthirina, the last name being that which was proposed by Ferris for the reception of the genus Hamatomyzus.

It some time during the latter part of the nineteenth centnry the idea became established in the minds ot entomologists that the sucking lice are related to the Hemiptera. Thus in the earlier editions of Comstock's "Yonnal tor the Study of Insects," and in fact in an edition as late as 1913, they are placed as the Suborder Parasita under the Hemiptera. In Vellorg's "American Insects" (1908) they are thus placed. On the other hand, the Mallophara we re recomized by Comstock as a separate Order as early as 1895.

In 1903, Cholodkovsky, in "Zoologischer Anzeiger," Volume 27, recomized the sucking lice as an independent Order and proposed the name Pseudorhynchota for them.

In this same journal and volume Shipley proposed the ordinal name Ellipoptera tor them in an attempt to establish a unitorm system ot endings for the names of the insect Orders.

Also in this same journal and volume Börner, in a projected classilication of the insects, recounized the sucking lice as the Order Siphunculata, crediting the name erroneously to Meinert.

In 1908 . Handlirsch, who probably had a hroader understanding of insect 
classification than any other man who has ever lived, recognized the sucking lice under the ordinal name Siphunculata and he adopted this assignment in a section of Schroeder's "Handbuch der Entomologie," which was published in 1923.

In 1908, Dalle Torre, in Wytsmann's "Genera Insectorum, " published a catalogue of the sucking lice, calling them the Order Anoplura.

In 1910, Mjöberg, in a work entitled "Studien über Mallophagen und Anopluren," which appeared in Volume 6 of "Arkiv för Zoologi," reverted to the opinion that these two groups constitute a single Order, for which he apparently used the name Siphunculata, while employing the subordinal names Anoplura for the sucking lice and Mallophaga for the biting lice.

In 1916, Lancelot Harrison, in a paper published in Volume 18 of the "Proceedings of the Cambridge Philosophical Society," also supported this view.

Apparently as a result of the conclusions of these last two authors, the writers of various textbooks-notably Imms in his "General Textbook of Entomology"-have adopted this opinion and have united the two groups, Imms employing the ordinal name Anoplura for both.

Ferris, in his series of papers entitled "Contributions Toward a Monograph of the Sucking Lice"-published in the Stanford University Publications, Biological Sciences Series, over a period from 1919 to 1934-considered the sucking lice to belong by themselves in the Order Anoplura.

Fahrenholz, in a paper published in 1936 in "Zeitschrift für Parasitenkunde," Volume 9, followed this procedure, but included in the sucking lice the peculiar genus Haematomyzus, which has but one species, the louse of the elephants. Ferris had shown earlier that this insect is not a sucking louse, being an insect with biting mouthparts and probably more closely related to the Mallophaga, to which Order he assigned it. Fahrenholz retained it in the sucking lice purely on the grounds that functionally it is a sucking form. He divided the Anoplura into two Suborders-Rhynchophthirina, a name previously proposed by Ferris as a Suborder of the Mallophaga for inclusion of Baematomyzus; and the new name Inrostrata, for the true sucking lice.

In 1939, Weber, in "Biologisches Zentralblatt, "Volume 59, took up Haeckel's name Phthiraptera, as already noted, placingunder it as suborders the three groups Anoplura, Mallophaga, and Rhynchophthirina, the last named including only the louse of elephants. In 1946, Eichler, in "Archiv für Naturgeschichte," Neue Folge, Volume 10, Heft 3, also adopted this arrangement.

In 1946, Webb, in "Proceedings of the Zoological Society of London," Volume 116, adopted the opinion that the lice constitute a single Order, to which he applied the name Anoplura.

In 1949, Hopkins, in Volume 119 of the same journal, followed Weber's procedure of placing all the lice in the Order Phthiraptera.

Throughout all this time the authors of various textbooks of entomology and parasitology, none of whom had any personal acquaintance with the insects involved, have adopted one or another of the various arraniements and one or another of the various names. It would be useless to consider these textbooks, since they contribute nothing original.

The problem of the name to be used for the sucking lice involves two aspects, one heing purely nomenclatorial, the other zoological.

The problem of nomenclature being the simpler may be disposed of f'irst. To the question of what name should be employed for the sucking lice there is no absolute answer. The International Rules do not cover situations of this kind, since they do not extend to the names of groups above the superfamily and even here are not definite. The only rule that can be followed is some mule of reason. The subject is subjudice at the moment, to be settied, perhaps, at Copenhiugen in 1953. 


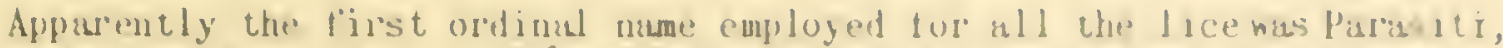
proposed by hitreille in 1796. It priority holds, this name would have to be muintained either lor ull the lice together as combined in a singre Urder, or tor one of the groups il' the Order be divided. But priority does not areessurily hold in such circunstances and there is the objection to this nime that it is entirely too broad in its commotations. Furthermore, the nume Parusitidae his been employed ulso tor a fimily ot mites.

The second available nane seems to be Anoplur'a, proposed by Leach in 1815. This nume has come into quite general use and conveys no surpestion of applicability to any group other than the lice. The opinion here held is that there is no reason why it should be replaced by any of the numes which were later proposed.

Now, since this name was originally proposed tor the hiting and the sucking lice as combined in a single group, the question arises as to which group should inherit it if the order is divided. The opinion is here maintained that since the biting lice were very early removed as the Order Mallophauga and were thus supplied with a name that has Ion: been employed, the reasonable procedure is to retain the name Anoplur'a for the sucking lice if they be recornized as an independent 0rder.

We come now to the zoological question involved, that of whether the two groups should be recomized as separate 0rders or merged in a single Order.

This problem has no objective solution, whatever answer is adopted being merely one of opinion. The two groups exist, but the rank to be assigned to them depends solely upon the mental processes of the protagonists of either opinion and upon subjective ideas concernin philosophical questions involved in the general process of classification. The groups are nearly enough alike to justify union, or they are sufficiently different to justify separation, either step being dependent upon the weight assigned to similarities of habit on the one hand or to differences in morphology on the other.

The author, being a morphologist, claims the greater weight for morphology. And from the point of view here adopted this argues for ordinal separation .

The principal distinction between the sucking lice and the biting lice (the latter including the Rhynchophthirina) lies in the mouthparts. The feeding mechanism of the sucking lice, which will be described in detail in a later section, differs very greatly from the mechanism tound in the biting lice and there are no known transitional forms between the two groups. Nor is this all. The arrangement of the thoracic elements is quite different in the two groups.

As a matter of fact, the idea that the biting lice and the sucking lice are related finds but little actual morphological support, although there is a suggestion of some sort of remote relationship. The feeling of relationship seems to arise chiefly from the fact that the biting lice offer the only known source from which the sucking lice could have been derived. The witer is not impressed by Kebb's insistence upon the evidence afforded by the tracheal system, in the light of the very profound differences in the feeding mechanism.

The opinion is here maintained, therefore, that the sucking lice should be recornized as the Order Anoplura.

\section{The Characteristics of the Order Anoplura}

An insect Order the members of which are, as far as known, ectoparasites exclusively upon mammals, living in the hair, feeding upon the blood of the host throughout their entire life cycle, and attaching their eggs to the hairs of the host. Metamorphosis of the type commonlycalled hemimetabolic, consisting chiefly of changes in size or proportions of parts, in the degree of sclerotization and in the development of the sexual apparatus. 
Antennae normally five-segmented, although at times apparently only three-segmented or four-se mented.

Youthparts highly modificd, being formed of three stylcts which are retracted into a trophic sac, lying beneath the pharynx, these stylets being protrusible.

Thorix with the three sermcnts closely fused but recognizable, the true notum bein: reduced in all sements to a narrow, median, membranous area or at times to a median pit and slight lateral extensions which surround the spiracles. The apparent thoracic nota formed almost entirely of subcoxal (=pleural) elements and these at times fused entirely across the notum, thus almost completely obliterating the true notal plates. Never more than one pair of thoracic spiracles, these beloning to the mesothorax.

ovipositor of the female present, but rcduced to at most a pair of flattened lobes which represent the jonopods of segment eight and a pair of small, sclerotized areas or mere tuft's of setae which probably represent the gonopods of se ment nine. Male never retaining the gonopods of segment nine and consequently wi thout claspcrs, hut usually retaining the parameres, the genitial structures being retracted into the body when at rest.

Lces modilicd as claspin or gans by havin: the distal, ventral angle of the tibia prolonged into a thumb which opposes the claw. Tarsus normally one-se mented and at most only obscurely two-segmented. Tarsal claws always single exccpt in a few instances where a very doubtful second, clawlike structure is present on the anterior legs.

NOTES. The extraordinary mouthpirts, which are among the most highly modified that are to be found in the Insecta, are the principal basis for the recognition of the Order as distinct from the Mallophaga. No transition between such mouthparts and those of the Mallophasa is known to exist. However, other distinctive characters are to be found in the thorax. In the Mallophaya the prothorax is always definitely scparated from and movable independently of the other semnents and the dorsa of at least the prothorax and the metathorax scem always to be composed of the true notal plates. In the Anoplura the prothorax is always fused with the mesothorax in such a manner that it cannot be independently movable, and the thoracic dorsum throuthout is composed primarily of the pleural (=subcoxal) elements. While it is highly probable that the two groups go back to some common ancestry, that ancestry is entirely hypothetical and even if dcfinitely known would still not prcclude their being considered as separate Orders.

The feeling that the two groups should bc united into a single order seems to rest chicfly upon the similaritics of habit and metamorphosis. Thus, the members of both groups attach their eggs to the hairs of their host, but exactly the same procedure is adopted by certain mites and by flies of the family Oestridae. Webb has considered the two groups to be closely related because of resemblances in their spiracles and tracheal systems. No comparative study of the spiracles through various Orders was made. Thus spiracles in some respccts very similar to those both of Anoplura and Mallophara appear in members of the fanilies Polyctenidae and Cimicidac of the Order llemiptera. We have here a sitmation very similar to that of the presence of" "combs", of setae, such as those on the fleas, which occur in virious cctoparasitic groups but which are also found in other forms that are not parasitic when once those forms are examined by the same methods which are cmployed in the case of the ectoparasitcs.

It is quite true that no other irroup than the Mallophaga is known to which the suckin!s lice mity be closely related, but this in itself is no arrument for combining the two groups into a single Order.

Conceruin: the general relationships of the sucking lice, it may simply be noted that if there is in fact some conncction with the Mallophaga then the Anoplura are probably remotcly related to the Corrodentia, since the Yallophara seem thus to be connected. 


\section{CHAPTER $V$}

\section{The Classification Within the Order Anoplura}

for maly years at ter the formal naming of the genus Perliculus ly Limas

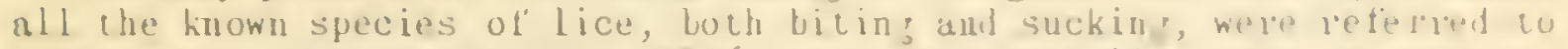
this genus. It was not until 1806 that the hiting lice vere lemoved and placed in the genus Ricinus. It was then not until 1815 this the suchin: lice remaining in Pediculus were in part trinsterred lo lwo new renera, Ho'matopinus and pthtrus. The next genus of sucking lice, liflelnu: has not nimed until 1814 and the next, Echinophthirlus, not until 1871. As Late as 1880 piaget recognized only these genern, most of the sprecies bein'? referred by him to Haematopinus. In 1891 Osborn mimed the genus Hoemutopinoides und in 1896 the genus Ruaematopinus, which is definitely is synonym of Haematopinoides. Duling all this time-perhaps fortunately-110 attemptis were made to develop a higher classification, Giebel, in 1874, placing all the species in the family Pediculina and Piaget, in 1880, using the sime arrangement with the alteration of' the family name to Pediculidae.

As late as 1904 but seven genera had been named as beloniring to the suching lice, and of these one was a symonym and one, Haematomyzus, is now known not to be a sucking louse.

In 1904, Enderlein began the publication of a series of papers which represent the fiist really iutelligent work done on the group. He rroosnized the superficial character of the genus Haematopinus and began the process of dismembering it. He numed a total of eitht new grenera, of wich six were removed directly from Haematopinus and two were based upon new species. At the $t$ me when Enderlein began his work there viere, according to a count later made by Fahrenholz, but 65 known species, one of which was later shown not to belong to the Anoplura, and nearly 60 were referred to the genus Haematopinus. Up to this time there was no need for a system of classification above the generic level. Enderlein essayed the beginnings of such a system and this was later tollowed by Dalla Torre and by Ferris.

Eliminating the genus Hacmatomyzus, the sole member of the family Haematomyzidae estallished by Enderlein, which we now know is not a sucking louse, Enderlein's system was as follows:
FAYILY Pediculidae Leach
Subfiunilies
Pediculinae Enderlein
Pedicininae Enderlein
FAYILY Echinophthiri idae Enderlein
FAYILY Haematopinidar Enderle in
Subfamilies
Haematopininae Enderlein
Euhaematopininae Enderlein
Linognathinase Enderlein

In 1909. Enderlein, in a paper on the lice of marine mammals published in the report of the Deutsche Südpolar Expedition, Volume $X$, divided the Echinophthiriidae into two subfamilies. Echinophthiriinae and Antarctophthiriinae.

In 1908. Dalla Torre published a catalogue of the Anoplura in Hy'sman's "Genera Insectorum." This work, while useful as a first attempt at a catalogue, was an entirely mechanical bitof bibliography involving no knowledpe of the insects on the part of the author and represented a none-too-thorouth search of the literature. Only 65 species were listed. The classification adopted by Enderlein was tollowed.

In 1916. Ferris published a "Catalogue and Host List of the Anoplura" in the "Proceedings of the California Academy of Sciences, " (Fourth Series), Volume VI. The system proposed by Enderlein was here tollowed. Some names were overlooked and there was some l'alse synonym, but the number of known 
species at this time must have been quite close to the 120 listed.

In 1929, Ewing, in a book entitled "A Manual of External Parasites," proposed an extended classification. This still included Haematomyzus and the family Haematomyzidae. Excluding the Haematomyzidae the system was as follows:

FAMILY Haematopinidae Enderlein

Subfamilies

Enderleinellinae Ewing Hybophthiriinae Ewing Hoplopleurinae Ewing Linognathinae Enderlein Neolinognathinae Ewing Haematopininae Enderlein

FAMILY Haematopinoididae Ewing

Subfamilies Haematopinoidinae Ewing Hamophthiriinae Ewing

FAMILY Pediculidae Piaget

Subfamilies

Pediculinae Enderlein

Pedicininae Enderlein

Phthirpediculinae Ewing

FAMILY Phthiriidae Ewing

Contains but one genus Phthirus

FAMILY Echinophthiriidae Enderlein

Subfamilies

Echinophthiriinae Enderlein

Antarctophthiriinae Enderlein

Lepidophthiriinae Ewing

In 1931, Ferris, in an extended paper in "Parasitology, "Volume XXIII, showed that Baematomyzus does not belong to the sucking lice. He transferred this genus doubtfully to the Mallophaga and proposed for it the subordinal name Rhynchophthirina.

In 1932, Bedford, in a check list of the parasites of birds and mammals of South Africa, published in the "18th Report of the Director of Veterinary Services of the Union of South Africa, "considered the biting lice and the sucking lice together to constitute the Order Anoplura, with three Suborders, Mallophaga, Rhynchophthirina, and Siphunculata. Under the Siphunculata he adopted the system proposed by Ewing.

In 1936, Fahrenholz, in a paper in "Zeitschrift für Parasitenkunde," Volume IX, Heft 1, proposed a classification in which he considered the sucking lice to constitute the Suborder Inrostrata of the Order Anoplura. Under this Suborder he proposed the following arrangement:

FAMILY Echinophthiriidae Enderlein Subfamilies

Echinophthiriinae Enderlein Antarctophthiriinae Enderlein

FAMILY Haematopinidae Enderlein Subfamilies

Haematopininae Enderlein Linognathinae Enderle in Polyplacinae Fahrenholz
Haematopinoidinae Ewing Lemurphthirinae Fahrenholz Hamophthirinae Ewing

FAMILY Neolinognathidae Fahrenholz Containing the single genus

FAMILY Pediculidae Leach Neolinogna thus

Subfamilies

Pedicininae Enderlein

Pediculinae Enderlein

In 1946, Eichler, in "Archiv für Naturgeschichte," Neue Folge, Volume X, Hef't 3, adopted the name Phthiraptera of Haeckel, for an Order which included the three Suborders Mallophaga, Anoplura, and Rhynchophthirina. Under the Suborder Anoplura he proposed the following arrangement. If we substitute the term "superfamily" for his "family series" we shall be more nearly in accord with usual entomological practice.

FAMILY Echinophthiriidae Enderlein

Subfamilies

Echinophthiriinae Enderlein

Antarctophthiriinac Enderlein

Polyplacinae Fahrenholz Lemurphthirinae Fahrenholz Hamophthirinac Ewing

FAMILY SERIES Pediculiformia Eichler FAMILY Pediculidac Leach

FAMIIY Haematopinidac Enderlein Subfamilies

Subfamilies

Hacmatopininae Enderle in

Pedicininac Enderlein

Linognathinae Enderlein

Pediculinae Enderlein

Phthirinae Ewing 


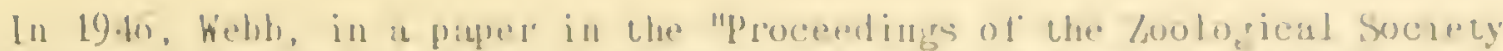

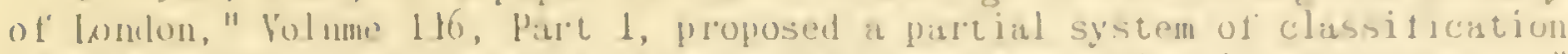
of the suctint lice "hased solely on diflerences in spiracle structure. .

as he himselt sitid, hit inlluenced to a considerable de rree ly considerations hisied on the distribution of the lice accordin, lo hosts. 'The system as there presentedwas only partial, since some seneral werenot placed iu it. Wehl's systen, us lar as it his been calleiedist the time of the present writing. is as follows: The hiting lice and sucking lice ale united in the Order Anoplura and are regarded as Sulorders, the names Mallophara and Siphunculitia teing employed tor them. The Siphnculata, so far as treated, are divided into six l'anilies-Docophthiriidue, Pediculidae, Eulinormathidae, linounathidare, Harnatopinidare, and kchinophthiriidie. No sullianilies are nimed.

In the opinion here held this chassification is in part correct. But in part it also rests upon some very peculiar concepts of taxonomy. 'Thus thr louse ot elephants, Haematomizus eleptantis, is not only repinded as is sucking louse but is even placed in the tanily Haematopinidat on the basis ol spiricle structure alone!

In 1949. llopkins, in the "Proceediugs of the Loologicis Society ol" London, "Yolume 119, recomized the bitins and suckin! lice together as constitutinir an Order Phthiraptera with the three Suborders Anoplura, Mallophage, and Rhynchophthilrint. Under the Anoplura he recomized but three tamilies-Pediculidae, llamalopinidae, and Veolinomathidae.

In attempting to develop an intraordinal classilication of the suchin, Lice, here considered to be the Order Anoplura, consideration has been given only to morphology. It is here held that the problems associated with the distribution of the lice on their various hosts should be approached only atter conclusions have t'il'st been reached by way of morphological studies. It may be very arreeable in the end to tind that the conclusions drawn from the lice themselves are in accord with those drawn from their hosts and if the two sets of conclusions serve to confirm each other we may be justified in feeling that some approach to truth has been achieved. But to use $A$ to develop $B$ and then to turn about and use $B$ to develop $A$ is a process that presents certain illogical aspects. This is especially true if $a$ priori ideas concernin. A and $B$ have been employed. On the other hand, if $A$ has been competently and lofically developed and then $B$ is found to aree closely with A there my very well be simations where, a point in $A$ being donbtful, B may at least be used as a tentative aid in testin' $A$ or in supplementing it.

Thus in developing a classification of the sucking lice, if on morphological rounds a certain set of relationships is clearly indicated and then a detinite correlation with the distribution of the lice according to hosts appears in harmony with these indications, we may be justified in employin? the evidence of distribution to supplement the evidence or morpholog where the latter is inadequate or confused. But we are certainly not justified in employing the evidence from distribution if it completely denies or is otherwise not in harmony with clear evidence from morpholon. Especially is this true when the evidence from distribution is itself based upon questionable concepts.

For example. the genus polyplax is a large group which is confined to rodents of the family Muridae, except for one or two species which occur on shrews. To say that since the shrews and the Muridae are not closely related to each other lice of the genus polyplax should not occur on shrews and that therefore these lice actually irom shrews do not belong to the genus poluplax, despite the morpholorical evidence, is an utterly illogical procedure. To say that such genera as Schizonhthirus and Ancistronlex cannot be related to the genus Hoplopleura because of the wide difterences in the assumed relationships of the hosts would be to deny the plain evidence 
of morpholoyy.

But in the case of the Enderleinellinae we have a different situation. The semus Enderleinellus, which is of considerable size, is known only from Sciuridae. There are two peculiar genera, Microphthirus and Werneckia, which in certain respectsare like Enderleinellus but which depart from that genus in the lack of a certain structure that we are inclined to accept as of morphological simificance. But in certain other respects these two genera are like Enderleinellus and all three genera are as far as known confined to the squirrels. The totality of the evidence thus indicates that the absence of the structure in question is probably not sufficient to indicate that the two genera which lack it should be excluded from the Enderleinellinae. We are not here denyin: the evidence from morphology, we are merely supplementing it where it is weak, for experience in other fields of taxonomy indicates that the loss of a structure in the course of evolution may occur without disturbing or invalidating the evidence of relationship that is derived from other sources. What it does disturb is really nothing more than the ease with which keys tor identification may be developed.

In attempting to develop a classification of the sucking lice certain considerations should be kept in mind.

1. This rroup is probably something of a remnant of what it once may have been. The living mammals represent but a very small part ot all the species of mammals that have existed in the past. Let us reflect upon the number of proboscideans that are known only as fossils. What were their parasites? The single louse-like parasite of the elephants is all that is left to accompany the dwindling line of its hosts. The same situation may very well hold in regard to other lice.

2. Being a very small, very specialized, and perhaps remnant group, we have left but t'ew or none of the connecting links that one may hope to find in the Orders of insects that still contain thousands of species.

3. There has evidently been a very large amount of evolution by loss among the Anoplura and this leaves us with a rather small complement of structures with which to work.

4. He still know probably not more than half of the species of sucking lice that exist in the world.

5. Under these conditions we have but limited bases for judgment as to the relationships of such forms as Hybophthirus notophallus, the louse of the aard vark; Haematopinoides squamosus, the louse of certain moles; the two known species of Neolinognathus from elephant shrews; as well as some other peculiar forms. Each of these genera contains the solitary or almost solitary representative of some ancient line and we have no basis for judgment as to whether its peculiarities are merely those of an individual species or were common to the members of what may once have been a much larger group.

Actually, whatever basis for classification we may adopt, the rrouping of the genera of the sucking lice is not at all clear. Certainly no satisfactory arransement can be obtained by focusing attention upon a single set of characters. We must take into consideration the totality of the characters which are available.

The opinion is here held that in the light of our present knowledge of the Anoplura any system of classification within the Order which elaborately divides it into supertamilies, families, subfamilies, tribes, subtribes, genera, and subrencra, can be nothinis more than pretentious nonsense. Such minute subdivision can very well wait until a substantially larger proportion of the species is known.

In the light of these considerations the system here adopted will be rather conservative, only families, subtamilies and genera being employed. It is presented with a full realization of the possibility that it may very well be inadequate and at some points may actually be wrong. However, there 
is the thonght that the number of species concerning which error is mo 2 likely to exist constitutes only a surll fart of the whole. Thus, there muy be question concerning the seven species relerred to the pediciniure and to certain isulated species. But the great mass of the species and grencin liall intu cleurly recognizuble groups.

The genern of Anoplura are reasonably clear and uncomplicated, except as they may the complicated subjectively by workers who see a new genus in every slight departure from the normal form. These genera to a cousideruble derree lull into groups, the central pattern of which is ruther evident. lut which becomes clouded as we pass out from it. In fact, around their peripheries these groups become so misty that no very definite outlines can be detected and it is here that the principal difticulties arise. To name tamilies that caunot be defined is to create difficulties for all luture workers, to overemphasize the differences that exist and exaggerale the boundaries among these differeuces.

At an earlier time, when little or nothing was known about the morpholog ol these insects, certain ideas concerning their classification seemed valid which now appear at least dubious. Thus it was assumed that the presence of a distinct lens marking each compound eye separated the Pediculidae from all the other lice and defined a family. We now know that such lenses are present in various other forms which seem not to be closely related to Pediculus and this once apparently beautifully defined family becomes extremely difficult to define. Evolution by loss has occurred so extensively in the Anoplura that the persistence of a structure, may indicate only the retention of what was once a widespread character in all the aucestors of the group. It is therefore difficult to properly evaluate the remants that are left.

One other quite secondary, but nevertheless important, problem arises. This has to do with the names which should be employed for the families and subfamilies that are recognized. This is a problem which is inherently difficult and which, probably because of this difficulty, is not even touched upon by the "International Rules of Zoological Nomenclature."

Should priority rule? If so, what constitutes priority? Does it date from the first recognition of the existence of a group in any status whatsocver or from the first unequivocal employment of a group name with a particular ending? Are family and subfamily or any lower category names such as tribes and subtribes to be regarded as nomenclatorially equivalent, in the nammer in which generic and subgeneric names are equivalent? that determines the type of any category? Should it be the oldest genus referred to the category-as some maintain-or should it be the genus upon which the category name was first based-as others maintain?

And who is to be cited as the author of a group name-if this recognition must willy-nilly be accorded to someone? Shall it be the person who first recognized the group and employed a group name of any rank? Or shall it be the person who used the name which is now employed? Thus, is the author of a subfamily name to be regarded as the author of the name if it is elevated to family rank, or shall it be the person who first used the name to characterize a family? If a subfamily is raised to family rank and then reduced again to a subfamily of some other family, who is the author of the name? Or should we refuse to bother about the name of the author of a troup?

There are no fixed answers to these problems and in the absence of answers one is left very much to follow whatever course seems reasonable.

The writer ol these lines has puzzled long over all these questions and has come to no answers to any of them that are entirely satisfactory to himself. As far as classification is concerned, there is on the one hand the undesirability of obscuring facts by too comprehensive trouping or on the other hand of going beyond all reasonable limits by the indiscriminate 
naming of groups that cannot be supported by any cocrent reasons.

As to nomenclature, the stand here adopted is in part based upon priority in actual recogaition of a roup, whatever caterory may have been assigned to it, and in some dergree upon arbitrary action in refusing to recognize a group-such as the Haematopinoididae-which would assign a family name to a large uroup on the basis of a very aberrant member.

As to authors ${ }^{1}$ names, it is here held that the matter is too unimportant to bother with, or above all to arirue very much about one way or another. The names of authors are indicated in accompanying discussions but not conjoined with the names of the groups in section headinis.

\section{THE SYSTEM HERE EMPLOYED \\ Fanily Echinophthiriidae}

This family, which was established as such by Enderlein in 1904, is retained. It was united with the Haematopinidae by Hopkins but this step is regarded as erroneous on morpholorical grounds. Two subfamilies-Echinophthiriinae and Antarctophthiriinae-were recomized by Enderlein and accepted by most later workers, but are here rejected since it does not appear that anything is gained by recomizing them.

\section{Family Haematopinidae}

First established by Enderlein to contain the vast majority of the sucking lice and later accepted by all workers with various restrictions. It is here accepted for two genera, Haematopinus and Pecaroecus.

\section{Family Hoplopleuridae}

This family contains within it the genus Haematopinoides which, under the synonymic name Euhaematopinus, was placed by itself' in the subfamily Euhaematopininae of the family Haematopinidae by Enderlein and later, under its correct name Haematopinoides, placed by Ewing in the family Haenatopinoididae. This family is rejected as zoolorically unjustitied and referred to the Hoplopleuridae. It may very well be argued, and perhaps correctly, that the family name Haematopinoididae should be employed for the family Hoplopleuridae, to which it is here referred, but it is a very aberrant form which is quite unsuited to be used as the type of the family.

The group of which Hoplopleura is here taken as the type was recomized by Ewing in 1929 as the sublamily Hoplopleurinae of the family Haematopinidae. Since at-ihe same time Ewing recognized the subfamily Ender leinellinae, it is necessary to make a choice between these two names for the family here considered to include the two groups. Hoplopleura is chosen as beinir more nearly central than is Enderleinellus.

\section{Subfamily Enderleinellinae Ewing}

Established by Ewing in 1929 as a subfamily of the Haematopinidae. Here accepted as a subfamily of the Hoplopleuridae, to contain three senera.

\section{Subfamily Hyophthirinae Ewing}

This group was named by Ewing in 1929 as a subtamily of the Haematopinidae. Hebl) has considered the members of this roup to be closely related to Hoematopinus and has placed them in the family Haematopinidae, but since he also placed in this family the grenus Haematomuzus- which is not even an Anopluran-the inportance of the spiracular characters which he employed may be somewhat discounted. 


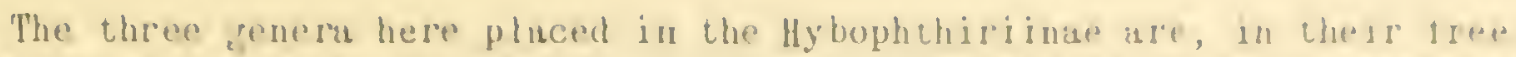
purintergit plutes of the abtomen, much more closely similis. to the membles of the Hoploplentidise thun to my other group. They durree umon! chemselves. in the possession of a cluw-like structure ar isin heside the claw un the unterior less and in this uppenr to be related nosi closely to each other.

\section{Subtunily Pedicininae Endertein}

It is concerning this group that there will probably be che reatest ditterence of opinion and the writer does not expect arrerment wilh lhe point of view here adopted.

The group was tirst recognized by Enderlein as a subtimily ot chr tanily Pediculidac, which was restricted to Pediculus, pthirus, mnd pedictnus. The genus Pedicinus has, ever since, been placed as a subtiamil! ut the Pediculidac because of two tactors. One of these tactors is undoubtedly that of the leeling that anything occurring or the l'rimates stould be related to Pediculus. The other factor is that of the common possession of cyes by pediculus and Pedictnus and this character was enployed as the distinguishing mark of the Pediculidae. But in the light of what is now known it does not appear that this character by itsell' is especially significant, since it is known that genera such as pecaroecus and yicrothorurius-wich certainly do not belong with Pediculus-have eyes and they can even he denonstrated in Haematopinus althouph they are not there so evident.

In fact, present evidence indicates merely that the presence of eyes represents merely the retention of a primitive character, once common to all the suckinir lice and their ancestors.

I I we remove the eyes f'rom consideration, the remainder of the body in Pedicinus contraindicates any association with Pediculus. In fact, wi th the eyes removed all the characteristics of the body seem much closer to what is found in the lloplopleuridae. The free paraterial plates and the absence or ireat reduction of the ronopods of seyment nine in the female are more nearly in harmony with what appears in this tamily.

He might raise pedicinus to tamily rank, but this is merely to increase the number of families by emphasizing the difterence in one structure.

with these thoughts in mind the author has decided to "take the bull by the horns" and remove the senus pedicinus from close association with Pediculus, assigning it to the family with which it shares the majority of its leatures. regardless of whether or not it ousht to be related to the Pediculidae.

\section{Subfamily Polyplacinae}

Established by Fahrenholz in 1936 as a subfamily of the Haematopinidae. It is here considered to contain the genus Hamophthirus, which ras employed by Ewing in 1929 as type of his subfamily Hamophthirinae of the family Haematopinoididae and thus on rounds of priority it might he areued that the name Hamophthiriidae should he employed for it. However, the senus Hamophthirus is very badly described and quite unsuitable to stand as the type of any group.

It contains also the genus Lemurphthirus which was employed by Fahrenholz in 1936 as type of the subtamily Lemurphthirinae of the family Hacmatopinidae. This subtamily is here rejected.

Family Linogmathidae

First recomized by Enderlein as the subfamily Linognathinae of the family Haematopinidae and retained in this position by later workers. It is he re elevated to family rank. 


\section{Family Neolinognathidae}

This group was first recognized by Ewing as the subfamily Neolinognathinae of the family Haematopinidae and later raised to family rank by Fahrenholz.

\section{Family Pediculidae}

This family was apparently established under a family name, with the family ending as now employed, by Piaget in 1880, although it had earlier been recognized by Giebel under the name Pediculina. It is here utilized for two genera only, the genus Pedicinus-which has usually been assigmed to the Pediculidae-here being regarded as belonging rather to the Hoplopleuridae. 


\section{CHAPTER VI}

Review of the Families, Subfamilies, Genera and Species of the Anoplura Funi ly EAINOPHTHIRIIDAE Ender le in

1904. Enderlein, Zoologischer Anzeiger 28:136. (Names the family.)

1909. Enderlein, Deutsche Süpolar Expedition 10:506. (Divides the tumily into two subfamilies, Fchinophthiriinae and Antarctophthirinae.)

1910. Mjoberg, Arkiv tör Zoologi 6:177. (Names the tamily Lepidophthiriidae.)

1916. Ferris, Proceedings of the California Academy of Sciences (Series 4) 6:190. (Rejects the fanily Lepidophthiriidae as a synonym of fohinoph thiriidae.)

1928. Freund, Die Tierwelt der Nord-und 0stsee, Teil XI d. (Reviews the family and accepts the two subtamilies Echinophthiriinae and Lepidophthirinae.)

1929. Ewing, A Manual of Lxternal Parasites, pase 148. (Recornizes three subtamilies, Echinophthiriinae, Antarctophthirinae, and Lepidophthiriinae.)

1936. Fahrenholz, Zeitschrit't fiir Purasitenkunde 9:56. (Recognizes the two subfanilies Echinophthiriinae and Antarctophthirinae.)

1946. Eichler, Archiv für Naturgeschichte, Neue Folge, 10:345-398. (Kecoynizes the family with two subfamilies, Echinophthiriinae and Antarctophthiriinae and places the family in the "Family Series Echinophthiri formia.")

DESCRIPTIOA OF THE FAYILY. Anoplura which occur exclusively upon marine mamunals of the Suborder Pinnipedia of the Order Carnivora. Eyes not externally evident. Antenuae four- or five-segmented. Body more or less thickly beset with setae which are in some species modified into scales, in others only somewhat flattened and in at least one species normally cylindrical. Abdomen never with sclerotized tergal, paratergal, or sternal plates, membranous or leathery. Abdominal spiracles of a distinctive type, with a long, slender, and more or less membranous atrial chamber, the walls of which do not bear transverse markings. Female with the gonopods of segment eight never torming free lobes. Males with the genital sac formin: a flattened, median plate, alongside which lie the flattened parameres. Thorax never with a sternal plate which is apically or marginally free, althou h at times with an irregular sternal sclerotization. Middle and posterior legs always with a very stout tibiotarsus, in which the tibiotarsal division is scarcely or not at all evident. Anterior legs usually small and slender, with the tibiotarsal division evident, but in at least one species similar to the others.

NOTES. Nothin is to be gained by dividing this family into two subfamilies, and still less by dividing it into three as has been proposed. Division on the basis of the presence or absence of scales is contraindicated by the fact that Proechinophthirius fluctus (Ferris), wich lacks scales, is in other respects very similar to Antarctophthirus callorhini (Osborn) in which the vestiture of scales is less than that to be found in other members of the latter genus. A division on the basis of number of antennal segments also is contraindicated, since such a division would cut directly across any division on the basis of the presence or absence of scales. Nor is anything to be gained by division on the basis of the distribution of the species for, upon whatever basis such division may be made, it does not follow the relationships of the hosts. 


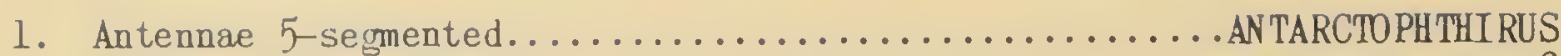

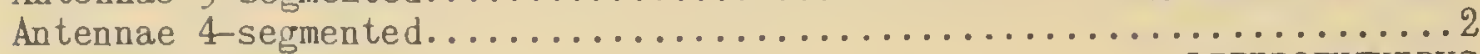

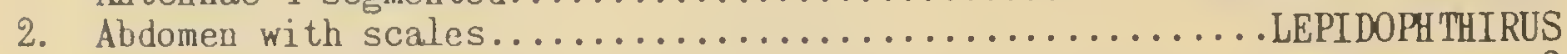

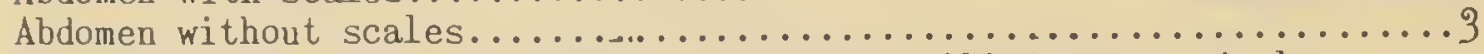

3. Legs all of same size and shape, with stout tibiotarsus and claw......

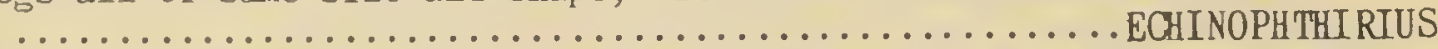
Anterior legs much smaller than the others and with small, slender claw . PROECHINOPHTHIRIUS

Genus ANTARCTOPHTHIRUS Enderlein

1906. Antarctophthirus Enderlein, Zoologischer Anzeiger 29:661.

1910. Arctophtirius Mjöberg, Arkiv för Zoologi 13:177.

1934. Antarctophthirus, Ferris, Contributions Toward a Monograph of the Sucking Lice, Part 7:484.

1941. Achimella Eichler, Archiv für Naturgeschichte, Neue Folge, 10:375.

GENERIC TYPE. The type of Antarctophthirus, by original designation, is Antarctophthirus ogmorhini Enderlein. The type of Arctophtirius Mjoberg is, by original designation, Baematopinus trichechi Bohemann. The type of Achimella is, by original designation, Baematopinus callorhini Osborn.

CHARACTERS. Echinophthiriidae with five-segmented antennae. Anterior legs small and with slender claw; middle and posterior legs very large and stout and with stout claw. Body more or less beset with flattened, scalelike setae.

NOTES. There is no justification for the recognition of the genus Arctophtirius Mjoberg. There is perhaps some justification for the recognition of Achimella, but that evidence is not considered sufficient.

\section{Key to Species of ANTARCTOPHTHIRUS}

1. Thoracic sternum beset only with slender setae; scales on the abdomen very f'ew, arranged more or less in patches on the dorsum of the abdomen and on the posterior portion of the venter; occurring on the

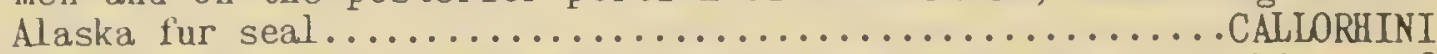

Thoracic sternum bearing scales; scales very abundant on the abdomen..2.

2. Thoracic sternum with a few long setae on its posterior border.......

Thoracic stemum without long setae along its posterior border.......4

3. Scales of the abdominal dorsum all very uniform in size and shape, ovoid, the apex slightly pointed; occurring on Phocarctos, Eumeto-

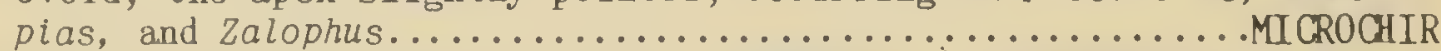

Scales of the abdomen (according to Enderlein) elongated-oval and of various sizes; occurring on Lobodon........................

4. Ventral side of the head beset with small, flattened, oval setae in ad-

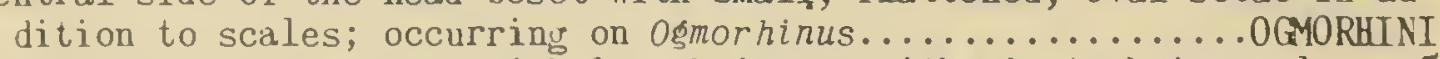

Ventral side of the head with long hairs or with minute hairs only...5

5. Ventral side of the head with many long hairs posteriorly..... TRICHECHI

Ventral side of the head with only 3-4 minute hairs posteriorly MAWSONI

\section{Antarctophthirus callorhini (Osborn)}

1899. Haematopinus callorhini Osborn, In The Fur Seals and the Fur-Seal Islands of the North Pacific 0cean 3:553; figure 1.

1915. Antarctophthirus monachus Kellog and Ferris, Anoplura and MalloWharil of North American Mammals, Stanford University Publications (no volume number), parte 49; text f'igures $17 \mathrm{~A}$ and 18 ; Plate III, t’igure 4. 
1934. Anturctophthlrus callorhint (0storn), Ferris, Contributions Towisd a Monugraph of the suchinir lice, Part 7:495; l'i rures 289, 2y0.

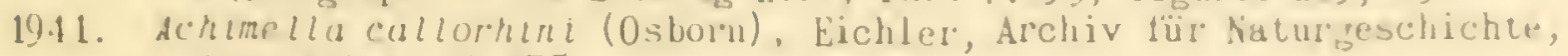
Nene folge, 10:275.

HOS'TS AND DIS'RIBUTION. The types of Osborn's Haematopunus rallarhbn were trom c'allorhlmus alaskanus t'rom the Pribilot Islands. The specinens upon which the nime monachus were based cane from 0stom is is loan but live no data other than as from "seal," but they were in all probabilitg trom the type lot. Since that time a tew more specimens have come to hand tront the type host on St. Panl and Pribilot Islands in the Berin: Sea.

\section{Autarctophthirus Lobodout is Enderlein}

1909. Antarctophthirus lobodont is Enderlein, Deutsche Südpolar Expedition $10: .510$; Fi rures $K K, N N$.

HOSTS AND DISTRIBUTION. Known ouly from the origillat record from Lobodon carcinophagus, Booth wandel Island in the Antarctic.

\section{Antarctophthirus matsoni Harrison}

1937. Antarctophthirus mawsoni Harrison, Australasian Antarctic Expedition, 1911-1914, Scientilic Reports, Series C-Zoology and Botany 2: $1: 11$; figure 1 .

HOSTS AND DISTRIBUTION. From Ommatophoca rossi, hing George $V$ lind in the Antarctic.

\section{Antarctophthirus microch ir (Trouessart and Neumann)}

1888. Rchinophthirius microchir Trouessart and Neumann, Le Naturaliste 10: 80; riisures.

1906. Antarctophthirus microchir (Trouessart and Neumann), Enderlein, Zoologischer Anzeicer 29:663; İigures 3, 4.

1934. Antarctophthirus microchir (Trouessart and Neumann), Ferris, Contributions Toward a Monograph of the Sucking Lice, Part 7:489; figures $285,236$.

1939. Antarctophthirus microchir californianus Fahrenholz, Mitteilungen aus dem entomologischen Verein Bremen, page 42.

HOSTS AID DISTRIBUTION. Types from Phocarctos hookeri, Aukland Island. Recorded also from Zalophus californianus and Eumetopias jubata from the coast of California.

NOTES. The supposed variety californianus was named by Fahrenholz purely upon the has is of differences in the illustrations presented by Enderlein and Ferris. These differences are of an order inevitably associated with differences in the preparation of specimens and involve no actual morphological characters. Actually the agreement between specimens from Calitiornia and the beautiful illustrations given by Enderlein is extremely close. The supposed variety is here rejected.

\section{Antarctophthirus ogmorhini Enderlein Finure 31}

1902. Echinophthirus setosus (Burmeister), Rothschild, Report of the Southern Cross Expedition, pare 224. (Yisidentitication)

1906. Antarctophthirus osmorhini Enderlein, Zoolopischer Anzeiger 29:662: text figures.

1909. Antarctophthirus ognorhini Enderlein, Enderlein, Deutsche Südpolar Expedition 10:509; 1 rures 174, 1,5, 181, 182.

1934. Antarctophthirus oemorhini Enderlein, Ferris, Contributions Toward a 


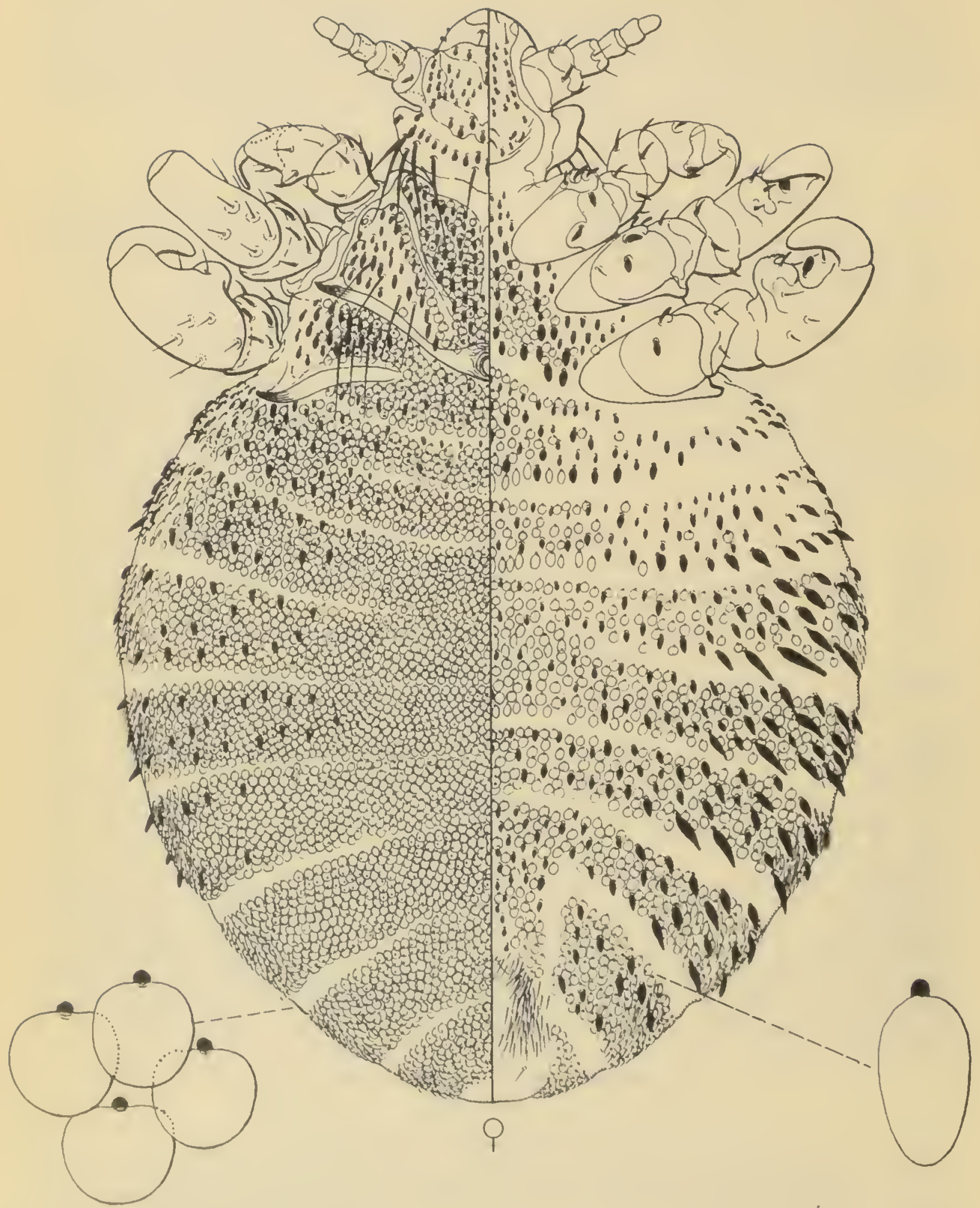

Antarctophthirus ogmorhini (Enderlein)

Figure 31 


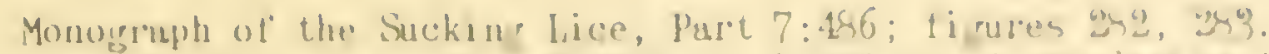

1937. Antarctophthtrus osmorhini bindoleiu, Harrisun, Au tralis lan Anl's re tic Expedition, 1911-1414, Lientitic Kepores, Series C, lavolós and thetiuny 2: $1: 11$.

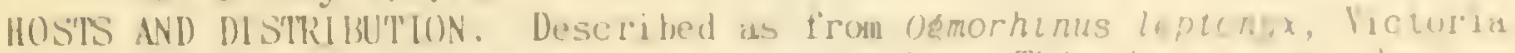
land and booth Wandel lstand in che Antaretic. This is apparent! won p) laced in the genus Hudrurga.

NOTRS. The accompany ing illustration was made from the ly gres in the Br.i tish Muse um.

\section{Autretophthirus trichechi (Bohmann)}

1865. Haematopinus trichechi Boheminn, Veteuskips Akademie forhandlumr. Kobnhaveu 22:557; Plate 35, l'igure 2.

1909. Antarctophthirus trichechi (Bohemann), Euderlein, beulsche Siudruliar Expedition 10:512; ri rures 172, 173, 185-188.

1910. Arctophtirus trichechi (Bohemaun), Mjoberg, Arkiv für Zoolori 10:13: 178; ligures 90-92.

1934. Antarctophthirus trichechi (lohemann), ferris, Contritutions Tonisd a Monograph of the Sucking Lice, Part 7:492; tigures 287, 288.

HOSTS AND DISTRIBUTION. Recorded by var'ious authol's from the walrus, odobaenus rosmarus and Odobaenus obesus, from various places in the Arctic.

\section{Genus ECINOPHTHIRIUS Giebel}

1871. Echinophthirius Giebel, Zeitschrift für die gesamten Naturwissenschaften $37: 177$.

1934. Echinophthirius, Ferris, Contributions Toward a Monougaph of the Sucking Lice, Part 7:475.

1946. Bchinophthirius, Hopkins, Annals and Marazine of Natural History, Series 11, 12:566. (Bears date of 1945, but published May, 1946)

GENERIC TYPE. Pediculus phocae lucas, which is considered to be a synonym of Pediculus horridus von Olfers.

CHARACTERS. With four-segmented antennae. Legs all of essentially the same size and form, stout and with stout claw. Abdomen thickly beset with stout, flattened, but not scale-like, setae.

HOSTS. Occurring as far as known only on seals of the genera Halichoerus and Phoca, of the family Phocidac.

NOTES. Ferris 11934) reviewed a considerable amount of material and concluded that this genus contains but one species. Hopkins (1946) suggested, althou'th apparently not on the basis of an examination of specimens, that "analogy with other genera suggests the possibility that it may prove necessary to divide the benus again into several species or subspecies." held that the genus contains but one species, as far as morphological evidence goes, al though at present nothing certain can be said concernin the supposed subspecies from seals in Lake Baikal.

\section{Echinophthirius horridus (von Olfers) Figures 32, 33}

1816. Pediculus horridus von 0lters, De vegetativis et animatis corporibus animatis reperiund is commentarius, Part 1, page 84. (Fide Fahrenholz)

1834. Pediculus phocae Lucas, Guerin's Magazin de Zoologie 4: Classe IX: Plate 121.

1838. Pediculus setosus Burmeister, Genera Insectorum. Species 12.

1857. Pediculus annulatus Schilling, Furlt, Archiv für Naturgeschichie 23: 281. 


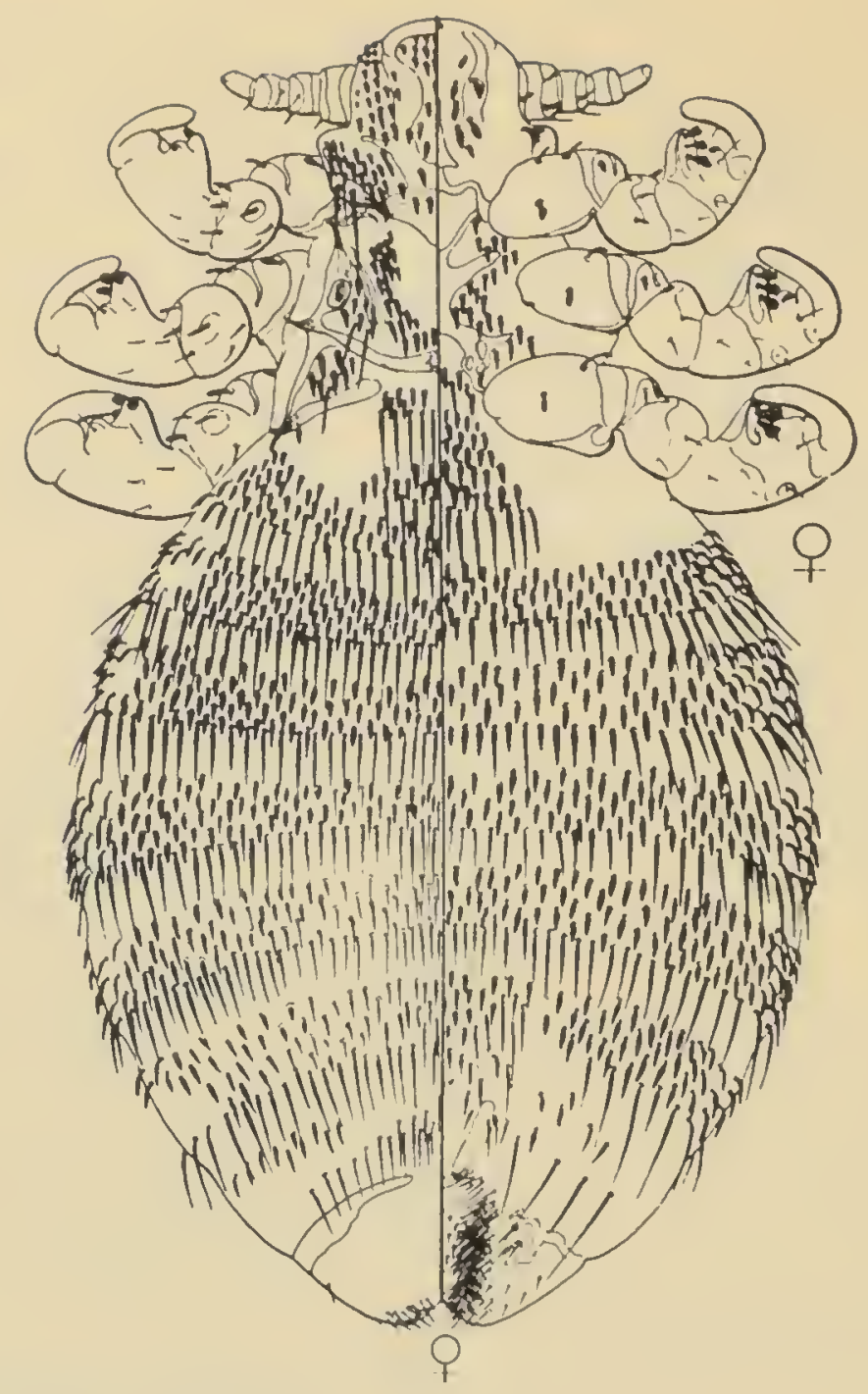

Echinophthirius horridus (von Olfers)

Figure 32

1874. Echinophthirius setosus (Denny) (sic), Giebel, Insecta Epizoa, page 42.

1880. Echinophthirius setosus (Lucas), Piaget, Les Pediculines, page 656; Plate 54, figure 1.

1886. Echinophthirius groenlandicus Becher, In Die Internationale Polarforschung 1882-1883, Beobachtungs Ergebnisse 3:60; Plate 5, fig. 1.

1897. Echinophthirius sericans Meinert, Vetenskabelige Meddelser Kjobenhavi 58: 177 .

1919. Echinophthirius horridus (von 0lfers), Fahrenholz, Jahresbericht des Niedersächsischen zooloyischen Vereins zu Hannover 5-10:22.

1928. Echinophthiriushorridus (von 0lfers), Freund, In Die Tierwelt der Nord- und 0stsee, Teil XI $d_{1}: 6$; figures 1, 2 .

1934. Echinophthirius horridus (von 0lfers), Ferris, Contributions Toward a Monograph of the Sucking Lice, Part 7:475; figures 277, 278.

1935. Kchinophthirius horridus baikalensis Ass, Travaux de la station limnologique de lac Buikal 6:21:25-29; 5 l'i gures.

1946. Echinophthirius horridus (von 0lfers), Hopkins, Annals and Magazine of Natural History, Series 11, 12:566. (Bears date of 1945, but puhlished May, 1946) 

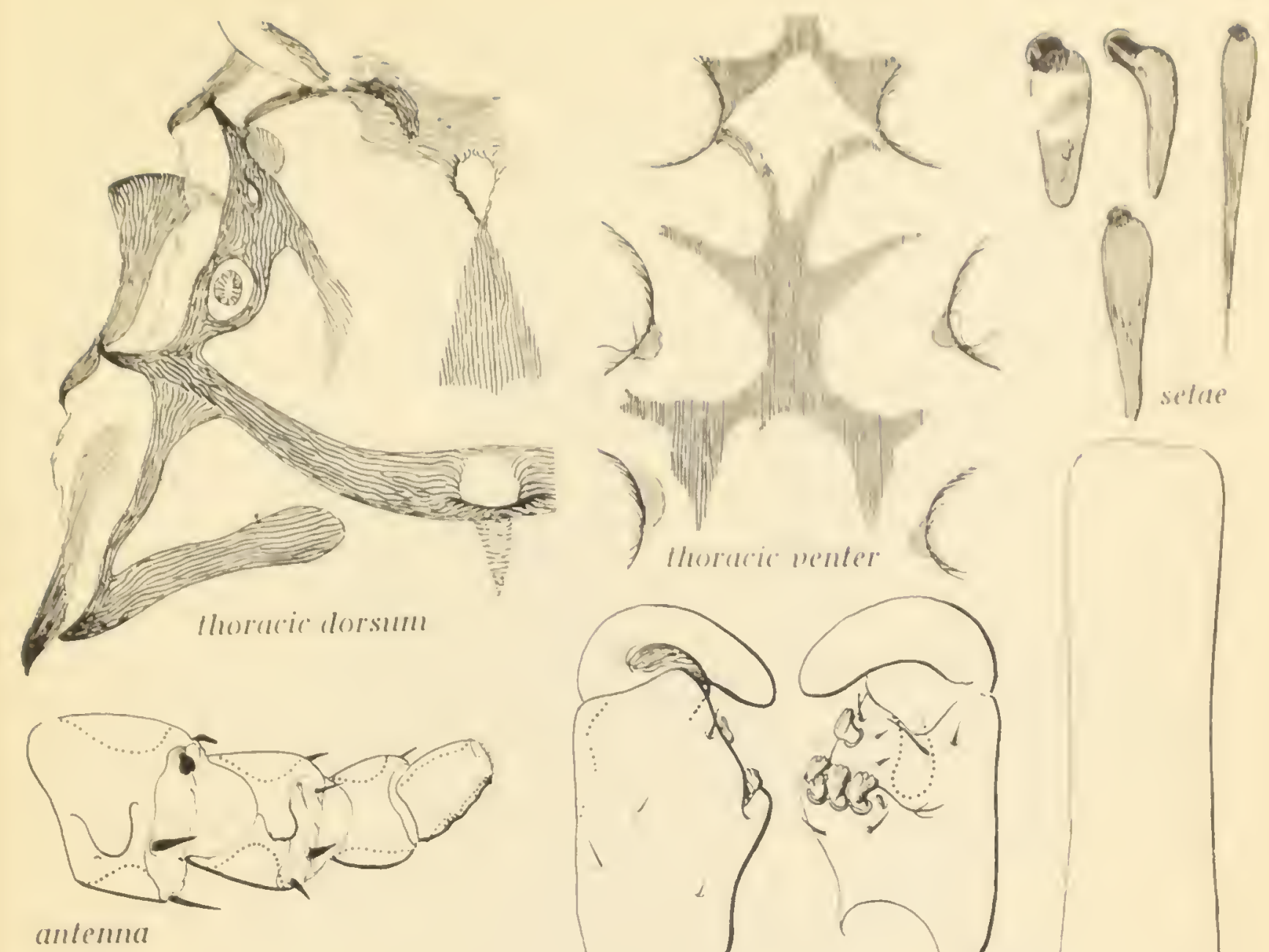

thoracie dorsum

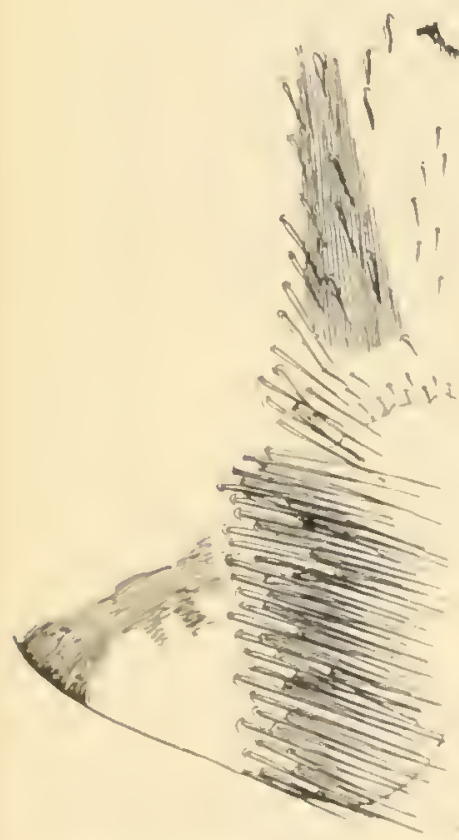

female genitalia

Echinophthirius horridus (von Olfers)

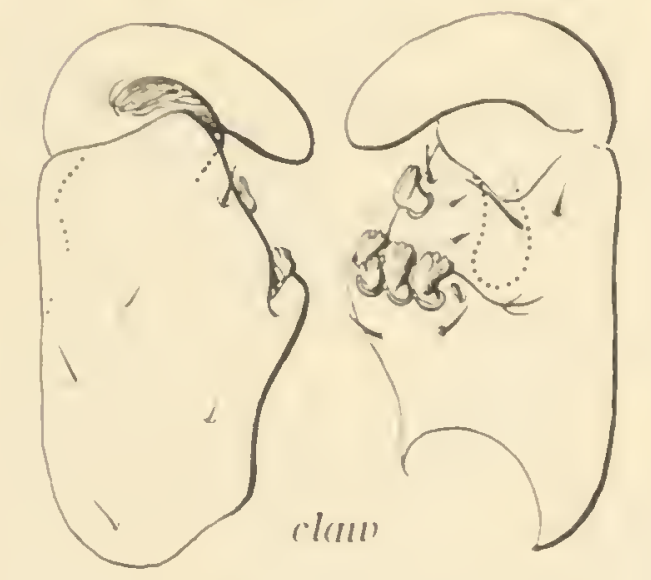

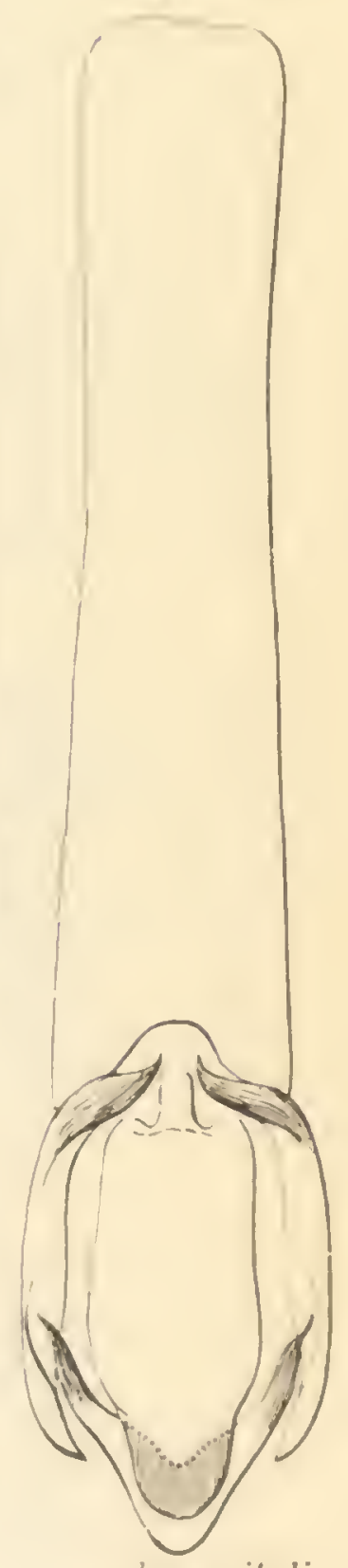

mule genitalia

Figure 33 
HOSTS AND DISTRIBUTION. Described by von Olfers as from Phoca vitulina. The type of phocae Lucas was said to have been taken from the same host species in a zoological garden in Paris. The type of sericans Meinert was from Phoca groenlandica and the type of groenlandicus Becher was ascribed to the same host. The species was recorded by Ferris from Phoca vitulina from the Shetland Islands, from Scotland, and from specimens taken at the Hambur's Zoological Garden; from Phoca hispida in the Beaufort Sea off Alaska; from Phoca richardi $i$ at Pacific Grove, California. The species has been recorded on various occasions from Phoca vitulina, Phoca variegata, and Halichoerus gryphus from the North Atlantic. Freund recorded specimens from Phoca baikalens is from Lake Baikal.

NOTES. Hopkins has reviewed the literature and has pointed out that the name annulata is a nomen nudum and that Burmeister's name setosus was proposed merely as a substitute for phocae Lucas.

The status of the supposed species groenlandicus is somewhat obscure. Ferris has examined specimens from "Greenland seal," but it is possible that this label meant nothing more than "a seal from Greenland." Mjöbern recorded specimens from Phoca groenlandica which he considered to be horridus. Freund, who reviewed the whole subject, considered it very questionable that a distinct species occurs on this host. It is here held that the evidence is all against the distinctness of the species Echinophthirius groenlandicus Becher.

Freund examined specimens from Phoca baicalensis which he considered to belong to horridus, this being anterior to the description of the supposed subspecies baikalens is from this host. We may therefore consider this supposed subspecies to be a synonym of horridus.

As already pointed out in connection with the discussion of the genus, the opinion is here held that there is no evidence to justify the naming of more than one species of this genus.

\section{Genus LEPIDOPHTHIRUS Enderlein}

1904. Lepidophthirus Enderlein, Zoologischer Anzeiger 28:44.

1934. Lepidophthirus, Ferris, Contributions Toward a Monograph of the Sucking lice, Part 7:498.

GENERIC TYPE. Lepidophthirus macrorhini Enderlein, the only included species.

CHARACTERS. Echinophthiriidae with four-segmented antennae. Anterior les much smaller than the others and with slender claw; middle and posterior less very larire and stout, with stout claw. Body very thickly beset with setae of various sizes and shapes, these mostly more or less flattened and the dorsum of' the abdomen also very thickly beset with scales.

Lep idophthirus macrorhini Enderlein Firrures 34,35

1904. Lepidophthirus macrorhini Enderlein, Zoologischer Anzeiger 28:46; figures $1-5$.

1929. Lepidophthirus macrorhini Enderlein, Bedford, Director of Veterinary Services, Union of South At'rica, Report 15: 507 .

1934. Lepliophthirus macrorhini Enderlein, Ferris, Contributions Toward a Monograph of the Sucking lice, Part 7:499; 'i gures 291, 292.

1937. Lepinophthirus macrorhini Enderlein, Harrison, Australasian Antarctic Expedition, 1911-1914, Scientific Reports, Series C-Zoology and lotany 2:Part 1:13.

HOSTS AND DISTRIBITION. Known only from the southern sea elephant or elephant seal, from Keroguelen Island and also from near Cape Town, South Africa, and from Macquaric Island. 


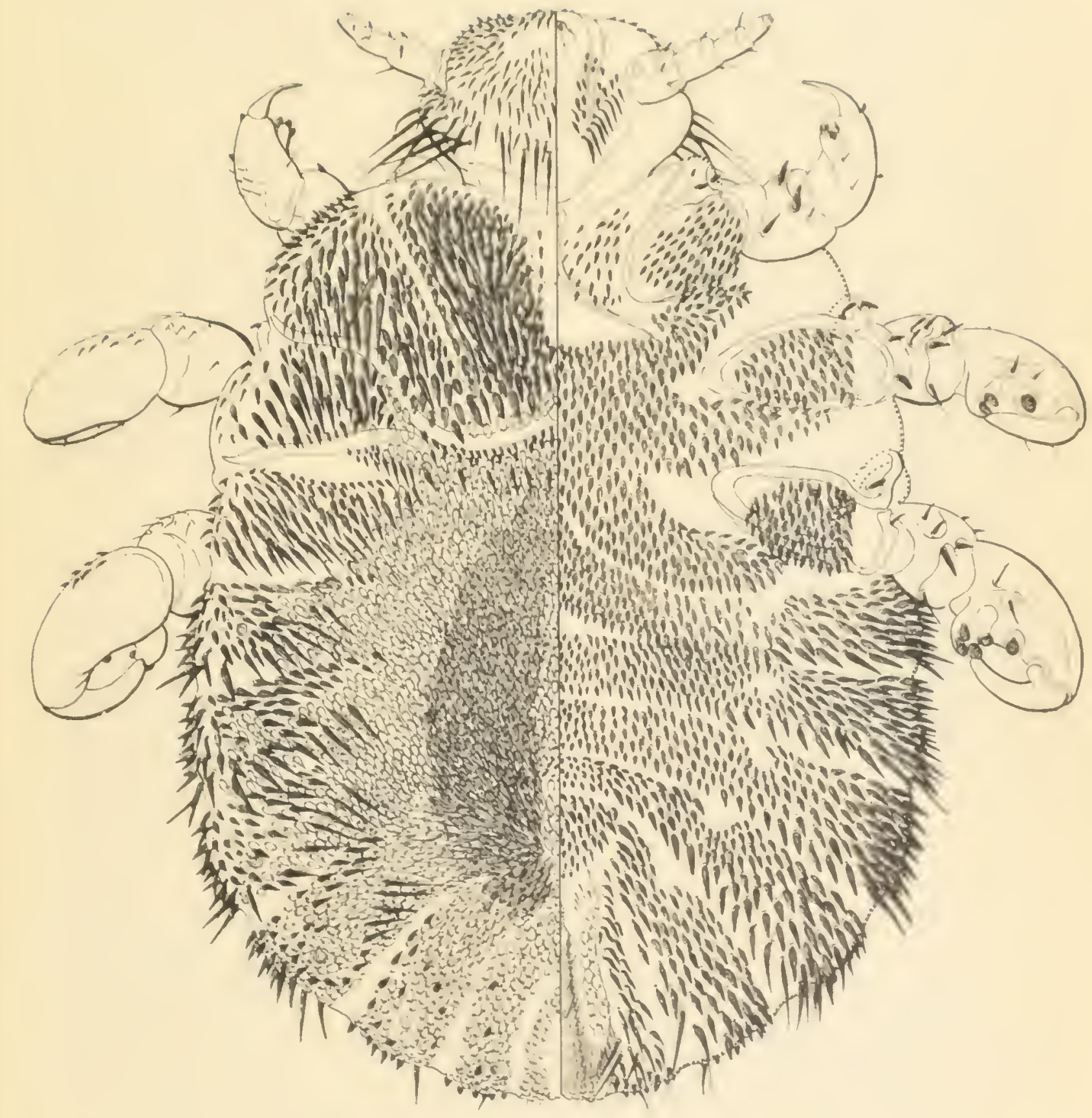

Lepidophthirus macrorhini Enderlein

Figure 34 


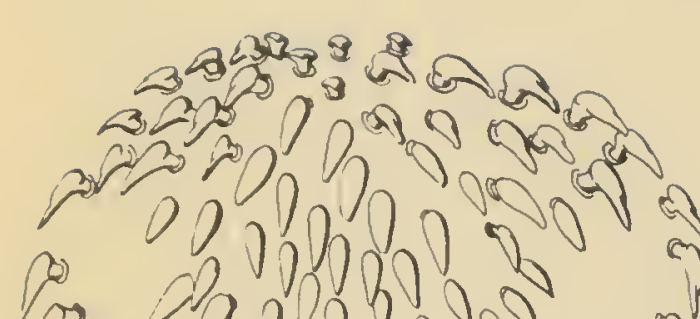

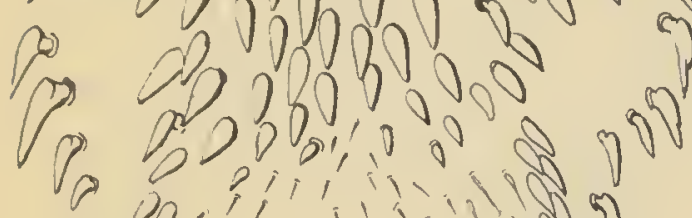

co (20)

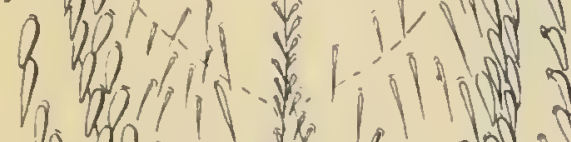
9010 ? B? Cow

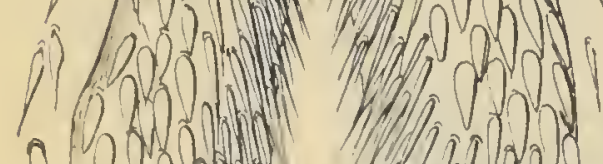
vishmo

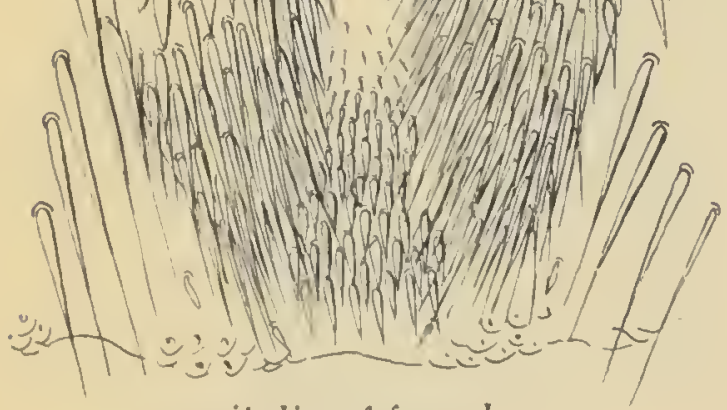

genitalia of female

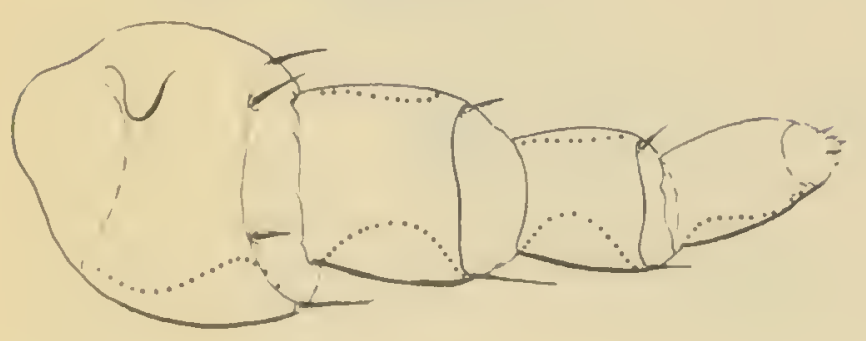

(Intenina
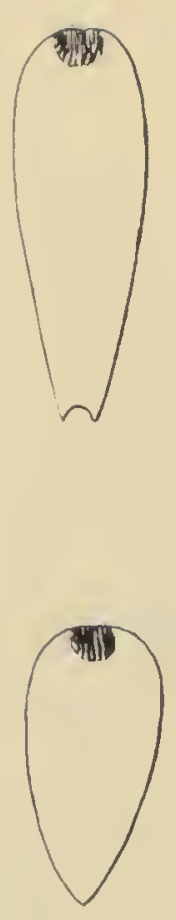

scules

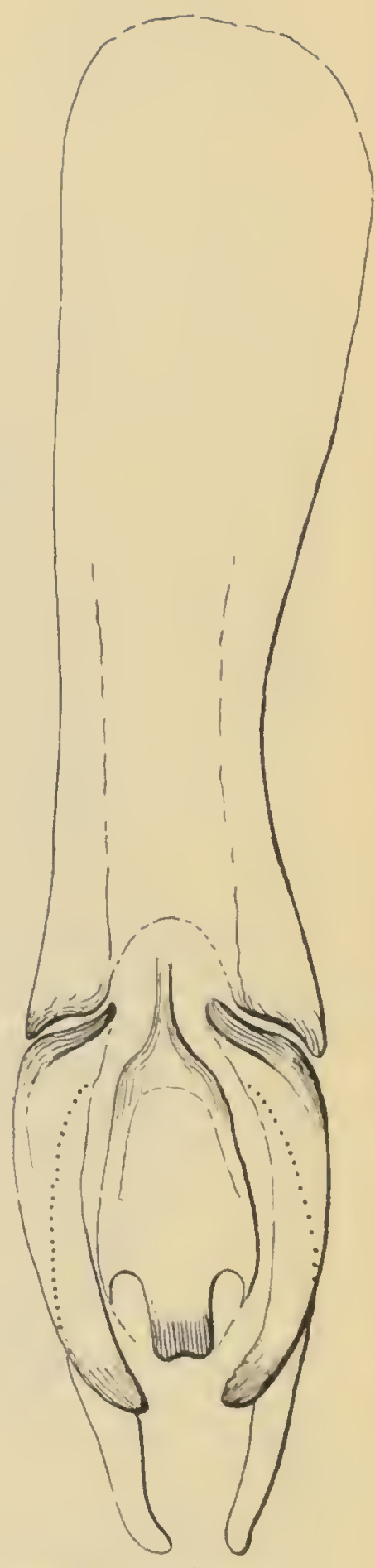

grnitalia of male

Figure 35 
19.33. Prouchlnophthlrus kiwing, Journal ot the hashington Academ of soiences 13: 149.

1934. Proechlnophthirius, Ferris, Contributions Toward a Mononguph of the Sucking lice, Parl 7:480.

LFNEKIC 'TYlE. E'chinophthrtus fluctus ferris, the only included species.

CHARACTERS. Echinophthiriidae with tour-se rmented antennue. Thorax with no sclerotized sternal areas. Abdomen beset with setae of various shupes and sizes, but none t'lattened and none being scale-like. Anterior legs small and with weak, slender claw; middle and posterior legs lurige and stout, with stout claw.

\section{Proechinophthirius fluctus (Ferris) pigure 36}

1916. Bchlnophthirius fluctus ferris, Entomological News 27:366; rigure. 1923. Proechinophthirus fluctus (Ferris), Ewing, Jourual of the hashington Acadeny of' Sciences 13:149.

1934. Proechinophthirus fluctus (Ferris), Ferris, Contributions Toward a Monouruph of the Sucking Lice, Part 7:481; t'igures 279, 280, 281.

HOSTS AND DISTRIBUTION. The types of the species were taken from the stut'ted skin of an Otariid pup in the collection of Stanford University, this bearing no data. The pup was identified as being that of a Stellar's sea lion, Eumetopias jubata, but this may have been an error. The species has since been taken from the Alaskan tur seal, Callorhinus alaskanus, on St. Paul Island and on the Pribilof Islands in Bering Sea.

\section{Fami ly HAEMATOPINIDAE Enderlein}

1904. Enderlein, Zoolorischer Anzeiger 28:136.

DESCRIPTION OF THE FAYILY. Anoplura in which the paratergites of the abdominal segments are strongly sclerotized and form lateral lobes or prominences but are never marginally tree from the body wall. Spiracles with the atrium beset internally with numerous points. Legs all of substantially the same size and with claws of the same size and shape. Clearly defined eyes present or absent, if absent the head with pronounced ocular points just posterior to the antennae. Thorax always with a well-defined notal pit and with a pair of sternal, apophyseal pits. Abdomen usually with the derm of the dorsum at least very finely wrinkled, at times slightly sclerotic, and with sclerotized areas, which, while somewtat more sclerotized than the surrounding derm, are defined more by the absence of this minute wrinkling. Gonopods of segment eight of the female always well developed. Genitalia of the male never with free parameres. Female apparently without spermatheca.

NOTES. At one time this family was considered to include the great majority of all the sucking lice, but it has been progressively reduced until here it is considered to contain but two genera, Baematopinus and Pecaroecus, the latter having but one species. Hebb (1936) considered it to include four genera-Haematopinus, Baematomyzus, Bybophthirus, and Scipio-and possibly also the genus vicrothoracius. Baematomyzus, as has already been and cannot too strongly be-emphasized, does not belong in this 0rder and the present writer is unable to see any special affinity between Baematopinus and the two genera Bybophthirus and scipio. There has been some temptation to include vicrothoracius in the family, but this has finally been resisted.

Actually the family is very difficult to define, unless it be restricted to the single genus Haematopinus. In the past, when the presence of defin- 


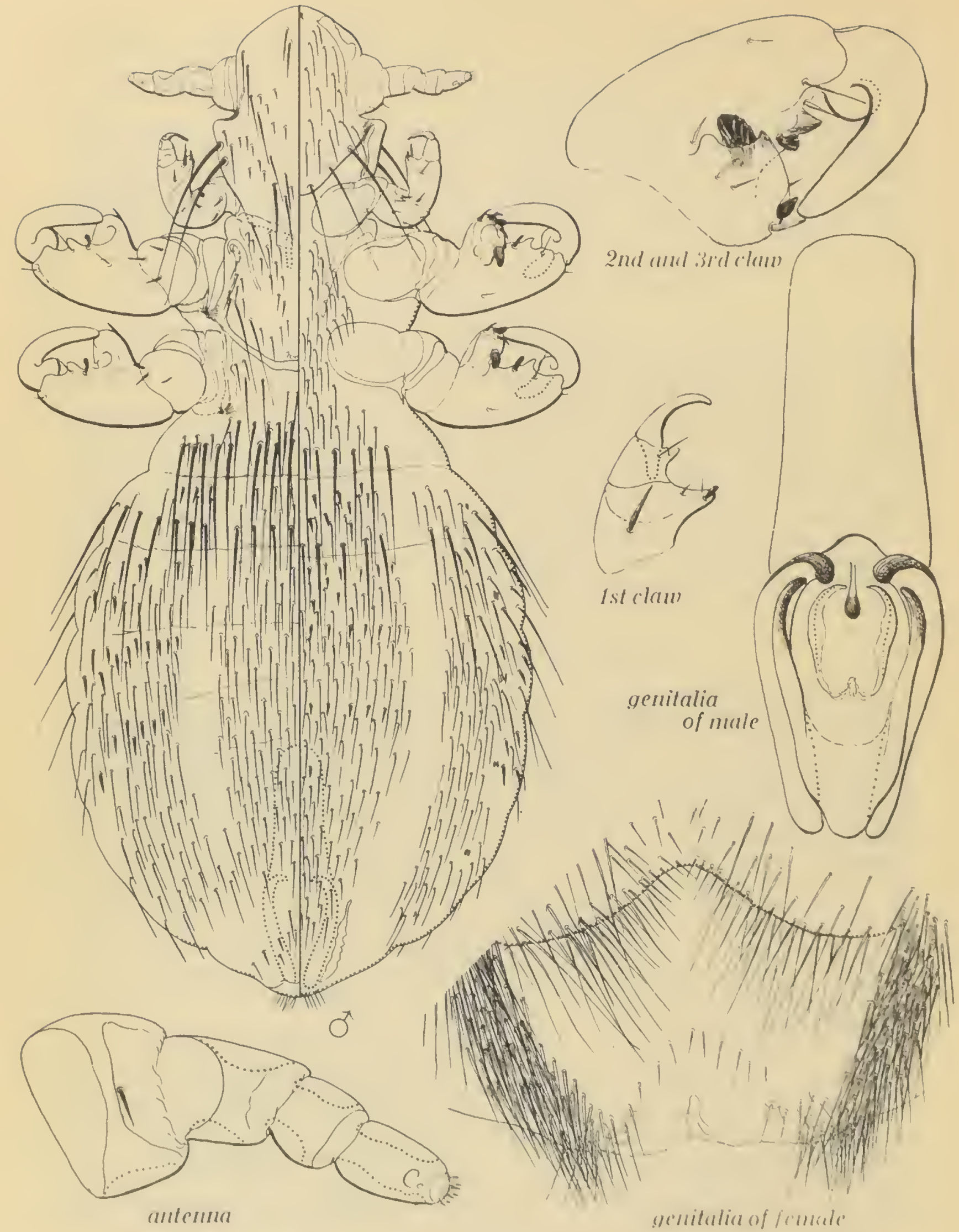

Proechinophthirus fluctus (Ferris)

Figure 36 
i te eyes was recornized only an peetculus, pentrus, and peductnus, the problem was not ditlicollt, hut now that well-delined eges with in distince

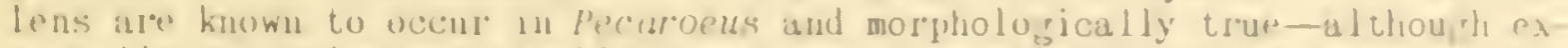

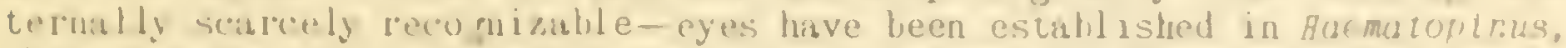
there remisins litue by which the Pediculidae and the Haematopindas can be separated. Perhats even yet it lias not been possible to tree our thinkin lrom the presuppusition that the classitication of the lice should tollow the phy lopeny of the hosts. This matter will be considered turther in cunnection with the discussion of the Pediculidie.

\section{Key to the Genera of llaematopinidae}

Head with pronomed ocular points posterior to the anteunae...llAFMATUYIS

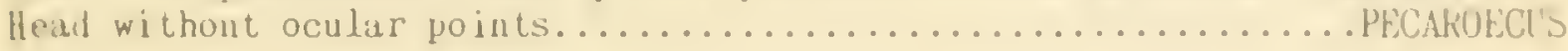

\section{TienUS IIAEMA'TOPINUS Leach}

1815. Hoematopinus Leach, Edinburgh Encyclopaedia, Supplenent 1:24.

1842. Haematopinus, Denyy, Yonorgraphia Anoplurorum br.itanniar, page 24.

1890. Haematopinus, Piaget, Les Pediculines, paye 633.

1904. Haematopinus, Enderlein, Zoolorischer Anzeirer 28:139.

1933. Haematopinus, Ferris, Contributions Toward a Yonogruph of the Suckinit Lice, Part 6:419.

1942. Haemutopinus, Webb, Proceediniss of the Zoological Society of London 118: 578 .

GFAERIC TYPE. Pediculus suis Linnaeus.

CHARACTERS. Haematopinidae in which the head is produced into distinct ocular points posterior to the antennae, but with distinct eyes lacking. leges with a prominent, apically free, and more or less sclerotized process on the ventral side between tibia and tarsus.

NOTES. The nembers of this genus occur on hosts of the families suidae, Bovidae, and Cervidae of the Order Artiodactyla and the family Equidae of the Order Perissodactyla.

\section{Key to Species of HAEMATOPINIS}

The species breviculus is omitted from this key because of the inadequate description.

1. Female with the gonopods of seigment eight slender, apically acute, curved and almost sickle-shaped; known from Equus burchelli in Africa

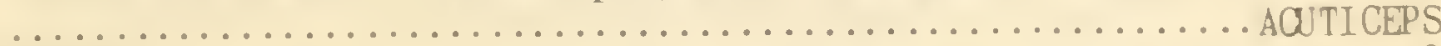

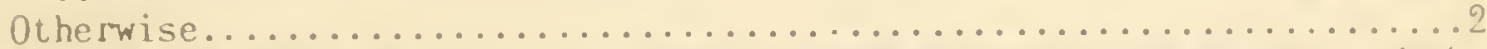

2. Female with the gonopods of seyment eight elongate and narrow, their mesal margins straight and divergent: occurring on Cervus unicolor in

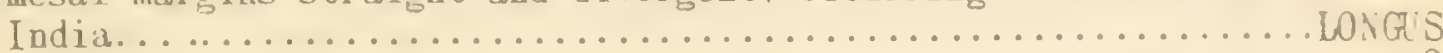

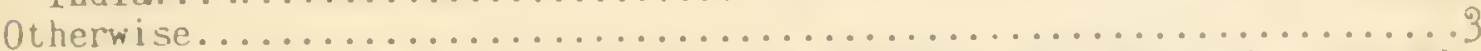

3. Genitalia of the male with the penis strongly asymetrical, stron:ly sclerotized at one side, this sclerotization much swollen and tormin

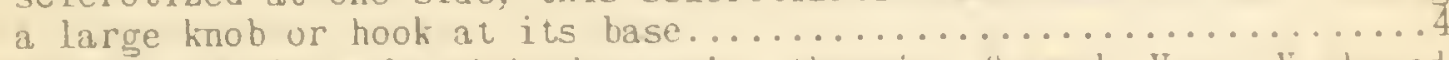
Genitalia ot the male with the penis otherwise formed, Y-or I-shaped

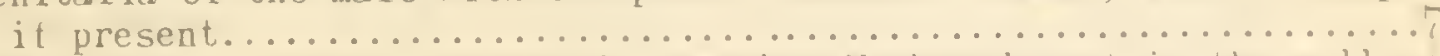

4. Female with a deeply pi mented, somewhat $W$-shaped spot in the wall of the vagina just anterior to the vulva: occurring on Taurotragus and

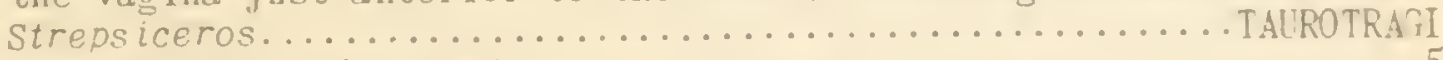

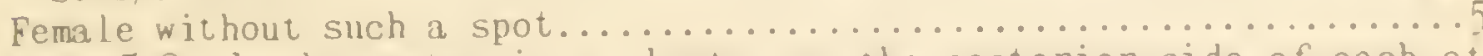

5. With 5-8 slender setae in a cluster on the posterior side of each ot the lateral lobes of the abdomen; occurring on Bos bubalus normally and apparently also on cimels.................... TUERCL'LATIS 
With not more than $2-3$ setae in this position on any segment.......6 6. Head very short and broad, the length only slightly greater than the breadth; occurring on domestic cattle throughout the world...........

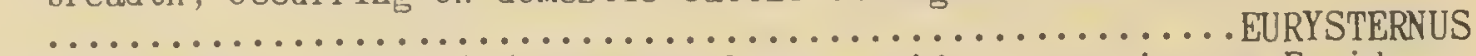

Head elonisate, from $2-2.5$ times as long as wide; occurring on Equidae.. .ASINI

7. An elongate, slender species in which the paratergal plates of the abdomen form prominent, acutely conical points; occurring on Syncerus

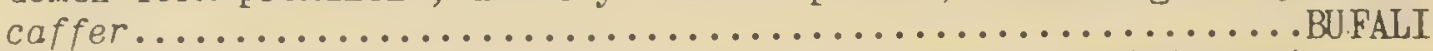

Stout-bodied species, the paratergal plates forming rounded prominences

8. Head very short and broad, the width of the hindhead mo

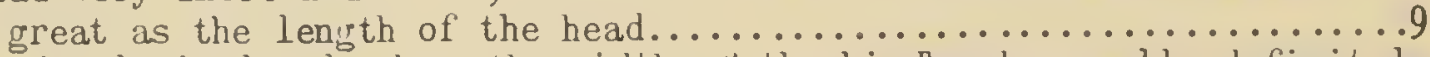

Head relatively slender, the width of the hindhead normally definitely

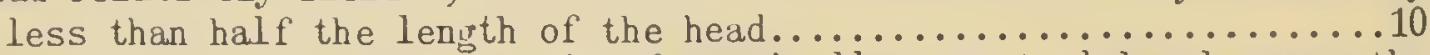

9. Marrin of the vulva with a pair of marginally serrate lobes between the bases of the gonopods; occurring on Phacochoerus...........PHACOCHOERI Margin of the vulva with an undivided and simple median lobe between the bases of the gonopods; occurring on Poramochoerus............LATUS

10. A stout-bodied form with well-developed, broad, paratergal plates and with the dorsum of the abdomen normally with sclerotized areas; oc-

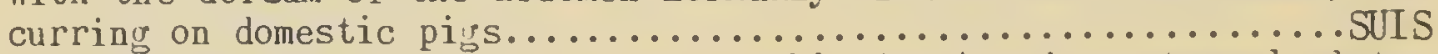

A more slender-bodied form with very weakly developed paratergal plates and with the dorsum of the abdomen membranous; occurring on the wild

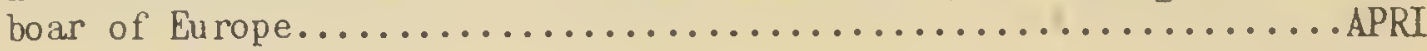

\section{Haematopinus acuticeps Ferris}

1933. Haematopinus acuticeps Ferris, Contributions Toward a Monograph of the Sucking Lice, Part 6:467; fi rure 275.

1948. Haematopinus acuticeps Ferris, Webb, Proceedings of the Zoological Society of London 118:581; Plate I, figure G.

HOSTS AND DISTRILUTION. Known only from the original record, from $B i p-$ potigris (=Equus) burchelli, Mpwapwa, Tanganyika Territory, East Africa. This host is later cited by Webb as Equus burchelli muansae.

NOTES. Whatever may be the status of the two supposed subspecies burchellis and elegans of Haematopinus asini which actually or presumptively occur on this same host, there can be no question of the status of acuticeps. The form of the gonopods of the female is alone sufficient to distinguish it.

\section{Haematopinus apri Goureau}

1866. Haematopinus apri Goureau, Bulletin de la Société des Sciences Historiques et Naturelles de l'Yonne, Auxerre 20:205.

1870. Haematopinus urius (Nitzsch), Giebel, Insecta Epizoa, page 45; Plate 2 , figure 2.

1880. Haematopinus urius (Nitzsch), Piaget, Les Pediculines, page 654; Plate 48 , figure 4.

1933. Haematopinus aperis Ferris, Contributions Toward a Monograph of the Sucking lice, Part 6:431; t'igures 252B, 253B, 255A-D, 256F, G, M, N.

1939. Haematopinus suis (Linnacus), Fahrenholz, Leitschrift für Infektionskrankheiten, parasitare Krankheiten und Hygiene der Haustiere 55: 2: 138 ; limures $1-5$.

UOSTS AND DISTRI UITION. From Sus scrofa, the wild swine of western Europe.

NOTES. The confusion of this species with Haematopinus suis (Linnaeus) will be discussed in more detail in connection with the latter species. It is sulficient here merely to remark that the lice of Sus scrofa, the wild 


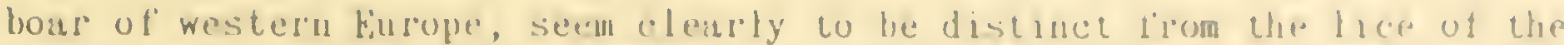
domesticaled swine ot the present dity, which are thou hit to histe heren dre rived from pirs of eastern Asia that have been luported inte burope.

The purely nomenclatorial problen concerning the proper name tor this species preseuls some diflicull points. In pre-linnaean limes the uane pediculus urius was used very evidently for lice trom the pi s of Europe which were derived from the wild swine ot Europe, but Linnaeus did not employ this mane. It was revived by Nitzsch in 1818 and used by him, clearly as a substitute tor the name suis employed by Linnaeus, since surs is placed as u synonym of urius.

In 1870 Giebel used the name urlus for lice of domestic and wild swine. His illustration was said by him to have been prepared by Nitzsch in 1805. In the writer's opinion it clearly represents the lice of wild swine. A case might, therefore, be made vut for the use of the name urius since the type of the name urius as eaployed by Nitzsch would "ix the application of the name it suis be reugaded as a separate species.

In 1880 piaget used the nane urius. The writer has exumined Piaget's material and used his specimens as the types for the name aperis, which wis published in 1933.

However, according to f'ahreuholz, the name Haematopinus apri foureau was proposed in 1866 for the lice of wild swine of' Europe. The present writer has not seen this work and accepts the name on Falirenholz' word. In any case this name certainly reduced aperis to synonymy.

Hopkins has expressed the opinion that this torm should be regarded as a subspecies of suis, but the writer cannot concur in this.

\section{Haematopinus asini (Linnaeus) Fivures 37,38}

1758. Pediculus asini Linnaeus, Systena Naturae, Edition $\lambda$, purge 612.

1829. Pediculus asini (Linnaeus). Stephens, Catalogue of British Insects 2: 329 .

1838. Pediculus macrocephalus burmeister, Genera Insectorum, Rhynchota, Species 18.

1916. Haematopinus ele@ans Fahrenholz, Archiv tür Naturgeschichte, Abteilun!s $\mathrm{A}, 31: 11: 22$; fi grure 8 .

1916. Haematopinus minor Fahrenholz, Zooloyischer Anzeiger 48:90.

1933. Haematopinus as ini (Linnaeus). Ferris, Contributions Toward a Yonograph of the Sucking Lice, Part 6:464; 1'igures 273, 274, 27.5C.

1948. Haematopinus asini asini (Linnaeus), Hebb, Proceedings of the Zoological Society ot' London 118: 578.

1948. Howatopinus asini macrocephalus (Burmeister), hebb, Proceedings of the Zoological Society of London 118: 578 .

1948. Baematopinus asini minor Fahrenholz, Hebb, Proceedings of the Zoological Society of London 118:580; firures $g-i$; Plate I, firure D.

1948. Haematopinus as ini burchellis Hebb, Proceedings of the Zoological Society of London 118:580; firures $d-f:$ Plate I, figures A, B, E.

1948. Baematopinus asini elegans Fahrenholz, Kebb, Proceedings of the Zoological Society of London 118: 780 .

HOSTS AND DISTRIBLTION. The type host is EOuUs asinus. Recorded also from domestic horses in various parts of the world and, in the opinion here adopied, apparenty occurring normally on zebras. The type hos of macrocephalus apparently was the domestic horse. That of minor was Equus burchelli, and it is recorded also from Equus burchelli Eranti. The type host of burchellis is Equus burchelli sranti. The type of ele fied, being recorded merely as from Gobabis, Southwest Africa.

NOTES. In these species from the genus Equns re have a most extraordinary situation. Hebl (1948) has reviened the group and adopter the point 


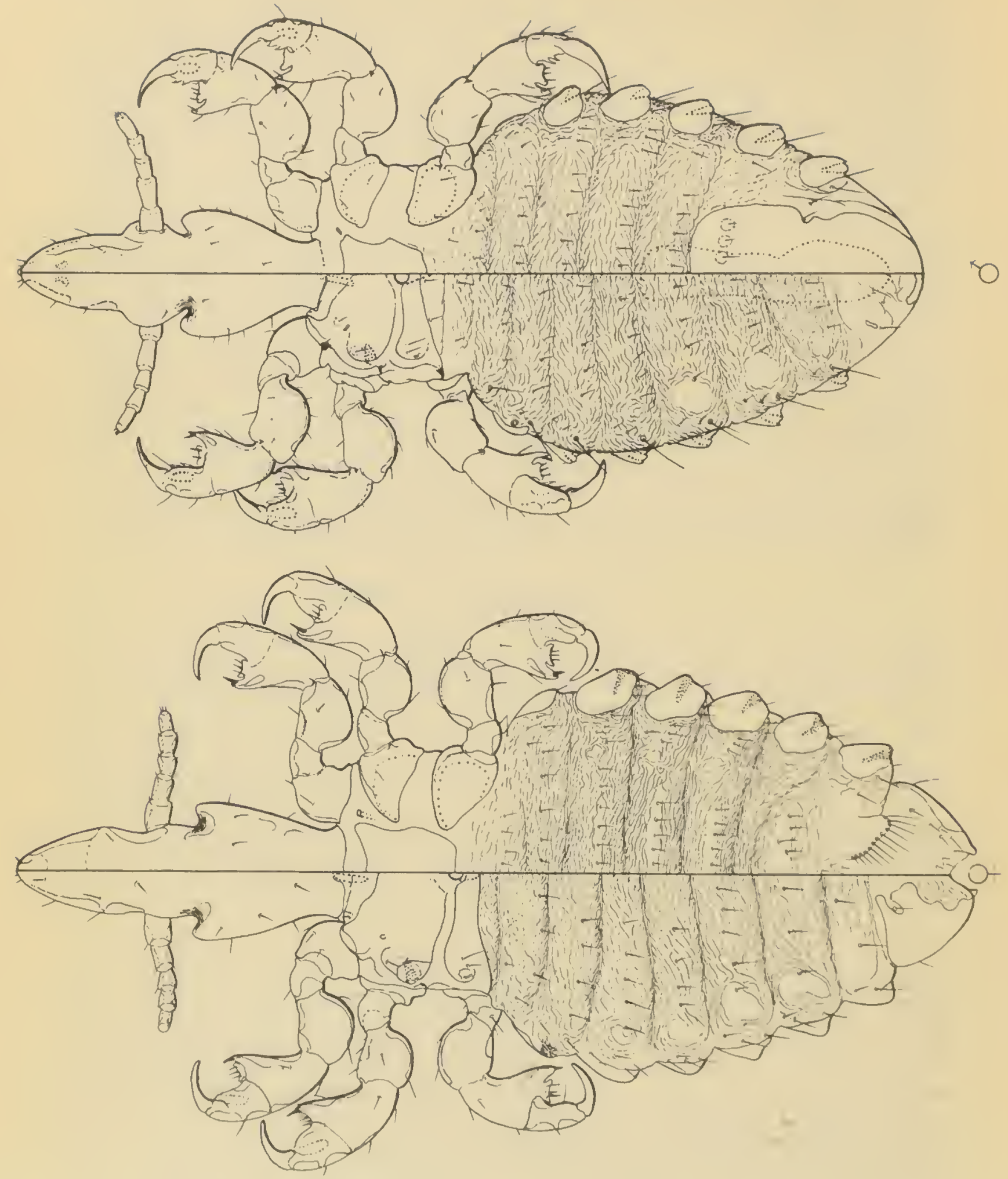

Haematopinus asini (Linnaeus)

Figure 37 


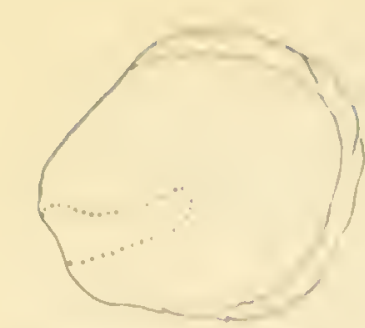

perateryul plate

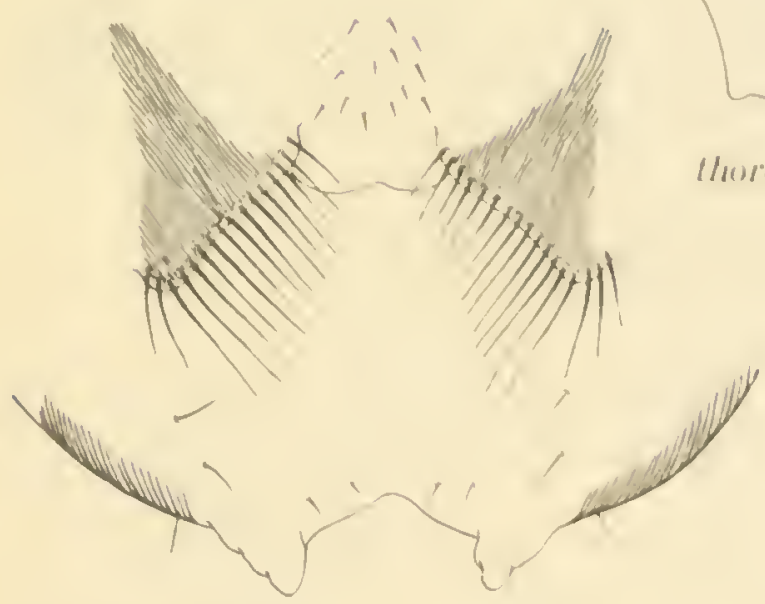

fenule semilulia

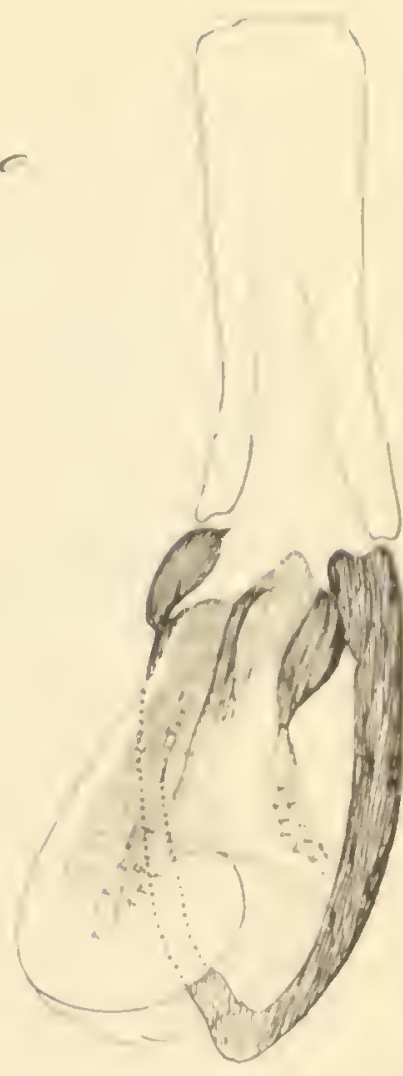

mule yenilalia

Figure 38

Haematopinus asini (Linnaeus), details

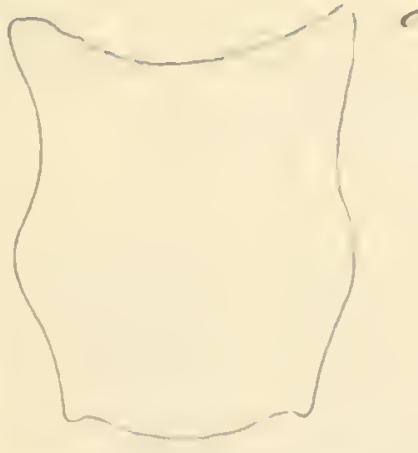

loraric stermul phult

of view that we have to do with a series of "subspecies," some of which occur upon the same host. They are described by him as differing only in the form of the head. It may be noted that Haematopinus acuticeps Ferris occurs also on Equus burchelli, but this species is very evidently distinct in every respect, includin the genitalia of the female.

The point of view adopted by the present writer toward the establishment of subsecies in this proup will be considered elsewhere in this paper. It is the opinion here adopted that in the case of these supposed subspecies the evidence for their separation from asini is not convincing except in the case of' the form identit'ied hy Hebb as minor. The present writer examined the types of this species in connection with his earlier work and noticed no difference which would justify the recomition of this form in any way, but the illustration jiven by Hebb (his Plate I, figure D) suggests that it may merit some recomition, although it is not evident that the form illustrated by him is the same as that to which the name was applied by Fahrenholz.

Haematopinus breviculus Fahrenholz

1939. Haematopinus breviculus Fahrenholz, Yitteilungen aus dem entomologischen Verein bremen, pare 32 : ti mures 1-3.

HOSTS AND DISTRIBUTIOY. Baser ujon a sinfle female, without indication of host or oripin. Said by Fahrenholz to be very close to eldysternus. 
1778. Pediculus bufali de Geer, Memoirespour servir a l'histoire naturelle des insectes apteres 7:68; Plate I, figures 11, 12.

1781. Pediculus bufali-capensis Fabricius, Species Insectorum, Volume 2.

1816. Pediculus papillosus von Olfers, De vegetativis et animatis corporibus in corporibus animatis reperiundis commentarius, page 85.

1844. Pediculus phthiriopsis Gervais, In Walckenaer, Histoire naturelle des insectes apteres 3:306.

1915. Baematopinus neumanni Fahrenholz, Archiv für Naturgeschichte, Abteilung $\mathrm{A}, 81: 11: 8$.

1935. Haematopinus bufalt (de Geer), Ferris, Contributions Toward a Monograph of the Sucking Lice, Part 6:460; figures 270-272.

HOSTS AND DISTRIBUTION. Originally described as from "le Buffle d'Afrique, "from the Cape of Good Hope. Later recorded from Buffelus caffer and "buffalo" in Nyasaland and the Congo Free State. Mr. G. H. E. Hopkins has kindly supplied specimens from Buffelus (or Syncerus) caffer radcl iffet on the shores of Lake Edward.

\section{Haematopinus eurysternus (Nitzsch)} Figures 39,40

1818. Pediculus eurysternus Nitzsch, Germar's Magazin für die Entomologie 3:305.

1829. Baematopinus eurysternus (Nitzsch), Stephens, Catalogue of British Insects 2:329.

1916. Haematopinus quadripertusus Fahrenholz, Archiv für Naturgeschichte, Abteilung A, 81: 11: 19; t'igures 15-17.

1916. Baematopinus parviprocursus Fahrenholz, Archiv für Naturgeschichte, Abteilung A, 81:11:21.

1933. Haematopinus eurysternus (Nitzsch), Ferris, Contributions Toward a Monograph of the Sucking Lice, Part 6:448; figures 263, 264.

1950. Haematop inus quadripertusus Fahrenholz, Muesebeck, Journal of Economic Entomology 43:119, 133.

HOSTS AND DISTRIBUTION. Originally described from domestic cattle in Europe and known from these hosts from many parts of the world.

NOTES. Baematopinus quadripertusus was described from males only, from cattle at Banjo, in the Cameroons. Haematopinus parviprocursus was described from females only from unknown host from the then German Southwest Africa. The types of both these supposed species were examined by Ferris, who came to the conclusion that they represent the same species and that this species is to be identified as Baematopinus eurysternus.

This question has been reviewed again in connection with the present work and the opinion previously expressed is still maintained. It was pointed out by Ferris (1933) that specimens from cattle in tropical countries seem to be much larger and of deeper pigmentation than those from northern areas, although no morphological differences could be detected. The only basis then for the separation of the cattle lice into two or more species is that of size. It must be noted, however, that the cattle of many tropical areas, such as Asia and Africa, are derived apparently from a different source from the cattle of Europe and North America, the former apparently having come largely from the "hump-backed" type and there may be an association with these differences of host origins.

Specimens of the large form have been collected in Florida in the United States. These were sent to the writer by Dr. C. F. W. Muesebeck of the United States lepartment of Arriculture and the information noted above was imparted to him. He elected to regard these specimens as representing a species different from that usually found in the United States and has pub- 


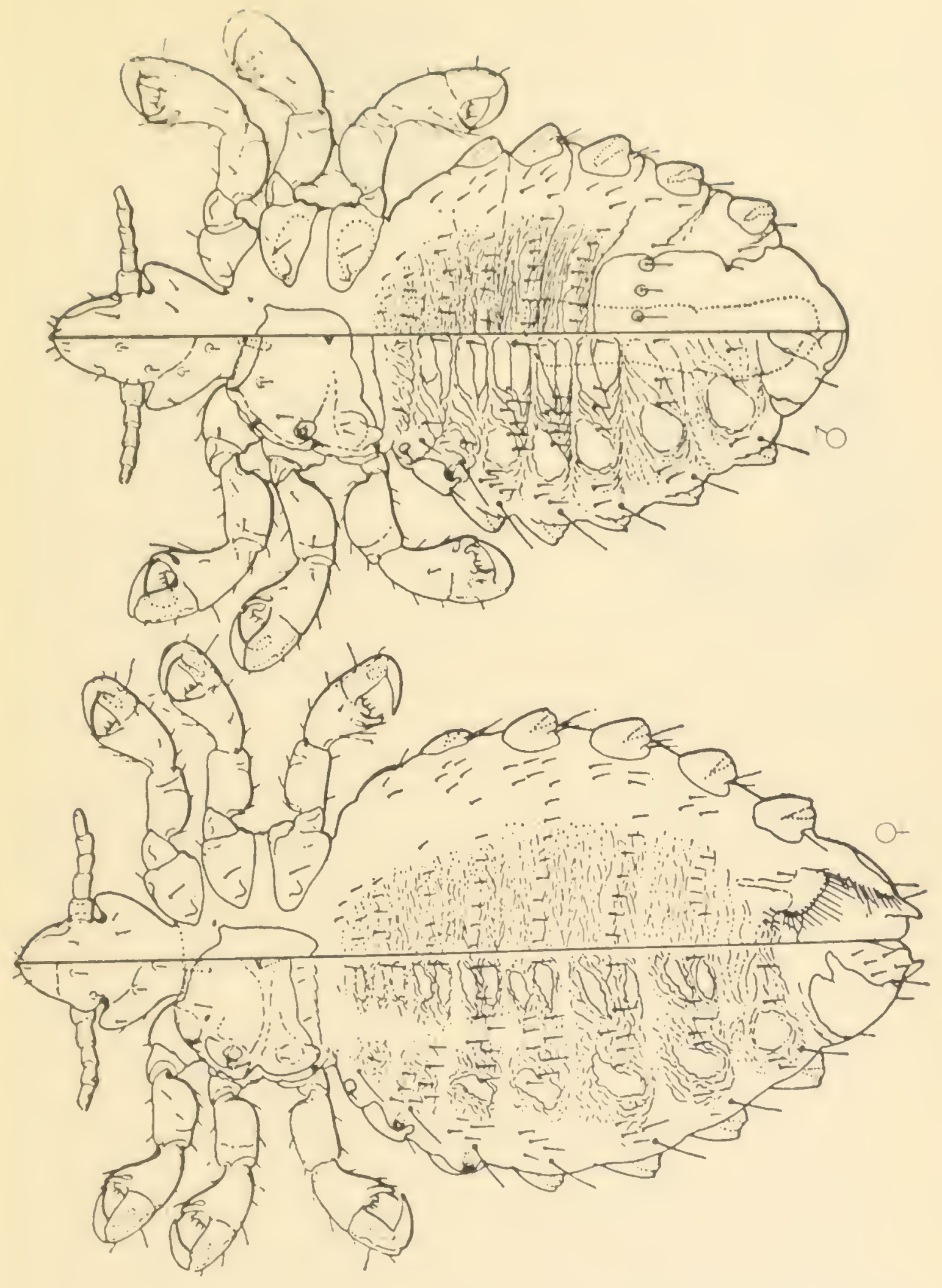

Haematopinus eurysternus (Nitzsch)

Figure 39 


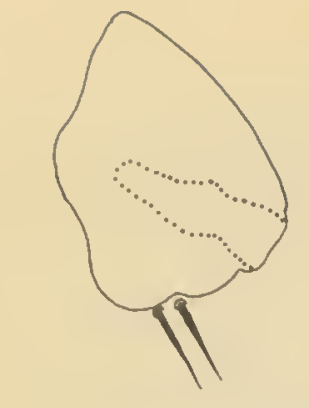

paratergal plate

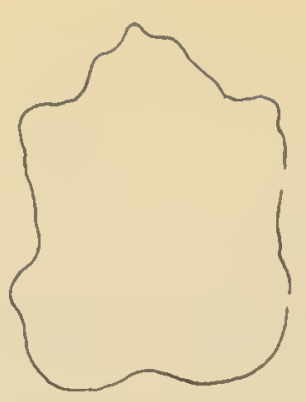

thoracic sternal plate

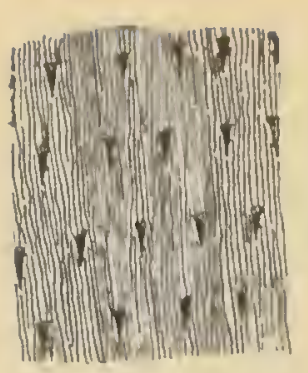

dermal ornamentation

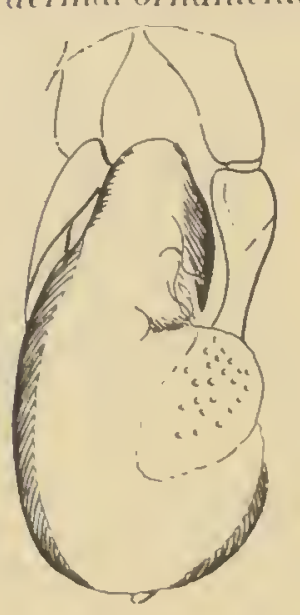

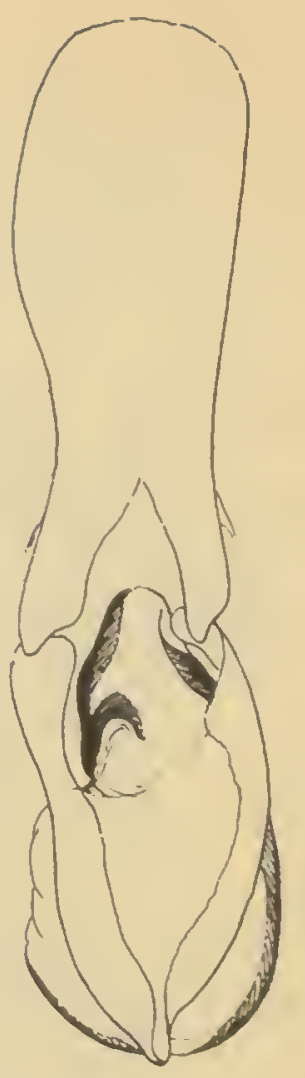

nentral- male genitalia - dorsal

Figure 40

Haematopinus eurysternus (Nitzsch), details

Lished the record, using the common name "Cattle tail louse," for this form.

The question of the specific name to be used for this form, if it be recognized, arises. It would appear that the name quadripertusus Fahrenholz is available. However, this form is not here accepted as distinct.

\section{Haematopinus Latus Neumann}

1909. Haematopinus latus Neumann, Archives de Parasitolorie 13:595: figures 6-9.

1911. Haematopinus peristictus Kellogr and Paine, Bulletin of Entomological Research 2:145. (In part)

1912. Haematopinus incisus Harms, Zoologischer Anzeiger 40:293.

1933. Haematopinus latus Neumann, Ferris, Contributions Toward a Monouraph of the Suckin Lice, Part 7:477: firures 260C, 262.

1939. Hoematopinus latus Neumann, Fahrenholz, Zeitschrift tür Infektionskrankheiten, parasitäre Krankheiten und $\mathrm{Hy}_{\mathrm{b}}$ iene der Haustiere 55:

151; Plate 4, firures 9-11.

1939. Haematopinus latus latissimus Fahrenholz, Zeitschrift'für Infektionskrankheiten, parisitïre Krankheiten und Hygiene der Haustiere 55: 152; Plate 4, limare 12.

HOSTS AND DISTRIBUT'ION. The types of latus were recorded as f'rom Potomochoerus africamus at Kaporo, Nyasaland. The types of the supposed variety latissimus are the specimens recorded hy ferris from Potomochoerus choeropotamus, Manjwa Vill ley, northcistern Rhodesia. Recorded firom the same host from lululaud aud South Africi and also from Potomochoerus affinis from the former ferman East Atrica. 


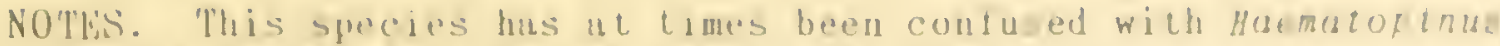
phacochoerl fiuderlein, bul is clualy distinct.

The witer sees 110 excuse lor the naming of the supposed variety lat stmus. Amont lhe specimens at hand are some of evidently very early whlt temules and others of tully molth individuals. There is enough difference amon ? chese sperimens 60 suggest the presence of two forms and this seems to be the only basis lor fiabrentoliz' supposed variety.

\section{Harmatopinus lonţrus Newnan}

1912. Haematop rnus longus Neumann, Bulletin de la Société Loologique de France $37: 141$; t"igure 1 .

1933. Haematopinus longus Neumann, Ferris, Contributions loward a Monograph of the Sucking lice, Part 6:469; t'igure 276.

HOSTS AND DISTRIBUTION. Known on ly trom the original record, from Cervus unicolor, at Kota, Nepal, India.

\section{Haematopinus phacochoeri knderlein}

1908. Haematopinus phacochoeri Enderlein, Wissenschatlliche Ergebnisse der Schwedische Expedition nach dem hilimandjaro, dem Meru, und dem umgebenden Massaische Steppen 11:7; figure.

1911. Haematopinus peristictus Kellog: and Paine, Bulletin of Entomological Research ": 145; Plate 4, figures 3-6 (in part).

193?. Haematopinus phacochoeri Enderlein, Ferris, Contributions Toward a Monopraph of the Sucking Lice, Part 6:444; figres 260, 261.

1939. Haematopinus phacochoeri Enderlein, Fahrenholz, Zeitschrift für Infektionskrankliei ten, parasitäre Krankheiten und Hygiene der Haustiere 55:149; firures 9a, 9 b.

1939. Haematopinus phacochoeri peristictus Kellogg and Paine, Fahrenholz, Zeitschrift für Infektionshrankheiten, parasi tåre krankheiten und Hyiene der Haustiere 55:150.

HOSTS IVD DISTRIBUTION. The types of phacochoeri were from Phacochoerus aeliani massaicus in the reyion of Mt. Kilimanjaro and thase of peristictus from Phacochoerus aethiopicus, at Akamanga, North Nyasa, Africa. The species has been recorded from Phacochoerus sp. in the former German East Africa, and from Phacochoerus sundevali in Zululand. In addition, there are records given as merely from "wart hog," in Eist Africa, northeastern Rhodesia and southern Rhodesia. Certain records from "buffalo, "in kenya are open to doubt.

NOTES. There has in the past been some confusion of this species with Haematopinus latus Neumann, but it appears that these two species are characteristic of different host genera. Fahrenholz has attempted to resurrect the name peristictus as a variety, but the types of this name are at hand and offer no justification for this procedure.

\section{Haematopinus suis (Linnaeus) \\ Figures 41,42}

1758. Periculus suis Linnaeus, Systema Naturae, Edition X, page 611.

1810. Haematopinus suis (Linnaeus), Leach, Encyclopaedia Brittannica, Supplement 1, page it.

1818. Pediculus urius Nitzsch, Germar's Magazin der Entomologie 3:305.

1903. Haematopinus irritans Law, Textbook of Teterinary Medicine 5:13.

1911. Haematopinus suis atventicius Neumann, Archives de Parasitologie 14: $406 ;$ ij jure 8 .

1916. Haematopinus suis chinensis Fahrenholz, Fahrenholz, Zoolo-ischer Anzeiger $18: 90$. 


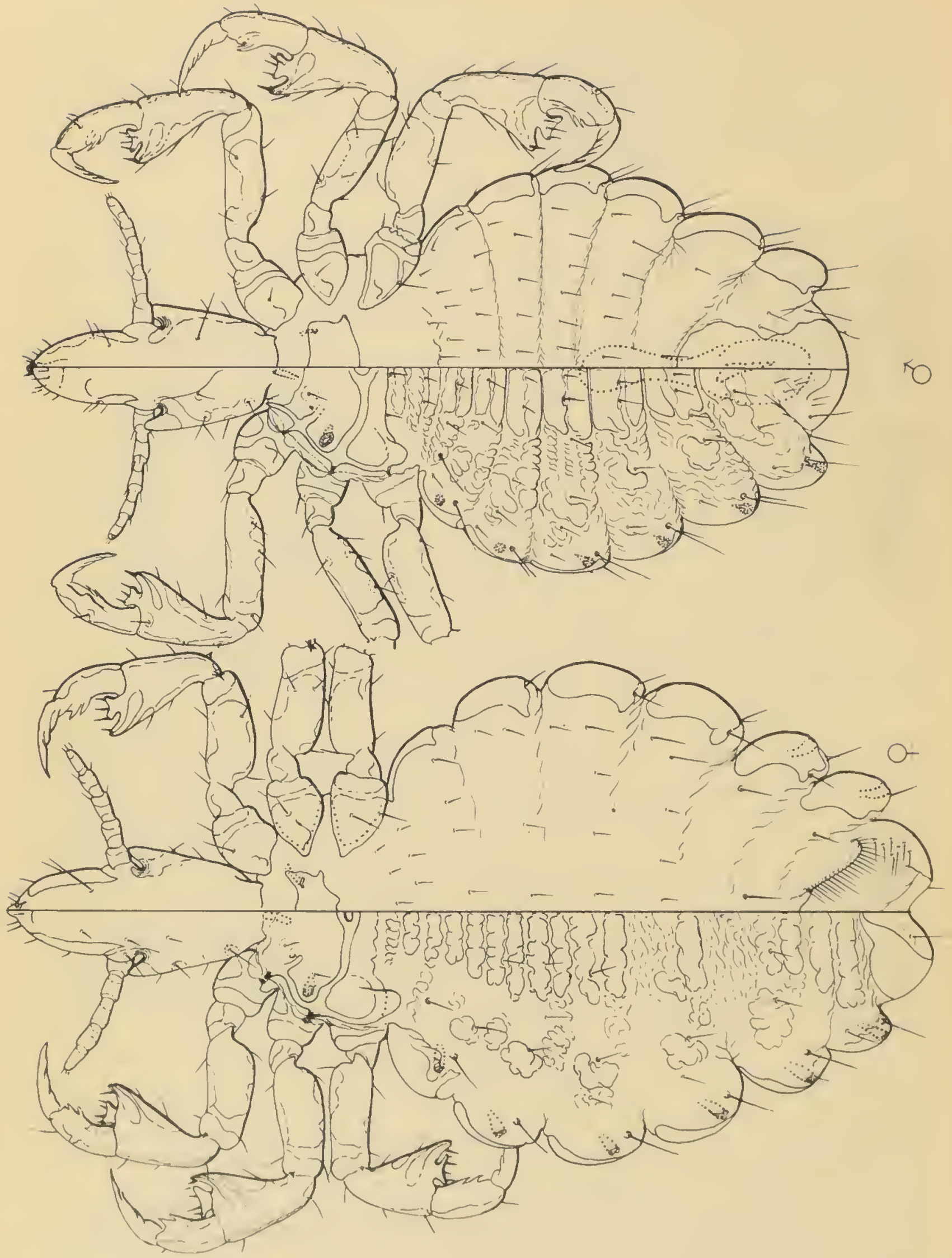

Haematopinus suis (Linnaeus)

Figure 41 


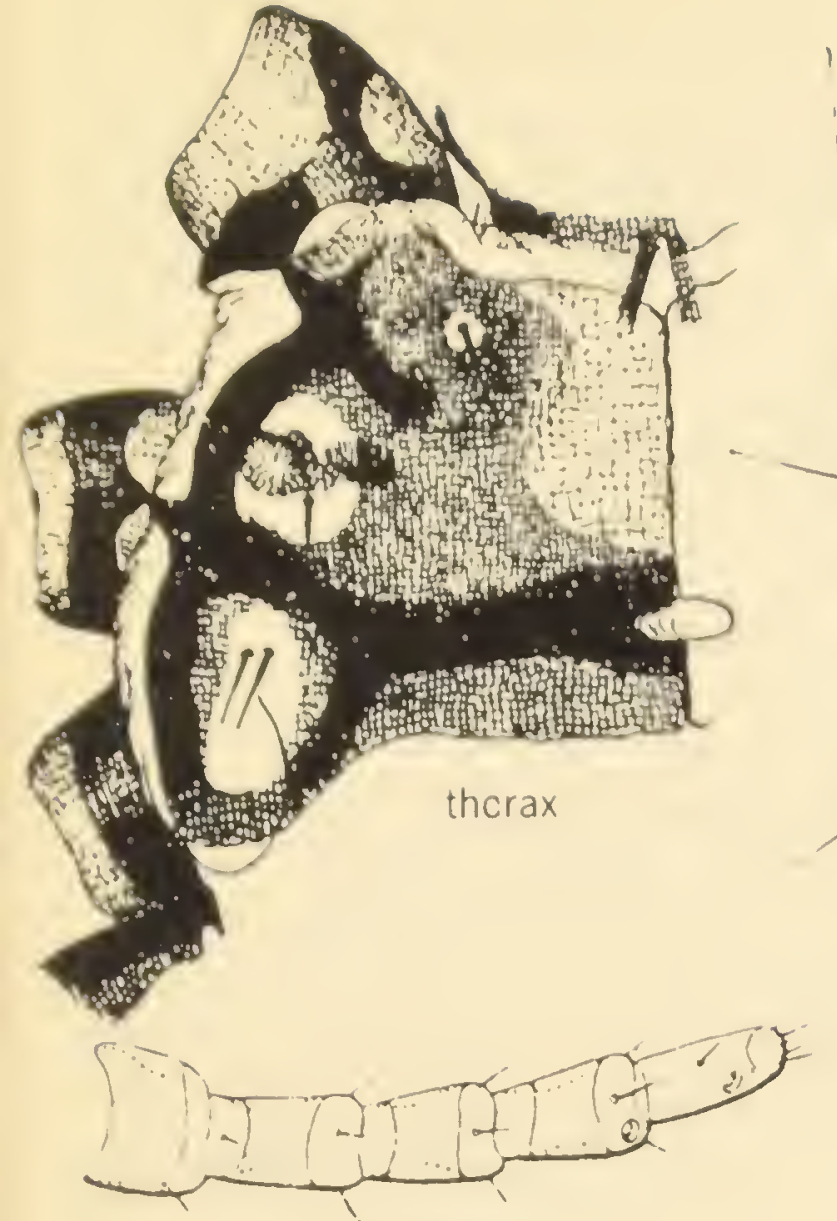

antenna

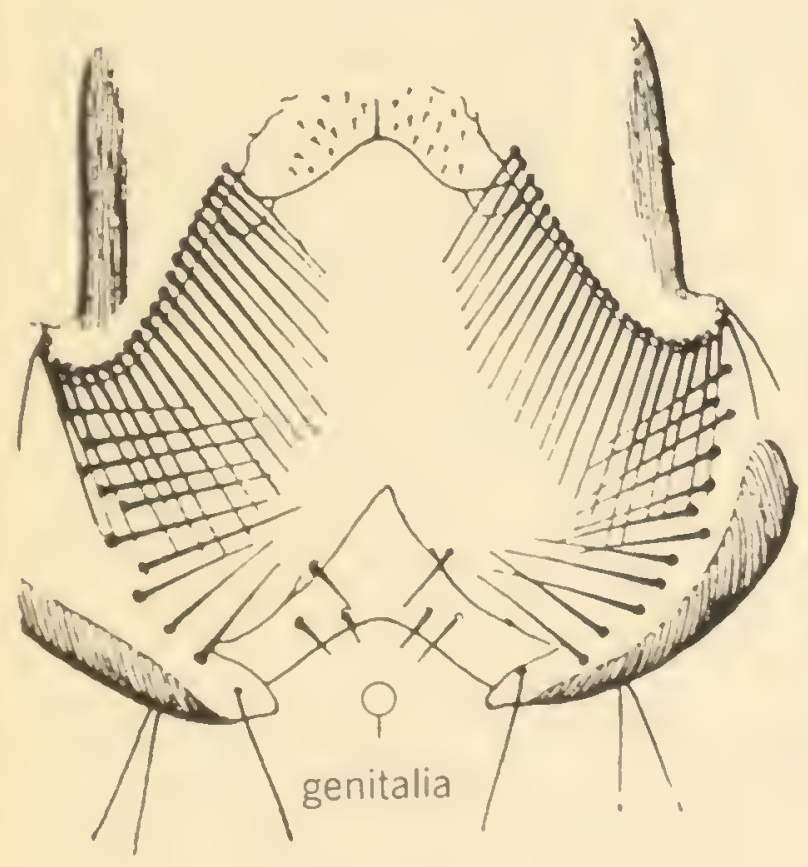

- Haematopinus suis (Linnaeus), details
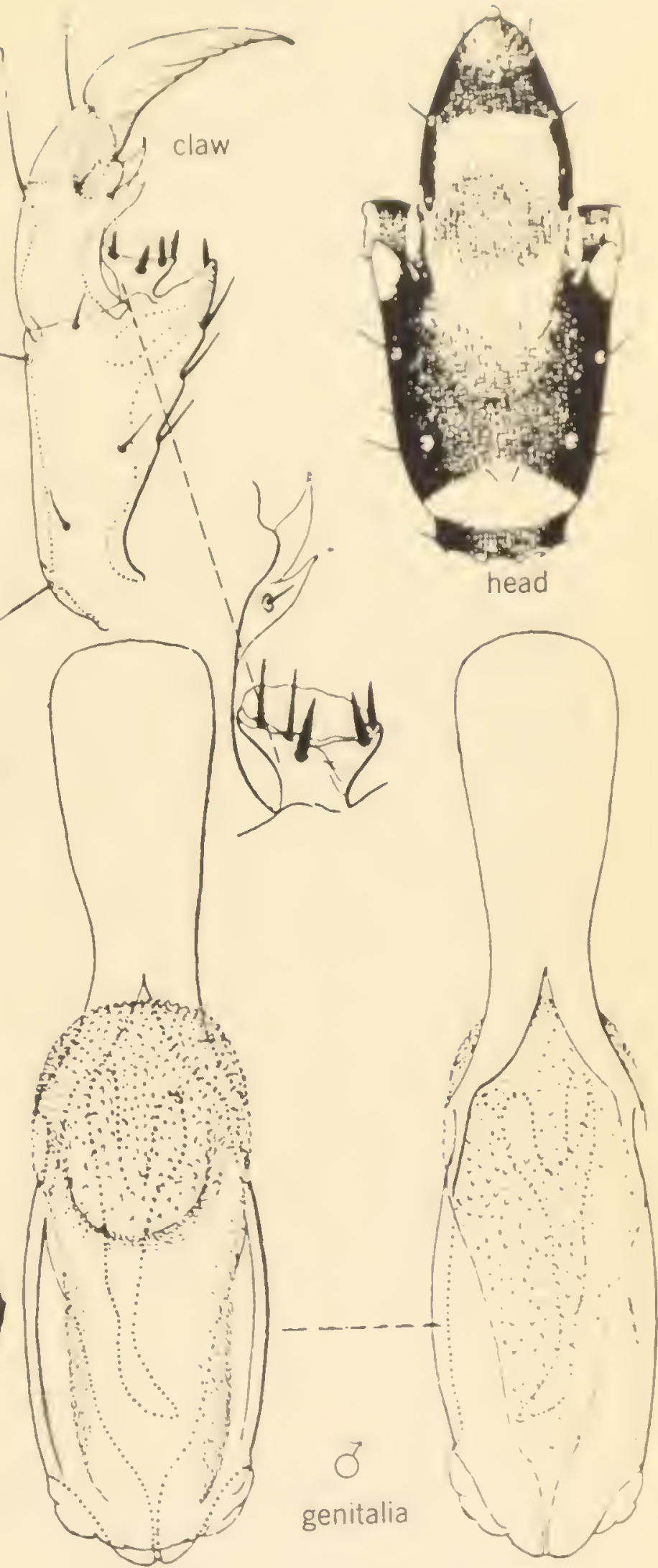

Figure 42 
1916. Haematopinus suis germanus (misprint for germanicus) Fahrenholz, Zoologischer Anzeiger 48:90.

1917. Haematopinus suis sardiniensis Fahrenholz, Jahrbuch der Hamburuischen Wissenschaftlichen Anstalten 34:Beihef't 2:10.

1933. Haematopinus suis (Linnaeus), Ferris, Contributions Toward a Monograph of the Suckinis lice, Part 6:425; figures 252A, $253 \mathrm{~A}, 254$.

1934. Haematopinus adventicius Fahrenholz, Ewing, Proceedings of' the Helminthological Society of Washiniton, pare 76.

1939. Haematopinus chinensis Fahrenholz, Fahrenholz, Zeitschrift für Infektionskrankheiten, parasitäre Krankheiten und Hy riene der Haustiere 55:Heft 2:138; Plate 3, t'irures 1-3.

HOSTS AND DISTRIBUTION. The name Pediculus suis was applied specifically by Linnaeus to the lice of domestic swine, presumably those of Sweden. Since that time it has been used for the lice of domestic swine, as recorded from almost all parts of the world. The only records from undomesticated swine seem to be those uiven by Ferris (1933) from sus cristatus, from Tanjong Badak, Tenasserim and from Dinapore, India.

NOTES. Concerning this species we have a proulem that is compounded of both nomenclatorial and zoological questions, for none of which is there at present a satisfactory answer. The story is lon: and complicated and nothing more than a mere abstract of it can here be presented.

The reasons for the complications rest largely upon the fact that the domesticated swine population of Europe has changed within relatively recent times. The domesticated swine of western Europe, throughout most of historic times, were presumably derived from the wild swine of that area. Early in the eighteenth century domesticated swine from eastern Asia were introduced into Europe and swine of this type have now become the common domesticated animals of almost all the world.

Because of these facts, references to the lice of swine in European literature, certainly prior to such a date as 1758, undoubtedly concerned the lice of the wild boar of Europe, Sus scrofa. Even at that date, 1758, the population of domestic swine in Europe was changing.

Now, if the native swine of Europe originally had upon them a louse of a species differcut from that of the domesticated swine of eastern Asia-as seems to be true-to which of these species should the name suis apply? There are two indirect approaches to the problem. One of these rests upon pre-Linnaean history and the other upon post-Linnaean history. On the basis of pre-linnaean history it is clear that the name suis should apply to lice from the wild swine of Europe. But on the basis of post-Linnaean history the name has been used for almost 200 years to apply to lice derived from the swine of eastern Asia, which even at the time of Linnaeus were berinning to replace the other type.

No one knows what Linnaeus actually had in hand when he named the species Pedicuius suis. The probabilitics certainly are that he used the name for lice of swine of the older European race, althou it it must be noted that the Asiatic swine had been introduced into Sweden a few years before the appearance of the tenth edition of the Systema Naturae and it is possiblesince they undoubtedly attracted a considerable amount of attention-lice may have heen taken from them and come to Iinnaeus' notice.

from the point of view of' the present writer the reasonable procedure is to accept the name suis for the lice of domestic swine as we now find them and to consider that as used by Linnaeus the name covered a compound species. We may legitimately argue that the grencral usage of the last 150 years or more constitutes a de t'acto restriction of this name to the form for which it has conmonly heen used and that to change this at the present date is unnecessary and confusin?

Furthermore, it should he noted that as early as 1818 Nitzsch revived the old, pre-Linnacan name urius as a substitute for suis, and that later 
evidence has indaciated that he actumbly had at had the lice of the wild

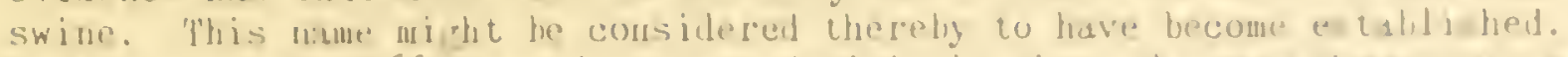

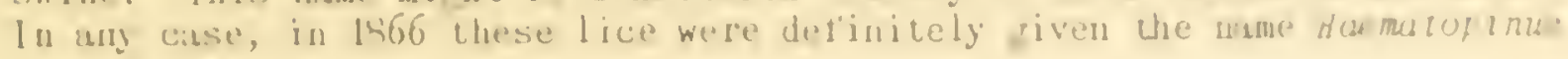
(1) 2 livureats.

huhrembl\% and fing have opposed the poim ot view here held and have matulained that the nume sus should be transterred to the lice of the wild swine of finlope, thus leaving it in le detergnined whis name should lie used for those trom the present-day domesticated swine. Fuhrenholz has main-

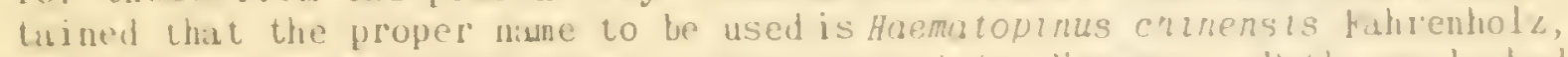
while Eiring has supported Homatop inus adventicius Neumann. Buth overlooked the earlier name Huematopinus irritans Law.

The problem cin in the end be settled only by a ruling ol the lnternistional Commission on Zoological Nomenchuture, and for the present the writer reluses to disturb the long-established nomencluture.

So much for the nomenclutorial problem. The zoolopical problem is atso involved and complicated.

To begin with, it appears that the lice of the wild swine ut furope dif"ier to such a degree from those of domesticisted swine that they ary justifiably be called a distinct species. Atier we have eliminated the lice of the wild swine of Europe from consideration, there remains the question of the forms to be tound anong the lice of domesticaled swine. Amonis these there is present a considerable variety of size, form, yi rmentation, and of sowe molpholopical characters. At least three of the forms have been first named as varieties and then elevated to the rank ot' species by fahrenholz.

fertis (1933), on the bas is ot an examination of specimens from numerous parts of the world, gave an extended account of the variations to be found anon: them. Here and there appeared individual collections which, if taken by thenselves alone, might justify some nomenclatorial recomition. But after these specimens are removed we are left with a residuc of material which presents almost every possible combination of the characters seen in the others, indicating a completely interlinked genetic chain wich conl'orms to the concept of species here adopted and previously discussed. In the end the problem can be settled-if at all-only by benetic studies. For the present the single name Haematopinus suis (Linnaeus) will here be used to cover this complex of forms.

\section{Haematopinus taurotragi Cumings}

1914. Hoematopinus taurotraśl Cumings, Bulletin of Entomological Research $5: 155$; rigures.

1933. Haematopinus taurotrae $i$ Cumming, Ferris, Contributions Toward a Monograph of the Suching Lice, Purt 6:453; t'i gures 265, 266.

HOSTS AND DISTRIBUTION. Type from Taurotraßus oryx (=Boselaphus oreas), from a menagerie in England. Later recorded by Bedford from the same host at various placed in South Africa and also from Strepsiceros kudu in South Atrica.

\section{Haemalopinus tuberculatus (Burmeister)} Figures 43, 44

1800. Pediculus bufalt-europaei Latreille, Histoire naturelle et particuliere des crustaces et des insectes S:96 (nomen dulium).

1839. Pediculus tuberculatus Burmeister, Genera Insectorum. Rhynchota. Species 20.

18.72. Hoematopinus tuberculatus (Burmeister). Lucas, Annales de la Société Entomologique de France (series 2) 10:529; Plate 11, number 2.

1869. Haematodinus punctatus Rudow, Zeitschrift für die gesamten Naturnissenschaten $31: 167$. 


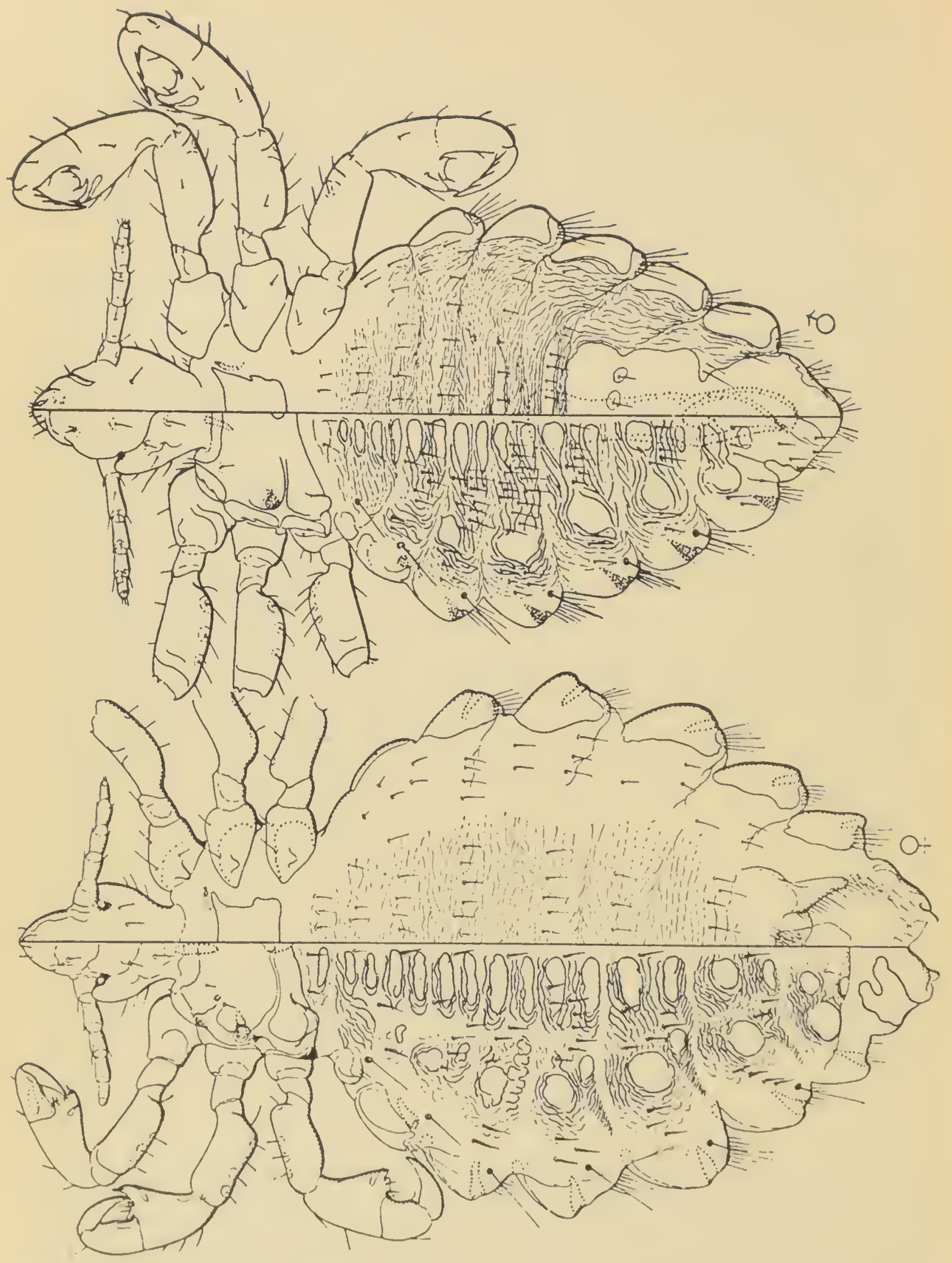

Haematopinus tuberculatus (Burmeister)

Figure 43 


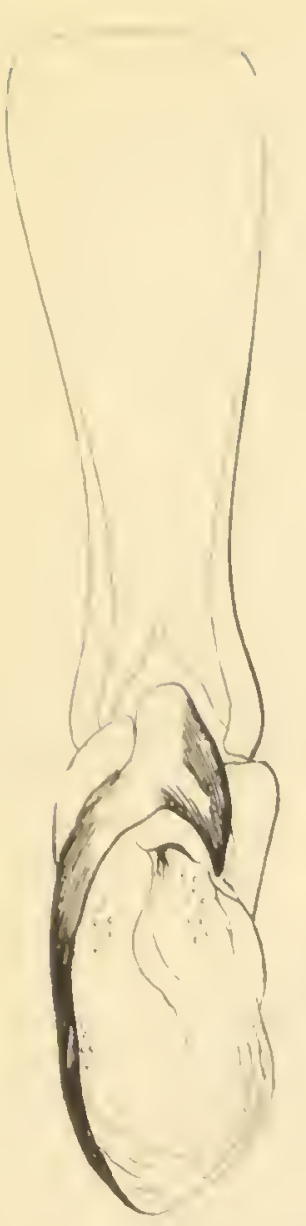

nemtral inulegenitalia dorsal

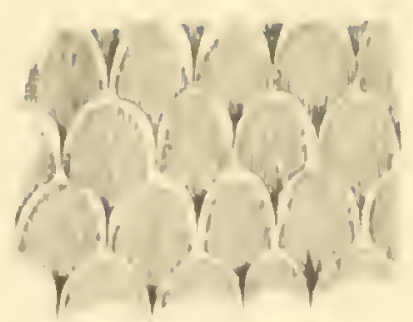

dermul ormamemlelent

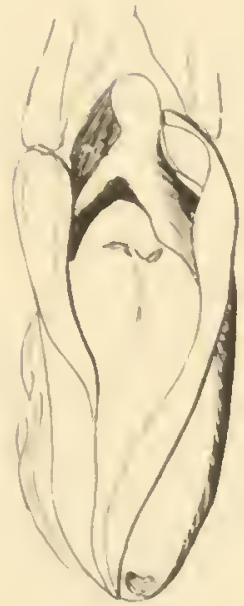

muraleryal phile

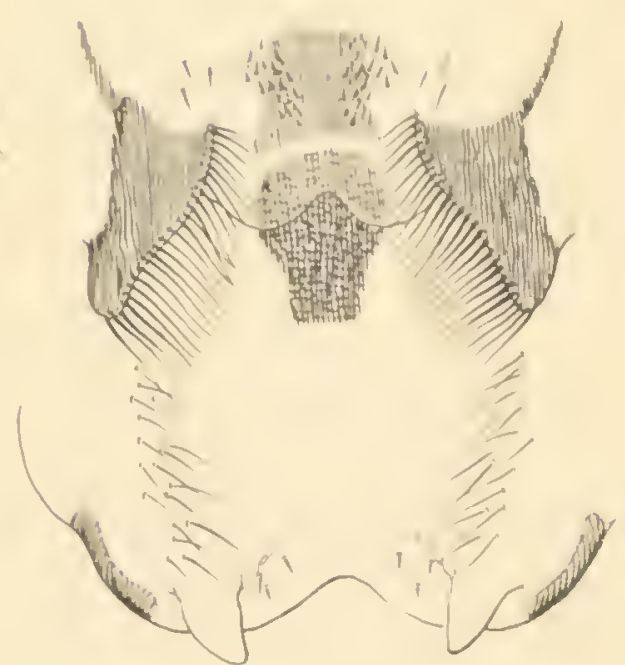

female genitalia

Haematopinus tuberculatus (Burmeister), details

Figure 44

1919. Haemotopinus bufali-europaei (Latreille), Fahrenholz, Zeitschrift tür angewandte Entomologie 6:154.

1933. Gaematopinus tuberculatus (Bumeister), Ferris, Cont ibutions Tonard a Monograph of the Sucking Lice, Part 6:455; figures 267-269.

HOSTS AND DISTRIBLTION. Burmeister's name was hased upon specimens from the "common butfalo or buffalo of India," presumably Bos bubalus, and there are many records of the species from this host in India, China, the Philippine Islands and Guam. In addition, there are records of the species from the yak, Bos erunniens, and from camel in Australia and Africa. Latreille's specimens were recorded as from buffilo from Italy.

NOTES. There is astrong probability that the species named by Latreille (1S00) is the same as that named by Burmeister in 1839, but the witer has in the past declined, and still declines, to accept the synonymy involved. A very considerable literature has grown up under the name tuberculatus, while under the clumsy name bufali-europae $i$ there have been but occasional passing references since it was first proposed.

Specimens from camel have been examined by the writer. Ther seem to differ from the typical form only in smaller size. 
1939. Pecaroecus Babcock and Ewin: Proceedings of the Entomolorical Society of Washington 40:197.

GENERIC TYPE. Pecaroecus javali $i$ Babcock and Ewin'.

CHARACTERS. Haematopinidae with distinct eyes, these being represented by a facet and a pigment spot just posterior to each antenna. Lers without a sclerotized plate in the "palm" of the tibia. Thorax without a sclerotized sternal platc. Abdomen with small, sclerotized, tubercle-like paraterites present.

NOTES. The single known species of this genus is a strange form which seems rather detinitely to be related to Haematopinus.

\section{Pecaroecus javalii Babcock and Ewing Firures 45,46}

1938. Pecaroecus javali $i$ Babcock and Ewing, Proceedings of the Entomological Society of Washington 40:199; figures 103 .

HOSTS AND DISTRIBUTION. Known from a single record, from Pecari angulatus, between Juno and the Pecos River, State of Texas, United States.

NOTES. Specimens from the type lot have been made available through the kindness of Mr. Babcock and the accompanying illustrations are based upon these.

\section{Family HOPLOPLEURIDAE Ferris, new family}

DESCRIPTION OF THE FAMILY. Anoplura in most of which there is no external indication of eyes, lenses being present in only one genus. Abdomen, in all but one species, with paratergal plates on at least one serment, these plates always at least in part with an apical portion which is free from the body and not forming a mere cap over the apex of lateral lobes of the abdomen. Thoracic sternal plate usually developed, commonly with its posterior apex free, but at times weakly sclerotized and at times lacking. Ventral prothoracic apophyseal pits lackin. Abdominal tergal and sternal plates very commonly present and well devcloped. Antennae normally l'ivesegmented, in one species described as three-seumented, at times with the terminal three serments tendin is to be more or less fused together, frequently sexually dimorphic, the male having either the apical preaxial angle of seyment three more or less produced and bearing one or more short, stout, retrorse setae dorsally, or having such a seta on the dorsal side cf each of the last three segments. Female with the gonopods of the ninth segment usually short and not strongly developed, never elonigated and leaf-like.

NOTES. As here understood this is the largest family of the Order, most of its members occurring on rodents, but a few on Inscctivora and Primates, and one on Ungulata.

The principal objection that may be urged arainst this family is the inclusion in it of the genus Pericinus, which has long been associated with the Pediculidae. This matter will he discussed at length under the subfamily Pedicininac and it may here simply be noted that in the writer's opinion the genus is more closely related to the lloplopleuridae than it is to Periculus.

The general pattern of the llop lopleuridae is reasonably consistent, beinis marked especially hy the development of the paraterigal plates of the aldomen, which always have at least an apical point free from the body wall.

The family name is chosen from a senus which is larige and in which the characters of the family are especially well developed.

The fumily is here divided into five subtimilies, which may be separated by the following key. 


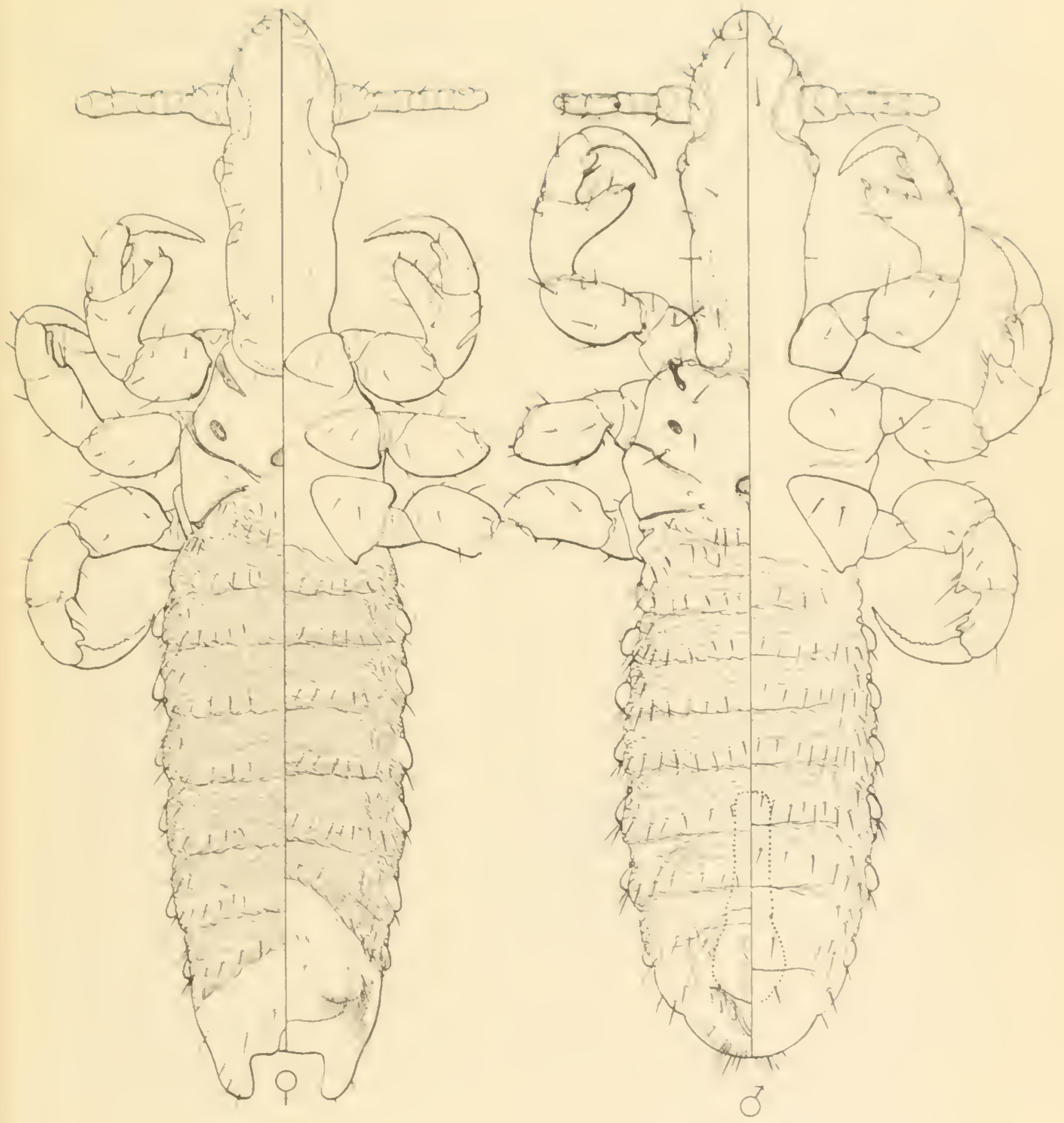

Pecaroecus javalii Babcock and Ewing 

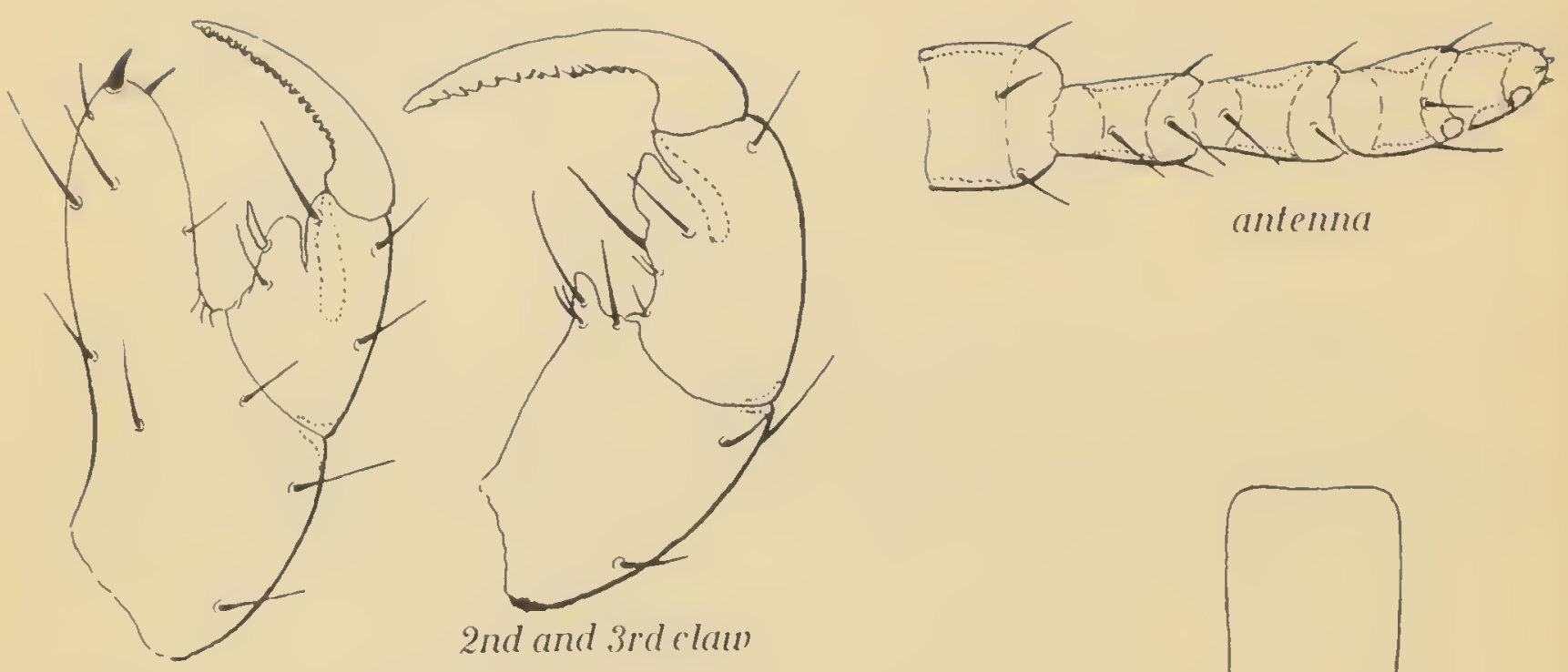

1st claul

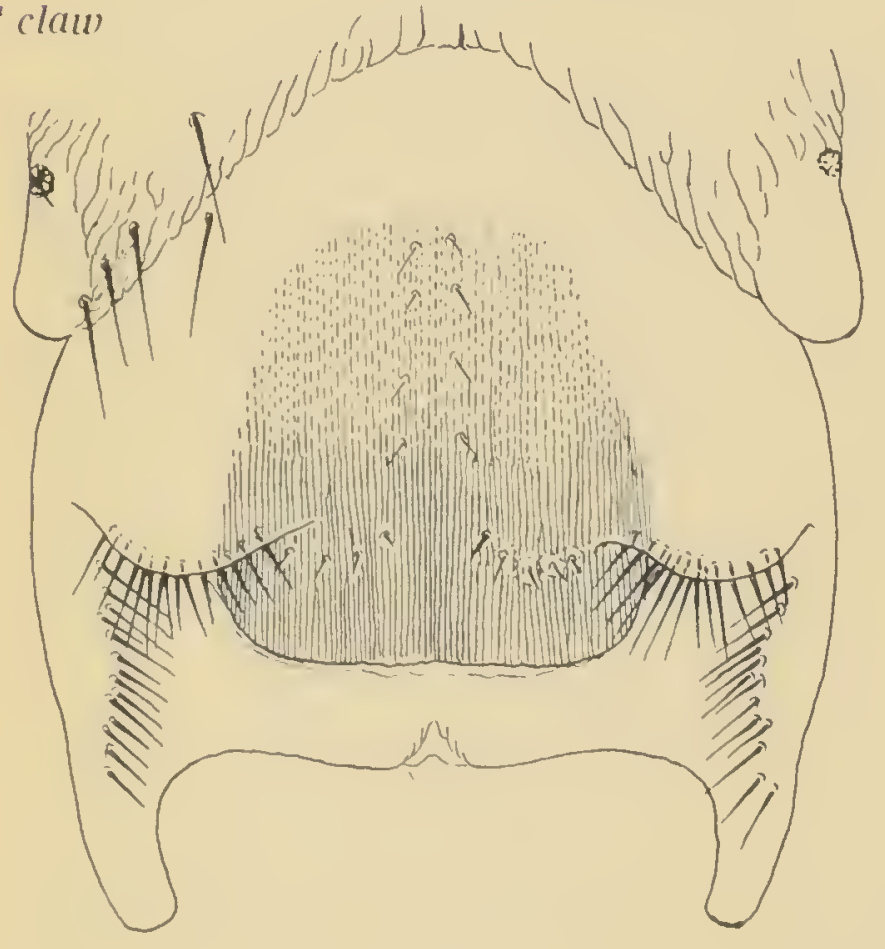

gemilalia of female

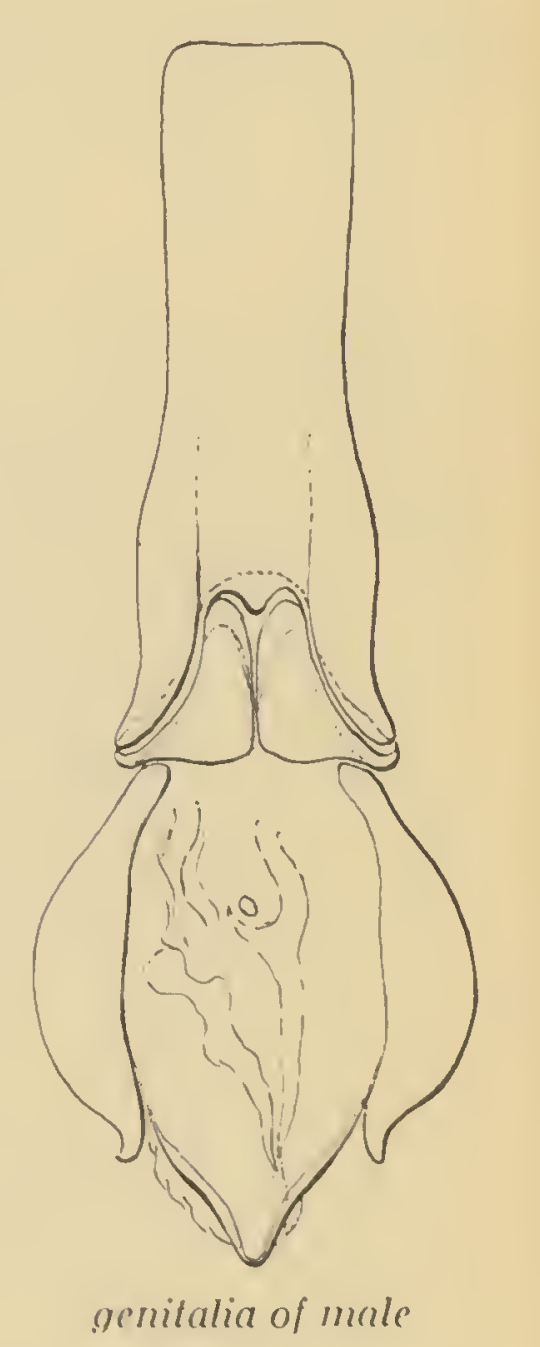

Pecaroecus javalii Babcock and Ewing,

Figure 46 
1. Fves present externally as a pair of distinct lenses; occurring on Old horld monkeys of the superfunily Cercopithecoidea.........PEDICININAE

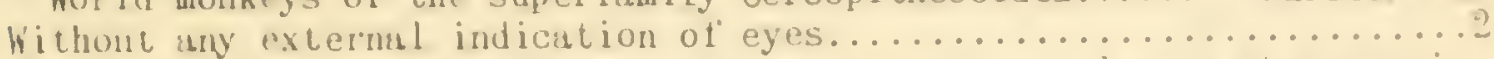

2. With u smill, claw-like process alongside the true claw on the anterior

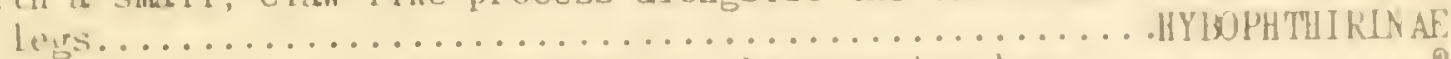

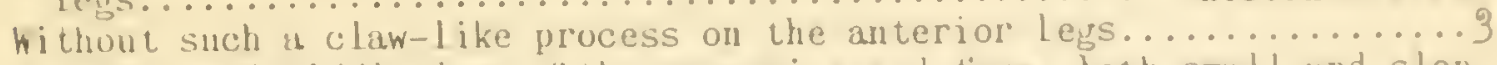

3. Anterior and middle legs of the same size and torm, hoth small and slender, with slender claw; ventral side ot the abdomen in all species except three, with a pair of small, sclerotized, detached plates orr the venter of abdominal segment two; restrictel to Sciuridue........ .

Anterior legs the sinallest of the three pairs, the second pair at least somewhat larger than the lirst and with stouter claw; venter of abdominal segment two without such a pair of detached plates, except as the paratermal plates of this segment may be longitudinally divided

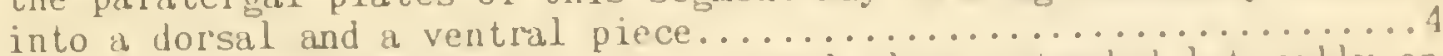

4. Second abdominal segment with its sternal plate extended laterally on each side to articulate with the corresponding paratergal plate.....

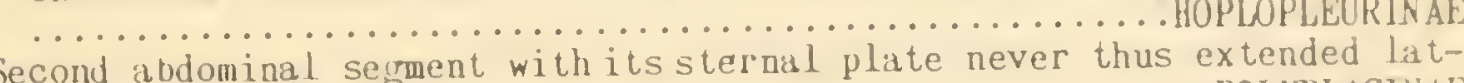

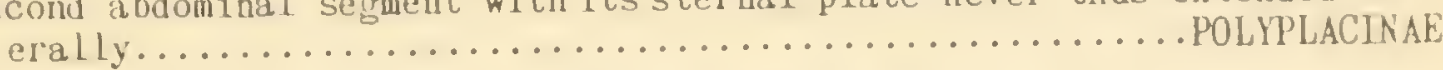

\section{Subfamily ENDERLELELLINAE Ewing}

1929. Ewing, A Manual of External Parasites, pare 132.

DESCRIPTION OF THE SUBFAYILY. Hoplopleuridae with the two anterior pairs of leus slender and with slender claw, the two pairs being of the same size and shape, the third pair stout and with stout claw. All but three of the included species provided with a pair of small, highly sclerotized plates on the ventral side of the second abdominal segment, each of these plates bearing a strongly sclerotized, flat projection. Usually very small species. All the known species occurring on the rodent family Sciuridae.

NOTES. The members of this subfamily are among the smallest of the Anoplura. some of them attaining length of scarcely more than $.35 \mathrm{~mm}$. The peculiar plates on the venter of the second abdominal segment are at present of undetermined homoloy. In some species each plate articulates laterally with the corresponding paratergite. It may be either a detached portion of the parater ite arising from some such phenomenon as the ventral portion of the lon ritudinally divided paratergites of this segment-such as appears especially clearly in the genus Fahrenholzia-or it may be an extreme development of the divided sternal plate of the second segment which appears in such genera as Schizophthirus and Baematopinoides and is at times indicated in Boplopleura itself. In any case the development seen in Enderleinellus is quile distincive.

Two genera-kicrophthirus and herneckia-totaling three species, which are here assigned to the Enderleinellinae, lack these plates but in other respects seem properly to be associated with gnderleinellus, both on the bas is of general structure and host relationships.

Key 20 the Genera of Enderleinellinae

1. The pair of plates on the venter of abdominal segment two present.....

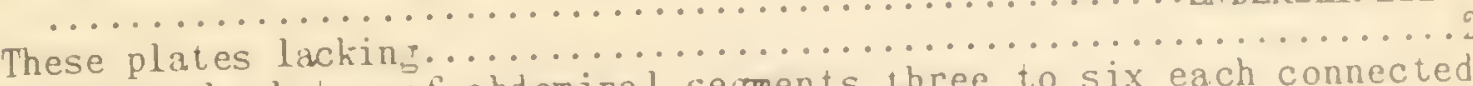

2. Paratergal plates of abdominal segments three to six each connected ventrally with the corresponding sternite by a narrow, sclerotized 
bridge; parateral plates with their posterior margin not free from the body wall; occurring on American flying squirrels...MICROPHTHIRUS

Paratergal plates of the audominal segments not thus connected with the sternites, their apices f'ree from the body wall; occurring on African

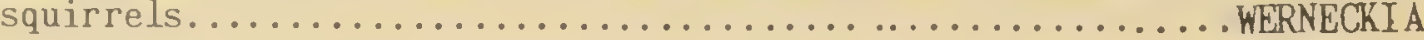

\section{Genus ENDERLEINELLUS Fahrenholz}

1912. Enderleinel lus Fahrenholz, Zoolouischer Anzeiger 39:56.

1919. Enderleinel lus, Ferris, Contributions Toward a Monograph of the Sucking Lice, Part 1:7.

1929. Cyclophthirus Ewing, A Manual of External Parasites, page 195.

1929. Euenderleinellus Ewing, A Manual of External Parasites, page 197.

1929. Hoplophthirus Ewin:r, A Manual of External Parasites, page 194.

1929. Rhinophthirus Ewing, A Manual of External Parasites, paye 196.

GENERIC TYPE. Pediculus sphaerocephalus Nitzsch = Enderleinellus nitzschi Fahrenholz.

GENERIC SYNONYMS. Cyclophthirus Ewing, type Haematopinus suturalis 0sborn. Euenderleinellus Ewing, type Enderleinellus larisci Ferris. Hoplophthirus Ewing, type Enderleinellus euxeri Ferris. Rhinophthirus Ewing, type Enderleinellus heliosciuri Ferris.

CHARACTERS. Enderleinellinae in which a pair of small, sclerotized plates is present on the venter of abdominal segment three, these plates bearing a flattened point which is apically free from the body. All the known members of the renus occur on hosts of the rodent family Sciuridae.

NOTES. In 1929 Ewng proposed to divide this genus, forming from it a total of five genera. Actually, if one wishes to overlook the basic similarities which exist throughout the group and to seize upon the peculiarities of individual species, this number of genera could be doubled with no special effort. It may very well be that when the numerous species that must still remain to be discovered have been incorporated into the system some division will be justified and at least a part of the names proposed by Ewing will descrve to be accepted. For the present nothing much seems to be gained by such division and all the species are here retained in Enderle inellus.

Certain very troublesome problems arise in connection with some of the groups of species within the genus. These can be illustrated especially by referring to the group which occurs on New Horld members of the genus Sciurus. A very considerable amount of material representing this group has been assembled, but there remain many host species from which nothin has yet been collected. Within this material it is possible to recomize a wide variety of form in the genitalia of the males, although all the differences represent merely modifications of a single pattern. Some specimens are so different from others that it would appear nonsensical to refer them to the same species, but there are numerous instances of intermediate forms differing only in some small detail. We have on the one hand the constantly pressing temptation to name a new species or "variety" for each of these slightly different forms, or on the other hand to throw all these variants into a few species. Either method produces results which are undesirable and which may equally effectually obscure any approximation to truth. At the time when the section on this genus was prepared by Ferris for his "Contributions Toward a Monograph of the Sucking Lice," he was but an inexperienced student of the systematics of insects. Disgusted by the results of "nurestrained "species mongering" he revolted atginst the practices of certain other workers and went to the other extreme. It now appears that this conserviatism was in its turn unsupportable and certainly some of the so-called species recognized by Ferris are actually species groups. 


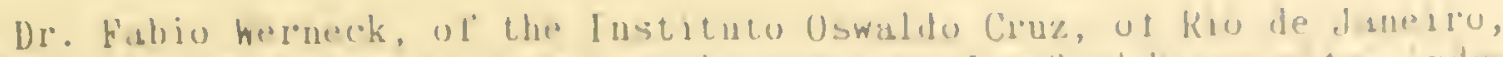

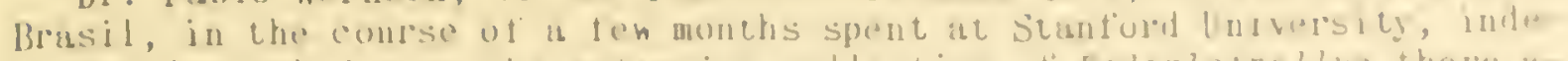
pendently worked over the axtensive eullection ot Enterletnellus there at vailable. He dotected some of the errors, not only of jud parent hut of ub servation, on the part of f'elris and maned certain nen species from the collection. However, a considerable amount of material was lett by him as still donblul and remisins tor turther study to elucidale it.

With the indition of the species lecoinized by herneck the uumber of species now assigned to the genus is 29 , which we ma suspect represents scarcely more than hall the species that exist. Ellender, in his levien of the rodents, recomizes 14 generd in the Sciuridae, these containing ap proximately 1300 named torms. The vast majority of these forms ure listrod us subspecies and as there appears to be an average ot about five subprecies for each species it may be assumed that about 300 actuin species pxi the fumily. Ot these only about 50 have as yet yielded species of Enterle tnellus, although the evidence indicates that "vel: Sciurid possesses is member of this genus. It theretore seems probahle that the total nunber of species of the genus in existence will probably he becteen 50 and 60 . When the majority of these ale known we shall be in a much better position than at present to develop a classitication ot the group.

\section{Key to Species of ENDERLEINELLUS}

1. Paired ventral plates of abdominal segment 2 each produced lacerally to

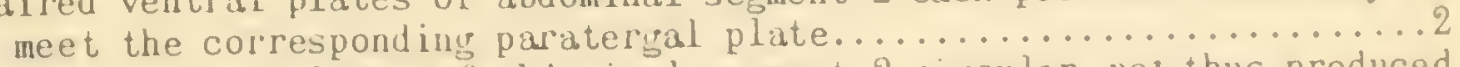
Paired ventral plates of abdominal segment 2 circular, not thus produced laterally and completely detached from the parater ites..........

2(1). Abdominal segmeuts 4-8 each with a pair of very long setae on the parateral plates or at the lateral margins of the body, the lateral margins thus fringed with pairs of long setae; occurring on

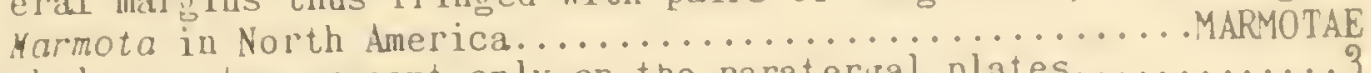
Such long setae present only on the paratergal plates............

3 (2). Female with $2-4$ very long setae on the dorsum of abdominal segment 4. these setae reaching to the apex of the body; known from Citellus beechelli, Citellus variesatus, and Citellus tereticaudus in southwestern and extreme restern United States..........SBORNI Female without such long dorsal setae; known from many species of

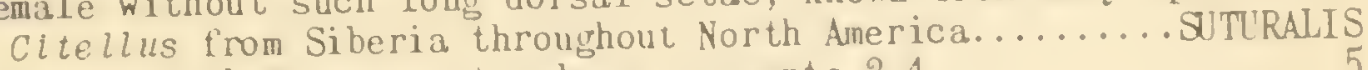

4 (1). Parutergal plates present only on sejments $2-4 \ldots \ldots \ldots \ldots \ldots \ldots . \ldots 5$

Paratergal plates present on seyments $2-5$ or $2-6 \ldots \ldots \ldots \ldots \ldots \ldots$

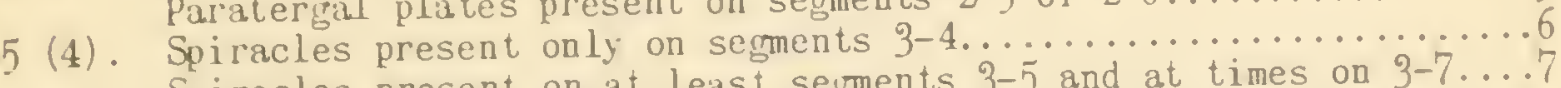
Spiracles present on at least seuments $3-5$ and at times on $3-7 \ldots 7$ 6 (5). Both sexes with abdominal setae, both dorsally and ventrally, large, llattened, elongate-cuneitorm; known from Funambulus palmarum in

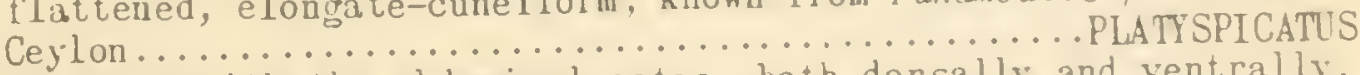

Both sexes with the abdominal setae, both dorsally and ventrally, all slender; known from Paraxerus in Africa...............

7 (6). Dorsum of the abdomen very sparsely haired, the female with not more than 4-5 setae on each half anterior to segment, these all very long; the male with not more than 3-4 such setae and with a median series of pairs of very small setae; known from Beliosciurus

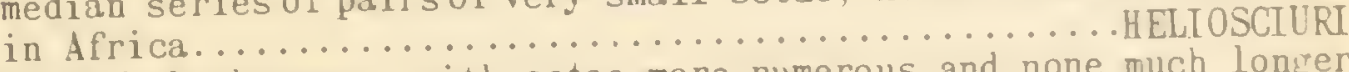

Dorsum, in both sexes, with setae more numerous and none much longer than the length of its segment.......................

8 (7). Dorsum of the abdomen with numerous setae, there being as many as $14-20$ in an almost continuous row across segments $4-6$ in hoth sexes; hnown from Lartscus in Borneo............................... Dorsum of the abdomen with not more than $8-10$ setae in any row in 
the female and less on the male; known from Menetes in Siam.....

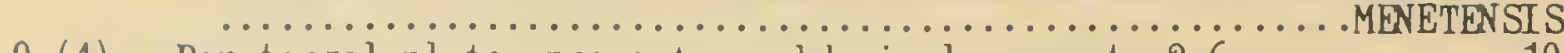

9 (4). Paratergal plates present on abdominal segments $2-6 \ldots \ldots \ldots \ldots . . .10$

Paratergal plates present on abdominal segments $2-5 \ldots \ldots \ldots \ldots \ldots 12$

10 (9). Thoracic sternal plate with a slender, median, anterior prolonga-

tion which extends forward between the anterior coxae; occurring

on the European Sciurus vulgaris.................................

Thoracic sternal plate without such anterior prolongation.......11

$11(10)$. Paratergal plates of abdominal segment 3 bearing a seta which is as long as the abdomen itself; known from Xerus erythropus in

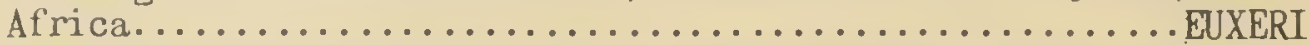

No seta on any paratergal plate longer than the plate itself; known from Dremomys pernyi in China...............DREMOMYDIS

12 (9). Thoracic sternal plate with a narrow, median, anterior prolongation extending forward between the anterior coxae..........15 Thoracic sternal plate without such median anterior prolongation..

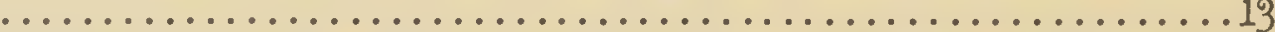

13 (12). All spiracles extremely large, their outside diameter equaling almost half the width of the plates which bear them; known from members of the genus Callosciurus in the Malayan Region........

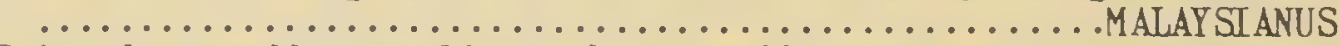

Spiracles small, equaling only a small fraction of the vidth of

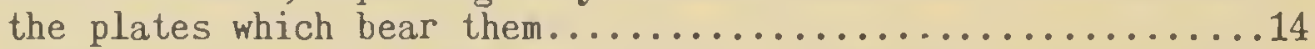

14 (13). Paratergal plates of segment 4 with 1 of their 2 setae equaling 2-3 times the length of the plate that bears it; attributed (possibly erroneously) to the North American Tamias striatus... $\ldots \ldots \ldots \ldots \ldots \ldots \ldots \ldots \ldots \ldots \ldots \ldots \ldots \ldots \ldots$ TAYIASIS

Paratergal plates of segment 4 with the setae much shorter than the length of the plates; known from Nannosciurus in Java......

15 (12). Thoracic sternal plate divided longitudinally into 2 oval, strongly sclerotized pieces which are separated from each other by a more or less membranous median area; occurring on New Horld squirrels of the genus Sciurus and closely related genera (see special key); the group of.....................NGICEPS

Thoracic sternal plate without such division; known from Sciuro-

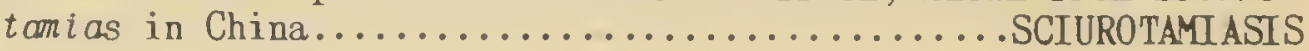

\section{The Longiceps Group}

The members of this group constitute an extraordinary complex of evidently closely related forms which occur on New World members of the genera Sciurus and Microsciurus, the latter being a little genus that is confined to Central America and northern South America. While a considerable amount of material is available, it represents only a small portion of the forms that probably exist. The development of an understanding of this complex has only begun and consequently uncertainty concerning the species which should be recognized must remain for a long time to come. All that has been accomplished thus far is to segregate a few of the forms that are clearly recognizable, while there are left on hand numerous specimens that cannot be assigmed to one species or another.

In his treatment of the genus Enderlelnellus in Part 1 of his "Contributions Toward a Monograph of the Sucking Lice," Ferris called attention to the existence of numerous variants of the males of the four species of this group which he recognized. Later, Werneck worked over this same material and from it and other specimens available to him later named six more species, bringing to ten the total number of species recognized in the group. Neither Ferris nor Werneck was able to point out characters by 
which the lemales conld be difterentiated and the species were bused almost entirely upon charucteristics of the genitalia of the males.

A renewel stuly of the rroup in connection with the present work has revealed certain minute churacters which serve to make at least some of the species identifiable in the female also, but even yet there remin some which can he associated with theil nales only by being found in company with then.

'The males present what is probably the most unusual complex of structures that is to be found in this scx in any of the sucking lice. Material upon which to buse the much-needed dissections to explain these structures has not been available in connection with this work and such a sidy wust be le lit to the future. All that can be done at present is simply arbitrar ily to identify the same structure throughout the series without attempting to discuss its morphological nature.

In the matcrial at hand and among the species which have been numed thcre arc males with genitalic structures so different that there is nothing to be done other than to regard them as distinct species. But between these extremes there exist many intermediate forms with which nothing can bc douc at prcsent. These must either be left unnaned or referred tentatively to the nearcst rccognized species.

Because of these lacts separatc key's are provided for males and females, that for the males bcing the most nearly complete.

\section{Key to Males}

1. Arms of the basal plate bent laterally at the posterior end, but not expanded at the apex nor with apical lobes or with any subapical spur

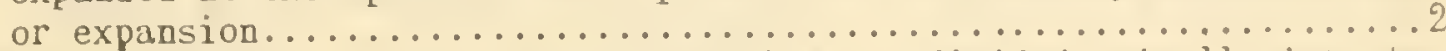

Arms of the basal plate expanded apically, or divided apically into two lobes or with a subapical, mesal spur or expansion...............

2. Piece $X$ elongate, widened posteriorly; known only from Sciurus griseus

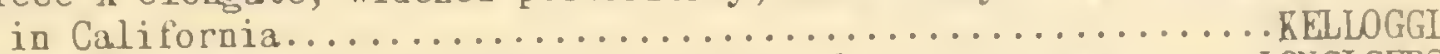

Piece $X$ very short, transverse; typical of Sciurus niger...... LONGICEPS

3. Arms of the basal plate with a distinct little subapical spur which is set well in from the acute and simple apex; type from Sciurus boothiae

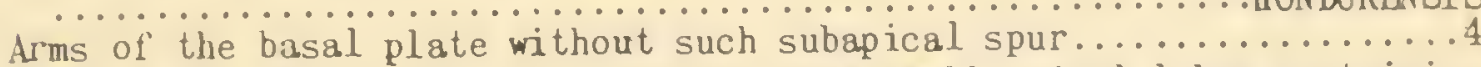

4. Arms of the basal plate with the two very small apical lobes containing the articulation of the corresponding arm of the pseudopenis and with a marked subapical, mesal expansion set well in from the apex; type

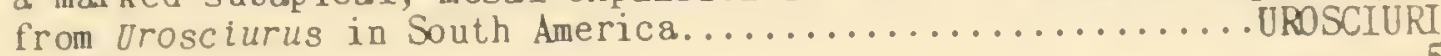

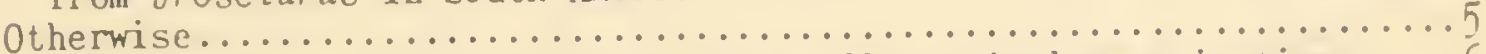

5. Arms of the basal plate with a quite shallow apical emargination.....6 Arms of the basal plate with a deeply $\mathrm{V}$ - or U-shaped emargination.... ?

6. Arms of the basal plate with the mesal apical lobe larger than the other and rounded at the apex; type from Sciurus aestuans in Brasil..

Arms of the basal plate with the outer lobe larger than the mesal lobe and with both lobes apically acute; type from Sclurus nesaeus in Ven-

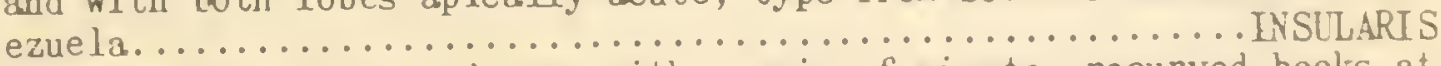

7. Median complex of the aedeagus with a pair of minute, recurved hooks at the mid-line, just posterior to the gonopore; type from Sciurus truei

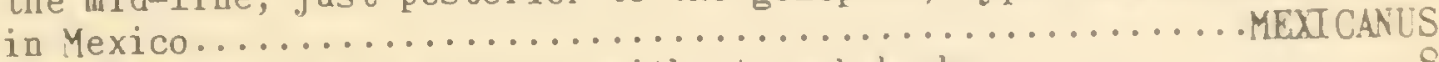

Median complex of the redearus without such hooks................

8. Arms of the basal plate with the mesal apical lobe shorter than the other; pseudopenis with its apical stem at least half as long as its arms; type from Sciurus arizonensis.............................. Arms of the basal plate with the two apical lobes equal in length: 
stem of the pseudopenis less than half as long as the arms, at times

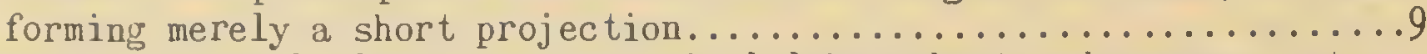

9. Arms of the basal plate with the apical lobes short and narrow, not expanded basally; from Microsciurus in Colombia.............MTCROSCIURI Arms of the basal plate with the apical lobes very large and broadened

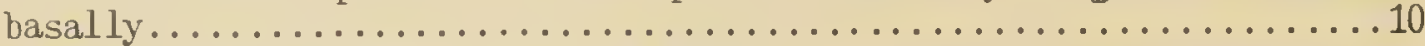
10. Arms of the basal plate with the mesal lobe definitely broader at the base than is the outer lobe; type from sciurus socialis in Guatemala.

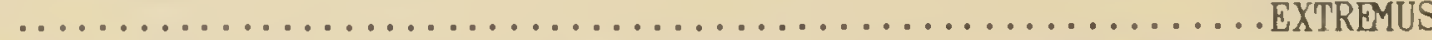
Arms of the basal plate with the apical lobes of the same width at the base; type from Sciurus griseogena in Venezuela...........VENEZUELAE

The distinctive characters in the females are to be found in connection with the genitalia. The anterior margin of the vulva is beset with small fimbriae, medially forming a relatively stout and somewhat sclerotized point. Just anterior to this median point is to be seen a sclerotized structure which is presumably the spermatheca. Its exact relation to the surrounding parts remains to be determined from fresh material and here nothing more can be done than to describe and illustrate its appearance. In one species of the group (kelloggi) it appears to be lacking. In other species its form is quite distinctive and it ranges in size from a large, oval body as seen in venezuelae (Figure 41) to a very minute structure as in microsciuri (Figure 41). This structure maintains its characteristic shape throughout all the specimens available from the type host and is here illustrated for nine of the eleven species. A careful special study of the entire group is needed.

\section{Key to Females}

Figure 47

Two species, brasiliensis and urosciuri, are omitted from this key because of lack of material.

1. Spermatheca apparently lacking; median tooth of the vulvar fimbriation strongly sclerotized, this sclerotization extending forward until it merges with the sclerotization of the genital platr...........ELLOGGI

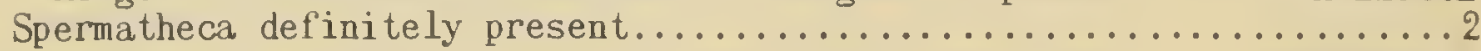

2. Spermatheca forming a relatively very large, oval body...... VENEZUELAE

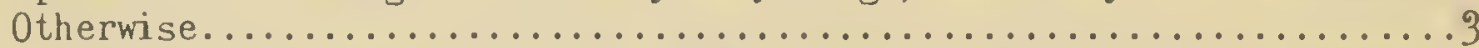

3. Spermatheca strongly bent, its ends expanded, the expansion of the anterior end being larger than that of the posterior end....ARIZONENSIS

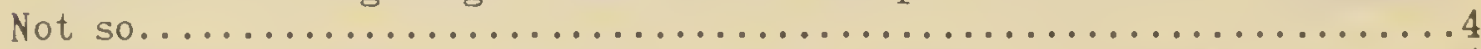

4. Spermatheca forming a relatively straight, simple, tapering tube.....5

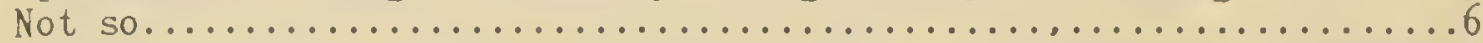

5. Spermatheca with a slender, tubular, posterior prolongation... LONGICEPS Spermatheca larger and stouter, without such posterior prolongation....

6. Spermatheca forming an elongate body which is anteriorly swollen, then reducinis by an abrupt constriction to expand agrain gradually toward the posterior end, then becoming terminally truncate with a small, strongly sclerotized terminal appendix................. EXTREMUS

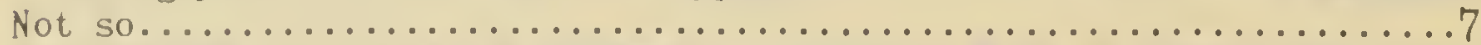

7. Spermatheca torming an elongate body which is more or less constricted

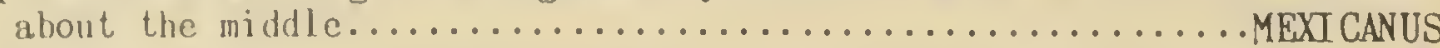

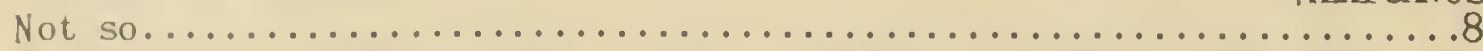

8. Spermatheca extremely minute, short, anteriorly swollen, and then constricting, its posterior end prolonged into delicate tube MICROSCIURI

Spermatheca similur in form but much larger and apparently without the

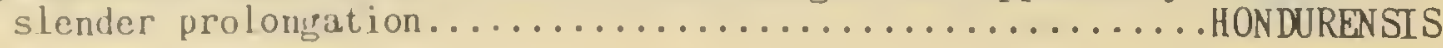




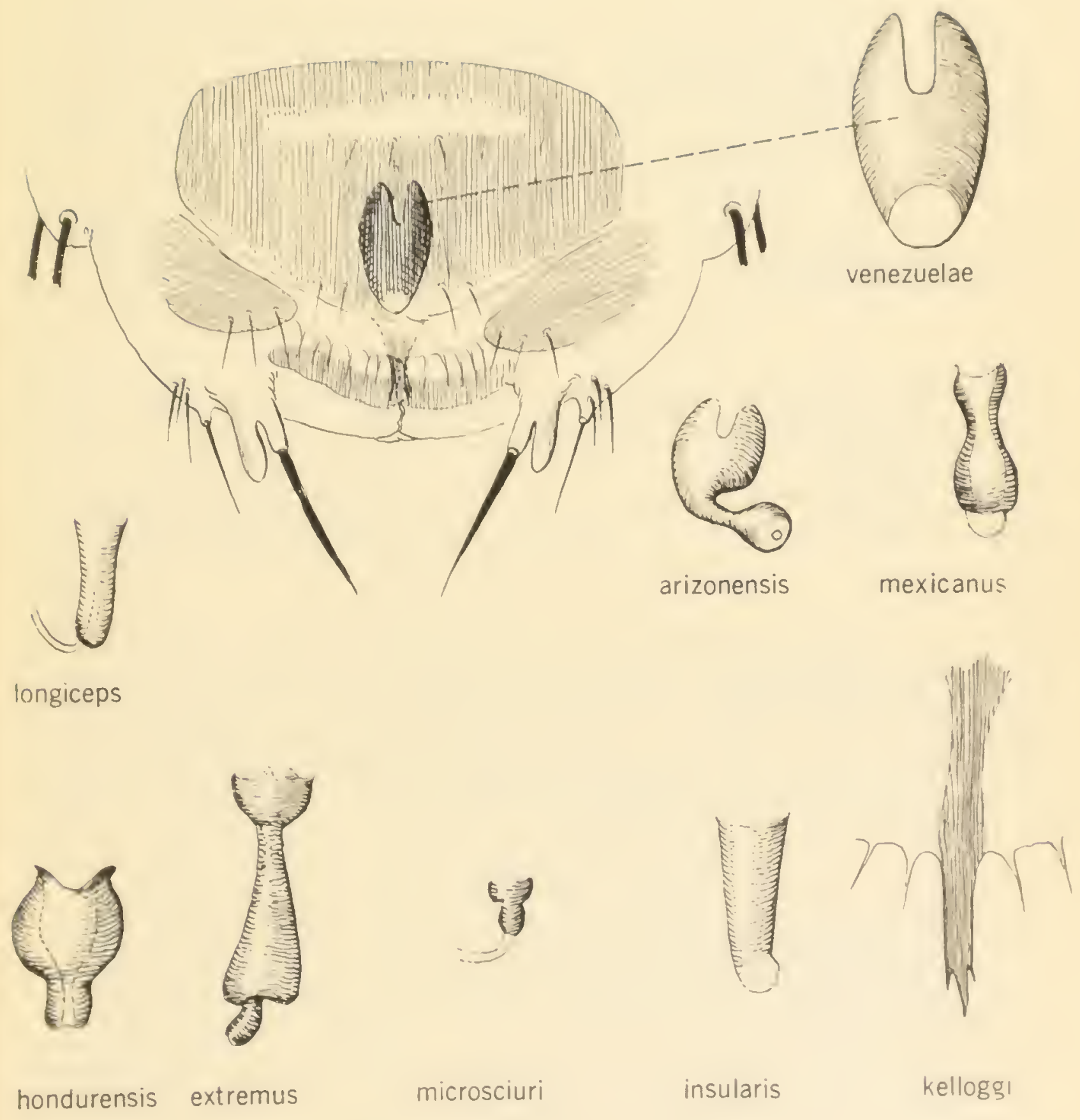

Details of genitalia of females of the Enderleinellus longiceps group

Figure 47 
1948. Enderleinellus arizonensis Werneck, Memorias do Instituto Oswaldo Cruz 45:288; figures 13-15.

HOSTS AND DISTRIBUTION. Type from Sciurus arizonensis from the Huachuca Mountains in Arizona. Also recorded by Werneck from Sciurus apache from Colonia Garcia, Chihuahua, Mexico; Sciurus alleni from the Sierra Guadelupe. and Sciurus nayarltensis from the Sierra Madre, Zacatecas, Mexico.

NOTES. 'This species was included by Herris in Enderleinellus extremus Ferris.

\section{Enderleinellus brasiliensis Werneck}

1937. Enderleinellus brasiliensis Herneck, Memorias do Instituto Oswaldo Cruz 32:399; f̈igure 11.

HOSTS AND DISTRIBUTION. f'rom Sciurus aestuans at Abaete, state of Para, Brasil.

Enderleinellus dremomydis Herris

1919. Enderleinellus dremomydis Ferris, Contributions Toward a Monograph of the Sucking Lice, Part 1:29; figure 16.

HOSTS AND DISTRIBUTION. From Dremomys pernyi, West Szechuan, China.

\section{Enderleinellus euxeri Ferris}

1919. Enderlelnellus euxeri Ferris, Contributions Toward a Monograph of the Sucking Lice, Part 1:37; fiurures 22, 23.

1929. Hoplophthirus euxeri (Ferris), Ewing, AManual of External Parasites, page 194.

HOSTS AND DISTRIBUTION. Described as from Euxerus microdon, which is a synonym of Xerus erythropus, from Wambugu and Oni, British East Africa.

Enderleinellus extremus Ferris

1919. Enderlelnellus extremus Ferris, Contributions Toward a Mono:raph of the Sucking lice, Part 1:24; figure 12.

HOSTS AND DISTRI BUTION. Type from Sciurus socialls at Nenton, luatemala. Also recorded from Sciurus aureogoster from the states of Vera Cruz and Oaxaca; from Sciurus deppei from the state of Tabasco; trom Sciurus griseoflavus, state of Chiapas; from Sciurus negligens, state of Tamaulipas; from Sciurus pollopus, state of Oaxaca; all these being from Mexico. All of these specimens are left in extremus by Werneck.

\section{Enderleinellus heliosciuri Ferris}

1919. Enderlelnellus helloscluri Ferris, Contributions l'oward a Monograph of the Sucking Lice, Part 1:40; figures 24, 25.

HOSTS AND DISTRIBUTION. Type from Beliosciurus gambianus (as undulatus) from British East Africa and from the same host (as rufobrachlatus and multicolor) from Uganda; from Hellosclurus ruwenzorit. Mt. Ruwenzori, British East Africa; from Protoxerus stangeri, British East Africa.

Enderleinellus hondurensis Werneck

1948. Rnderlelnellus hondurensis Werneck, Memorias do Instituto nswaldo Cruz 45:286; figures 7-9. 


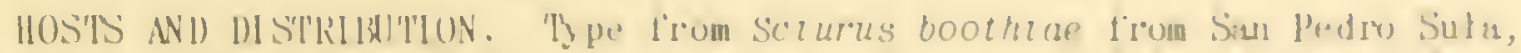

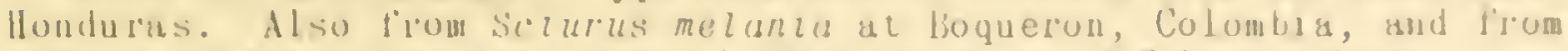
Sclurlus varleghtolde's (as goldmanl) from the slate of Chiapas, Mexico.

Noths. This species, with the above records, was included by ferris in

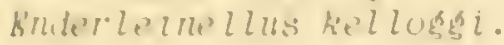

\section{Enderleinellus insular is heruech}

1915. Enderleinellus insularis Werneck, Menorius do Iustituto Oswaldo Cru

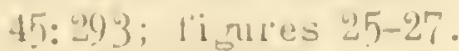

host'S AND DISTRIBUTLON. Type from Sciurus nesueus from Marparila IsLand, Venezuela.

NOTES. This species was included by f'eris under Enderle lnellus extremus.

Enderleinellus kelloggri fer'is

1916. Enderleinellus kelloggi Ferris, Psyche 23:105.

1919. Enderleinellus kelloggi Ferris, Ferris, Contributions Toward a Mono"raph of the Sucking Lice, Part 1:22; Iirure 11.

HOSTS AND DISTRIBUTION. From Sciurus griseus, Stanford University, Calitiornia.

NOTES. Specimens erroneously recorded as kelloge $i$ are here placed under hondurensis.

\section{Enderleinellus Larisci Ferris}

1919. Enderleinellus larisci Ferris, Contributions Toward a Monograph of the Suckin: Lice, Part 1:17; rirures 7, 8.

1929. Euenderleinellus larisci (Ferris), Ewing, A Manual of External Parasites, parge 197.

HOSTS AND DISTRIBUTION. From Lariscus insignis (as diversus), from Lanchut, southwest Borneo.

NOTES. This species was designated as type of the genus Euenderleinellus Ewing?

\section{Enderleinellus lon riceps kellogg and Ferris}

1915. Enderleinellus longiceps hellog and Ferris, Anoplura and Mallophaga of North American Yammals, Stantord University Publications, University Series (no volume number), page 44; Plate 2, figure 5; Plate 4 , figure 12 ; Plate 6 , figure 2.

1919. Enderleinellus lonsiceps Kellopg and Ferris, Ferris, Contributions Toward a Yonoriph of the Suckin' Lice, Part 1: 19; figures 9, 10.

1948. Enderleinellus lungiceps Kellogis and Ferris, Herneck, Yemorias do Insti tuto 0swaldo Cruz 45:284; figures 1-3.

HOSTS AND DISTRIBUTION. Type from Sciurus niger or Sciurus carolinensis, at Lincoln, Nebraska. Recorded from Sciurus niger at Valentine, Nebraska, and Waterloo. Indiana; from Sciurus carolinensis at Bayou Saint Louis, Mississippi: from Sciurus kaibabensis from the Kaibab National Forest, Arizona: from Sciurus aberti at Estes Park, Colorado: from Sciurus alleni, Colonia Garcia, Chihuahua, Mexico; from Sciurus oculatus, state of Vera Cruz, Mexico.

NOTES. The records iven above are those of Ferris, which have been accepted by herneck. Specimens I'rom Sciurus apache in Chihuahua, Mexico, referred by Ferris to longiceps have been placed by herneck in Enderleinellus arizonensis as have specimens from Sciurus ar izonensts in Arizona and from sciurus nayaritensis, state of Zacatecas, Yexico. 
1919. Enderleinellus malaysianus Ferris, Contributions Toward a Monograph of the Sucking Lice, Part 1:12; figures 3, 4.

HOSTS AND DISTRIBUTION. Type from Callosciurus caniceps (as Sciurus lucas) from Saint Lukes Island, Mergui Archipelago, Malaysia. Also recorded from the same host (as Sciurus bentinckanus) from Bentinck Island in the same archipelago, (as Sciurus domelensis) from Domel Island in the same archipelago, (as sciurus lancavensis) from Pulo Teratau, and (as Sciurus davisoni) from Tronir, lower Siam; and from Callosciurus prevosti (as Sciurus borneoensis) at Pulo Kanchut, Borneo.

\section{Enderleinellus marmotae Ferris}

1919. Enderleinellus marmotae Ferris, Contributions Toward a Monograph of the Sucking lice, Part 1:47; figure 30.

HOSTS AND DISTRIBUTION. Type from Marmota monax from Grafton, South Dakota; also recorded from the same host at Elk River, Minnesota, and Marble Cave, Missouri, at Sandy Springs, Maryland, and Washington, District of Columbia.

\section{Enderleinellus menetensis Ferris}

1919. Enderleinellus menetensis Ferris, Contributions Toward a Monograph of the Sucking Lice, Part 1:14; figures 5, 6.

HOSTS AND DISTRIBUTION. From Menetes berdmorei, Koh Kut Island, southeast Siam.

\section{Enderleinellus mexicanus Herneck}

1947. Enderleinellus mexicanus Werneck, Memorias do Instituto Oswaldo Cruz 45:289; figures 16-18.

HOSTS AND DISTRIBUTION. Type from sciurus truei at Chacala, Mexico. Also recorded from Sciurus nelsoni from the state of Morelos, and from Sciurus colliae, state of Nayarit, Mexico.

NOTES. The specimens recorded above were recorded by Ferris under Enderleinellus extremus.

\section{Enderleinellus microsciuri Werneck}

1947. Enderleinellus microsciuri Werneck, Memorias do Instituto Oswaldo Cruz 45:287; figures 10-12.

HOSTS AND DISTRIBUTION. From Microsciurus mimulus from unspecified locality in Colombia.

NOTES. The specimens upon which this species was based were previously recorded by Ferris as Enderletnellus kelloşi.

\section{Enderleinellus nannosciuri Ferris}

1919. Enderleinellus nannosciuri Ferris, Contributions Toward a Monograph of the Sucking Lice, Part 1:30; ligure 17.

HOSTS AND DISTRIBUTION. From Nannosciurus melanotis from Batavia, Java.

Enderleinellus nitzschi Fahrenholz

firgures 48,49

1818. Pediculus sphaerocephalus Nitzsch, Germar's und Zincken's Magazin für die Entomologie 3:305. (Not Periculus sphaerocephalus von Olfers) 


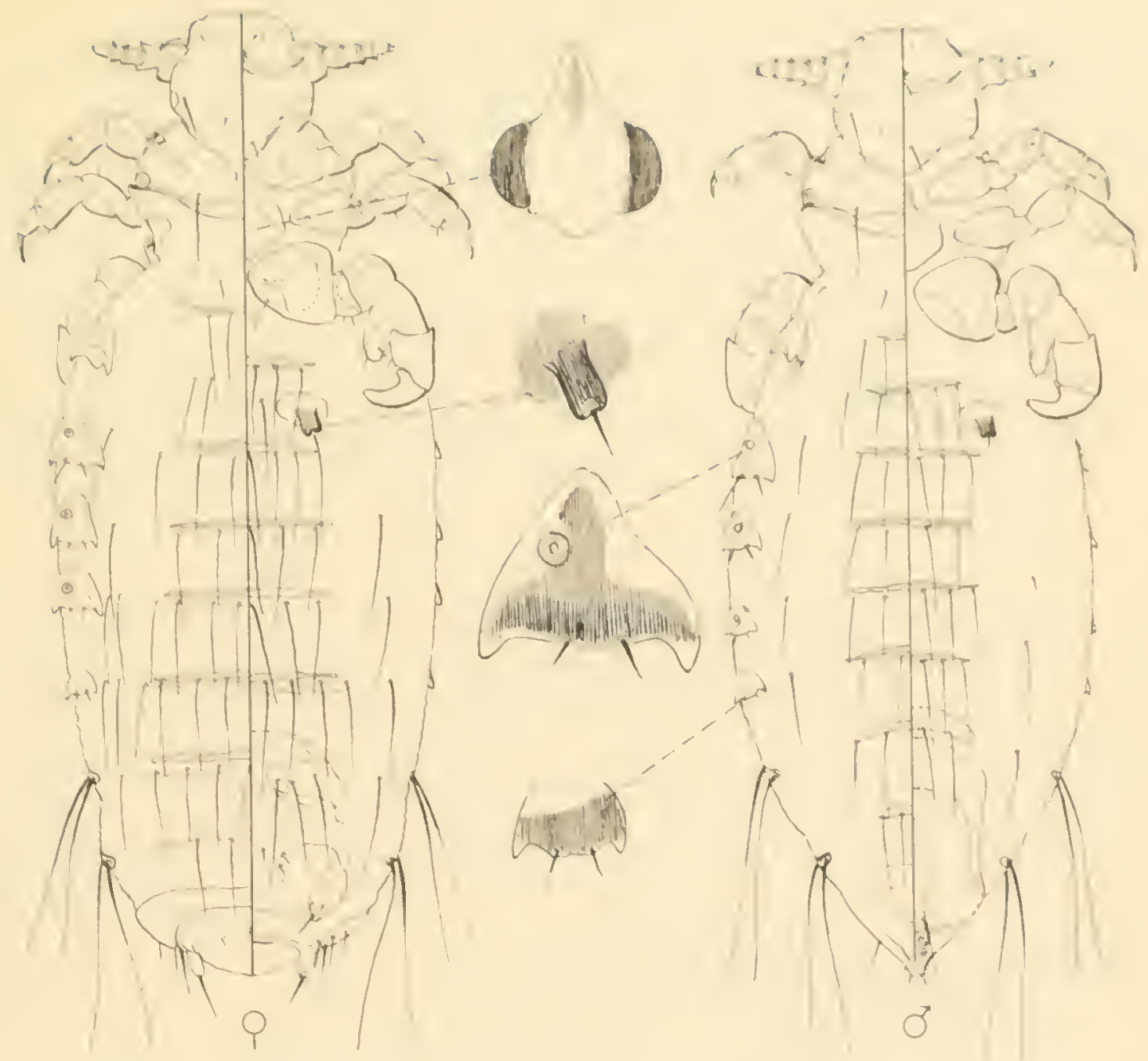

Enderleinellus nitzschi Fahrenholz

Figure 48

1912. Enderleinellus sphaerocephalus (Nitzsch), Fahrenholz, Jahresbericht des niedersachsischen Zoologischen Vereins zu Hannover 2-4:52; text figures 22, 23; Plate 2, figures 5-7.

1916. Enderleinellus nitzschi Fahrenholz, Archiv für Naturgeschichte, Abteilung A, 81:29.

1919. Enderleinellus nitzschi Fahrenholz, Ferris, Contributions Toward a Monograph of the Sucking Lice, Part 1:8; figures 1, 2.

HOSTS AND DISTRIBUTION. Originally described from Sciurus vulegris in Europe and recorded numerous times from this host. Recorded also from Sciurus anomalus (as syriacus) from Syria; from sciurus hudsonicus from Alaska; from Sciurus douglasil from western United States; from Sciurus fremonti from Colorado.

NOTES. Hemeck, who examined all the material recorded above, has arreed that no specific differences exist amon: the specimens from the different hosts. 


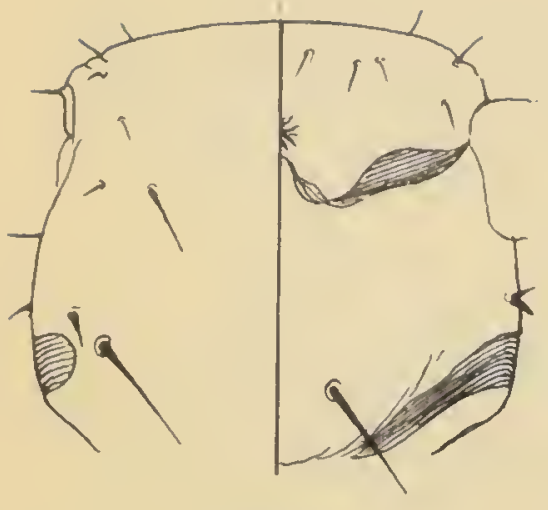

head
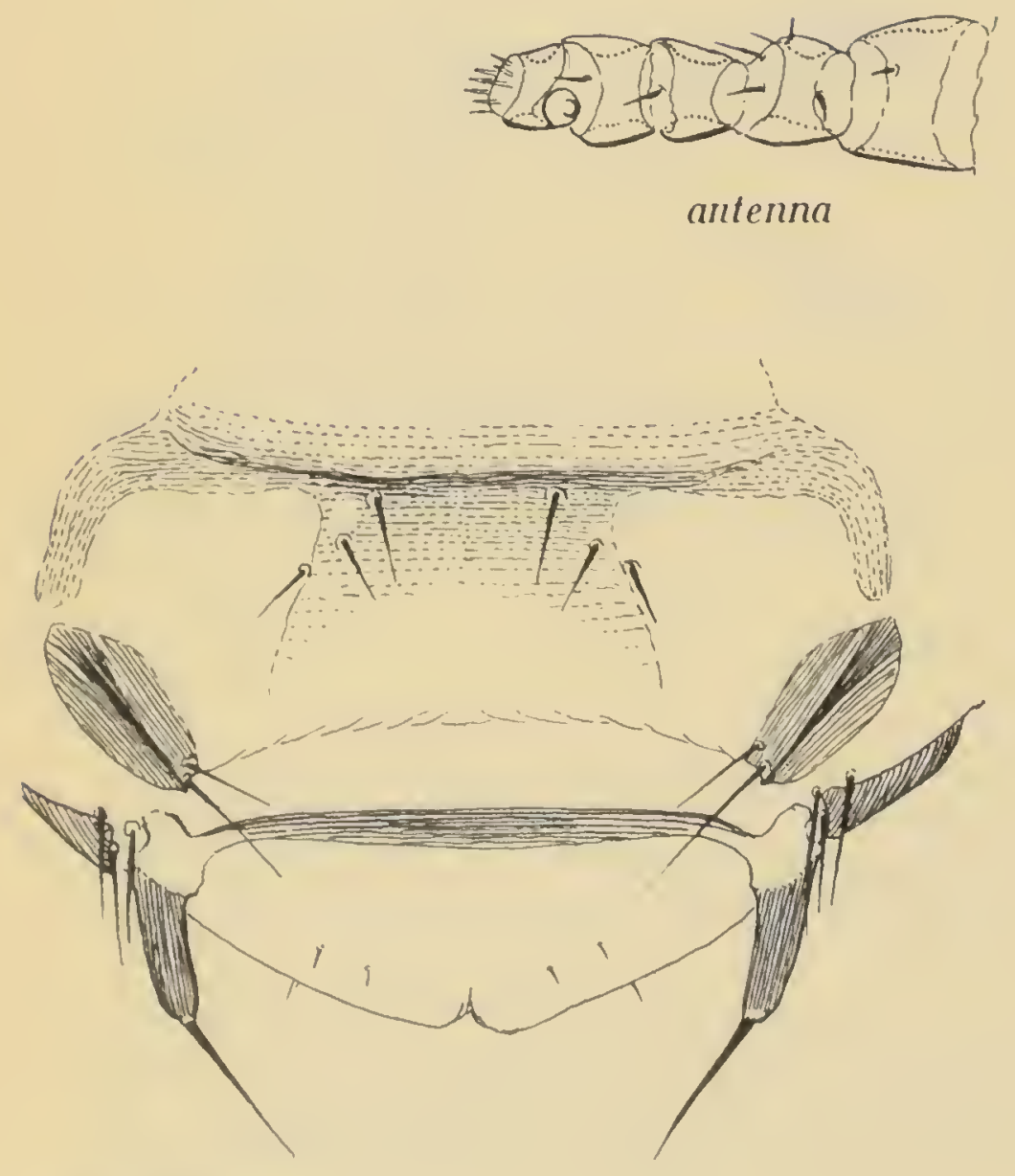

female genitalia

Enderleinellus nitzschi Fahrenholz, details

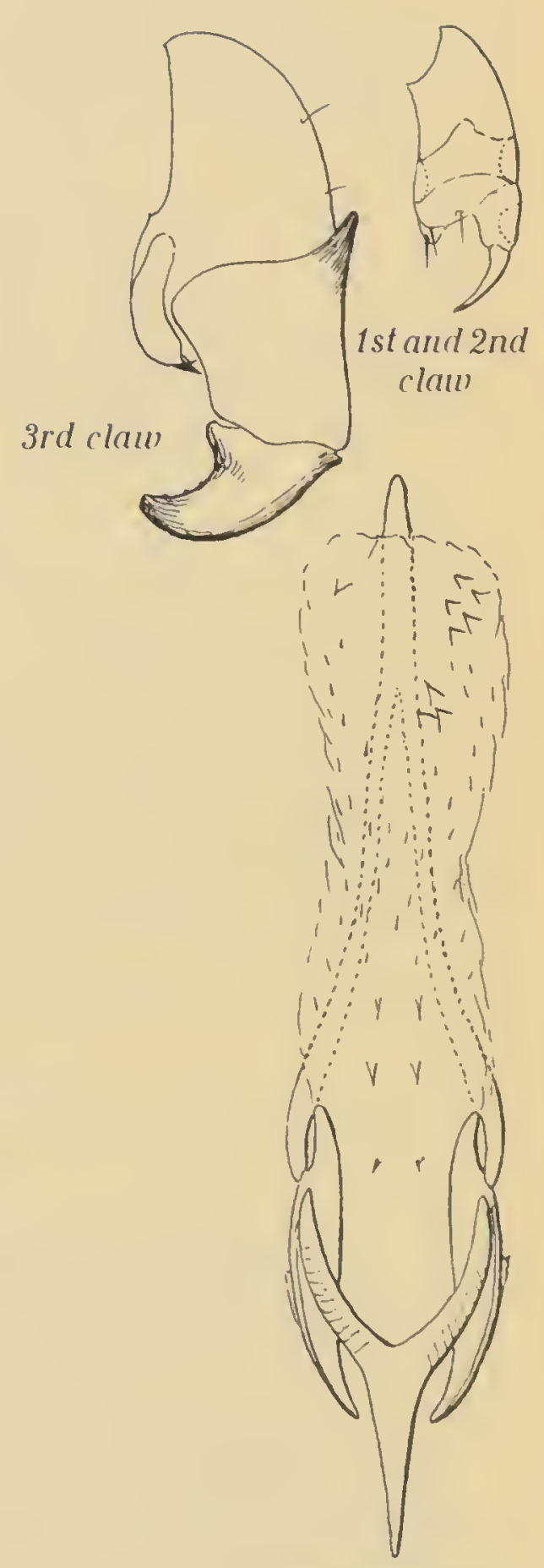

male genitalia

Figure 49 
1915. Rnderlelnellus usborml hellogg and fierris, Anoplura and Malluphliaris of North American Mammals, Stantorel University l'ull ications, [ni versily sories (no volume number), pare 43; text tigure 15; Plate 1: Iisure 11; Plate 6, ligure 6.

19 19. Enterleinellus usborni Kelloger and ferris, Ferris, Contrilutions

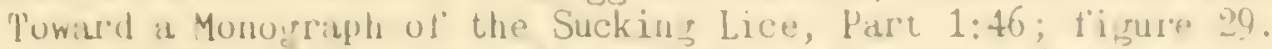

IIOSTS AND DISTRIBITION. Type from Citellus beecheyl (as douglast) ut Covelo. Mendocino County, Citlitornia, and recorded trom this host species al varions localities in California. Also trom Citellus voritegotus (us buckleyl) in Texus and (as grammurus) in Arizonis. From cltellus (us Xerospermophilus) tereticaudus, Imperial Counly, Calitornia.

\section{Enderleinellus platyspicatus Ferris}

1919. Enderleinellus platuspicatus Ferris, Contributions Toward a Monosraph of the Sucking Lice, Part 1:26; 1"i rures 14. 15. Ceylon.

HOSTS AVI) DISTRTBUTION. From funambulus palmarum (as tristrtatus) in

\section{Enderleinellus replicatus Redikorzev}

1937. E'nderleinellus replicatus Redikorzev, Parasitolog 29:4; figure.

HOSTS AND DISTRLBUTION. From Sciuropterus volans, Tartar Republic, without closer indication of locality.

NOTES. Members of this yenus very commonly in dy ing contract in such a manner that the head is drawn back over the body as the result of opisthotonos, and in preparing specimens for study they must be untolded. Unfortunately, in describin! this species its author made his illustrations from a specimen that was thus contracted and consequently his illustration is entirely useless. It is impossible to determine what the species is actually like and to include it in the key.

\section{Enderleinellus sciurotamiasis Ferris}

1919. Enderleinellus sciurotamiasis Ferris, Contributions Toward a Monograph of the Sucking Lice, Part 1:45; figures 20, 21. China.

HOSTS AND DISTRIBUTION. From Sciurotamias davidianus, Shensi Province,

\section{Enderleinellus suturalis (Osborn)}

1891. Haematopinus suturalis 0sborn, United States Department of Agriculture, Division of Entomology, Bulletin (old series) 7:27: fig. 15.

1915. Enderleinellus sutural is (0sborm), hellogs and Ferris, Anoplura and Yallophaga of North American Mammals, Stanford University Publications, University Series (no volume number), paje 40; Plate 4, figure 9.

1916. Enderleinellus suturalis occldentalis kellogg and Ferris, Anoplura and Mallophaya of North American Mammals, Stanford University Publications, University Series (no volume number), page 42; Plate 2, 1igure 3: Plate 4, figure 10; Plate 5, figure 17.

1919. Enderleinellus suturalis (Osborn), Ferris, Contributions Toward a Yonograph of the Sucking Lice, Part 1:42; figures $26,27.25$.

1929. Cyclophthirus suturalis (0sborn), Ewing, A Manual of External Parasites, paje 196.

HOSTS AND DISTRIBUTION. Originally described as from Citellus tridecim- 
lineatus and Citellus franklini (as Spermophilus) at Ames, Iowa. The first of these has been desirnated by Kelloguand Ferris as the type host. Ferris has recorded the species from a long series of species of Citellus as follows: eversmanni, Altai, Siberia; mongolicus, Kansu, China; beldingi, California; elegans, Colorado; franklini, North Dakota; mollis, Nevada; osgoodi, near Circle, Alaska; townsendi, state of Washington; tridecimlineatus, Kansas and Oklahoma; madrensis (as Callopsermophilus), Chihuahua, Mexico; nelsoni (as Ammospermophilus), California; Cynomys gunnisoni, Colorado; Cynomys leucurus, Colorado and Wyoming.

NOTES. In the rather extensive material at hand there is a quite wide range of variation in various details, but a study of the material by Dr. Edwin Cook has shown no clear basis for recomizing more than one species. The two species, osborni and marmotae, which have in the past been separated from suturalis are the only ones in which the situation seems reasonably clear. Studies are continuing with an accompanyin attempt to secure additional material and it is hoped eventually to publish a detailed report upon the group.

\section{Enderleinellus taniasis Fahrenholz}

1916. Enderleinellus tamiasis Fahrenholz, Archiv tür Naturgeschichte, Abteilung A, 81:11:27; text figure 22 .

1919. Enderleinellus tamiasis Fahrenholz, Ferris, Contributions Toward a Monograph of the Sucking Lice, Part 5:288; fi sure 176.

HOSTS AND DISTRIBUTION. Known only from the ori ginal record from Tamias striatus in the Berlin Zoolo ical Garden.

NOTES. It is entirely possible that Tamias striatus, which is a native of eastem and central United States, is not the normal host of this species, no species of Enderleinellus having yet been recovered from this host under natural conditions.

\section{Enderleinellus urosciuri Werneck}

1937. Enderle inellus urosciuri Werneck, Memorias do Instituto Oswaldo Cruz 32: 400; f'igure 12.

HOSTS AND DISTRIBUTION. Recorded from Sciurus (as Urosciurus) ignivent$r$ is from Acajutuba, Rio Neưro, state of Amazonas, Brasil.

\section{Enderleinellus venezuelae Ferris}

1919. Enderleinellus venezuelae Ferris, Contributions Toward a Monograph of the Sucking lice, Part 1:25; figure 13.

1948. Enderleinel lus venezuelae Ferris, Werneck, Memorias do Instituto Oswaldo Cruz 45:292; figures 22-24.

HOSTS AND DISTRIBUTION. Type from Sciurus griseogena from Macuto, Venezuela. Also recorded from the same host (as meridensis) from Merida, Venezuela, and from Sciurus serrardi (as versicolor) from Rio Aurare, Venezuela.

\section{Enderleinellus zonatus Ferris}

1919. Enderleinellus zonatus Ferris, Contributions Toward a Monouraph of the Sucking lice, Part 1:32; f'igures 18, 19. (In part)

1948. knderleinellus zonatus Ferris, Werneck, Memorias do Instituto Oswaldo Cru\% 45:295; r'igure 28.

HOSTS AND DISTRIBUTION. Type from Paraxerus ochraceus (as jacksoni), Kijalie, British East Africa.

NOTES. Werneck has pointed out that two distinct species were included in the material recorded by Ferris. 


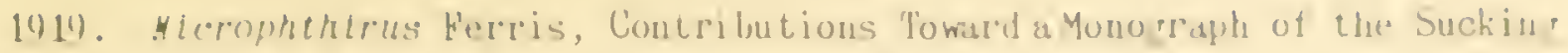
lice, l'art 1:49.

litWERC TYPl. finderleinellus unc lmatus ferris.

CIARAC"TkKS. Enderleinellinise in which the pair of little, sclerotized phates on the venter of the second alxlominal se ment is lasking. Harater al phatesol' serments 3-6 each continuous with the correspondino sternal plate, heing connected with it hy a nislow, sclerutized bridge. Pal'istergal plates not ilee trom the body at any point. Antennae with the froxima, postaxial urgle ol serments $2-3$ produced into a sclerotized hook.

NO'lES. As known at present this genus contains but a siuple sprecies. This is a very peculiar torm, known only from Nor'th American lly in? squirrels of the genus Glaucomys. The assigrunent of the genus to the Enderleill ellate is based entirely upon the charicter of the Leigs, since there is lit the else to connect it with any other group of the Anoplura. The hast association supports this assignent and in this particular case hus been taken into consideration in placing the genus.

\section{Microphthirus meinatus (Ferris) Figures 50, 51}

1916. Enderleinellus unclnatus Ferris, Psyche 23:108; figures 6, 7. 1919. Microphthirus unc inatus (Ferris), Ferris, Contributions Toward a Monorruph of the Sucking Lice, Part 1:49; firures 31-32.

HOSTS AND DISTRIBUTION. Known only from the original record from Glaucomys sabrinus at Yosemite National Park, California. The host is a member of the rodent family Sciuridae.

NOTES. This is one of the very smallest of all suchinis lice, the male attaining a length of on $\mathrm{ly}$ about $.35 \mathrm{~mm}$. The insects are so small that as seen upou their host they are very likely to be mistaken for young of one of the other species which occur on these squirrels.

\section{Genus hERNECKIA Ferris, new gुenus}

GENERIC TYPE. Enderleinel lus minutus Herneck. One other species, Enderle inellus paraxeri Werneck, is here included.

CIARACTERS. Enderleinellinae in which the paired sclerotizations of the second abdominal sternum are lacking. Differing from Nicrophthirus in which this also is true, in not having the paratergal plates connected with the sternites by sclerotizations.

0ccurring on African squirrels of the genus Paraxerus.

NOTES. Since each of the two included species is known from but a single male very little can be said about the group. It is by no means certain that these two species should be placed in the same genus, since they differ materially in various respects and it appears possible that they are independent derivatives t'rom species of Enderleinellus that also occur on their hosts.

\section{Key to Species of HERECKIA}

Cenitalia of the male with all parts of the terminal complex slender......

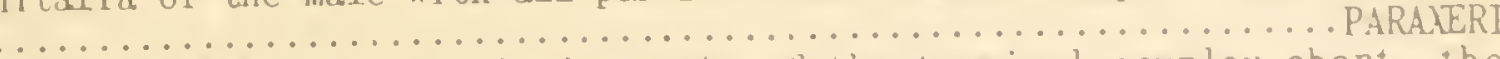

Genitalia of the male with the parts of the terminal complex short. the

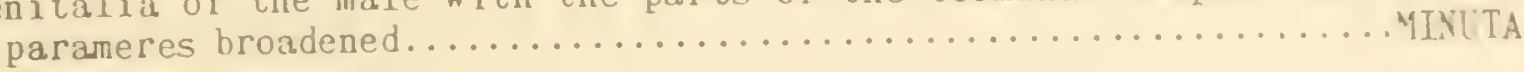




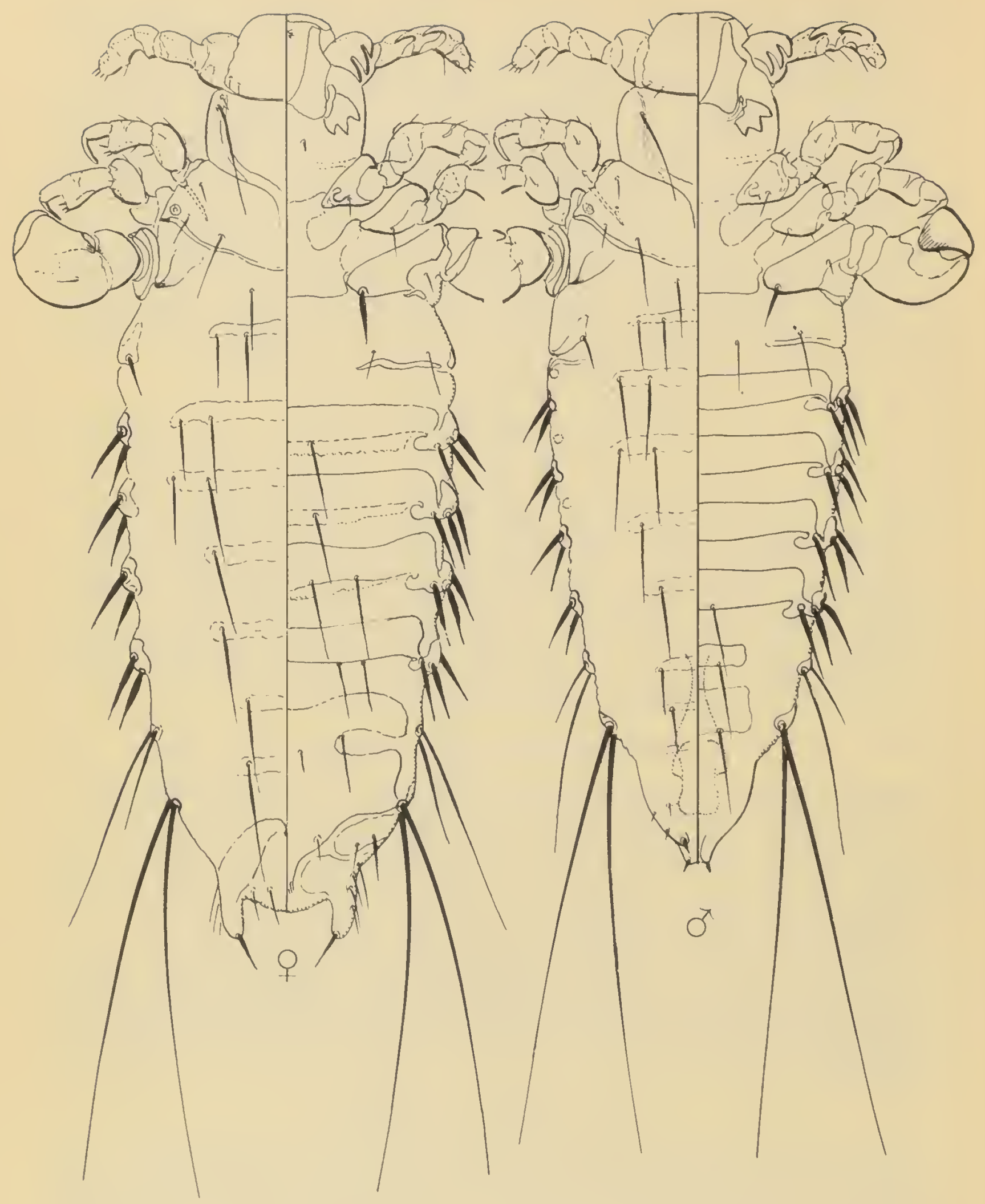

Microphthirus uncinatus (Ferris)

Figure 50 


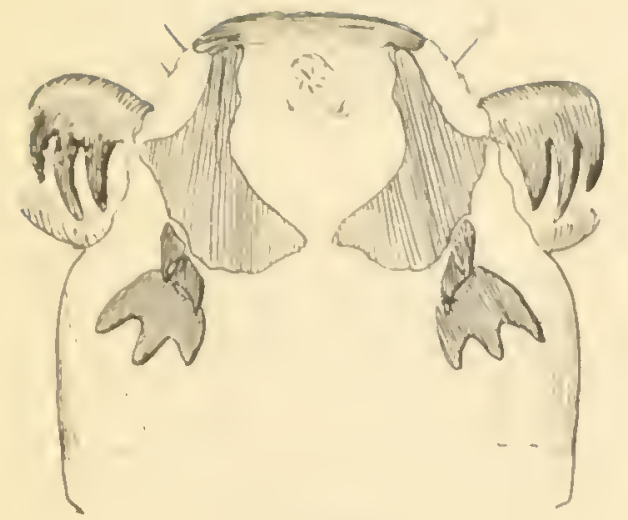

he'lle

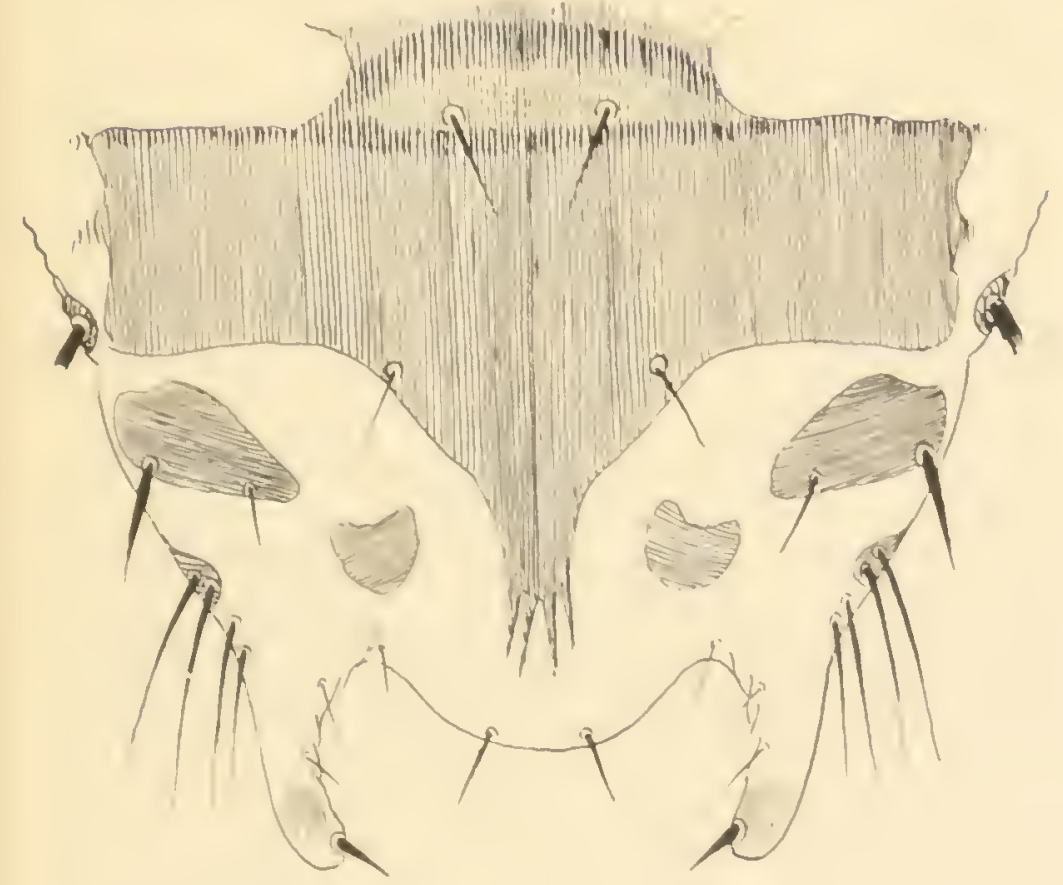

female genitalia

Microphthirus uncinatus (Ferris), details

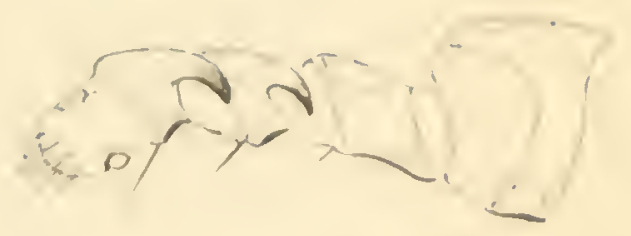

(Inle'llum

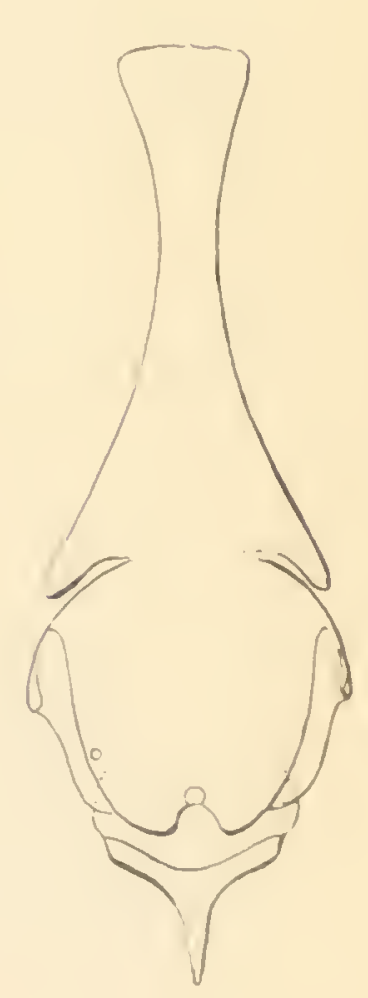

male genitalia

Figure 51 


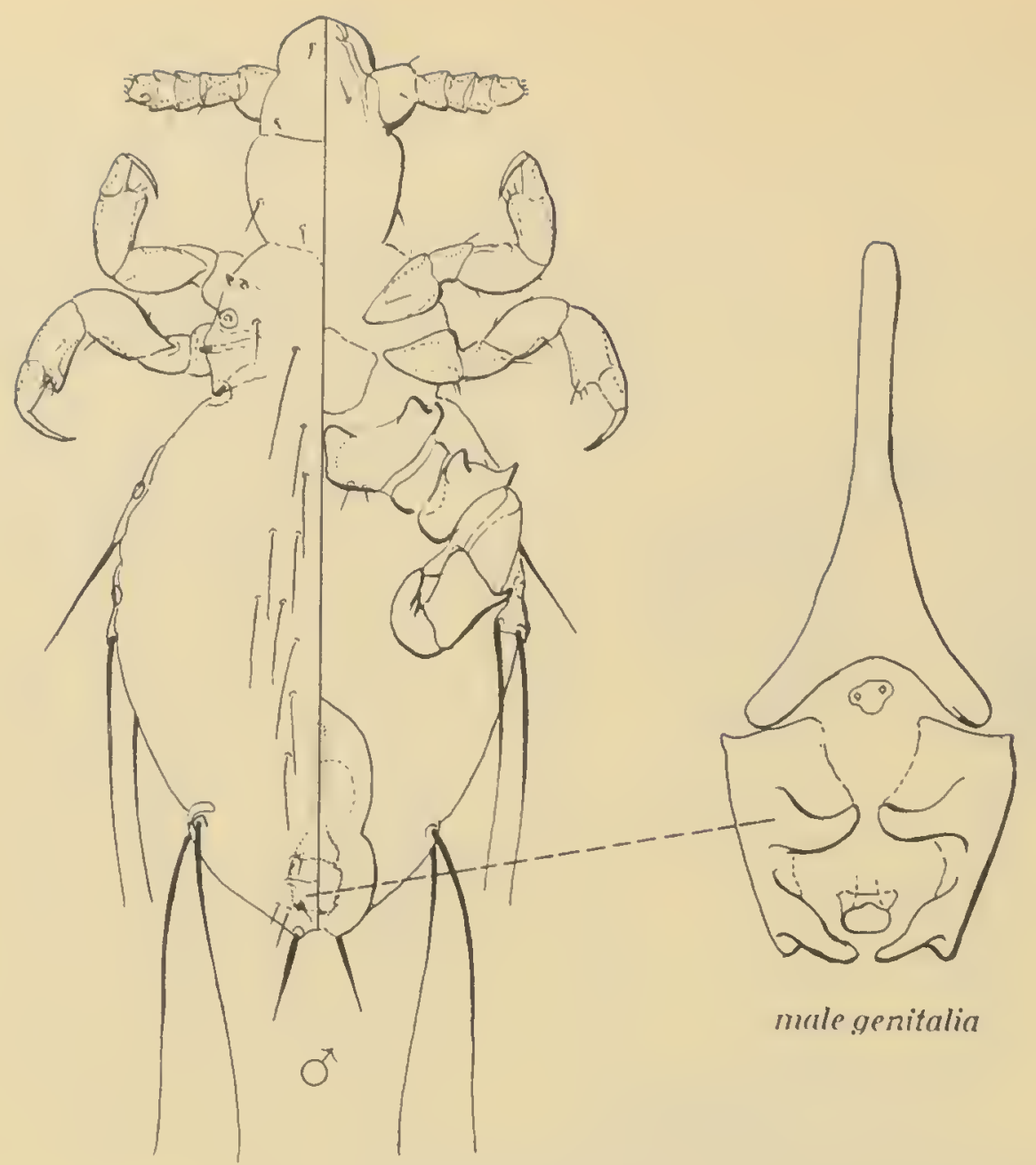

Werneckia minuta (Werneck)

Figure 52

Werneckia minuta (We rneck)

Figure 52

1947. Enderleinellus minutus Werneck, Memorias do Instituto Oswaldo Cruz 45: 296 ; fi gure 30.

HOSTS AND DISTRIBUTION. Known from but a single male, from Paraxerus jacksoni (=ochraceus), from Kijabe, British East Africa.

NOTES. The single male representing this species was discovered by Herneck among the type material of Enderleinel lus zonatus Ferris and described by Werneck who, however, did not note the absence of the paired ventral plates of the second abdominal serment.

Werneckia paraxeri (Werneck)

1917. Knderle inellus paraxeri Werneck, Memorias do Instituto Oswaldo Cruz 45:295; lignre 29.

IIOSTS ANI) DISTRIBUTION. Known from hut a single female, from Paraxerus palliatus, from luitish East Africa.

NOTES. The circumstances surrounding this species are the same as those connected with minuta. 


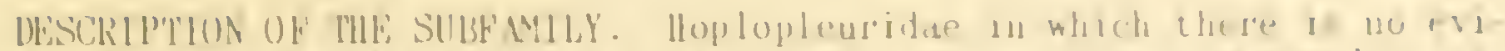

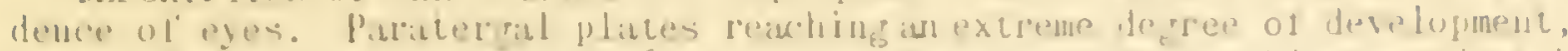

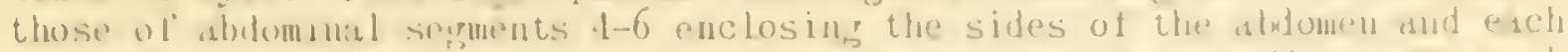

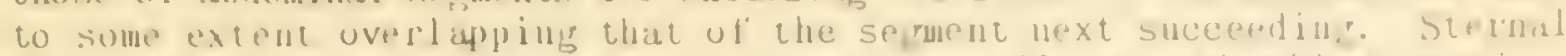

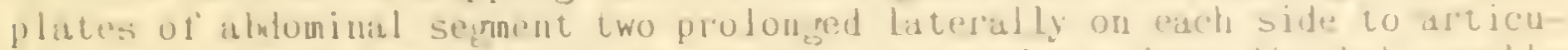
late with the corresponding piralergil plate and at times divaled mmall!

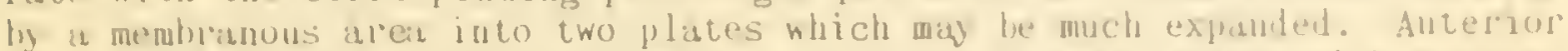

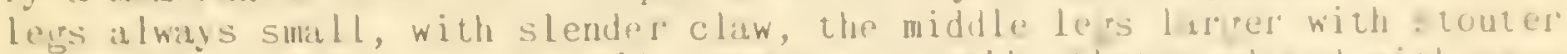

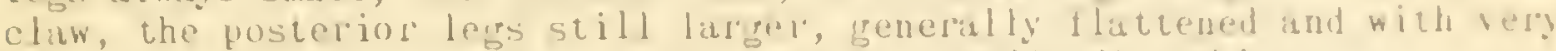
broid claw. Antemare 45 segnented, never sexmally dimolphic.

NuTES. In its basic pattern this group is quile homo reneums, al thomph some of its species present sone extraordinary specializutiuns. The troup is as a whole probably the most specialized of the tnopluri.

The live included renera mily be separated by the lolluwing key.

Key to the Gener'u of HOPLOPILURINAE

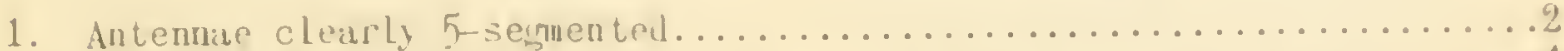

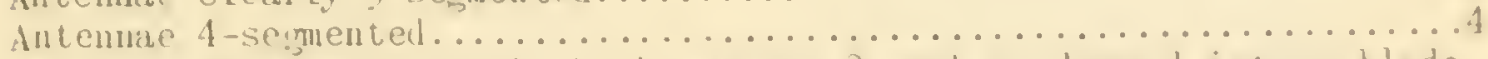

2. Parater pal plates of abdominal sement 2 each prolonged inco a blade-

like process which projects t'rom the hody wall......... PTEKOPHTHIRIS

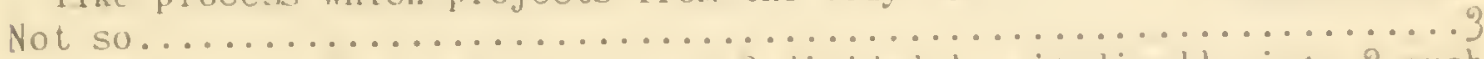

3. Sternal plate of abdoninal semment 2 divided longitudinaly into 2 much

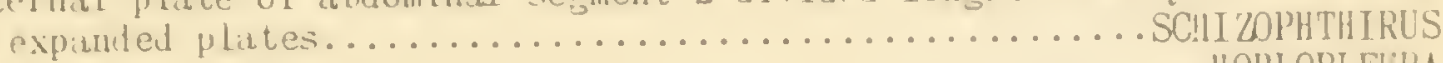

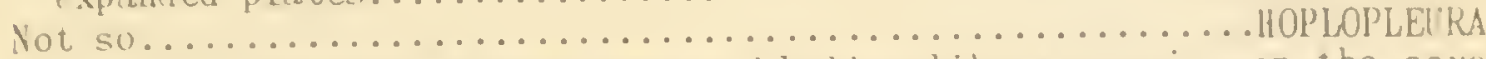

4. Posterior le

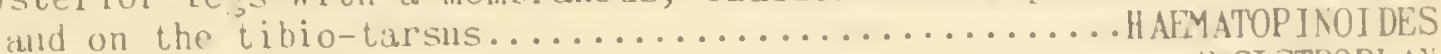

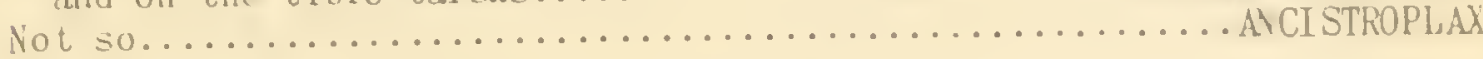

\section{Genus AYCISTROPL, LX hatersion}

1929. Ancistronlar Waterston, Parasitolor 21:161.

1932. Ancistronlax. Ferris, Contributions Toward a. Monorraph of the Suckin: Lice, Part 5:38.

GENERIC TYPE. Ancistroplar crocidurae liaterston.

CHARICTEKS. Ioplopleurinae in wich the antennae are four-semented. Parater pal plates of abdominal sements $3-7$ each having the appearance of be ill divided into two equal parts by a lon ritudinal line of neak sclerotization. Ter ral and sterual plates of the abdomen stronily developed in both sexes, the female having three plates and three rows of setae, both dorsally and ventralla, on segments 3-6; the male having but one plate, either dorsally or ventrally, on any se ment, but this on se rments 4-6, both dorsally and ventrally having two rows of setae and presenting an appearance which sumests that it is composed of two transverse plates which have partially fused. Terpal plate of sement six of the male having its posterior an les each produced into a free process which is bent apically toward the mid-line ot the body. Posterior less strongly expanded and flattened, with broad claw. Stemal plate of abdominal se ment iwo divided longitudinally into two expanded plates. First sternal plate of sement three not produced laterally to articulate with the corresponding paraier rites.

IOTES. The alfinities of this enns seem to be most closely with schizophthirus. It seems also to he more or less closely related to the jenus Haenatopinolies. 
1929. Ancistroplax crocidurae Haterston, Parasitology 21:161; figures.

1932. Ancistroplax crocidurae Waterston, Ferris, Contributions Toward a Monograph of the Sucking Lice, Part 5:308; figures 188, 189.

HOSTS AND DISTRIBUTION. There is but a single record of this species which attributes it to a shrew, Crocidura horsfieldi, in Ceylon.

\section{Genus HAEMATOPINOIDES 0sborn}

1891. Haematoptnoides Osborn, United States Department of Agriculture, Division of Entomology, Bulletin (old series) 7:28.

1896. Euhaematopinus Osborn, United States Department of Agriculture, Division of Entomology, Bulletin (new series) 5:186.

1929. Haematopinoides, Ewing, A Manual of External Parasites, page 140. 1932. Haematopinoides, Ferris, Contributions Toward a Monograph of the Sucking Lice, Part 5:289.

GENERIC TYPE. Haematopinoides squamosus 0sborn. The genus Euhaematopinus Osborn, with Euhaematopinus abnormis Osborm as type, is synonymous, its type species being synonymous with squamosus.

CHARACTERS. Hoplopleurinae in which the antennae are 4-segmented. Posterior legs with a membranous, bladder-like expansion arising from the anterior margin of the coxae and a similar structure on the anterior wall of the tibia. Apart from the usual sclerotizations of the terminal and genitalic segments, tergal plates are developed only on segments 1-3 and sternal plates on segments $2-3$ in the female, while they are present on all segments except the first in the male. Female with two rows of setae both dorsally and ventrally on most of the abdominal segments, the male with but one. Sternite of the second abdominal segment divided longitudinally into two expanded plates each of which articulates by a lateral extension with the corresponding paratergal plate. First plate of abdominal sement three not produced laterally.

NOTES. This genus (as Euhaematopinus) was employed by Enderlein in 1904 as type of the subfamily Euhaematopininae of the family Haematopinidae and in 1929 this was elevated to the rank of a family, under the name Haematopinoididae, by Ewing. Actually, the genus is very closely related to Hoplopleura. The membranous expansions on the posterior legs are unique structures but do not in any way justify the assignment of the genus to an isolated position.

Haematopinoides squamosus (0sborn) Figures 55, 56

1891. Haematopinoides squamosus 0sborn, United States Department of Agriculture, Division of Entomology, Bulletin (old series) 7:29; figure 16.

1896. Euhaematopinus abnormis 0sborn, United States Department of Agriculture, Division of Entomology (new series) 5:187; figure.

1922. Euhaematopinus abrormis Osborn, Ferris, Contributions Toward a Monoyraph of the Sucking Lice, Part 3:150; figures 98, 99.

1929. Haematopinoides squamosus Osborn, Ewing, A Manual of External Parasites, pirge 140 .

HOSTS AND DISTRIBUTION. First recorded, undoubted ly quite erroneously, from a rodent of the family Geomyidae in lowa. Later described again as a new genus and species from its true host, a mole, scalopus aquaticus, at Ames, Towa, United States. It has since been recorded from this host from localities in Kansas, Illinois, and New York. Also specimens are at hand 


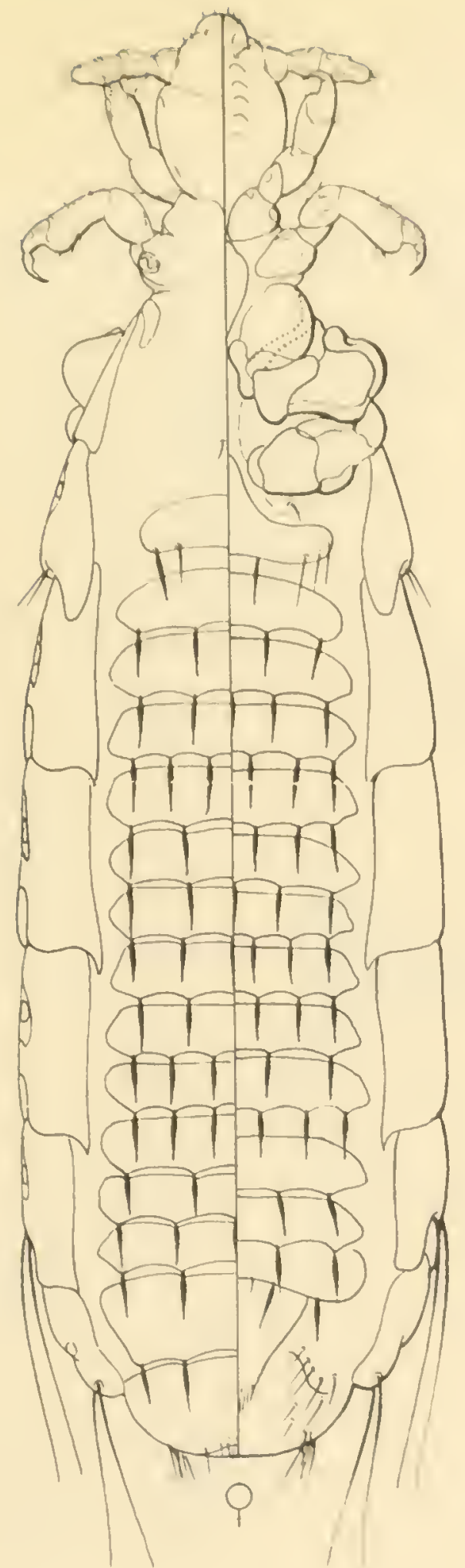

Ancistroplax crocidurae Waterston

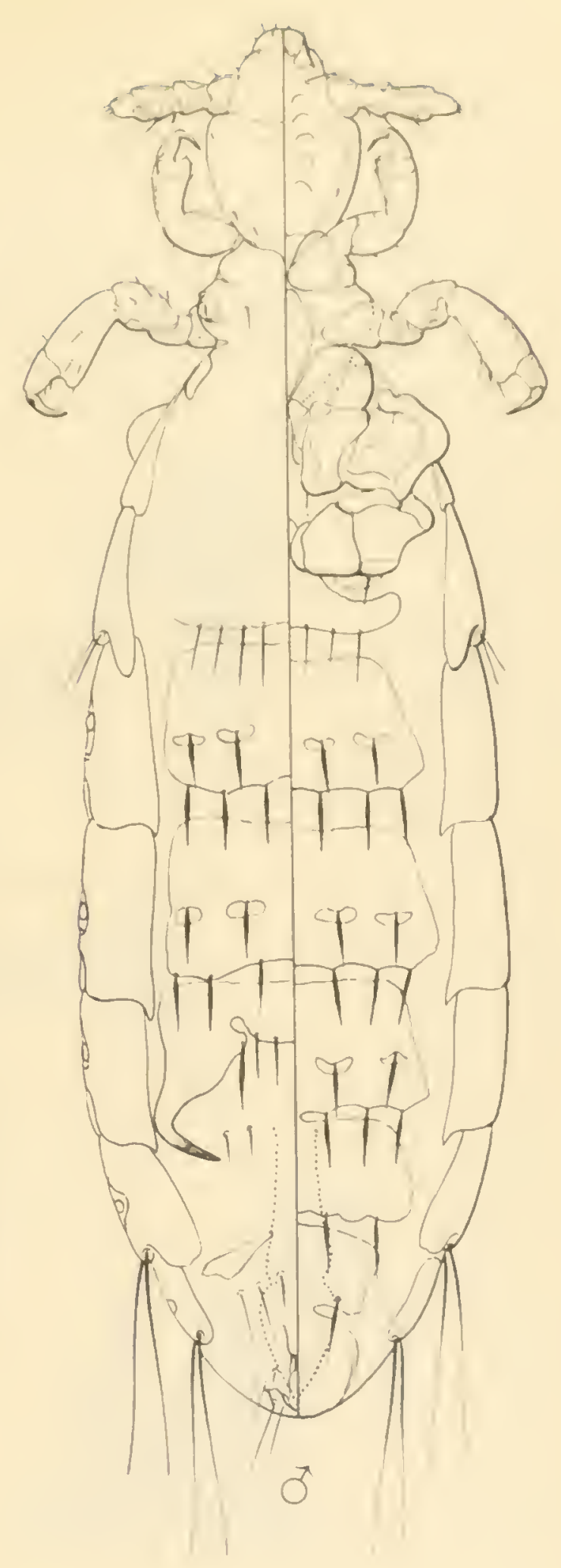

Figure 53 


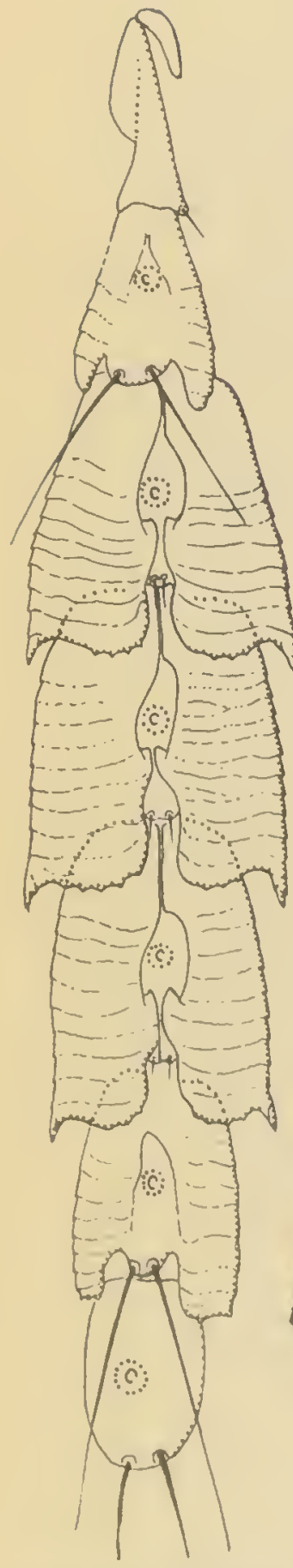

paralerengl plates
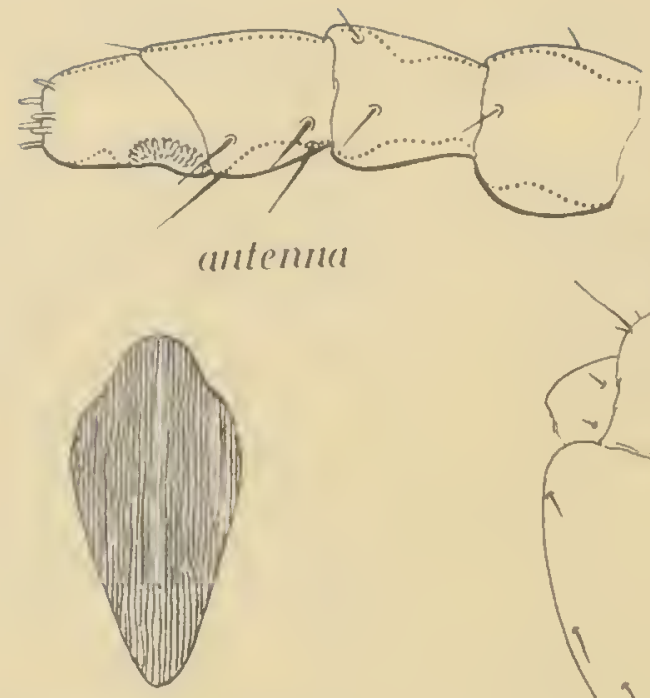

thoracic sternal plate
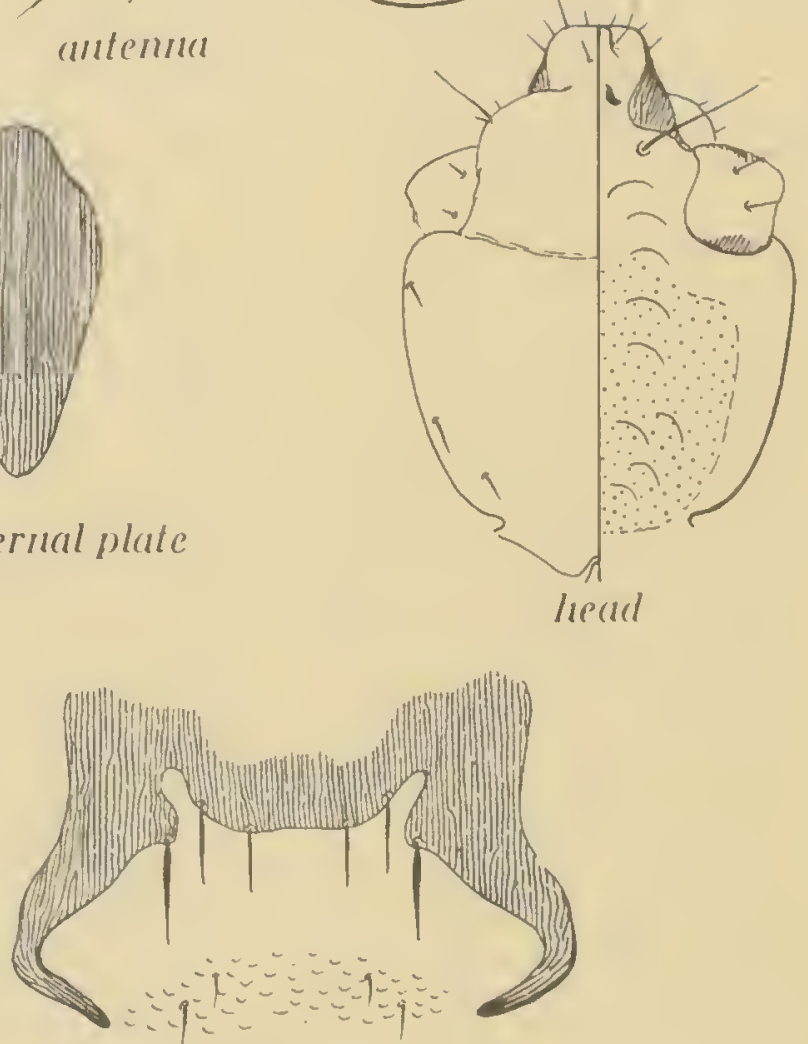

J6th tergite

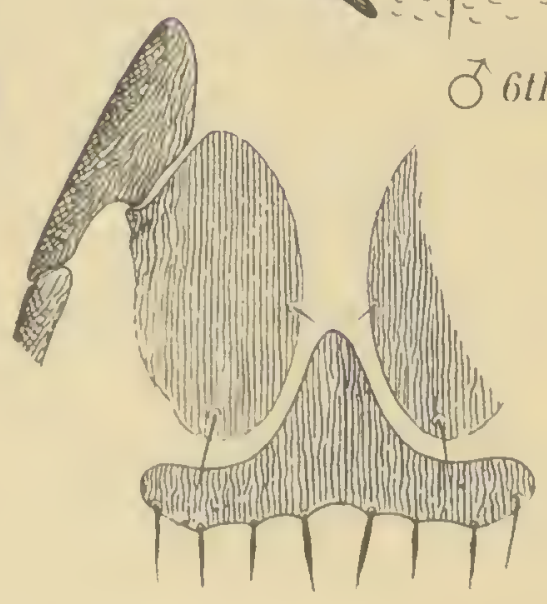

2nd and 3rd stermiles

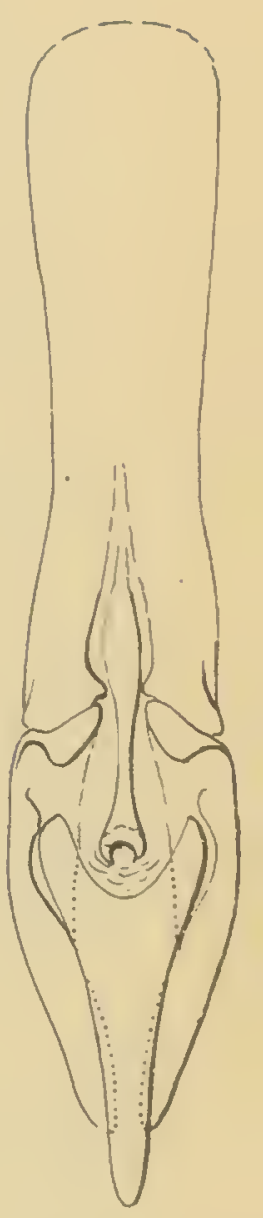

male yenitalia

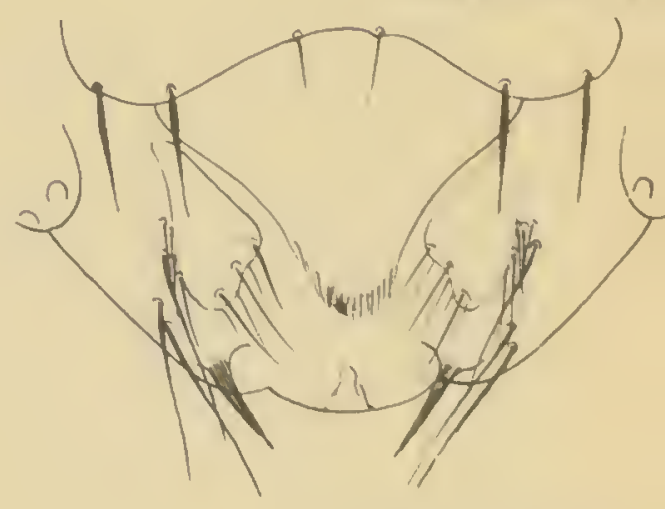

female genitalia

Ancistroplax crocidurae Waterston, details

Figure 54 


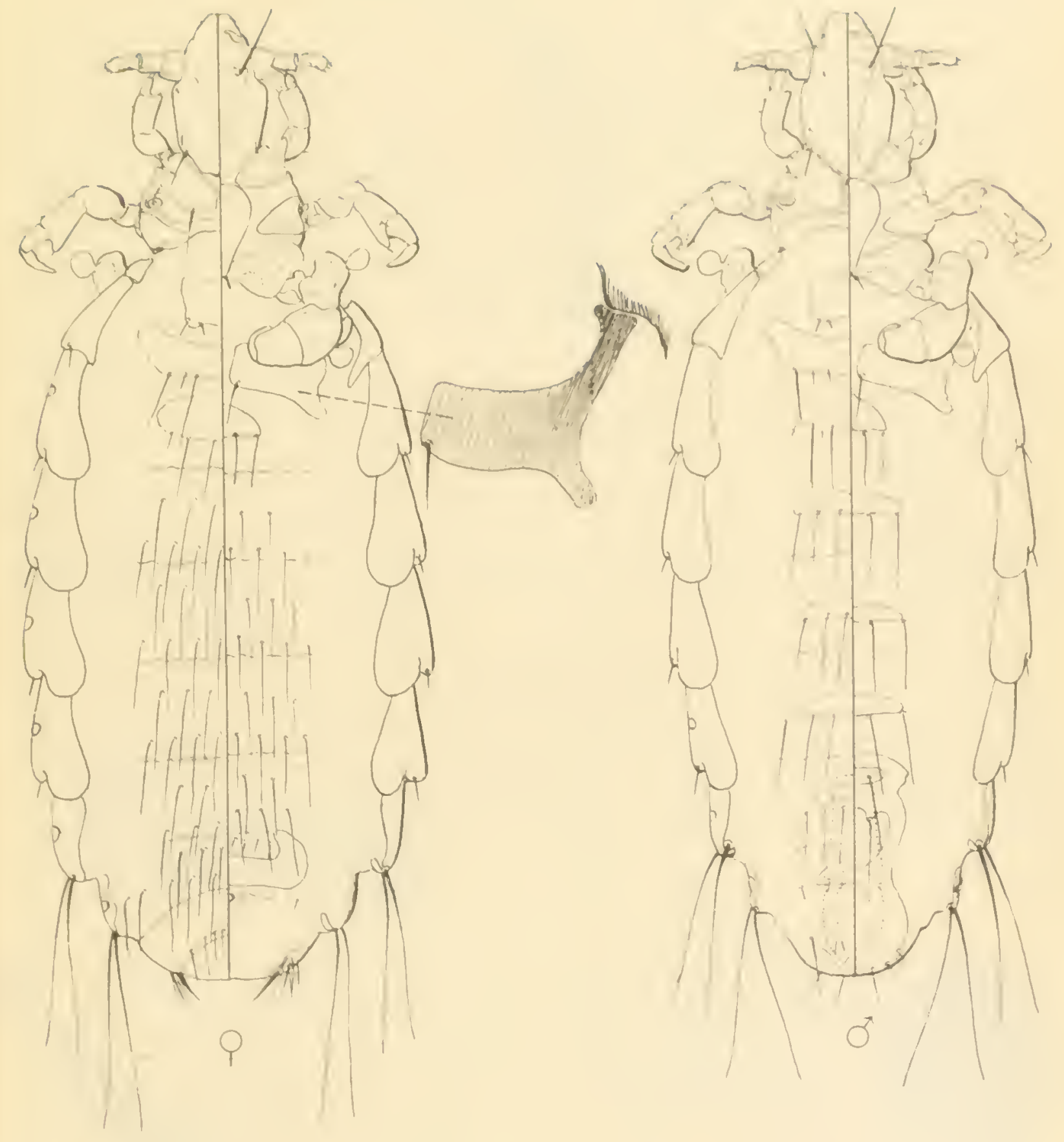

Haematopinoides squamosus Osborn 


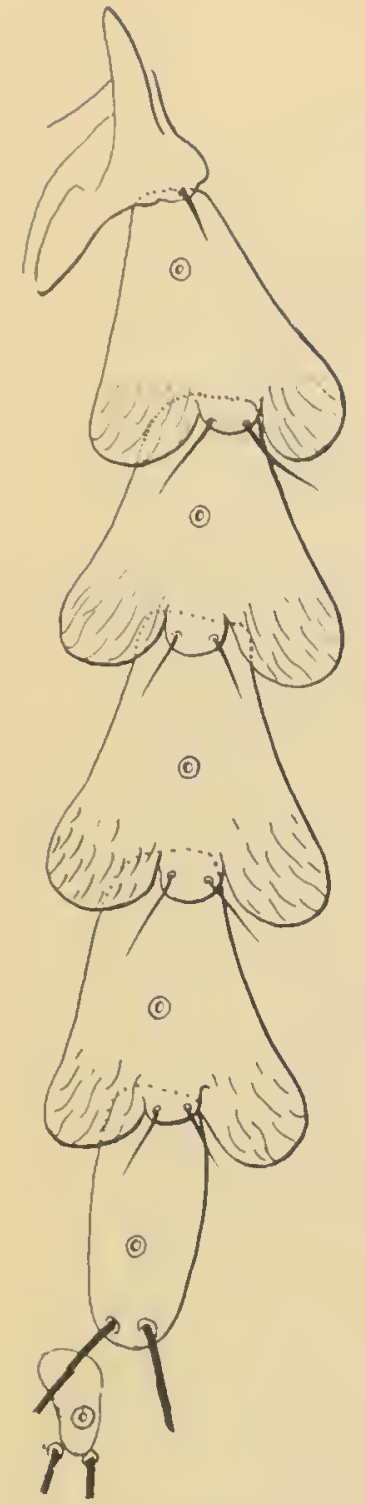

priralergal plates

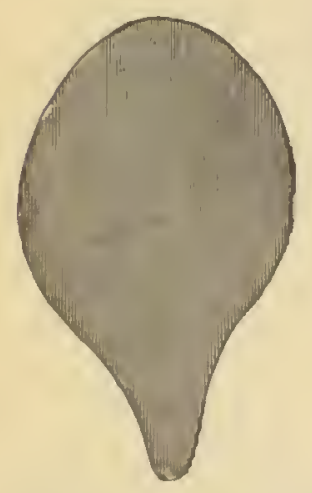
thoracir sternal plute

Haematopinoides squamosus Osborn, details
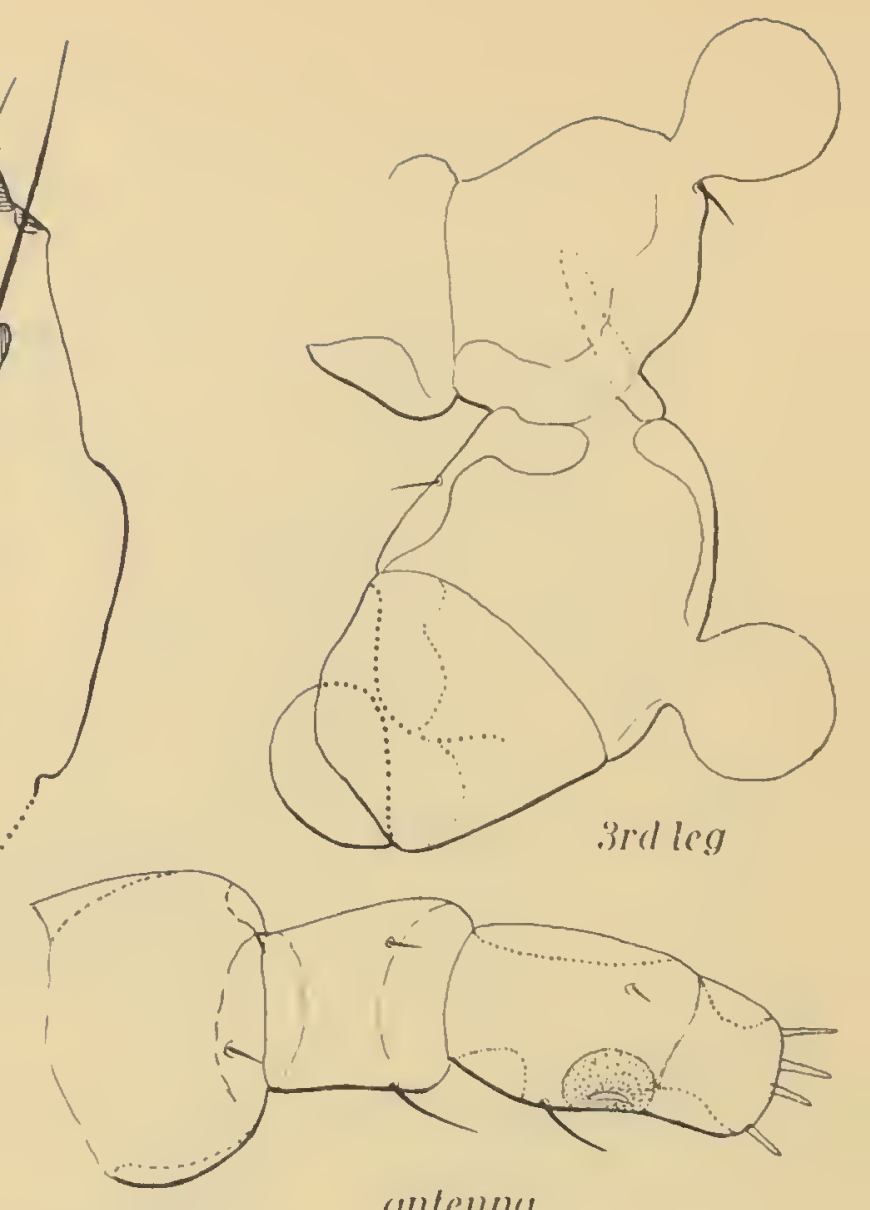

antennu
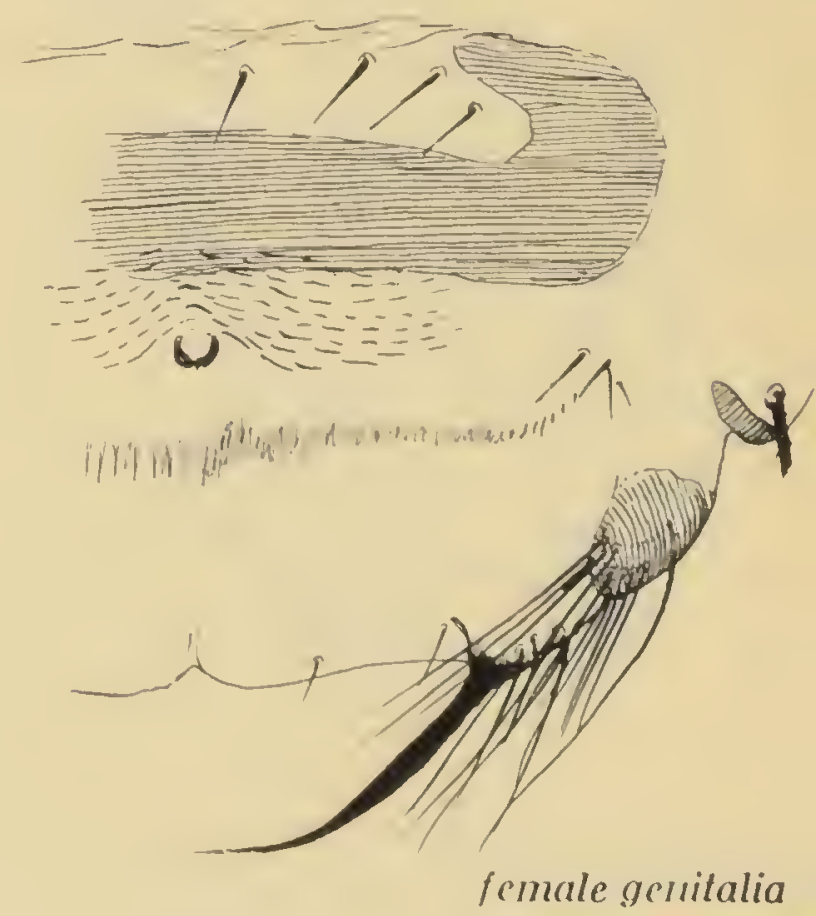

Figure 56 


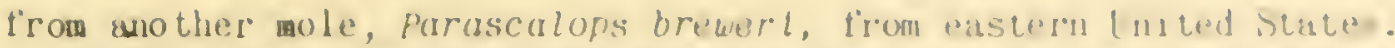

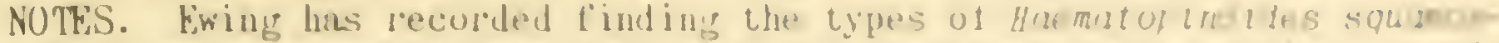
us, which hat presumbly then losh, and has conligmed the suspicion, previously expressed by ferris, to the eflect that fuhbematoplnus abnormis is the sime species. Apparently 0storn wis nisled into niuning two renera sinply by ditterences in the niature of the preparations then at hand.

\section{Genus HOPLOLLEURA Finderlein}

1904. Hoplopleura kinderlein, Zoologischer Anzei re 28:221.

1921. Boplopleura, Ferris, Contributions 'Toward a Monopraph ot' the Suching Lice, Part 2:59.

1929. Ctenura Ewing, A Manual of External Parasites, pare 199.

1929. Euhoplopleura Ewing, A Manual of External Parusites, page 195.

1929. Ctenopleura kining, A Manual of kixtermal Parusites, paye 199.

1929. Perrisella Ewing, A Manual of External Parasites, paye 199.

GENERIC TYPE. Pediculus acanthopus burme ister.

GENERIC SYNONYMS. Ctenopleuru kwing, type Hoplopleura cryptlca ferris; Clenura Ewing, type Hoplopleura pectinata Cummings; Euhoplopleura Ewing, type Hoplopleura trispinosa hellogs and ferris; Ferrisella Ewing, type Hoplopleura ochotonae Ferris.

AIARACTERS. Hoplopleurinae in which the sternal plate of abdominal segment two is always, and the first sternal plate is usually, extended laterally to articulate with the corresponding paratergites, these two plates always being narrowly trinsverse. First sternil plate of sement three usually with two or three enlarged, stout setae in two groups, rarely these not developed. Paraterutes of the abdominal sements never showing any indication of a partial longitudinal division into dorsal and ventral parts. Antennae clearly five-sermented. Posterior legs with no bladder-like, membranous expansions. Paratergites of abdominal sement two not produced into a long, blade-like extension.

NOTES. This genus, as here understood, forms a very homo:neous group. In two or three species the first sternal plate of abdominal se not attain the paratergal plate of the sement but any attempt to separate these species into a different genus on this basis seems to gain nothing and would result only in the formation of an evidently unnatural grouping.

The four genera named by Ewing and listed above do not, in the opinion here held, merit recognition, but the genus Pterophthirus, named by Ewing, is here accepted.

\section{Key to Species of Hoplopleura}

1. First sternal plate of abdominal segment 3 extended laterally to approximate or articulate with the corresponding paratergal plates...5 First sternal plate of abdominal sement 3 not extended laterally.....2 2 (1). Parateryal plates of abdominal segments $4-6$ in the female and ot at least segment 4 in the male with a pair of short, stout, apically flattened and truncate setae; known from octodontomys in Bolivia.

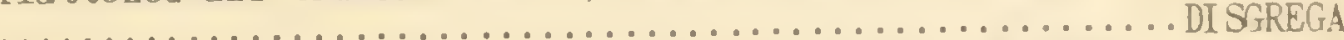

Not so, ali setae of the parater yal plates apically acute........

3 (2). Parateriral plates of abdominal sement 6 with the dorsal apical ansle prolonged into a thumb-like process, the ventral an rle round-

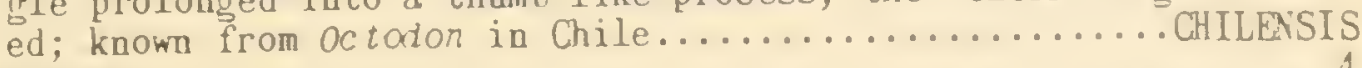

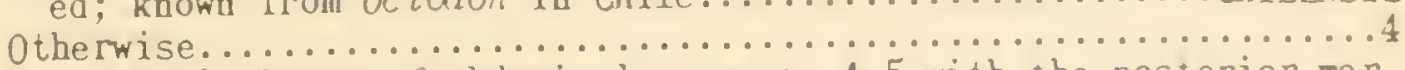

4 (3). Paratergal plates of audominal segments $4-5$ with the posterior maryin almost straight, the posterior angles each forming but a slight looth; known from the squirrel genus Sciurotamias in China

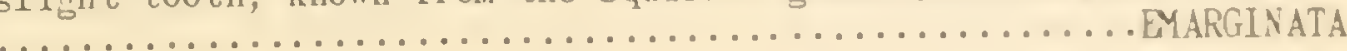


Paratergal plates of abdominal segments 4-5 with the posterior margin presenting a deep, median emargination between the two broad Lateral lobes; known from Hydromys in Australia.........BIDENTATA

5 (1). Paratergal plates of abdominal segment 8 in both sexes with each posterior angle prolonged into a tapering apically acute lobe.66

Paratergal plates of abdominal segment 8 never with more than one apical lobe or process, usually with none................

6 (5). Paratergal plates of abdominal segment 2 with each posterior angle prolonged into a tapering, apically acute point; known from unde-

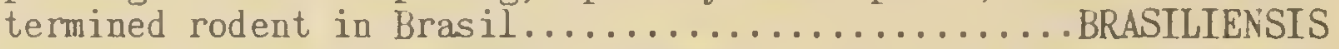

Paratergal plates of abdominal segment 2 with the posterior margin truncate, the angles not at all prolonged into points; female with the apex of the abdomen bearing a comb of stout setae; known from Rattus surifer in the Malayan region..................

7 (5). First sternal plate of abdominal segment 3 with two groups of def-

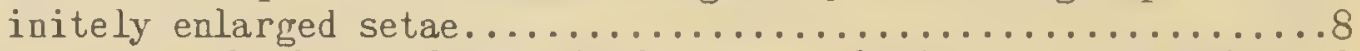

First sternal plate of abdominal segment 3 without such pairs of enlarged setae; occurring on Ochotona in Asia.......... OCHOTONAE

8 (7). Enlarged setae of the first sternal plate of abdominal segment 3

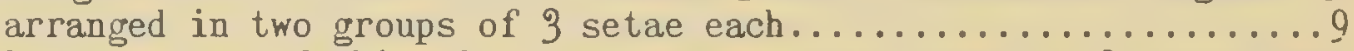

Enlarged setae of this plate arranged in two groups of 2 setae each

9 (8). Paraterai plates of abdominal sements $3-6$ each with the posterior border bearing 4 prominent, almost equal points or processes... 10

Paratergal plates of these segments with merely the apical angles prolonged into points; occurring on North American flying squir-

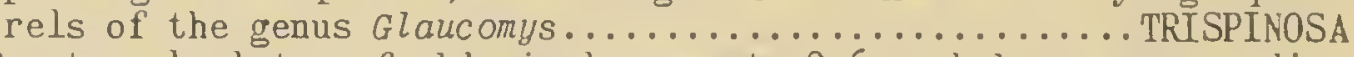

10 (9). Paratergal plates of abdominal segments $2-6$ each borne upon a distinct prominence; tergal and sternal setae of the abdomen extremely numerous and heavy; known from Tatera liodon in Africa..

CRYPTICA

Paratergal plates of abdominal segments 2-6 not thus borne upon prominences; setae of abdominal tergites and sternites slender and of normal number; known from Tatera boehmi in Africa........

- VEPRECULA

11 (8). Paratergal plates of abdominal segment 8 with 1 apical angle produced into an elongated, apically free process...............12

Paratergal plates of abdominal segment 8 entirely devoid of any apical process or with only a very slight lobe.............14

12 (11). Paratergal plates of abdominal segments $3-6$ each with the posterior margin divided into 4 slender processes of which the dorsal process is longer than the plate itself; probably normal to Lemniscomys in Africa......................................

Parate ral plates of abdominal segments $3-6$, if divided into lobes, having the dorsal lobe no longer than the others.....13

13 (12). Paratergal plates of abdominal segment 7 with the posterior margin divided into 2 equal major lobes, each of which is divided into 2 equal minor lobes; known from Arvicanthis in Africa....

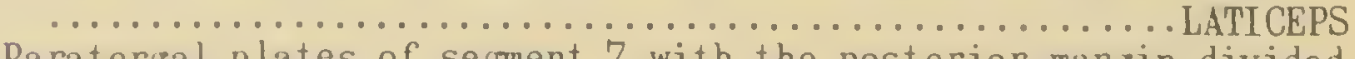

Paratergal plates of segment 7 with the posterior margin divided into 2 lobes of which one is apically acute and the other apically truncate or slightly emaruinate; knowin from various hosts

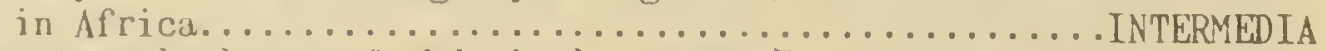

14 (11). Paratergal plates of abdominal segment 7 with at least one of the apical angles produced into a lobe which is in some instances

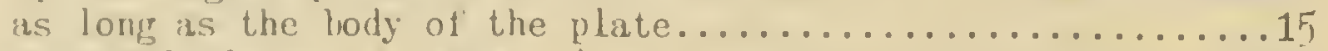

Paratergal plates of segment 7 with neither of its apical angles

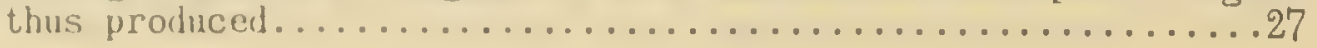


15 (1.1). Paralereral plutes of ubdomimal sement 7 with hut one of it up

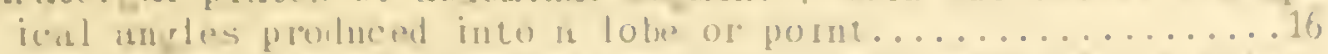

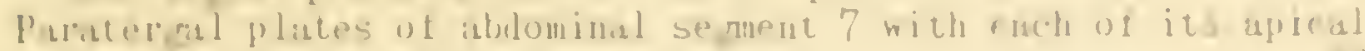

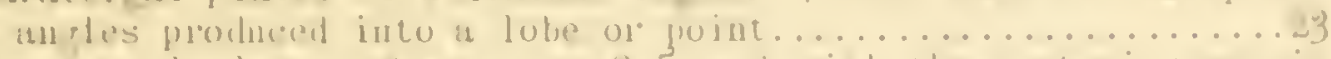

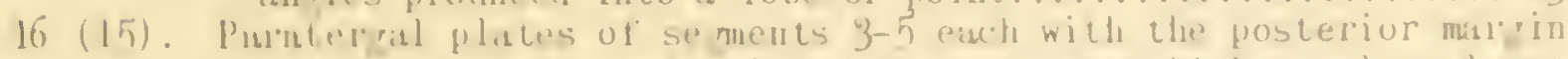
divided into 4 slender lobes or processes which rqual ut least hitli the lempth of the horly or the plate..................

Paritererial plates of abdominal sements 3-5 with the pouterior margin divided into 2 major lobes, eixch of which may lie apically more or less emaryinate or deeply disided into 2 minor lotee

17 (10). Dorsib apical process of the parater pal plates of abdominal ter ments 3-7 very long, lonere this the body of the pliste; knowis

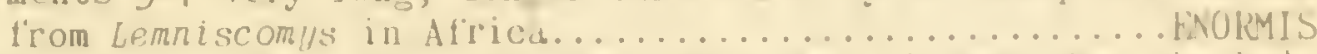

Dorsal apical process on no parateresil plate lonrer thisn the borly of the plite or longer thin the ocher processes........ Nitmavi I

18 (16). Ventral lobe of paraterial plates of ablominal semment 3 divided into 2 apically rounded, equal lotes: irom species of oryzomys

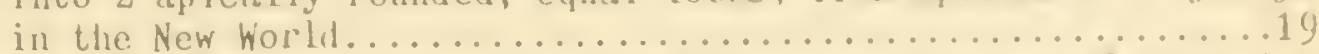
Yentral lobe of parricergal plates of abdominal segment 3 othernise

19 (18). Ventrit iobe of abdoninal segment 6 divided into equil iobules; known from Oryzom!s in sontheastern United states....ORYZOMYDIS Ventral lobe ut abduminal se pment 6 toming sin.le, acute point; known l'lom species of Oryzomys in South America... NHSORY704IDIS

20 (18). Ventral lobe of paratergal plates of abdominal se rment 3 acute...

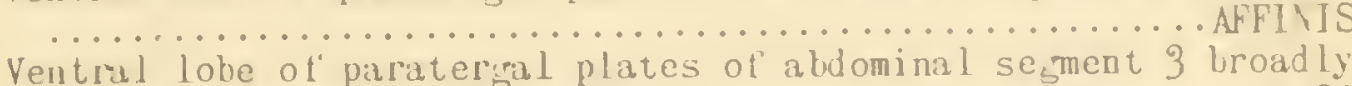

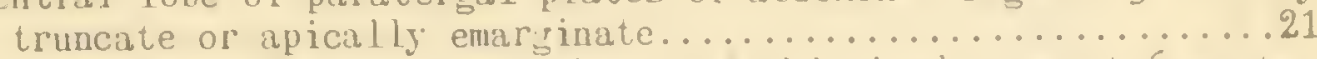

21 (20). Ventral lobe of paraterigal plates of abdominal segment 6 acute: known f'rom the genus Apomys in the thilippine Islands.. AP0MIDIS Ventral lobe of pariterigal plates of sement 6 truncate or emar-

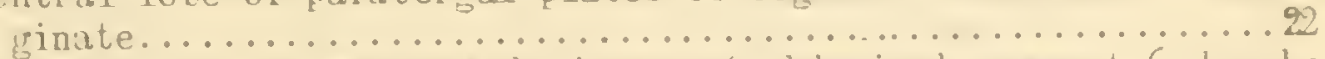
(21). Ventral lobe of parater pal plates of abdomina sement 6 deeply cmar riuate; known trom Dasymus ye lukus in Atrica........SOMERENI

Ventral lobe of paratergal plates of abdominal segment 6 truncate; known trom valious rodents in South America.......... TRAVASSOSI

23 (15). Both dorsal and ventral apical lobes of paraterigal plates of ab-

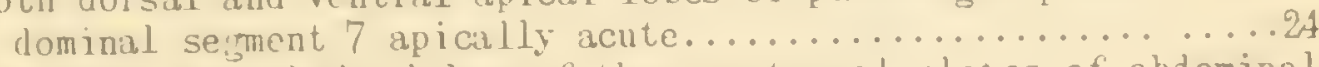

At least one of the lobes of the paratergal plates of abdominal

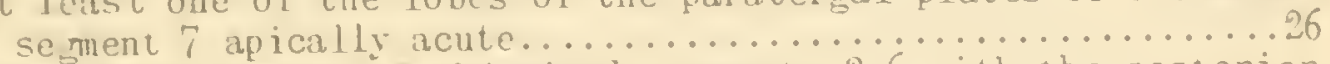

24 (23). Paratergal plates of abdominal segments 3-6 with the posterior margin divided into 4 nearly equal, apically rounded lohes; occurring on the genera rectomys and oryzomus in South America...

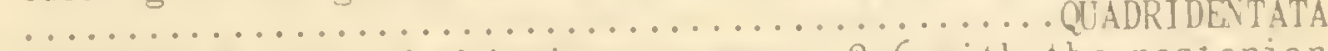

Paratergal plates of abdominas se ments 3-6 with the posterior maruin divided into 2 apically truncate or sliphty emarginate

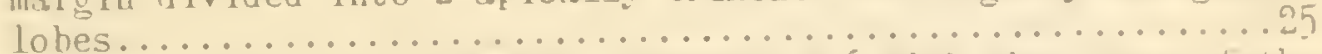

25 (24). Parateral plates of abdominal segments $4-6$ with the setae of the posterior maroin extremely minute: occurrin characteristically on members of the New horld jenera Peromyscus and onychomls, but recorded also from Mus musculus in North Anerica and Eurasia

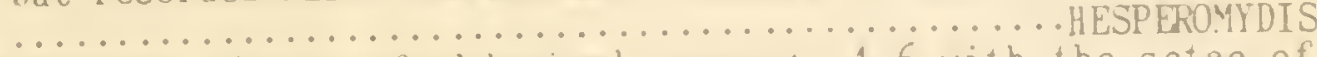

Paratersal plates of ahdominal sements $4-6$ with the setae of their posterior maryin almost equaling in length the depth of the median emargination in which they are placed; occurring as far as known on the renus Cricetuliss in China..........CRICETILI 
26 (23). Dorsal lobe of the paratergal plates of abdominal segment 7 definitely truncate, the ventral lobe acute; from members of the New World genus Re ithrodontomys............REITHRODONTOMYDIS Both dorsal and ventral apical lobes of the paratergites of abdominal segment 7 narrowly rounded apically; known from Mus

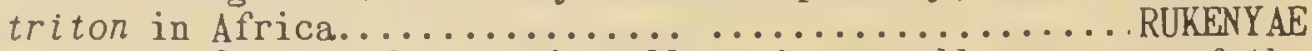

27 (14). Female with 3 rows of setae dorsally and ventrally on most of the

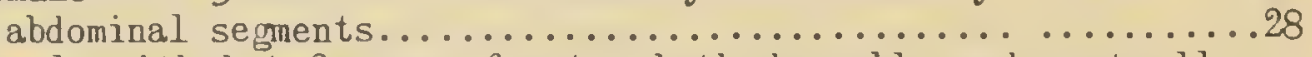

Female with but 2 rows of setae both dorsally and ventrally on most of the abdominal segments; probably normal to species of

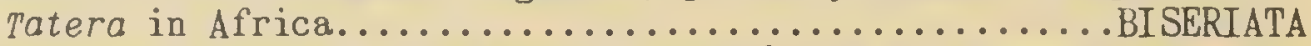

28 (27). Paratergal plates of abdominal segment 6 with the posterior angles

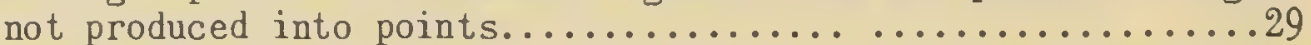

Paratergal plates of abdominal segment 6 with at least one of the posterior angles produced into a definite point or lobe.....30

29 (28). Sternal plate of the thorax broadly triangular, occurring on the

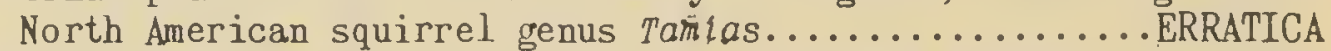

Sternal plate of the thorax narrowly produced posteriorly; known

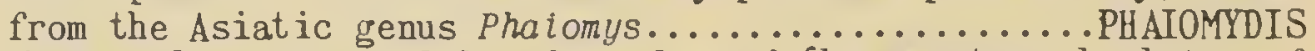

30 (28). Both dorsal and ventral basal angles of the paratergal plates of abdominal segments $4-5$ with a process which projects toward the

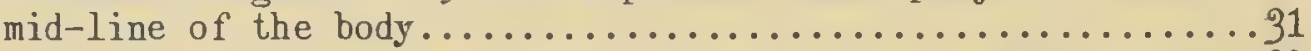

Basal angles of these paratergal plates without such processes. 32

31 (30). Outer seta of the pairs of enlarged setae on the first sternite of abdominal segment 3 longer than the other and distinctly bent; known from the squirrel genus Callosciurus in China......

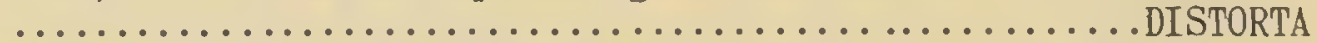

Outer seta of these pairs not longer than the other and not bent; known from the squirrel genus Callosciurus in the Malayan area.

32 (30). Paraterial plates of abdominal segment 6 with 4 almost equal, slender processes on its posterior border; known from Mylomys

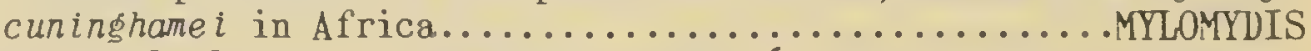
Paratergal plates of abdominal segment 6 without such processes..

33 (32). Paratergal plates of abdominal segments $4-6$ without setae, even

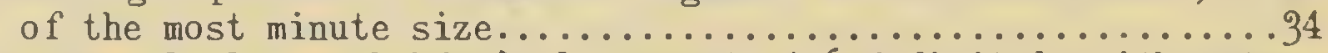
Paratergal plates of abdominal segments 4-6 definitely with setae, even if small, on the posterior margin................. 36

34 (33). Both dorsal and ventral lobes of the paratergal plates of abdominal segment 3 broadly truncate; occurring on Micromys in Europe

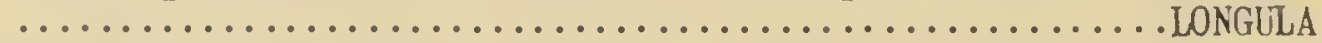

Both dorsal and ventral lobes of the paratergal plates of abdominal sement 3 apically acute............................. 35

35 (34). Dorsal apical lobe of the paratergal plates of abdominal segments 4-5 apically broad and emarginate; known from oxymycterus judex

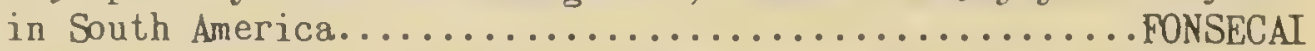

Ventral apical lobe of the paratergal plates of abdominal seyments 3-6 acute; from 0xymycterus in Peru..............XXMYCTERI

36 (33). Apical lobes of paratergal plates of abdominal segment 6 both a-

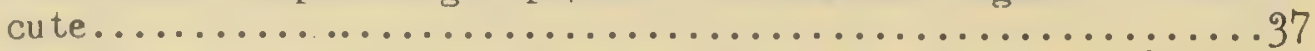

Apical lobes of paratergal plates of abdominal segment 6 other--

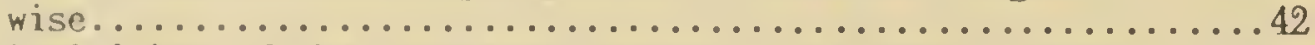

37 (36). Apical lobes of the paratergal plates of abdominal segment 3 with the dorsal lobe apically acute, the ventral lobe broad and slightly emarginate; occurring on various members of the subfamily Microtinae of the Muridae in Europe, North America, and

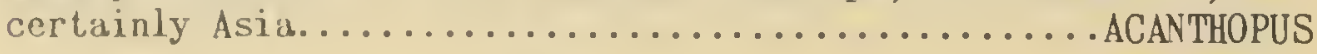


Apical lobes of the paratergal plates of ablomanal se guent 3 oth-

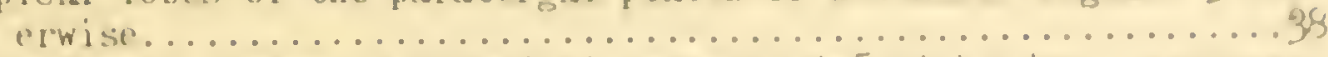

38 (37). Parmler pal plutes of utdominal serments $1-5$ with a deep, rectingular, median emargination in the posterior border, this dividing the plate into two broad, apical lobes; known from Retthrodon

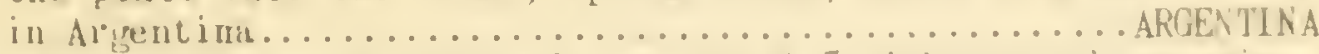

Parateririal plates of abdominal seyments $4-5$ without such emargination of the posterior border............................

39 (33). Hith hut 1 or occasionally 2 setac between the ends of the ter fal and sternal plates of the abdomen and the corresponding paratergal plates; known trom the squirrel genus funambulus in Asia

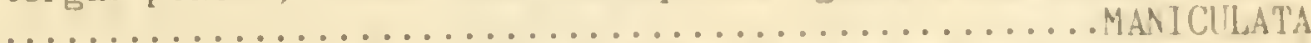

With not less than 2 and usually more setae vetween the ends of the terimal and sternal plates of the abdomen and the correspond-

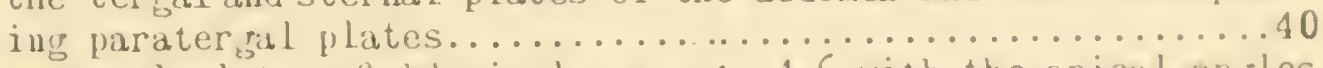

40 (39). Paratergal plates of abdominal serments $4-6$ with the apical andes strongly produced and acute, the posterior border of the plate arcuately and quite deeply emar isinate.................

Parateral plates of abdominal sements $4-6$ with the margin between the toothed apical angles almost straight, not at all emarginate; occurring on the grenus Sigmodon in North America....

41 (40). Parameres of the male apically notched; occurring on the fenus Neotamias (better known as Eutamias) in North America..........

Parameres of the male apically entire; known from the genus Sciurus

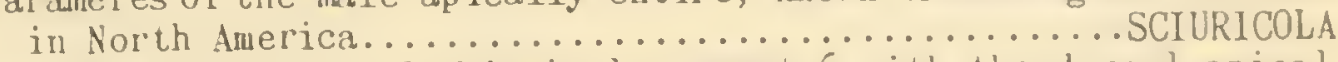

$42(36)$. Paratergal plates of abdominal segment 6 with the dorsal apical angle forming a slight tooth, the ventral angle without a tooth;

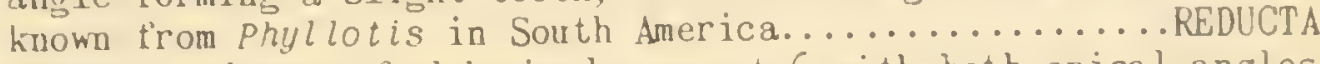

Parateriral plates of abdominal segment 6 with both apical angles

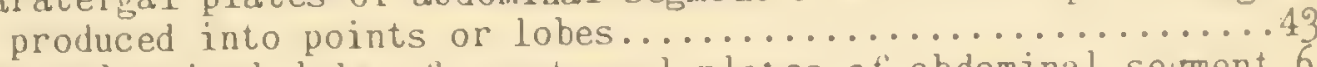

43 (42). Ventral apical lobe of paratergal plates of abdominal segment 6 acute, the dorsal lobe more or less truncate.............44

Dorsal and ventral apical lobes of paratergal plates of abdominal sement 6 essentially similar, truncate or apically serrate or

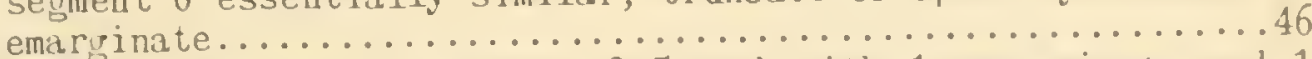

44 (43). Paratergal plates of sements $3-5$ each with 1 very minute and 1 longer seta on the posterior margin: known from various hosts, includins domestic rats, in various parts of the world.........

Paratergal plates of abdominal segments $3-5$ each with 2 setae which are as long as or longer than the depth of thd emargination in which they are placed......................... 45

45 (44). Ventral apical lobe of the paratergal plates ot segments 3-5 acutely pointed; known from the genus Chrotomys in the Philippine

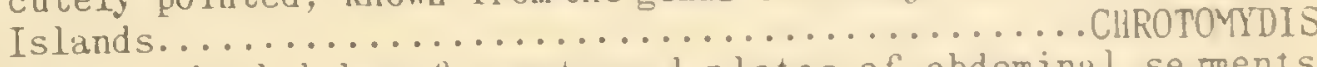

Ventral apical lobe of paraterial plates of abdominal se gments 3-5 narrowly rounded or truncate apically: known from Rattus

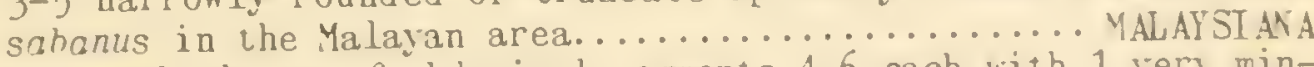

46 (43). Parateral plates of abdominal segments $4-6$ each with 1 ver minule seta and 1 seta which is about as long as the depth of the emargination in which it is placed; known from Rhipidorys in

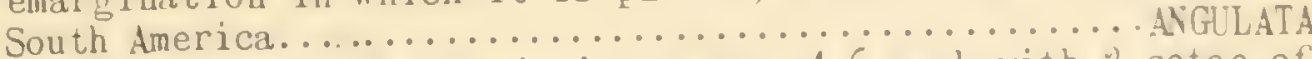

Paraterial plates of abdominal sements 4-6 each with " setae of nearly equal lenth, these as $l_{0} \mathrm{lon}_{\mathrm{s}}$ as or longer than the depth of the emargination in which they are placed; known from veriones

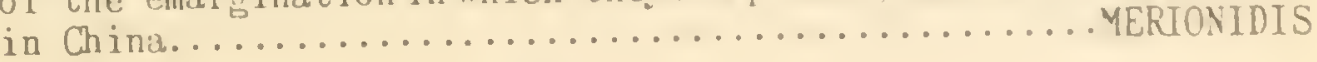


1839. Pediculus acanthopus Burmeister, Genera Insectorum, Rhynchota, Number 5; Plate 1, figure 2.

1842. Haematopinus acanthopus (Burmeister), Denny, Monoyraphia Anoplurorum Britanniae, page 25; Plate 24, figure 3.

1880. Haematopinus acanthopus (Burmeister), Piaget, Les Pediculines, page 638; Plate 52, figure 4.

1904. Polyplax acanthopus (Burmeistar), Enderlein, Zoologischer Anzeiger 28: 142 .

1904. Hoplopleura acanthopus (Burmeister), Enderlein, Zoologischer Anzeiger 28: 221; figures 1, 2 .

1915. Hoplopleura acanthopus, variety americanus Kellogg and Ferris, Anoplura and Mallophaga of North American Mammals, Stanford University Publications, University Series (no volume number), page 16; text figure 3; Plate 4, figure 2; Plate 5, figure 8.

1916. Hoplopleura acanthopus, variety aequidentis Fahrenholz, Archiv für Naturgeschichte, Abteilung A, 81:26; figure 21b.

1921. Boplopleura acanthopus (Burmeister), Ferris, Contributions Toward a Monograph of the Sucking Lice, Part 2:63; figures 34, 35.

HOSTS AND DISTRIBUTION. First described from Microtus (as Arvicola) arvalis, somewhere in Europe. It has since been recorded from Nicrotus asrestis and Microtus nivalis in Europe; from Microtus constrictus, Microtus californicus, Microtus intermedius, and Microtus ochrogaster in various parts of the United States; from Lemmus alaskens is in Alaska; from Synaptomys borealis at Athabasca Landing in Canada; from Pitymys pinetorum in eastern United States. It has also been recorded from Kus musculus in Rumania and Mus spicilegus in Sweden, these records very probably being due to contamination or straggling.

NOTES. An examination of the abundant material at hand offers no excuse for the naming of the supposed variety americanus. Furthermore, on the basis of such evidence as was given by its describer there is no apparent reason for the supposed variety aequidentis.

\section{Hoplopleura affinis (Burmeister)}

1839. Pediculus affinis Burmeister, Genera Insectorum, Rhynchota, No. 10. 1842. Haematopinus affinis (Burmeister), Denny, Monographia Anoplurorum Britanniae, page 36 .

1904. Polyplax affinis (Burmeister), Enderlein, Zoologischer Anzeiger 28: 142.

1921. Hoplopleura affinis (Burmeister), Ferris, Contributions Toward a Monograph of the Sucking Lice, Part 2:75; figures $42,43$.

HOSTS AND DISTRIBUTION. First recorded from Apodemus agrarius and Apodemus sylvaticus in Europe. Later recorded by Ferris from both these hosts, from agrarius in Germany and from sylvaticus in Manchuria and Siberia. In addition, Ferris has recorded the species from a number of South American mammals, includin! Akodon mollis in Peru; Akodon arviculoides in Paragray; Akoron amnicola in Argentina; Phyllotis pictus (as Euneomys sp.) in Peru; Phyllotis micropus in Argentina. Certain other records by Ferris from South American mammals are here transferred to other species as will be noted below.

NOTES. Specimens from Cricetuls incanus from China, previously referred to affints are here described as hoplopleura cricetuli new species, and specimens from Reithrodon hatchert from Patagonia, are referred to Hoplopleura argentina Werneck.

The records of affints from other South American hosts appear to be ut- 


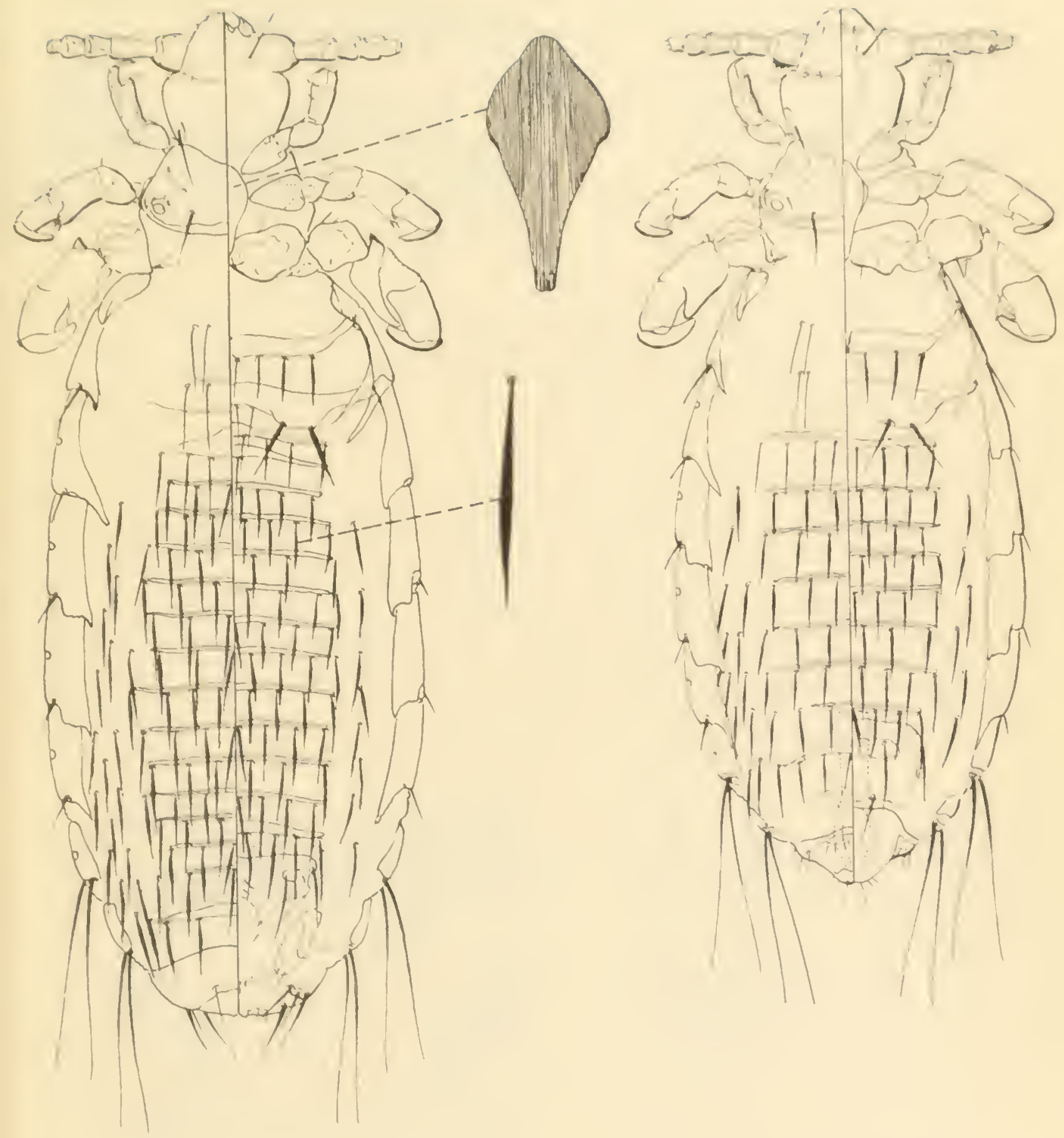

Hoplopleura acanthopus (Burmeister) 

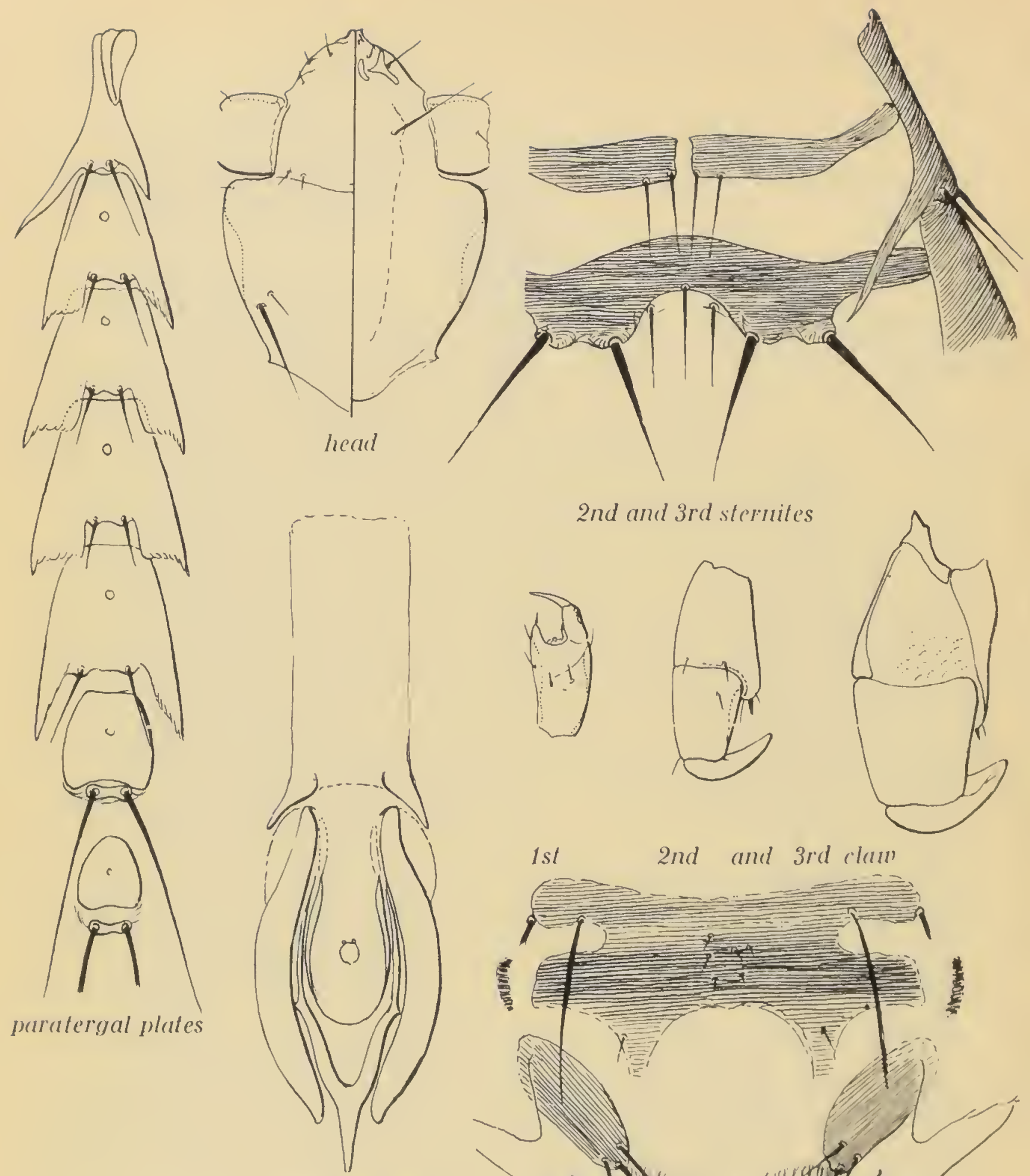

male genitalia
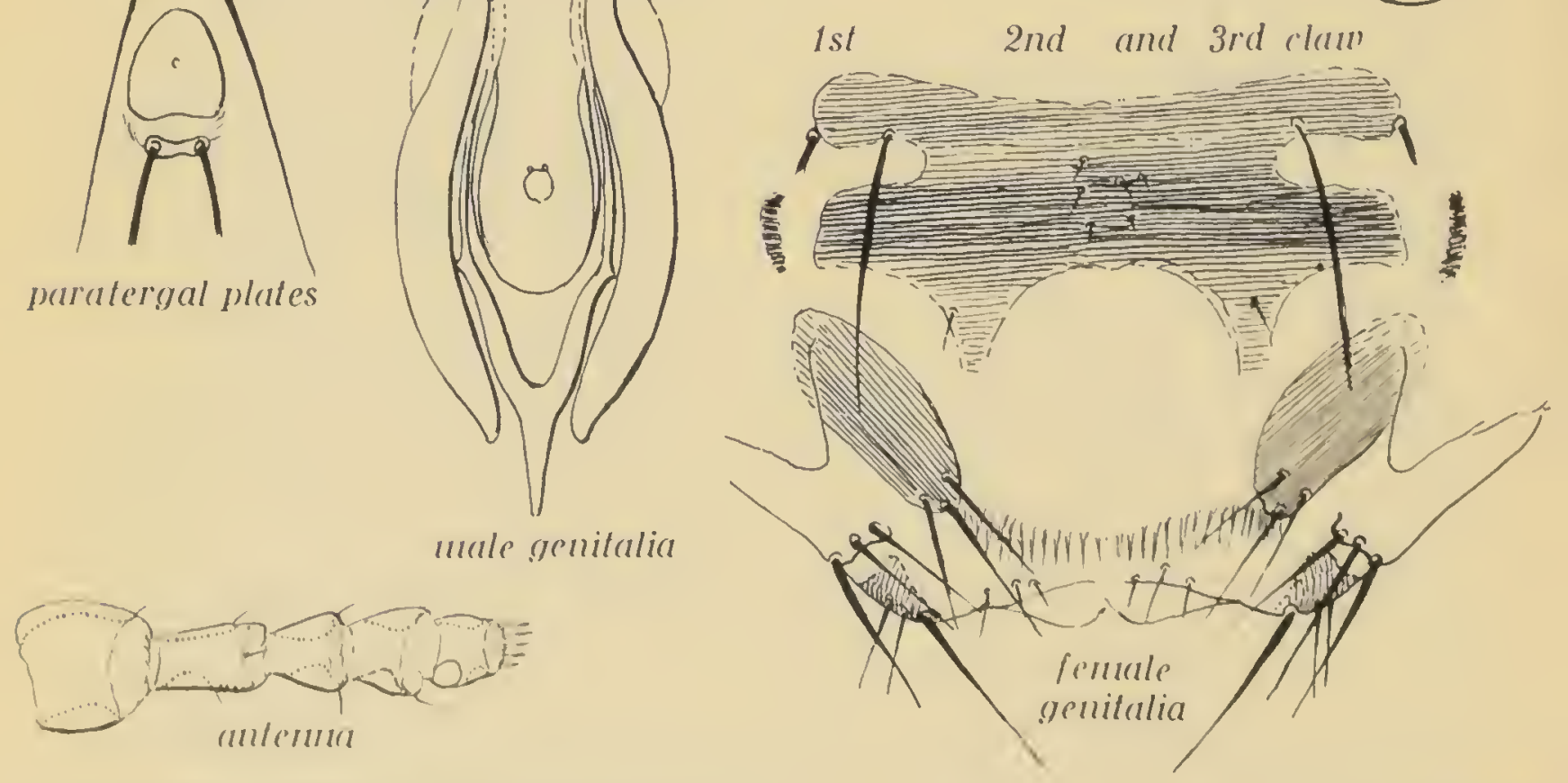

Hoplopleura acanthopus (Burmeister), details

Figure 58 
terly unreasonable, hut a re-exanination of the material at hand ofters no hasis tor their separation. It nould seem very probable that biolopically mole than one species is involved, but nothing morpholofical appenrs that will justify a separation.

\section{Hoplopleuria angulatio Feris}

19:21. Hoplopleura angulata ferris, Contributions Tovard a Monopruph of the Sucking lice, Part 2:73; figures 40, 41.

HOSTS AND DISTRIBUTION. Type from Rhipidomys venezuelae, somenhere in Venezuela. Also recorded by Ferris from Rhiptdomys sp. (ascertained by Hopkins to be Rhipidomys leucordactylus), from the Rio Sin Miguel, Peru; trom Rhipidomys venustus, Merida, Venezuela; and from Thomasomys cinereus, Balsas, Peru.

\section{Hoplopleura apomydis Ferris}

1921. Hoplopleura apomydis Ferris, Contributions Toward a Monograph of the Sucking Lice, Part 2:84; tigures 49, 50.

HOSTS AND DISTRIBUTION. Described as from ADomys bardus, which is Apomys insignis, from Malingdang Peak, Yindanao, Philippine Islands.

\section{Iloplopleura arboricola hellogro and Ferris}

1915. Hoplopleura arboricola Kellorg and Ferris, Anoplura and Mallophara of North American Mammals, Stantord University Publications, University Series (no volume number), page 19; text figures 6, 7 ; Plate 4 , figure 8 . (Part)

1921. Hoplopleura erratica arboricola Kellogig and Ferris, Ferris, Contributions Toward a Monouraph of the Sucking Lice, Purt 2:109.

HOSTS AND DISTRIBUTION. This species occurs on members of the genus Neotamias, which has usually been referred to in North American literature as Eutamias, under which generic name the host records have in the past been $p$ laced. Type from Veotamias hindsi, Inverness, Marin County, California. Recorded from various other species of this genus in California.

\section{Hop Lopleura argentina Herneck}

1921. Hoplopleura affinis (Burmeister), Ferris, Contributions Toward a Monouraph of the Sucking Lice, Part 2:75. (Part; misidentilication) 1837. Hoplopleura affinis arêntina Herneck, Memorias do Instituto Oswaldo Cruz 32: 404.

HOSTS AND DISTRIBJTION. Type from Reithrodon sp. from the Republic of Arrentina. Specimens recorded by Ferris from Reithrodon hatcheri from Cordilleras. Pataronia, as Boplopleura affinis, seem definitely to be this.

NOTES. The differences between this form and Hoplopleura affinis are very slight, as indicated in the key to species, but in accord with the practice here adopted of not recomizing any form below the species, it is here regarded as a species.

\section{Hoplopleura bidentata (Neumann)}

1909. Haematopinus (Polyplax) bidentata Neumann, Archives de Parasitolobie $13: 515 ;$ igure 18 .

1916. Hoplopleura bidentata (Neumann), Ferris, Contributions Toward a Monopraph of the Sucking Lice, Part 2:129: finures 86, ST.

HOSTS AND DISTRIBUTLON. Originally described as from Rottus rattus at Lake Torrens, Australia, this undoubtedly an error in host attribution. It 
has since been recorded from what seems undoubtedly to be its normal host, Hydromys chrysogaster, from Sydney and an undetermined locality in New South Wales, Australia.

\section{Hoplopleura biseriata Ferris}

1921. Hoplopleura biseriata Ferris, Contributions Toward a Monograph of the Sucking Lice, Part 2:103; figure 64A.

1949. Hoplopleura biseriata Ferris, Hopkins, Proceedings of the Zoological Society of London 119:477.

HOSTS AND DISTRIBUTION. Originally described as from Malacothrix typicus at Bothaville, Orange Free State, Africa. Hopkins has pointed out that this record was undoubtedly due to contamination and has recorded the species from Tatera brantsi, Tatera lobensulae, Tatera joanae, and Tatera ancolae from unspecified localities in Africa.

\section{Hoplopleura brasiliensis Werneck}

1932. Hoplopleura brasiliensis Werneck, Comptes rendus de séances de la Société de Biologie de Rio de Janeiro 119:754; figure.

1932. Hoplopleura brasil iensis Werneck, Werneck, Memorias do Instituto Oswaldo Cruz 26:235; Plate 45.

HOSTS AND DISTRIBUTION. From an undetermined rodent from the state of Goyaz, Brasil.

\section{Hoplopleura chilensis Werneck}

1937. Hoplopleura disßreछa, variety chilensis Werneck, Memorias do Instituto 0swaldo Cruz 32:406; figures 15, 16.

HOSTS AND DISTRIBUTION. From Octodon deछus from Chile, without closer indication of locality.

NOTES. On the basis of the very clear illustrations given by Werneck this appears certainly to be a distinct species and not merely' a "varicty" of disßrega.

\section{Hoplopleura chrotomydis Ferris}

1921. Hoplopleura chrotomydis Ferris, Contributions Toward a Monograph of the Sucking Lice, Part 2:81; figure 46.

HOSTS AND DISTRIBUTION. Known only from the original record from a skin of Chrotomys whiteheadi at Irisan, Benguet, Benguet, Philippine Islands.

\section{Hoplopleura cricetuli Ferris, new species}

1921. Hoplopleura affinis (Burmeister), Ferris, Contributions Toward a Monograph of the Sucking Lice, Part 2:75. (Misidentification)

HOSTS AND DISTRIBUTION. Several specimens, both male and female, from Cricetulus incanus, Shensi, China; from skin number 172,550 in the United States National Museum.

CHARACTERS. In all respects practically identical with Hoplopleura affinis, as that species is described by Ferris (1921), differing significantly only in the form of the paratergites of abdominal sement seven. In affints the parateritites of this serment have the dorsal, posterior angle produced into an elonsated point which is free from the body for most of its length and the posterior margin of the plate is straight or but slightly emarinate. In cricetuli, the dorsal lobe-while of the same shape as in affinis-is free from the body only at its apex and the posterior margin of the plate is deeply emarginate, this emargination forming a ventral lobe 
which is only slishty shorete than the dorsal lobe hut is not frees trom the body.

Holotber and paritypes deposited in the collections of Stantord lniver sily. Parntyres deposiled in the United States National Yuseum.

NotES. Complete illurtrations and an extended description of this species will be presented elsewhere. Enough is presented in the alove descliption and in the accompany ing key wo permit the identilication of the species.

\section{Hoplopleura cryptica ferris}

19:1. Hoplopleura cryptica Ferris, Contributions loward a Mono rraph of the Sucking Lice, Part 2: 104; ti gures 65, 6613, D, E, G.

1929. Ctenura cruptica (Ferris), Ewins, A Munual ot External P'arusites, yauge 199.

HOST'S AND DISTRLBUTION. H'rom Tatera liodon al hikondu, Uganda.

\section{Hoplopleura disirera Ferris}

1921. Hoplopleura disgrega ferris, Contributions Toward a Monograph of the Sucking Lice, Part 2: 132 ; t'igures 88, 89.

HOSTS AND DISTRIBUTION. From Octodontomys simonsi, which is placed by llopkins as Octodontomys gliroides, at Orura, Bolivia.

\section{Hoplopleura distorta Ferris}

1921. Hoplopleura distorta Ferris, Contributions Toward a Monograph of the Sucking Lice, Part 2:115; tigures 72C,

HOSTS AND DISTRIBUTION. Recorded as from Rhinosciurus sp. Hopkins, who has investigated the matter, states that the host is actually Callosciurus vestitus.

Hoplopleura edentulus Fahrenholz

1916. Hoplopleura acanthopus, variety edentulus Fahrenholz, Archiv tür Natur reschichte, Abteilung A, 81:26; figure 21c.

HOSTS AND DISTRIBUTION. Described as from Evotomys rutilus "aus Siebenburgen, Kronstadt." From the description and the accompanying figure it seems probable that this is nothing more than a slight variant of Hoplopleura cacanthopus.

\section{Hoplopleura emarginata Ferris}

1922. Hoplopleura emarsinata Ferris, Contributions Tonard a Monorraph of the Sucking Lice, Part 3:130; figures 90, 91.

HOSTS AND DISTRIBUTION. Described as from Sciurotamias davidianus, a skin from Shensi, China.

NOTES. This is a peculiar form which in some respects more closely resembles members of the genus Yeohaematopinus than it does Boplopleura. It is retained in Boplopleura because of the character of the sternal plate of the second abdominal segment. Future authors may possibly wish either to remove it to Veohomatopinus or to name a new genus for it.

Hoplopleura enormis kellogs and Ferris

1915. Boplopleura enormis Kellogy and Ferris, Annals of the Durban Yuseum 1:155; Plate 16, figures 4, 4c.

1921. Boplopleura enormis enormis Kellogs and Ferris, Ferris, Contribu- 
tions Toward a Monograph of the Sucking Lice, Part 2:94; figures $57,58 \mathrm{~B}, \mathrm{C}, 59 \mathrm{~B}$.

HOSTS AND DISTRIBUTION. Described as from Arvicanthis dorsalis from Mfongosi, Zululand, for which the name Lemniscomys griselda is now employed. Later recorded by Ferris from Lemniscomys barbarus from Gondokoro, Africa.

NOTES. The supposed subspecies of enormis named by Ferris are here regarded as species.

\section{Hoplopleura erismata Ferris}

1921. Hoplopleura erismata Ferris, Contributions Toward a Monograph of the Sucking Lice, Part 2:113; fivures 72B, E, F.

HOSTS AND DISTRIBUTION. From Sciurus ferrugineus from Southeast Siam. This host belonis to the genus Callosciurus. Recorded also from Callosciurus caniceps (as Sciurus davisoni) from Lower Siam and from Callosciurus maclellandi (as Tamiops sp.) from Tenasserim.

\section{Hoplopleura erratica (0sborn)}

1896. Haematopinus erraticus 0sborn, United States Department of Agriculture, Division of Entomology, Bulletin (new series) 5:186.

1921. Hoplopleura erratica erratica (Osborn), Ferris, Contributions Toward a Monograph of the Sucking Lice, Part 2:106; figures 67, 68.

HOSTS AND DISTRIBUTION. Type recorded as taken f'rom a gull in Iowa, but this very evidently in error. The host is clearly Tamias striatus, from which the species has been recorded by Ferris from Indiana, Tennessee, New York, and the District of Columbia; all in the United States.

NOTES. The supposed subspecies recognized by Ferris are here considered to be species.

\section{Hoplopleura fonsecai Herneck}

1934. Hoplopleura fonsecai Werneck, Memorias do Instituto 0swaldo Cruz 27 : 412; figures 7-12.

IIOSTS AND DISTRIBUTION. Type f'rom Oxymycterus judex at Humboldt, state of Santa Catharina, Brasil.

\section{Hoplopleura hesperomydis (0sborn)}

1891. Haematopinus hesperomydis Osborn, United States Department of Agriculture, Division of Entomology, Bulletin (old series) $7: 26$; figure 14.

1915. Hoplopleura hesperomydis (Osborn), Kellogg and Ferris, Anoplura and Mallophaga of North American Mammals, Stanford University Publications, University Series (no volume number), page 17; text figures 4, 5; Plate 1, figure 3; Plate 4, figure 2. (The name Boplopleura hesperomydis occidental is, appearing in the legend of Plate 4, figure 2, is due to an error.)

1921. Hoplopleura hesperomydis (Osborn), Ferris, Contributions Toward a Monograph of the Sucking Lice, Part 2:70; figures 38, 39.

HOSTS ANI) DISTRIBUTION. Originally described as from Peromyscus ( peromys) leucopus at Ames, Iowa. Recorded by Kellogg and Ferris and by Ferris f'rom Peromyscus bollle $i$ and Peromyscus maniculatus in California. Recorded by Ferris from onychomys torridus in California and onychomys leucosaster in Colorado. All these localities are in the United States. Recorded by Ferris from Oryzomys fulvescens at 0rizaba, Mexico; from Oryzomys choparensis at Suntos, Bolivia; and from Eligmodontia collisae (which Hopkins has determined to be Hesperomys callosus) at Goya, Argentina. 
Ferris hus also recorded it lron Mus musculus in Virginia, I. S. A., and Russiun thrtestun; lrom kus gonsus, which is apparenzly us synomy of Mus musculus, from Chinn; from Nus wasnerl, which is also a syllonym ot yus musculus, trom C'rina.

NOTES. The material recorded above has been examined in comection with this work und still appeurs to be Hoplopleura hesperomydls. The normal hosts of this specios seem quite definitely to be species of Peromyscus and the closely related genus onychomys. Some of the other records way be due to contamination. The occurrence of the species on wus musculus in the Uniled States may possibly be due to an actual transfer from the normal hosts, but its occurrence on this host in Asia is very strange.

Certain specinens from hosts of the genus Reithrodontomys, which have previously been referred to hesperomydis, ure here qransterred to it new species, Hoplopleura re ithrodontomydis.

\section{Hoplopleura hirsuta Ferris}

1916. Boplopleura hirsuta Ferris, Psyche 23:112; t'igures 8, 9A, 10, 111 .

1921. Hoplopleura htrsuta Ferris, Ferris, Contributions Toward a Monorraph of the Sucking Lice, Part 2:117; figures 75, 76.

HOSTS AND DISTRIBUTION. Type trom Sigmodon hispidus, Raleigh, Niorth Carolina. There are various records from this host throughout southern United States, as far west as Yuma, Arizona. Ferris has recorded it from Stgmodon ocrognathus from the state of Chihuahua, and firom Sigmodon peruanus from Peru. Two records by Ferris, each of a single specimen, from skins of Rhipldomys venustus in Venezuela and Xenomys nelsoni in Mexico, are most probably due to contamination.

\section{Hoplopleura hispida (Grube)}

1851. Pediculus hispidus Grube, In Middendorff's Reise, Parasiten, page 497; Plate 2, fiurure 2.

1921. Hoplopleura hispida (Grube), Ferris, Contributions Toward a Monograph of the Sucking Lice, Part 2:67.

HOSTS AND DISTRIBUTION. Recorded as from Lemnus obensis "am Taimyrsee," in Siberia.

NOTES. On the basis of the illustration accompanying the original description this species seems to be a Boplopleura and should be identifiable if taken from the type host.

\section{Hoplopleura intermedia Kellog: and Ferris}

1915. Boplopleura intermedto Kellogg and Ferris, Annals of the Durban Museum 1:153; Plate 16, figures 5, 5a-d.

1921. Hoplopleura intermedla kellogg and Ferris, Ferris, Contributions Toward a Monouraph of the Sucking Lice, Part 2:90; figures 54.55B, C, $.56 \mathrm{~B}$.

HOSTS AND DISTRIBUTION. Type from Rattus coucha, Mfongosi, Zululand, South Africa. Also recorded from Rattus tullbergt and Rattus (as Zelotomys) hildegardae, British East Africa and from Dendromus insignis from Brilish East Africa, this last record probably due to contamination.

\section{Hoplopleura laticeps Ferris}

1921. Boplopleura laticeps Ferris, Contributions Toward a Monosraph of the Sucking Lice, Part 2:92; fipures 55A, $56 \mathrm{~A}$.

HOSTS AND DISTRIBUTION. Known only from the original record from Hybomys (as Arvicanthis) untult tatus from Benito River, hiest Africa. 
1909. Haematoplnus (Polyplax) longula Neumann, Archives de Parasitologie 13:513; figures 15, 17.

1910. Hoplopleura lineata Fahrenholz, Zoologischer Anzeiger 35:715.

1921. Hoplopleura longula (Neumann), Ferris, Contributions Toward a Monograph of the Sucking lice, Part 2:68; figures 36, 37.

HOSTS AND DISTRIBUTION. Described by Neumann from kicromys minutus at Colchester, Essex, England, and by Fahrenholz from the same host, presumably from Germany.

\section{Hoplopleura maniculata (Neumann)}

1909. Haematoplnus (Polyplax) maniculatus Neumann, Archives de Parasitologie 13:521; figures 21, 22.

1921. Hoplopleura maniculata (Neumann), Ferris, Contributions Toward a Monouraph of the Sucking Lice, Part 2:112; figures 71, 72A, D, C.

HOSTS AND DISTRIBUTION. Described from Funambulus (as Sciurus) palmarum, Rajkote, Rajkote, India, and at the same time erroneously attributed to a bat. Later recorded by Ferris from the type host from Navapour, India, and from Ceylon.

\section{Hoplopleura malaysiana Ferris}

1921. Hoplopleura malaysiana Ferris, Contributions Toward a Monograph of the Sucking Lice, Part 2:79; figures 44, 45.

HOSTS AND DISTRIBUTION. Recorded as from Rattus vociferans lancavensis, which is apparently Rattus sabanus, from Lankavi Island, Malay Straits.

\section{Hoplopleura merionidis Ferris}

1921. Hoplopleura merionidis Ferris, Contributions Toward a Monograph of the Sucking Lice, Part 2:98; figure 60.

HOSTS AND DISTRIBUTION. Recorded from Meriones psammophilus from Shansi, China, this apparently being identical with Meriones meridianus.

\section{Hoplopleura mylomydis Ferris}

1921. Hoplopleura enormis mylomydis Ferris, Contributions Toward a Monograph of the Sucking lice, Part 2:97; figure $59 \mathrm{C}$.

HOSTS AND DISTRIBUTION. Known only from the original description from Mylomys roosevelti, which is apparently a synonym of kylomys cuninghamel, British East Africa.

\section{Hoplopleura nesoryzomydis Ferris}

1921. Hoplopleura nesoryzomydis Ferris, Contributions Toward a Monograph of the Sucking Lice, Part 2:90; figure 53A.

HOSTS AND DISTRIBUTION. Recorded as from Nesoryzomys narborousht and Nesoryzomys defessus in the Galapayos Islands. According to Ellender, Nesoryzomys is merely a subgenus of Oryzomys and evidently defessus is an error for indefessus.

\section{Hoplopleura neumanni Fahrenholz}

1901. Haematopinus praecitus Neumann, Archives de Parasitologie 5:600. (In part: error for praecisus)

1902. Haematopinus praecisus Neumann, Archives de Parasitologie 6:144. (In part) 


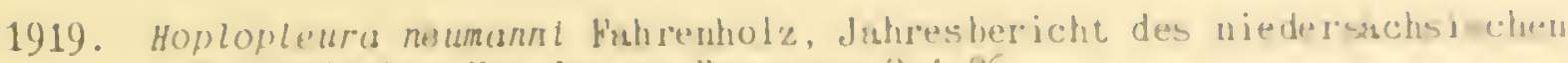
Tax) lo gische'u Vereins zu llannover 2-4:26.

1921. Hoplopleura neumunt Finrenhol\%, Ferris, Contribucions Toward a Monogruph of the Sucking lice, l'art 2:101; f"igure 63.

IIOSTS AND DISTRIBUTION. liased upon specimens pecorded merels as "eros rats," rrou Abysinia. ferris has recorded the species from Tatera nigrtcoumda trom Brilish bist Alrica. Hopkins has noted that this species occurs in Abssinia and it is probable that it was the type host.

\section{Hoplopleura ochotonase ferris}

192:. Hoplopleura ochotonae fierris, Contributions Tuward a Monogruph of the Sucking Lice, Part 3:142; l'igure 92.

HOSTS AND DISTRLBUTION. Described us from Ocholonc cansus, which is is syuonym of Ochotona thibetana, from Trochao, Chius. Recorded also t'roun ochotona danurica. Tabool, Mongolia, and l'rou Ochotona royle'l withoul indication of Locality.

Hop lop leura oenomydis Ferris

$$
\text { Figures } 59,60
$$

1921. Hoplopleura oenom!dis Ferris, Contributions Toward a Monograph of the Sucking Lice, Purt 2:82; figures $47,49$.

1924. Hoplopleura pacifica Ewing, Bishop Museum Bulletin 14:9; figure 1b, e. 1932. Hoplopleura oenomydis Ferris, Ferris, Bishop Museum Bulletin 98:121; ligures $37 \mathrm{a}-\mathrm{i}, 38 \mathrm{a}-\mathrm{k}, 39$.

1947. Hoplopleura oenomydis Ferris, Pritchard, The Journal of Parasitology $35: 374$.

HOSTS AND DISTRIBUTION. Type from Oenomys hypoxanthus at Molo, Brit ish East Africa. Also recorded from Dasymys incomtus and Grammomys (as Thamnomys) surdaster from British East Africa; trom Rattus exulans (as calcis) and Rattus mearnsi from the Philippine Islands. Described by Eving as Hoplopleura pacifica from Rattus exulans (as hawailensis) from the Hawaijan Islands, and recorded from this same host from the Marquesas Islands. It has recently been shown to be the most common louse on Rattus norvegicus in southeastern United States.

NOTES. Hopkins has recently expressed doubt concerning the synonym indicated above, considering it to be "extremely improbable" that all the published records can refer to Hoplopleura oenomydis. A re-examination of all the available material reveals no reason for altering the opinions previously expressed by Ferris in regard to the matter, whatever the "improbabilities" may be.

\section{Hoplopleura oryzomydis Pratt and Lane}

1951. Hoplopleura oryzomudis Pratt and Lane, Journal of Parasizolog 37 : 141; figures 1-3, 5.

HOSTS AND DISTRIBUTION. Type irom Oryzomys palustris, Oatland Island, Chatham County, Georgia, and other specimens from the same host species in Delaware, South Carolina, and Florida, United States.

\section{Hoplopleura oxymy cteri Ferris}

1921. Boplopleura oxymycterl Ferris, Contributions Toward a Monograph of the Sucking Lice, Part 2:122; firures $79,80$.

Peru.

HOSTS AND DISTRIBUTION. From Oxymycterus Daramensis at Occabamba Pass. 


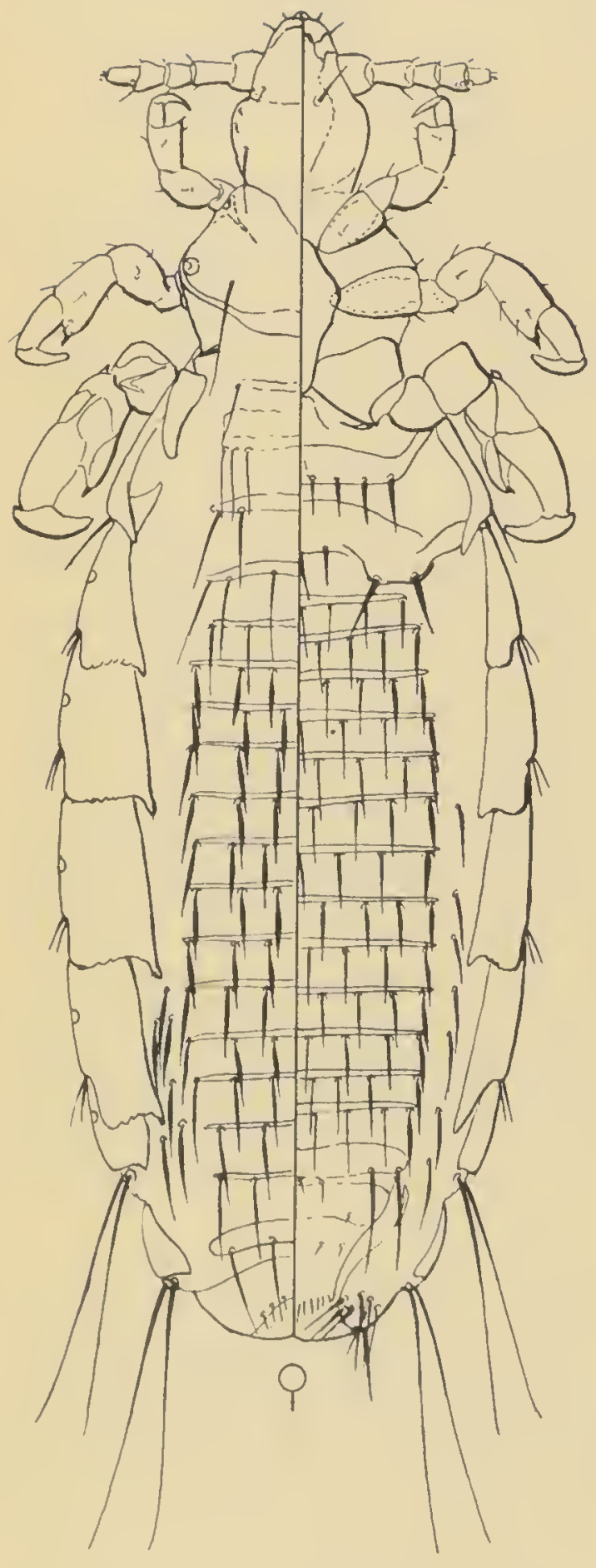

Hoplopleura oenomydis Ferris

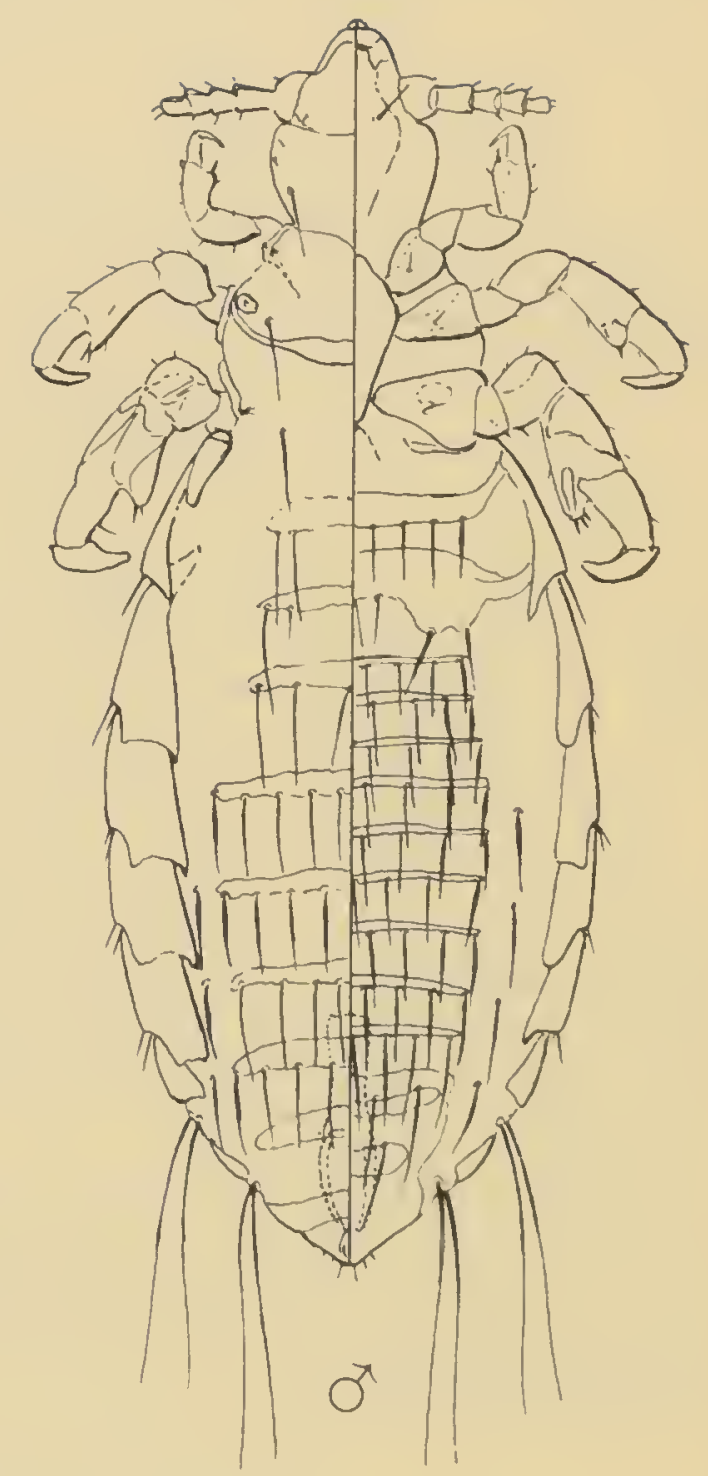

Figure 59 

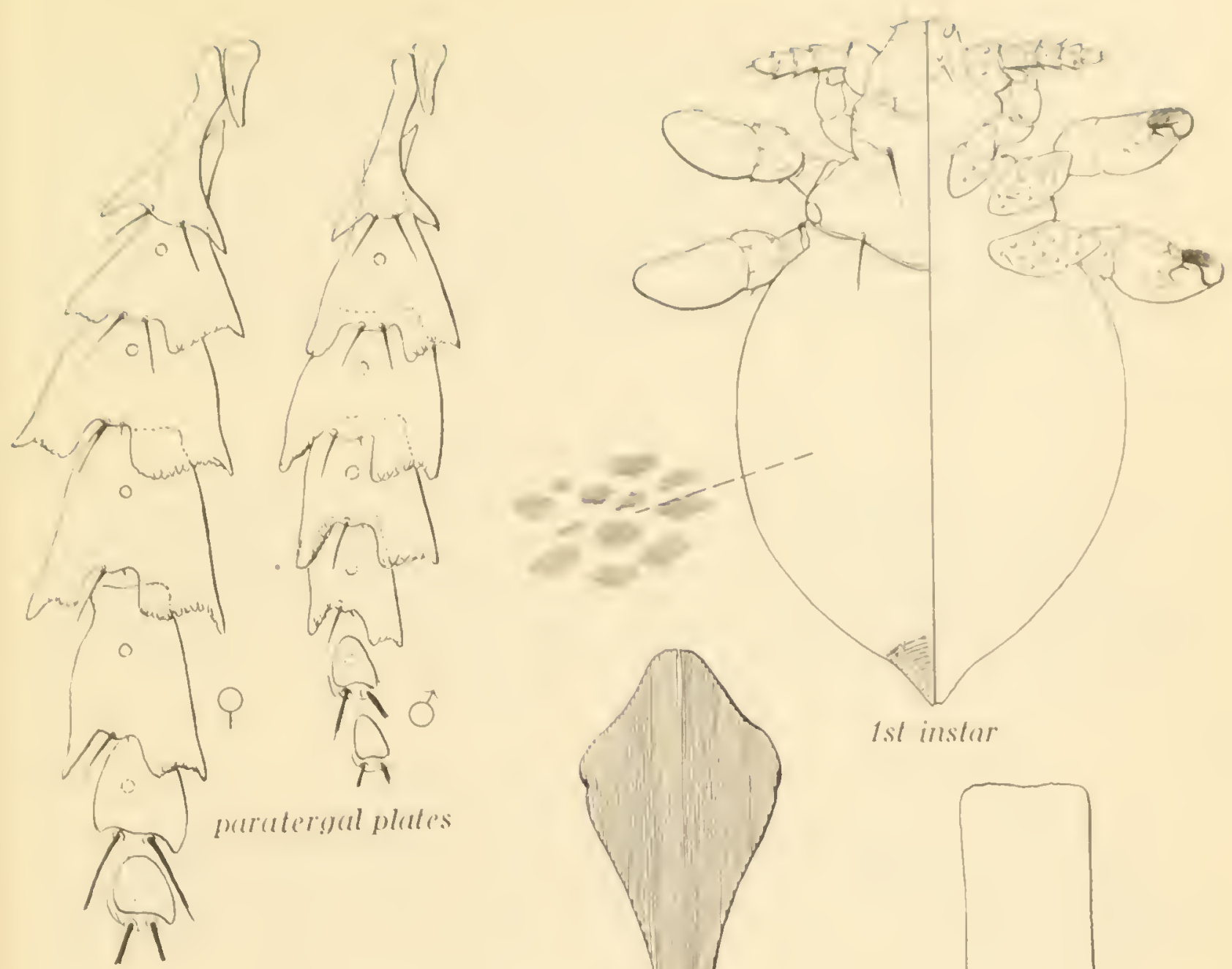

lhoracie slernal plate

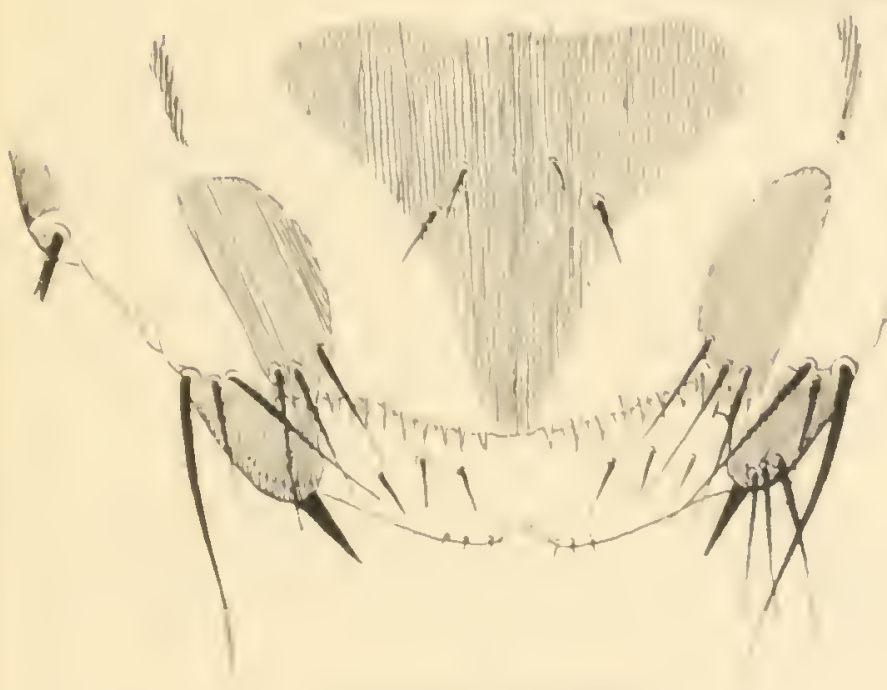

frumle genitalia

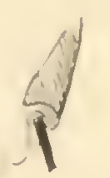

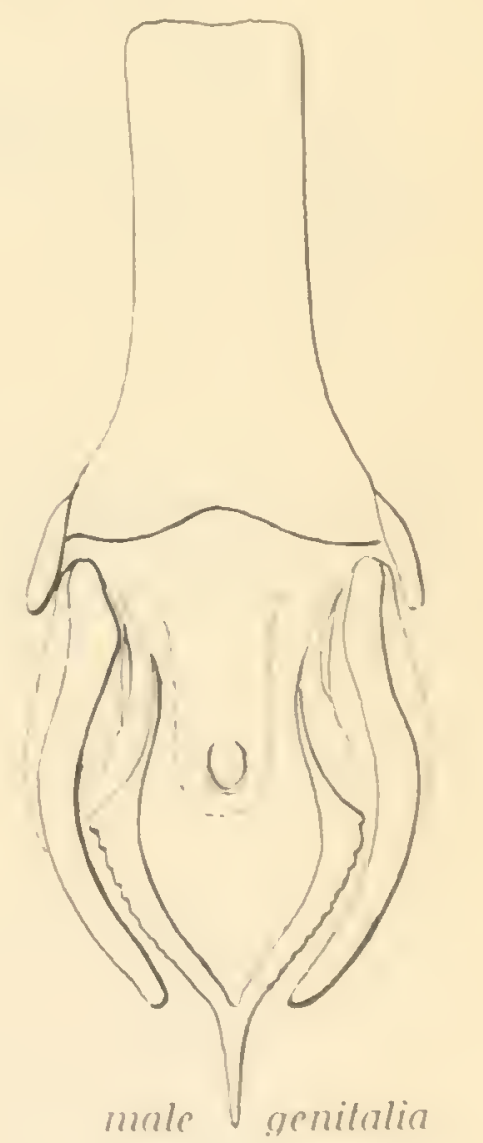

Figure 60 
1913. Hoplopleura pectinata Cumings, Bulletin of Entomological Research $4: 35$.

1921. Hoplopleura pectinata Cummings, Ferris, Contributions Toward a Monograph of the Sucking Lice, Part 2:99; figures 61, 62.

1929. Ctenura pectinata (Cummings), Ewing, A Manual of External Parasites, page 199.

1932. Hoplopleura pectinata Cumings, kerris, Contributions Toward a Monograph of the Sucking Lice, Part 5:282.

HOSTS AND DISTRIBUTION. Described f'rom Rattus (as Epimys) surifer at Biserat, Jalor, Malay Peninsula, and later recorded from the same host from Trong, lower Siam.

NOTES. This species has been desirnated as type of the genus Ctenura, a genus which is here rejected.

\section{Hoplopleura pelomydis Ferris}

1921. Hoplopleura enormis pelomydis Ferris, Contributions Toward a Monograph of the Sucking Lice, Part $2: 96$; figures $58 \mathrm{~A}, 59 \mathrm{~A}$.

HOSTS AND DISTRIBUTION. Described as from Pelomys fallax, Summit Sagalla, British East Africa. Also recorded from Lemniscomys striatus (in part as pulchellus) from the Cameroons and from British East Africa. It is probable that the species of Lemniscomys are the true hosts.

\section{Hoplopleura phaiomydis Ferris}

1921. Hoplopleura phaiomydis Ferris, Contributions Toward a Monograph of the Sucking lice, Part 2:120; figures 77, 78.

IIOSTS AND DISTRIBUTION. Recorded as from an undetermined species of Phaiomys from East Ladak, Kashmir. Hopkins has ascertained that the host species was Phaiomys blythi, which Ellender considers to be a synonym of Phaiomys leucurus.

\section{Hoplopleura quadridentata (Neumann)}

1909. Haematopinus (Polyplax) quadridentatus (Neumann), Archives de Parasitologie 13:5:3-15; figures 13-14.

1921. Hoplopleura quadridentata (Neumann), Ferris, Contributions Toward a Monograph of the Sucking Lice, Part 2:87; figures 52, 53B, C, E.

HOSTS AND DISTRIBUTION. Recorded by Neumann from Bolochilus squamipes, which apparently is Nectomys squamipes, from Haut Peru. Later recorded by Ferris from this same host at Sapucay, Parayay, and from Nectomys palmipes, which is perhaps the same as squamipes, from the island of Trinidad; from orizomys fulvescens from Orizaba, Mexico; and from Oryzomys rostratus from Alta Mira, Tamaulipas, Mexico.

\section{Itoplopleura reducta Ferris}

1921. Hoplopleura reducta Ferris, Contributions Toward a Monograph of the Suckins lice, Part 2:124; figure 81.

1935. Hoplopleura reducta Ferris, Ferris, Contributions Toward a Monograph of the Sucking Lice, Part 8:615.

HOSTS ANI) ILLSTRIINTION. Described is from phyllotis micropus from Todos Santos, fuatemalis. Liater recorded from an undetermined host from unspecified locality in South Merica. 


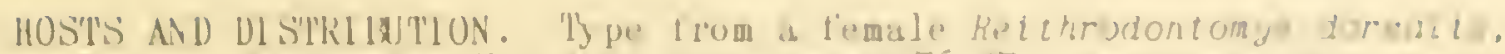

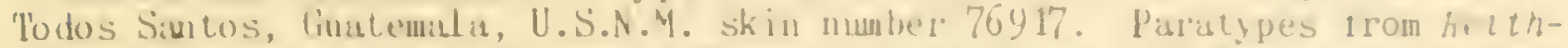
rodontomys australes, Volcan de Irizu, Custe Kica, U.S.A.Y. Skin number $116623)$, ind Relthrodontomys rhrllsopsts, Ajusco, 11 al Mexico Ciry, Mexico.

CHikAcliks. Female in all respects identicul with Hoplopleura hesperomylls, except tor the shape ot the paratergites of abdunillal segnent sema, which in hesperomydis have both dorsal and ventral lobes definitely acute abically. While in reithrotontomytis the dorsal lobe is hroad and apically tinncate or stighty emarginate. All of the rather unwerous specimens at hund from the three host species and three localities mree very closely. An extended description and illustrations of the species will be presented elsewhere.

\section{Hoplopleura rukenyae ferris}

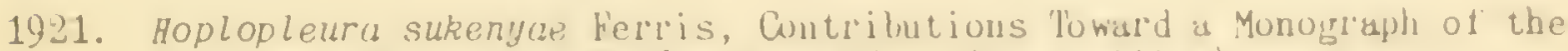
Suckini lice, Part 2:86; t'i gure 51. (Yisspelling)

HOSTS AND DISTRINTION. Known lrom a single male fron kus triton, Mount Rukenya, British Eisst Atrica.

NOTES. Mr. G. II. E. Hopkins has called atlention to the lact that the type Locality ot this species is more comnonly, and perhaps more correctly, spelled Rukenya rather than Sukenya. Il is probable that an error in reading a label was committed and under thesc circumstances it seems justiliable to change the spelling of the specit'ic name to rukenyae.

\section{Hoplopleura sciuricola Ferris}

1921. Hoplopleura sciuricola Ferris, Contributions Toward a Monograph ot the Suching Lice, Part 2:110; figures 69, 70.

HOSTS AND DISTRIBUTION. Ty pe from Sciurus carolinensis at Bayou St. Louis. Mississippi. Also recorded from other species of Scturus as follows: hudsonicus iu Alaska, douglasi in California, ignitus in Peru, nesaeus in Venezuela, variabilis in Colombia, and undetermined species in Bolivia and Peru.

\section{Hoplopleura somereni haterston}

1923. Hoplopleura somereni Waterston, Bulletin of Entomolorical Research 14:99; figure $1 b, c$, d; figure $2 c$, d.

IIOSTS AVD DISTRIBUTION. From Dasymus helukus at hamia, Okedi Camp, Kenya.

\section{Hoplopleura travassosi herneck}

1932. Hoplopleura travassosi herneck, Revista Medico-Cirurgica do Brasil, anno $40: 345$; figure.

1934. Hoplopleura travassosi Werneck. Memorias do Instituto Oswaldo Cruz

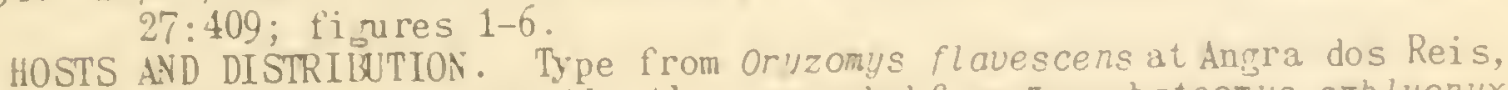
state of Rio de Janeiro, Brasil. Also recorded from $\mathbb{a}$ annabateomys amblyonyx and oxymycterus judex at the same locality.

\section{Hoplopleura trispinosa Kello:s and Ferris}

1915. Boplopleura trispinosa Kellogs and Ferris. Anoplura and Mallophaga of North American Mammals. Stanford University Puhlications. University Series (no volume number), page 22: text fipure G: Plate 4. tisure 3. 
1921. Hoplopleura trispinosa Kellogg and Ferris, Ferris, Contributions Toward a Monograph of the Sucking Lice, Part 2:115; firures 73, 74. 1929. Euhoplopleura trispinosa (Kellogg and Ferris), Ewing, A Manual of External Parasites, pages 135, 199.

HOSTS AND DISTRIBUTION. Type from Glaucomys sabrinus, Brownsville, 0regon. Also recorded from the same host at Yosemite National Park, California, and from Glaucomys volans from Maryland.

NOTES. This species has been designated as type of the genus Euhoplopleura, which is here rejected.

\section{Hoplopleura veprecula Ferris}

1921. Hoplopleura veprecula Ferris, Contributions Toward a Monograph of the Sucking Lice, Part 2:105; figures 64B, 66A, C, F.

HOSTS AND DISTRIBUTION. From Tatera boehmi at South Guaso Nyiro, British East Africa.

\section{Genus PTEROPHTHIRUS Ewing}

1923. Pterophthirus Ewing, Journal of the Washington Academy of Sciences 13:147.

1932. Pterophthirus, Ferris, Contributions Toward a Monograph of the Sucking Lice, Part 5:280.

GENERIC TYPE. Hoplopleura alata Ferris. Three other species are here referred to the genus.

CHARACTERS. Hoplopleurinae with five-segmenied antennae. Paratergal plates of abdominal se gment two produced into a long, tapering, blade-like process which projects from the body. First sternal plate of abdominal segment three not produced laterally to articulate with the corresponding paratergal plates. Otherwise essentially as in Hoplopleura.

NOTES. This genus is very close to Hoplopleura, diftering from the latter only in the form of the paratergal plates of abdominal segment two. Even here it appears from the illustrations presented in connection with the description of Pterophthirus imitans Werneck that this species is somewhat of an intermediate between the two genera. As known at present the genus is confined to South American rodents.

The four known species may be separated by the following key.

\section{Key to Species of PTEROPHTHIRUS}

1. Paratergal plates of abdominal segments 3-4 each with the ventral, api-

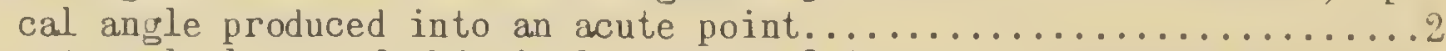

Paratergal plates of abdominal segments $3-4$ with the ventral apical an-

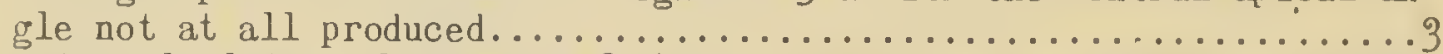

2. Paratergal plates of seyments $3-5$ with both dorsal and ventral, apical

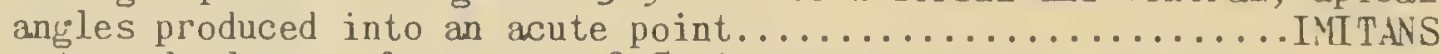

Paratergal plates of segments $3-5$ with the ventral, apical angle produced into an acute point, the dorsal angle broadly truncate. HERNECKI

3. Paratergal plates of seuments $3-4$ with the dorsal, apical angle pro-

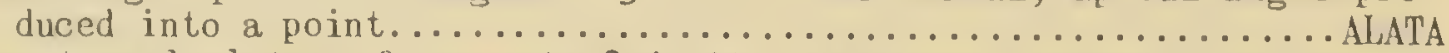

Paratergal plates of segments $3-4$ with the dorsal, apical lobe broadly

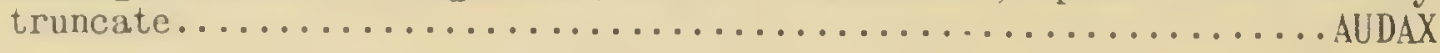

Pterophthirus alata (Ferris)

Figures 61,62

1921. Hoplopleura alata Ferris, Contributions Toward a Monograph of the Sucking Lice, Part 2:127; tigures 84, 85. 


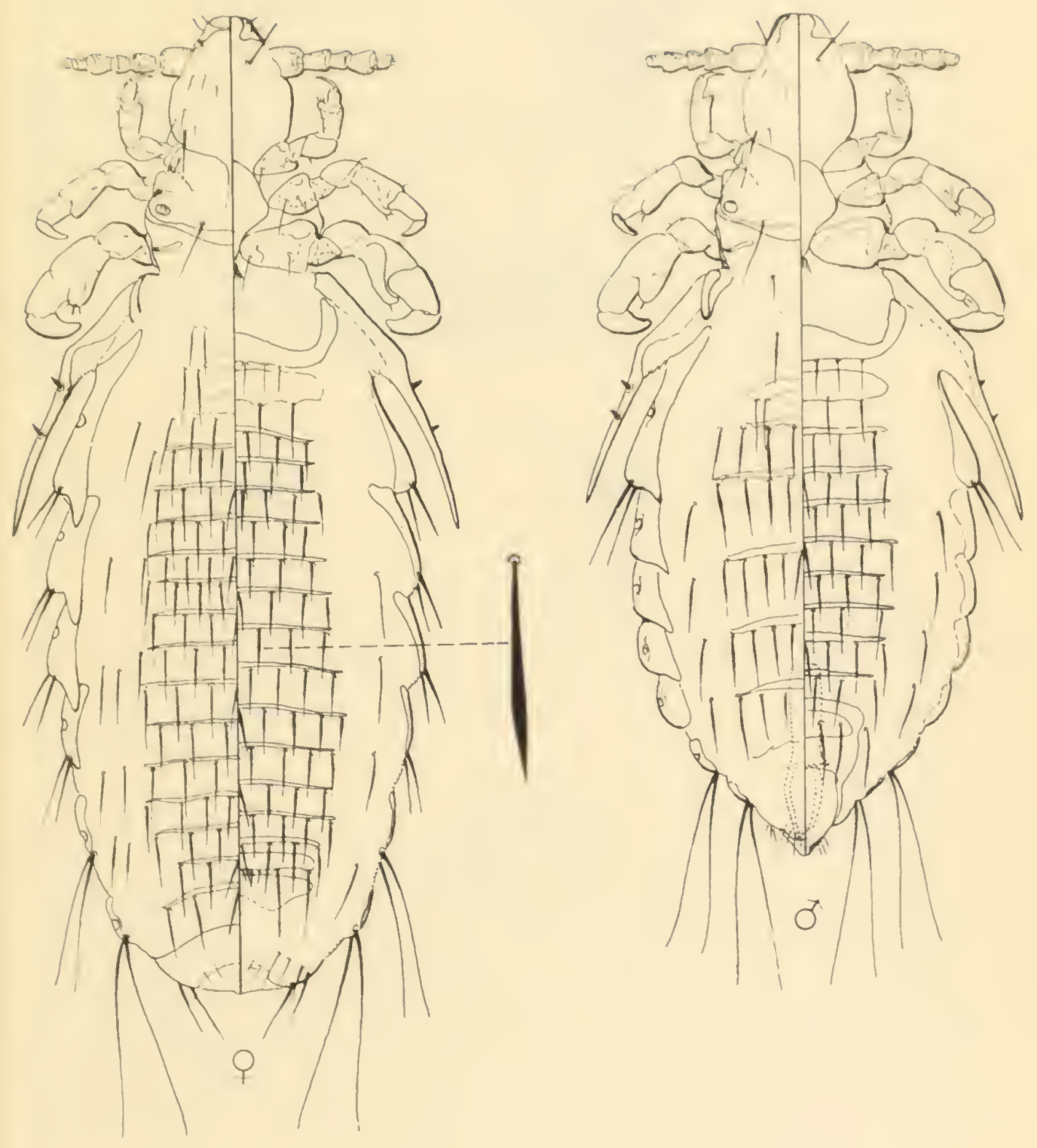

Pterophthirus alata (Ferris)

Figure 61 


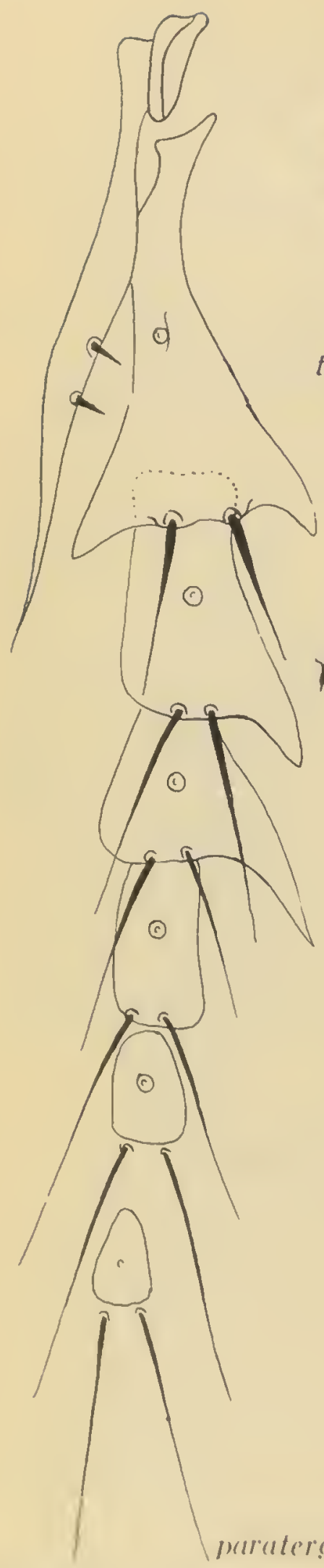

marutergal plates

Pterophthirus alata (Ferris), details

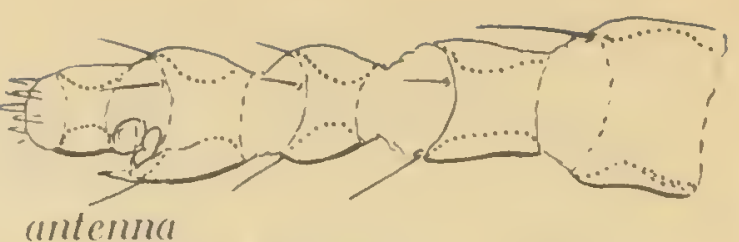

anterna
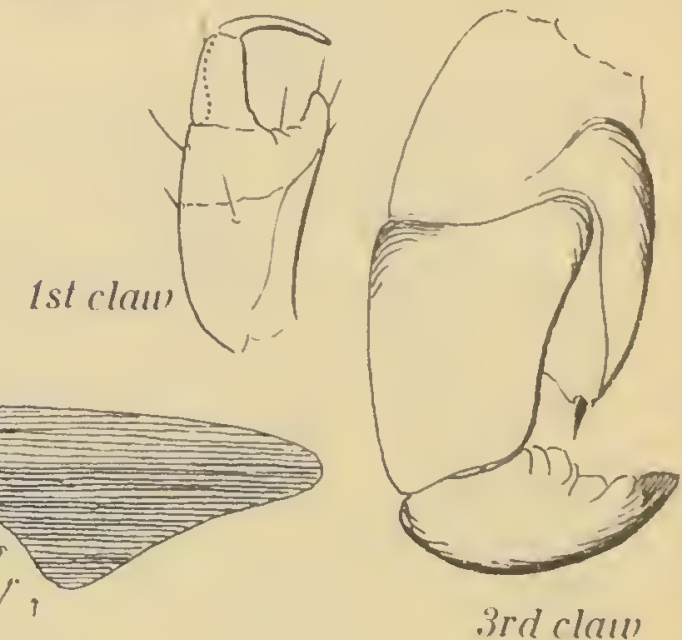

3rd clauv

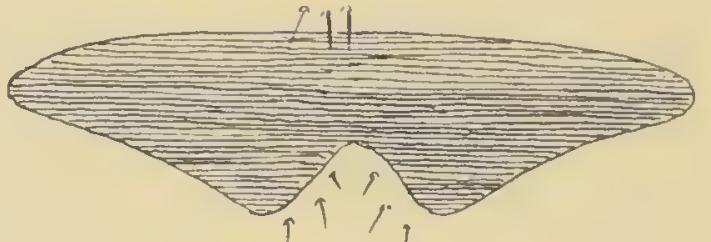

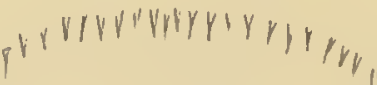

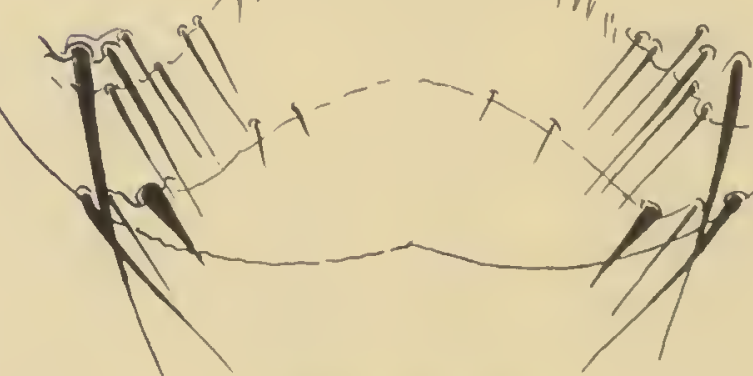

female genifulia

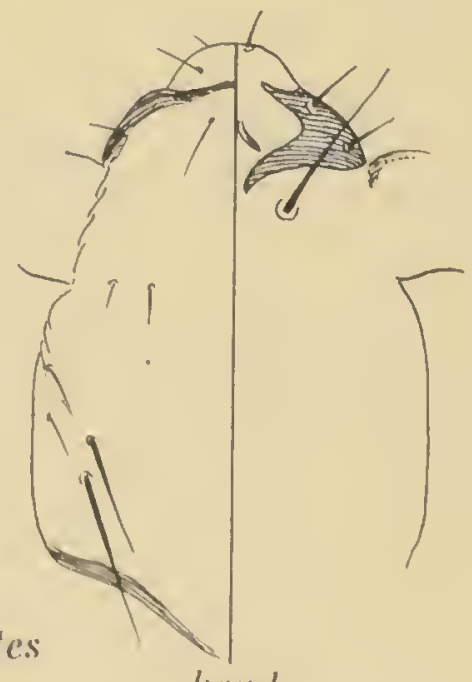

lin'ul

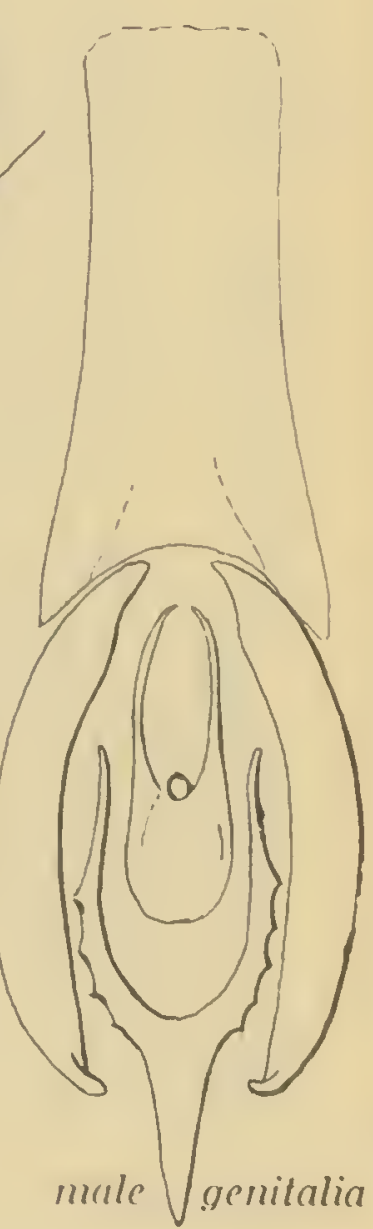

Figure 62 


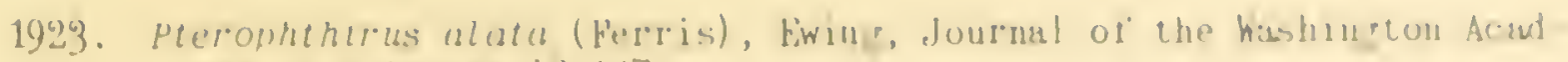
ems of soiences $13: 147$.

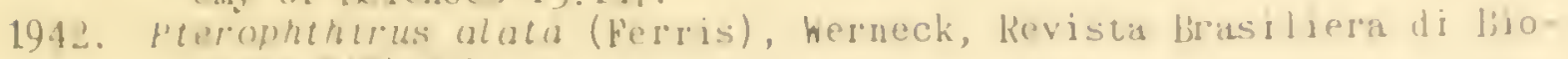
lo: $:$ iit: $:(3): 317$.

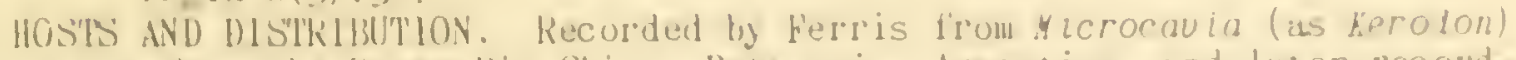
custralts lrom the Upper Rio Chico, Patidonia, Arrentiua, and later record

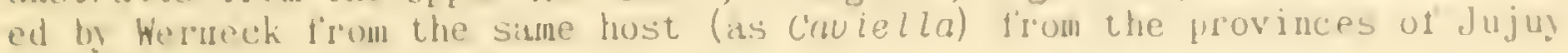
and Catiumitra, in Argentinit.

\section{Pterophthirus audax (f'erris)}

1921. Hoplopleura audax l'erris, Contributions 'luward a Yonomaph of the Suckinu Lice, Part 2:125; ligures 82, 83.

1923. Pterophthirus audax (Ferris), Ewing, Journal of the Washington Acadeny of Sciences 13: 149.

1923. Pterophthirus audax (Ferris), Ferris, Contributions Toward a Monograph of the Suckin' Lice, P'at 5:281.

1942. Pterophthirus audax (Ferris), Herneck, Kevista Brasiliera di bioloria $2(3): 317$.

HOSTS AND DISTRIBUTION. Types tron Proechimys semispinosus and other specimens trom Proechimys (as Velomys) mincae at San Javier, North Ecuador. Recorded by Werneck from Proechimys or is at Abiete, Para, Brasil.

\section{P'terophthirus imitans Herneck}

1942. Pterophthirus imitans Herneck, Revista Brasiliera di Biologia 2(3):

317 ; "irures.
hoSTS AND DISTRIBUTION. From Cavia aperea, Santo Amaro, state of Sáo Paulo, Brasil.

Pterophthirus wernecki Guimiräes

1950. Pterophthirus wernecki Guimaráes, Papeis Avulsos do Departamento de Zoologia, Secretaria da. Apricultura, Sáo Paulo, Brasil 9:8:83; fípures.

HOSTS AND DISTRIBUTION. From Proechimys theringi at Boraceia, state of ST̃o Paulo, Brasil.

\section{Genus SCHIZOPHTHIRIS Ferris}

1922. Schizophthirus Ferris, Contributions Toward a Monopraph of the Suckin Lice, Part 3:143.

1932. Hosellus Jancke, Zeitschrift tür Parasitenkunde 4:532.

GENERIC TYPE. Pediculus pleurophoeus Burmeister, by original designation. One other species is included in the genus.

GENERIC SYNONIY. Hasellus Janclie, by community of type.

CHARACTERS. Hoplopleurinae with five-segmented antennae. Abdominal segments, exclusive of the usual terminal and genital segments, without tergal or sternal plates in the female except for plates belonging apparFemale with three rows of setae on most of the segments both dorsally and ventrally, the male with one row on each segment both dorsally and ventral1y. Sternal plate of segment two divided longitudinally into tro much expanded plates, each of which articulates by means of a process with the corresponding paraterial plate and each of which hears on its posterior border $2-3$ stout, thorn-like setae.

The members of this genus occur on rodents of the family Gliridae. 


\section{Key to Species of SCHIZOPHTHIRUS}

Dorsal and ventral lobes of the paratergal plates of abdominal segments 3-6 deeply divided into 2 very unequal lobes, the dorsal lobe being much narrower than the ventral lobe; known from the European genera Muscardinus

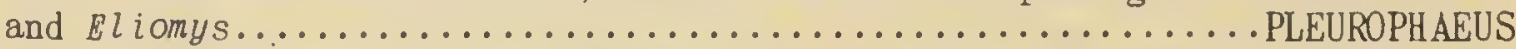

Paratergal plates of these abdominal segments not thus deeply divided, and with the lobes equal; known from the genus Graphiurus in Africa. GRAPHIURI

\section{Schizophthirus graphiuri Ferris}

1922. Schizophthirus graphiuri Ferris, Contributions Toward a Monograph of the Suckini Lice, Part 3:147; figures 93A, 96, 97.

HOSTS AND DISTRIBUTION. Type f'rom Graphiurus murinus from British East Africa. and recorded also as from Graphiurus murinus (as raptor) from the same region; from Graphiurus nanus from Natal, South Africa; from Graphiurus alticola, locality not specified in avalable reference.

\section{Schizophthirus pleurophaeus (Burmeister) Figures 63, 64}

1839. Pediculus pleurophaeus Burmeister, Genera Insectorum, Rhynchota, Number 7.

1922. Schizophthirus pleurophaeus (Burmeister), Ferris, Contributions Toward a Monograph of the Sucking Lice, Part 3:145; figures 94, 95.

HOSTS AND DISTRIBUTION. Type from Dryomys nitedula (as Myoxys nitella) from somewhere in Europe. Also recorded from Eliomys quercinus (as pallidus) from Italy and from Muscardinus avellanarius from Germany.

\section{Subfamily HYBOPHTHIRINAE Ferris, new subfamily}

DESCRIPTION OF THE SUBFAMILY. Hoplopleuridae in which there is no external indication of eyes. The most distinctive character is the presence of a short, claw-like structure which arises beside the true claw on the anterior le:rs. Paratergal plates present on abdominal segments 2-8 or 3-8, with at least one of the posterior apical angles forming a lobe or point which is free from the body wall. Abdomen with but a single row of setae on any segment, both dorsally and ventrally, in either sex and without sclerotized tergal and sternal plates other than those normally present on the terminal and genitalic segments, except at times in the male. Antennae five-segmented, sexually dimorphic only to the extent that the male may bear a single enlariged seta near its apex.

Occurring on African mammals of the rodent family Echimyidae, subfamilies Thryonomyinae and Petromyinae, and the family Orycteropodidae of the Order Tubulidentata.

NOTES. A considerable amount of doubt is felt concerning the validity of this subfamily. The presence of the peculiar claw-like structure alongside the true claw on the front tarsi seems to link the included species and there are no other characters which specifically deny such an association.

Webb referred the two included genera to the Haematopinidae, but the present writer is quite unable to agree with this assignment.

\section{Key to the Genera of HYBOPHTHIRINAE}

Hindhear almost triangular, the lateral margins strongly convergent; occurring on the genus orycteropus of the Order Tubulidentata.....HYBOPHTHIRUS Hindhead with the lateral mareins approximately parallel; occurring on rodents of the fumily Echimyidac..................................... 


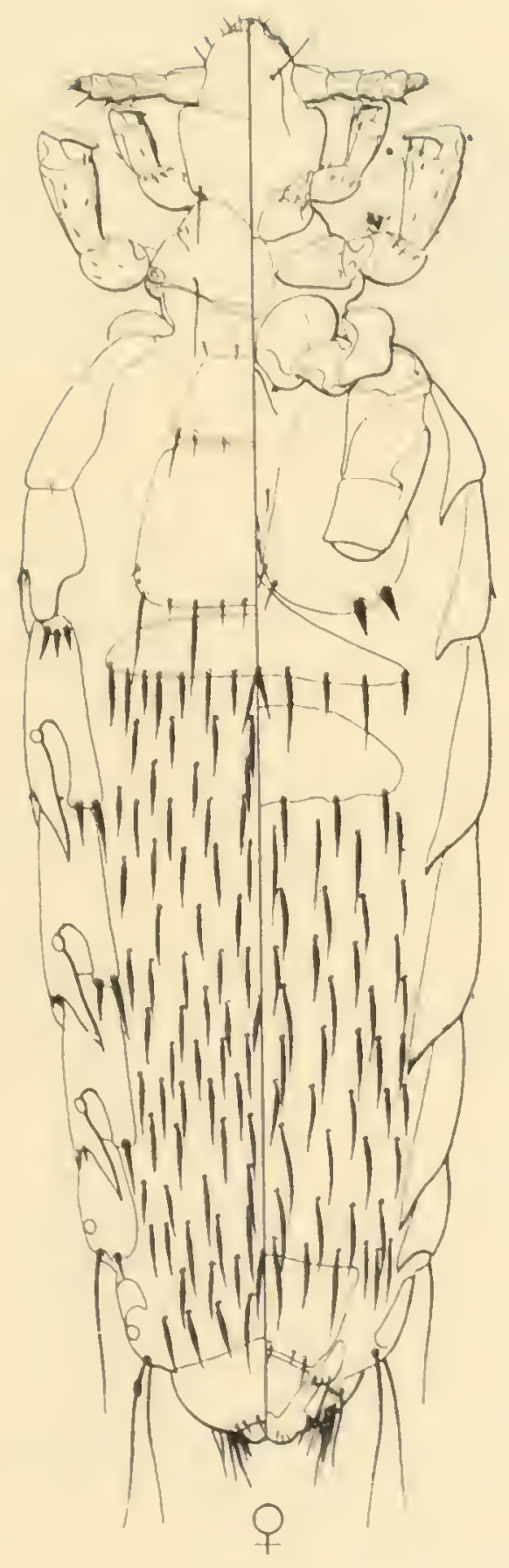

Schizophthirus pleurophaeus (Burmeister)

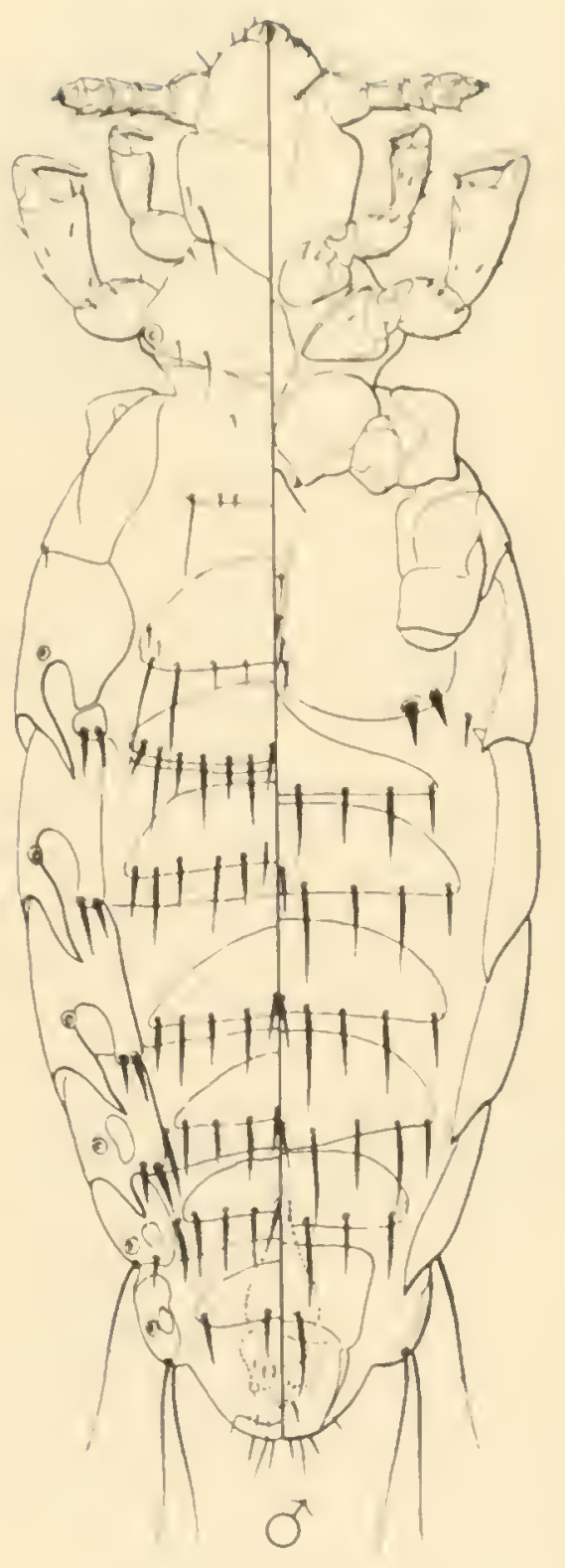

Figure 63 


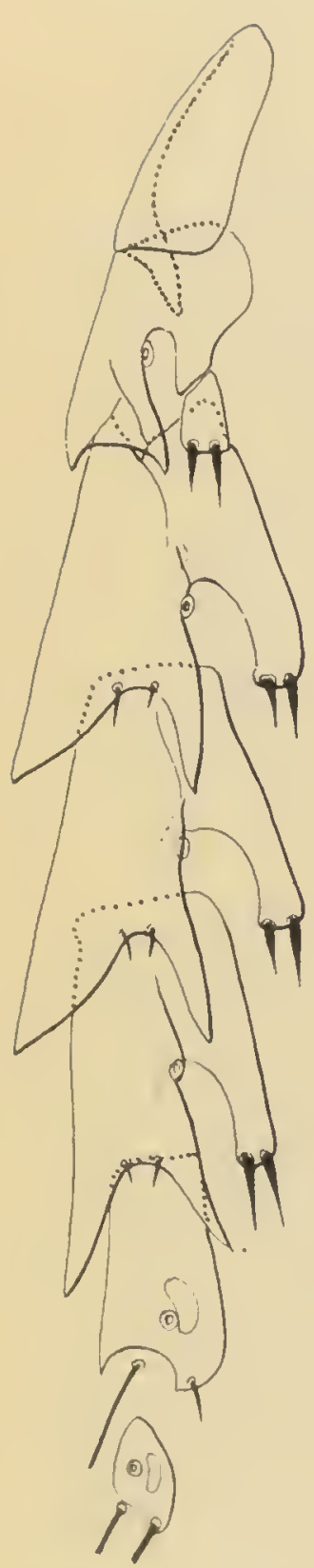

paratergal plate
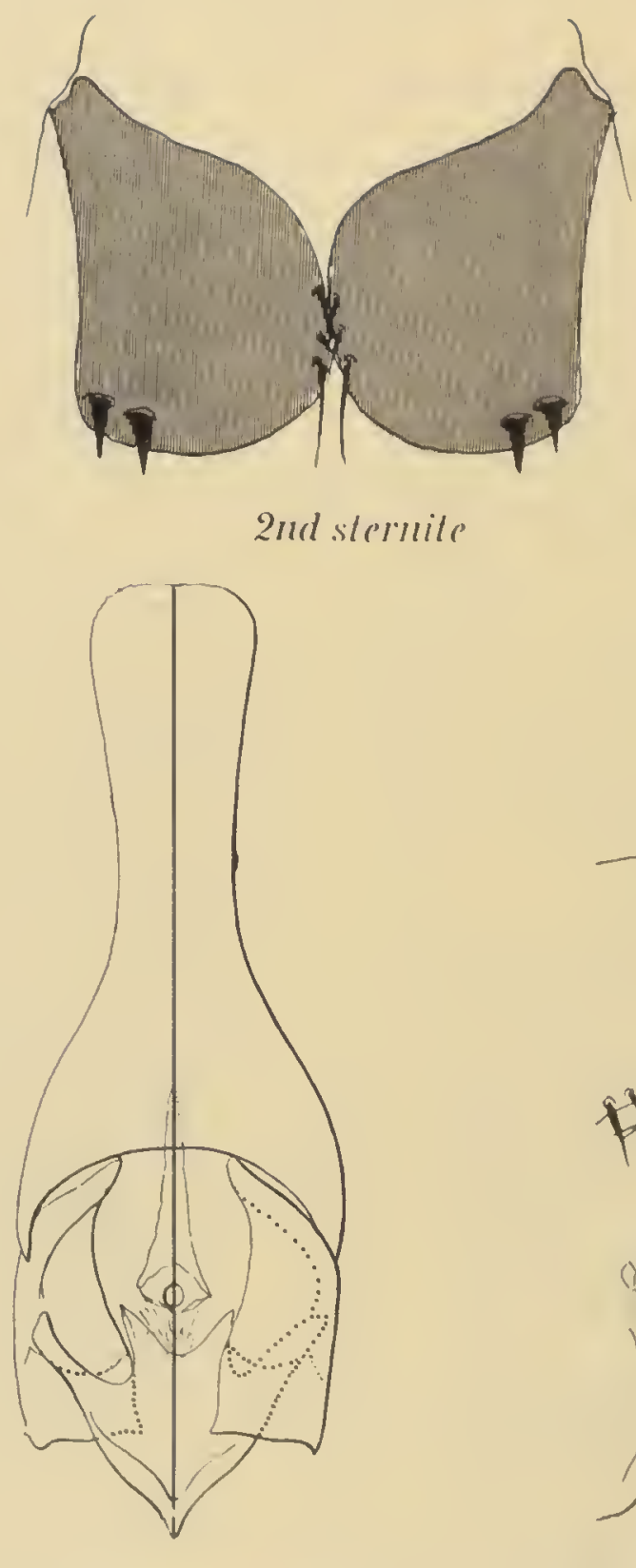

male genitalia
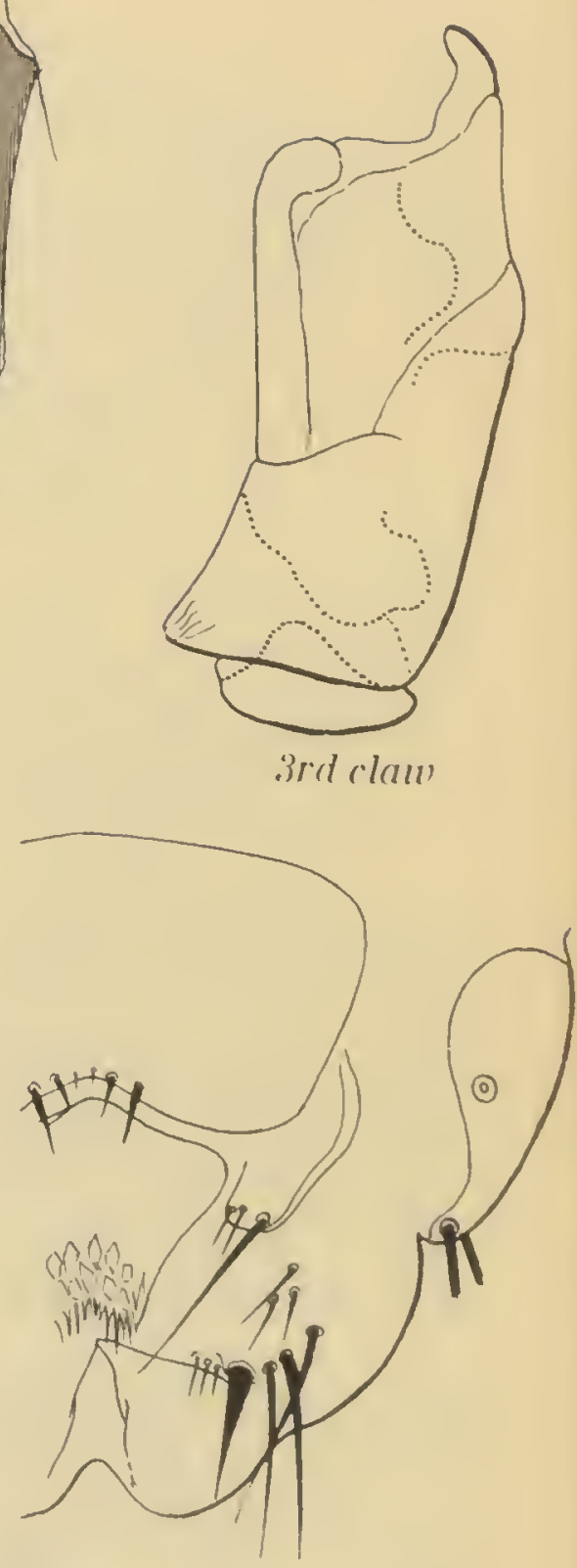

female genitalia 
1909. Hymphthurus Emberloin, Konkschrith der medicinislen-maturwissen sehalt-ichen (iere!lschitti zu dera 14:79).

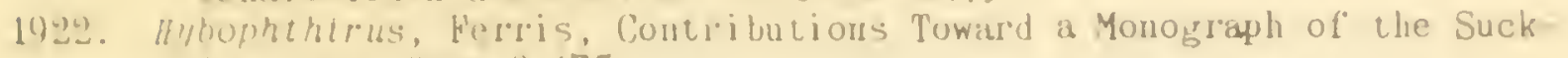
in" lice, Purt 3: 175.

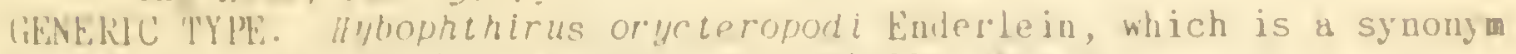
of the earlied lessolibed homatopinus notophallus Neuman.

Cllatiactiks. Hybophthirinae in which the head is short and broad, sharpIy expanded posterior to the antennae and then constricting sharply, the hindheal be ing almost triangular. 'lhoriux wi thoul ary sternal plate; prothorar ic sternal apophyses present, forming a pair of pits on the ventral side; with the metanotum torning a distinct, apically tree lobe at each posterior angle. Fis'st pair of le;s slenter, with slender clisw; second and third less equal to each other, lar ge and stout, with scout clan. Abdomers with paraterial plates present on segments "2-5, euch with the poscerior, dorsul angle plolonged into an apically rounded, tree lobe. Abdomen with hut one row of sinall setae actoss each se grment, both torsilly and ventrilly, in loth sexes.

\section{Hybophthirus notophallus (Neunaur) \\ Fivures 65,66}

1909. Haematopinus notophallus Veuman, Jahresuericht des Nassinische Vereins lur Naturkunde in Hiesbalen, page 2.

1909. Hybophthirus notophallus Enderlein, Denkschrift der medicinischennaturwissenschat"t-ichen Gesellschaft zu Jena 14:79-80; Plate 8, t'i rures $1-3$.

1922. Hubophthirus notophallus (Neumann), Ferris, Contributions Toward a 'Yonograph of' the Suckin: Lice, Part 3:176; t'i gures 117-118.

HOSTS AND DISTRIBUTION. Neumann's ypes were trom orycteropus afer (=capensis), the "Cape ant bear", "at "Gochas, Afrique occidentale allemande," and Enderlein's types were from the same host in "Klein-Namaland, Umigbung von Steinkopf." The species has later been recorded from the same host in South Atrica.

NOTES. The priority of Neumann's specific name over that applied by Enderlein has been pointed out by Cummings. The accompanying illustrations are trom specimens from the type host in the Zoolobical Garden at Pretoria, Sorth Atrica.

\section{Genus SCIPIO Cummin:s}

1913. Scipio Cumninss, bulletin of Entomolojical Research 3:393.

1916. Veumannellus Fahrenholz, Archiv für Naturgeschichte, Abteilung A, $81: 11: 31$.

1922. Scipio, Ferris, Contributions Toward a Monograph of the Susking Lice, Part 3:170.

1936. Berfordia Fahrenholz, Zeitschrift für Parasitenhunde 9:55.

GENERIC TYPE. Haematopinus aulacoti Neumann, the only included species at the time of the naming of the genus. Neumannellus Fahrenholz has the same type. Bedfordia Fahrenholz, type Scinio trinedatus Ferris, is here considered to be a synonym.

CHARACTERS. Head with the posterior lateral margins more or less nearly parallel. Antennae of the male with the third se ment somewhat modified by the presence of a stout, subapical. dorsal seta. Thorax at the most with a very small sternal plate which is not apically or marginally tree. Posterior-lateral angle of the metathorax dorsally with a pronounced lobe, except that this is weakly developed in one species. Abdomen with definite 


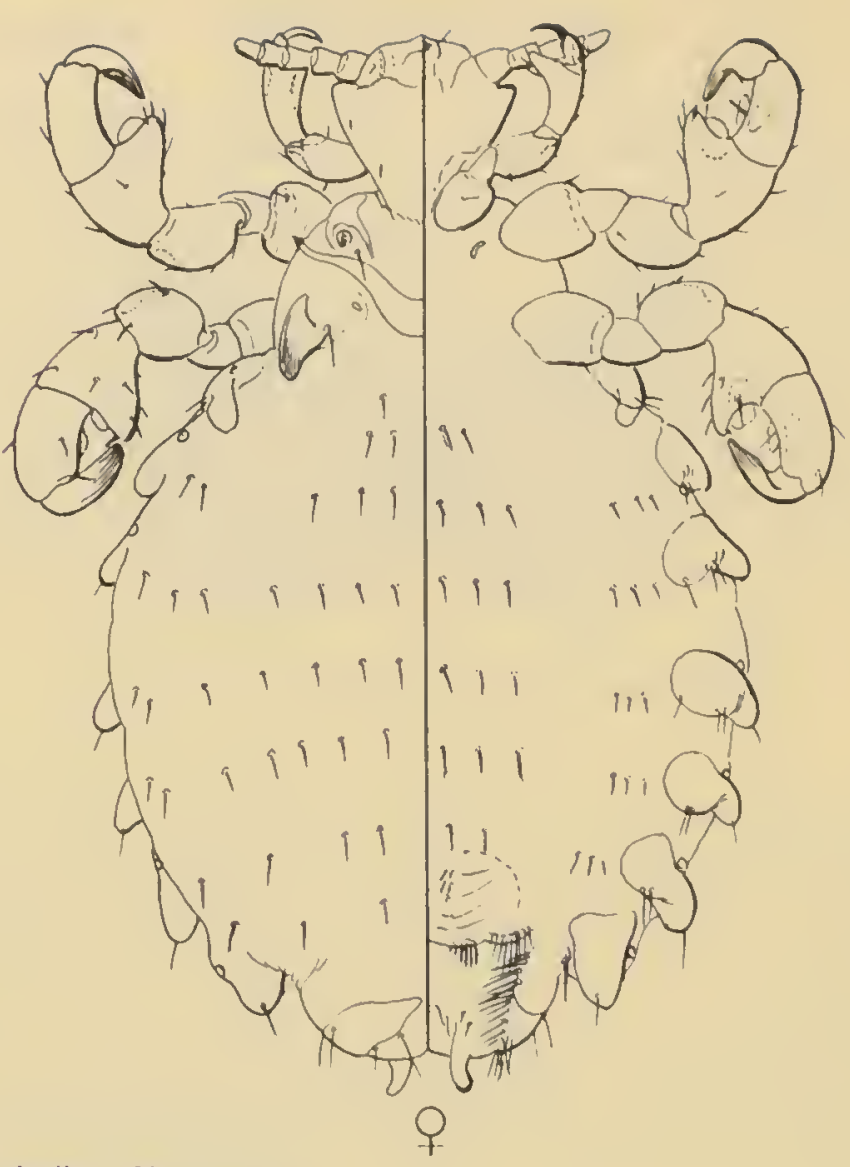

Hybophthirus notophallus (Neumann)

Figure 65

paratergal plates on segments $3-8$. Female in all the species with the abdomen membranous except for the usual ninth tergite and the genital plate; male in two species with a single, very small, tergal plate on each of most of the seiments. Anterior legs small and with slender claw with a short, claw-like process arisin: beside it. Middle and posterior legs enlarged and with stout claw or middle legs larger and stouter than the posterior pair.

NOTES. Four species, one probably invalid, are here referred to this genus. Of these, one-Scipio tripedatus Ferris-is a rather peculiar torm, havin's the middle legs enlarged and with stout claw, but the posterior legs definitely smaller and with slender claw. Fahrenholz has considered this sufficient to justify the erection of a new genus, Bedfordia, but this is not accepted here, as the relationships of the species seem very definitely to be with Scipto. All the species occur upon hosts of the rodent family Echingy idae.

\section{Key to Species of SCIPIO}

One supposed species, longlceps Ewing, is omitted from this key.

1. Yiddle legs larger than posterior legs and with stouter claw.TRIPEDATUS Middle and posterior leis of approximately equal size.............

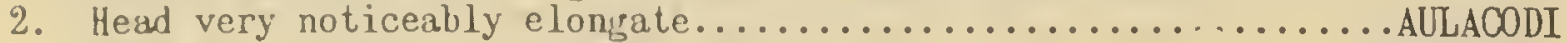

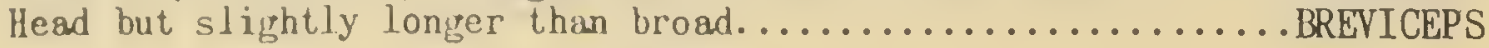




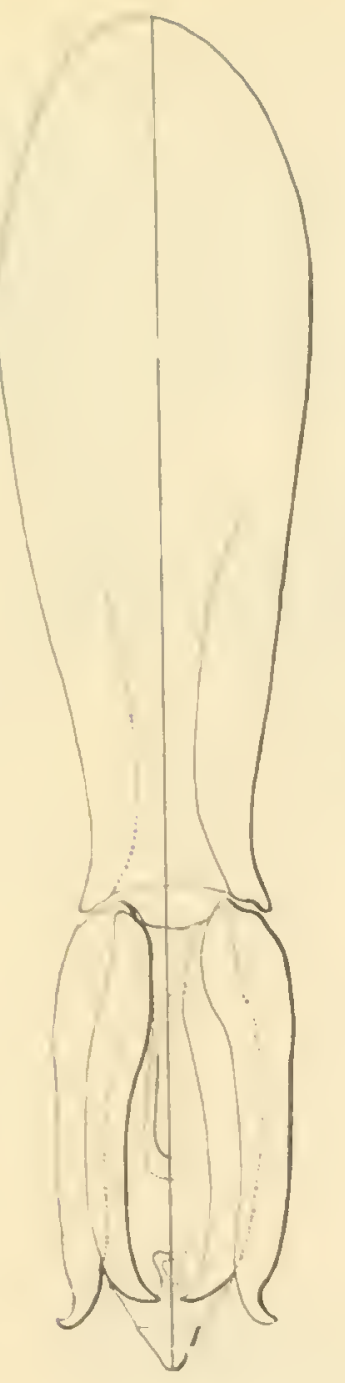

mule enenitulin
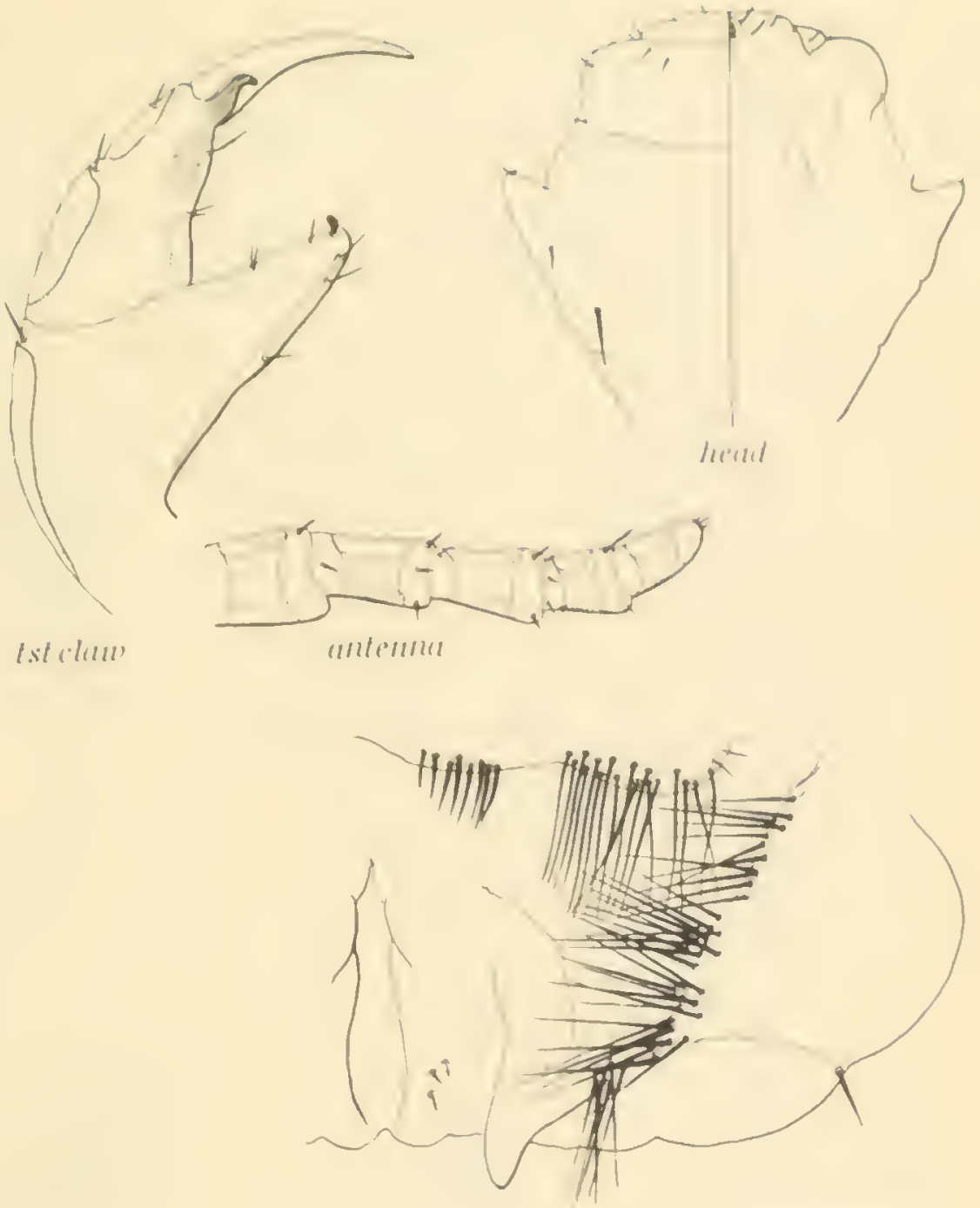

female genitalia

Hybophthirus notophallus (Neumann), details

Figure 66

\section{Scipio aulacodi (heumann) \\ Fipures 6\%. 65}

1911. Haematopinus aulacodi Neumann, Archives de Parasitologie 14:403: firures $5-7$.

1913. Scip io aulacori (Neumann), Cummin;s. bulletin of Entomological hesearch 3:393.

1922. Scipio aulacodi (Neumann). Ferris, Contributions Toward a Monograph of the Suckins Lice. Part 3:170: figures 113-111.

HOSTS AVD DISTRIBITION. Ori cinally described from Thryonom's (=Aulacoius) swinterianus from Diahome?. Africa. Later recorded from Thryonnmys sp.. Mfonipos, Zululand, anil trom Thryonom, suinferionus (aulacolus) varifentus from Rustentury. Transvial District, South Alrica. The hosts are memkers of the rodent tamily Echimidae. 

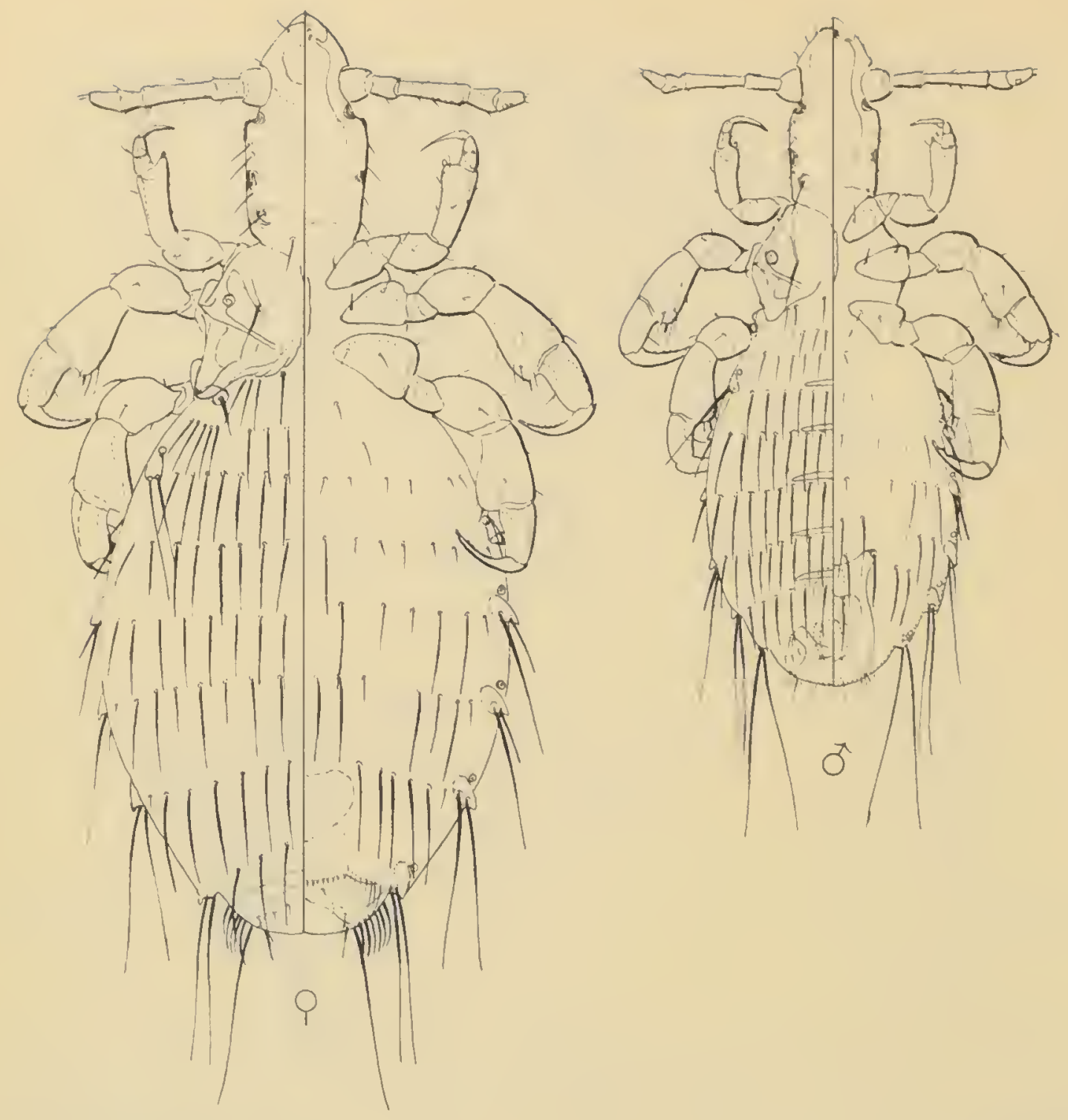

Scipio aulacodi (Neumann)

Figure 67

\section{Scipio breviceps Ferris}

1922. Scipio breviceps Ferris, Contributions Toward a Monorraph of the Sucking Lice, Part 3:173; firures 114, 115, 116.

HOSTS AND DISTRIBUTION. Originally described from Thryonomys sp., Zululand, and later recorded by kedford from Thryonomys swinderianus variegatus. The hosts are members of the rodent family Echimyidac.

Scipio longiceps Ewing

1937. Scipto longiceps Ewinir, Proceedings of the Helmintholorical Society of Washington, paure 81 ; figure 29.

HOSTS AND DISTRIBUTION. From Thryonomys Eregor pusillus from Majiyaclgumvi, British East Africa. The host is a member of the rodent family Ech imy idac.

NOTES. The description and very inadequate accompanying illustration, 

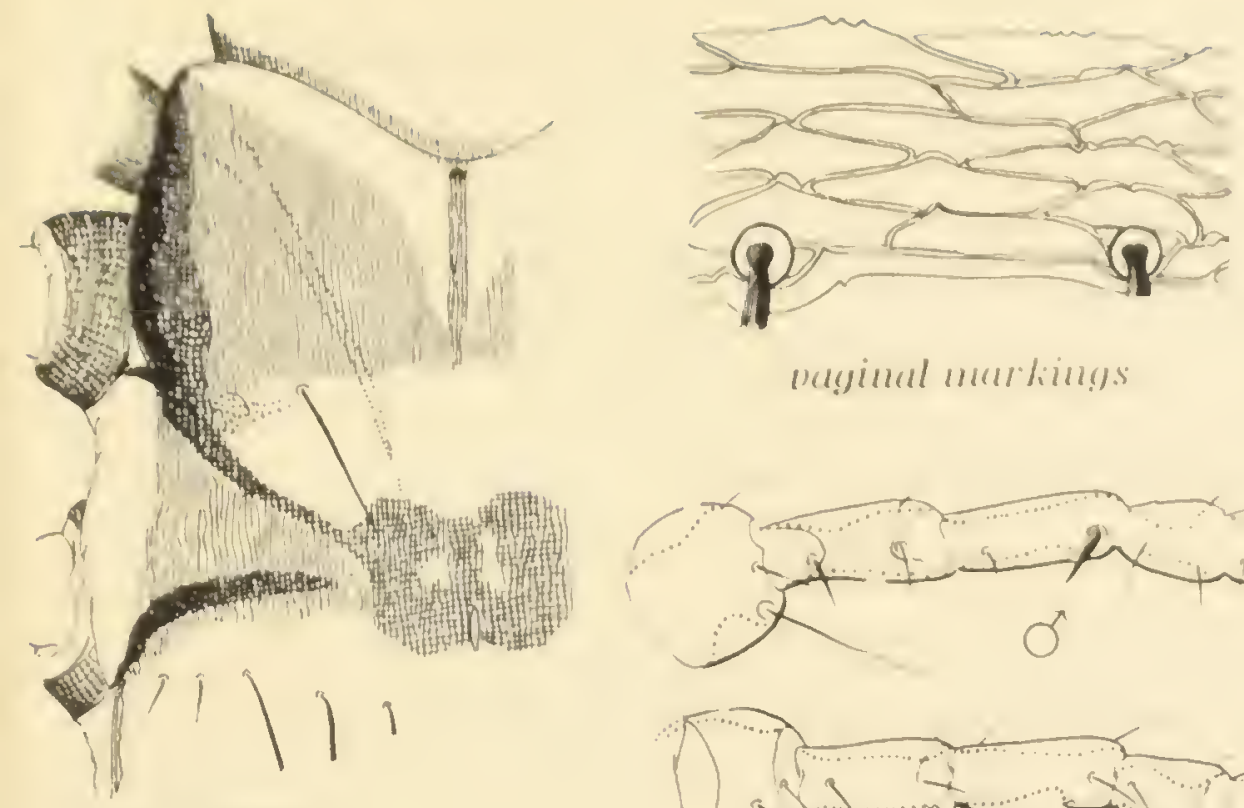

thoratid notam
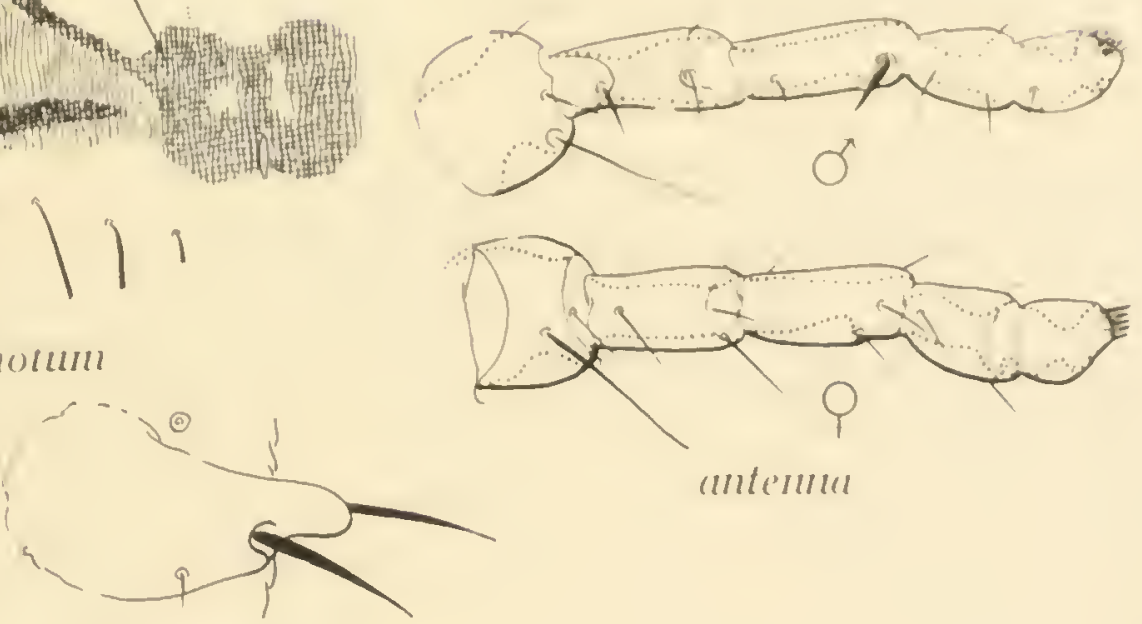

parateryal plate

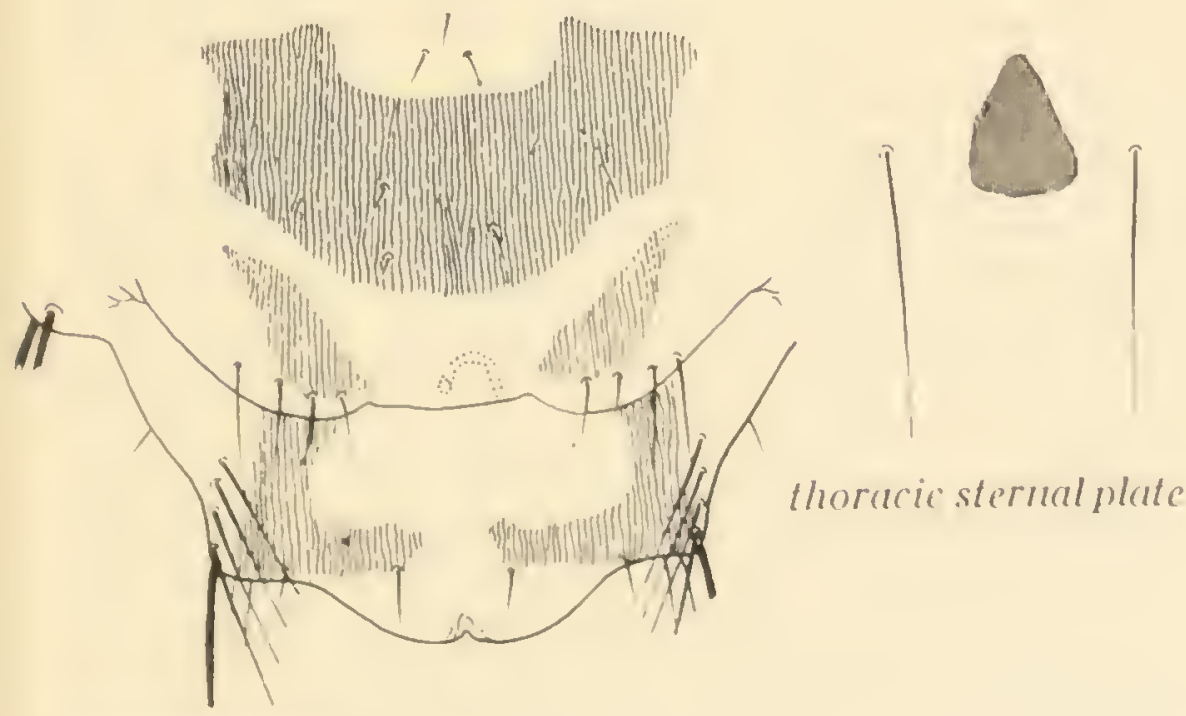

female gemitalia

Istilum

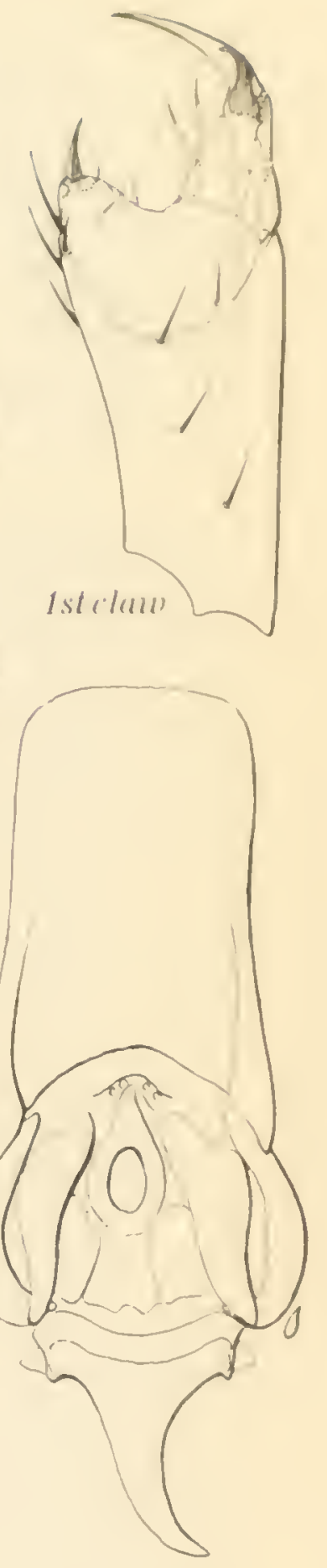

male genitalia 
both based upon the male alone, offer no convincing evidence that this species is distinct from scipio aulacodi.

\section{Scipio tripedatus Ferris}

1932. Scipio tripedatus Ferris, Contributions Toward a Monograph of the Sucking Lice, Part 5:285; figures 173-175.

1936. Bedfordia tripedata (Ferris), Fahrenholz, Zeitschrift für Parasitenkunde 9:55.

HOSTS AND DISTRIBUTION. Type from a "rock rat," one of the species of the renus Petromus (=Petromys) without locality other than South Africa and also recorded from Petromus typicus tropicalis, Windhoek, South Africa, and from Petromus sp. at Khan River, Southwest Africa. The hosts are members of the rodent family Echimyidae.

NOTES. This species has been designated as type of the genus Bedfordia Fahrenholz, but this genus is here rejected.

\section{Subtamily PEDICININAE Enderlein}

1904. Enderlein, Zoologischer Anzeiger 28:136, 138.

DESCRTPTION OF THE SUBFAMILY. Hoplopleuridae in which distinct eyes are present as extermal lenses accompanied in life by pigment spots. Antennae five-segmented, the last three segments at times more or less fused togrether; sexually dimorphic, the males having a small, stout seta on the dorsal side of each of the last three segments. Paratergal plates present on abdominal seyments 4-6 or 5-6 in the form of distinct plates of which at least one of the apical angles is free from the body. Abdomen otherwise membranous except for the usual terminal and genitalic plates. Spiracles present on abdominal serments 3-8. Legs variable in torm, either all more or less similar and relatively slender or the first pair slender and the others larger and stouter. Gonopods of sement eitht of the female always obsolete, their position represented only by a row of setae. Gonopods of segment nine likewise represented merely by a row of setae, the apex of the body never with lobes or processes. Genitalia of the male always with parameres which are fused basally to the base of the aedearus.

0ccurring on 0ld World monkeys of the superfamily Cercopithecoidea.

NOTES. The removal of the genus Pedicinus from the family Pediculidae, with which it has lon been associated, has been decided upon only after much doubt. The morphological community with the Pediculidae has lain only in the presence of distinct eyes, but it is now known that the eyes are present in various forms and they presumably mean nothing more than the retention of a primitive character which was once common to all the lice. In the remainder of its morpholory Pedicinus departs as widely from Pediculus as do most of the other genera. Even the spiracles, which have been insisted upon by Webb as indices to relationship, have not been claimed by him to have any special resemblance to those of the Pediculidae. In other respects the members of the ifenus approach quite closely various f'orms of the Hoplopleuridae and, considering the morphological evidence, there have been but two alternatives apparent. One of these is to name it new family for the genus Pedicinus. The other is to regard this genus as constituting a subfamily of the Hoplopleuridae. The second alternative has been chosen.

The removal of Pedic inus l'om the Pediculidae and its assignment to the Hoplopleuridae will doubtless be viewed with hor'ror by those whose ideas of the relationship of the various genera of lice are at least colored-if not determined-by the relationships of the hosts. The senus Pedicinus, being from a Primate, ought to be related to Pediculus, but the morphological evidence does not support such a relationship. Possibly future workers will see some other solution of the difl'iculty. 
18.4. Penternus liervais, In halekenter's ll istoile naturelle des ineectro itpléress 3: 301.

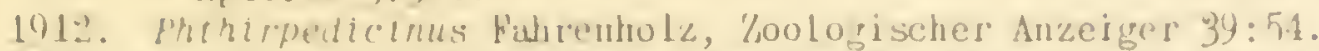

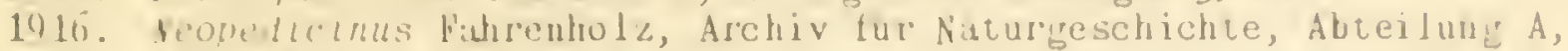
81: 11:7.

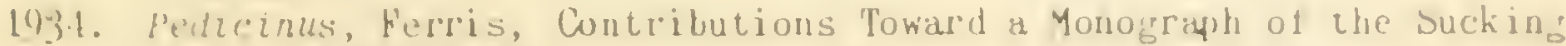
lice, Purt $7: 50:$.

GENERlC TYPE. The question ol just what name the type of this genus shomld bear is upen to a difterence of opinion, the genus havin been based upon a misidentiltied species. The genus was based by Gervais upon specimens which he identilied as being the pediculus eurysaster of Burmeister, but which on the basis of his description and illustrations was clearl! misidentit'ied. The opinion is here held that the generic nune belongs with the species which he actually had betore him and upon which he lased his reneric concept, not with the species which helongs with the name that he mistakenly employed. The question then remains as to what species fervais actually had.

Ferris has maintained that in all probability it was the species later described by Piaret as Pedicinus longiceps. Hopkins, however, has maintained the opinion that longiceps should be regarded as a synonym of the earlier nime Haematopinus obtusus Rudow. This opinion is here reluctantly accepted and the type of the genus Perictnus thus may be given as Baematopinus oblusus kudow.

GEXERIC STNONYMS. Neopedicinus fahrenholz, type reopedicinus patas Fahrenholl; phthirpedicinus Fahrenholz, type Phthirpedicinus micropilosus Fahrenholz, which is here considered to be a synonym of Pedicinus eurygaster (Burme ister).

Cll ARACTERS. With the same characters as the subfamily, of which it is the only included genus.

NOTES. In the opinion of the writer there is no justification for the two genera named by Fahrenholz, although the names are available should future workers desire to enploy them.

\section{key to Species of PEICINUS}

1. Hith but 2 pairs of paratergal plates on the abdomen.........ERYGASTER

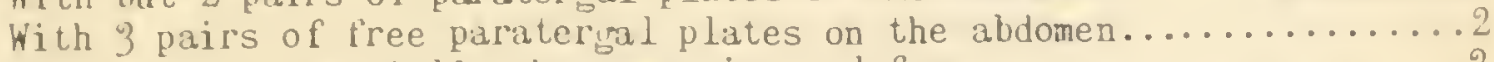

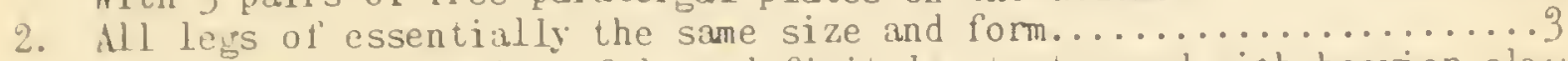
Second and third pairs of legs definitely stouter and with heavier clak

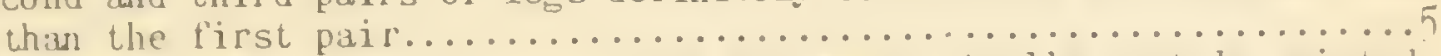

3. Le?s very lon: and slender: penss of the male apically acutely pointed.

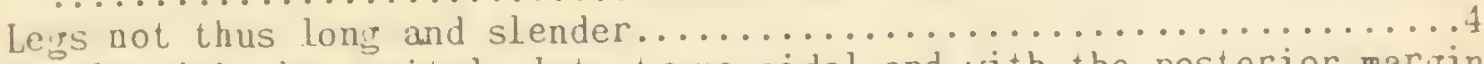

4. Femisle with the genital plate trapezoidal and with the posterior margin deeply emarginate: male with the penis apically flattened and produced into two slight points......................................

Female with the genital plate transversely narrow: male with the penis merely sli htly swollen at the apex........................

5. With sinall parateral sclerotization on sejments $7-3$, in addition to the 3 pairs of paraterisal plates in both male and female......PICTIS

without such sclerotizations in addition to the three pairs of parater-

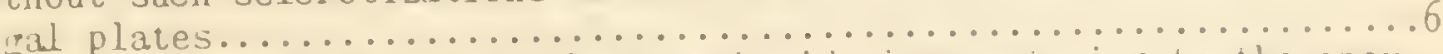

6. Penis of the male with a tooth on each side just anterior to the apex..

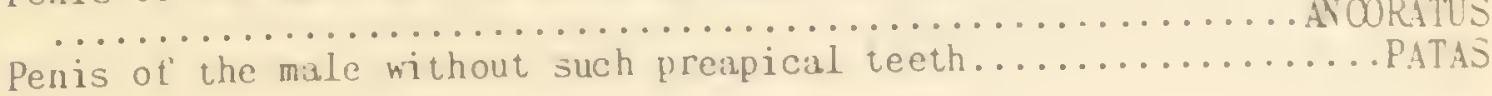


1869. Haematopinus albidus Rudow, Zeilschrift für die gesamten Naturwissellschaften 34:168.

1934. Pedicinus albidus (Rudow), Ferris, Contributions Toward a Monograph of the Sucking Lice, Part 7:511; figure 296.

HOSTS AND DISTRIBUTION. Type from the "barbary ape, "Macaca sylvanus. Ferris has recorded the species from the same host from Morocco and in the London Zoological Garden.

\section{Pedicinus ancoratus Ferris}

1934. Pedicinus ancoratus Ferris, Contributions Toward a Monograph of the Sucking Lice, Part 7:518; figures 299, 300A, F, H, I.

HOSTS AND DISTRIBUTION. Type from Presbytis pullata, Pulo Sebang, East Sumatra. Also recorded from Presbytis cristata and Presbytis germaini from the Yalay an reirion, from Presbytis schistacea from Kashmir, from Presbytis rubicunda from Borneo, doubtfully from Pygathrix priamus from Ceylon.

\section{Pedicinus euryzaster (Burmeister)}

1838. Pediculus euryछaster Burme ister, Genera Insectorum, Rhynchota, Species 21.

1864. Pediculus microps Nitzsch, Giebel, Zeitschrift für die gesamten Naturwissenschaften 23:32.

1880. Pedicinus eurygaster (Burmeister), Piaget, Les Pediculines, page 630. (In part)

1880. Pedicinus longiceps Piaget, Les Pediculines, page 632. (In part)

1880. Pedicinus breviceps Piaget, Les Pediculines, page 632. (In part)

1881. Pedicinus piageti Stroebelt, Jahresbericht der zoologischen Sektion des Westfälischen provincial-Vereins für Wissenschaft und Kunst $9: 82$; Plate 1 , figure 3.

1912. Phthirpedicinus micropilosus Fahrenholz, Zoologischer Anzeiger 39:55. 1932. Phthirpedicinus microps (Nitzsch), Werneck, Annales da Academia Brasiliera de Sciencias 4:163; figures 1-5.

1934. Pedicinus eurygaster (Burmeister), Ferris, Contribulions Toward a Monorraph of the Sucking Lice, Part 7:521; firures 303-305.

HOSTS AND DISTRIBUTION. Recorded by Burmeister from Innuus sinicus, without locality data, presumably froma captive animal. Recorded by Piaret under three specific names from Macacus cynomolgus, Cercopithecus cynomolcus, and Cercopithecus mona; by Stroebelt from Macacus erythraeus; by Mjöberi from Macacus silenus; by Fahrenholz from Macacus rhesus and silenus and from Cercopithecus sp.; and by Ferris from a lons series of hosts of the genera Macacus, Pithecus, and Rhinopithecus; from skins of wild animals from Kashmir, the Malayan area, and the Philippine Islands. The full list will be t'ound in the "Host List" at the end of this volume.

NOTES. The original description griven by Burmeister fortunately mentions specifically the distinguishin character of this species, which is the presence of but two pairs of abdominal parater plates. Since in the lon: series of specimens examined by Ferris no other species havin: this character appears, and since the one species that does appear is frequently cncountered on captive monkeys, the identification may be accepted as practically certain. Ferris was able to examine the specimens of the three species eurysaster, breviceps, and lonsiceps-recorded by Piatret and found all of these to be compounded of' euryeaster and oitusus. It is probable that various published records under the name of eurygaster are erroneous, as was the identification employed hy Gervais when he founded the genus Pedic lnus. 


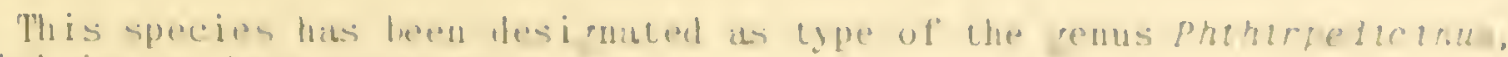
which is not hele atereterl.

P'erlicimus hamialryas Mjóberer

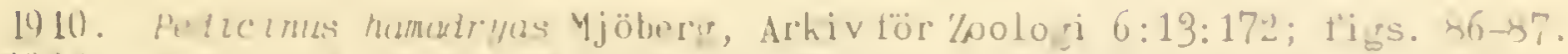

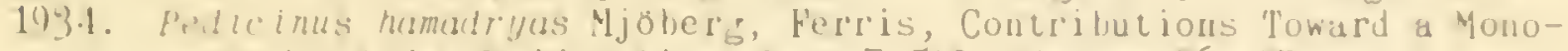

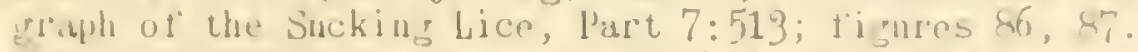

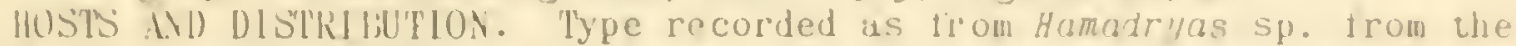
loolorical Garden at flanbur, fermany. Ferris recorded the species. 1 rom is silngle specimen trom "monkey," heuring no indiculion ot place ot ori,jin.

\section{Pedicinus obtusus (Rudow)}

Figures 6y, 70

1844. Pelic inus euryģaster (Burme ister'), Gervis, In Walchenaer"s llistoire nuturelle des insectes aptéres 3:301; Plate 19, t'igrures 1, 1 h. (Misidentification)

1869. Haematopinus obtusus Kutow, Zeitschrift lür die gesumten Niaturwissenschalten 34:169.

1850. Pedic inus eurygaster (Burme ister), Pianget, Les Pediculines, pisge 630. (Part; misidentiticition)

1850. Penic inus longiceps piaret, les Pediculines, paje 632. (In part)

1880. Pedic inus breviceps Piajet, Les Pediculines, pare 632. (In part)

1985. Pedicinus Eraciliceps Piaget, Les Pediculines, Supplenent, pare 141.

1910. Perlicinus paralleliceps Mjöberi, Arkiv för Loologi 6:13:174; 1i.. 85.

1912. Pedicinus rhesi Fahrenholz, Zooloyischer Anzeiger 39:54.

1916. Pedicinus vulgar is Fahrenholz, Archiv für Vaturgeschichte, Abteilung A, 81:11:32.

1917. Pedicinus paralleliceps, variety colobi Fahrenholz, Jahruuch der llambur gischen wissenschattlichen Anstalten 34:2:3, 8.

1934. Peticinus longiceps Piaret, Ferris, Contributions Toward a Monopraph of the Suckin: Lice, Part 7:505: timures 293-2960.

1946. Pedicinus obtusus (Rudow), Hopkins, Annals and Magazine of Natural History (Series 11) 12:564.

HOSTS WD DISTRIBUTION. The types of Haematopinus obtusus Rudow were said to be trom semnopithecus maurus, without indication of locality. The lectotype selected from among the material of Piaset is from Semnopithecus pruinosus. The types of pedicinus graciliceps piaget were recorded merely as from monkey. The types of Pedicinus paralleliceps Mjober: were said to be from Macacus rhesus. Peric inus vulgar is Fahrenholz was named, on the hasis of the literature only, for the specimens recorded by Piaget from: Innuus nemestrinus, these here bein: considered actually to represent Piaret's Pericinus lonsiceps, and therefore heing obtusus. All of the specimens noted ahove were apparently taken from captive animals.

The list of hosts, other than as recorded above, is very lon and is iven in full with all available corrections in the host list at the end of this volume. Some ot these records are of specimens taken trom captive animals, but others are from wild animals or their skins, and the indications are that the species may occur on almost any Cercopithecoid monkey. It is apparently the species which is most likely to be found on captive animals.

VOTES. Ferris was able to examine the types of the four supposed species recorded by piajet, of which three were described by Piajet as nek. He reports (1934) that there were but two actual species recorded under tour names and that in some of the preparations both were included on the same slides. He selected the lectotypes for lons iceps as indicated above.

In the same work Ferris placed Acematopinus obtusus Rndow as unrecognizable other than supposedly as a species of Pedicinus, althou th he recorded 


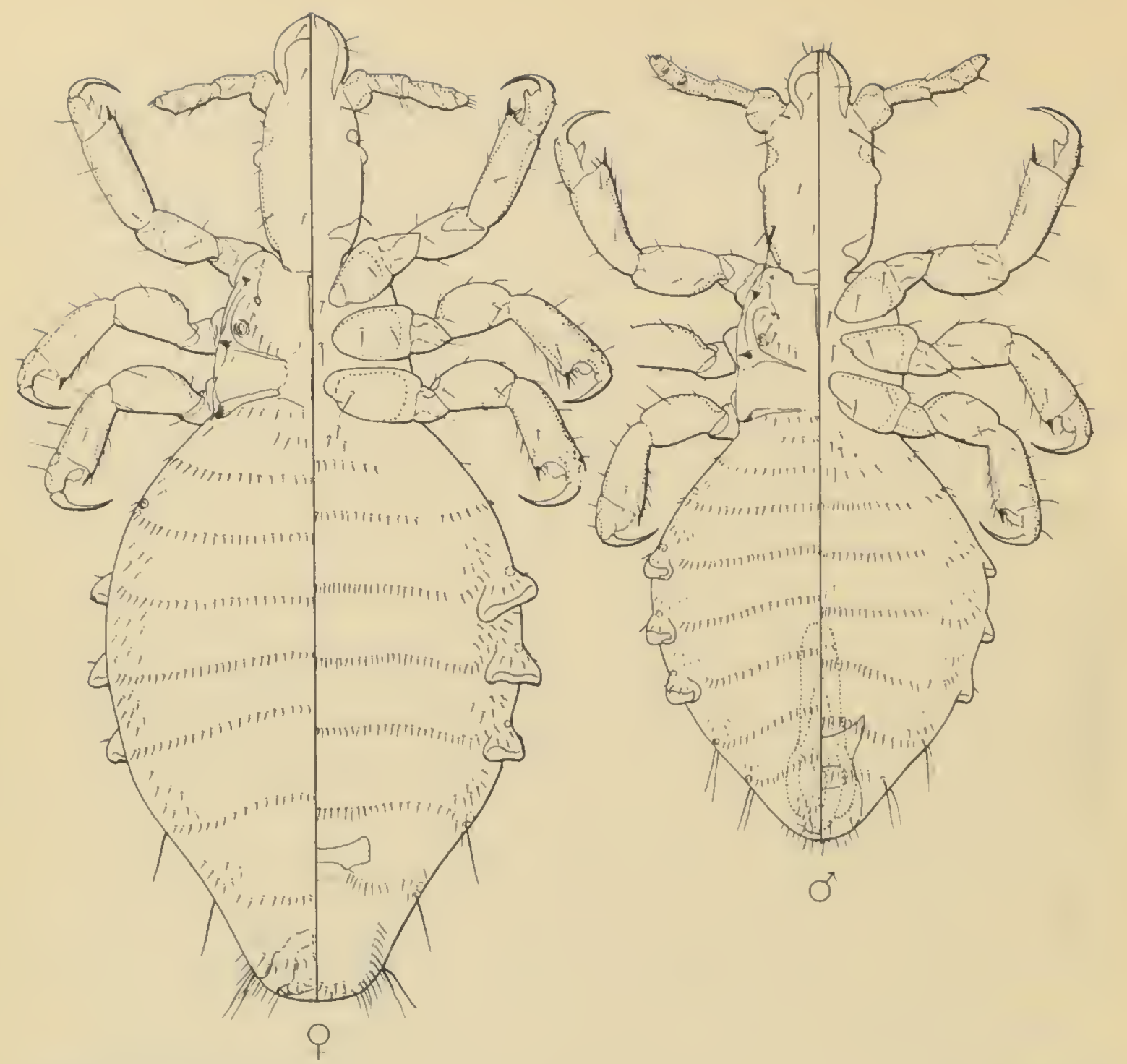

Pedicinus obtusus (Rudow)

Figure 69

the examination of specimens from the Hamburg Museum which might conceivably contain Rudow's types. Hopkins (1946) has alopted a different point of view, advocating that a neotype be selected from among the specimens in the Hamburg Muscum. By doing so no name would be left as belonging to an unrecomizable species and as obtusus antedates longiceps the latter would become a synonym.

We need not go into all the arguments concernin: this matter. In principle the writer is opposed to the replacement of any name, the application of which is certain, by any name which is at all uncertain or clouded. Nor is the opinion here held that every name which has heen proposed and of which the type is lost or apparently lost should have a neotype named for it. To adopt such a procedure is to open endless vistas for abuse and nomenclatorial instahility. In this particular case, however, there is some legritimate argument for following the suggestion made by Hopkins and for selectini a ncotype from amoni the specimens in the Hamburg Museum, thus getting rid of an unat tached name that has been cluttering the literature for more than seventy-five years. The point is here somewhat reluctantly conceded and the name obtusus is employed. 
1916. Neopedicinus patas Fahrenholz, Archiv für Naturgeschichte, Abteilung A, 81:11:6; Plate f, figure 2; text figure 7 .

1934. Pedicinus patas (Fahrenholz), Ferris, Contributions Toward a Monograph of the Sucking Lice, Part 7:515; figure 300G.

HOSTS AND DISTRIBUTION. Type recorded as from Cercopithecus patas without indication of locality. Recorded by Ferris from Erythrocebus whitei, Lasiopyga kolbi, and Las iopyga albogular is from East Africa.

\section{Pedicinus pictus Ferris}

1934. Pedicinus pictus Ferris, Contributions Toward a Monograph of the Sucking Lice, Part 7:518; figures 301, 302.

HOSTS AND DISTRIBUTION. Type from Colobus caudatus from Mount Kenya, British East Africa. Also recorded from Pygathrix entellus from the London Zoological Garden.

\section{Subfamily POLYPLACINAE Ferris, new subfamily}

DESCRIPTION OF THE SUBFAMILY. Hoplopleuridae in which the antennae are always five-segmented (with the exception of one poorly described species in which they are said to be three-segmented) and are very commonly sexually dimorphic, the male having the apical, preaxial angle of sement three more or less prolonged and terminating in a sclerotized point or bearing one or two short, stout, retrorse setae dorsally. Anterior legs (except in one species) small and with slender claw; middle legs larger than the first and with stouter claw; third less (with the exception of a few species) distinctly larger than the second and with stouter claw, but not flattened. Paratergal plates always present on at least one abdominal segment (with the exception of one species in which they are entirely lacking) and always with at least one of the posterior angles formin a point which is free from the body; never forming the apices of spiracle-bearing abdominal tubercles; never overlapping. Abdomen most commonly with well-developed teriral and sternal plates; althoush in a few cases without such plates other than on the terminal and genitalic segments. Sternal plate of segment two never extended laterally to articulate with the corresponding paratergites. Thoracic sternal plate well developed, except in a few species in which it is lacking.

NOTES. This subfamily is a bit difficult to define definitely because of the existence of a f'ew species which in one respect or another depart from the normal form. Thus the genus Lemurphthirus, with one included species, has paratergal plates only on the second abdominal segment, although in other respects it is a typical member of the group. One species assifned to the genus Haemodipsus entirely lacks paratergites and other abdominal plates, although an apparently closely related species has paratergal plates, even though they are very small. In a few species the sternal plate of the thorax is lacking, although in most species it is well developed.

These departures from the normal f'orm, however, are limited to a few species and do not disturb the generial homoreneity of the group.

The hosts of the sulfamilyare found amonir various groups of the rodents, although a lew occur on insectivores and the Layomorpha, and one doubtful member of the isoup occurs even upon an unimate.

Sixteen fenerit are here recounized as belonging to the subfamily. 
1. Ancenmize desoribed us 3-sonnented; uscribed to a lemur in Borneo.......

Anternum detinitely 5-sennented.

2. hith no lrace of purateral plates on any abdominal sement; trom turu-

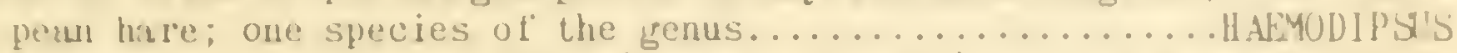

hith parater ral plates delinitely present out least one se guent of the

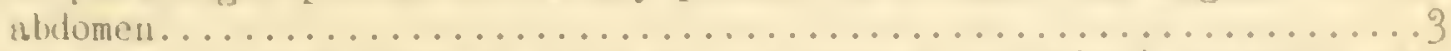

3. Paraterial plates present only on the second abdominal segnent; us-

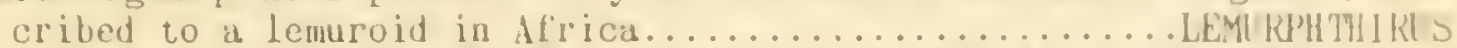

Paratergal plates present on more than the second abdominal serment...4

4. With the parateriral plates present only on abdominal se nuents 4-6; us-

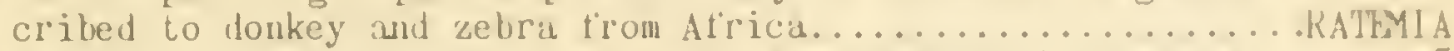

Paratergal plates present on at least tour ablominal segments.......5

5. Paratergal plates of abdominal se ments $2-7$ consisting merely of rarow, lontritudinal, sclerotized strips; ascribed to a South American rodent

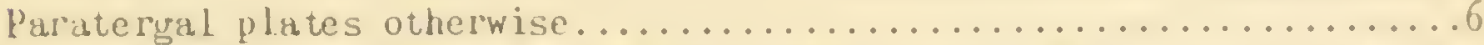

6. Paratergal plates of the abdominal segments very sinall, consisting of is single point which projects from a slight base; ascribed to hares and

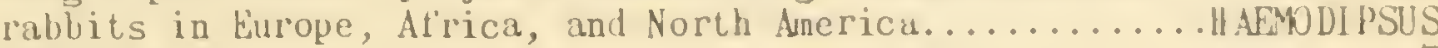

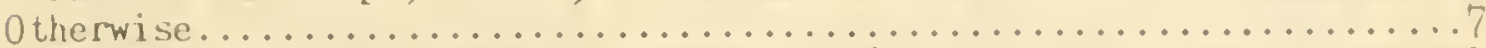

7. Paraterigal plates of abdominal segments $3-6$ each with the basal, ventral an ple produced, the angle bearing 2 slender setae; ascribed to a

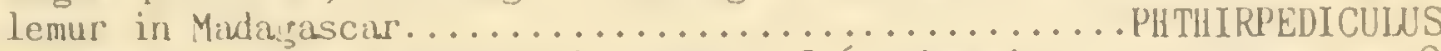

Parater pal plates of atdominal segments $3-6$ otherwise.............

8. Both sexes with one of the transverse rows of setae on the abdominal terites and steruites with setae which are flattened and leaf-like or cune i form; ascribed to a South American rodent........CTENOPIITHIRUS

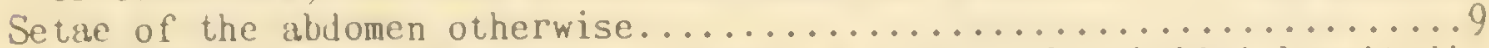

9. Paraterital plates of abdominal segment 2 definitely divided longitudinally into 2 plates, one of which lies on the dorsum and one on the venter, the ventral portion with a l'lat, raised, apically free point; occurring on the New horld rodent family Heteromyidae... FAHRENHOLZIA

Paratergal plates of segment 2 of the abdomen with at the most slight evidence of being thus divided, the ventral part never independent of

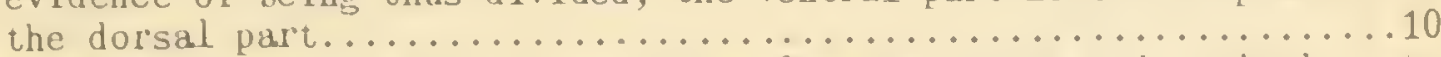

10. Abdominal seuments with not more than 2 median setae and a single seta on each side near the lateral margin on any segment, either dorsally or ventrally; occurring on the South American genus Lagidium.......

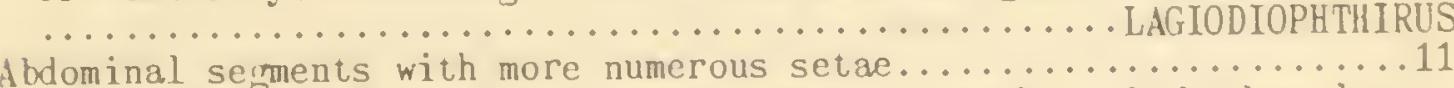

11. Antennae with both basal and distal anterior anjles of the basal segment prolonged into a distant hook; knowin from Anathana in India....

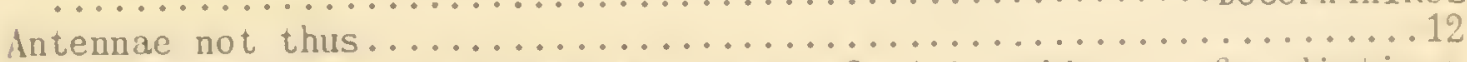

12. Parater ral plates of abdominal segment 2 with evidence of a distinct

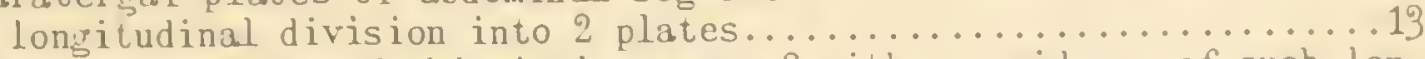

Parater plat plates of aldominal se gment 2 with no evidence of such lon-

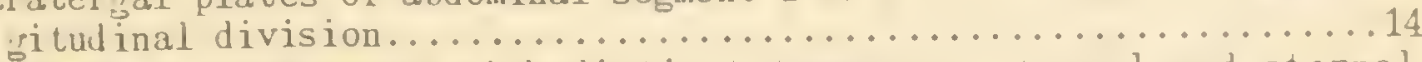

13. Abdomen in both sexes with distinct transverse tergal and sternal

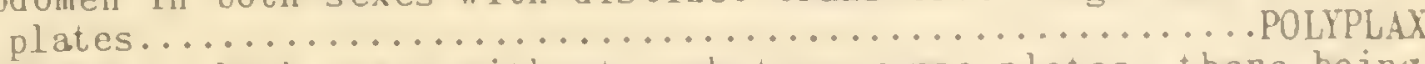

Abdomen in both sexes without such transverse plates, there being merely a small, tubercle-like. sclerotized area about the base of each seta: occurring on Atrican rodents of the tenus Cricetom?s....

14. Paratergal plates present on a variable number of abdominal se ments 
but never on segments $7-8 \ldots \ldots \ldots \ldots \ldots \ldots \ldots \ldots$ EULLNOGNATHUS

Paratergal plates present on abdominal segments $2-8 \ldots \ldots \ldots \ldots \ldots \ldots 15$

15. Second plate of the second abdominal tergite in the male always at

least slightly modified, havini its posterior border emarinate and with a group of setae set in an aster-like fashion at each end of this emargination; if the ter ite is not sclerotized some modification of the row of setae still appears; occurring chiefly on the

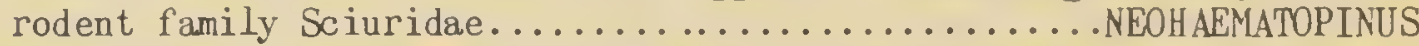
Second plate of the second abdominal tergite in the male not thus modified; occurring on the Murid genus Acomys in Africa..........SYMOCA

Genus CTENOPHTHIRUS Ferris

1922. Ctenophthirus Ferris, Contributions Toward a Monograph of the Sucking Lice, Part 3:153.

GENERIC TYPE. Ctenophthtrus cercomydis Ferris, at present the only known species.

CHARACTERS. Hoplopleuridae of the subfamily Polyplacinae in which the antennae are five-segmented and not sexually dimorphic. Paratergal plates present on abdominal segments 2-8; those of segment two very small; those of segments 3-6 narrow and with each posterior angle produced into a pronounced point. Female with a distinct tergal plate on abdominal segment one, two tergal plates which are more or less fused together on segment two and two tergal plates on segment eight, the remaining segments with three tergal plates. The posteriormost plate on segments 3-8 bears a single row of flattened, almost foliate setae. On the ventral side the arrangement of the sternal plates is similar except that segment three bears three plates which are fused together. Male with two terial plates on segment three, these more or less fused, and two sternal plates on se:ments 3-7, the posteriormost plate with a row of mingled, simple, and flattened setae. Spiracles present on segments 3-8. Sternal plate of the thorax present.

Ctenophthirus cercomydis Ferris Figures 71, 72

1922. Ctenophthirus cercomydis Ferris, Contributions Toward a Monograph of the Sucking Lice, Part 3:153; figures 100-101.

HOSTS AND DISTRIBUTION. Known only from the original record, from Cercomys cunicularis (recorded as fosteri) from Sapucay, Paraguay. The host belongs to the rodent family Echimyidae.

\section{Genus DOCOPHTHIRUS Waterston}

1923. Docophthirus Haterston, Bulletin of Fntomological Research 14:101. 1932. Docophthirus, Ferris, Contributions Toward a Monograph of the Sucking Lice, Part 5:303.

GENERIC TYPE. Docophthirus acinetus Waterston, the only known species.

CHARACTERS. Polyplacinae with f'ive-segmented antennae which are not sexually dimorphic; with the first seyment having the anterior maryin produced basally and ventrally into sclerotized hooks. Second and third le gs both enlariged and practically equal in size. Parater ral plates of the abdomen present on at least segments $2-6$, those of sement three not lonitudinally divided, those of all the semments with each posterior angle produced into a distinct point. Alulomen of the temale with two rows of tergal setac on segments 3-7, and one row on seiments one and eirht, with a small tergal plate present in connection with the anteriormost row of setae on segments 2-7; with two rows of setac on the sternites of segments 2-7, but with a distinct plate present only on segment two. Male with a single row 

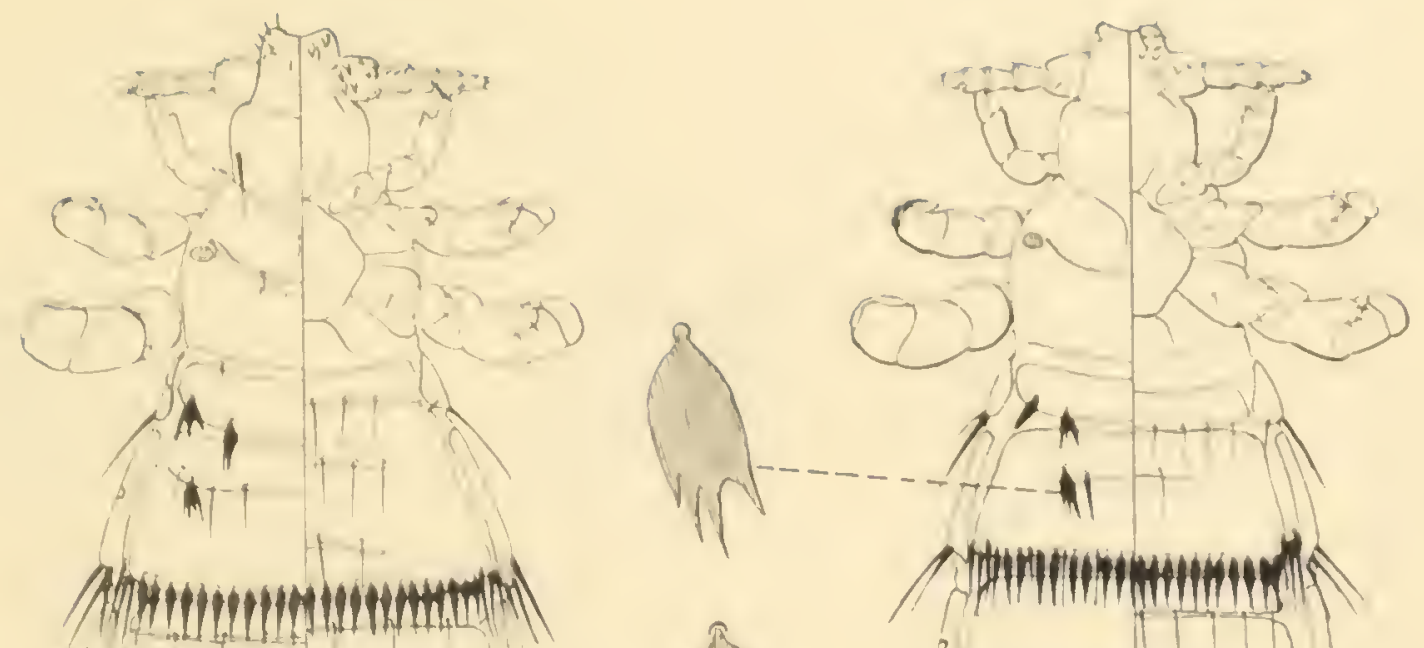

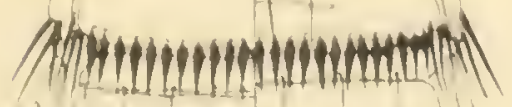

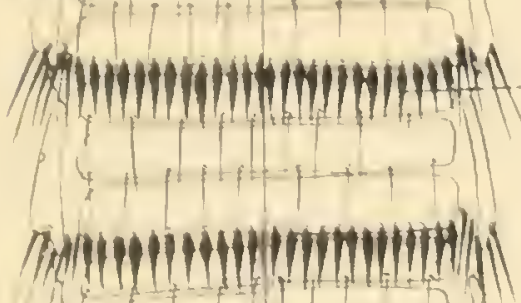
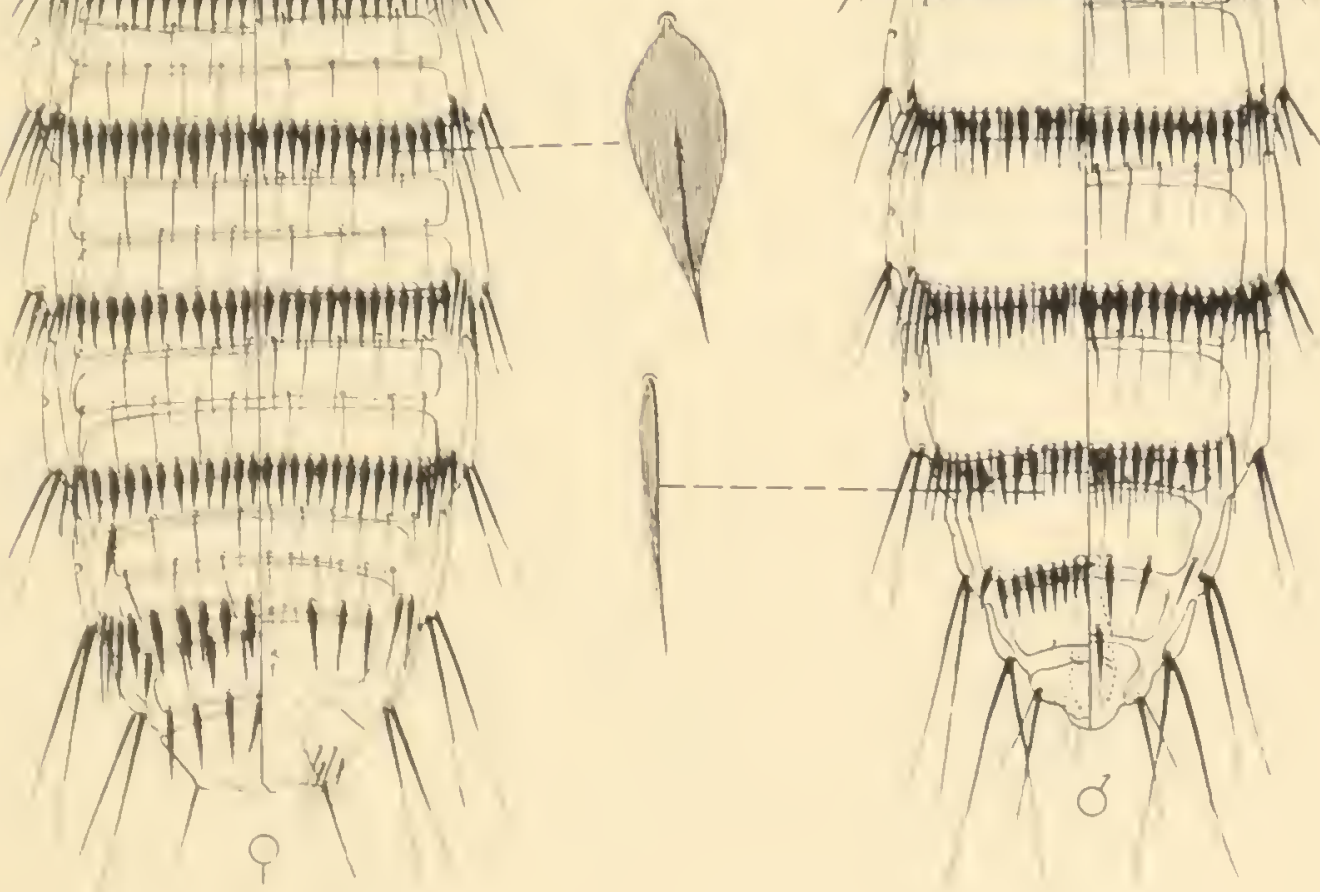

Ctenophthirus cercomydis Ferris

Figure 71

of terpal setae on all tergites except segment two, which has two rows, with one row and one plate on segments one and $4-7$ and tro plates on segment two; ventrally with but one plate and one row of setae on segment two and with but one row of setae on any other segment and no plates except on serments seven and eight. Spiracles present on segments 2-8. Thoracic sternal plate not developed.

NOTES. None of the known material is in very good condition and possibly the above description will require some modification. 

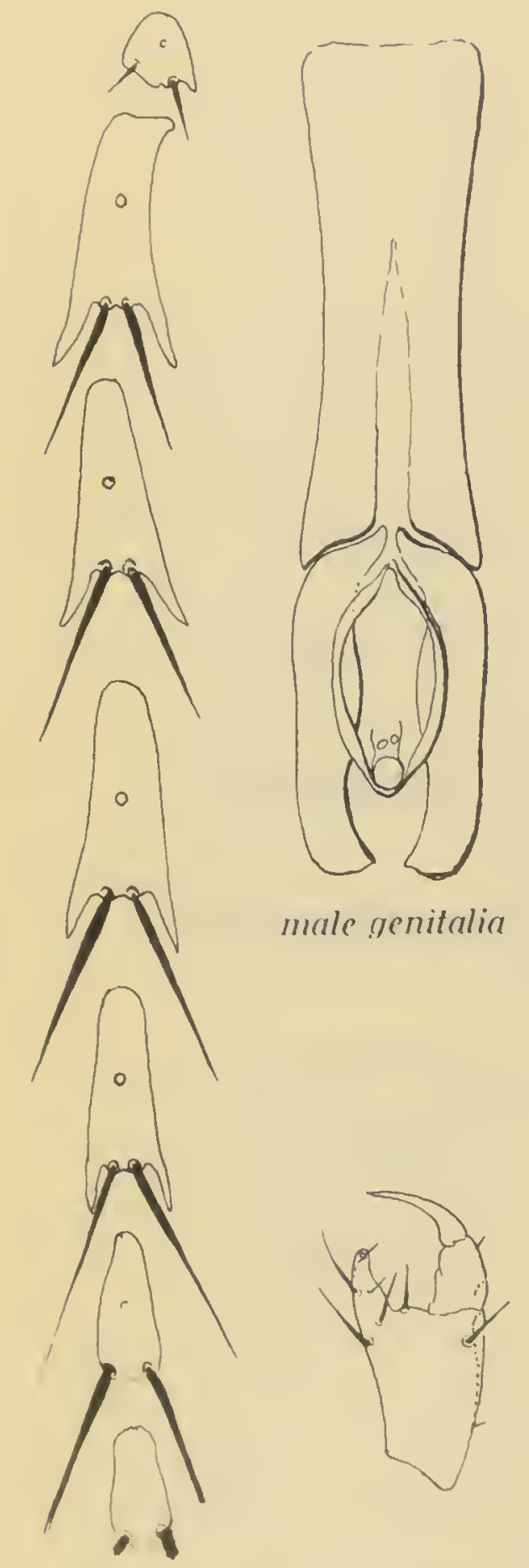

paratergal plates lains
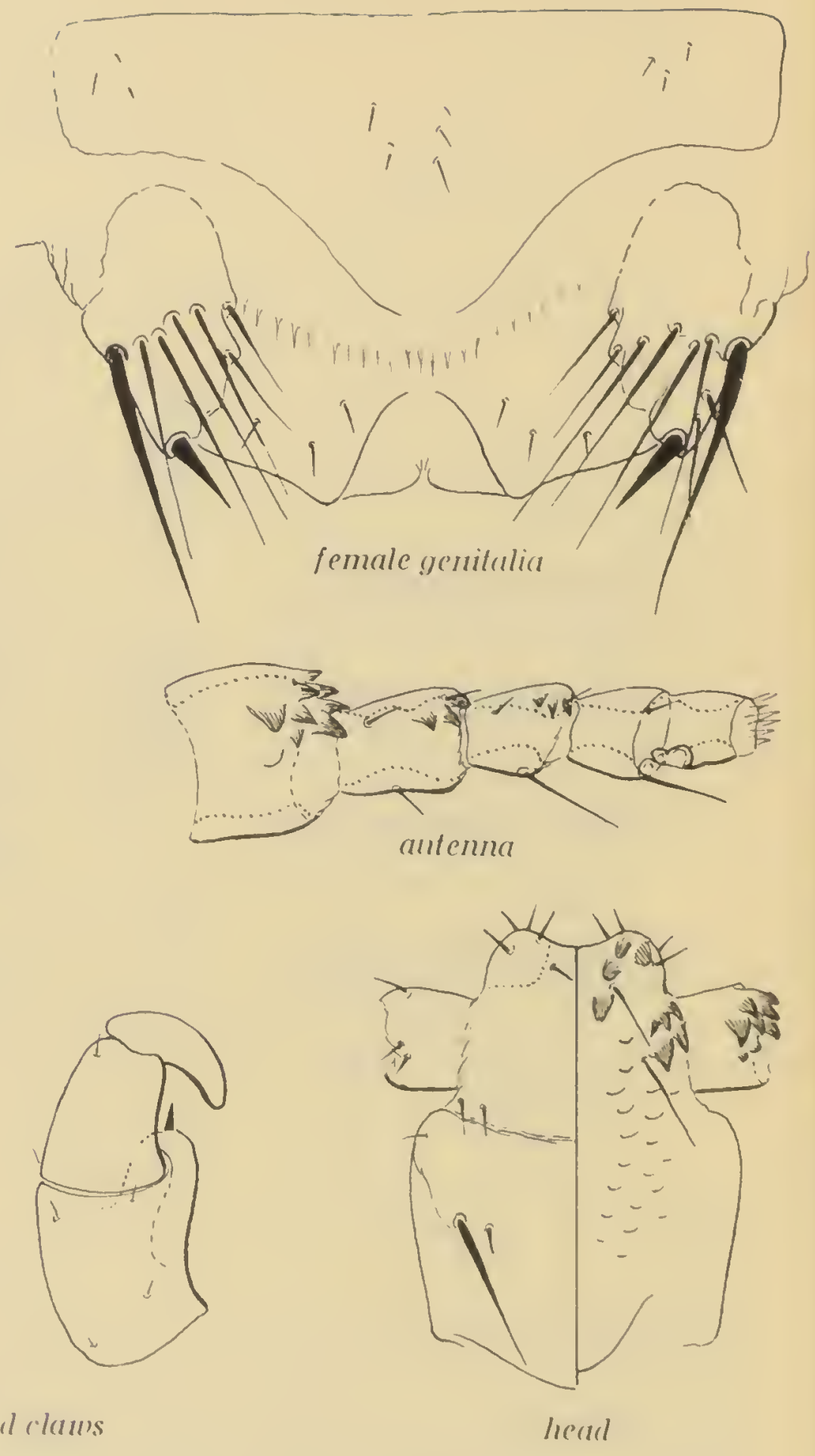

Ctenophthirus cercomydis Ferris, details

Figure 72 

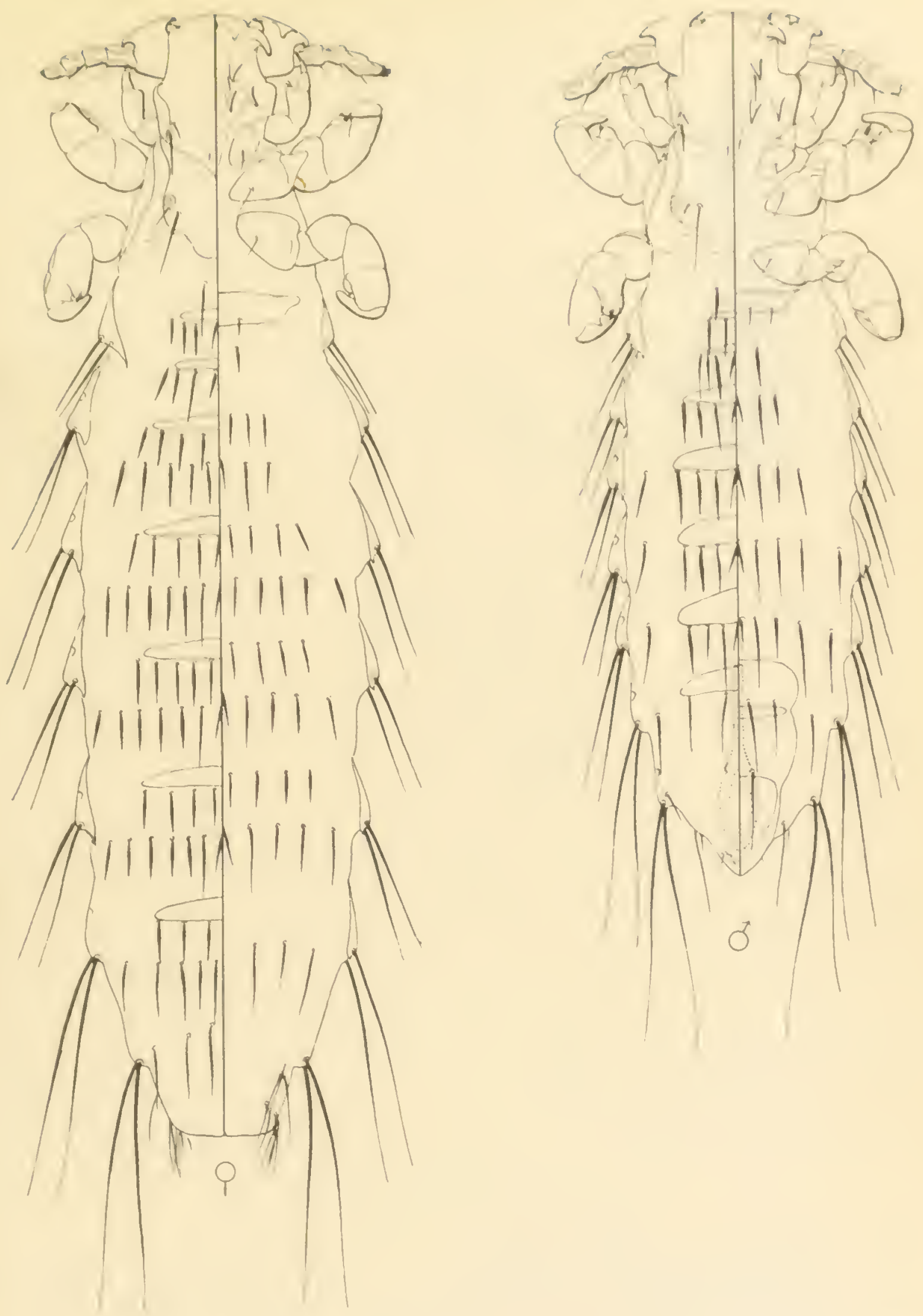

Docophthırus acinetus Waterston

Figure 73 


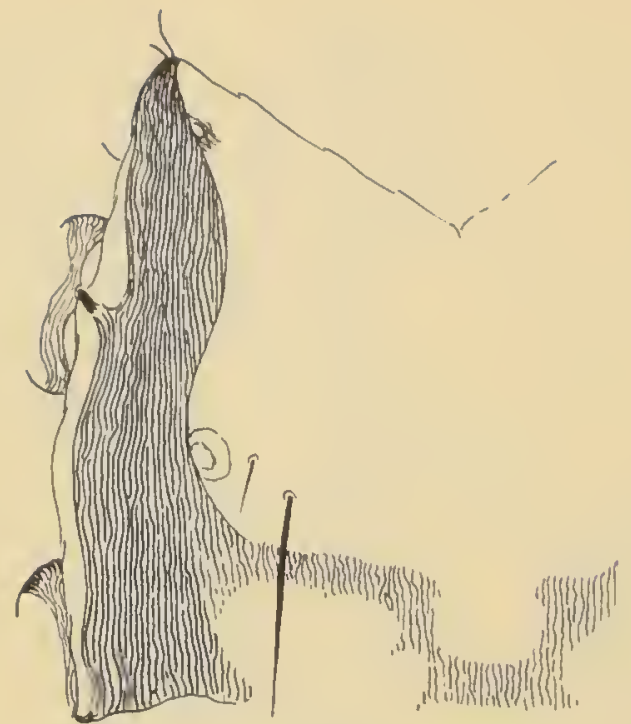

thoracic notum
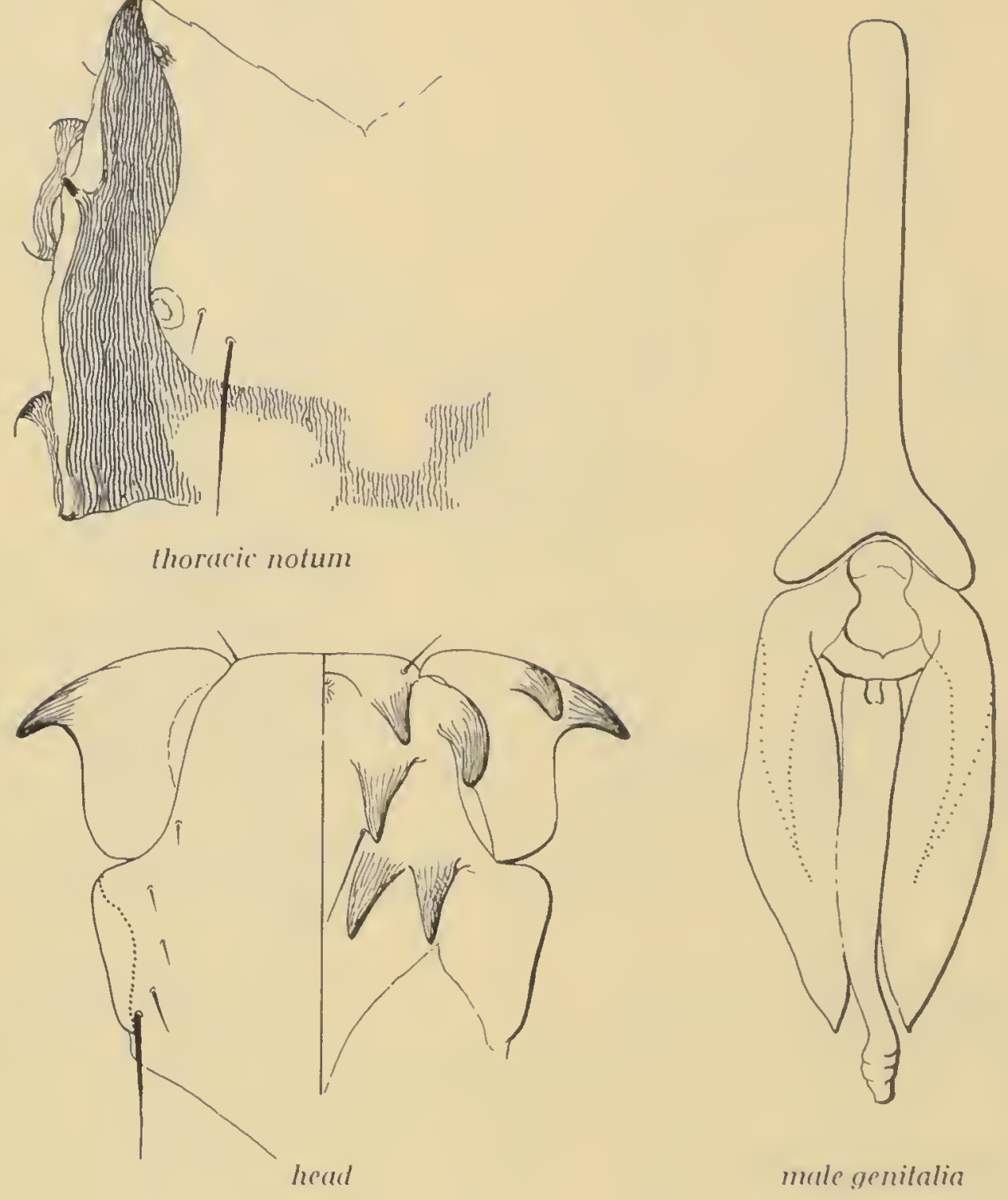

Docophthırus acinetus Waterston, details

Figure 74

\section{Docophthirus acinetus Waterston \\ Figures 73, 74}

1923. Docophthirus ac inetus Waterston, Bulletin of Entomological Research $14: 101$; figures $21 \mathrm{a}$ and $21 \mathrm{~b}$.

1932. Docophthirus acinetus Waterston, Ferris, Contributions Toward a Monourraph of the Sucking Lice, Part 5:304; figures 185, 186.

HOSTS AND DISTRIBUTION. Known only f'rom the origrinal record in which it was ascribed to Anathana ell lot 1 , which belongs to the family Tupaiidae,
the tree shrews. 


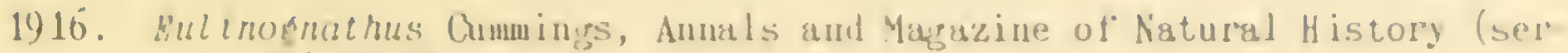
ies 8) $17: 90$.

1959). Bathyerglcola bedford, Anmual heport of the Director of Veterinury S'rvices, Union of South Africa 15:505.

1930. Bathyerstcols, rerris, Contributions Toward a Monograph ot the buck in: lice, Pall 5:311.

1932. Eulinognathus, Ferris, Contributions Toward a Monograph of the Suckins lice, Part 5:318.

SYNONYM. Rathyersicola Bedtord.

GENERIC TYPE. Bul inognathus denticulatus Cummings, by orjginal designation. The type of Bathyersicola is Bathyergicola hllli bedtord, by original designation.

CIARACTERS. Polyplaciuge with t'ive-segmented antennae which iste not sexually dimorphic. Anterior leis smill, with slender claw. Middle legs larger than the f'irst, with stouter claw and at times as large as the posterior lers. Paratergal plates present on abdoninal segments $2-6$ at least, except that they are lacking on sement two in one species. Audomen alwas membrunous throurhout except for the ninth tergite and the usual genital plates. Abdominal segments with either one or tro transverse rows of setwe on most of' the segments, both dorsally and veutrally, in the lemale and always with but one row in the male. Spiracles present on segnents 3-7 or 3-8.

NOTES. A most unsatistiatory situation exists in regard to this genus. Ferris (1932) recornized Eul inosnothus and Bathyer althourh it was indicated that neither of these genera was entirely homogeneous or sharply defined. A re-study of the question in connection with the present work does not support the separation there accepted. In 1932 , it was indicated that the two renera could be separated by the number of abdominal spiracles, Eulinognathus having spiracles only on segments 3-7 while Bathyergicola has them also on segment eight. But this seems to separate species which are actually more or less alike on the basis of other character's. A separation on the basis of the rows of setae on the abdominal segments of the temale will not permit a separation of the males. A separation of one species called Bathyerkicola laurensis Bedford, on the basis of the absence of paratergal plates on sement two of the abdomen would remove this suecies l'rom association with others which resemble it in other respects. A separation of the species which have tubercles on the head brings torether certain torms which seem to be connected by host associations, but is not supported by other characters. A separation on the basis of the presence or absence of the thoracic sternal plate leads to an evidently ariificial grouping. Any arrangement that may be made seems to receive no support from host or geographical distribution, yet all the species seem to share a general similarity. The solution of naming several genera suggests itself but seems to offer no especially sensible arrangement, although this may be the eventual solution.

This solution is in part here accepted by recognizing the two genera Lugidiophthirus and Galeophthirus which have previously been named for species referred to Eulinosnathus.

\section{Key to Species of EULINOGNATHUS}

1. Head with at least 1-2 stout, sclerotized, hook-like processes or tubercles on the ventral side near the bases of the antenna...........

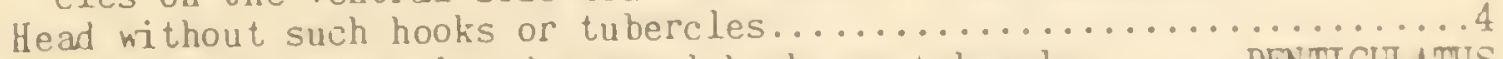

2. Head with both dorsal and ventral hooks or tubercles.......DENTICULATUS Head with hooks or tubercles only on the ventral side.............. 3. Ventral side of first antennal segment with hooks...........ACULEATIS 
Ventral side of first antennal segment without such hooks..... BIUNCATUS

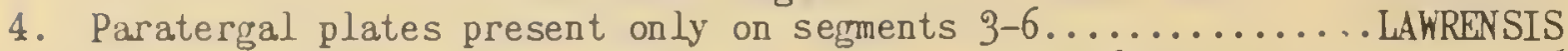

Paratergal plates present on at least segments $2-6 \ldots \ldots \ldots \ldots \ldots \ldots . \ldots$

5. Abdominal segment 7 with distinct, apically free paratergal plates....

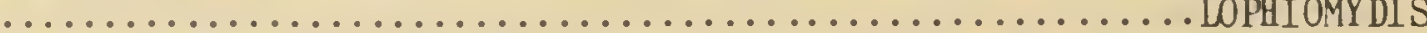

Abdominal segment 7 without distinct, apically free paratergal plates ó

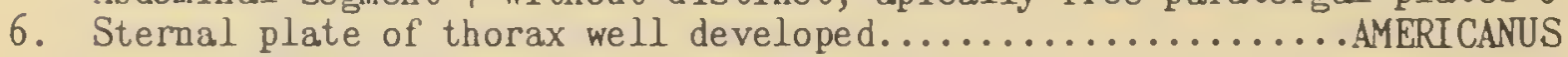

Sternal plate of thorax not at all developed......................LI

\section{Eulinognathus aculeatus (Neumann)}

1912. Baematopinus aculeatus Neumann, Bulletin de la Société Zoologique de France 37:143; figures $5,6$.

1916. Eulinognathus aculeatus (Neumann), Ferris, Proceedings of the California Academy of Sciences (Series 4) 6:168.

1932. Eultnognathus aculeatus (Neumann), Ferris, Contributions Toward a Monograph of the Sucking Lice, Part 5:321; figures 196, 197.

HOSTS AND DISTRIBUTION. Originally recorded from "Dipus sp., " at Djerba, Tunis. According to Ellerman's list this is probably a species of Jaculus. Recorded by Ferris from Allactaga mongolica which, according to Ellerman, is Allactaga siberica. These hosts are members of the family Dipodidae.

NOTES. There is a possibility of a misidentification in the record by Ferris, since the types of the species were not seen.

\section{Eulinognathus americanus Ewing}

1923. Eulinognathus americanus Ewing, Journal of the Washington Academy of Sciences 13:148.

1932. Eul inognathus americanus Ewing, Ferris, Contributions Toward a Monograph of the Sucking lice, Part 5:325; figure 200.

HOSTS AND DISTRIBUTION. Type from Ctenomys brastliensis on the Salade River, Paraguay. Recorded by Ferris from Ctenomys sertcus from the Upper Rio Chico, Paraguay. The hosts belong to the family Echimyidae.

NOTES. The curiously modified setae on the paratergal plates of segments 3-5 offer a basis for the generic separation of this species if this should prove desirable. It is at present known only from the female.

\section{Eulinognathus biuncatus Ferris}

1932. Eulinoछnathus biuncatus Ferris, Contributions Toward a Monograph of the Sucking Lice, Part 5:324; figures 198, 199.

HOSTS AND DISTRIBUTION. From Dipodtpus sowerbyi in Shensi, China. According to Ellender this is Dipus sagitta.

\section{Eulinognathus denticulatus Cummings Figures 75,76}

1916. Eulinognathus denticulatus Cummings, Annals and Magazine of Natural History (Series 8) 17:90; figure.

1932. Bultnognathus dentlculatus Cummings, Ferris, Contributions Toward a Monograph of the Sucking Lice, Part 5:319; figures 194-195.

1940. Eul inognathus denticulatus surdastert Werneck, Revistade Entomologia $11: 724$; figure.

HOSTS AND DISTRIBUTION. Recorded by Cummings from Pedetes caffer without indication of locality, and by Bedford from the same host in South Africa. Ferris has recorded it from Pedetes larvalts and Pedetes sp. at Nairobi and Machakos, British East Africa, and from Mastomys coucha and Rattus rattus at Nairoli. Wertieck has described the supposed subspecies or 


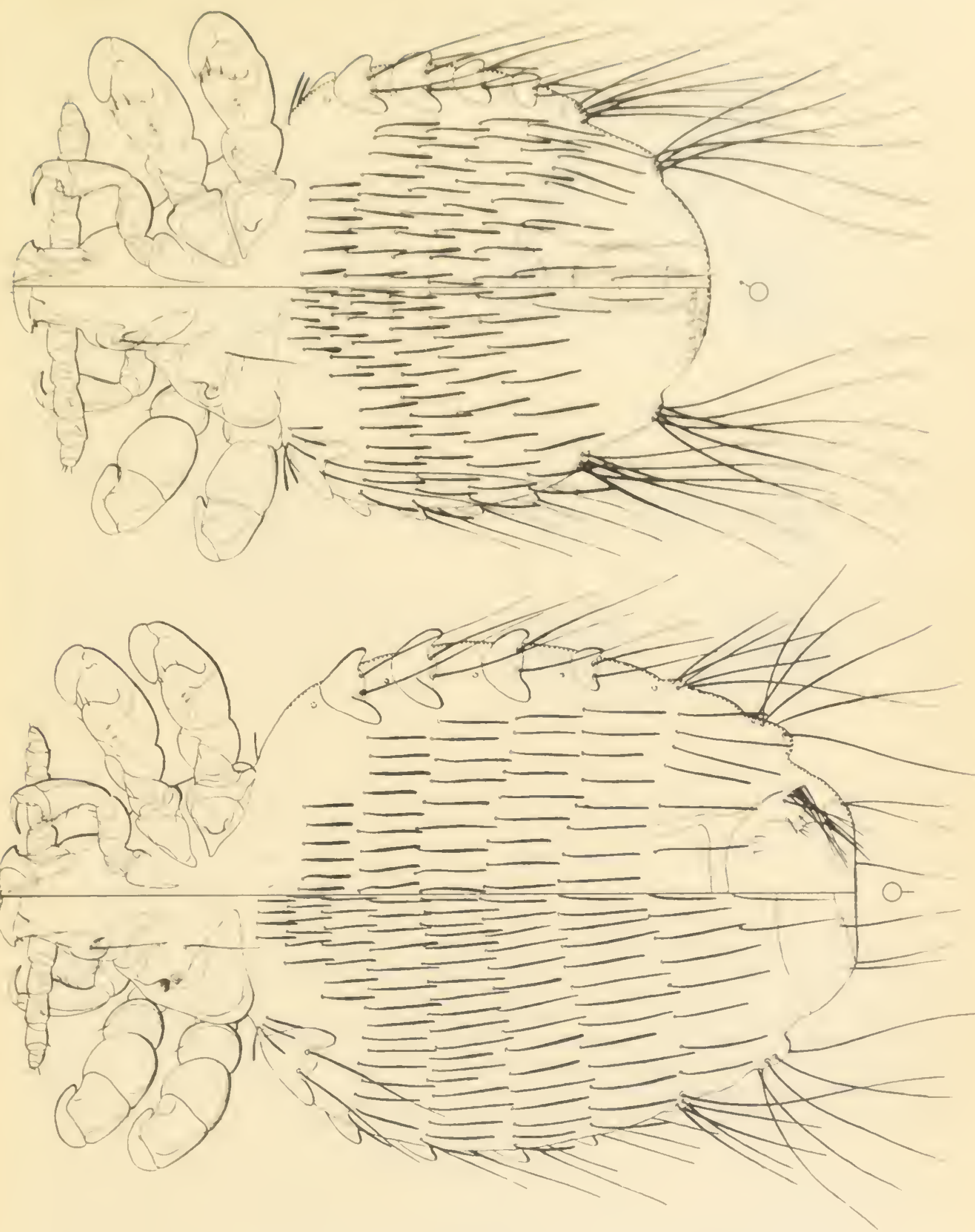

Eulinognathus denticulatus Cummings

Figure 75 


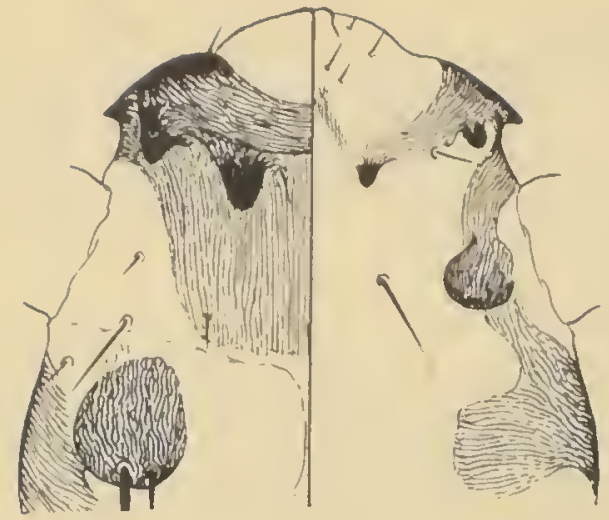

head

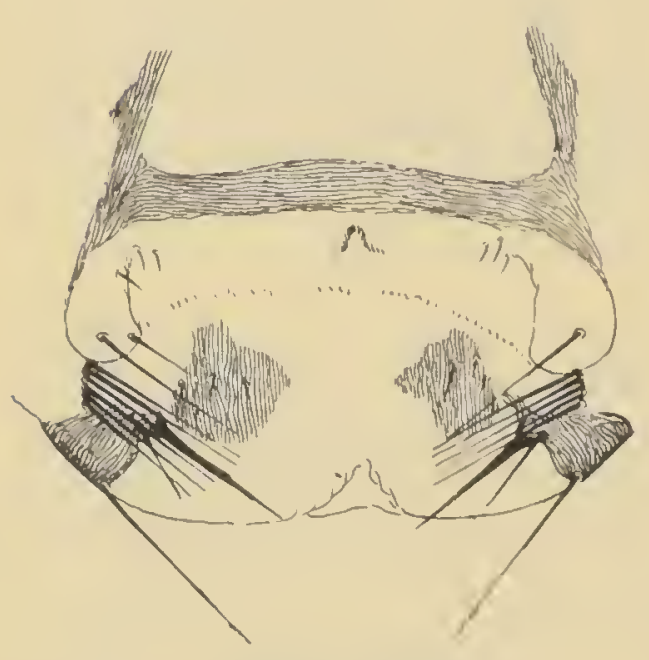

female genitalia

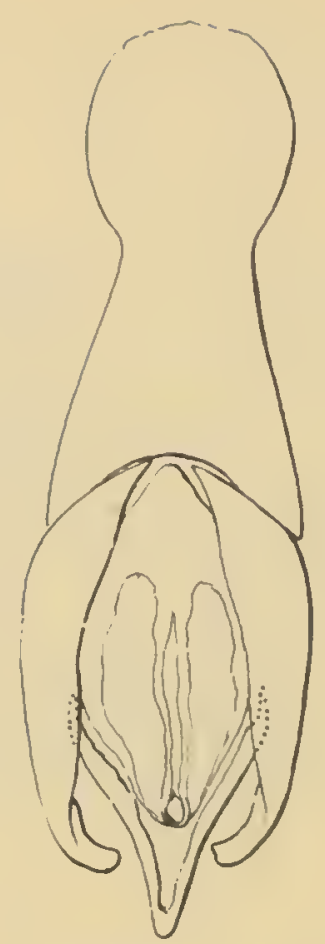

male genitalia

Eulinognathus denticulatus Cummings, details

Figure 76

variety surdasteri from Pedetes surdaster larvalis at Nairobi, basing it upon slight differences in the form of the pseudopenis of the male. Males at hand from the type host at Nairobi show definitely that the supposed difference depends merely upon whether or not the pseudopen is happens to be turned upward. The subspecies surdaster $i$ is consequently rejected. According to Ellerman's list there are but two species of Pedetes, these being caffer and surdaster, larvalis being a subspecies of the latter. The hosts belong to the rodent family Pedetidae.

\section{Eulinopnathus hilli (Bedford)}

1929. Bathyerkicola hilli Bedford, Report of the Director of Veterinary Services, Union of' South Af'rica, 15:506; 1'i gures 6, 7, 7a, 8.

1932. Bathyerficola hillt Bedtord, Ferris, Contributions Toward a Monograph of the Sucking lice, Part 5:312: f'izures 190, 191.

1932. Proenderleinellus hilli (Bediord), Bedford, Report of the Director of' Veterinary Services and Animal Industry, Union of South Africa, $18: 401$. 


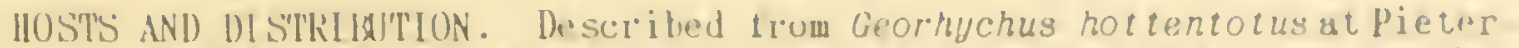

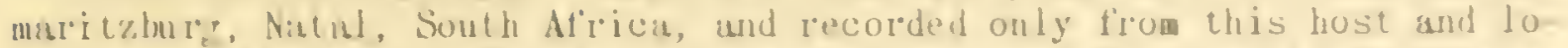
cultity. Accordin to fillender the generic nume of the host is cryptomye. It ix lones to the tiunily liathyrigidase.

\section{linlino muthus lawrensis (Bradiond)}

19:-4). Bathyergicola laurensis Bedford, Anunil Report of the Director of Veterinary Services, Union of South Alrica, 15:506; fi:s. 7b, 9, 10. 1932. Bathyergicola laurensis bedturd, Kerris, Contributions Toward a Monorraph of the Sucking lice, Part 5:314; 1̈igure 192.

1932. Proenterleinellus lawrensis (Bedtord), Bediord, Anuual Reprort of the Director of Veterinury Services and Auinal Industry, Union of South Atrica, 18:401.

HOSTS AND DISTRILUTION. Described l'rom Buthyergus suillus (=marttimus) from unspeciried Locality in Cape Colony, South Africa. The host belongs to the lamily Bisthyerigidac.

\section{Eulinognathus Lophiomydis (Ferris)}

193:. Bathyergicola lophiomydis Fer.is, Contributions Toward a Monograph of the Sucking Lice, Part 5:315; Higure 193.

19.40. Bathyersicola lophiomydis Ferris, herneck, Revista de Entonologia $11: 7^{4} 8 ;$ f'i mures.

HOSTS AND DISIRIBUTION. Type, the temale, described as from Lophiomys thomasi trom Mount Garguez, and recorded also from Lophiomys ibeanus at Nitroru, British East Africa. The male was described by herneck from Lophiomys sp., "probably testudo," from henya, British East Africa. According to Eilender all these names represent subspecies of Lophiomys imhausi. The host senus belongs to the family Lophiomyidae.

\section{Genus FAHRENHOLZIA kellom and Ferris}

1915. Fahrenholzia hellops and Ferris, Anoplura and Mallophaga of North American Mammals, Stanford University Publications, University Series (no volume number), paise 32.

1922. Fahrentolzia, Ferris, Contributions Toward a Monograph of the Suckin: Lice, Part 3:158.

GENERTC TYPE. Fohrenholzia pinnata hellogg and Ferris.

CHARACTERS. Polyplacinate with five-sermented antennae wich are not sexually dimorphic. Anterior less small, with slender claw. Middle and posterior legs equal in size, with very large tibiotarsus and stout clan, the tarsus with a sclerotized, retrorse point at the outer basal angle. Paraterifal plates of the abiomen present on a variable number of segments, alnays, however, with at least three pairs present. The paratergal plates of what is apparenty sement two consist each of two plates, one lying on the dorsum. the other on the venter, distinctly separated from each other, the ventral piece provided with a flat. apically free process which arises somewhat anterior to the apex of the plate. It is possible that we have to do with the parater pal plates of segments one and two, one or the other of which has been somerhat displaced posteriorly. Following these plates there are always plates on se ments three and four, these having the apical angles free from the body. Plates which do not have the apex thus free may occur as tar posteriorly as se ment eight. Abdomen entirely membranous except for the usual dorsal and ventral plates of the terminal and genital segments, each se gment with but a single row of setae, both dorsally and ventrally, these setae strikinsly stout. Spiracles present on se ments 3-8. Thoracic sternal plate stron ly developed. 
The members of this genus occur exclusively on members of the rodent family Heteromyidae, which occurs in North America and northern South America.

NOTES. The status of some of the species included in this genus is not clear. The author has in the past named certain "subspecies, "a practice which he would not now approve, for some of these forms. These are here considered as species. It is probable that a considerable number of forms remain still to be discovered and until more is known about the group it is hopeless to talk about subspecies.

\section{Key to Species of FAHRENHOLZIA}

1. Paratergal plates present only on abdominal segments $2-4 \ldots \ldots \ldots \ldots .2$

Paratergal plates present on more than these segments..............

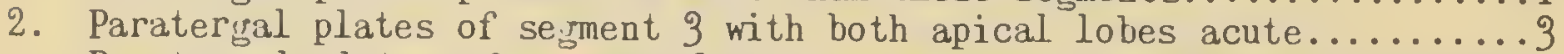

Paratergal plates of segment 3 with the dorsal lobe apically broad and

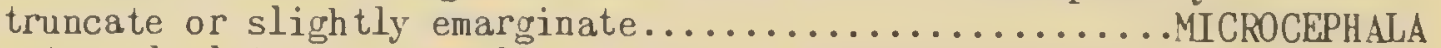

3. Paratergal plates very small and slight; male with free, elongated parameres and with a distinct pseudopenis..............................

Paratergal plates well developed; parameres of the male broadly expand-

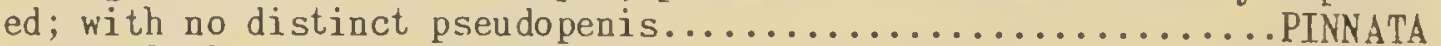

4. Paratergal plates of sement 3 with but a single lobe........TRIBULOSA

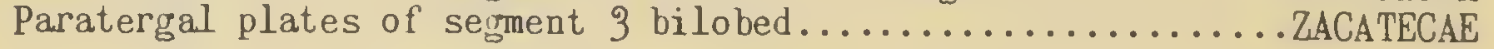

\section{Fahrenholzia microcephala Ferris}

1922. Fahrenholzia microcephala Ferris, Contributions Toward a Monoyraph of the Sucking Lice, Part 3:161; fi fures 106, 107.

HOSTS AND DISTRIBUTION. Holotype recorded as from Heteromys pictus at San Carlos, Vera Cruz, Mexico, which, according to Ellender, belongs to the genus Liomys. Also recorded from Heteromys goldmani at Achotal, state of Vera Cruz, Mexico, and from Liomys irroratus in Texas and Mexico.

Fahrenholzia pinnata Kellogg and Ferris Figures 77,78

1915. Fahrenholzia pinnata Kellogg and Ferris, Anoplura and Mallophaga of North American Mammals, Stanford University Publications, University Series (no volume number), page 32; text figure 13; Plate 3, figure 2; Plate 5, figure 5; Plate 6, f'igure 10.

1922. Fahrenholzia pinnata Kellogrand Ferris, Ferris, Contributions Toward a Monouraph of the Sucking Lice, Part 3:159; firgures 104, 105.

HOSTS AND DISTRIBUTION. Type from Dipodomys californicus at Covelo, Mendocino County, California. Recorded also from Dipodomys merriami at Independence, Cali formia, and Dipodomys deserti at Mecca, California; from Dipodomys ornatus at Valparaiso, state of Zacatecas, and Dipodomys phillipsi at Anecameca, Mexico; from Perodipus sp. at Coulterville, California; from Peroßnathus parvus in the Pine Forest Mountains, Nevada.

Fahrenholzia reducta Ferris

1922. Fahrenholzia tribulosa reducta Ferris, Contributions Toward a Monograph of the Sucking Lice, Part 3:165; fimure $109 \mathrm{~b}$.

HOSTS AND DISTRIBJTION. Recorded only from Perognathus formosus at Victorville, California.

Fahrenholzia tribulosa Ferris

1922. Fahrenholzia tribulosa tribulosa Ferris, Contributions Toward a Mon- 


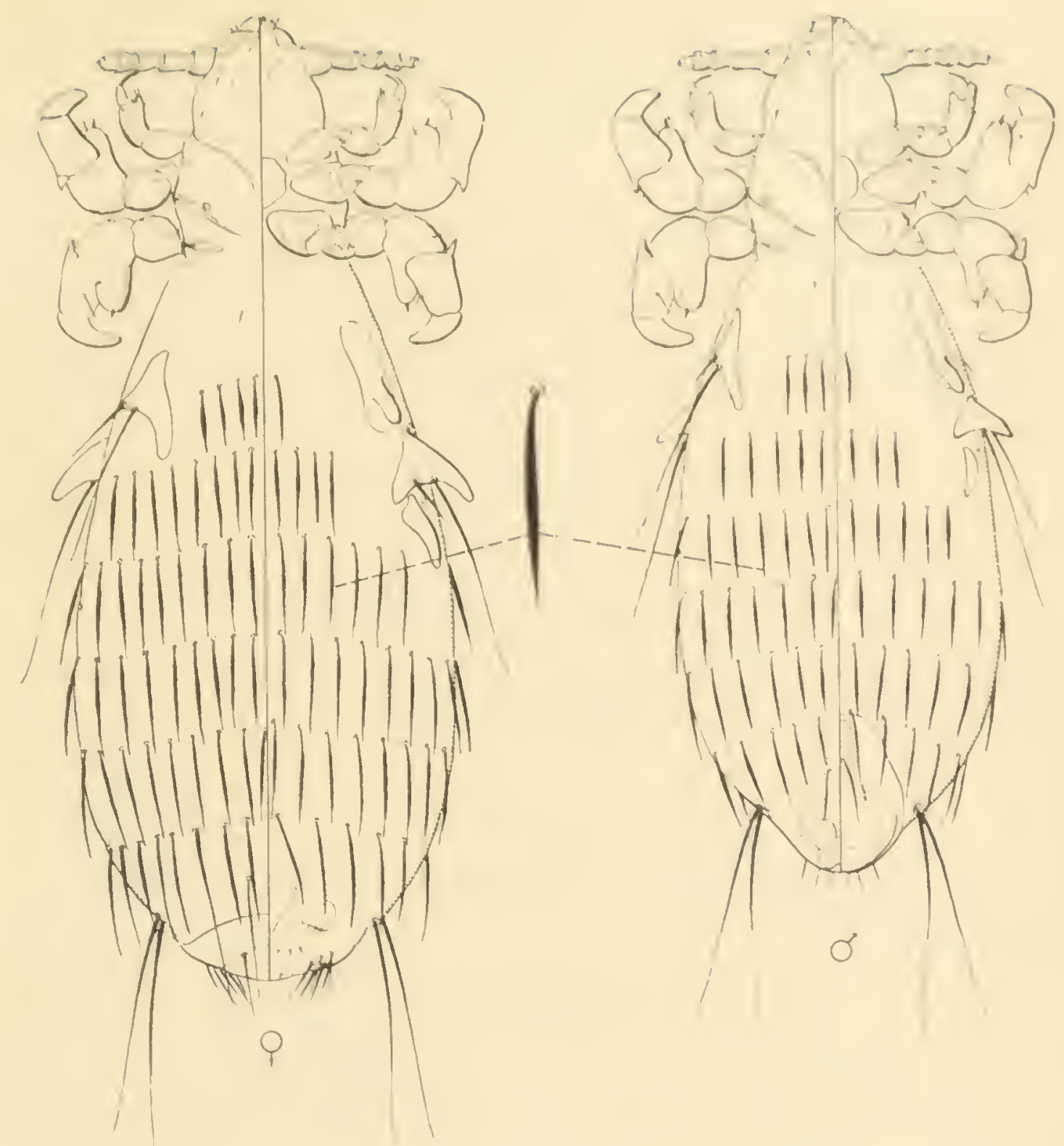

Figure 77

Fahrenholzia pinnata Kellogg and Ferris

ograph of the Suckin' Lice, Part 3:163, figures 108, 109 A, D. E. HOSTS AYT DISTRIBUTION. Known on ly from Perosnathus californicus at Pleasant Valley, Merced County, California.

Fahrenholzia zacatecae Ferris

1922. Fahrenholzia tribulosa zacatecae Ferris, Contributions Toward a Mono praph of the Sucking Lice, Part 3:166; figure $109 \mathrm{C}$.

HOSTS AVD DISTRIBUTIOV. Type Irom Perognathus hispitus at Valparaiso, state of Zacatecas, Mexico. Specimens are at hand from the same host species in Savalia County and at Somerset, Atasco County, Texas. 


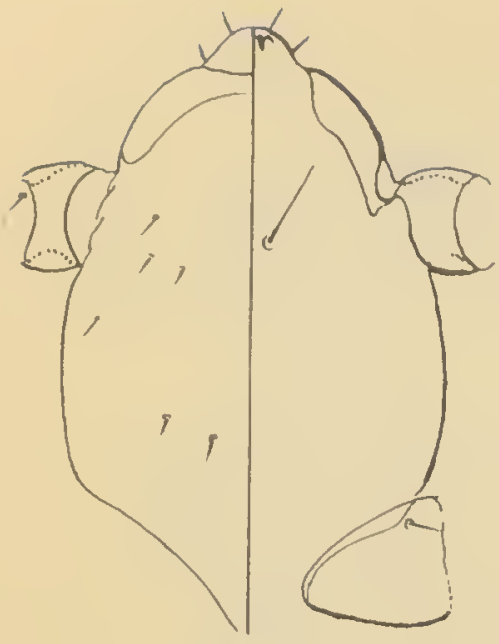

head

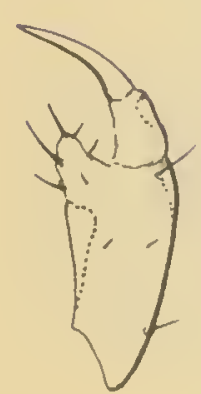

1st and 3rd clauns
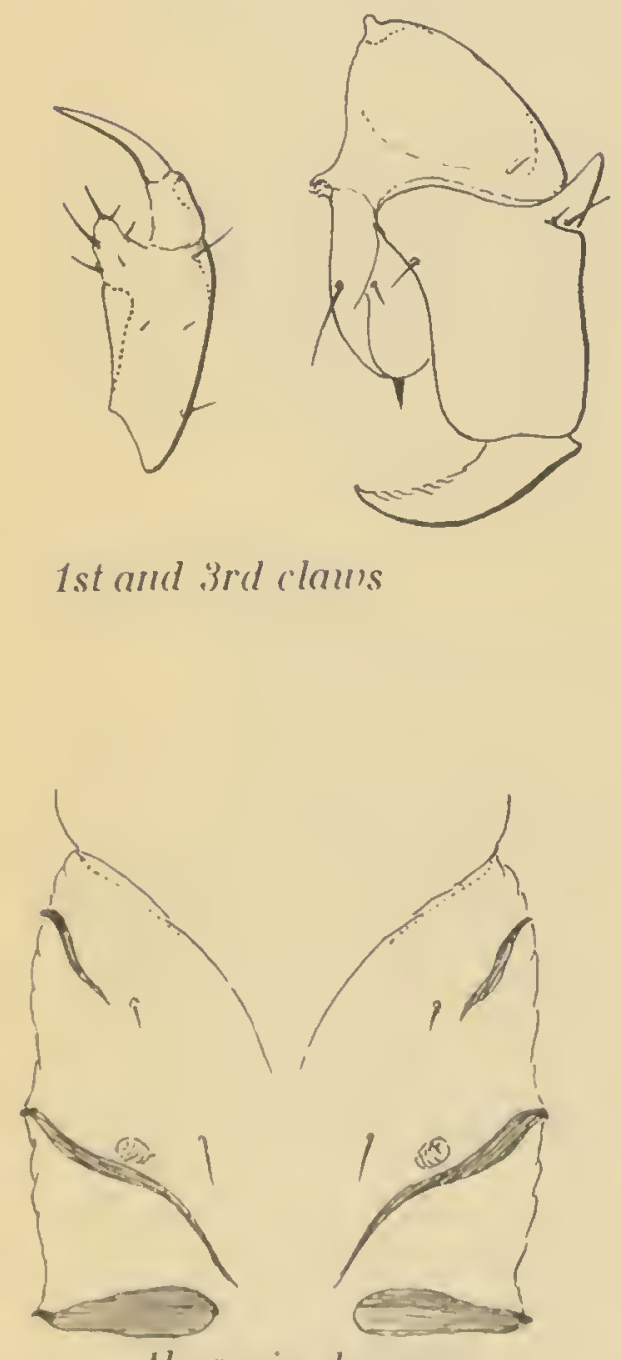

lhoracir dorsum

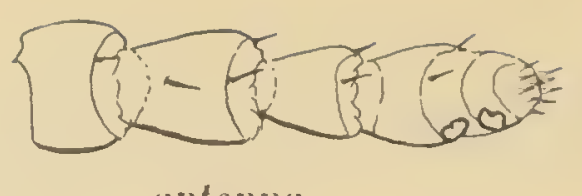

antenna
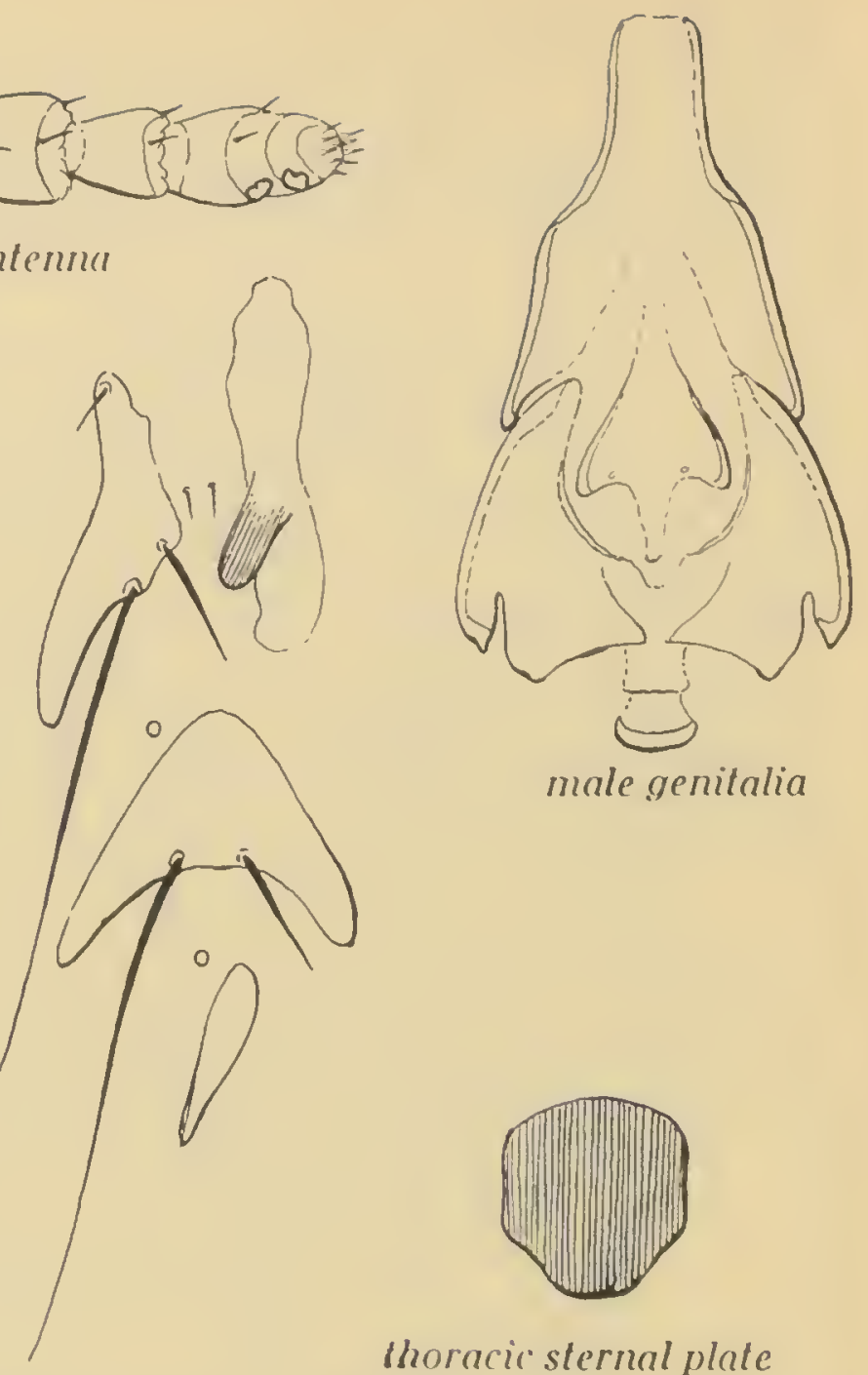

male genitalia

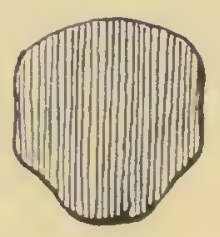

thoracir sternal plate

paratergal plates
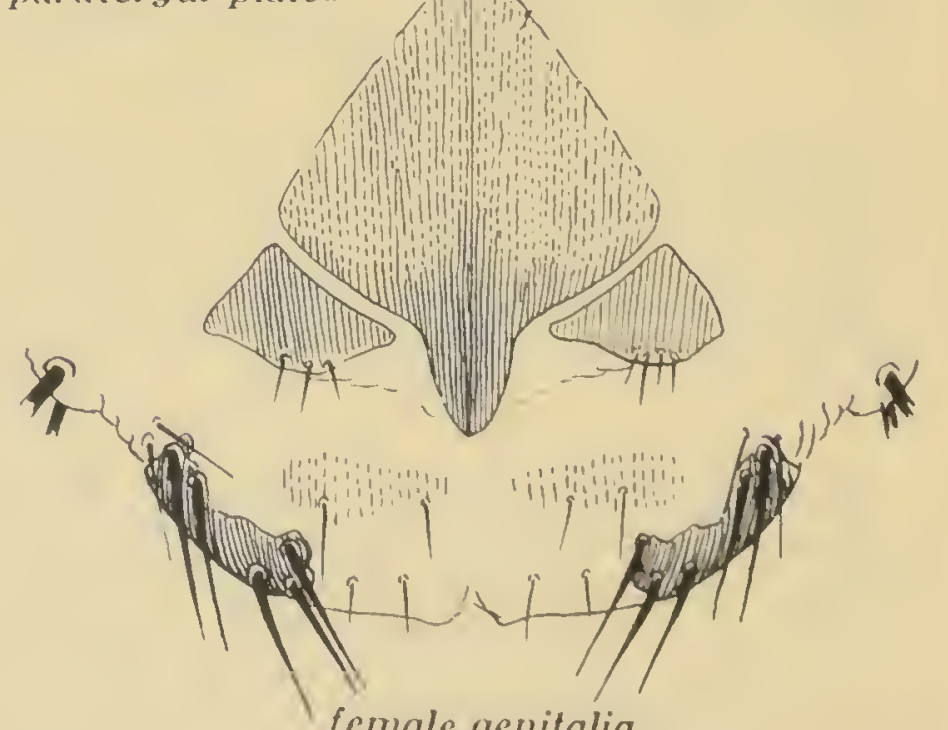

female genitalia

Figure 78 


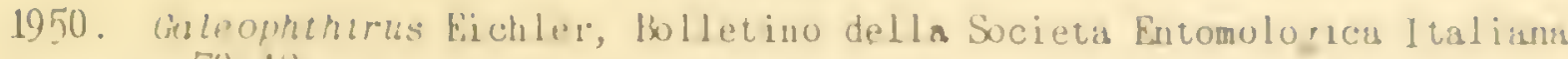
(9): : 1 ".

GENERIC 'TYPk. Rul nosmathus coular herneck, the only included species.

CHARAC'lERS. Antennise tive-segutented, not sexually dimorphic. First legs small and weak, with slender $\mathrm{claw}$. Second and third lees about equis to eints other, larre and stout, with stout claw. Paratergal plates prest on abdoninal sernents 3-7, each consisting of an elongated, narrow, sclerotized area which bear's two long setae at the apex, the apex not frpe frum the hody wall. Aldomen membranous throughout in both sexes except 1 or the usual sclerotizations of the terminal and genital segments. Female with two rows or partial rows of setae on euch of most of the serments, the male nith but one row. Ablominal spiracles present on segnents $3-8$. 'lhuracic sternal plate present.

NOTES. About the only basis tor recognizing this genus appears in the lonn of the paratergal plates. The writer is somewhat dubious concerning it, but it is here accepted.

\section{Galeophthirus caviae herneck Figure 79}

1934. Eulinognathus caviae. Werneck, Memorias do Instiluto Uswaldo Cru\% 29: 183: 1"igures 6-11.

1950. Galeophthirus caviae (Werneck). Eichler, Bolletino della Societa intomologica Italiana 79:12.

HOSTS AYD DISTRIDUTION. Known only from the original record, from Galea leucoblephara, which, according to Ellender, is a subspecies of Galea musteloides at Jujuy, Republic of Argentina. The host belongs to the faun ily Cavi i dae.

\section{Genus IIAEMODIPSUS Enderlein}

1904. Haemodipsus Enderlein, Zoologischer Anzeiser 2s: 139, 143.

1932. Haemodipsus, Ferris, Contributions Toward a Monobraph of the Sucking Lice, Part 5:59.

GENERIC TYPE. Pediculus lyriocephalus Burmeister. Two other species are included in this genus.

CHARACTERS. Anoplura referable to the Polyplacinae. Antennae fivesemented, not sexually dimorphic. First pair of less small and with slender claw; second and third leirs moderately stout and with stout clar, ahout equal to each other. Type species with the abdomen membranous throughout and without trace of parater pal plates; in other species of the genus with small pariaterial plates on segments $3-6$, these being merely a slipht, sclerotized point which projects from the body wall and is supported by a slight, expanded sclerotization at the base. Abdominal segments in both sexes with a single row of setae on each, both dorsally and ventrally. Thoracic sternal plate present, but very weakly developed and at no point iree trom the body. Spiracles present on abdominal sements $3-3$.

The members of this genus occur on hares and rabbits of the family Leporidae of the Order Lasomorpha.

NOTES. The situation concerning this genus is very unsatisfactory. The type species is unfortunately but little known and the intornation concernin it quite incomplete. It is possible that the other species wich are referred to this genus are so placed chiefly because of their hosts. As lased upon the type species the genus can scarcely be referred to the Hoplopleuridae, but the other species seem to belong to this tamily and to the subtamily Polyplacinae. A thorough redescription of both sexes of the type species is much needed. 


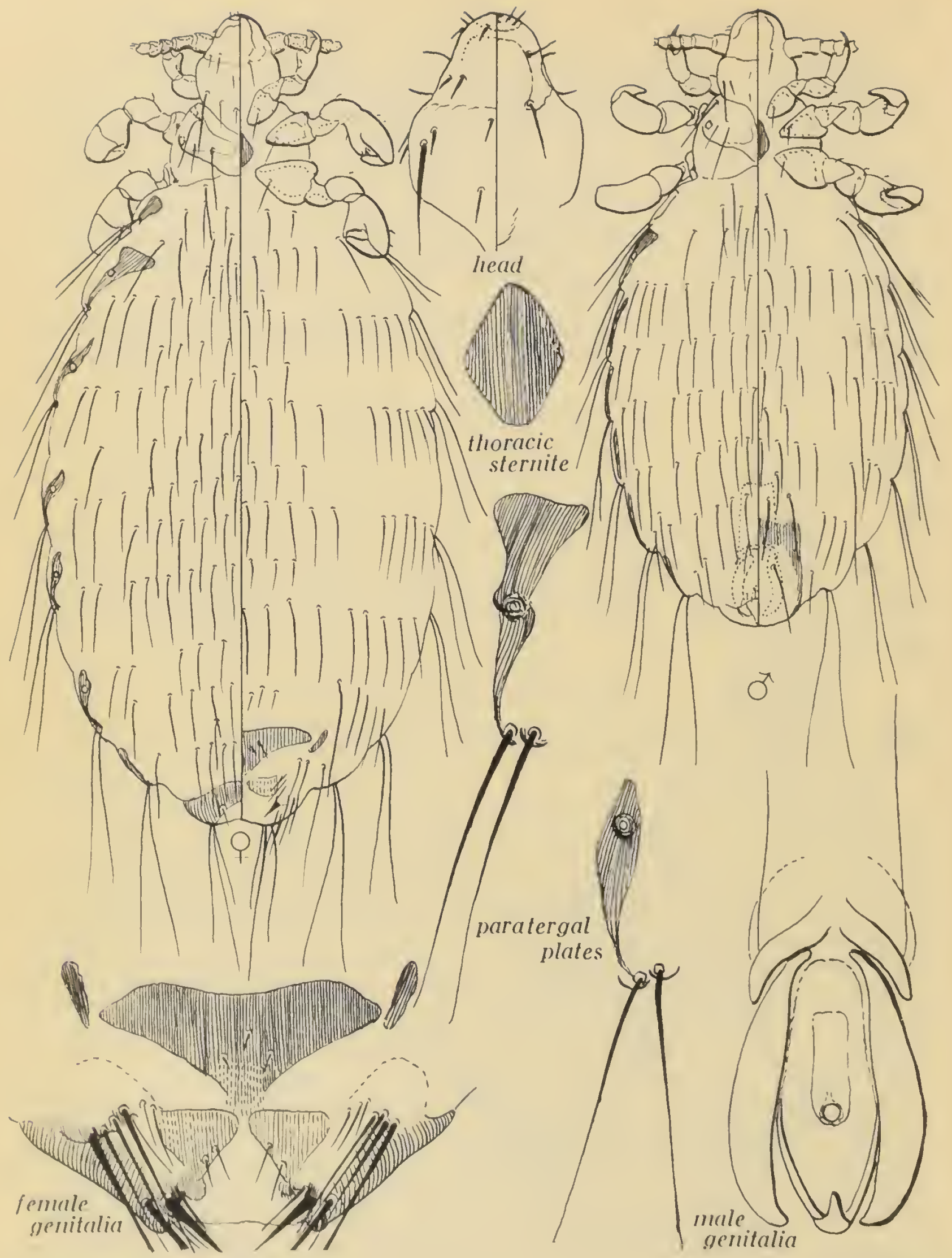

Galeophthirus caviat (Werneck)

Figure 79 


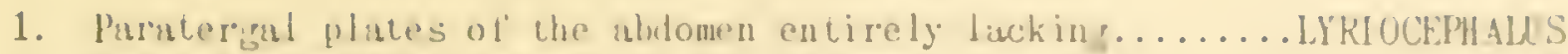

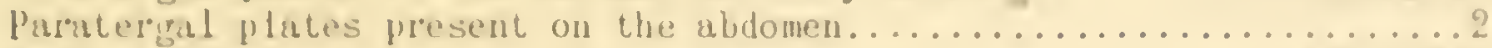

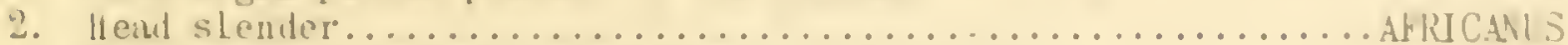
Hem stron 1 y widened posterior to the antennue....................

3. Sternal plate of the thorax forming a rather uarow, transverse bar....

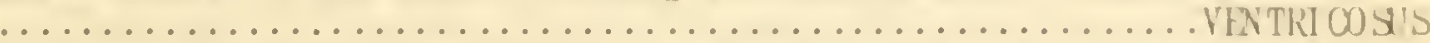

Stemul plate of the thorux tilling the space amon: the coxise and more or less hexiugonal.........................................

lla emodipsus af'ricunus bediord

1934. Haemodipsus africanus Bedtord, Ouderstepoort Journal of Veterinary Science and Animal Industry 2:48; f̈igure 10.

HOSTS AND DISTRIUTION. Recorded trom Lepus zuluensis al Jericho, Trinsvarl, South Africa.

\section{Haemodipsus lyriocephalus (burmeister) Figure 80}

1839. Pediculus Lyriocephalus Burmeister, Genera Insectorum, Rhynchota, Species 11.

1842. Baematopinus Lur locephalus (Burneister), Denny, Monographia Anoplurorum britanniae, page 27; Plate 24, figure 4.

1904. Haemoripsus lyriocephalus (Burmeister), Enderlein, Loologischer Anzei grer 28: 143 .

1932. Haemodipsus lyriocephalus (Burmeister), Ferris, Contributions Toward a Monouraph of the Sucking Lice, Part 5:330; figures 202, 203.

1935. Haemodipsus lyriocephalus (Burmeister), Freund, Die Tiernelt Mitteleuropas, band 4, Lieferun: 3:20; ti gures 87-89.

HOSTS AVD DISTRIBUTION. Described from Lepus timidus in Europe. Ferris has recorded it from Lepus glacialis without further data. Hopkins records it from Lepus europaeus in Europe.

\section{Haemodipsus setoni Ewin:}

1924. Haemodipsus setont Ewing, American Journal of Tropical Medicine 3: 548. 1932. Haemodipsus setoni Ewin, Ferris, Contributions Toward a Monograph of the Suckinir lice, Part 5:335; fiirures 20513, E.

HOSTS AND DISTRIBUTION. Described from Lepus californicus at kichita, Kansas, and recorded from the same host at San Diego, California. Recorded by Kellogg and Ferris from the same host in Calitornia and Arizona. Specimens from an undetermined species ol "cotton tail rabbit," presumably a species of Sylvilagus, are at hand from the state of Montana.

\section{Haemodipsus ventricosus (Denny) Figures 81,82}

1842. Haematopinus ventricosus Denny, Monographia Anopluromm Britanniae, page 30 ; Plate 25, ligure 6.

1904. Haemodipsus ventricosus (Denny), Enderlein, Zoologischer Anzeiger $28: 113$.

1932. Haemodipsus ventricosus (Denny), Ferris, Contributions Toward a Monograph of the Sucking Lice, Part 5:332; fi zures 204, 205.

HOSTS AVD DISTRIUUTION. Described from the European rabbit, Oryctolasus (=Lepus) cuntculus, from England and many times recorded from this host and from domestic rabitis which are supposed 20 have been derived from this species in many parts of the world. 


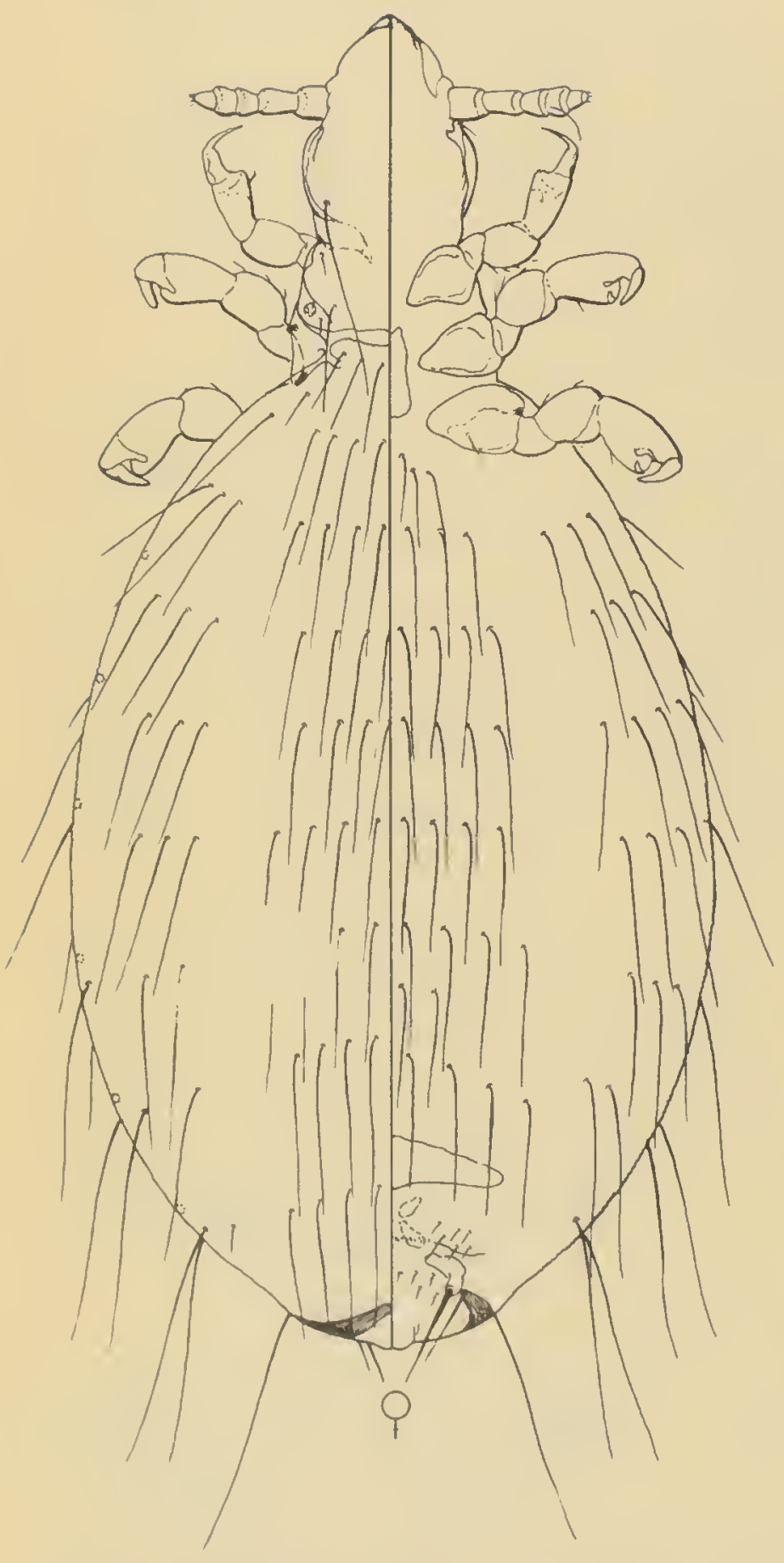

Haemodipsus lyriocephalus (Burmeister)
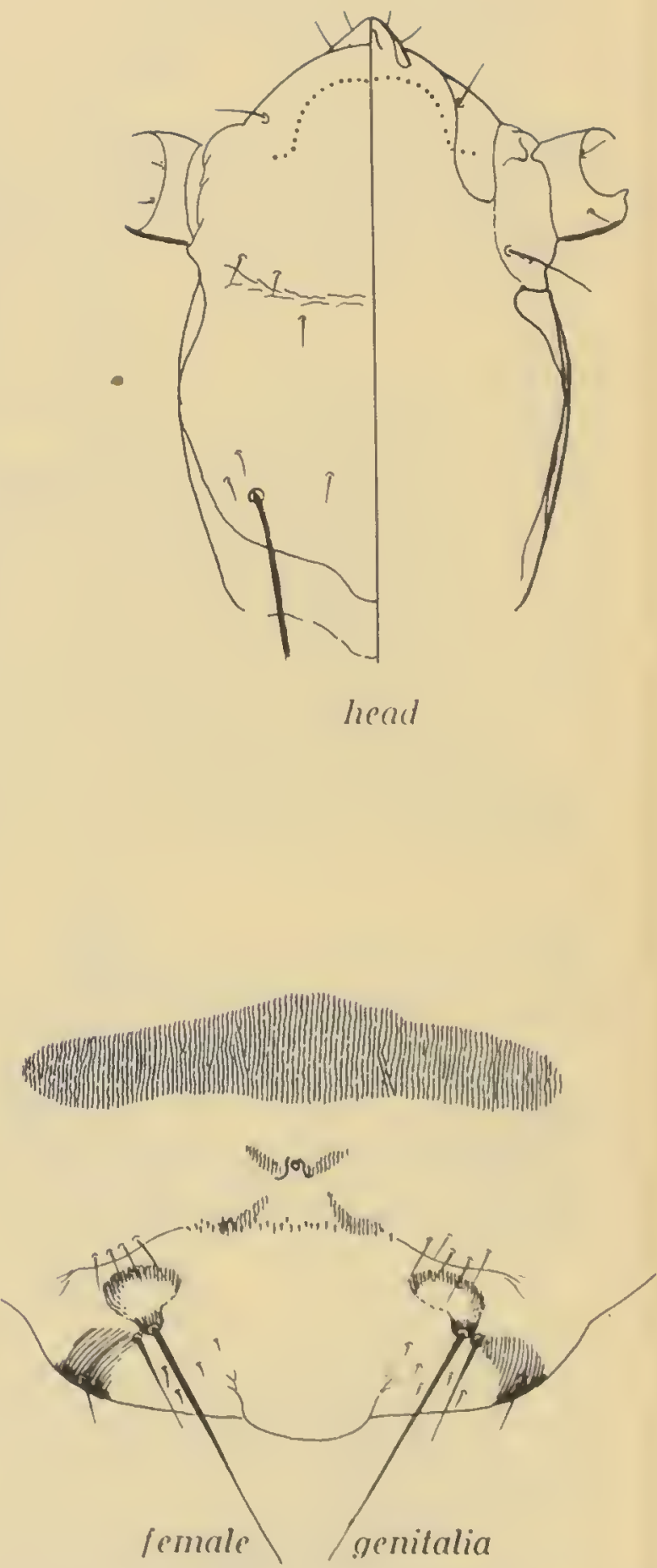

Figure 80 

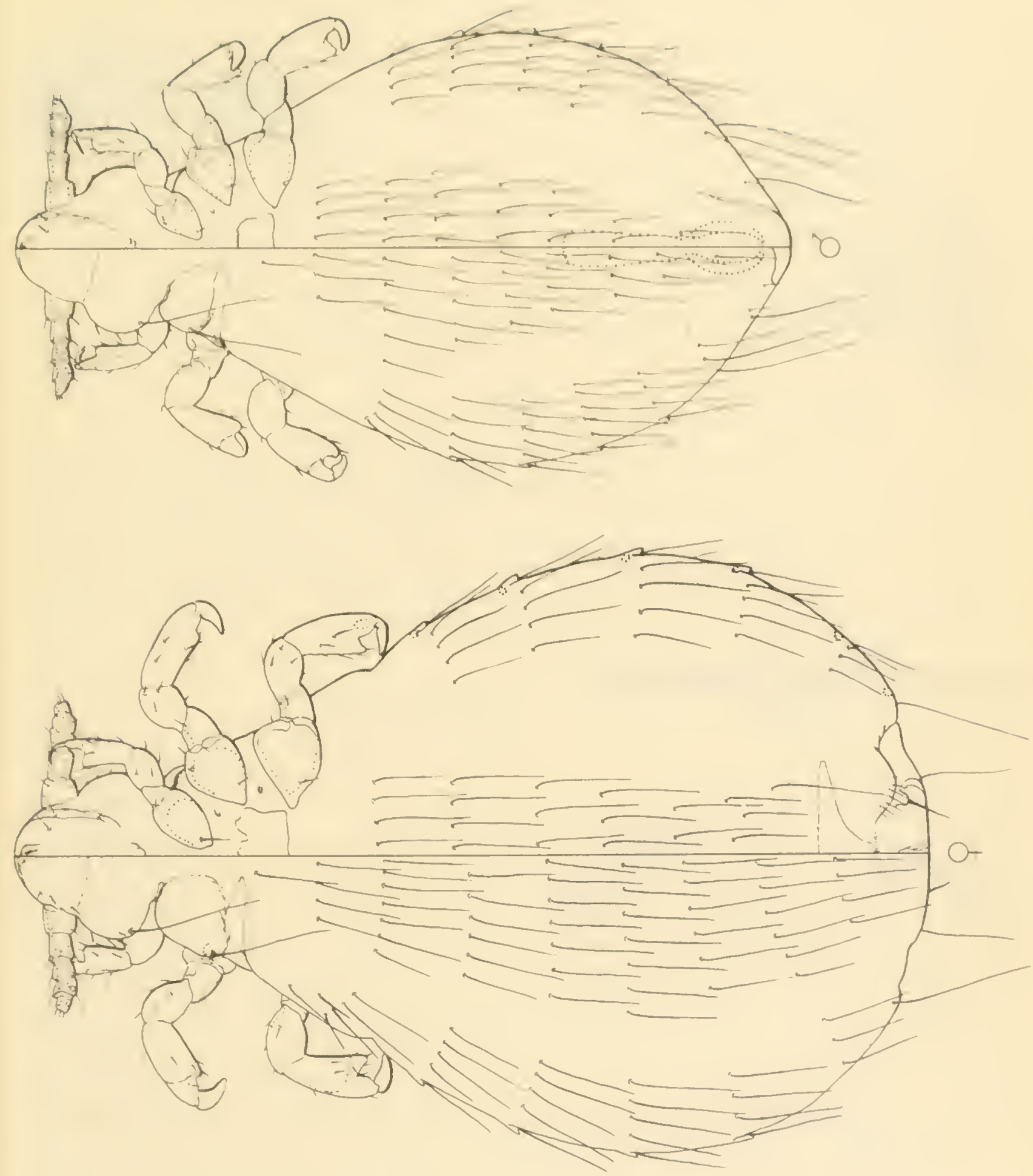

Haemodipsus ventricosus (Denny)

Figure 81 

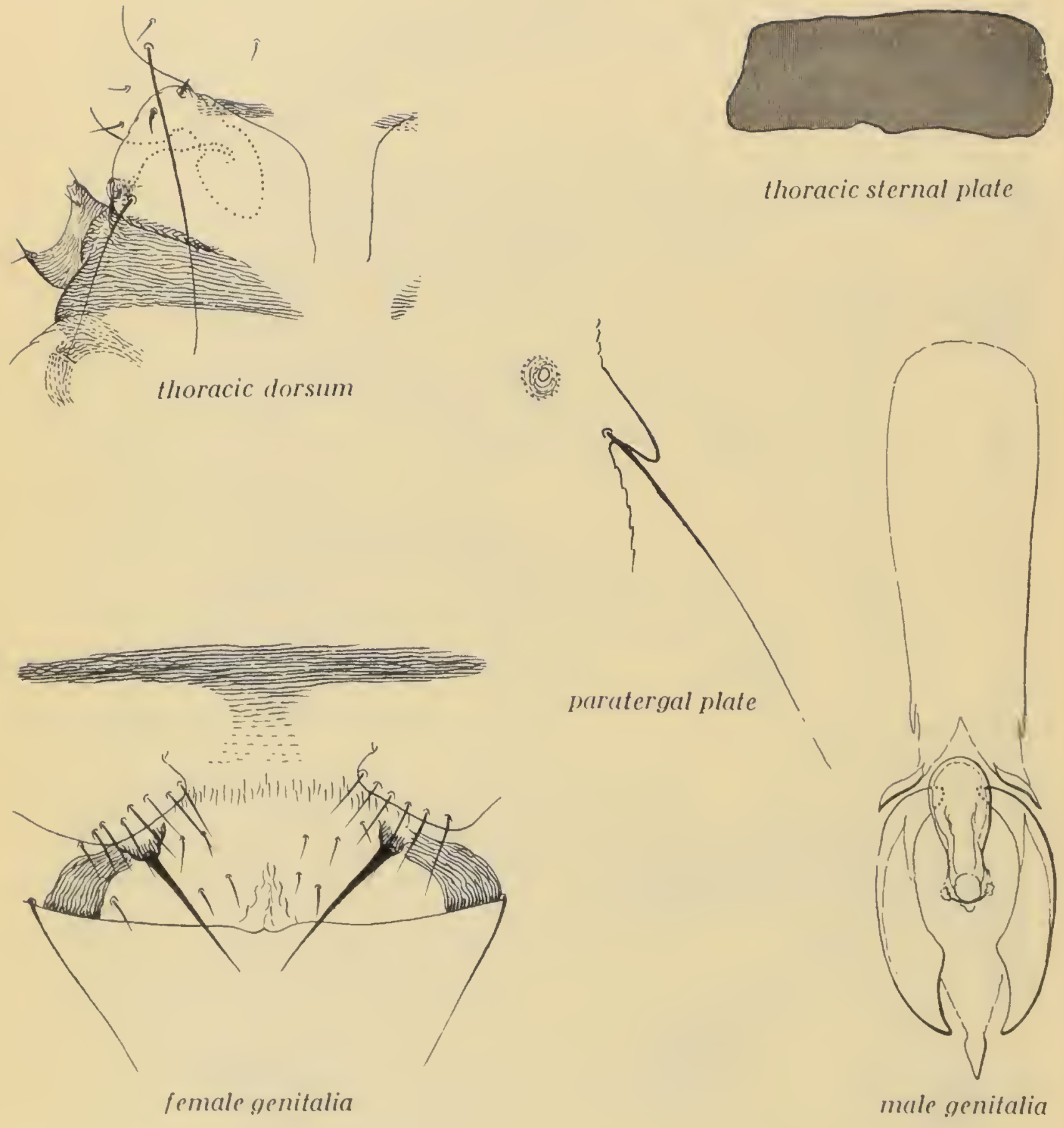

female genitalia

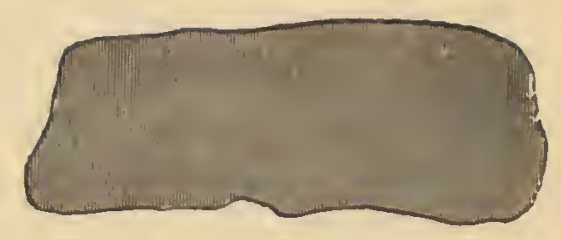

thoracic sternal plate

Haemodipsus ventricosus (Denny), details

Figure 82 


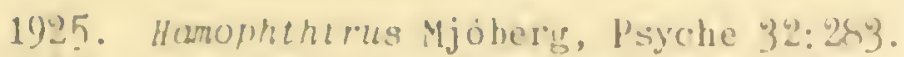

193:. Humopthtrus, ferris, Contributions towad a Monopraph of the Suchin: lice, Parl 5: 306.

GiNERLC TYPE. Hamophthirus galeoplthect Yjobers, the only included species.

Aakicreks. Intortunutely this genus is known on ly lirom the urifinal, very indequate description and the accompanying crude tipures. The 1olLowing abtract of the important characters which can be gained trom these is riven.

Polyplacinae with three-segmented antennae, the basal se ginent much enlarred and with an apical hook at the anterior distal angle. Head very broad, its posterior angles produced each into a prominent point. Praraterral plates present on abdominal se ments $3-7$. Legs suid to be "lairly equally deve loped."

There is in this description and the accompany'ing firmes a sumpestion that this genus is rather closely related to Docophthtrus, altiough the three-se mented antennae would inuediately sultice to separate it from all the other member's of the subfanily.

\section{Hauphthirus galeopi theci Mjöber."g}

1925. Hamophthirus Ealeoptheci Mjober's, Psyche 32:283; 1"i pure.

1932. Hamophthirus galeopitheci Yjober;, Ferris, Contributions Toward a Monouraph of the Suching Lice, Part 5:307; figure 187.

liOSTS AND DISTKIBUTION. From a Dermopteran, Goleopithecus sp., at Fesseltan, british North liormeo. This is a Cynocephalus variegatus.

NOTES. In spite of the inadequate description and poor illustrations it should be possible to recomize this species it it is recovered. Ferris (1932) merely reproduces the description and t'i gures given by Mjober fo.

\section{Genus LAGIDIOPHTHIRUS Eichler}

1950. Laģidiophthirus Eichler, bolletino della Societa Entomolofica Italiana $79: 12$.

CEVERIC TYPE. Hoemoripsus parvus kellogr and Ferris, the only included species.

CHARACTERS. Polyplacinae with tive-segmented antennae, which are not sexually dimolphic. Anterior legs small and weak; second and third legs larise and stont, about equal to each other. Parater fal plates of the ahdomen present on sesments 2-6, these quite smill and with each posterior ungle produced into a strong point. Abdomen otherwise membranous except for the usual plates of the terminal and genitalic segments. Body setae very few, there being a single row, both dorsally and ventrally, on each abdominal se ment, each row having a median roup of $2-4$ setae and there being a single seta, both dorsally and ventrally, close to the lateral maryin. Spiracles present only on abdominal se ments 3-7. Prothoracic sternal plate rell developed.

NOTES. Recognizing a new genus for the single species included in this genus is the only way of escaping from the problems which it presents in regard to its generic assismment, in spite of the weakness ot the characters on which the genus is based.

Lagidiophthirus parvus (hellog and Ferris) Fiore 83

1915. Haemodipsus parvus Kellop and Ferris, Anoplura and Mallopha;a of 


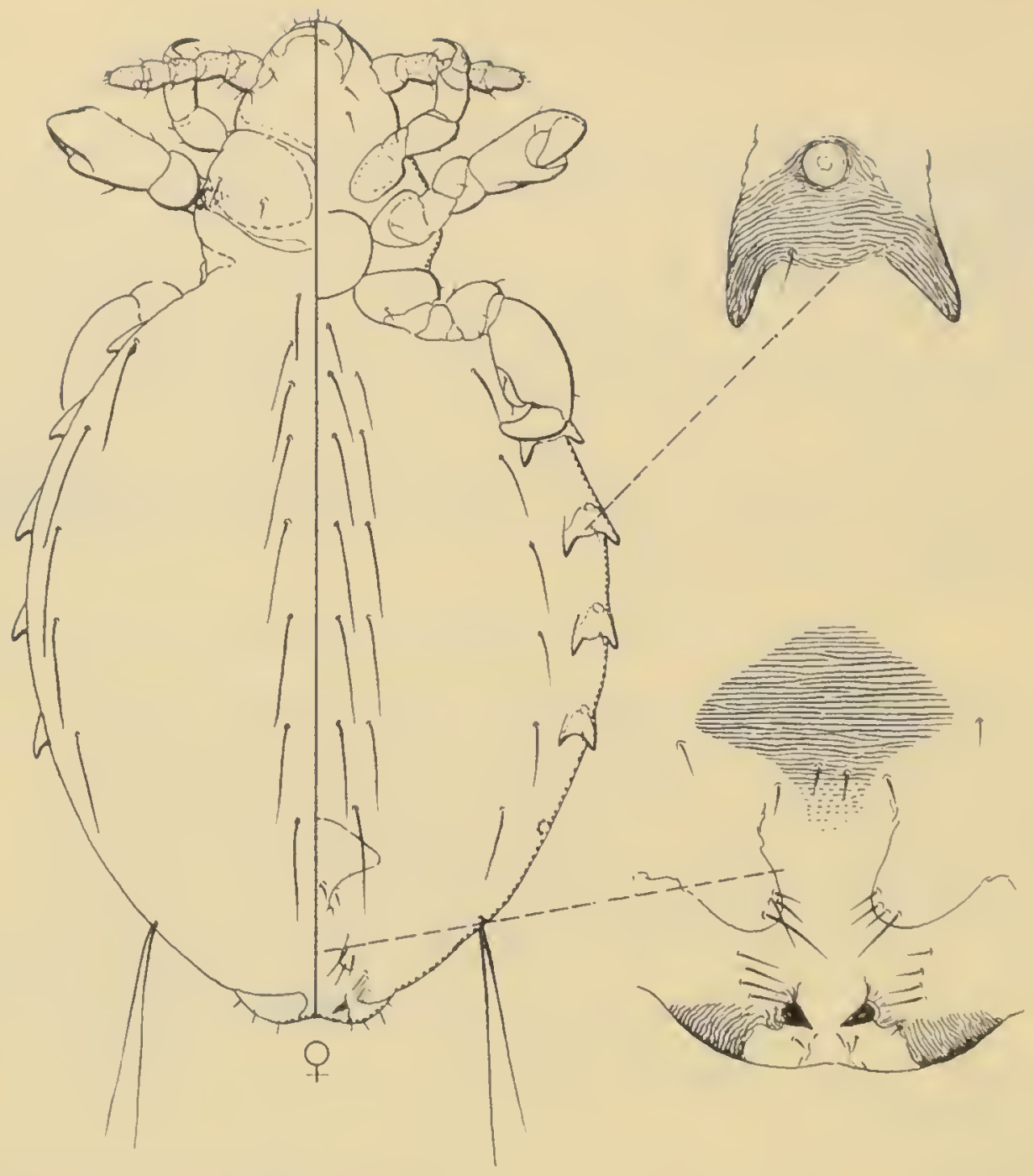

Lagidiophthirus parvus (Kellogg and Ferris)

Figure 83

North American Mammals, Stanford University Publications, University Series (no volume number), page 30; text figure 12; Plate 2, figure 4; Plate 4, figure 6.

1932. Eulinognathus parvus (Kellogg and Ferris), Ferris, Contributions Toward a Monouraph of the Sucking Lice, Part 5:397; figure 201.

1940. Eulinognathus parvus (Kellogig and Ferris), herneck, Revista de Entomo logia $11 ; 726$; figure.

1950. Lagidiophthtrus parvus (Ke llogg and Ferris), Eichler, Bolletino della Societa Entomolorica I taliana 79:12.

HOSTS AND IISTRIBUTTON. Type from Laǵidium peruanum trom an unspecified locality in Peru. Werneck has recorded the species from Lasidium incawhich, according to Ellender, is the same as peruanum-from the Cordilheira Songo, Province of Murillo, Department of La Paz, Bolivia.

NOTES. This species wis originally described from the temale alone but Werneck has described the male. It is possible here to illustrate only the temale. 
19:4. Lemurphthlrus liedturd, Piansitolog 19:263.

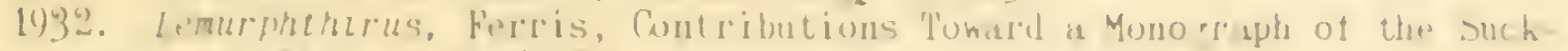
intr lice, Pialt $5: 2(14)$.

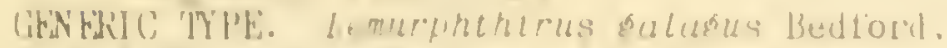

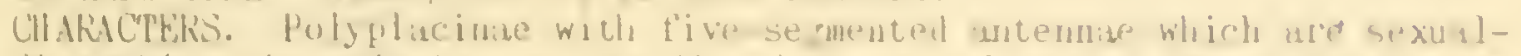

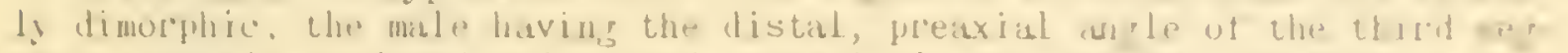

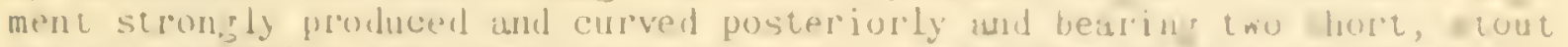
setace. duterior leges small and weak, with weak cian; midalle and pusterlor lers definitely harger, hut not greatly so, about equal to each uther. Parater ral plates present only on the second aluluninal sement, concistin. of a simple, that, somewhat cunietorm, sclerotized piect, the extrem apex of which is tree lirum the hody. Aludomen, in buth sexps, with a sin le plate aud a single row of hairs on eakch segment, both dors 11 ly and ventrially, except that the femile appears to hive two plates and two row's of setae ou sement two. Thorax unusually elonerte, with a vers lare, mar rinally free, stermal plate. Spiricles present on abdominal se ments 3-8.

No'trs. The hear and thorax ut the species ot this perus mi rhe very well belon: to a species of veohotemetoplmus, hut the uhdumen is quite diflerent. The genus contains tro known species.

\section{hey to Species ot Lhil'RPHTHIKlS}

Sternal plate of the thoras with a slender, mediun, anterior prolongition..

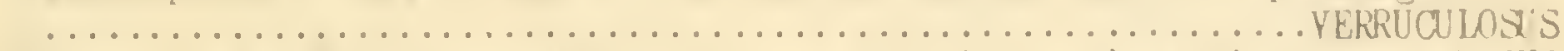
Sternal plate ot the thorax without such anterior prolongation..... r.ILACUS

Lemurphthirus galarus Bedtord Figures 84, 85

1927. Lemurphthirus salas us bedtord, Parasitoloy 10:263: fi rures.

1932. Lemurfhthirus galnéls Bedford, Ferris, Contributions Toward a Mono'praph of the Sucking Lice, Pirt 5:300; ti gures 193, 181.

HOSTS AND DISTRINUTION. Type trom GalaEus moholi (which, according lo hopkins, is senegalensis), a Lenuroid, trom Onderstepoort, Transvad, South Atrica and recorded at the sime time trom Sonthwest Ifrica. Ferris has recorded the species trom the sume host, without data, in the British Yuseum. Hopkins records it without locality from Golnko demidovit.

\section{l.emurphthi rus verruculosus hard}

1951. Lemurphthirus uerruculosus Hart. Entomological Nevis 6a:190; ti pures. HOSTS AVD DISTRIBITION. Known onl! from "mouse lemur" f'rom lemangidy. Fort Diuphin Disirict. Tulear Province. Yadajascar. Presumably this refers to some species of the genus Cheirogaleus.

\section{Genus KEOHAEYATUPLIS Yjöber⿳⺈}

1910. Seohaematopinus Yjöbery. Arkiv 1ör Zoolori 6:13: 160.

1910. Acanthopinus Yjöberg, Arkiv för Zoologi 6:13: 160.

1914. Linognathoi tes Cumminrs, Bulletin of Entomological Research 3:393.

1916. Luiesus Fahrenholz, Archiv fïr laturseschichte, Abteilung A, 51:11:31.

1923. Yeohaenatopinus. Ferris, Contributions loward a Monograph of the Sucking Lice, Part 4:23i.

19:29. A brmatoninus Ewin?, I Yanuil of External Piarasites, page 197. 1949. Petauristophthirus Eichler. Bolletino della Societa Entomologica Italianc $79: 12$. 


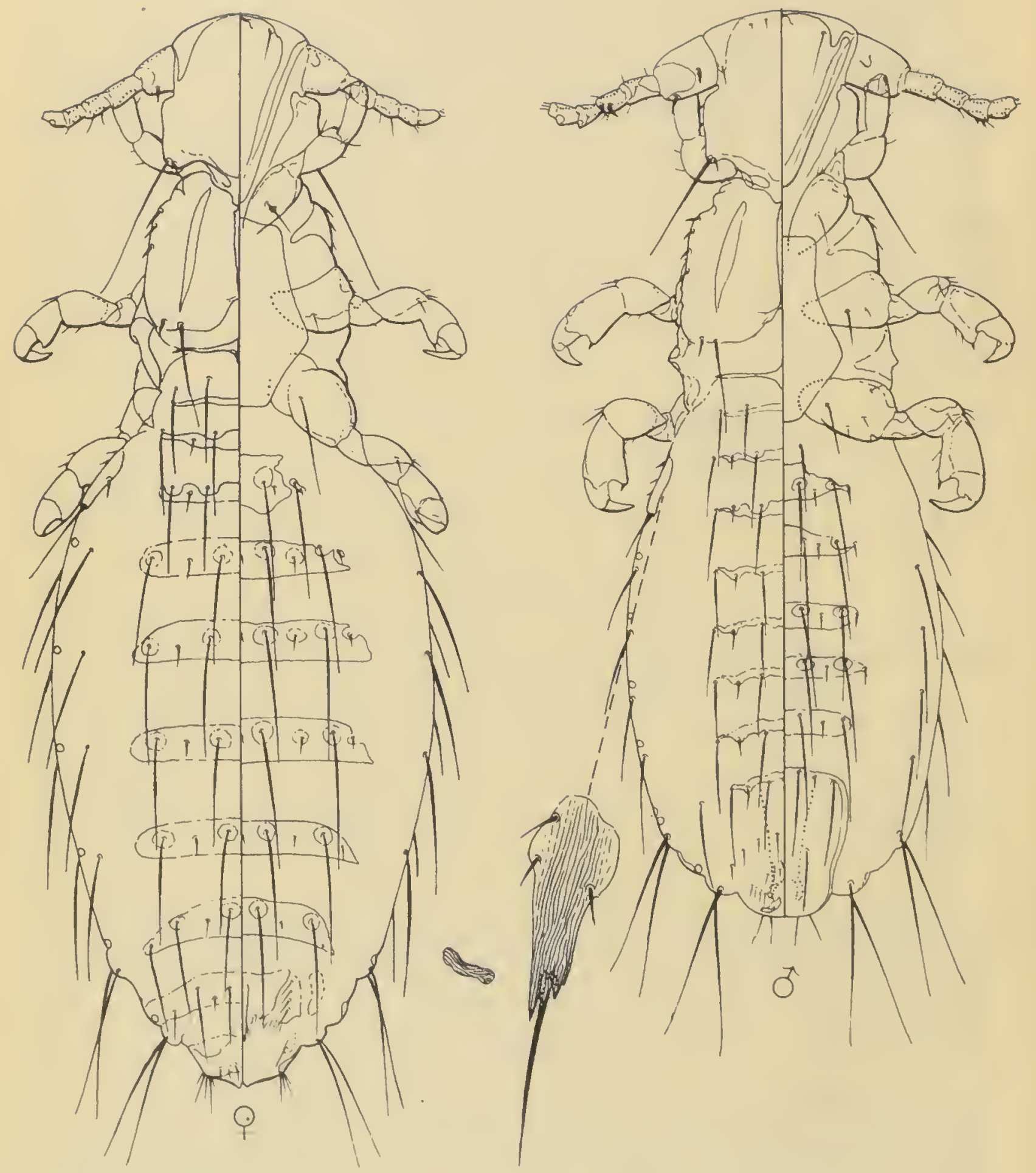

Lemurphthirus galagus Bedford

Figure 84 


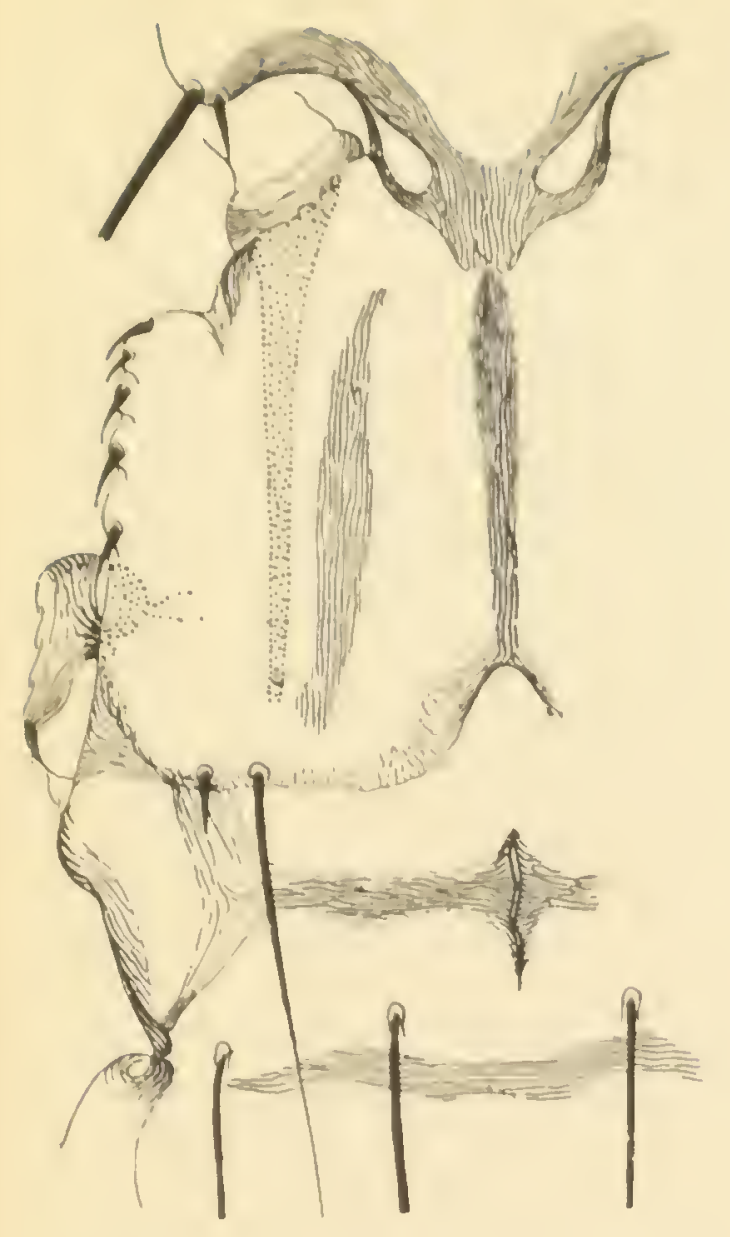

thoracic dorsum

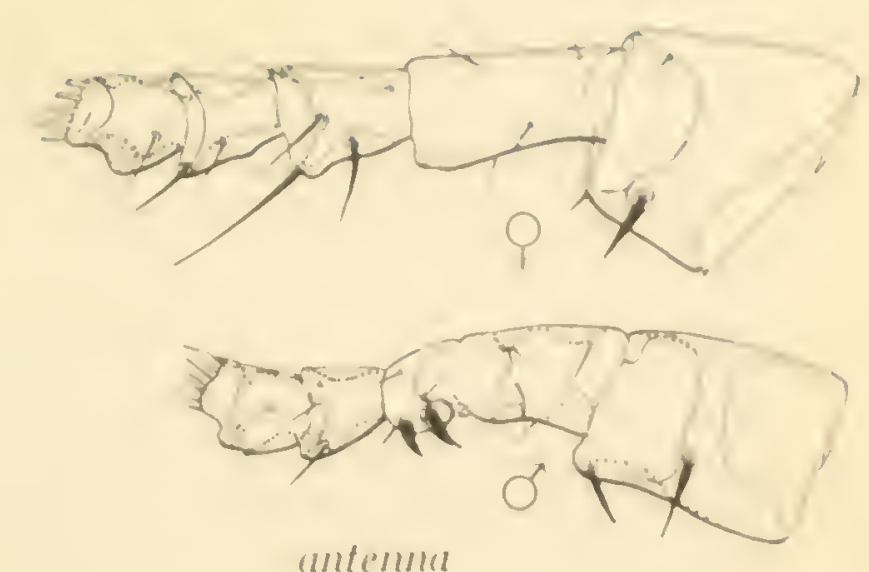

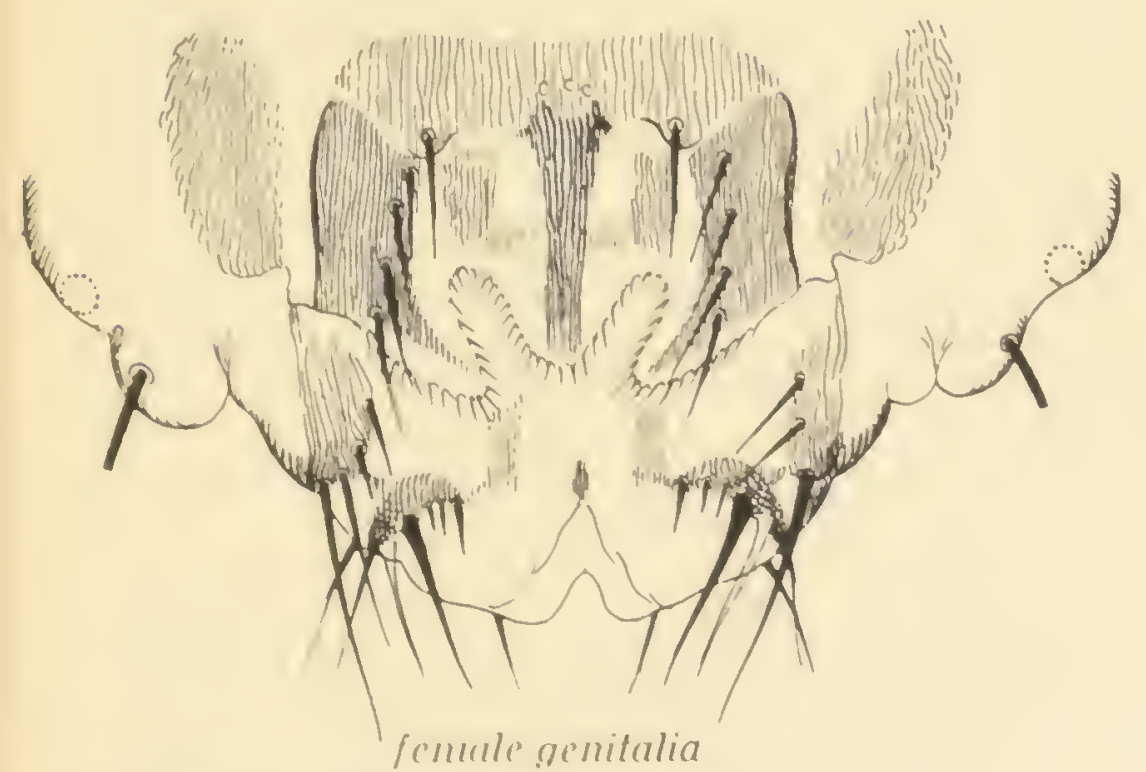

Lemurphthirus galagus Bedford, details thoracic sternal plate

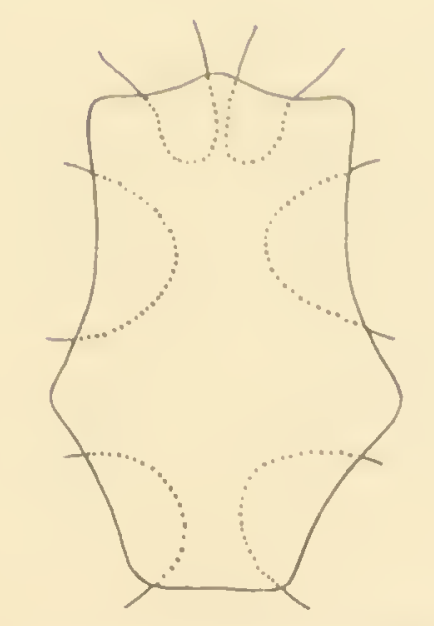

P

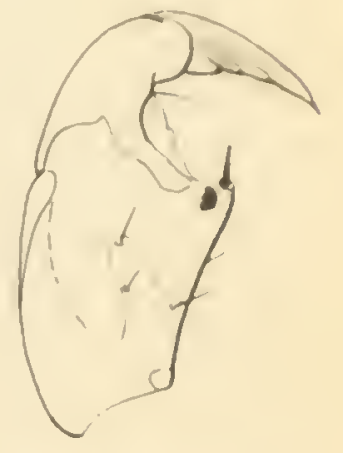

2nd or 3rd claun

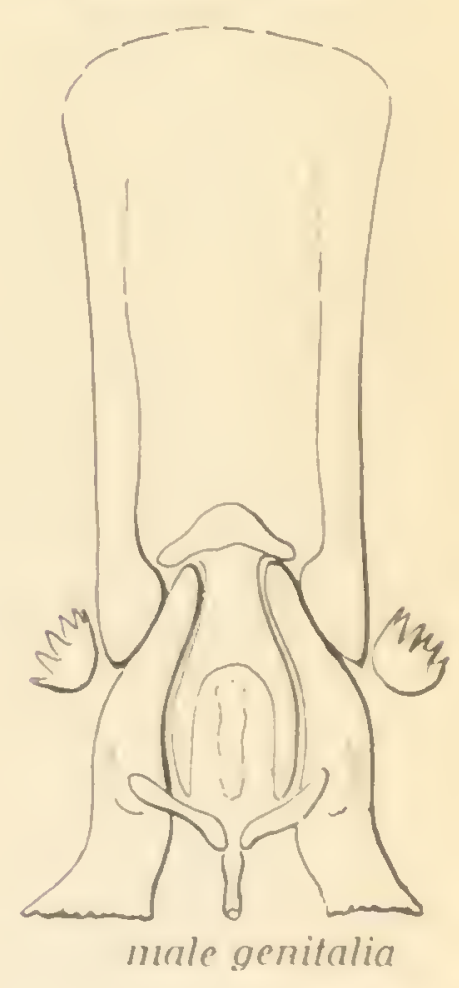

Figure 85 
GENERIC TYPE. Huematopinus sciuropteri Osborn.

GENERIC SYNONYMS. Acanthopinus Mjöberg, type Haematopinus antennatus Osborn; this specific name being preoccupied was later changed to Acanthopinus sciurinus Mjöberg. Linognathoides Cummings, type Linognathoides citelli Cummings. Lutegus Fahrenholz, type Haematopinus (Polyplax) pectinifer Neumann. Ahaematopinus Ewing, type Neohaematopinus inornatus Kellogg and Ferris. Petauristophthirus Eichler, type Neohaematopinus petauristae Ferris.

CHARACTERS. Polyplacinae in which the antennac are usually at least slightly sexually dimorphic, the third segment in the male having the distal preaxial angle slightly prolonged and bearing dorsally 1-2 small, stout, recurved setae. Head usually abruptly broadened posterior to the antennae. Legs with the first pair small and with slender claw; second and third pairs larger and with stout claw, usually almost equal but the third pair at times larger than the second, although never flattened and expanded. Thoracic sternal plate usually well developed, although lacking in one species. Abdomen always with paratergal plates on segments 3-8, and occasionally with a vestige of such plates on segment one, the plates of segment two never divided longitudinally. Abdomen always with some development of tergal plates in the male and usually so in the female, but in some species with the plates very weakly developed or present only on segment two or 2-3. Female normally with two transverse rows of setae on segments 2-7 dorsally and segments 3-6 ventrally, but in a few species with three rows on these segments. Male normally with but one row of setae on any segment dorsally, except that segment two has two rows; normally with two rows of setae on segments 2-6 ventrally. In all known species the row of dorsal setae which is probably the second row of segment two is associated with an at least slightly developed tergal plate which is posteriorly emarginate, with some of the setae at the lateral ends of the plate somewhat differentiated in size or form from the others and more or less radiately arranged. In some species this character is weakly developed but in all it is to some degree indicated.

NOTES. In spite of some departures by certain species from the characteristic pattern of the venus this group, as here understood, seems to be quite natural and relatively homogeneous. The group of species for which the name Linognathoides might be employed departs most widely from the typical form, especially in its type species, but it would be very difficult to advance any very cogent reason for its separation. The genus Lutegus would, in any event, be a synonym of Linognathoides. The genus Ahaematopinus is utterly without justification and there is no satisfactory reason for the naming of the genus Petauristophthirus.

The genus Neohaematopinus is characteristically associated with members of the rodent family Sciuridae, but two species occur on North American species of the genus Neotoma and perhaps some other closely related genera, these being members of the Murid subfamily Cricetinae. One species recorded from a South American rodent of the family 0ctodontidae probably does not belong to Neohaematopinus.

\section{key to Species of NEDHAFMATOPINIS}

1. Stemal plate of the thorax entirely lackinis; known from Spermophtlus

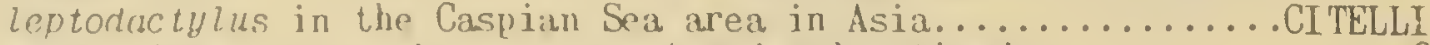

Sternal plate of the thorax present and sclerotized...............

2(1). Thoracic stemal plate always with the posterior angles each pro-

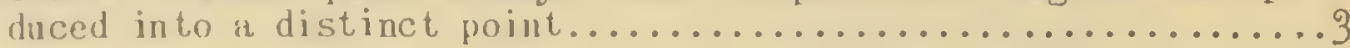
Thoracic sternal plate not with its posterior angles thus produced.

3(2). Paratergites of aldominal segments $4-6$ wi th not more than 2 setae 


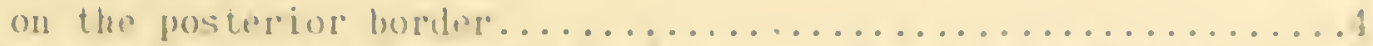

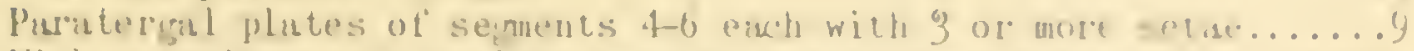

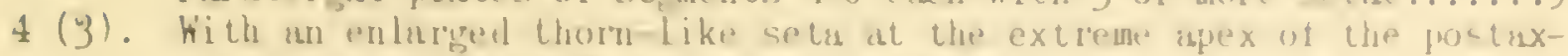
iul angle of the tir'st intennial serment................

hithont such a seta, or if an enlareal, thorn-like seh is developed it is nut at the apex ot the poitaxial distal wape, beine more or less removed theretrou............................ 6

5 (4). Andomen of the fenale with a definitely developed ter al plate assuciated with the interior row of setae on segments 3-7; utribu-

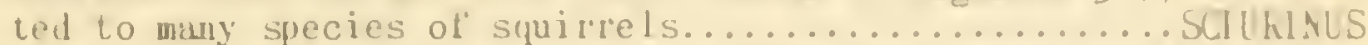

Abdomen of the female with no tergal plate on se rments 3-7; hnowu only from Sciurus griseus in western United State.... rikI SEICULIS

6 (4). Head very broad, detinitely brouder than long; knuwn from Aorth American t'lying squirrels of the genus Glauromds......SCIUN) THI

Head de linitely longer thas broid.......................

7 (6). Known trom Sciurus vulgaris in kurope (see notes under specirs)....

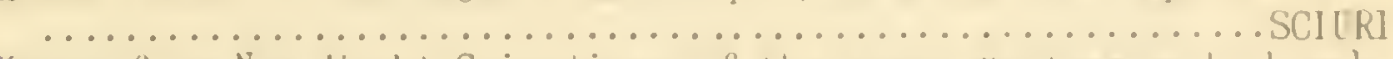

Known from New World Cricetinae of the grens feotoma and clusely

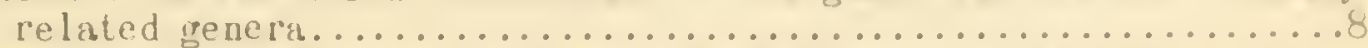

8 (7). Female with no trace ot abdaninal teral and sternisl plates other than those normally present on the terminal and genital segments and extremely small tergal. plates on abdoninal segnent 2: knom irom Neotoma clnerea in western United States........... INORNATUS

Female with definitely developed terial and sternal plates associated with the first row of setae on each abdominal segment; known from Neotoma albigula, Neotoma fuscipes, and Neotoma micropus in southwestem United States and Hodomys alleni in Mexico..NEOTOMAE

9 (3). Paratergal plates ot abdominal segments $3-6$ each with 3 setae on

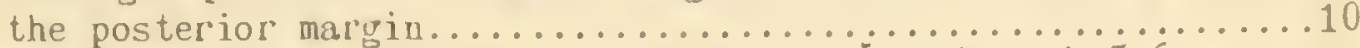

Paratergal plates of abdominal sements $3-6$ each with $5-6$ setae on

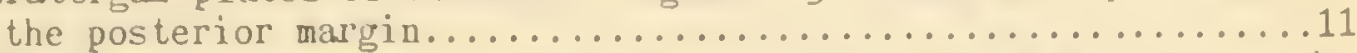

10 (9). First antennal segment with a stout, thorn-like seta borne at the apex of the distal postaxial angle; known from members of the

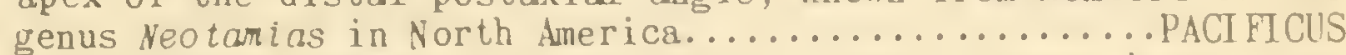

First antennal segment with no trace of such a seta; known Irom Citellus teretlcaudus in southwestern Unuted States... CITELLINUS

11 (9). Paratergal plates of abdominal segments $3-6$ each with 6 setae on the posterior border, these arranged in 2 groups of 3 setae each; known from Sciurus anomalus in Syria............. STRIACUS

Paratergal plates with the setae otherwise arranged.............12

12 (11). Paratergal plates of abdominal segments $3-6$ each with 5 setae which are arranged with a single seta near the ventral angle and a group of $\$$ near the dorsal angle; known from Funambulus

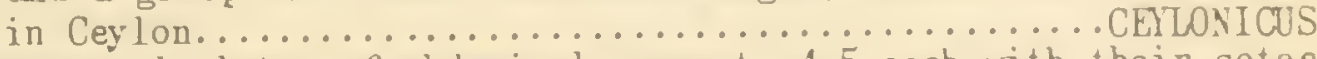

Paratergal plates of abdominal sements 45 each with their setae arranged in 2 groups, the dorsal group with 4 and the ventral group with 3; known from Funambulus palmarum in India ECHIXATUS

13 (2). Paratergal plates of abdominal segments $3-6$ each with one or both of their posterior angles produced into a short, slender, somewhat finger-like process; known from Abrocoma cinerea (a Crice-

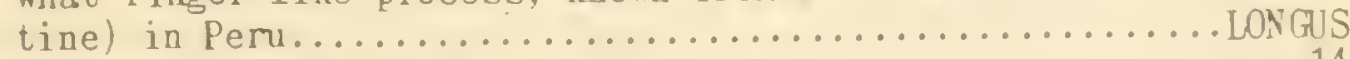

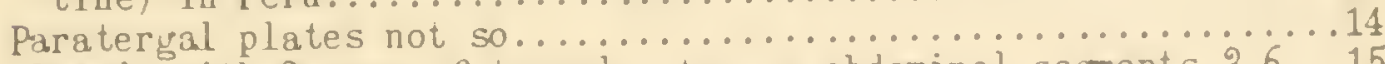

14 (13). Female with 3 rows of tergal setae on abdominal segments $3-6 \ldots 15$ Female with 2 rows of setae on these segments.................

15 (14). Abdomen of the fenale with sclerotized tergal and sternal plates present only on the terminal and genital segments: male with the pseudopenis joined to the apices of the parameres: known frow Atlantoxerus getulus in Alrica................... 
Abdomen of the female with well developed tergal and sternal plates in both sexes; male with the pseudopenis enclosed between the parameres; a group of species from African squirrels

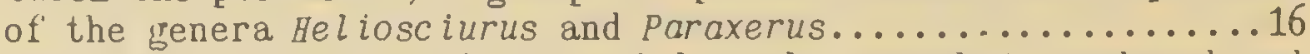

16 (15). Antennae with the distal postaxial angle somewhat produced and vearing a stout, apically blunt seta at its extreme apex.......

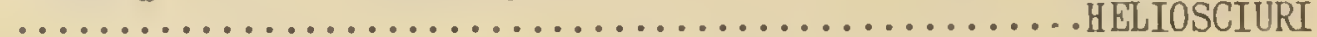

Antennae with the distal postaxial angle not at all produced and if it bears a seta this is small and apically acute.........17

17 (16). Genitalia of the male with the parameres having their lateral

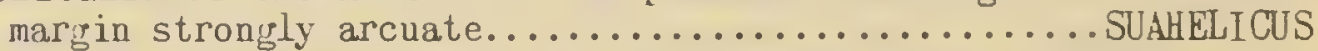

Genitalia of the male with the outer margin almost straight......

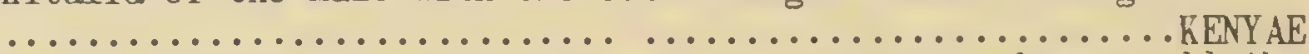

18 (14). Thoracic sternal plate in the shape of a 7-sided polygon, all the

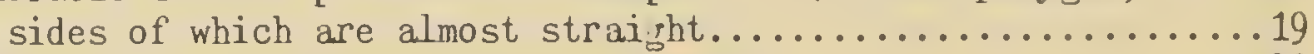

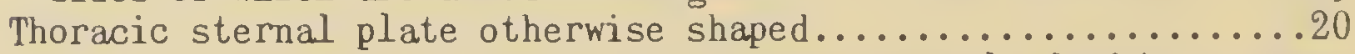

19 (18). Tergal and sternal plates in both sexes entirely lacking except for those present on the terminal and genital seyments; paratergal plates extremely small; known from Petaurista petaurista

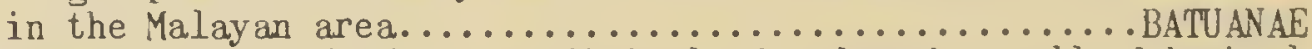

Tergal and sternal plates definitely developed on all abdominal segments in both sexes; paratergal plates strongly developed; known from Petaurista inornatus in Kashmir...........PETAURISTAE

20 (18). Thoracic sternal plate longer than wide, relatively narrow, somewhat irrerular in shape; known from Xerus inaur is in Africa....

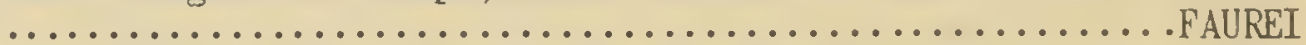

Thoracic sternal plate as wide as long or wider, usually more or less transversely oval; a sroup of forms occurring on the Marmota section of the Sciuridae (see notes under laeviusculus) .21

21 (20). Thoracic spiracles notably large, their diameter equaling about one-half the length of the second coxae; known f'rom Marmota and perhaps occurring on some species of Citellus in North America.

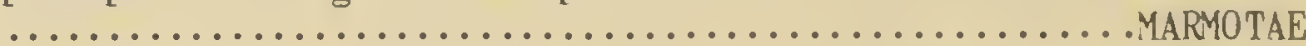

Thoracic spiracles smaller, scarcely exceeding one-fourth the lenith of the second coxae and usually smaller............22

22 (21). Rows of tergal and sternal setae on the abdomen continuous across each seyment, not interrupted by bare areas..............23 Rows of tergal and sternal setae across the abdomen interrupted by bare areas which divide them into lateral and median groups

23 (22). Setae of the ventral rows of segments all noticeably stout (according to the original description); described as occurring on

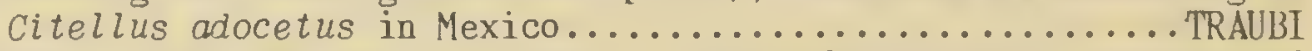
Setae of all the ventral rows slender; 2 described species of which one, PATIKI, is probably a synonym of.........LAEVTUSCULUS

\section{Neohaematopinus batuanae Ferris}

1923. Neohaematopinus batuanae Ferris, Contributions Toward a Monograph of the Sucking lice, Part 4:261; rigure 16713.

HOSTS AND DISTRIBUTION. From Petaurista batuana from the Batu Islands, Malaysia.

\section{Neohirmatopinus ceylonicus Ferris, new species}

1922. Neohaematopinus echinatus (Neumann), Ferris, Contributions Toward a Monograph of the Sucking lice, Part 4:250; figure 161. (Misidentification) 


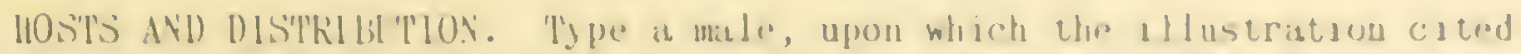

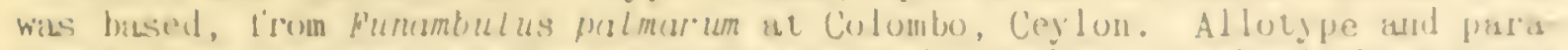

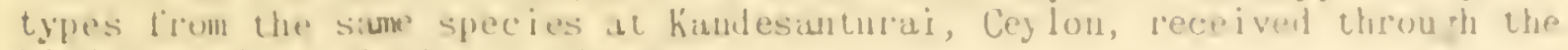
kindness ut" Yr. liorilon 13. Thumpsun.

Chakd'Tliks. Male as describel and illustrated in the reterence cited. f'emale about "num. long. As in the male the paratergites of abdominal seg ments ") each bear lour stout setae of varying lemgth on the dorsal hall and a single seda on the ventril hall, this being well separated trom the others.

NOTES. It was inlicated by ferris that the single specimen upon which his description was hased did not arree entirely with the description fiven by Neunam and it is now elear that it does not represent Neunann's species, since specimens of the litter are now availuble which afree with the types. It is undoubtedly close to the true echinatus.

\section{Neohaematopinus citelli (Cumminos)}

1914. Linonnuthoiles spermophlli Cummings, Bulletin of ḱntomological Research 5:160; ri rure 3. (Specillic name preoccupied)

1916. Linognathoires citelli Cunminiss, Annuls and Margazine of Nitural History (Scries 8) 17:107.

1923. Neohaematopinus citelli (Cumnings), Ferris, Contributions Toward a Mono rriph of the Suchin' hice, Part 1: 261; 1"i jures 169, 169.

IOSTS AND DISTRIBUTION. Orisinally recorded t'rom citellus leptodactylus and from Cricetulus phaeus from Trunscaspia. The record from Cricetulus is almost certainly an error aud can probably safely be disregarded. The probable true host is now known as Spermophilonsis leptodact!llus.

\section{Neohaematopinus citellinus Ferris}

1942. Neohnematopims citellinus Ferris, Microentomolon 7:85; figure 41. HOSTS AND DISTRIBUTION. Type from Citellus teret icaudus at Tucson, Arizona, and other specinens attributed to Ammospermophilus harrissi from the Santil Rita Mountains, Arizona, United States.

\section{Neohacmatopinus echinatus (Neumann)}

1909. Hoematopinus (Polyplax) echinatus Veumann, Archives de Parasitologie 13: 517; figures 19, 20.

1912. Hohaematopinus echinatus (Neumann), Cumnings, Bulletin of Entomolopical Research 3:393.

HOSTS AND DISTRIBUTION. Recorded from Funambulus palmarum t'rom Rajkote, India, this being some other species of the genus. Specimens are at hand t'rom the same host genus at Arra, India, which arree with the original description, these received through the kindness of Mr. Gordon B. Thompson.

NOTES. The specimens at hand trom Asra indicate clearly that this species was misidentified by Ferris. The species attributed by him to echinatus is here described as reohaematopinus ceylonicus.

\section{Neohaematopinus faurei (Bedtord)}

1920. Linoenathoiles faure $i$ Bedford, Report of the Director of Veterinary Research, Union of South At'rica 7-9:710; Plate 1, figure 2; Plate $r$, ligure 3.

1932. Neohaematopinus faurei (Bedford), Ferris, Contributions Toward a Yonograph of the Sucking Lice, Part 5:292; figures 178, 179.

HOSTS AND DISTRIBUTION. Recorded by Bedford from Geosciurus capensis, which is now known as Xerus inaur is, Bloemfontein, Orange Free State. It 
was later recorded by Bedford from this host in other localities in South Africa, and from Tatera and Rattus coucha. Specimens at hand received from Bedford are indicated as being from Mongoose. It is practically certain that the true host is the species of Xerus.

NOTES. This is an extreme member of the genus, even of the section to which the name Linognathoides has been applied. The male has no sclerotized tergites and the characteristic form of tergite two, with its associated grouping of setae, is here represented only by a slitht irrergularity.

\section{Neohaematopinus griseicolus Ferris}

1923. Neohaematopinus sciurinus griseicolus Ferris, Contributions Toward a Monograph of the Sucking Lice, Part 4:248.

HOSTS AND DISTRIBUTION. Type from Sciurus griseus at Inverness, Marin County, California, U. S. A. Also recorded from the same host at other localities in California.

NOTES. It is perhaps inconsistent to recomize this form as a species, in view of the wide range of forms retained in sciurinus, but all the specimens at hand agree in the almost complete absence of abdominal tergal and sternal plates in the female, while in all other specimens included in sciurinus no such departure occurs.

\section{Neohaematopinus heliosciuri Cummings}

1913. Neohaematopinus heliosciuri Cummings, Bulletin of Entomological Research 3:393; figure 1.

1923. Neohaematopinus heliosciuri Cummings, Ferris, Contributions Toward a Monograph of the Sucking Lice, Part 4:255; figures 164, 165A, C, $\mathrm{E}, \mathrm{H}$.

HOSTS AND DISTRIBUTION. Type from Paraxerus (as Heliosciurus) palliatus from Uchweni Forest, Witu, British East Atrica. Also recorded from Paraxerus ochraceus (as Paraxerus jacksoni and as Parasciurus animosus) from various localities in British East Africa.

\section{Neohaematopinus inornatus (Kellom and Ferris)}

1915. Linognathoides inornatus Kellogg and Ferris, Anoplura and Mallophacra of North American Mammals, Stanford University Publications, University Series (no volume number), page 25; text figure 10; Plate 4, figure 7; Plate 5, figure 5; Plate 6, fizure 3.

1923. Neohaematopinus inornatus (Kellowg and Ferris), Ferris, Contributions Toward a Monograph of the Sucking lice, Part 4:252; figures $162,163$.

1929. Ahaematopinus inornatus (Kellogg and Ferris), Ewing, A Manual of External Parasites, page 198.

1942. Neohaematopinus inornatus (Kellogg and Ferris), Ferris, Microentomology 7:84; fiinure 39.

HOSTS AND DISTRIBUTION. Type f'rom Neotoma cinerea, South Yolla Bolly Mountain, Tehama County, California. Recorded also f'rom the same host from Yosemite Valley, Cal ifornia, and from "mountain rat," which was almost certainly the same host, from Colorado.

NOTES. 'This species has becn designated as type of the genus Ahaematcpinus kwing, a genus for which there is, in the opinion here held, no excuse whatsoever.

Neohaematopimns kenyae Ferris

1923. Neohaematopinus kenyae, Ferris, Contributions Toward a Monograph of 


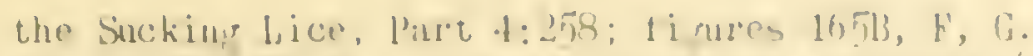

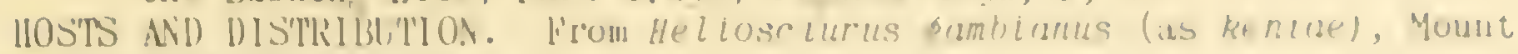
kenyat, British liast Aloicit.

\section{Neohiminitopims linvinsculus (finube)}

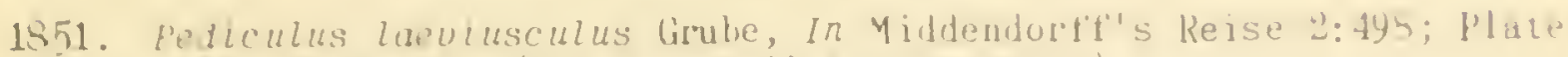
32, linule 7. (Fi rure labelled spermophlli)

1596. Haematopinus montamus 0sborn, United States Department of Arriculture, Division ot kintomolopy, bulletin (ntew ser.ies) 5: 18.1; 11i. 107.

1900. Hoematoplnus columblanus Osborn, Canalian Enloublo;ist 32:215.

190.1. Polyplar laeviuscula (Grube), tuderlein, Wolo pischer tuze iger an: 14:.

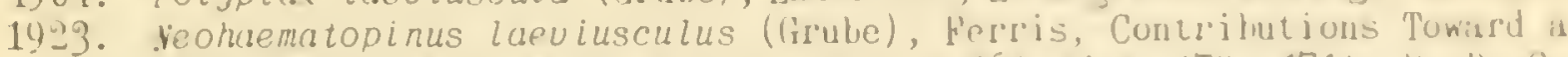

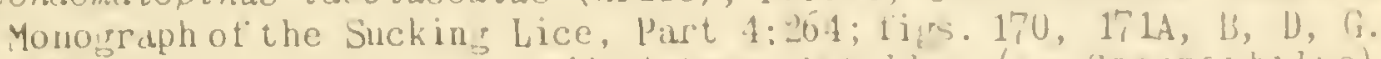

llosl's AND DISTRIBITION. Described trom l'Ltellus (is Spermophtius) eversmanni, Jakutsk, Siberia. Later recorded lrom this host 1 rom Altai, siberia, and from a long $\mathrm{L}$ ist of other species of chellus from North America ranfinf from Point barrow through western United Stites into Mexico, and from Cynomys leucurus Prom Colorudo in the United States.

NOTES. A re-examination ot" all the available material shows no sulistactory basis tor breating this species up, althou a considerable degree of variation exists. Kubin has named three species ot this roup, which will here be listed as distinct although the opinion is held that they cinnot be definitely recoinized. Even the species marmotae, which is probahly the most definitely difterentiated form in the proup, presents no very precise limits and some specimens have been seen which are dubiously referable either to this or to laeviusculus.

The prayer may be voiced that future students will at tempt to learn somethin: about the group before enguring in the indiscriminate naming of new species.

\section{Neohaematopinus longus herneck}

1949. Neohoematopinus lonsus herneck, Revista brasiliera de Biologia (8) 2: 175; fi rure.

HOSTS AND DISTRIBUTION. Recorded Irom Abrocoma cinerea at Caccachara near Llave, Peru. The host is a member of the subtamily Abrocominae of the family Echimyidae.

NOTES. This species is known trom but a single lemale wich was evidently very impertectly prepared tor study. It is hishly probable that it does not belong to this genus.

\section{Neohamatopinus mamotae Ferris}

1923. Neohoematopinus marmotae Ferris, Contrihutions Toward a Monograph of the Sucking Lice, Part 4:265: figures 171C, E, F.

HOSTS AND DISTRIbUTION. Type from yarmota flaviventris, losemite National Park, California. Recorded also from Yarmota species at Florence. Yontana. Specimens which ayree very closely with the type are at hand from Ferris has previously doubtfully referred a specimen from varmota aurea from Panir, Asia, to this species.

NOTES. While in its typical torm this species seens clearly to be separable trom lneviusculus, specimens have been exanined from sormota and from species of Citellus which raise some question as to the validity of the species, or at least as to its limits and definition. The study o more material will be required for any satisfactory solution of the problem. 
1946. Neohaematopinus mathesoni Rubin, Proceedings of the Entomological Society of Washin rton $48: 121$; firure 1.

HOSTS AND DISTRIBUTION. Described from "Citellus v. couchi," which is presumably Citellus variegatus couchi from the state of Nuevo Leon, Mexico.

NOTES. A specimen from the type lot of this and other specimens from the same host species (as subspecies srammurus) are at hand from Arizona. It is very doubtful that the species can be distinguished from laeviusculus.

\section{Neohaematopinus neotomae Ferris}

1942. Neohaematopinus neotomae Ferris, Microentomolosy 7:84; f'igure 40.

HOSTS AND DISTRIBUTION. Type from Neotoma albiछula at Tucson, Arizona, and other specimens from the same host near Tucson. Also recorded from Neotoma streatori from the Hastings Reservation near Monterey, California, and from Hodomys alleni from Manzanillo, Mexico. Specimens from Neotoma micropus from White Sands, New Mexico, have been somewhat doubtfully referred to the species.

\section{Neohaematopinus pacificus Kellogg and Ferris}

1915. Neohaematopinus pacificus Kellogig and Ferris, Anoplura and Yallophara of North American Mammals, Stanford University Publications, University Series (no volume number), page 38; text t'igure 14C, D; Plate 5, figures 3, 7a, b.

1923. Neohaematop inus pacificus Kellogg and Ferris, Ferris, Contributions Toward a Monograph of the Sucking Lice, Part 4:249; f'igure 160A-D.

HOSTS AND DISTRIBUTION. Type from Neotamias townsendi $i$ at Freestone, Sonoma County, California. Recorded also from Neotamias hindsi, merriami, alpinus, and speciosus (as Eutamias) from various localities in California, U. S. A.

\section{Neohaematopinus patiki Rubin}

1946. Neohaematopinus patiki Rubin, Proceedings of the Entomological Society of Washington $48: 121$; f'igures 2, 5 .

HOSTS AND DISTRIBUTION. Recorded as from an undetermined species of the subgenus Ammospermophilus of the genus Citellus at Delta, Utah.

NOTES. Unfortunately no material from any species of Ammospermophilus is available and consequently it is not possible to offer any observations in regard to this supposed species of Neohaematopinus, other than to express extreme doubt that it can be recognized.

\section{Neohaematopinus pectinifer (Neumann)}

1885. Haematopinus setosus Piayet, Les Pediculines, Supplement, page 143; Plate 15, figure 6 (preoccupied).

1909. Haematopinus (Polyplax) pectinifer Neumann, Archives de Parasitolouie $15: 528 ;$ fiimures $28,29$.

1914. Linognathoides pectinifer (Neumann), Cumminis, liulletin of Entomological Research 5:160.

1916. Lutegus pectinifer (Neumann), Fahrenholz, Archiv für Naturgeschichte, Ahteiluag $A, 81: 11: 31$.

1923. Neohaematoplnus pectinifer (Neumann), Ferris, Contributions Toward a Monoisaph of the Sucking Lice, Part 4:268; figure 172. (Description of male)

1932. Neohaematopinus pectinifer (Neumann), Ferris, Contributions Toward a 


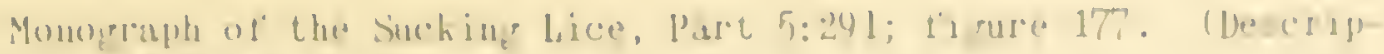
tion of lem.teles)

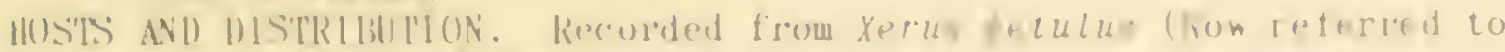

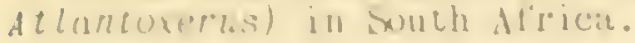

Teohimmistupinus petare istase ferr is

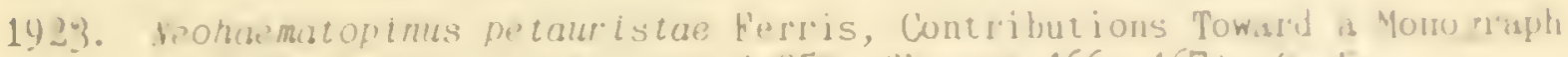
of the Sucting lice, Part 4:258s; ti pures 166, 167 A, C, E.

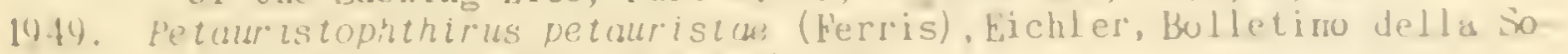
cieta fintomolo ricis I tal iava 79: Lu.

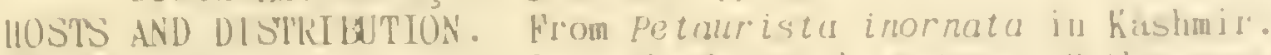

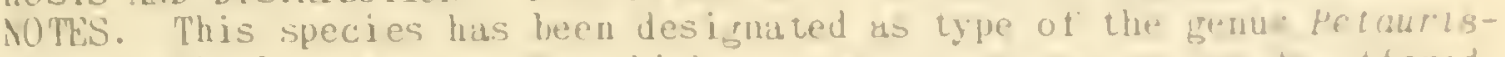
tophthirus lichler, a genus tor which no very cogent reasun cin te offered.

Neohuematopiuns sciur i dincke

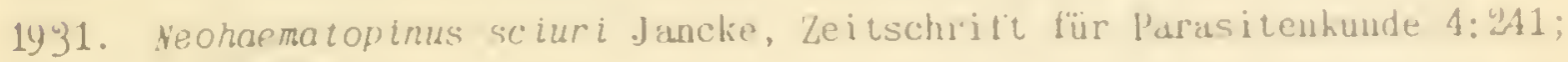
limures.

HOSTS AND DISTKLBUTION. Described fron Sc iurus unlsarts in liermany and later recorded from the sime host in that country. North american and Asiatic material that mipht be referred to this species is as follows: from Sciurus aberti in Arizoni, Sciurus corolinensis tron Yississippi, Sciurus poliopus trom 0axuca, Yexico-all these from liorth America; from "Maliayan squirrel" in the Zoological Gitrdens of' London, from Callosciurus finlaysoni, caniceps, and procerus in the Yalayan area. Other specimens approach the condition seen in these with various derrees ol closeness.

See notes under teohaematopinus sciurinus.

\section{Neohaematopinus sciurinus Mjölerg}

1891. Hoematopinus anternatus Osborn, United States Department of Apriculture, Division of Entomolog, Bulletin (old series) 7:25; fi pure 13. (Not Hoematopinus antennatus Piagret)

1910. Acanthopinus antennatus (Osborn). Mjöberg, Arkiv tör Zoologi 6:161. 1910. Acanthopinus sciurinus Mjöber, Arkiv för Zoolori 6:161.

1915. Neohaematopinus antennatus (Oshorn), hellog and Ferris, Anoplura and Millopha of North American Yammals, Siantord University Publications. University series (no volume number), page 36 ; text figure 14A, B; Plate 5 , figure 10; Plate 6, t’igure 5.

1916. Veohamatopinus antennatus semifasciatus Ferris, Psyche 23:100.

1919. Neohaematopinus macrospinosus Fahrenholz. Jahreshericht des niedersächsischen zoologischen Vereins zu Hannover 5-10:24.

1923. Neohomatopinus sciurinus (Yjöberg). Ferris, Contribulions Toward a Yonorraph of the Suckin: Lice, Part 4:243: tigures 155, 158. 159.

IIOSTS AND DISTRIBUTION. The types of'Oshorn's Haematodinus antennatus were tron Sciurus rieer rufiventer at Ames, Iowa. The types of Mjober p's Acanthopinus sciurinus were recorded as trom sciurus lulpinus, which is a synonym of niger, in the Hambur: Zoological Garden, Germany. Later recorded by ferris from a lon; list of species of Sciurus and related genera from North America, Central America and Suth America and from the Malayan Region. The list will not here he repeated. since it will be necessary for future workers to reconsider the entire situation in any case lelore the problem of the extent ot the species can be settled. This is considered in the tollowing notes.

NOTES. The very considerable amount of material at hand has heen carefully reviewed in connection with this work, with results but little more satistactory than those recorded hy feris in 1923. Hithin this material 
the only character that seems to offer any basis for a separation into species is that of the enlarged seta on the first antennal segment. In typical sciurinus this seta is quite large and is borne upon a prolongation of the posterior apical angle of the segment, the whole structure forming a pronounced hook. Every degree of variation in this structure is present in the material at hand, down to specimens in which the seta is scarcely present at all. Attempts at arrangin this material in groups according to hosts and according to geography have revealed no logical pattern. Thus, specimens from squirrels of the genus Callosciurus in the Malayan area are practically identical with specimens from Sciurus aberti from Arizona in the United States.

Certain of the material at hand would apparently be referable to Neohaematopinus sciuri Jancke, described from the European Sciurus vulgaris, on the basis of the development of this seta on the first antennal segment. But if we attempt to group specimens on this basis, arain no logical pattern appears. While the species sciuri is here listed, this is done solely in order not to prejudice any development of later studies and for the present all other material of this type is referred to sciurinus.

The problem must be left to future workers who may be able to accumulate a great mass of material from a long series of squirrel species.

\section{Neohaematopinus sciuropteri (Oshorn) Figures 86,87}

1891. Haematopinus sciuropteri Osborn, United States Department of Agriculture, Division of Entomology, Bulletin (old series) 7:23; fig-
ure 12.

1910. Neohaematopinus sciuropteri (Osborn), Mjöberg, Arkiv för Zoolori 6: 160 ; figure 79.

1923. Neohaematopinus sciuropter $i$ (Osborn), Ferris, Contributions Toward a Mono 'rraph of the Sucking Lice, Part 4:241; figures 156, 157.

HOSTS AND DISTRIBUTION. Described as from Sciuropterus volucella, which is a synonym of Glaucomys volans, at Ames, Iowa. Later recorded from Glaucomys sabrinus at Yosemite National Park, California.

\section{Neohaematopinus suahelicus Ferris}

1923. Neohaematopinus suahelicus Ferris, Contributions Toward a Monograph of the Sucking Lice, Part 4:258; figures 165B, F, G.

HOSTS AND DISTRIBUTION. Described as from Paraxerus palliatus from British East Africa, and recorded from Paraxerus ochraceus (as jacksoni and as Parasciurus animosus) from the same area.

\section{Neohaematopinus syriacus Ferris}

1923. Neohaematopinus syriacus Ferris, Contributions Toward a Monograph of the Sucking lice, Part 4:250; fiinure 160E.

HOSTS AND DISTRIBUTION. From Sciurus anomalus (as syriacus) from Syria.

Neohaematopinus traubi Rubin

1946. Neohaematopinus traubi Rubin, Procecdings of the Entomolorical Socicty of Washington 48:120; figures 3, 4 .

HOSTS AND DISTRIBUTION. Described as from Citellus adocetus from the state of Michaocin, Mexico.

NOTES. This species is supposed to be separable from laeviusculus and other members of that gronp by having the abdomen with three rows of setae on each "typical sement." However, the accompanying illustration does not 


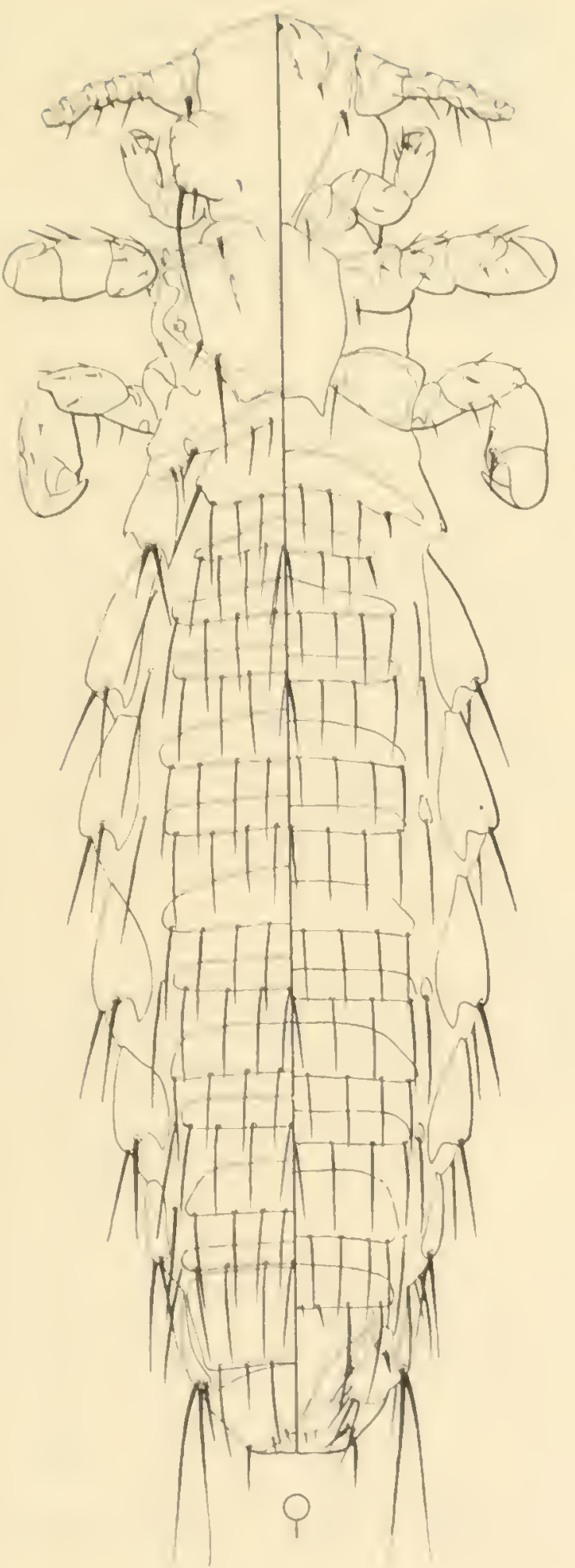

Neohaematopinus sciuropteri (Osborn)

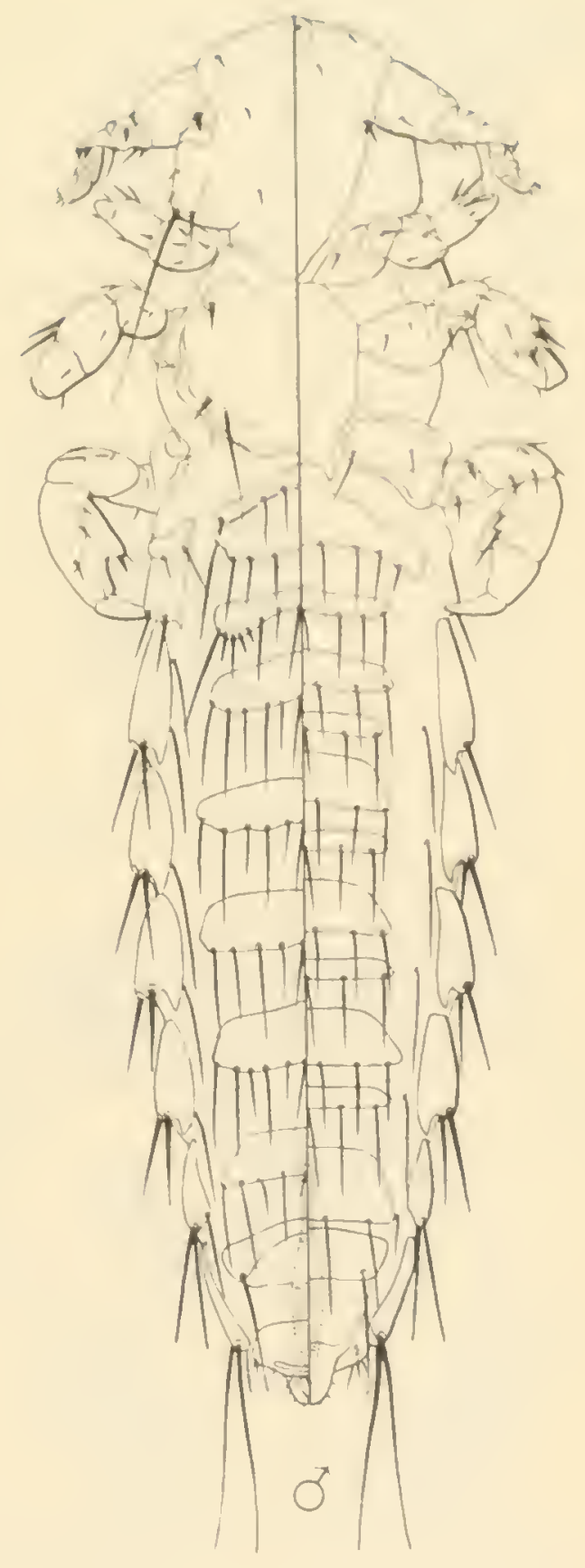

Figure 86 


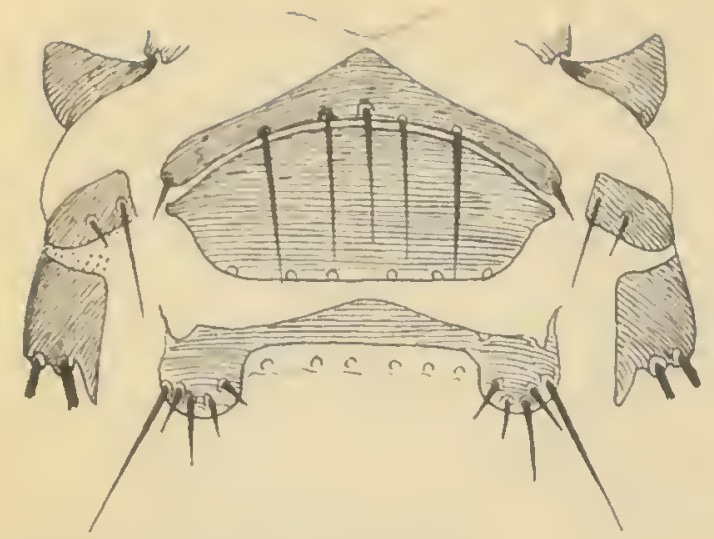

basal abdominal tergites
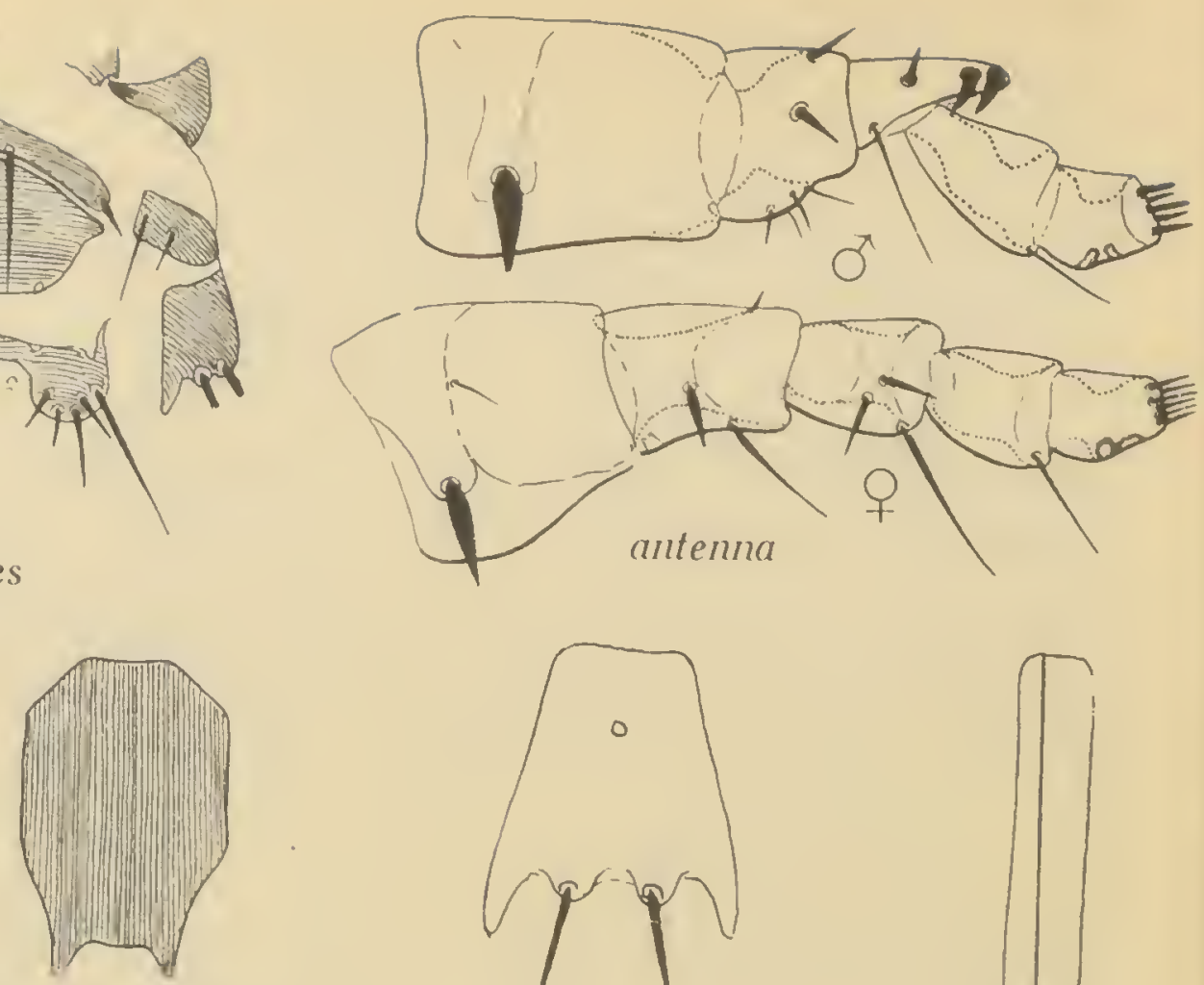

thoracic sternal plate
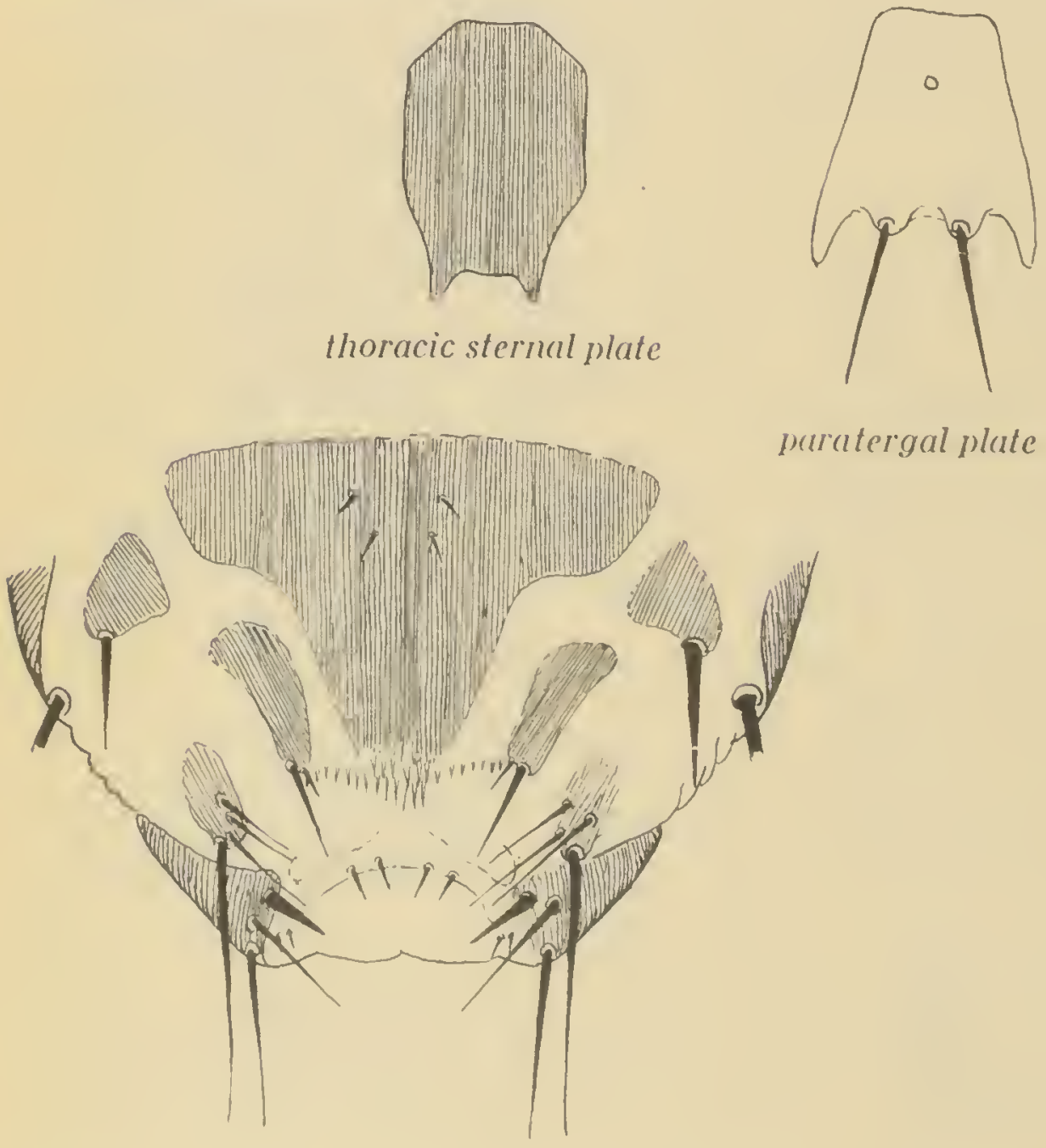

Mratergal plate

female yenitalia

mule genitalia

Neohaematopinus sciuropteri (Osborn), details

Figure 87 
arree with the description. It provides on ly tourteren rows of se tae he he

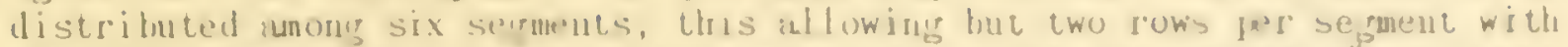
two lelt over, which does not indicate chat a "typical se mont" can have

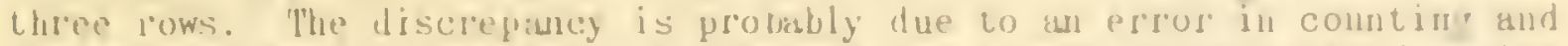
the surmise maty he hatarded thut thr species is uot distinguished as its anthol suphoseil. However, inceording to the illustrition iven, the stont110 is of the velltial setive mity pussibly utturd a bisis for its recurnition.

Genus PHIHI RPEDICLLIS kwine

192.). Phthirpentculus kiwin, Journal of the hishin rtun Acadeng uf Sciences 13: 1.48 .

1932. Phthirpediculus, f'eris, Contributions Toward a Munoprespli of the Sucking Lice, Part 5:245. cies.

GENERIC TYPE. Phthirpeniculus propitheri Ewing, the only included spe-

CAARACTERS. Polyplacinae wilh tive-segnented untemase which are sexully dimorphic, the male having the distal, preaxiul ungle of the third segment produced and henring dorsally two, stou, petrorse setare. Anterior leirs small, with weat cliw; inidule and posterior leirs about equal to each other, enlarged and stuut, with scout cliw. Palatergal plates present on abdominal seuments $3-6$, distinctly developed and with tree apical angles; marked by having the bisal, mesal anple produced into a distinct sclerotization which extends somewhal toward the inid-line of the body and bears two slender setae. Jtherwise the abdumen in both sexes is membranous except for the usual terminal and genitalic plates. Fach abdominal segment, both dorsally and ventrally, with one row of setae except that in the female the dorsum of segment two apparently has two rows. Abdominal spiracles present on sements $3-8$. Prothoracic sterual plate distinctly developed, of a peculiar type, bein! divided longitudinally into two plates, each of which bears a pair of slender setue at its posterior end.

\section{Phthirpediculus propitheci Ewing} Fi gures 88,89

1922. Phthirpediculus propitheci Ewing, Journal of the Hashington Academy of Sciences 13: 119 .

1932. Phthirpediculus propitheci Ewing, Ferris, Contributions Toward a 'Monorraph of the Sucking Lice, Part 5: 296; figures 190, 181.

HOSTS AND DISTRIBITION. From Propithecus eduardsi, a lemur, from Madagascar.

\section{Genus POLYPLAX Enderlein}

1904. Polyplax Enderlein, Zooloyischer Anzeiger $3: 142,223$.

1907. Eremophthirius Glinkiewicz. Sitzungsberichte der mathematischnaturwissenschaftlichen Class der kaiserlichen Akademie der Hissenschaften zu wien 116:381.

1909. Haematopinus (Polyplax), Neumann, Archives de Parasitologie 13:529.

1923. Polyplax. Ferris, Contributions Toward a Monograph of the Sucking Lice, Part 4:184.

1929. Polyplax, Ewinip, A Yanual of External Parasites, pare 137.

1935. Polyplax, Ewing. Proceedings of the Biological Society of Hashington 48: :01.

1935. Bremophthirius, Ewing, Proceedinss of the Biological Society of Washin:ton 49:201.

1838. Polyplax, Fahrenholz, Zeitschrift für Parasitenkunde 10:239.

1938. Eremophthirius, Fahrenholz, Zeitschritt für Parasitenkunde 10: 242. 


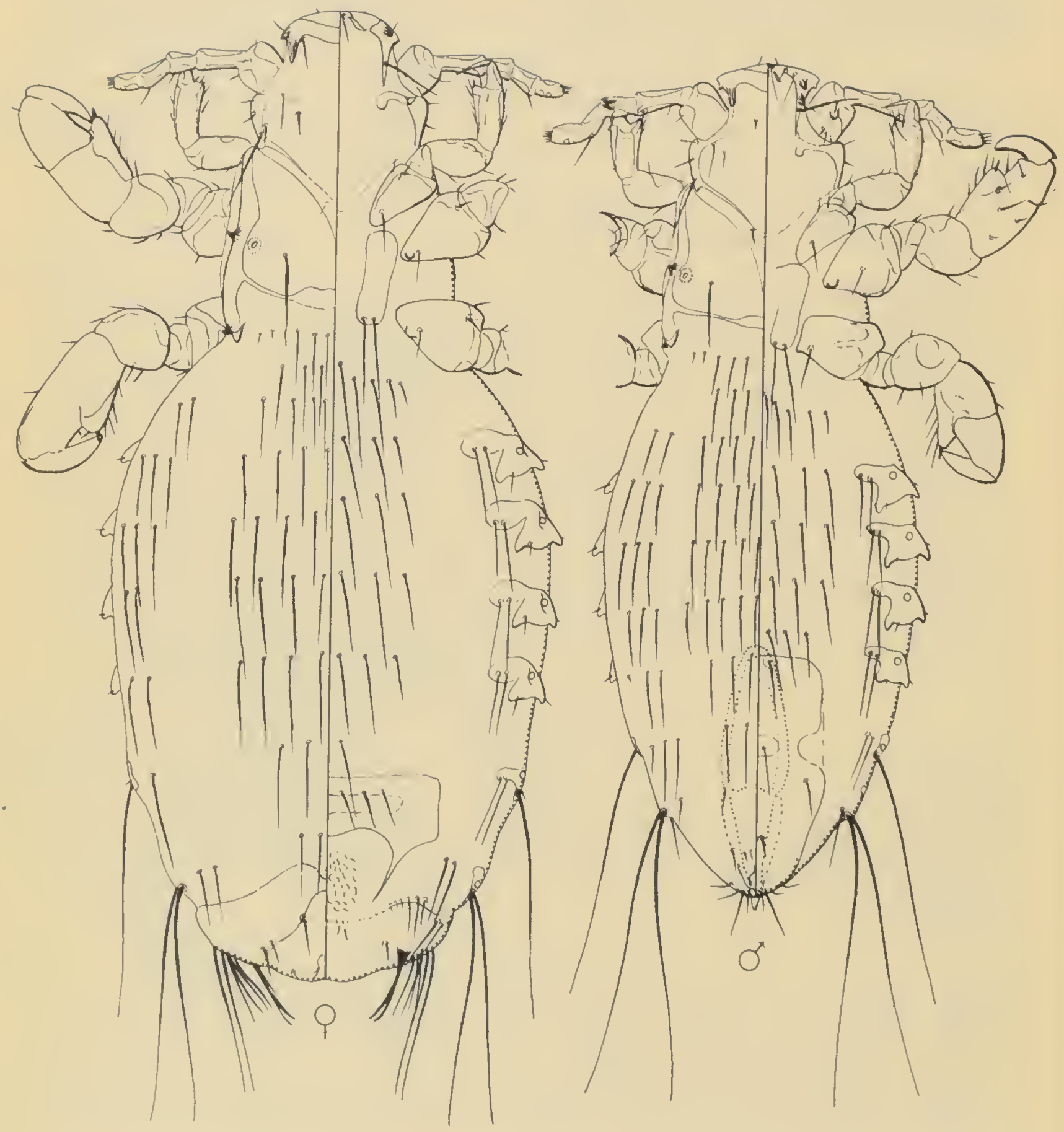

Phthirpediculus propitheci Ewing

Figure 88 


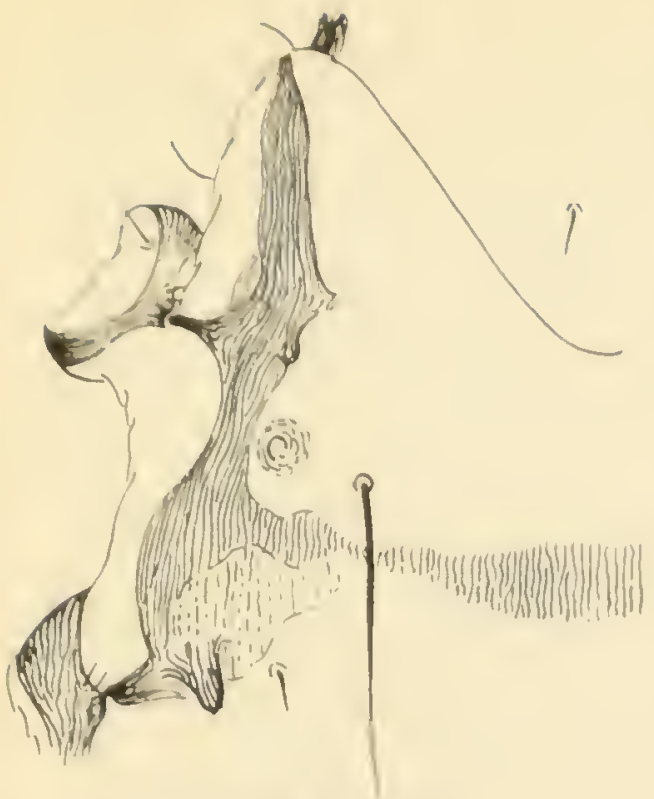

thoreacic dorsmun
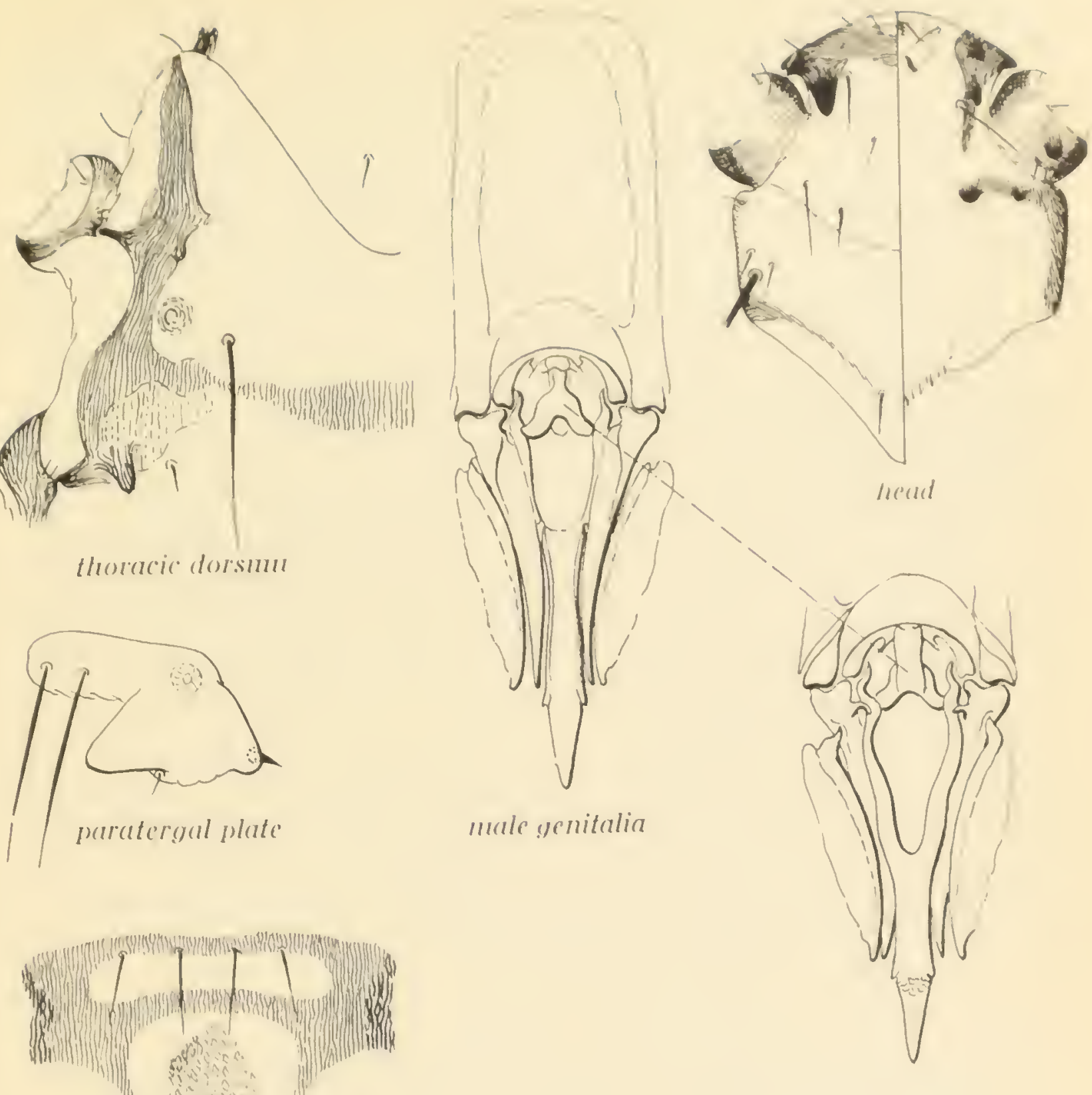

hend

male yenitalio
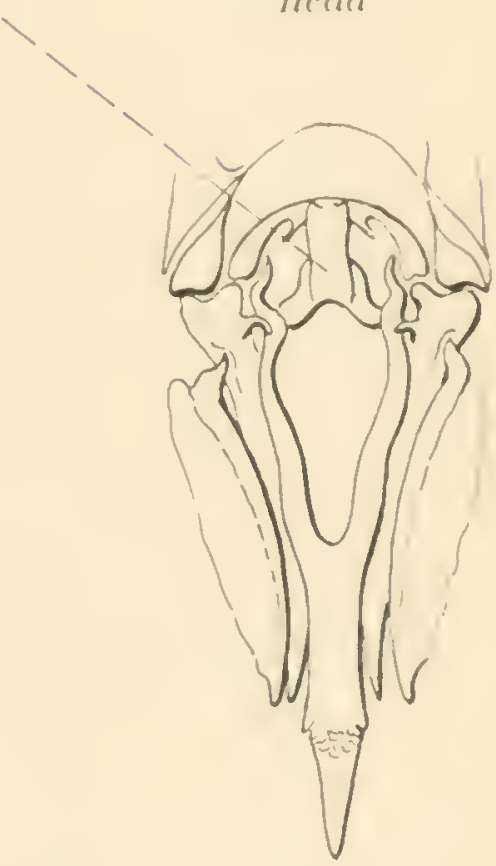

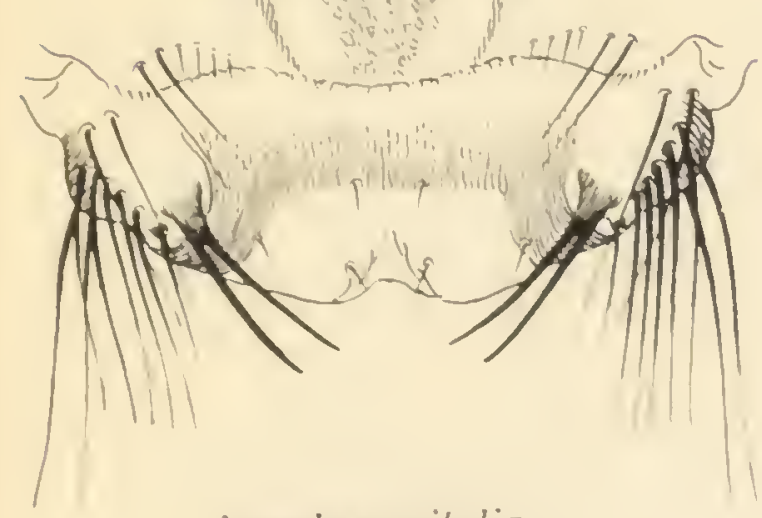

female yemitalia

Phthirpediculus propitheci Ewing

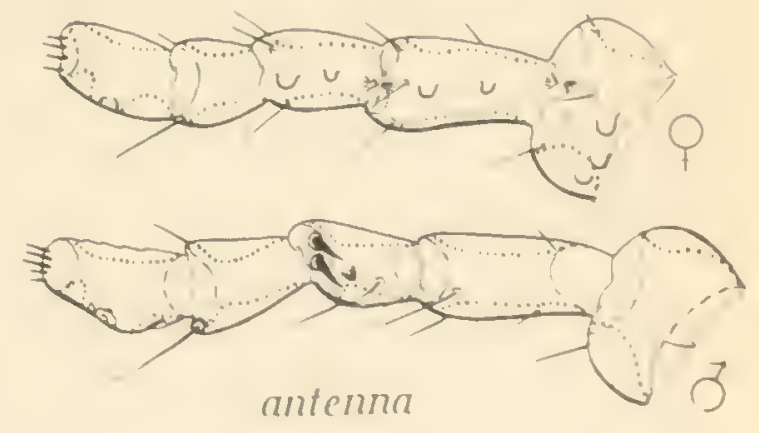

Figure 89 
GENERIC TYPE. Pediculus spinulosus Burmeister.

GENERIC SYNONYM. Eremophthirius Glinkiewicz, of which the type by monotypy is Eremophthirius werneri Glinkiewicz.

CHARACTERS. Polyplacidae with five-segmented antennae which are usually at least slightly dimorphic, the males commonly having the distal, preaxial angle of the third segment somewhat produced and bearing at its apex a recurved spine or short, recurved, stout seta. Head usually abruptly widened behind the antennae, but not always so. Thorax usually with a well developed sternal plate which around its margins is free from the body wall. Anterior legs small and weak, with slender claw. Middle legs definitely somewhat larger, with stouter claw. Posterior legs similar to the second but still larger, with stouter claw, but never strongly flattened or expanded. Abdomen with paratergal plates always developed on segments $2-8$, the plates of segment two having the appearance of being divided longitudinally into two pieces, one of which lies upon the dorsum. It is possible that this dorsal piece actually represents the paratergite of segment one, although occasionally the plates of segment three are similarly divided. Parater rites of segments 4-6 usually with each posterior angle produced into a slight point, or occasionally into a slender process, the posterior margin between these points being entire; at times with only the ventral angle produced. Teryal and sternal plates always developed and sclerotized, the female having two plates and two rows of setae on segments 4-7 dorsally and on segments $3-7$ ventrally; the male with not more than one plate and one row of setae on any semnent dorsally and with either one or two plates on the abdominal segments ventrally. The ventral plates on segments $2-3$ are never produced laterally to articulate with or approximate the paratergal plates of these sergments.

NOTES. The opinion previously expressed by Ferris that Eremophthirius should not be separated from Polyplax is here still maintained. Fahrenholz has attempted to revive Eremophthirius on the basis of the presence in the male of but one ventral plate on any abdominal segment, but any such division results merely in quite meaningless groupings of the species.

The members of the genus polyplax occur almost exclusively upon members of the rodent family Muridae, although at least one species seems to occur nomally upon members of the insectivore family Soricidae.

\section{Key to Species of POLYPLAX}

A very considerable degree of difficulty has been encountered in preparing a key to the species of this genus. The characters separating some of the species are clear enough when specimens are compared directly, but are not sufficiently trenchant to be of much use in a key, or are of such a nature that they cannot be expressed with the conciseness which is desirable in a key. Furthermore, of some species only one sex is known. In some other instances the male only may present especially distinctive char acters. Because of these facts the presentation of separate keys to the sexes is no more practicable than it is to include both in the same key. This introduces serious dif'iculties, but at the present time there seems
to he no way to avoid them.

It should be remembered, also, that some of the species are known from hut very lew specimens and consequently the possible range of variation is unknown. Under these circumstances the key must be used with caution.

The following species, known only from their original descriptions, are omitted from the key: dentaticornis Ewing, eriopepll (Eving), spinigera
(kurmeister). 


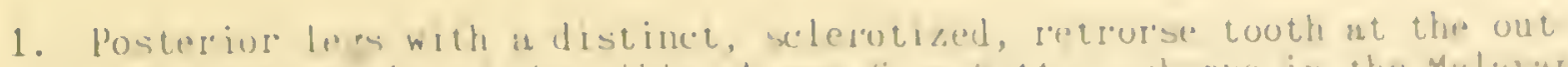

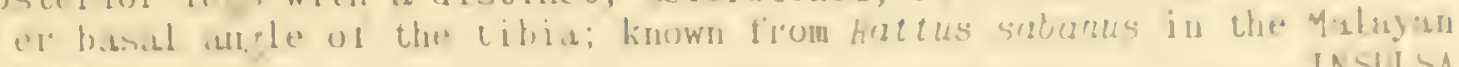

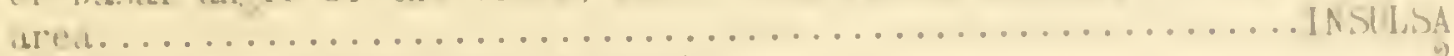

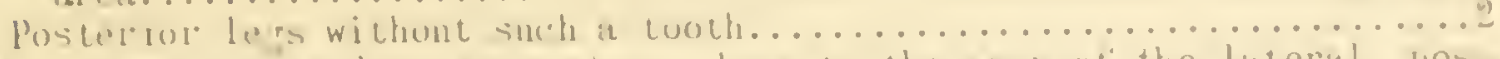

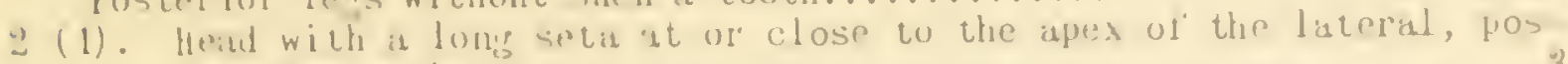

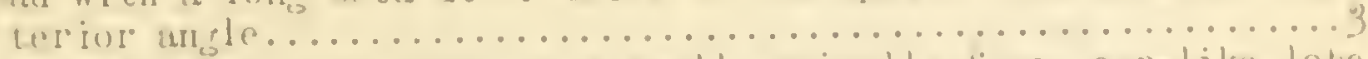
Heiul with this seta borne on a small, apically lree, ear-like lobe which is somewhat removed trom the apex of the posterior lateral ansle; oceurrin: on New horld species of the renera Peromyscus, Onjehomys, ind Re ithrorlontomys.................................

3 (2). Abdomen with ter zul and sternal plates undeveloped in the lemale, except for those associated with the penital segments and one or two very small tergal plates at the base of the abdomen; knowil

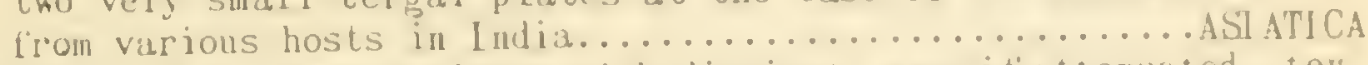

Abdomen ot the lemale always with distinct, even it’atlenuated, ter-

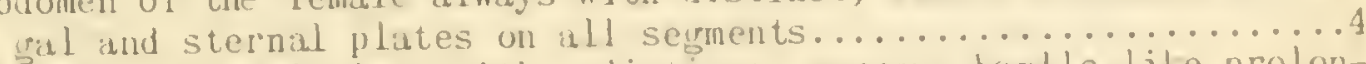

4 (3). Thoracic sternal plate with a distinct, narrow, hanlle-lihe prolonration extending torward hetween the anterior coxis, this prolonvation be ing one-fourth as long ws the plate itself or longer...5

Thoracic sternal plate at the most with nothing more than a slight

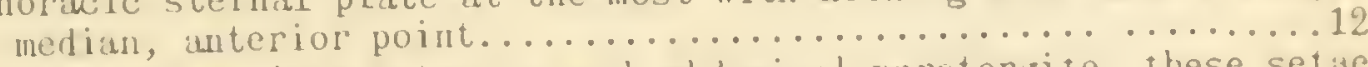

5 (4). With a pair of long setae on each abdominal paraterite, these setace

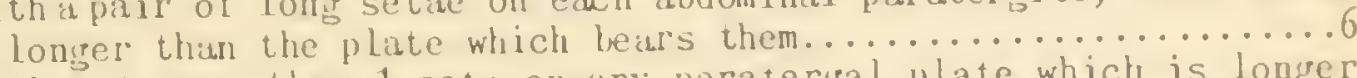

with not more than 1 seta on any paratergal plate which is longer than the plate which bears it, and such setae not present at all

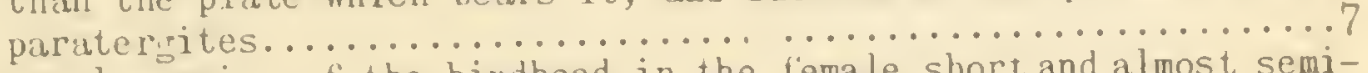

6 (5). Lateriul marrins of the hindhead in the lemale short and almost semicircularly convex (hnown only from the fiemale); from undetermined

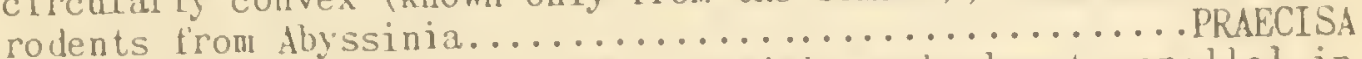

Lateral maryins of the hindhead strai rht and almost parallel in both sexes: known trom Tatera indica in India.......... STEPHENSI

7 (5). Male with a row of very short, almost thorn-like, setae on the terral plates of segments 4-7, in addition to the usual slender setae: known fron Tatera hörmi in Atrica..............BSERIATA Yale with only the usual row of slender setae on any abdominal ter-

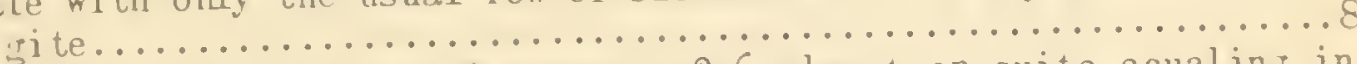

$8(7)$. Setae on parater piles of sements $3-6$ almost or quite equaling in length the plate that bears them except for one longer seta on sement 3: known trom Tatera vicina in Africa............TATERAE

Setale on paratersites of se ments 3-6 shorter than the plate which

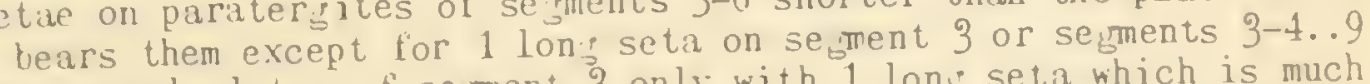

9 (3). Paratergal plates of sement 3 only with 1 lon: seta which is much longer than the plate that hears it.................... TOMYDIS

Parater fal plates of segments 3-4 each with 1 lont seta which is much longer than the plate that bears it......................

10 (9). Ventral apical angle of paraterites of abdominal sements 3-6 formin: a process that is about twice as wide at its base and trice as long as the tooth at the dorsal anjle; known from Ger-

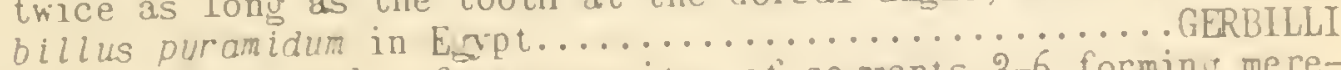

Ventral apical an ly a sli, tht tooth wich is not larger than that of the dorsal

11 (10). Lateral maryins of the hindhead in the male (female untinown) stronply conver rent: occurrin: on Pac yyurorys in Espt.. HERUERT Lateral margins of the hindhead in the male divergent or practically parallel: trom yeriones auceds in China.......... CHIAEISIS 12 (4). Parater jices of abdominal se ments $9-6$ with both posterior anjles
produced into a slender, apically acute process which is heset 


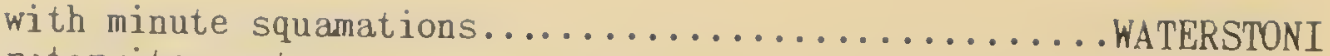

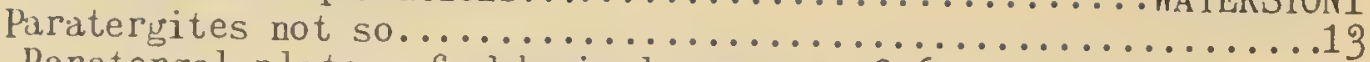

13 (12). Paratergal plates of abdominal sements $3-6$ posteriorly emarginate, the setae borne close to the apices of the points formed

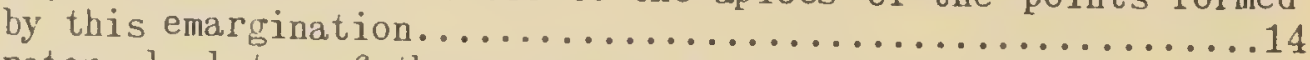

Paratergal plates of these sciments not so.......................

14 (13). Paratergites of abdominal sements $3-6$ only shallowly emarinate; tergal plates of abdominal segments 3-6 occupying scarcely more than half the width of their respective sesments; occurring on Arvicanthis in Africa...............................

Paratergites of segments $3-6$ deeply emarginate; tergal plates of segments 3-6 occupying at least three-fourths of the width of their respective segments; occurring on Arvicanthis in Africa..

15 (13). Termi plates of abdominal sements $3-6$ each with the ventral $\ldots \ldots \ldots$. terior angle only forming a tooth and each with a pair of setae which are about as long as the plate which bears them.......16

Tergal plates of abdominal segments 3-6 not presenting this combination of characters; if the setae are as long as the plates each angle forms a tooth, if one angle does not form a tooth

16 (15). Head truncate anteriorly immediately in front of the antennae;

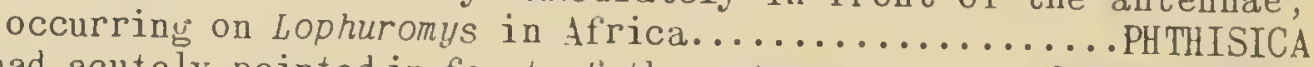

17 (15). Genitalia of the male with the pseudopenis enti........ XXYRRHYNCHUS in the apices of the parameres; tergal plates in the female wil of almost uniform length in the longitudinal axis of the body; occurring on Saccostomus in Africa.................. JONESI

Genitalia of the male with the pseudopenis articulating to the apices of the parameres; anterior tergal plate of abdominal sements $4-7$ in the female distinctly longer in the longitudinal axis of the body than the posterior plate of the same se

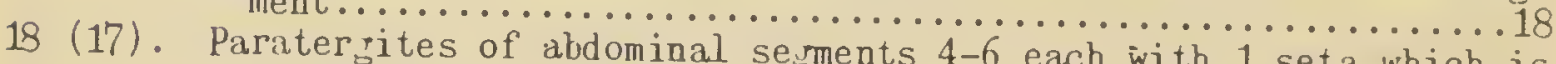
as lony as or lonuer then with 1 seta which is seta somewhat variable but never so whort bears it, the other

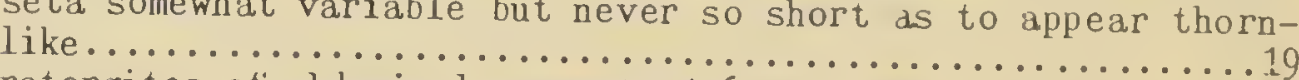

Paratergites of abdominal segments $4-6$ with seta otherwise...... 20

19 (18). Paraterites of abdominal sements $3-6$ with well developed points at the posterior angles, these points set somewhat anterior to the posterior maryin of their plate, this posterior margin projecting posteriorly beyond the points; spiracles noticeably large; two supposed species which are probably identical; oc-

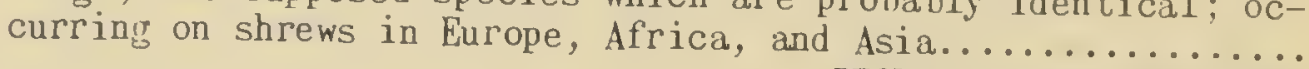

paratergites of abdominal serments $3-6$. posterior angles very small, or perh with the points at their terior margin of these paraterites not produced lacking; postremely small and obscure; occurring on Rattus apoensis les exPhilippine Islands........................................

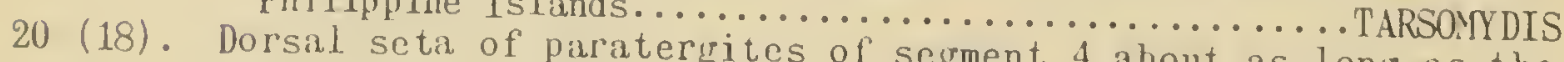
plate itself the other of sements 2, the other scta of these plates and of the plates slender-bodied 3,5 , and 6 hein much shorter than the plate; a house mouse and other which, as far as known, occurs on the members of the other closely related species of Mus and on

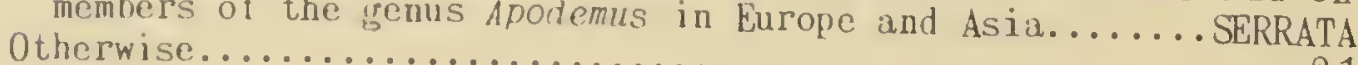




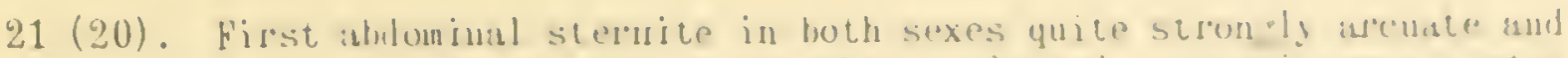
with its laterial angles somewhat prolon red; occurein; un yerotus und related torms in norlhern Enrope and nor thern North Amerseas

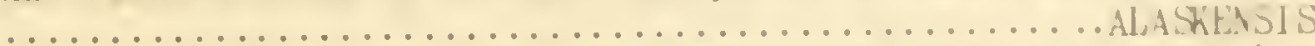

Filst alulominal sternite in both sexes not thus; its mosterior matrill ulmost straiplit and the laterial anples not prolon red. .2"

2u (21). Dorsil lobe of the psendopenis very short, scircel! one-1ourth the lenpth of the ventral lobe; parameres rell developed, exwending forward between the posterior alms ol the basal plate; occurring especially on species of Rattus throu hout the world.

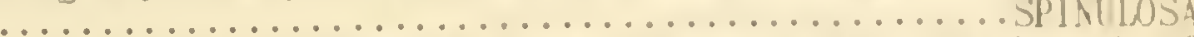

Dorsal lobe of the pseudopenis equaling atrout half the length of the ventral lobe; parameres quite neakl! developed and extent ing forward only slighty past the apex of the arms of the bisal plate; occurring on species of yicrotus and relited genera

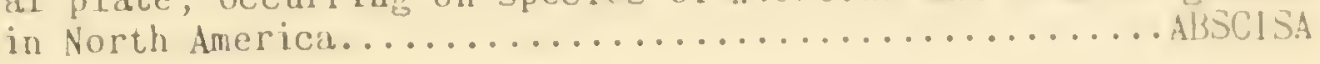

Polyplax abscisu fiarentol\%

1925. Polyplax spinulosa (burmeister). Ferris, Contritutions Toward a Monorraph of the Sucking Lice, Part 4:187. (In part; misidentification)

1938. Polyplax abscisa Fuhrenholz, Zeitschriti 1ür Parasitenkunde 10:257; figures $13,14$.

1942. Polyplax abscisa Fahrenholz, Ferris, yicroentomolop 7:96; 1"ipure 12.

HOSTS NDD DISTRIBUTION. Described as from "Arvicola spec., Californien." This was in all probability a species of Hicrotus, much less probably of Phenacomys. The species has been recorded ly Ferris, under the name of Polyplax spinulosa, from yicrotus californicus and yicrotus sp. in California, from icrotus intermedius from Nevala, from yicrotus penns!lvanicus from New York, United States.

NOTES. This species is exceedinfly close to Polmplax spinulosa, applarently differing only in certain details of the genitalia ol the male as indicated in the accompanying key"

\section{Polyplax abyssinica Ferris}

1923. Polyplax abyssinica Ferris, Contributions Toward a Yonograph of the Suckin! Lice, Part 4:230; 1im 150.

1940. Poluplax abyssinica Ferris, Werneck, Revista de Entomolopica 11:722; ficure 1.

HOSTS AVD DISTRIBUTION. Type from Arvicanthis abyssinicus at luondo Teso, U:randa, and recorded by Ferris from the same host from other localities in Uyanda. Recorded by Ferris from otomys tropical is and oenomys bacchante in Uganda. Recorded by Herneck from a sulspecies of the type host at various localities in Uganda; from Arvicanthis sp., and from Nastom coucha from the West Nile District in Upinda.

10TES. It is probable that the normal hosts of this species are species of the renus Aruicanthis. Ferris described only the female. The male has been described by werneck.

\section{Polyplax alastensis Ening}

1927. Polyplax alaskensis Eving, Proceedings of the Entomolopical Society of hashin ton 29:11s.

1933. Polyplax boreal is Ferris. Parasitolo o 25:127; t'i nures 1, 2.

1935. Poluplax alaskens is Ewing. Ewing. Proceedings of the IBiological Sociecy of Washington 29: 119. 
HOSTS AND DISTRIBUTION. Described by Ewing from vicrotus sp. from unspecified locality in Alaska. Described by Ferris from Evotomys sp. (rufocanus?) from Beskenjarrga, Finmark, Norway. This host is Clethrionomys rufocanus.

NOTES. It is here accepted that borealis is a synonym of alaskens is.

\section{Polyplax arvicanthis Bedford}

1919. Polyplax arvicanthis Bedford, Report of the Division of Veterinary Research, Department of Arriculture, Union of South Africa 5-6:716; Plate 1, figures.

1923. Polyplax arvicanthis Bedford, Ferris, Contributions Toward a Monograph of the Sucking Lice, Part 4:227; figures 148, 149.

HOSTS AND DISTRIBUTION. Described as from Arvicanthis pumilio at Onderstepoort, Pretoria, South Africa, and later recorded from a subspecies of this host from Mount Kenya, British East Africa. The correct name for this host is Rhabdomys pumilio.

\section{Polyplax asiatica Ferris}

1923. Polyplax asiatica Ferris, Contributions Toward a Monograph of the Sucking Lice, Part 4:233; figure 1520.

HOSTS AND DISTRIBUTION. Type from Crocidura caerulea (a shrew) from Rangoon, Burma. Also recorded from Nesokia hardwicki $i$ from Quetta, Baluchistan. Material not previously recorded is at hand from Bandicota bengalensis at Akyab, Burma, and from Rattus concolor at Bellary, Madras, India.

NOTES. The additional material now at hand tends to substantiate the suspicion, previously expressed by Ferris and by Hopkins, that this species is normal to a rodent and not to shrews.

\section{Polyplax auricularis Kellogg and Ferris}

1915. Polyplax auricularis Kellog and Ferris, Anoplura and Mallophaga of North American Mammals, Stanford University Publications, University Series (no volume number), page 13; Plate 1, figure 4; Plate
4, finure 8.

1923. Polyplax auricularis Kellogg and Ferris, Ferris, Contributions Toward a Monograph of the Sucking Lice, Part 4:218; figures 140, 141.

1933. Polyplax auricularis, variety californiae Fahrenholz, Zeitschrift für Parasitenkunde 10:270; fiưures 19, 21. 1938. Polyplax paine $i$ Fahrenholz, Zeitschrift für Parasitenkunde 10:270;
figures 20, 22.

HOSTS AND DISTRUBUTION. Type from Peromyscus maniculatus at Inverness, Marin County, California, and recorded from the same host at Yosemite National Park, California. Also recorded from Peromyscus sitchensis from Forrester Island, Alaska, from Onychomys torridus at Victorville, California, from onychomys leucogaster at Colorado Springs, Colorado, and at Liberal, Kansas. All these records are from within the United States. Also recorded from Reithrodontomis mexicanus at "Tehontepec, Chiapas, "which is probably Tehuantepec, in Oaxaca, and from Neotomodon allstoni near
Mexico City, Mexico.

NOTES. Fahrenholz has described the supposed variety californiae as from Perodipus streator $i$, which is a member of the family Heteromyidae. If it came actually from this host there must have been contamination, since there is very good evidence that the members of this family harbor only Lice of the ienus fahrenholzla. There is a Peromyscus maniculatus streatort and Hopkins suigests that there may have been an error in reading a label. No reason appears for naming the supposed variety. 


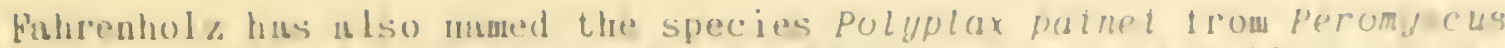
californiens tron Sin Mateo County, Calitormia, but in the li ght ot lhro available material there seems to he no reason for recomizing this sprecies.

\section{Polyplax biseriata ferris}

19:3. Polmplar blseriata lerreis, Contributions 'Toward as Monosraphr of the Wicking lice, Purt 4:199; t"i pres 125A, 126.

1933. Eremophthrius bisertatus (Ferris), kahrenholl, Zeilschritt türlarasitenkinule 10:243.

HOSIS AND DISTKIHUTION. Fron Tatera bohmi at South Guaso Nyiro, Brit ish East Atrica, and from Tratera lobengulae at Lothiville, Orimre free State, South Atricic.

\section{Polyplax chinensis ferris}

1923. Polyplax chinensis ferris, Contributions 'Toward a Yonograph of the Sucking Lice, Part 4:209; l'i rures 132, 133.

hOSTS AVD I)ISTRIBUTION. Lut one record, from yeriones auceps, Shensi, China. According to Ellernan this is listed as a subspecies ot weriones meridianus.

Polyplax deltoides Fahrenholz

1923. Polyplax reclinata (Nitzsch), Ferris, Contributions Toward a Yonopraph of the Sucking Lice, Part 4:192; figures 120C, 1206. (Misidentilication?)

1938. Polyplax deltoides Fuhrenholz, Zeitschrift für Parasitenkunde 10:256; firure 12 .

HOSTS AND DISTRIBUTION. This species was based by Fahrenholz upon the specimens recorded by Ferris as from Crocidura coerulea at Ranjoon, Burma; from Crocidura sp. at Atchebal, Valley of Kashmir; Pach!ura luzonensis at Manila, Philippine Islands, and from Scut isorex sp. at "Medjie," this place name being without other data and perhaps being a misspelling.

NOTES. Since this species name was based entirely upon the records published by Ferris, the type must be selected from among the material recorded by Ferris. The type is therefore designated as a f'emale from Pachyura Luzonensis at Mauila, Philippine Islands, which is in the Stanford University collection.

As far as any evidence griven by Fahreuholz is concerned, no good reason appears for regarding this species as anything more than Poluplax reclinata. But since specimens from the type host of the latter are not availahle the name is here accepted.

\section{Polyplax dentaticornis Ewing}

1935. Polyplax dentaticornis Ewing. Proceedings of the Biological Society of Washington $48: 20 \%$; tigure $2 \mathrm{c}$.

HOSTS AND DISTRIBUTION. Recorded, on the basis of a single male, from Cricetulus antersoni, Shensi, China.

\section{Polyplax eriopepli Ewing}

1935. Eremophthirius eriopedi Ewing, Proceedinis of the Biological Society of rashington $43: 209$.

HOSTS AVD DISTRIBUTION. From Eriopeplus incanus fram Celebes. This host is Cricetulus longicauriatus. 
1923. Polyplax gerbilli Ferris, Contributions Toward a Monograph of the Sucking Lice, Part 4:203; f'igures 128, 129. 1938. Eremophthirius gerbili $i$ Ferris, Fahrenholz, Zeitschrift für Para-
sitenkunde $10: 243$.

HOSTS AND DISTRIBUTION. From Gerbillus pyraminum at Khartoum, Eyypt.

\section{Polyplax gracilis Fahrenholz}

1910. Polyplax gracilis Fahrenholz, Jahresbericht des Niedersächsischen zoologischen Vereins zu Hannover 2-4:42; text figures 16, 17; Plate 1, figures $10,11$.

1923. Polyplax gracil is Fahrenholz, Ferris, Contributions Toward a Monograph of the Sucking Lice, Part 4:234.

1938. Polyplax sracilis Fahrenholz, Zeitschrift für Parasitenkunde 10:263; figure 231.

HOSTS AND DISTRIBUTION. Recorded from Mus minutus, presumably in Germany. The host is now known as Micromys minutus.

\section{Polyplax insulsa Ferris}

1923. Polyplax insulsa Ferris, Contributions Toward a Monorraph of the Sucking Lice, Part 4:231; figures 151, 152A, C.

1929. Ahaematopinus insulsus (Ferris), Ewing, A Manual of External Parasites, page 198.

HOSTS AND DISTRIBUTION. Known only from the original record, from Epimys (-Rattus) sabanus from Bunguran, Natuna Islands, Malaysia.

\section{Polyplax jonesi Kellogg and Ferris}

1915. Polyplax jonesi Kellogg and Ferris, Annals of the Durban Museum 1: 151; Plate 15, figures $3-3 \mathrm{e}$.

1923. Polyplax jonesi Kellogg and Ferris, Ferris, Contributions Toward a Monograph of the Sucking Lice, Part 4:216; figures 138, 139.

HOSTS AND DISTRIBUTION. Known only from the original record, from Saccostomus campestris, at Mfongosi, Zululand, South Africa.

\section{Polyplax otomydis Cummings}

1912. Polyplax otomydis Cummings, Bulletin of Entomological Research 3:
395-7; figures.

1916. Polyplax gracil is Fahrenholz, Ferris, Annals of the Durban Museum 1: 240 ; figures 23C, 24 . (Mi sidentification)

1916. Polyplax cummingsi Ferris, Annals of the Durban Museum 1:240; fid-

1923. Polyplax otomydis Cummings, Contributions Toward a Monouraph of the Sucking Lice, Part 4:211; figures 134, 135.

1923. Polyplax cummingsi Ferris, Ferris, Contributions Toward a Monograph of the Sucking Lice, Part 4:213; figures 136, 137.

HOSTS AND DISTRIBUTION. Described by Cummings from otomys irroratus f'rom Mount Kenya, British East Africa. Also recorded from this host from Onderstepoort, Pretoria, and from Mfongosi, Zululand, South Africa. Recorded from Otomys angonlensis from Naivasha, British East Atrica, and from otomys brantst without indication of locality, this last host now being referred to parotomys. Recorded by Ferris as Polyplax cummingsi from Dasymys incomtus from Mfonirosi, 7ululand, and from Kaimosi, British East Africa, and from Rattus (now known as Aethomys) chrysophilus from Mtonirosi, Zululand. 


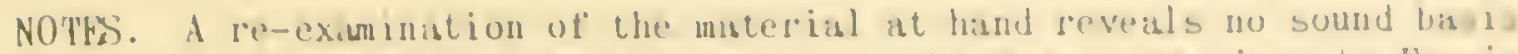
for the recomition of the species cummengl, the characters jiven by fer'is for the separation of the latter species now appearing to have heen quite i 11 แsory.

\section{Polyplax oxyrohyuchus Cunmings}

1915. Poluplax oxyrrhynchus Curmings, Proceedings of the Zoolorical Society of London, puge 251 ; text tigures $4-6,8,9,11,13$.

1923. Polyplax oxyrrhynchus Cumnings, Ferris, Contributious Toward a Monograph of the Sucking lice, Part 4:225; ti fures 146, 147.

1938. Polyplax oxyrrhynchus, variety hystrellae fiarenholz, Leitschrift lïl Purasitenkunde 10:275.

HOSTS AND DISTRIBUTION. Type from Acomus cahirinus at Assiur, Eiry pl. Recorded by Ferris from Acomys hystrella from Numule, Ugandu, and 1 rum Acomys perctualt, British Eust Africa.

NOTES. Fahrenholz, apparently without seeing any specimens and working merely from the illustrations accompanying the original description of this species and the later record by Ferris, assumed to establish the supposed "variety" hystrellae for the specinens illustrated by Ferris. The type of this name will therefore be among these specimens. The differences cited by Fahrenholz for his "variety" are merely such as are inevitable in illustrations made by different persons from specimens which were differently prepared and this supposed variety is here reduced to synonymy.

\section{Polyplax phthisica Ferris}

1923. Polyplax phthtstca Ferris, Contributions Toward a Monograph of the Sucking Lice, Part 4:223; figures 144, 145.

HOSTS AND DISTRIBUTION. Type from Lophuromys aquilus from Ngani Narok River, and from the same host species (recorded as zena) from Molo, British East Africa; from Lophuromys sikapust, Rhino Camp, Uganda; from Lophuromys sp. from Nyasaland. A record from Thamnomys tbeanus, British East Africa, is probably due to contanination.

\section{Polyplax praecisa (Neumann)}

1901. Baematopinus praecttus Neumann, Archives de Parasitologie 5:600. (In part; also typographical error for praecisis, later corrected by Veumann)

1902. Baematopinus praectsus Neumann, Archives de Parasitologie 6:144; fig. 1904. Polyplax praecisa (Neumann), Enderlein, Zoologischer Anzeiger 28: 143 (part).

1919. Polyplax praecisa (Neumann), Fahrenholz, Jahresbericht des Niedersächsischen Zoologischen Vereins zu Hannover 5-10:25.

1923. Polyplax praecisa (Neumann), Ferris, Contributions Toward a Monograph of the Sucking Lice, Part 4:196; figure 123.

1938. Eremophthirtus praectsus (Neumann), Fahrenholz, Zeitschrift für Parasitenkunde 10:243.

HOSTS AND DISTRIBUTION. Recorded as from "gros rats," in Abyssinia. Hopkins notes that Tatera nigrtcouda occurs in Abyssinia and assumes the species to have been from this host.

NOTES. Neumann included two distinct species in his praectsus. This was recognized by Fahrenholz, who in 1919 named one of the two as Hoplopleura neumannt and thus restricted the name to the other, which is a Poluplax. Ferris saw the type specimens and confirmed this procedure. Polyplax praecisa is suill known only from the female and without precise host designation. 
1864. Pediculus reclinatus Nitzsch, Zeitschrift für den gesamten Naturwissenschaliten 25:23.

1874. Haematopinus reclinatus (Nitzsch), Giebel, Insecta Epizoa, page 37. 1904. Polyplax reclinata (Nitzsch), Enderlein, Zoologischer Anzeiger 28: 142.

1910. Haematopinus (Polyplax) reclinatus (Nitzsch), Neumann, Archives de Parasitologie 13:524; text figure 24.

1912. Polyplax reclinata (Nitzsch), Fahrenholz, Jahresbericht des niedersächsischen zoologischen Vereins zu Hannover 2-4:37; text figures 11,$12 ;$ Plate 1, figures 12, 13; Plate 2, figures 2, 4; Plate 3,
figure 7 .

1923. Polyplax reclinata (Nitzsch), Ferris, Contributions Toward a Monograph of the Sucking Lice, Part 4:192. (In part)

1932. Polyplax reclinata, variety leucodont is Jancke, Zeitschrift für Paras itenkunde 4:525; figure 2 .

1938. Polyplax reclinata (Nitzsch), Fahrenholz, Zeitschrift für Parasitenkunde 10:254; figures 9, 10, 11.

HOSTS AND DISTRIBUTION. Originally recorded from the European shrew, Sorex araneus, and since recorded a few times from this host. Also recorded, as variety leucodont is, from another European shrew, Crocidura leucodon.

NOTES. Ferris has previously referred to this species specimens from various Asiatic shrews, but Fahrenholz has considered these to represent a distinct species to which he has applied the name deltoides. Also Jancke has recorded material from a European shrew, Crocidura leucodon, as a variety of reclinata. In the absence of specimens from the type host it is not here possible to come to any deflinite decision regarding this variety. On the basis of the published notes and descriptions by Jancke and Fahrenholz, the present writer still believes all these to represent a single species for which the name reclinata is correct. The supposed "variety" leucodontis is here placed in synonyny with reclinata, but the species name deltoides is admitted, in the absence of the material which is necessary before it is definitely reduced to synonymy.

\section{Polyplax serrata (Burmeister)}

1839. Pediculus serratus Burmeister, Genera Insectorum, Rhynchota, No. 6. 1842. Haematopinus serratus (Burmeister), Denny, Monographia Anoplurorum Britanniae, paise 36.

1904. Polyplax serrata (Burmeister), Enderlein, Zoologischer Anzeiger 28: 142.

1912. Polyplax affinis (Burmeister), Fahrenholz, Jahresbericht des niedersächsischen zoologischen Vereins zu Hannover 2-4:39; figures 13-15. (Misidentification)

1923. Polyplax serrata (Burmeister), Ferris, Contributions Toward a Monograph of the Sucking Lice, Part 4:191; figure 120B, E.

1932. Polyplax serrata (Burmeister), Jancke, Zeitschrift für Parasitenkunde 4:252.

1938. Polyplax affinis Fahrenholz, Zeitschrift für Parasitenkunde 10:261.
(As a new species)

HOSTS AND DISTRIBUTION. Originally described from the house mouse, wus musculus, in Europe. Later recorded as Polyplax affinis (Burmeister) from Apodemus sylvaticus in Europe. Ferris has recorded it from this host from Switzerland, Bohemia, and England; from Apodemus agrarius from Manchuria and China; from Apodemus spectosus from China; from kus spicilegus, which is merely a subspecies of musculus, from Spain; and from Mus musculus from Scot] and and Enigland. 


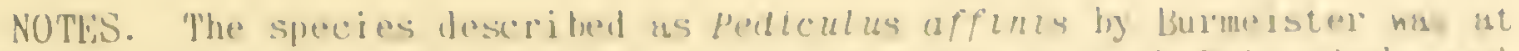
one time placed in polyplax lut is now re ritrded by foth fuhrenhedz anl ferris as beim at Hoplopleura. A species of polyplax which has been watidentified as affints is considered by fremis to be the same as Polymlan serrala. Fuhnenhola (19y), however, has maintaned that this species is distinct mul has described it as new, giving offonis as a new name for it. linder the revised kinles (lulletin of Koological Nomenclature 4:97-125. 1950) this nume is availuble, since ut the time of its proposal (1939) it was as nonconcurrent secondary homonym.

In connection with the present work the miterial at hand from yus muaculus and the various species of Aporfomus has been carefully re-exinined. The opinion is here maintained that there is abolutely nothing in these specimens which will justify a specific separiation. Poluplax affinis Fahrenholz is therefore placed as a synonym of polyplax serrata (Isurme ister).

\section{Polyplax spinigera (Bumeister)}

1339. Pertculus spinlger Burmeister, Genera Insectorum, Rhynchota, No. 9. 1909. Haematopinus (Polyplax) spintger (bumeister), Nenuan, Archives de Purasitolorie 13:524; it rure 24.

HOSTS AND DISTRI BUTTON. Described from a rodent ciled by the older authors as Hypudacus amphiblus, which is now reterred to the genus Arvicola.

NOTES. Since its original description only one author, Neuinann, has seen specimens trom this host and the species camot be definitely identified from his notes and tigures. It is apparently distinct from polyplax splnulosa and the sugirestion that it is the same as, and theretore antedates, either Polyplax alaskensis Ewing or Polyplax abscisa Fahrenholz will need to be explored when specimens are obtained from its type host.

$$
\begin{gathered}
\text { Polyplax spinulosa (Burmeister) } \\
\text { Firures 90, } 91
\end{gathered}
$$

1839. Pediculus spinulosus Burme ister, Genera Insectorum, Rhynchota, No. 8. 1842. Haematopinus spinulosus (Burmeister), Denny, Monopraphia Anoplurorum Britanniae, pase 26 ; Plate 24, figure 5.

1864. Pediculus denticulatus Nitzsch, Zeitschrift für den gesesamten Naturwissenschaften 23:24.

190.5. Polyplax spinulosa (Burmeister), Enderlein, Zoologischer Anzeiger 28: 142.

1923. Polyplax spinulosa (Burmeister), Ferris, Contributions Toward a Monopraph ot the Sucking Lice, Part 4:197; fi gures 119, $120 \mathrm{~A}, \mathrm{D}, \mathrm{F}, \mathrm{H}$.

1929. Polyplax praomydis Bedford, Annual Report of the Director of Veterinary Services, Union of South Africa 15: 503; figures 2-5.

1938. Poluplax spinulosa (Burme ister), Fahrenholz, Zeitschrift fir Parasitenkunde 10:249; 1'igures 1-8, $23 \mathrm{c}$.

1945. Polyplax camplopteri Zavaleta, Anales del Instituto de Bioloria (Mexico) 11:431; fiçre.

HOSTS AVD DISTRIBUTION. Originally described from the brown rat, Rat tus (= uus = EDimys) norveģicus, in Europe. Later many times recorded from this host and from Rattus rattus and some of its subspecies in many parts of the world. It has been recorded by Ferris from Rattus calcis, which is considered to be exulans, in the Philippine Islands and Rattus stridens in the Malay Peninsula and from Banticota (as Gunomys) bengalensis in Burma. Described by Bedford as Poluplax praomydis from Proomys (now called Thallomys) namaquensis at Onderstepoort, South Africa.

Records by Ferris of the occurrence of this species upon various species of ylcrotus, Synaptonys, and Phenacomis are erroneolls and are here transferred to Polyplax abscisa Fahrenholz. 


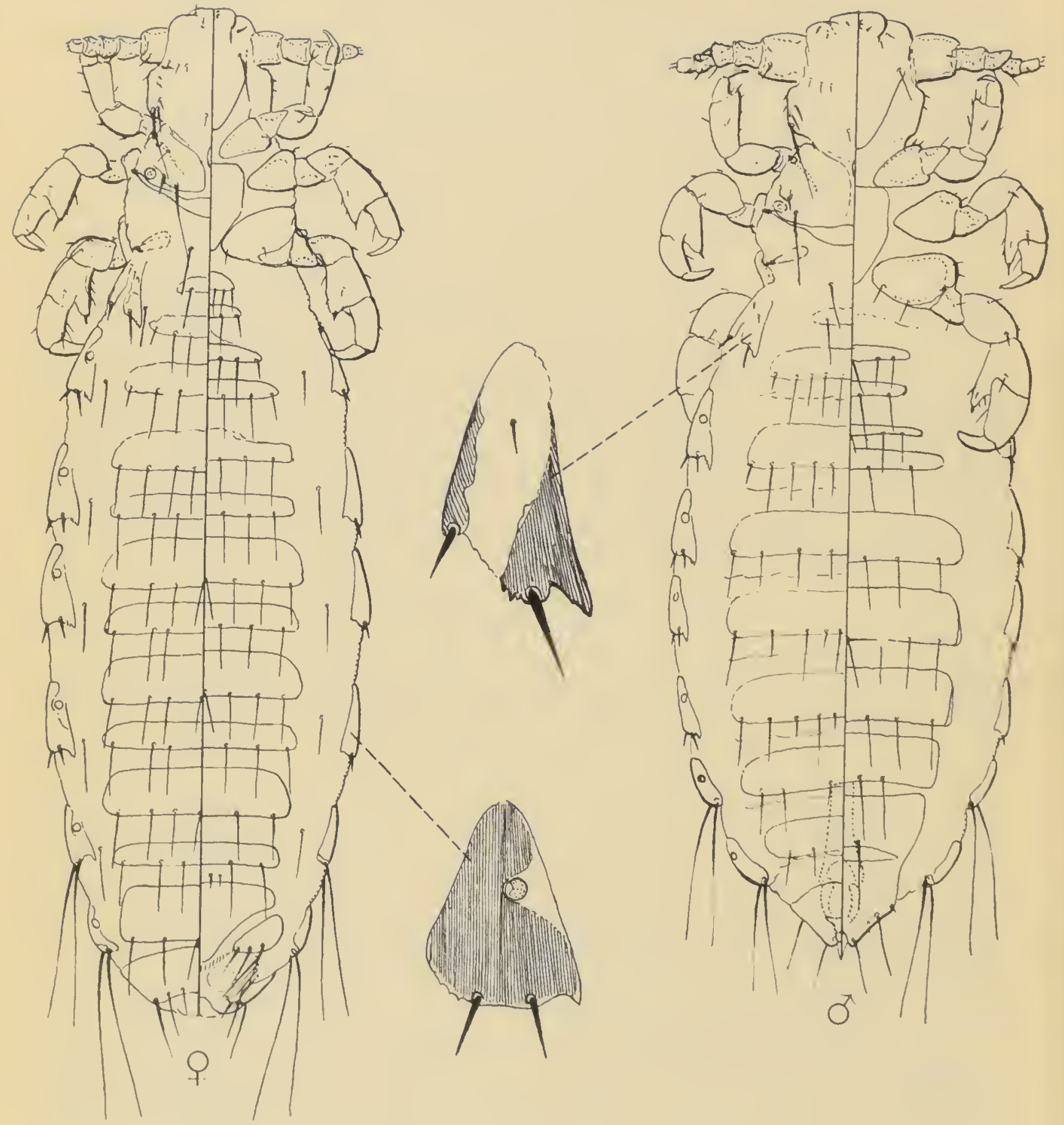

Polyplax spinulosa (Burmeister)

Figure 90 

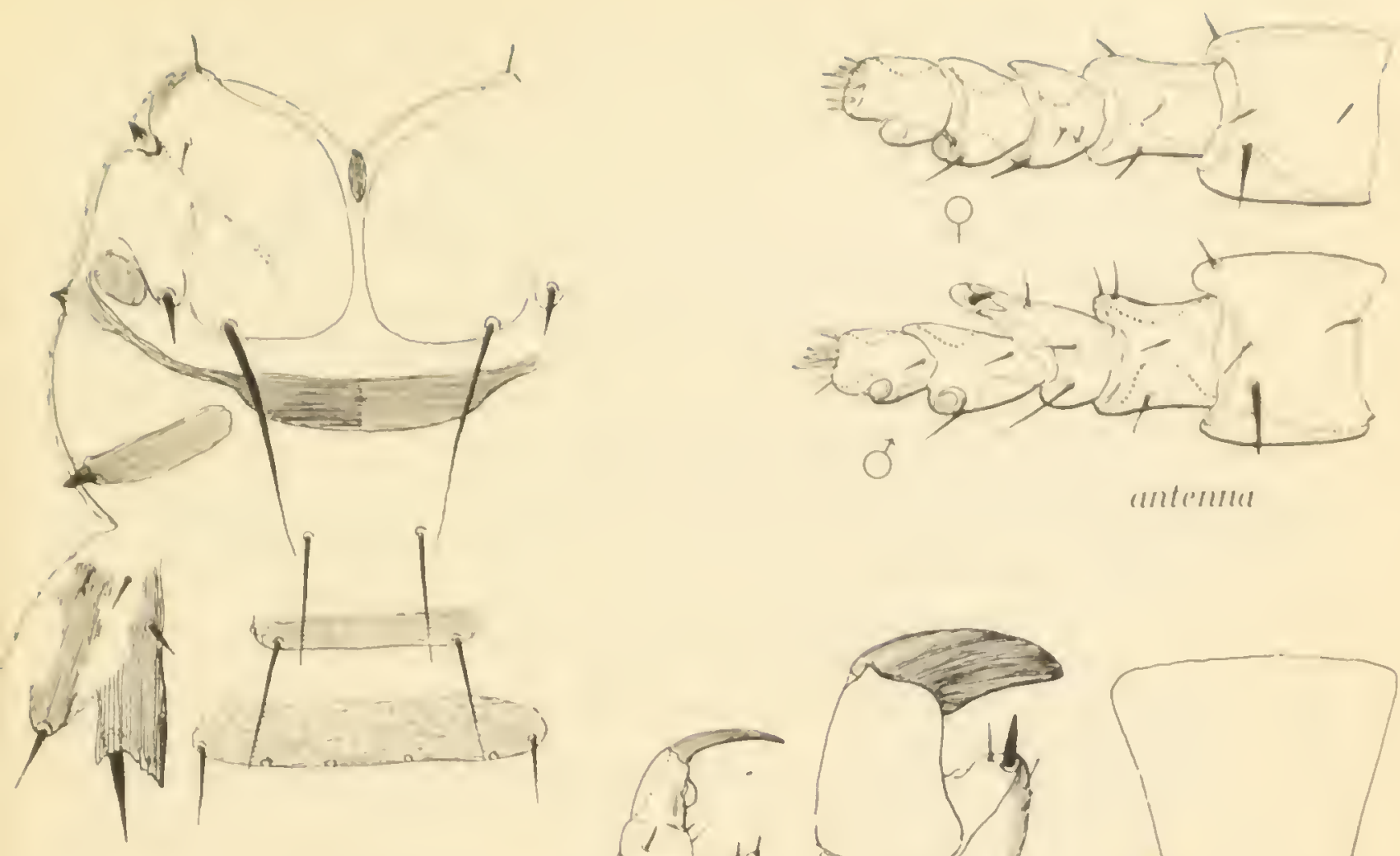

dorsumb of thorax and basul (i) lominal segments
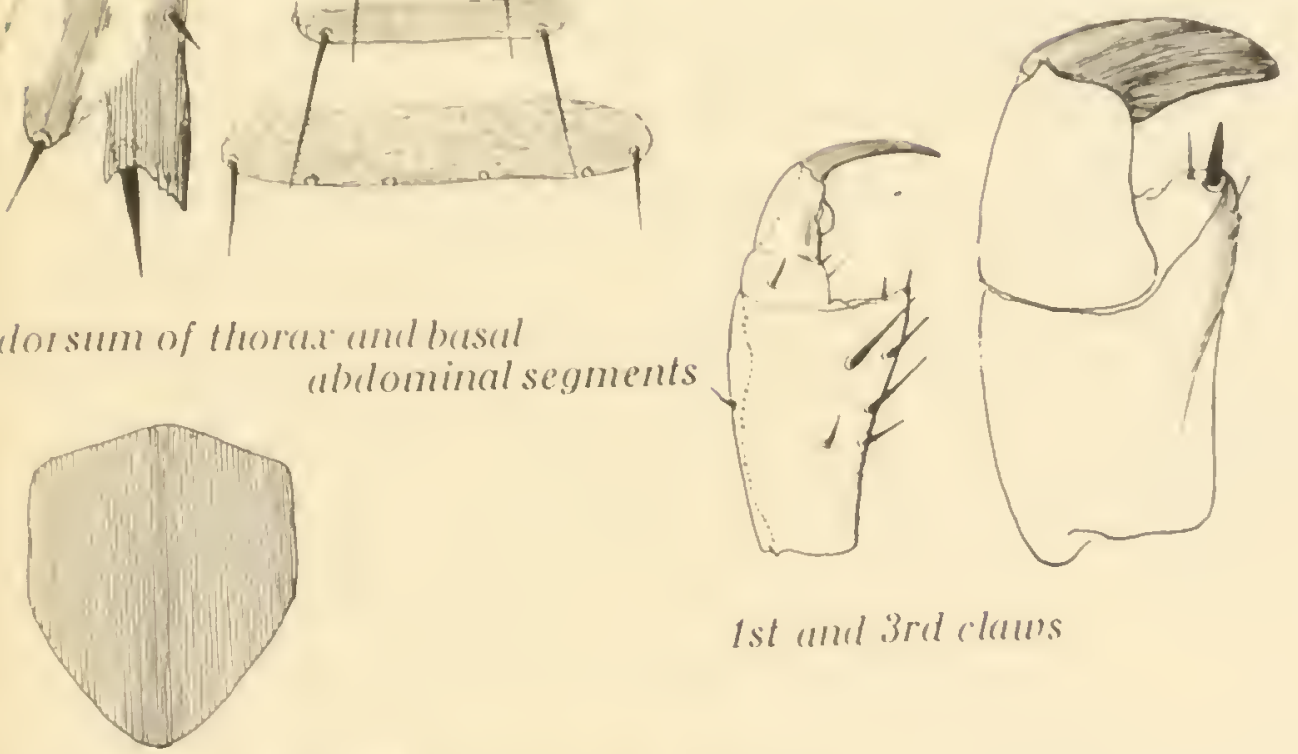

1st and 3rd claums

thoracic stermal plate
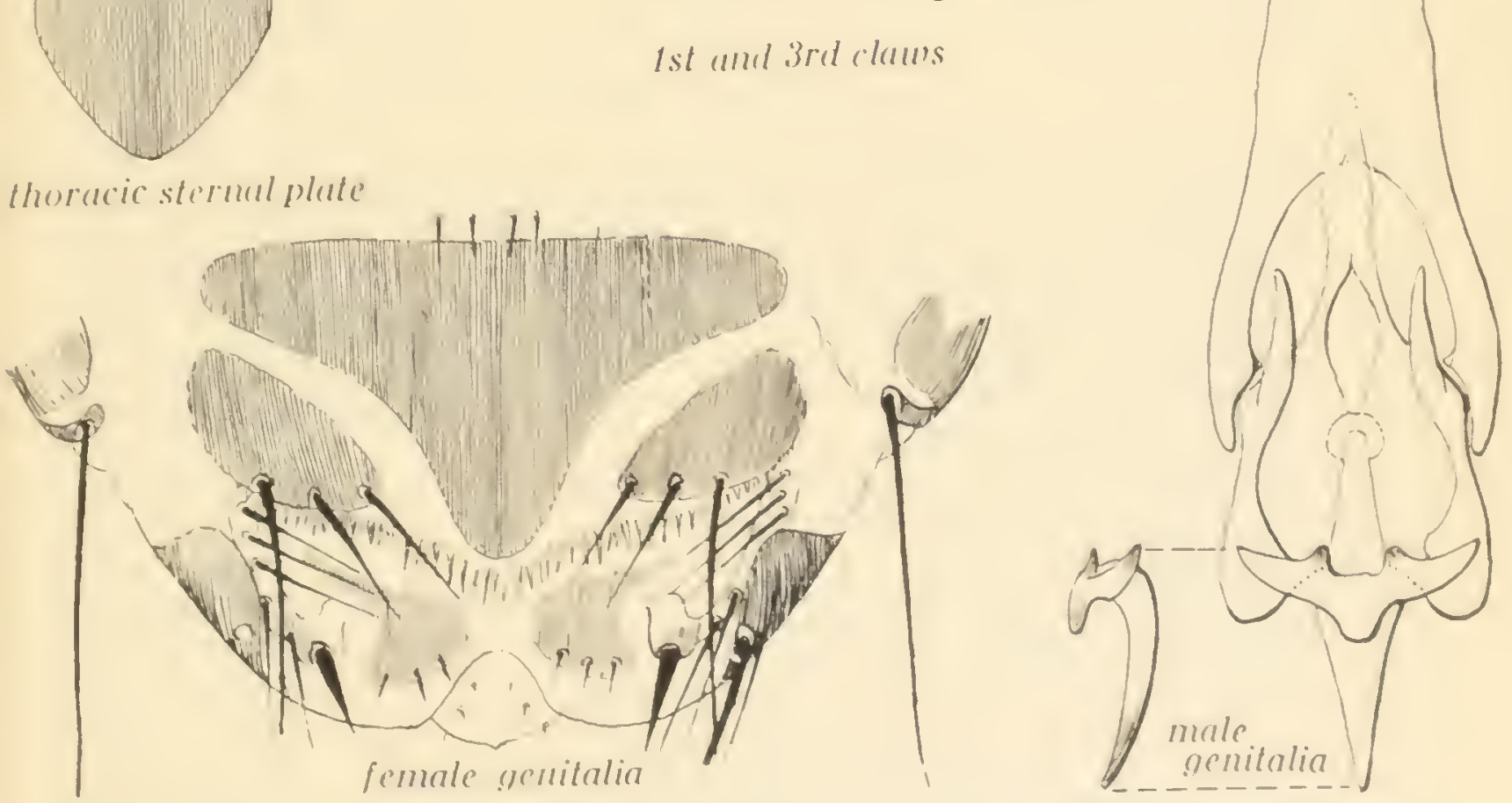

Polyplax spinulosa (Burmeister), details

Figure 91 
NOTES. A male from the type lot of Polyplax praomydis Bedford is available and is very precisely spinulosa. Polyplax campyloptera Zavaleta, described as from a bird, is, on the basis of illustrations presented by its author, very obviously nothing more than spinulosa.

\section{Polyplax stephensi (Christophers and Newstead)}

1906. Haematopinus stephensi Christophers and Newstead, Thompson, Yates and Johnston Laboratories Report (new series) 7:3; Plate 1.

1923. Polyplax stephensi (Christophers and Newstead), Ferris, Contributions Toward a Monograph of the Sucking Lice, Part 4:206; figures 130, 131.

1938. Eremophthirius stephensi (Christophers and Newstead), Fahrenholz, Zeitschriftt für Parasitenkunde 10:243.

HOSTS AND DISTRIBUTION. First described from Gerbillus (=Tatera) indica from India, without precise indication of locality. Cotype specimens are labeled as from Madras. Later recorded by Ferris from the same host from various localities in India.

\section{Polyplax tarsomydis Ewing}

1935. Polyplax tarsomydis Ewing, Proceedings of the Biological Society of Washington 48:206.

1938. E'remophthirius tarsomydis (Ewing), Fahrenholz, Zeitschrift für Parasitenkunde 10:243.

HOSTS AND DISTRIBUTION. Described by Ewing as from Tarsomys (a subgenus of Rattus) apoensis f'rom the island of Mindanao, Philippine Islands. One male taken from a skin in the United States National Museum. Two females which may be considered to belonir to this species are at hand from the same host, taken from a skin, United States National Museum Number 144616, from the summit of Mount Bliss, on the island of Mindanao.

NOTES. This species was described from a sinile male. It is not practicable here to describe the female except as it is included in the key to the species.

\section{Polyplax taterae Ferris}

1923. Polyplax taterae Ferris, Contributions Toward a Monograph of the Sucking Lice, Part 4:198; figures 124, $125 \mathrm{D}$.

1936. Polyplax subtaterae Bedford, Onderstepoort journal of Veterinary Science and Animal Industry 7:63; firure 7.

1938. Eremophthirius taterae (Ferris), Fahrenholz, Zeitschrift für Parasitenkunde 10:243.

1938. Eremophthirius subtaterae (Bedtord), Fahrenholz, Zeitschrift für Parasitenkunde 10:243.

HOSTS AND DISTRIBUTION. Type of taterae from Tatera vicina from Mount Rukenya, British East Africa. Type of subtaterae from Tatera liodon at Kampala, Uyanda.

NOTES. Specimens of subtaterae are at hand, throu the kindness of the late G. A. II. Bedford, and it is upon these that the ahove synonymy is based.

lolyplax waterstoni bedford

1919. Polyplax waterstoni Bedford, Krport of the Division of Veterinary Rescarch, Department of' Aisiculture, Union of' South Af'rica 6-7: 715 ; Plate 1, fiimures $1,2,4,5$.

1923. Poluplax waterstonl Bedford, Firis. Contributions Toward a Monopriaph of the Suckinis Lice, Pitrt 1:193; f'igures 121, 122. 


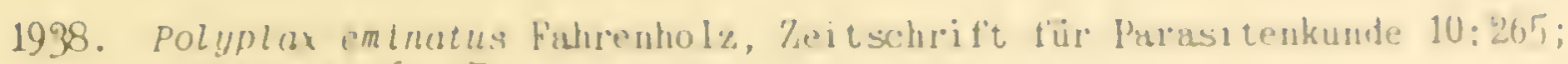
"i rures $16,17$.

HOSTS AND DISTKI LUTION. H'irst described as from "several rats, " at On derstepoort, Pretoria, South dirical. Recorded by ferris from Epimys feromyscus, tor which the proper nime is apparenty Rattus tullberét, at Molo, British East Alrica. Described as poluplax eminutus by f'ahreuholz trom "Paderoructes Éadal," f'rom kisst Atrical. No such host name appears in awy" available lists. Hopkins has hazarded the guess that this is a corruption of Tachyorycte's aurtax, but this is purely a surnise unsupported by any special evidence.

NOTES. On the hasis of the description and illustriations riven by fahreuholz, there is not the slightest justification tor the separation of polyplar eminatus lrom waterstoni.

\section{Polyplax werneri (lilinkiewica)}

1907. Eremophthirlus wernert Glinkiewicz, Sitzungsuerichte der mathemati sch-naturwissenschaf'tlichen Classe der kuiserliche Akademie der Wissenschaften zu Wien 116:381; "igures.

1923. Polyplax werneri (Glinkiewicz), Ferris, Contributions Toward a Monosraph of the Sucking Lice, Part 4:202; tigure 127.

1938. Eremophthirlus werneri Glinkiewicz, Fahrenholz, Zeitschrifit lür Parasi tenkunde 10:243. “.

HOSTS AND DISTRIIDUIION. Described irom Pachyuromys duprasi, Natron Valley, Eypt, and recorded hy Ferris from the same host and locality.

NOTES. This species is the type of the genus Eremophthirius.

\section{GenuS PKOENDERLEINELLUS EWIn:}

1923. Proenderleinellus Ening, Journal of the Washington Academy of Sciences $13: 147$.

1938. Waterstonia Fahrenholz, Zeitschrift für Parasitenkunde 10:244. (Pre-

1939. Symysadus Pahrenholz, Mitteilungen aus dem entomologischen Verein bremen (no volume number), paje 44.

CENERIC TYPE. The genus was based upon Proenderleinellus africanus Ewing, which is a synonym of Polydlax calvo katerston. The reneric names proposed by Fahrenholz were based upon polyplax calva Haterston. This is the only included species.

CHARACTERS. Polyplacinae in which the antennae are five-semented, not sexually dimorphic. Anterior legs moder ately lar:e, but with slender clan; middle legs but slightly laryer than the first and with slender clan; third legs much larger than the others and with stout clan. Paratergal plates of the abdomen present on seyments 2-8, those of segment two divided longitudinally into two pieces. Abdomen entirely membranous in hoth sexes except for the usual sclerotizations of the terminal and fenitalic segments and base. Abdomen of the male with one row of such setae on all sements dorsally except perhaps the second, which has two. and with two rows on most of the serments ventrally. Sternal plate of the thorax well developed. Abdominal spiracles present on sements $3-8$.

NOTES. The writer, suspecting that Proenderleinellus ofricanus Evin: might be a synonym of the earlier Poluplax calua katerston, enlisted the aid of Mr. C. F. W. Yueseheck, who examined the single male tope of the former and a,reed. 


\section{Proenderleinellus calva (Waterston) \\ Fi grures 92, 93}

1917. Polyplax calva Waterston, Parasitoloy 9:199; figures.

1923. Polyplax calva Waterston, Ferris, Contributions Toward a Monograph of the Sucking Lice, Part 4:234; ti gures 153, 154.

1923. Proenderleinellus africanus Ewing, Journal of the Washington Academy of Sciences 13:147.

1938. Waterstonia calva (Waterston), Fahrenholz, Zei tschrift für Parasitenkunde 10:244.

1938. Waterstonia calva zanzibariensis Fahrenholz, Zeitschrift für Parasitenkunde 10:244.

1939. Symysadus calva (Waterston), Fahrenholz, Mitteilunigen aus dem entomologischen Verein Bremen (no volume number), paise 44.

HOSTS AND DISTRIBTION. Described by Waterston from Cricetomys gambianus at Accra, French West Africa, and also recorded from Cricetomys sp. from Zanzibar. The supposed subspecies zanzibariensis was based solely upon the illustration fiven by Waterston of the male, this male havin come from Zanzibar. The supposed species africanus of Ewing was based upon a sinile male which had been taken from a skin of Thryonomys gregorianus which had come from British East Africa. There are at hand specimens from the type host at Accra and also from Cricetomys from Zanzibar.

NOTES. The specimens at hand deny the slight differences oftered by Fahrenholz as a basis for the naming of his supposed form zanzibariensis.

\section{Genus RATEMIA Fahrenholz}

1916. Ratemia Fahrenholz, Archiv für Natur łeschichte, Alteilung A, 81:11:31. 1922. Ratemia, Ferris, Contributions Toward a Monograph of the Suckinis 1949. Ratemia, Webb, Proceedings of the Zoological Society of London 119: 164.

GENERIC TYPE. Haematopinus (Linognathus) squamulatus Neumann, the only included species.

CHARACTERS. Polyplacinae with five-segmented antennae which are not sexually dimorphic. Anterior legs relatively small, with slender claw; middle and posterior le grs about equal to each other, lurger than the first and with somewhat stouter claw. Paratergal plates of the abdomen occurring on segments 3-6. Abdomen otherwise memuranous in both sexes except for the usual terminal and genital areas. Abdominal serments in both male and female, both dorsally and ventrally, with a single transverse row of setae which alon: the mid-line of the body becomes merged with a median cluster of two or three rows of setae. Spiracles present on abdominal se gments 3-9. Thoracic sternal plate well developed.

The type species of the genus apparently occurs normally on hosts of the Perissodactylous family Equidae.

NOTES. Because of the hosts of the type species it is difficult to shake off' a prejudgment that this genus should not be assimed to the Hoplopleuridac, which are primarily parasites of the rodents, and there is a pressince to tind some excuse for placinit it in the Hacmatopinidae or the Lino fnathidae. However, no morphological reason for either of these latter assi gments appears and it is here placed in the Hoplopleuridae. Webb (1949) his assumed the renus to he related to Linonnathus because of similarities of the spiracles, but the present writer remains unimpressed by this supposed resemblance, especially in the face of other morphological features. 


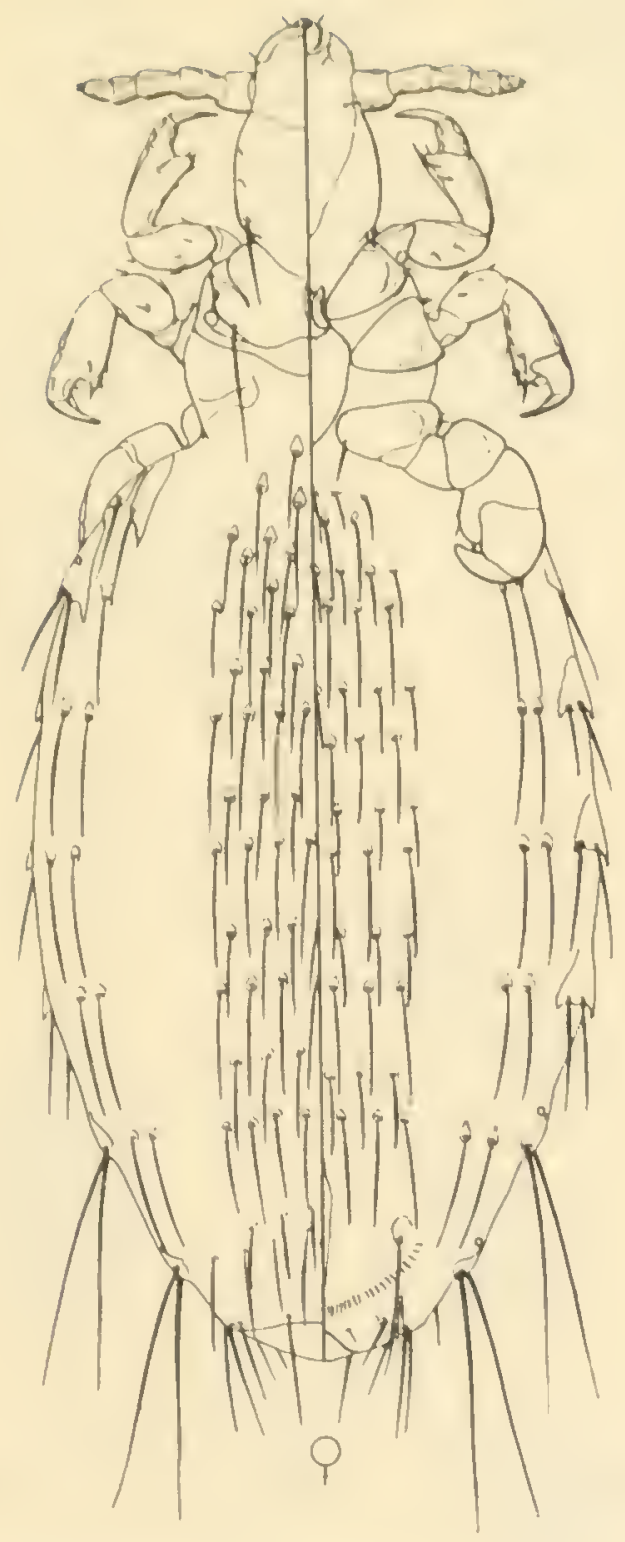

Proenderleinellus calva (Waterston)

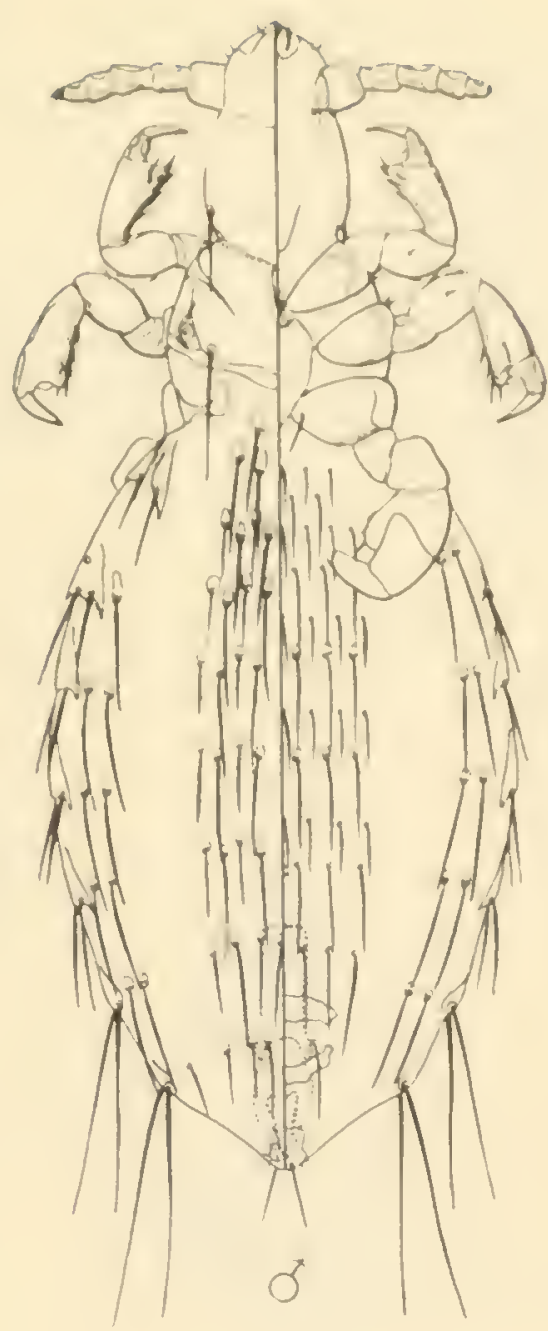

Figure 92

\section{Ratemia squamulata (Neumann) \\ Figure 94}

1911. Haematopinus (Linoknathus) squanulatus Veumann, Archives de Parasitolorie 14:401: figures.

1916. Ratemia squamulata (Neumann), Fahrenholz, Archiv für Naturosechichte, Abteilun: A, S1:11:31.

1929. Ratemin squamulatn (Neumann). Ferris. Contributions Toward a Monoraph of the Sucking Lice, Part 3:157; figure 103.

1946. Ratemia squamulatn (Neumann), Hopkins, Annals and Yarazine of Natural History (Series 11) 12:565. (Dated Ausust, 1945, but available copy bears the notation that it was published in May. 1946) 

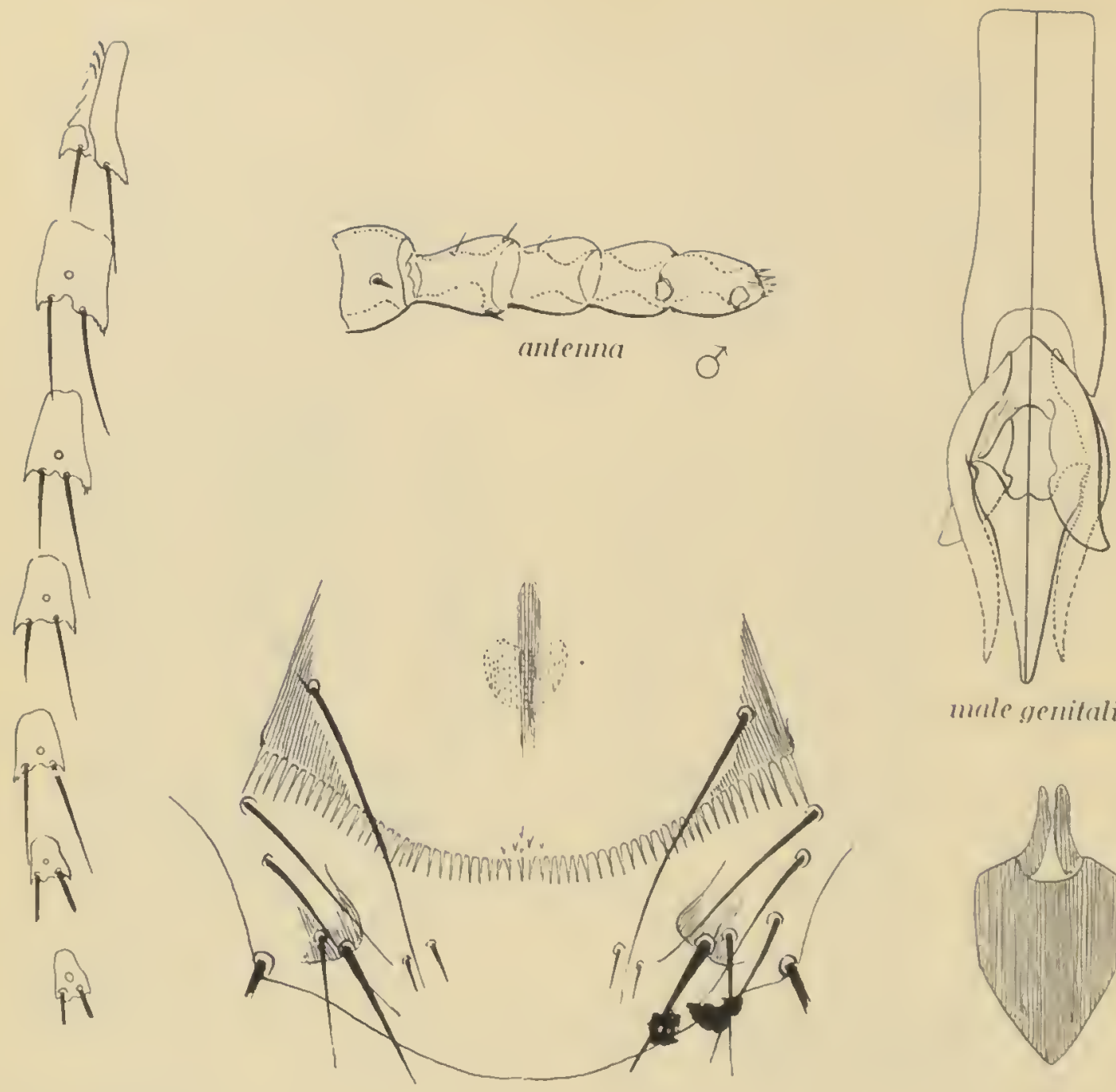

male gerritalia

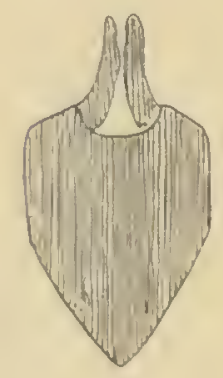

paratergal plates

female genitalia

thoracic sternal plate

Proenderleinellus calva (Waterston), details

Figure 93

HOSTS AND DISTRIBUTION . Originally described from an undetermined host at Dire-Daoua, Abyssinia. Since that time Hopkins has recorded the species from domestic donkey at Liro, Lango District, Uyanda, and from burchell's zebra, Equus (Htppotigris) burchellt, taken on the Athi Plains near Nairobi, Kenya, thus apparently establishing the normality of the species to members of the Perissodactylous family Equidac. It should, therefore, enter into any list of the parasites of domestic animuls.

NOTES. Through the kindness of Mr. Hopkins it has been possible to see specimens from both the hosts recorded hy him. In the accompanying illustrations, that of the 'cmale is from a specimen in the original type lot; that of the male is from a specimen from Equus burchelli, which was received as a loan from Mr. Hopkins. 


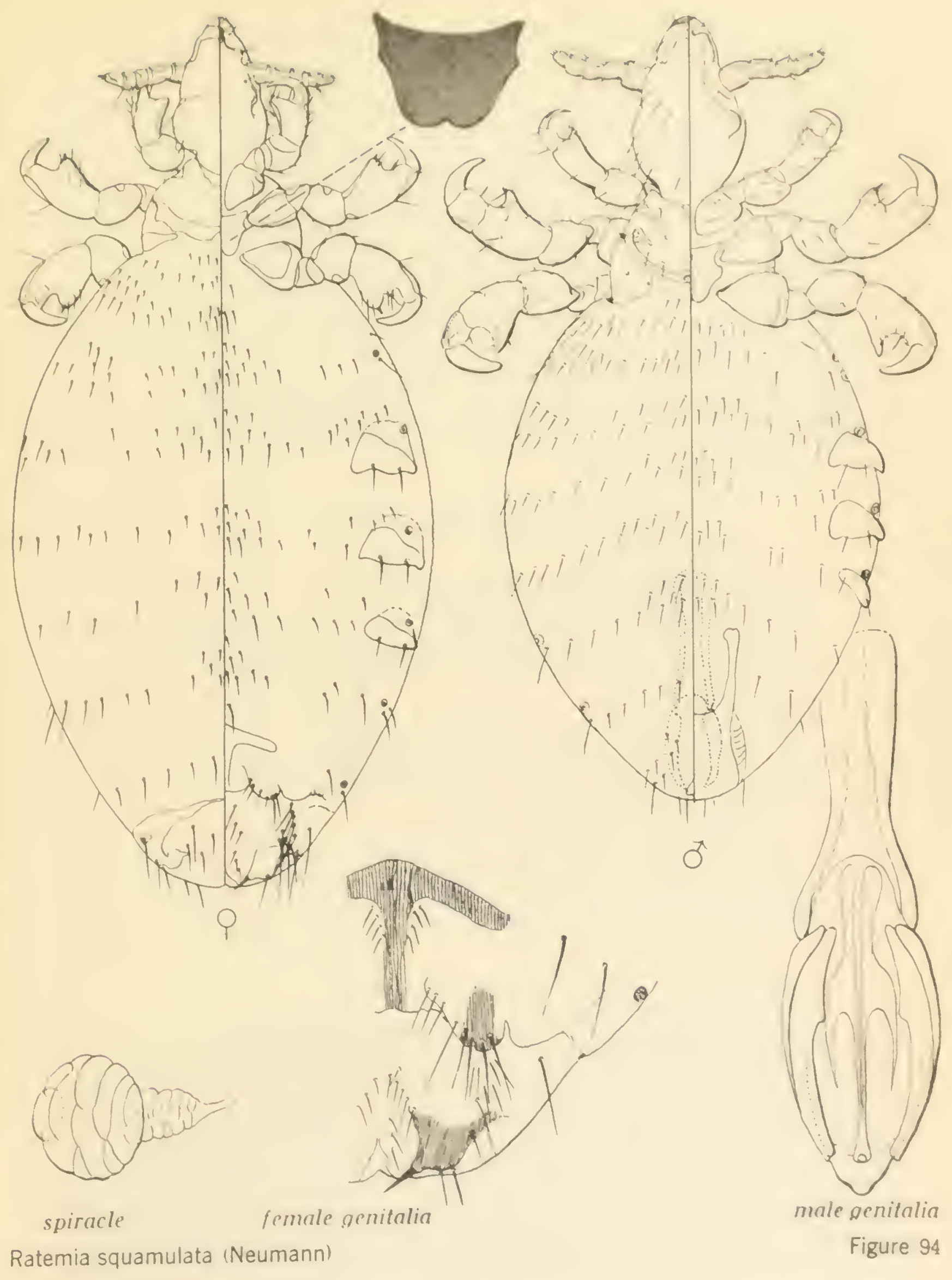


1938. Symoca Fahrenholz, Zeitschrift für Parasitenkunde 10:245. cies.

GENERIC TYPE. POlyplax brachyrrhynchus Cummings, the only included spe-

CHARACTERS. Polyplacidae with five-semmented antennae which are sexually dimorphic, those of the male having the distal, preaxial angle of the third segment slightly prolonged and bearing a stout, recurved seta at its apex. Head with the basal segment of the antennae set very close to the truncate anterior margin. Thorax narrow and somewhat elongate, with no distinct sternal plate. Anterior legs small and weak and with slender claw; middle leigs distinctly larger and with somewhat larger claw; posterior legs with the tibio-tarsus much enlarged and with a stout, heavy claw. Abdomen with paratergal plates present on segments $2-8$, the plates on segment two apparently not divided longitudinally. Female with abdominal segments 4-7 each with two plates and two transverse rows of setae both dorsally and ventrally. Male with but one row of setae on any segment both dorsally and ventrally, except for the sternum of segment three which apparently has two rows. Sternal plates not developed in the male.

NOTES. While the relationships of this genus are certainly with polyplax and the bases for a generic separation are not especially convincing, the genus is here accepted.

\section{Symoca brachyrrhyncha (Cuminins)}

Figures 95, 96

1915. Polyplax brachyrrhynchus Cummings, Proceedings of the Zoological Society of London, page 246 ; figures $13,14$.

1923. Polyplax brachyrrhynchus Cummings, Ferris, Contributions Toward a Monograph of the Sucking Lice, Part 4:220; figures 142, 143.

1938. Symoca brachyrrhyncha (Cummings), Fahrenholz. Zeitschrift fur Parasitenkunde 10:245.

1939. Symoca brachyrrhyncha, variety minor Fahrenholz, Mitteilungen aus dem entomologischen Verein Bremen, page 32.

HOSTS AND DISTRIBUTION. Described as from Acomys cahirinus at Assiut, Egypt. Recorded by Ferris from Acomys hystrella in Uganda and f'rom Acomys percivali in British East Africa.

NOTES. Fahrenholz based the supposed variety minor entirely upon a comparison of the description and illustrations given by Cummings with those given by Ferris, although Ferris had compared his specimens with the types. The differences cited by Fahrenholz are merely such as may readily appear in the work of two individuals, even utilizing the same material.

\section{Family LINOGNATHIDAE Webb}

1904. Trichaulinae Enderlein, Zoologischer Anzeiger 28:138.

1905. Linosnathinae Enderlein, Zoologischer Anzeiger 29:194.

1946. Linognathidae Webb, Proceedings of the Zoological Society of London $116: 107$.

DESCRIPTION OF THE FAMILY. Anoplura in which external evidence of eyes may or may not be present. Abdomen entirely membranous in both sexes except for plates associated with the terminal and genital segments and rarely (one species) terigal plates in the male. Abdominal segments each with at least one row of hairs both dorsally and ventrally, usually much haired. Second and third legs almost always equal to each other and much larger than the first pair. Thorax usually wi thout any trace of a sternal plate but it present always without the apex free from the body. Spiracles, as 


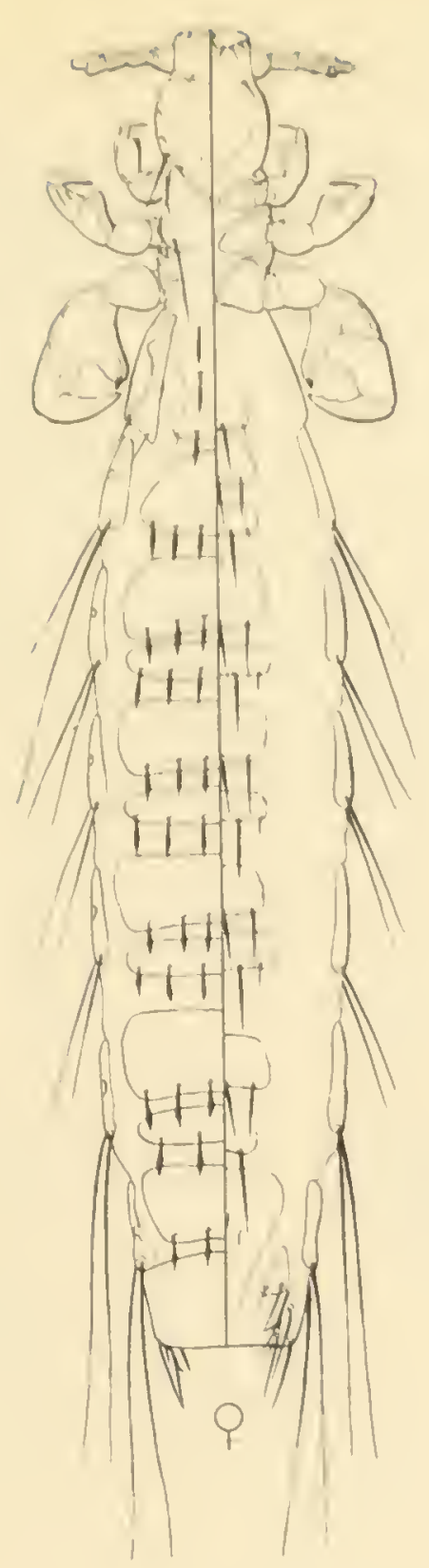

Symoca brachyrrhyncha (Cummings)

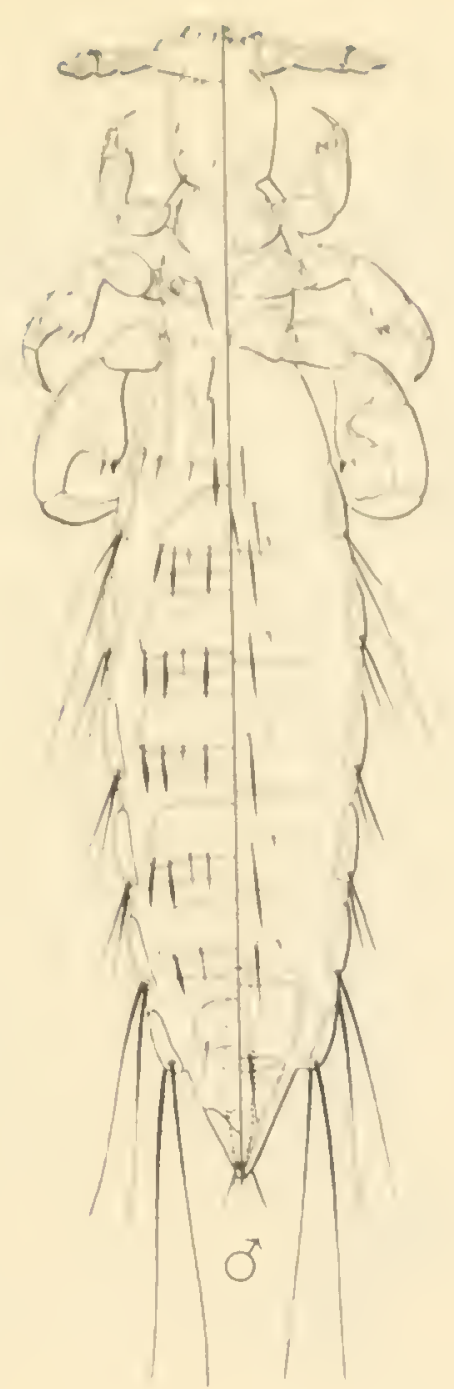

Figure 95

far as known, with distinct internal ledges which show externally as rings, or with the ledges forming internal points.

The members of the family are restricted to members of the Orders Artiodactyla and Hyracoidea, except for two species from Carnivora.

NOTES. To this family there are here assigned four genera-Linognathus, vicrothoracius, Solenopotes, and Prolinognathus. A certain amount of doubt is felt concernin the renus vicrothoractus since an aryument can be made for its assimment to the Haematopinidae. One other question, that of the genus Eaemolipsus, is troublesome. The type of this genus is unfortunately an imperfectly known species and, because of its relation to certain other species which are assirned to the genus, it is here placed in the Hoplopleuridae. Taken by itselt it mi tht very properly be assigned to the Linognathidae and eventually it may be necessary to break up the senus Hoemodipsus, assigning its type species to a position near Linoknctius. 

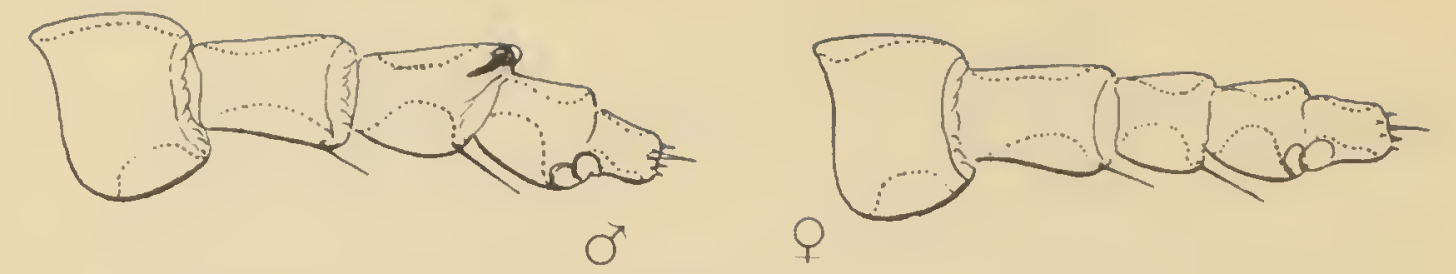

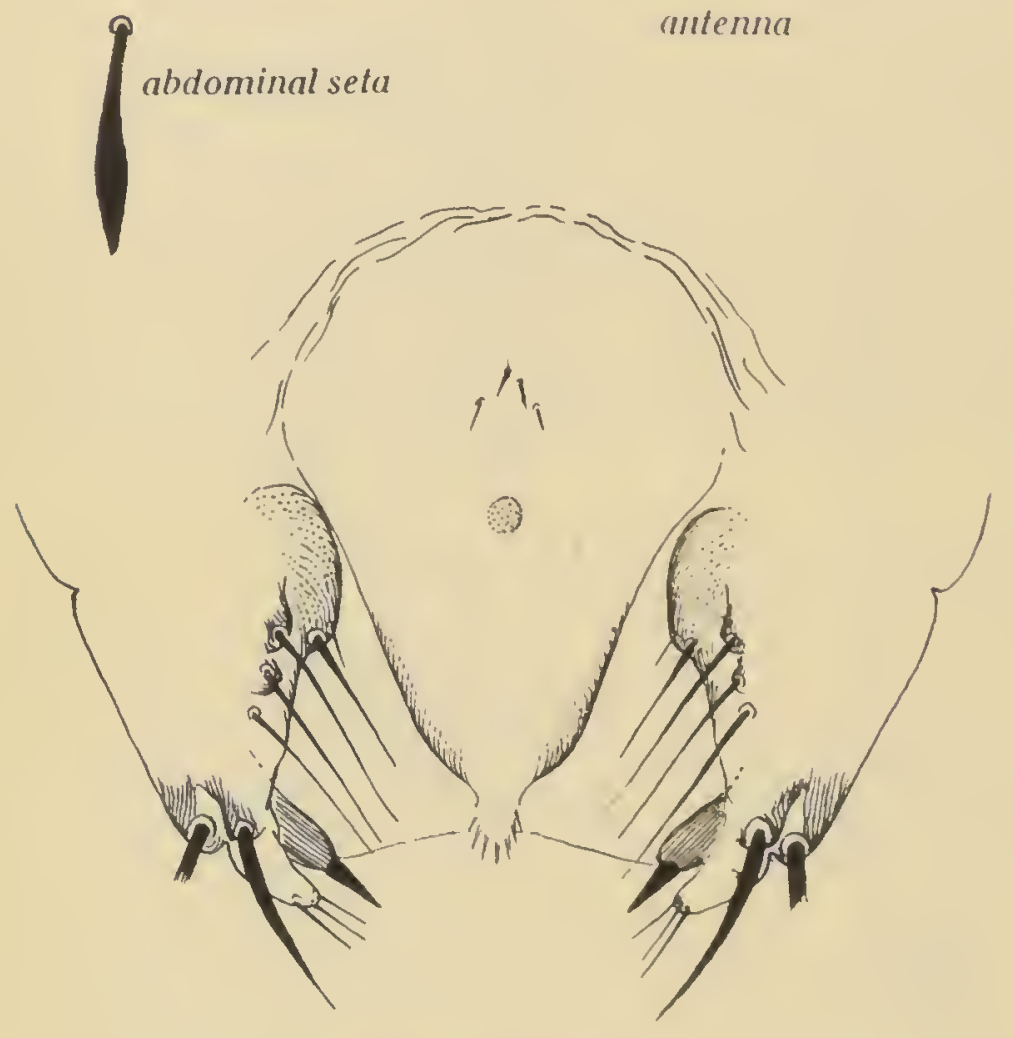

fenıale genitalia

Symoca brachyrrhyncha (Cummings), details

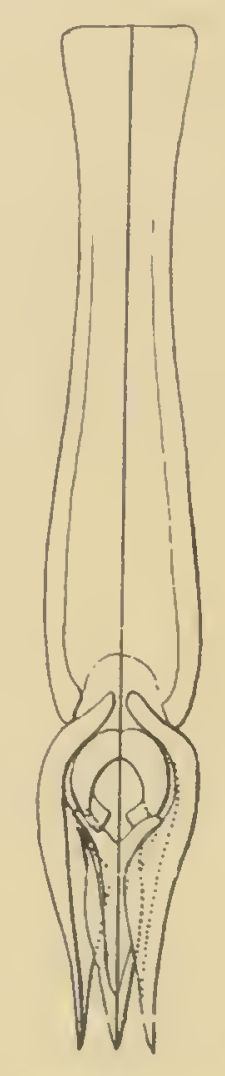

male genitalia

Figure 96

\section{Key to the Genera of LINOGNATHI DAE}

1. Eyes indicated externally by a definite lens; occurring on Camelidae...

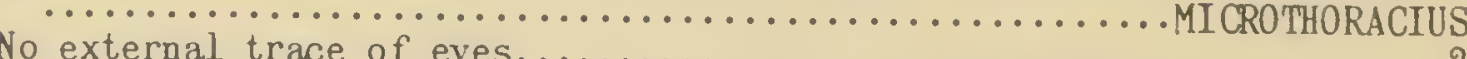

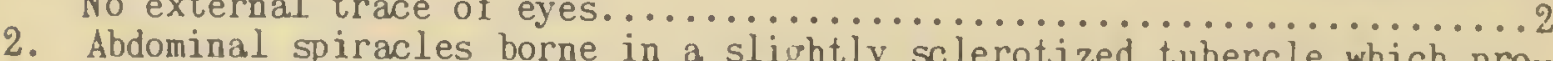
jects at least slightly from the body; but 1 specis

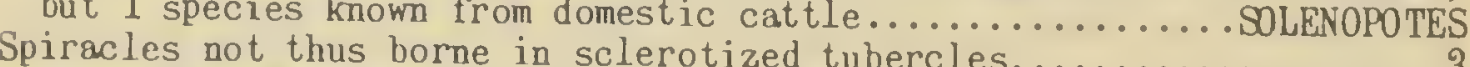

3. Setac of abdomen greatly reduced in number, there beino normally but ${ }_{2}$ setae in each median group, both dorsally and ventrally, on any abdominal segment, these in a single row; spiracles extremely small; occurring as far as known only on members of the Order Hyracoidea....

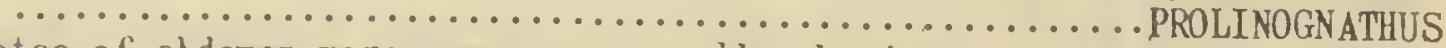

Setac of aldomen more uumerous, usually abundant, and in 2 or more rows on each seigment; spiracles not minute; occurring for the most part on members of the Order Artiodactyla, but represented on the family Canidue of the Order Carnivora................................... 
1904. Prohumlus fimlerlein, \%oolorischel Anzeiger 98:139, 141. (Preoccupied)

1905. Wmognatms linterlein, Luologischer Anzeiger 29:191.

1909). Litnomuthus (Hopmutoptmus), Aeuminn, Archives de Parasi tolorie 13:529.

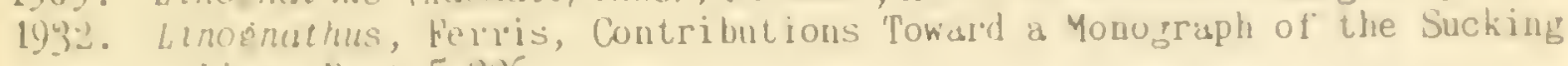
lice, Hut $5: 336$.

194(). Stobbella bichler, bolletino della Societa Entomologica Italiana $70: 13$.

CHERL TYPE. Pediculus piliferus burmeister, which is considered to be a synum ot Pediculus setosus von 0lters.

CIEYEIC SYNOYYS. Stobtiella Eichler, type Linognathodes pithodes Cummin $\mathrm{s}$.

CllAKICTEKS. Lino ruathidae in which there is no external evidence of eyes. Antennire t'ive-sermented, the tourth and fifth segnents not fused. Spirates of the ablomen usually moreor less spherical, the internal lediges ot the atrium appearing externally us partial rings; never elonguted and never horne in a scleroticed tubercle. Thoracic sternisl plate laching, or il present very weakly developed and divided longitudinally into two smisl plates. Abdominal segments usually moch haired both dorsally and ventrally, with the hairs in al least two rows. Andomen terminally with a pair of ventral lokes, hut these never produced into t'lat processes. Genitalia of the male al ways with parameres well developed and enclosing the oedeagus.

NOTES. This is a renus ot considerable size, 26 species now be ing known. These are cont'ined to the timilies bovidae and Giratifidae of the Order Artiodactyla, except tor two species which occur on carnivores of the family Cinidae.

Eichler hus recently named the grenus Stobbella, with Linoenathus pithodes as its type, but this genus is here rejected.

\section{Key to Species of LINOrNATHUS}

1. Abdomen heset with short, stout, more or less fusiform setae.......2

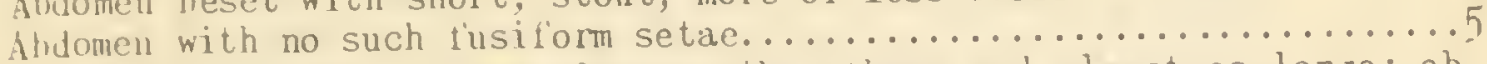

(1). Anterior le rs of same form as the others and almost as larre: abdonen very thichly and uniformly beset with fusiform setae; on

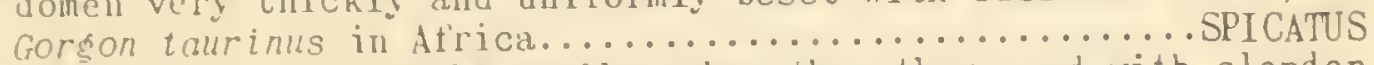
Anterior Legs definitely smaller than the others and with slender claw: fusiform setie more or less numerous, but leaving bare

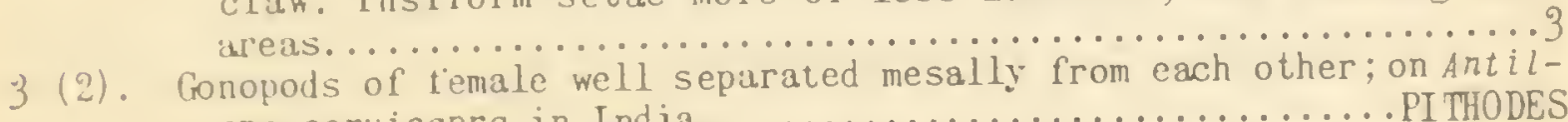
ope cervicopra in India........................... THODES

(n) nopods of female very broad and leaf-like, meeting each other

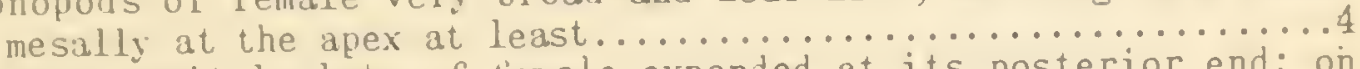

4 (3). Median benital plate of temale expanded at its posterior end; on

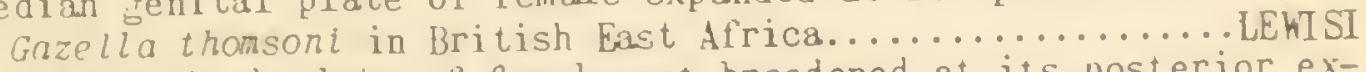

Yedian genital plate of female not broadened at its posterior extremity; on Antidorcas marsupialis in South Africa.......BEDFORDI

5 (1). Female with no trace of a sclerotized, median, genital plate....6 Female with at least a small, median, nenital plate...........11

6 (5). Conopods of the female apically truncate, emarginate or serrate...7 Conopods of the female apically rounded or acnte................

7 (6). Gonopods of the temale with the posterior border somenthat emarjinate and hearing a sclerotized hook at the mesal angle: forehead elongate and apically acute, hindhead longer than wide, almost rectan ular: occurrin; on domestic cattle throughout the world... 
Not with this combination of characters................... 8

8 (7). Head long and slender, the forehead acute, the hindhead with the lateral margins slightly convex; gonopods of female with a slimt tooth close to the posterior border near the mesal angle; occurring especially on domestic goats, but also at times on sheep and recorded from the European Capra ibex and Caprella rupicapra.....

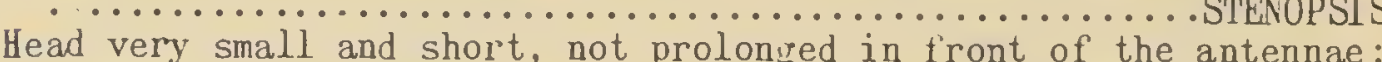
conopods of the female with the posterior in front of the antennae; gong sorgin irregularly serrate; widely distributed on domestic sheep................EALIS

9 (6). Head elongate and slender; dorsum of metathorax with an apically free lobe close to the margin just above the posterior coxal condyle; occurring on Cervicapra in Africa................AHENHOLZI Head short and broad, the anterior margin broadly rounded, the forehead not at all prolonged anteriorly .....................

10 (9). Abdomen in both sexes with very few elongate setae, there being a median pair and a sinsle seta near the margin, both dorsally and ventrally, in either sex, with a few extremely minute setae between the median and lateral setae; occurring on Gorgon taurinus

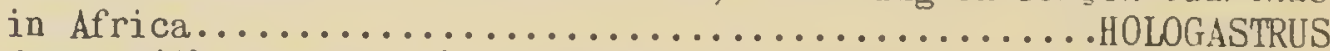

Abdomen with numerous slender selae both dorsally and ventrally in both sexes; occurring on Canis brasiliensis in South America....

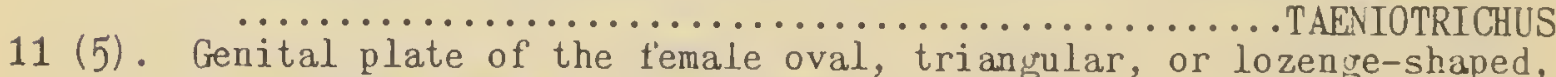
and never with a slender median, stalk-like prolongation con-

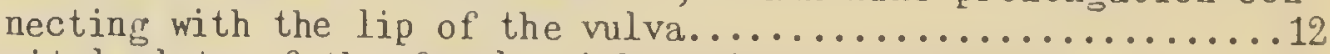

Genital plate of the female with various configurations, but not

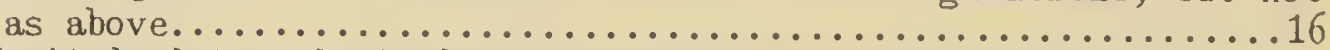

12 (11). Genital plate relatively very large and definitely lozenge-shaped; head unusually elongate and narrow; occurring on "North African

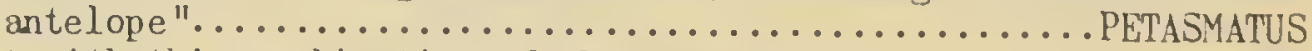

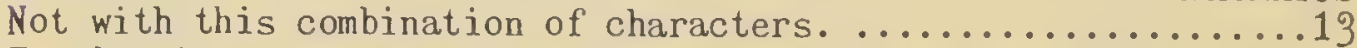

13 (12). Female with the genital plate transversely oval and with a slitht median, posterior point; gonopods elon rate, apically somewhat spatulate; male with the terminal sternite produced and with a flattened, sclerotized lobe on each side; occurring on Conno-

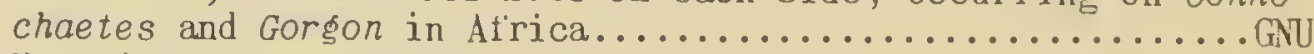

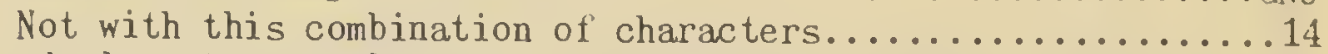

14 (13). Head elongate and slender, anteriorly acute; genital plate of the female forming an almost equilateral triangle; occurring on

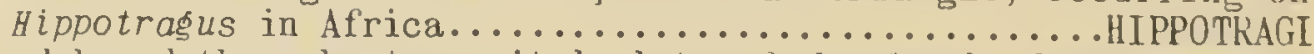

Head broad throughout, genital plate of the female forming merely a small, slightly elongate, oval area.................. 15

15 (14). Head very short and broad, scarcely longer than wide; occurring on domestic dogs and on foxes; occasionally taken from other

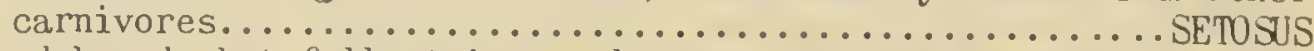

Head broad, but fully twice as lon as wide; on domestic sheep in

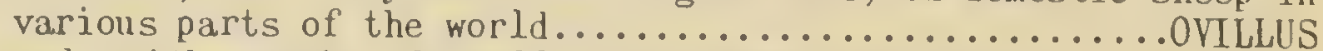

16 (11). Female with a pair of small, hook-like processes on the lip of the vulva between the gonopods; male with a deeply pi.mented, transverse plate just in front of the anus; occurring on Tauro-

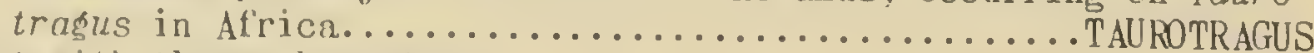

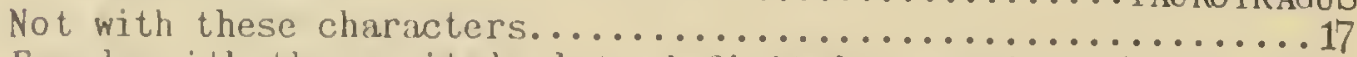

17 (16). Female with the genital plate definitely spatulate (not me slightly expanded anteriorly) and with a slender, stalk-like posterior prolongation nearly or quite connecting with the lip

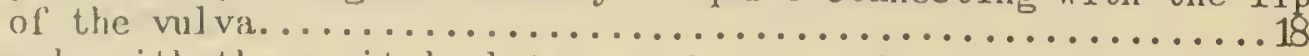

Female with the genital plate not thus spatulate.............21 
18 (17). Cienital plate of the temale described as moge or leas I-shaped,

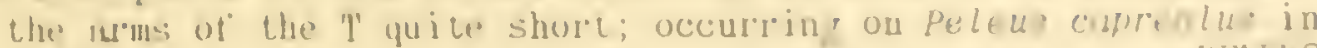

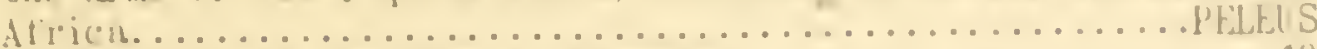

Genitul plate of the tearde otherwise................... 19

19) (18). (ionopols of the temale curved, their apices directed toward the mill-line ot the body and with setae extending from the lateral inargin around the apex and well up the mesal margin; head rather smoothly fusiform; occurringon Cephalophus muxuellz, an Alricaul

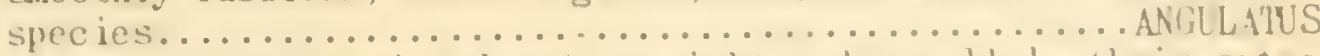
Gonoporls of the female almost straight and parallel, their setae contined to the mesal maryin.......................

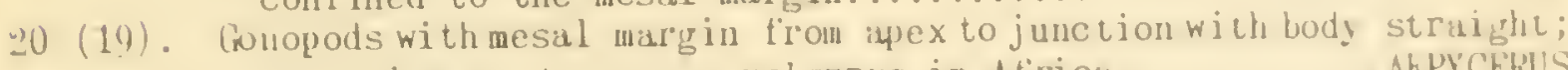

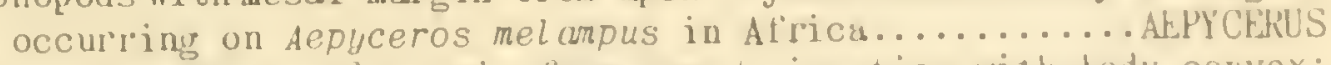

fonopods with mesal marrin from apex to junction with hody convex;

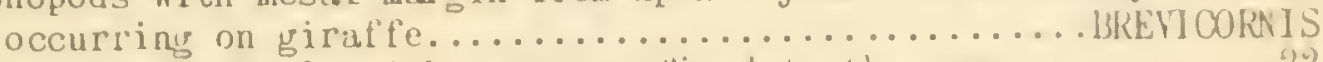

$21(17)$. Conopods of fenale with setae contined to the asex..........22 Gonopods of temale with setac extending well up the mesal margin

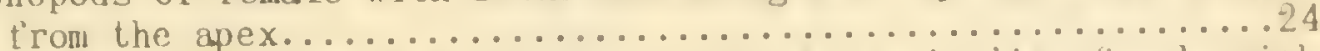

Ig (21). Conopods of the female apically convergent; genitalia of male with detinite pseudopenis and with parameres not basally swollen..23

Gonopods of temale described as parallel; trenitalia of male described as having the parameres hasally swollen and as lacking pseudopenis; occurring on Antilope cervicapra, an Indian spe-

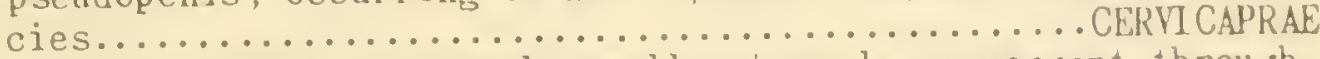

23 (22). Gonopods of female extremely small, strongly convergent throughout their length; occurring on Ant ilope euchore and various other species of Antilope in Africa................ TIBIALIS Gonopods of female with sclerotization elongate and strongly curved at the extreme apex; occurring on domestic sheep, widely distributed, and perhaps on Oreotragus saltator in Africa.....

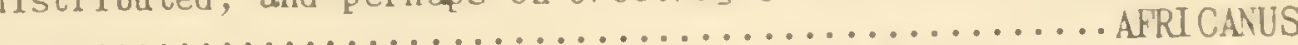

24 (21). Forehead slender and apically acute; lateral margins of the hindhead smoothly convex; gonopods of the female short and quite broad; genital plate of the female elongate, somewhat expanded anteriorly but scarcely to be described as spatulate; occurring

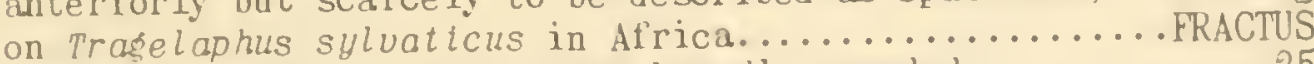

Forehead truncate or at the most broadly rounded...........25

25 (24). Conopods of the f'emale with their mesal mar ins straight, parallel and only these margins bearing setae; genital plate of the female shoe sole-shaped, projecting slightly from the vulva apioally; known from Tragelaphus gratus in Africa........LIMOTRAGI 0 therwise, occurring especially on species of Cepholophus........

\section{Linognathus aepycerus Bedford}

1936. Linosnathus aepycerus Bedford, Onderstepoort Journal of Veterinary Science and Animal Industry 7:62; figures 5, 6.

HOSTS AYD DISTRIBUTION. From Aepycerus melampus, commonly called impala, between Pretoria and Johannesbur:, South Africa.

Lino:rnathus africanus Kellogg and Paine Figures 97,98

1911. Linonnathus a ricanus Kellogg and Paine, Bulletin of Entomological Research 2:146: Plate 4, fijures 1, 5.

1916. Linognathus stenonsis (Burmeister), Ferris, Proceedings of the California Academy of Sciences (Series 4) 6:155. (Part: misidentification) 

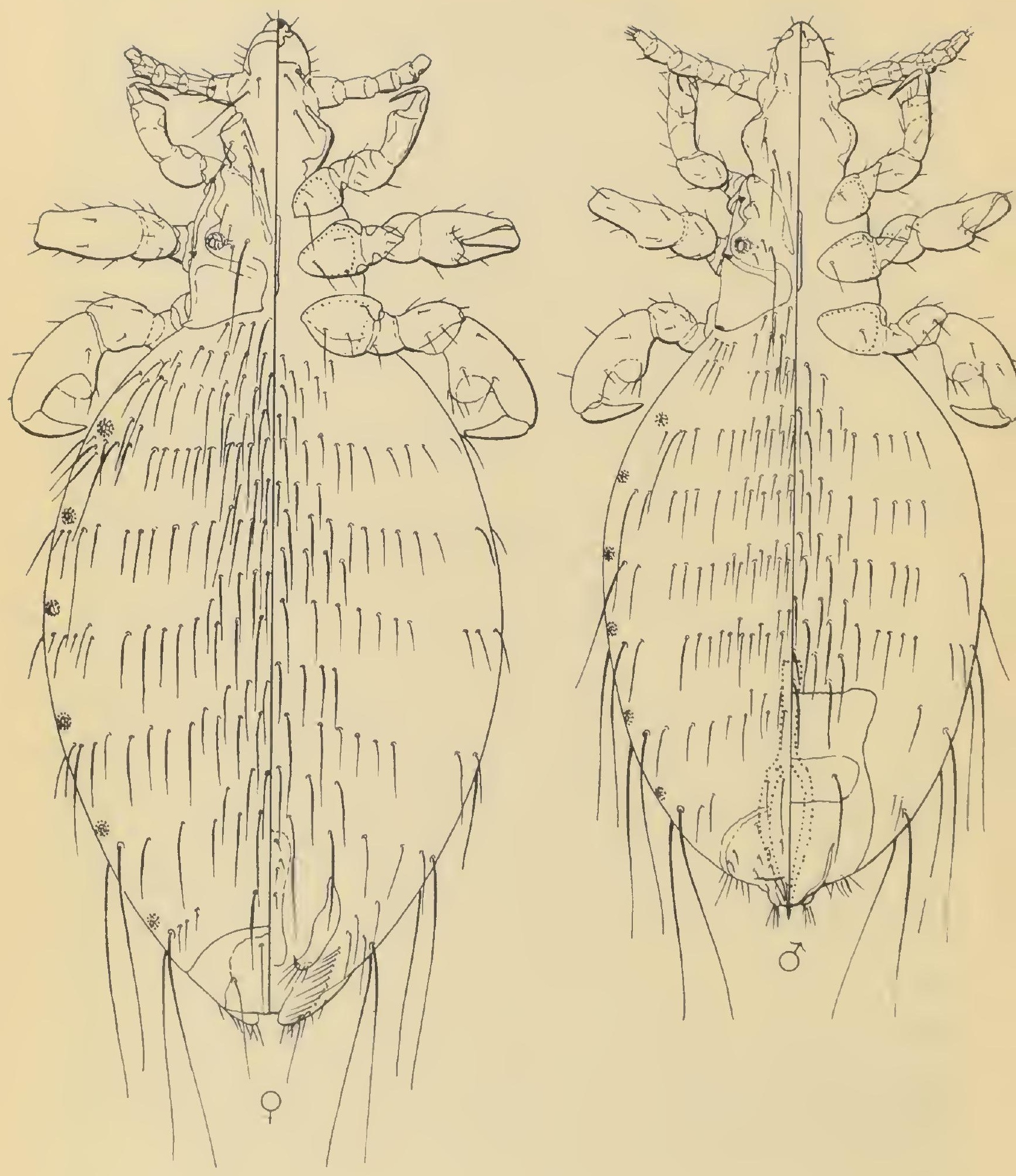

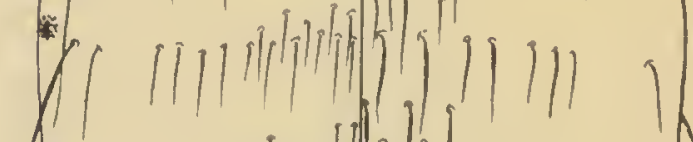

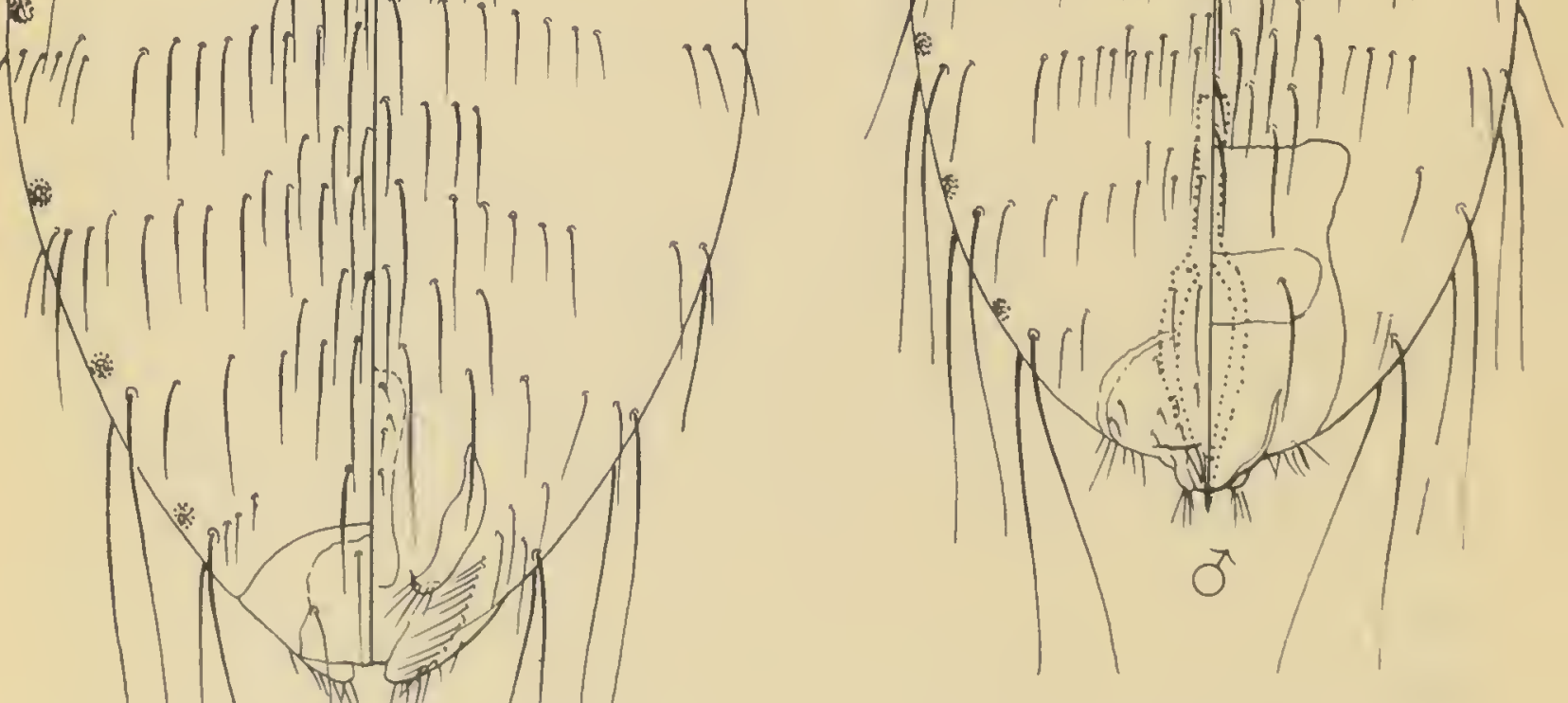




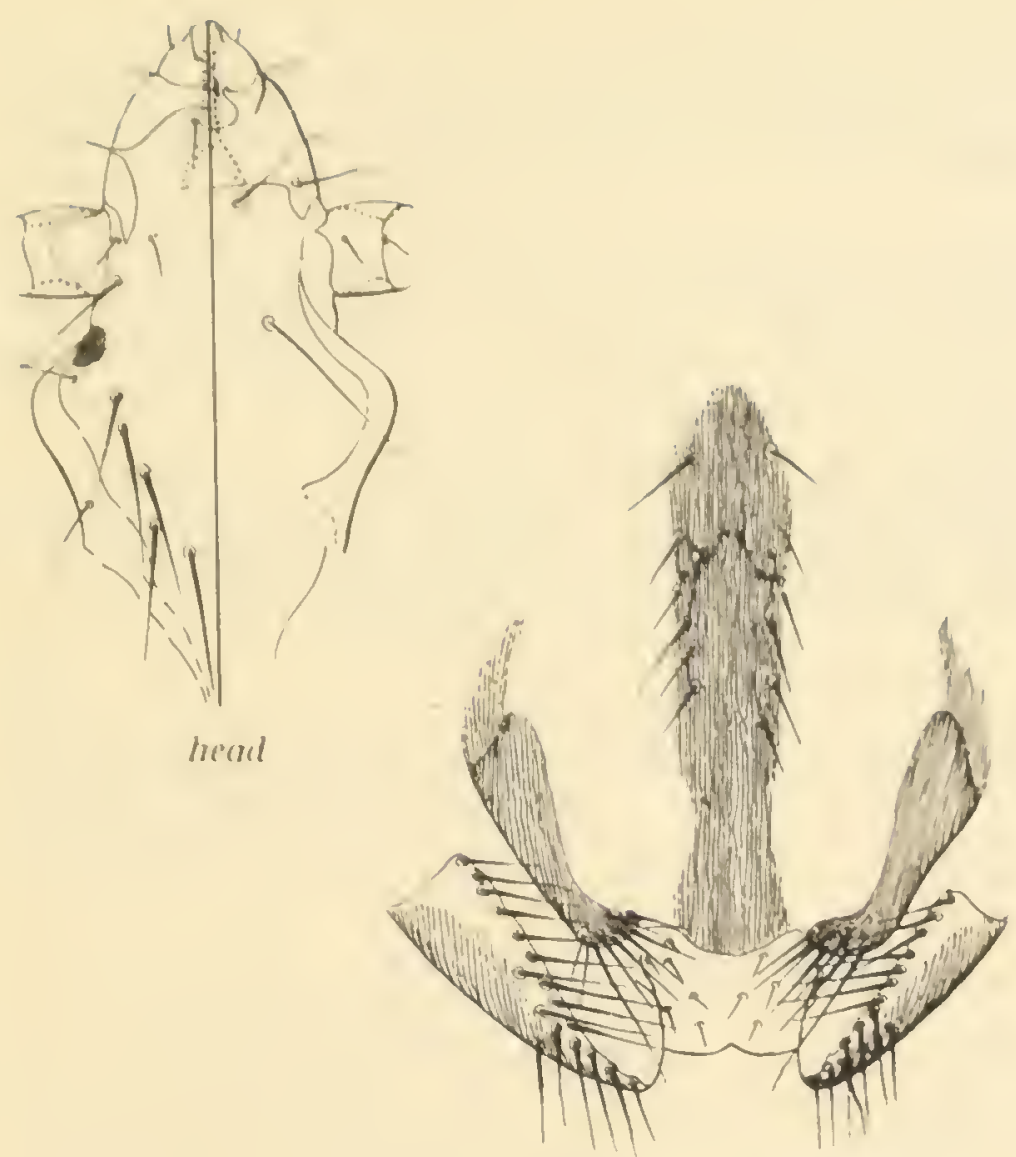

female senitalia

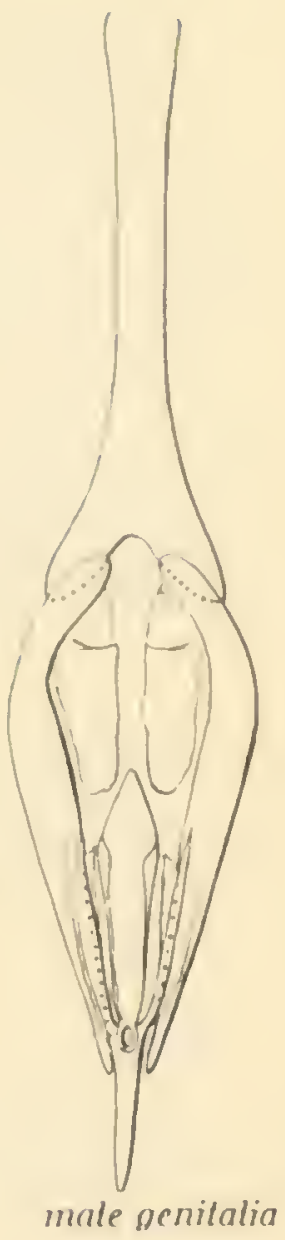

Figure 98

Linognathus africanus Kellogg and Paine, details

1927. Linoßnathus stenopsts (Burmeister), Bedford, Report of the Director of Veterinary Education and Research, Union of South Africa 11-12: 737. (Part; misidentification)

1932. Linosnathus africanus Kellowand Paine. Ferris, Contributions Toward a Mono 1932. Linognathus africanus Kellogs and Paine, Bedtord, Report of the Director of Veterinary Services and Animal Industry, Union of South Africa 18:408.

1939. Linognathus africanus Kellogg and Paine, Fahrenholz, Mitteilungen aus dem entomoloyischen Verein, Bremen, paye 35.

HOSTS AVD DISTRIBUTION. Type from "sheep," Abeohuta, southern Nigeria, Africa. Later recorded from domestic sheep and domestic goats from various localities in South Africa, Abyssinia, India, and the United States. Recorded by Fahrenholz from Ouis longlpes from Algeria, North Africa.

NOTES. There are apparently four species of Linosnathus-namely, ovilius, pedalis, stenopsis, and africanus-which may be encountered on domestic sheep and goats. They are quite distinct species and the probability is that here has been some interchange of hosts. 
1885. Haematopinus ungulatus Piaget, Les Pediculines, Supplement, page 144; Plate 15, figure 7. (A misprint for angulatus, since that name appears on the plate and on the label of the type specimens.)

1932. Linoछnathus anछulatus (Piaget), Ferris, Contributions Toward a Monograph of the Sucking Lice, Part 5:380; figures 231D, 232G, 233.

HOSTS AND DISTRIBUTION. Type from Cephalophus nigrlfrons without indication of locality .

NOTES. Since this species was described from the same host genus as was breviceps, it might be suspected that synonymy is involved, but apparently the two species are distinct. There may have been some mixing of material or some misidentification involved. Actually the species aepycerus approaches it very closely.

Fahrenholz has maintained that the spelling ungulatus should be preserved, but it seems clear that this was a typographical error, the spelling angulatus being used in connection with the plate accompanying the original description and on the label of the type specimens.

\section{Linognathus bedfordi Ferris}

1932. Linognathus bedfordi Ferris, Contributions Toward a Monograph of the Sucking Lice, Part 5:387; figures 236, 238B, C, H, I, and 239A, D.

HOSTS AND DISTRIBUTION. From Antidorcas marsupialis at Anderstepoort, Union of South Africa.

\section{Linognathus breviceps (Piaget)}

1885. Haematopinus breviceps Piaget, Les Pediculines, Supplement, page 142; Plate 15, figure 5.

1910. Linognathus छazella Mjöberg, Arkiv för Zoologi 6:157; figure 78 .

1910. Linognathus gilvus Fahrenholz, Jahrbuch der Hamburgischen Hissenschaftlichen Anstalten 34:2:18; figure 5.

1932. Linoenathus breviceps (Piaget), Ferris, Contributions Toward a Monograph of the Sucking Lice, Part 5:107; figures 216A, 231B, C, E, $\mathrm{F}, \mathrm{H} ; 232 \mathrm{~A}$.

1932. Lino gnathus छazella Mjoberg, Ferris, Contributions Toward a Monograph of the Sucking Lice, Part 5:111; figures 232B, E, F, 234.

HOSTS AND DISTRIBUTION. First described Ẽom Cephalophus maxwe lli with"gazelle," in the Hamburg Zoological Gardens. Described as Linognathus giluus Fahrenholz from Cephalophus sp. from the same Gardens, these having been some of the same specimens, apparently, as the lot that Mjoberg had. Erroneously recorded by Ferris and by Bedford as Linognathus an हुulatus (Piaget) from Cephalophus natalensis and Sylviacapra grimmi from Zululand and Transvaal.

NOTES. Concerning this species, or perhaps closely related group of species, there is very muoh of a problem. Ferris, in connection with the reference cited above, was able to examine types of all of them and a considerable range of this material is still at hand. This material has been examined and re-exanined in connection with the present work and no consistent basis for the separation of these species has appeared. Perhaps even Linosnathus limnotras $i$ cannot definitely be separated.

In specimens from the type lot of gazella the forehead is almost rectangular, lut there is some variation in this and the character does not hold.

Specimens Irom Cephalophus er immi and Cephalophus natalens is-over 30 specimens from the first being available-show cnough variation in head form to represent two or three species il these characters can be taken 
serionsly. Sone specimens have the himberul definitely ungulate laterally, while in others it is prarallel silfed.

The typical "shue sole shaped" renital plate of the lemale appears in the types of lametrabl, but does not hold in other specinens rifich are at hand from the siune host. There is also some range of vidiation in the form of the ponopods, some bejur inute and ochers rounded. However, the species

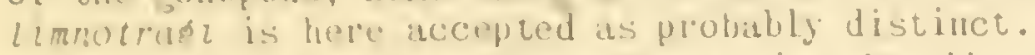

The resule has bern that the species gazello and glluus are here placed in sinemy nith breviceps.

This species has sometimes leen placed in synonym with Linoenathus unsulatus (Pinfet), which also is atributed co Cepholophus, but the two are clearly distinct.

Linornathus brevicornis (Giebel)

1in.4. Huenatopinus brevicornis fiebel, Iusecta kpizoa, page 43.

1932. Linoonuthus brevicornis (Giebel), Ferris, Contributions loward a Monorgraph ol the Suching lice, l'a't 5:365; ligures 216D, 219.

IIOSTS AND DISTRIBUTIOA. From Came lopardal farden.

Nilks. The redescription siven by ferr is was based upon specimens in the piaset collection. Whether or not these belonged to the same lot as did Giebl's types is not known.

\section{Lino mathus cervicaprae (Lucas)}

1847. Haematopinus cervicaprae Lucas, Annales de la Société entomolo rique de France (2) $5: 534$; Plate 8 , figures II, 1-1h.

1938. Linosnathus cervicaprae (Lucas), herneck, Libro jubilar do Prof. Travassos, pare 527: figures $1-5$.

HOSTS AID DISTRIBUTION. Described by Lucas from Antilope cervicapra, from a menagerie in Paris. Not seen again until recorded by herneck from specimens taken from the same host species in the Zoolorical Garden of Lond on.

NOTES. In 1939 Fahrenholz recorded under this name and described specimens f'rom the Museum d'Histoire Naturelle de Paris which he assumed to have been left by Lucas and therefore possibly to be the types of the species. However, Hernect had already redescribed the species and later published a note in which he indicated that Fahrenholz arreed that these specimens were probably not those recorded by Lucas and accepted the interpretation given by werneck. The species involved was referred by herneck to Linosnathus tibialis (Piaset) and the pertinent reference will be found under that name.

\section{Linograthus damaliscus Bedford}

1936. Linosnathus damaliscus Bedford, Onderstepoort Journal of Veterinary Science and Animal Industry $7: 61$; fi gures 3, 4.

HOSTS AND DISTRIBUTION. Type from Damal iscus albifrons in the zoolorical gardens at Johannesburg; also from Damaliscus dorcas at Bredasdorp, South Africa.

VOTES. On the hasis of the illustrations yiven by Bedford this appears to be identical with Linognathus taurotragi, but disposal of it must arait a re-examination of its types.

Linognathus tahrenholzi Paine

1911. Linognathus forficulus Kelloge and Paine. Bulletin of Entomological Research 2:47: Plite 4. tigures 2.4. (Sot Baematoninus forficulus 
Rudow, which is supposed to be also a Linognathus)

1914. Linognathus fahrenholzt Paine, Psyche 21:117.

1932. Linognathus fahrenholzi Paine, Ferris, Contributions Toward a Monograph of the Sucking Lice, Part 5:370; figures 224, 225.

HOSTS AND DISTRIBUTION. Described as from Cervicapra arund inarum, Marimba District, Nyasaland, and later recorded from Cervicapra fulvorufula at Mfongosi, Zululand.

\section{Linognathus fractus Ferris}

1932. Linognathus fractus Ferris, Contributions Toward a Monograph of the Sucking Lice, Part 5:366; figures 220, 221.

1932. Lino@nathus sp., Bedford, Report of the Director of Veterinary Services and Animal Industry, Union of South Africa 18:409.

HOSTS AND DISTRIBUTION. From Tragelaphus sylvaticus at Onderstepoort, South Africa.

\section{Linognathus gnu Bedford}

1927. Linognathus snu Bedford, Transactions of the Royal Society of South Africa 14:349; figures 3, 4.

1927. Linognathus ferr $i s i$ Bedford, Transactions of the Royal Society of South Africa 14:351; f'i vures 5, 7 .

1929. Linognathus gorgonus Bedford, Report of the Director of Veterinary Services, Union of South Africa 15:502.

1932. Linognathus छnu Bedford, Ferris, Contributions Toward a Monorraph of the Sucking Lice, Part 5:368; figures 222, 223.

HOSTS AND DISTRIBUTION. The type of Linognathus gnu was from Connochaetes gnu at Clocolan, Orange Free State, and the type of gorgonus was from Gor gon taur lnus, Zoutpansberg District, Northern Transvaal. The species was later recorded from this host at Maastrom, northern Transvaal, and in the Zoological Gardens at Pretoria.

NOTES. This species was described by Bedford as @nu and as ferris $i$ because of the fact that he had the two sexes separately from different hosts. The name ferrist, being preoccupied, was later changed by him to sorgonus. He later concurred that they represent the same species. Fahrenholz, in 1939, without seeing any specimens, considered the two to be distinct merely on the basis of illustrations given by Bedford and by Ferris. There is no reason to accept this opinion.

\section{Linognathus hippotragi Ferris}

1932. Linognathus hippotragi Ferris, Contributions Toward a Monograph of the Sucking Lice, Part 5:373; figures 226, 227.

HOSTS AND DISTRIBUTION. From Hippotragus niger, in the zoological garden at Johannesburg, South Africa.

\section{Lino:gnathus hologastrus Werneck}

1937. Linognathus hologastrus Werneck, Memorias do Instituto Oswaldo Cruz 32:397; fi rures $7-10$. Airica.

HOSTS AND DISTRIBUTION. From Gorgen taur tnus at Grootfontein, Southwest

NOTES. Although this species occurs upon the same host as does Ltnognathus gnu, the two species are very distinct and no confusion between them need arise. 
1934. Linosnathus lowtsi Bediord, Onderstepoort Journal of Veterinary Science and Animal Industry 2:48; ligure 11.

HGSIS AND DISTRIBUTION. From Gaze ta thomsont at Naivisha, British Erst Alrica.

\section{Linognathus limotrayi Cummings}

1913. Limnognathus limnotragt Cumings, Bulletin of Entomological Kesearch $4: 36 ;$ l'i gure.

1932. Llnognathus timnotras $t$ Cummings, Ferris, Contributions Toward a Monograph of the Sucking Lice, Part 5: 333 ; figs. 231A, I, J, 232C, D.

HOSTS AVD DISTRIBUTION. Types Iiom Limnotragus (= Tragelaphus) gratus in the zoological garden of London. Recorded ulso lrom Tragelaptus sylvaticus at Onderstepoort, Pretoria, and from tragetaphus scriptus in the zoological grarden at London.

NOTES. See the discussion under Linognathus breviceps.

\section{Linognathus oviformis (Rudow)}

1869. Haematoptnus oviformis Kudow, Zeitschrift lür die gesamten Naturwissenschat'ten $34: 170$.

1916. Linognathus ovi formis (Rudow), Fahrenholz, Archiv für Naturgeschichte, Abteilung A, 81:11:33.

HOSTS AND DISTRIBUTION. Recorded by Rudow from "Hircus manifricius," a host name that appears in no available lists. The host was presunably a gout.

NOTES. This is an utterly unreconizable species that Fahrenholz assigned to Linognathus purely as a guess.

\section{Linomathus ovillus (Neumann) \\ Figures 99, 100}

1907. Haematoplnus ovillus Neumann, Revue veterinaire 32:520; tii rure.

1932. Linognathus oviltus (Neumann), Ferris, Contributions Toward a MonoGraph of the Sucking Lice, Part 5:346; figures 209, 210A, B, C, E.

HOSTS AND DISTRIBUTION. Described by Neumann as from domestic sheep from New Zealand and Scotland. There have been various records wich are dubious because three other species of this genus occur on domestic sheep. The types were examined by Ferris and, on the basis of this, records from domestic sheep in the Falkiand Islands and rew South Hales are here accepted.

$$
\begin{gathered}
\text { Linognathus pedalis (0 sborn) } \\
\text { Figures 101, } 102
\end{gathered}
$$

1896. Haemctopinus pedatis Osborn, United States Department of Ajriculture, Division of' Entomolong, Bulletin (new series) 5:170: 1'i grure 99.

1911. Baematopinus microcephatus Gamett, Journal of Comparative Patholon and Therapeutics, page 2; figures 1, 2.

1932. Linognathus pedalls (Osborn), Ferris, Contributions Toward a Monograph of the Sucking Lice, Part 5:341; figures 2071, D, E, 11, 208.

HOSTS AND DISTRIBUTION. First described irom domesic sheep in the United States and recorded from this host in South America, New Zealand, Australia, and South Atrica.

\section{Linognathus peleus Bedford}

1936. Linognathus peleus Bedford, Onderstepoort Journal of Veterinary Sci- 

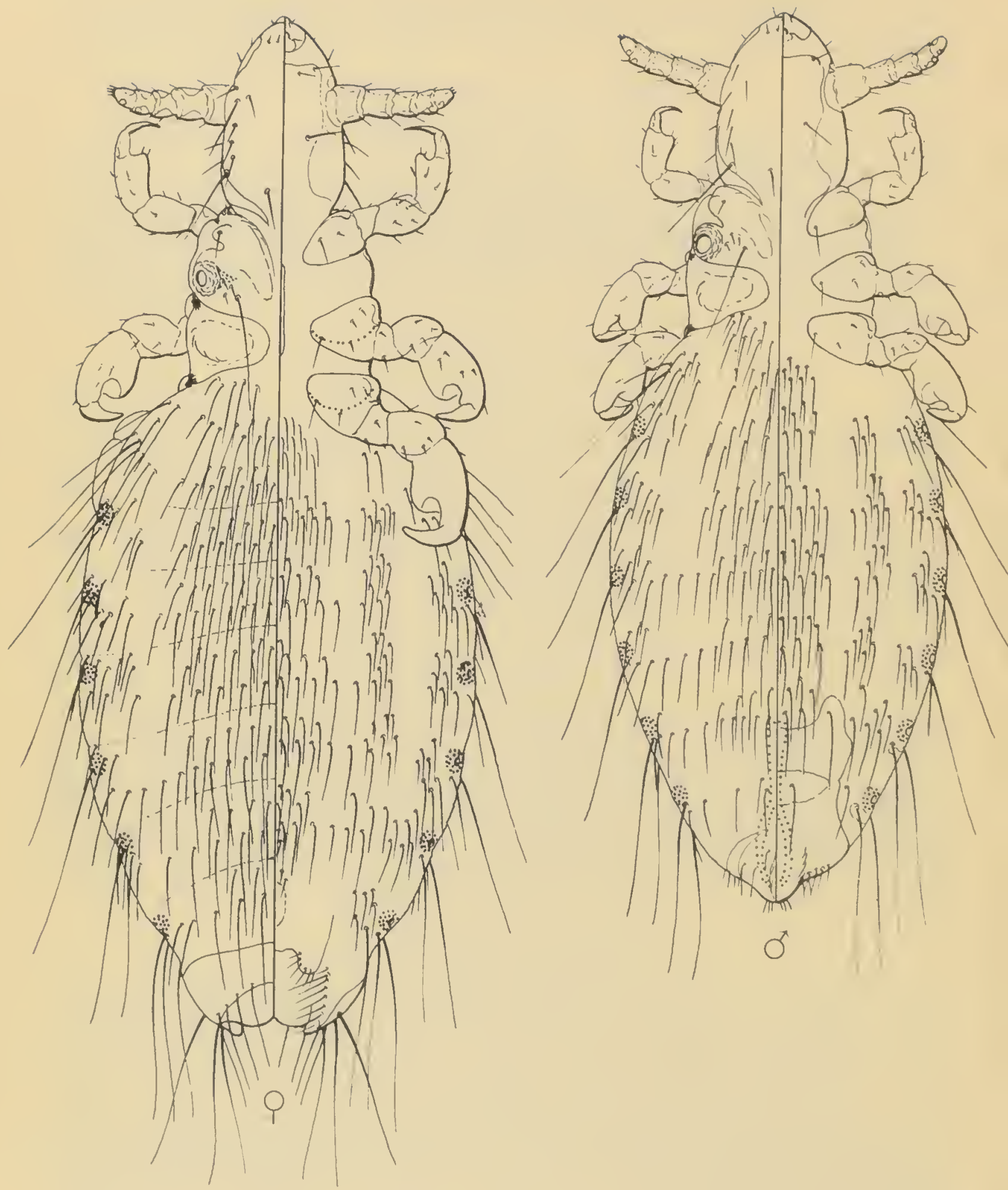


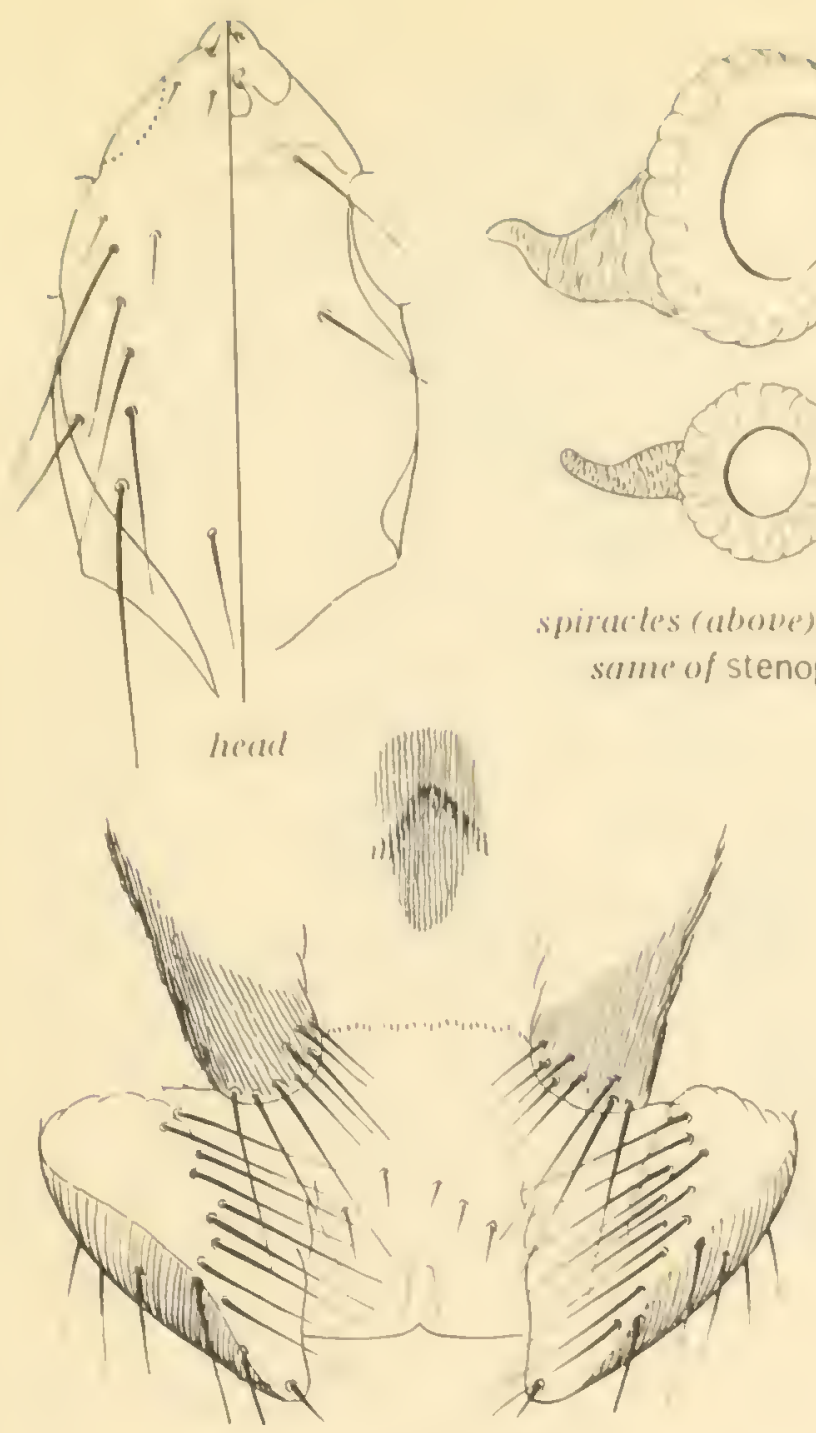

female acnilalia

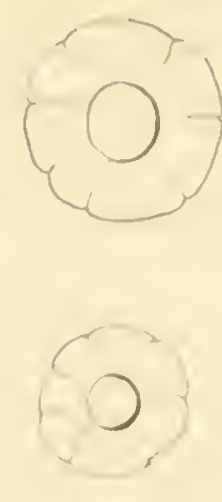

mantel milli (or (oni')

Linognathus ovillus (Neumann), details

mule genitalia

Figure 100

ence and Animal Indusiry $7: 59 ;$ t'i gures 1 , 2. Africa.

HOSTS AND DISTRIBUTION. From Pelea capreolus at Onderstepoort, south

\section{Lino mathus petasmatus Ferris. new species}

HOSTS ANI) DISTRIBUTION. Holotype, a female, allotype, and several paratypes, young and eigs. from "Yorth African antilope. "presumably trom a zoological garden in lauchester, Ensland. Types in the collections of Stanford Iniversity, California.

FEMALE. About $2.25 \mathrm{~mm}$. in len th. Body form rather slender. llead elongate and relatively slender, ver smoothly fusiform, the torehead only slightly shorter than the hindhead and apically acute, the widest point ol the hindhead heing slightly posterior to the center of this portion. Thorax and legs entirely normal. Abdomen with an uninterrupted row ot short setae and a median cluster of similar setae on segments $3-6$ toth dorsally and ventrally. Median genital plate of the female unusually lar:e. very definitely lozenge-shaped. the anterior extrenity sliphty prolonged. Fonopods of female slishtly conversent posteriorly. narrowly rounde apically and with setae around the apex and slighty up the mesal martin. 


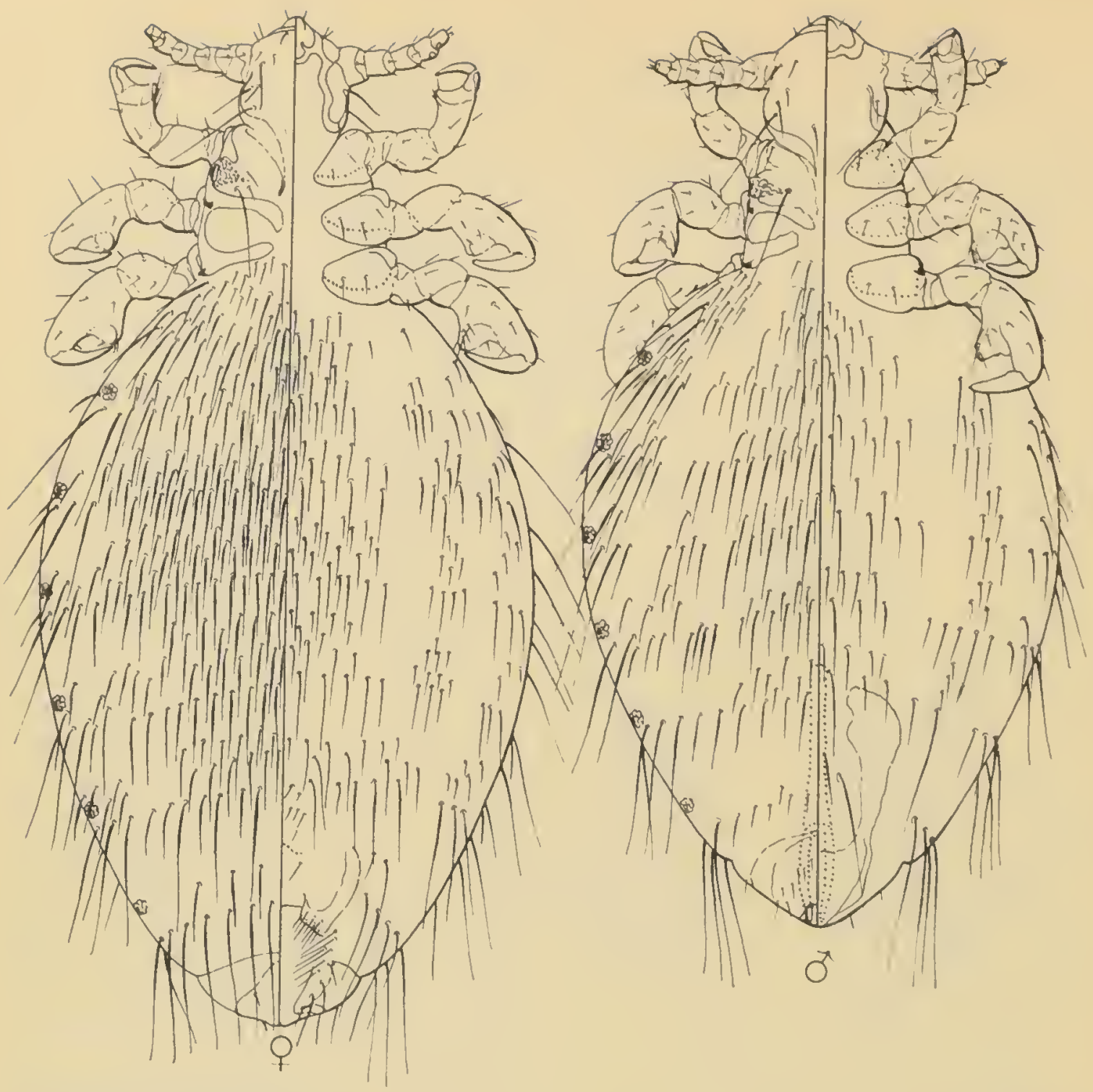

Linognathus pedalis (Osborn)

Figure 101

MALE. About $2 \mathrm{~mm}$. long. Genitalia with basal plate long and slender, slightly expanded and slightly bifid at posterior end and somewhat expanded at the anterior end. Parameres apparently strongly curved dorsoventrally; the pseudopenis very short and indistinct, the endoineral piece either lackin's or very weakly developed.

NOTES. This species wis received some years agro fron a correspondent in Birmingtam, England, whose name has unfortunately been lost, and it is not clear whether the specimens came directly from North Africa or from an animal in a zoolorical garden. The species seems to be quite distinct from anythins else that has been described.

\section{Lino,gnathus pithodes Cumnings}

1916. Linosnathus pithodes Cumminirs, Proceedinus of the Zoological Society of London, pispe 260; tioures 3-5.

1932. Linoknathus plihodes Cummings, Ferris, Contributions Toward a Monograph of the Suckinis lice, Part 5:385; 'imures 235, 238D, 239F, G. 


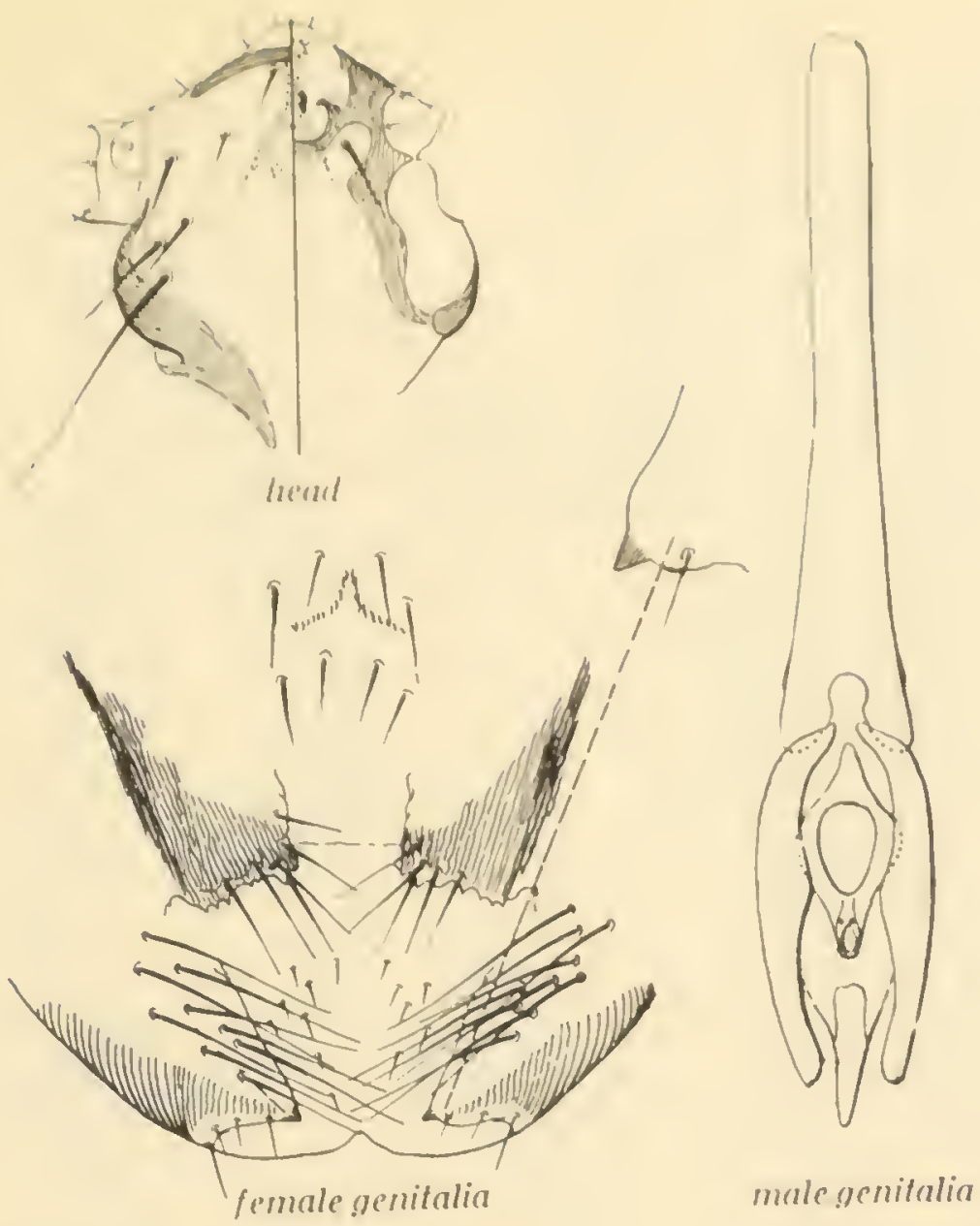

Linognathus pedalis (Osborn), details

Figure 102

1949. Stobbella pithodes (Cumnings), Eichler, Bolletino della Societa Entomolouica Italiana 79:13.

HOSTS AND DISTRIBUTION. From Antilope cervicapra from India, in the zoolo pical arden at London.

NOTES. Eichler has desigmated this species as type of the genus Stobbella, which is not here accepted.

\section{Linognathus saccatus (Gervais)}

1845. Haematopinus saccatus Gervais, In Halckenaer, Histoire Naturelle des Insectes Aptéres 3:307.

1905. Linognathus saccatus (Gervais), Enderlein, Zoologischer Anzeiger 29: 194.

HOSTS AND DISTRIBUTION. Known only from the original record from "un bouc d'Esypte." An utterly unrecosnizable species which has been placed in Linoşrathus purely as a guess.

\section{Linomathus setosus (von 0lfers) Figures 103, 104}

1916. Pediculus setosus von 0lfers, De veretalivis et animatis corporibus in corporibus animat is reperiundis commentarius, page 80. 


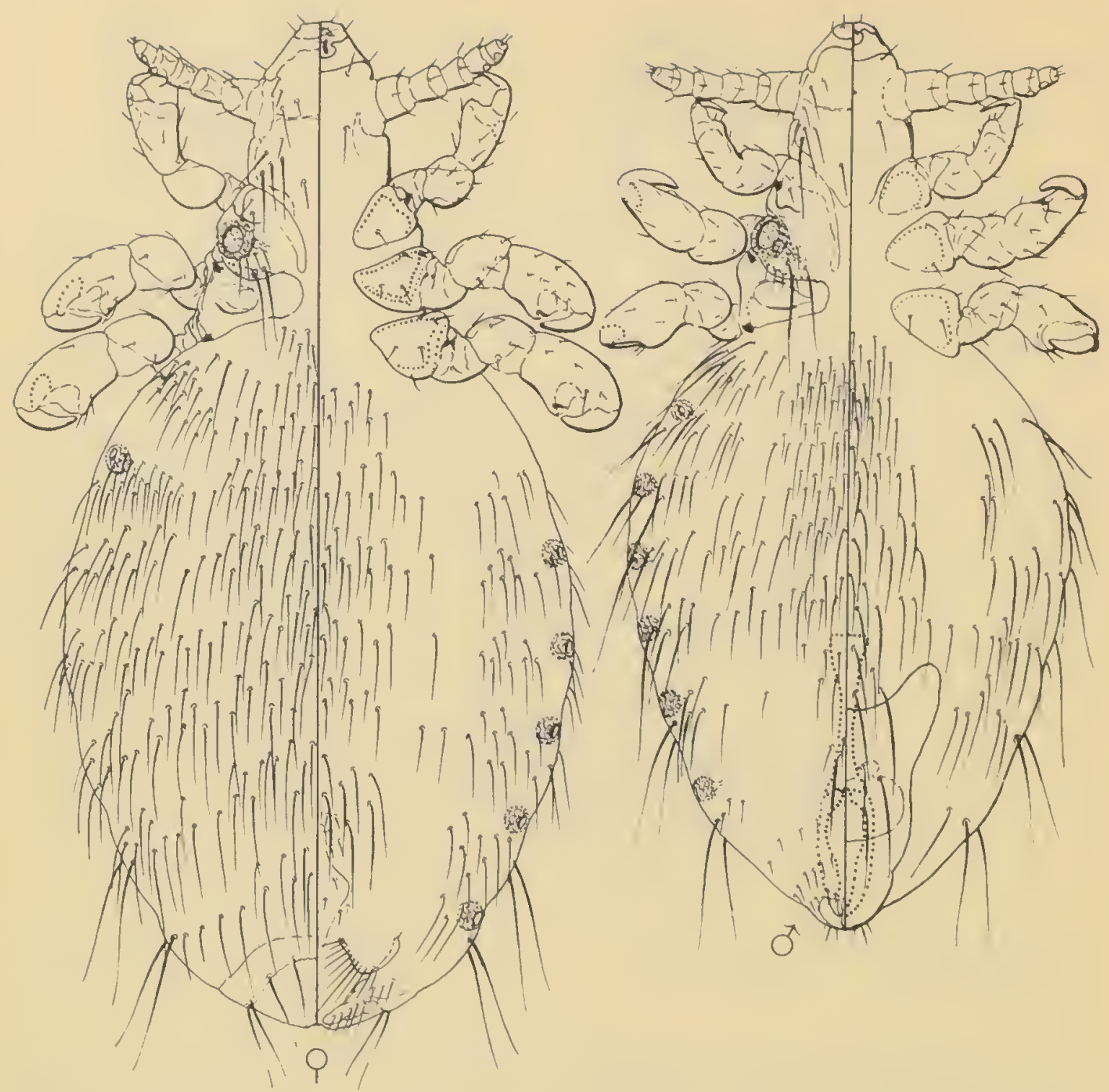

Linognathus setosus (von Olfers)

Figure 103

1838. Pedtculus piliferus Burmeister, Genera Insectorum, Rhynchota, Species 13.

1842. Haematopinus piliferus (Burmeister), Denny, Mono raphia Anoplurorum Britanniae, pave 28: Plate 25, figure 4.

1847. Haematopinus bicolor Lucas, Annales de la Société Entomolorique de France (2) 5:538; Plate 9, firrure 2a.

1861. Pedtculus isopus Nitzsch, Zeitschrift für die resamten Naturwissenschaften 18:290.

1864. Pedtculus flavidus Nitzsch, Zeilschritt fïr die gesamten Naturwissenschalten 23: 27.

1874. Haematoptnus pillferus (Burmeister), Giebel, Insecta Epizoa, paige 40.

1905. Linoenathus piliferus (burmeister), Enderlein, Zoolorischer Anzeiger 29: 194 .

1919. Linosnathus setosus (von 0lfer's), Fahrenholz, Jahresbericht des Niedersïchsischen zoolorischen Vereins zu Hannover 5-10:23. 


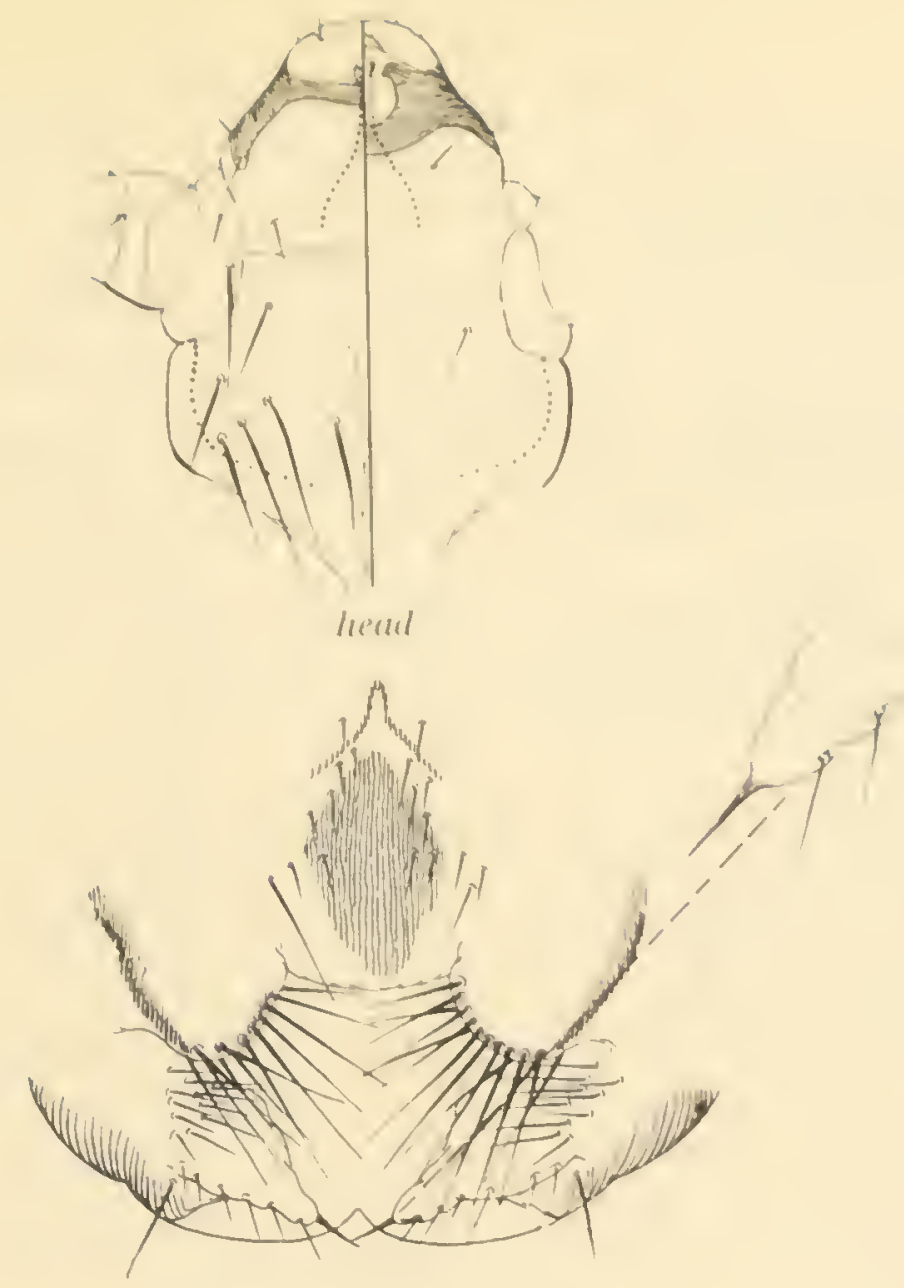

fermale genilalia

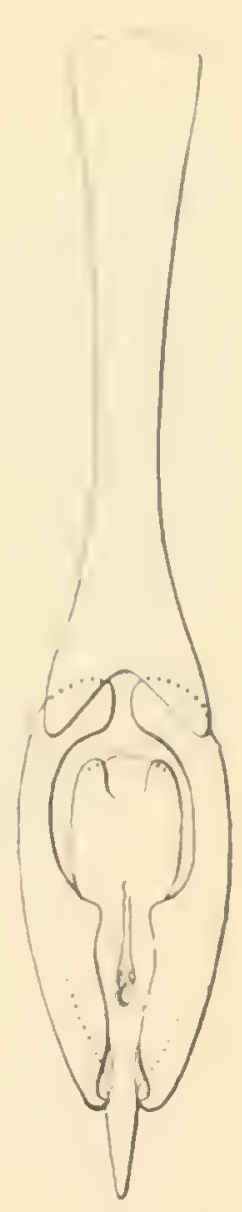

mule genitalia

Linognathus setosus (von Olfers)

Figure 104

1932. Linognnathus setosus (von 0lters), Ferris, Contributions Toward a Monograph of the Suching Lice, Part 5:70; figures 206, 207A, C, F, G and $216 \mathrm{E}$.

HOSTS AND DISTRIBUTION. Described from the domestic dog in Europe and reported from this host throu hout the world. Also recorded from the "white lox," or "Arctic fox," presumably Alopex lagopus, from various localities in Canada and Alaska; from fox in Manchuria; from Cants cupus in Croatia; from unspecified captive fox in the United States; from "coyote," (Canis sp.) in the United States and even recorded from ferret and from rabbit.

NOTES. This is the type of the genus Linosnathus.

\section{Linognathus spicatus Ferris}

1932. Linognathus spicatus Ferris, Contributions Toward a Monograph of the Suckin Lice, Part 5: 388; fizures 237, $238 \mathrm{~A}, \mathrm{G}$, and $239 \mathrm{E}$.

HOSTS AID DISTRIBUTION. From Gorķon tour inus, Yaastrom, northern Transvaisl.

NOTES. This species need not be confused with either of the other two members of this genus which occur on Gorkon. They are very distinct forms. as will be seen hy reference to the key. 
1838. Pediculus stenopsis Burmeister, Genera Insectorum, Rhynchota, Spe-

1842. Baematopinus stenopsis (Burmeister), Denny, Monographia Anoplurorum Britanniae, page 36.

1864. Pediculus schistopyśus Nitzsch, Zeitschrift für die gesamten Naturwissenschaften 23:30.

1869. Haematopinus forficulus Rudow, Zeitschrift für die gesamten Naturwissenschaften 34:169.

1869. Haematopinus rupicaprae Rudow, Zeitschrift für die gesamten Naturwissenschaften 34: 170 .

1905. Linognathus stenopsis (Burmeister), Enderlein, Zoologischer Anzeiger

1916. Linognathus forficulus (Rudow), Fahrenholz, Archiv für Naturge-

1932. Linognathus stenopsis (Burmeister), ferris, Contributions Toward a
. Monograph of the Sucking Lice, Part 5:349; figures 210 D, 211,

HOSTS AND DISTRIBUTION. Originally described from domestic goats in Europe and since recorded many times from this host in various parts of the world. Some of the numerous records are perhaps erroneous because of the presence of other species of this genus on this host. Described by Rudor as forficulus from Capra ibex and as rupicaprae from Caprella rupicapra.

NOTES. Ferris (1932) has discussed at length the problems connected with this species and the various names that have been employed for it. He had at hand specimens from Capra tbex and Caprella rupicapra which he considered to be identical with those from domestic goats and consequently reduced the names forficulus and rupicaprae to synonymy with stenopsis. A review of the matter in connection with the present work indicated no reason to change this opinion in spite of the fact that Jancke has attempted

\section{Linognathus taeniotrichus Werneck}

1937. Linognathus taeniotrichus Werneck, Memorias do Instituto Oswaldo Cruz
32: 391; figures 1-5.

HOSTS AND DI STRIBUTION. Described from Canis brasiliensis at São Bernardo das Russas, state of Ceará and recorded also from Canis azarae from Lassance, state of Minas Geraes, Brasil.

NOTES. This species secms clearly to be distinct from Pediculus setosus, which occurs on the domestic dog and also on arctic foxes.

\section{Linognathus taurotrasus Bedford}

1927. Linosnathus taurotragus Bedford, Transactions of the Royal Society of South Africa 14:347; figures 1, 2.

1932. Linognathus taurotraǵus Bedford, Ferris, Contributions Toward a Monofraph of the Sucking Lice, Part 5:375; t'i gures 228, 229.

IIOSTS AND DI STRIIUTION. Described from Taurotragus oryx at Clocolan, Orange Free State. Also recorded from the same hostin Natal, South Africa.

Linopnathus tibialis (Piaget)

1880. Haematoptnus tibialis Piaget, Les Pediculines, page 646; Plate 52 ,
figure 8. 1880. Haematoptnus tibialis, variety antennatus Piaget, Les Pediculines,
page 647 . 


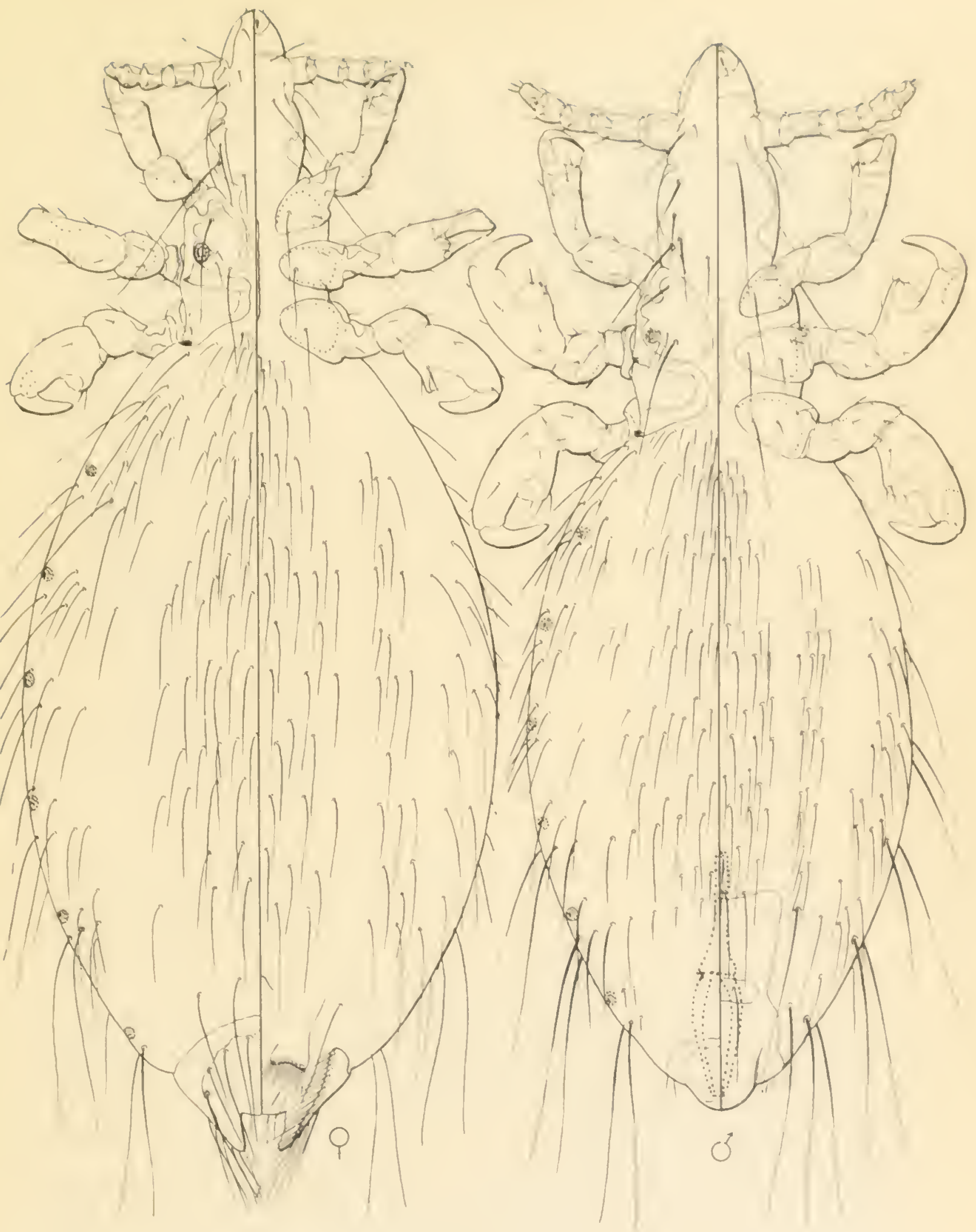

Linognathus stenopsis (Burmeister)

Figure 105 


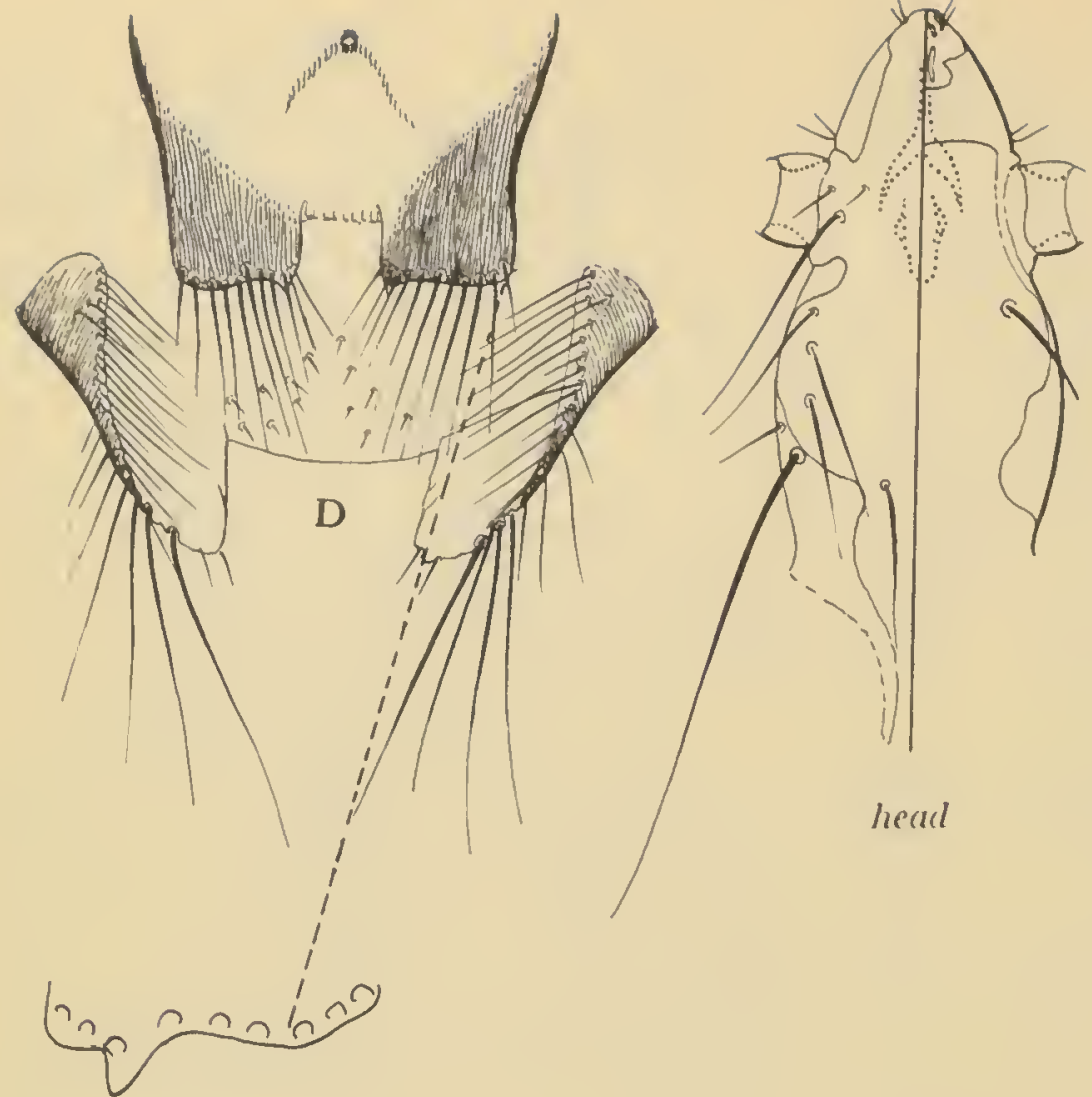

female genitalia

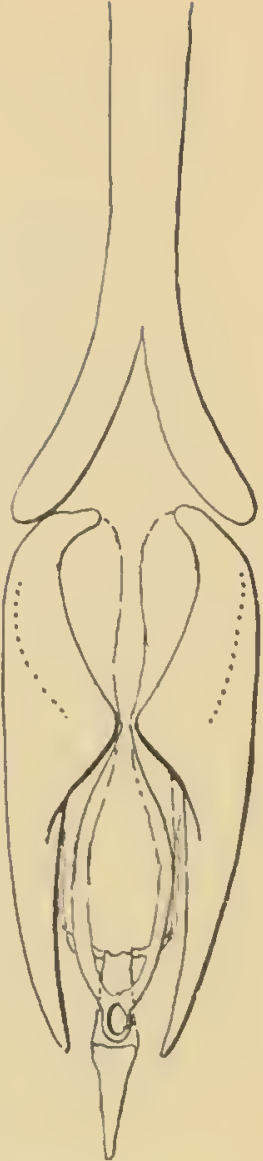

male genitalia

Figure 106

Linognathus stenopsis (Burmeister), details

1880. Haematopinus tibialis, variety appendtculatus Piaget, Les Pediculines, paye 647.

1916. Linognathus tibialis, variety euchore Waterston, Annals of the South African Museum 10:275; figure.

1932. Linognathus tibialis (Piaget), Ferris, Contributions Toward a Monorraph of the Sucking Lice, Part 5:360; fi gures 217, 218.

HOSTS AND DISTRIBUTION. Type from "Antilope maori" from the zoological garden at Rotterdam and recorded also by Piaget fror Antilope subgutturosa and Antilope sp. from the same place. The type of Waterston's variety euchore was from Antilope euchore in South Africa and the species has been recorded by Bedford from Aepyceros melampus from South Africa.

NOTES. Ferris, in connection with the reference cited, cxamined the types of the forms recorded above.

Specimens from Antidorcas marsupialts from Onderstepoort, Pretoria, South Africa, which were recorded by Ferris as tibtalis have been re-examined and raise some doubt as to their identification. They are certainly very close to tibtalis, but differ in the forn of the igenital plate of the female. Other specimens from Raphlcerus campestris from the Rustenburg District in the Transval, South Africa, are extremely close to tibial $i s$ but are somewhat different. Questions concerning these may be allowed to rest until someone with more material can approach the problem. 


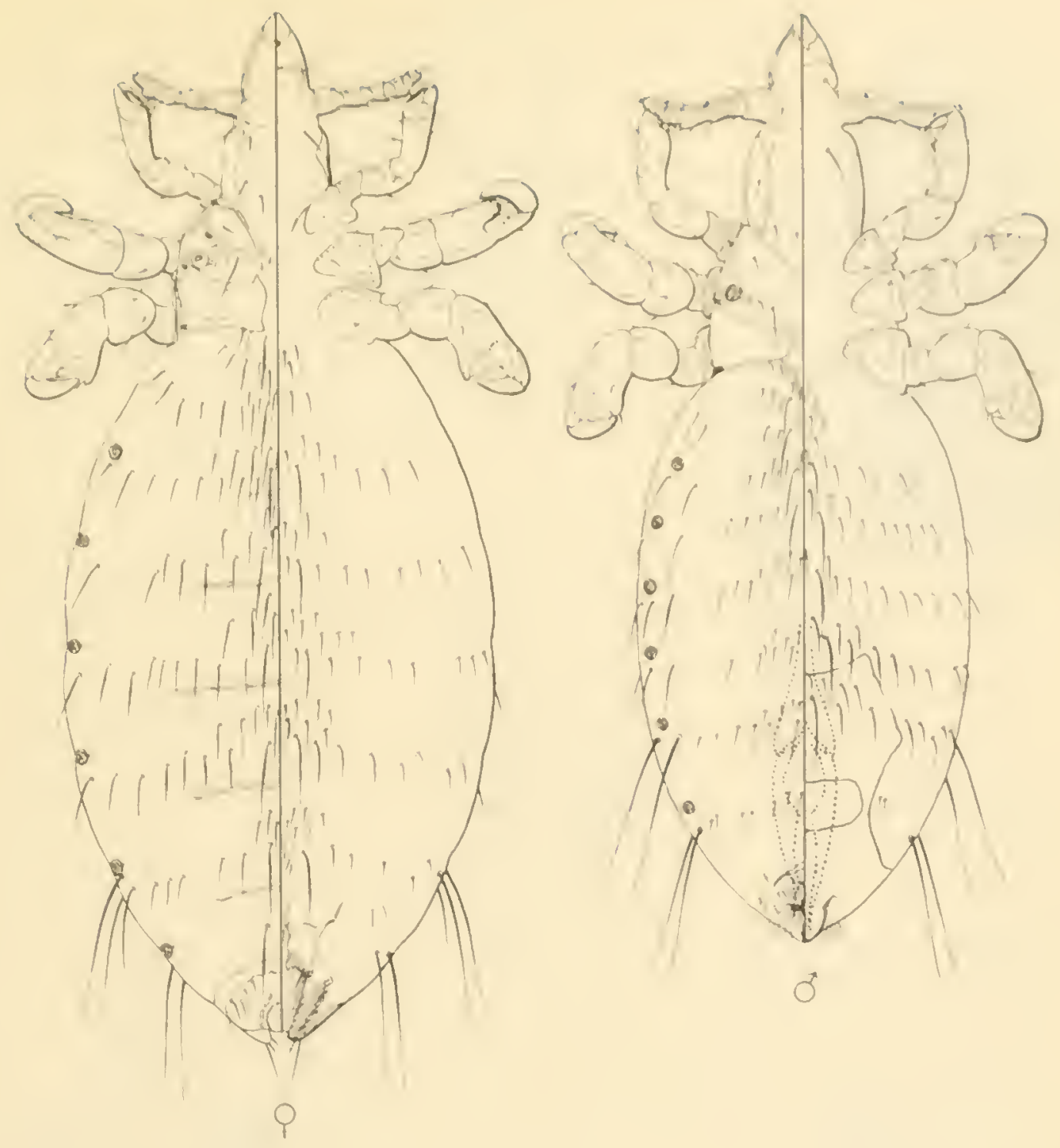

Lınognathus vituli (Linnaeus)

Figure 107

Linognathus vituli (Linndeus)

Finures $10 \%$. 108

1758. Periculus vituli Linnaeus, Systema Naturae, Edition X, pare 611.

18:9. Haematodinus vituli (Linnaeus), Stephens, Catalogue of British Insects $2: 329$.

1839. Periculus tenuirostris burmeister. Genera Insectorum, Rhynchota, Species 17 .

1864. Pediculus oxyrrhynchus Nitzsch, Zeitschrift für die gesamten Naturwissenschaften $23: 21$.

1932. Linognathus vituli (Linnaeus), Ferris, Contributions Toward a Yonoraph of the Sucking Lice, Part 5: 356 ; tï gures 214, 215, 216C.

HOSTS AVD DISTHLUTION. Ori inally described from domestic catte in Europe. Since reported from domestic cattle in all parts of the world. There are certain unusual records from wild hoar in Europe. from sheep, and even from domestic dog, which may result from erroneous information as to the host. 

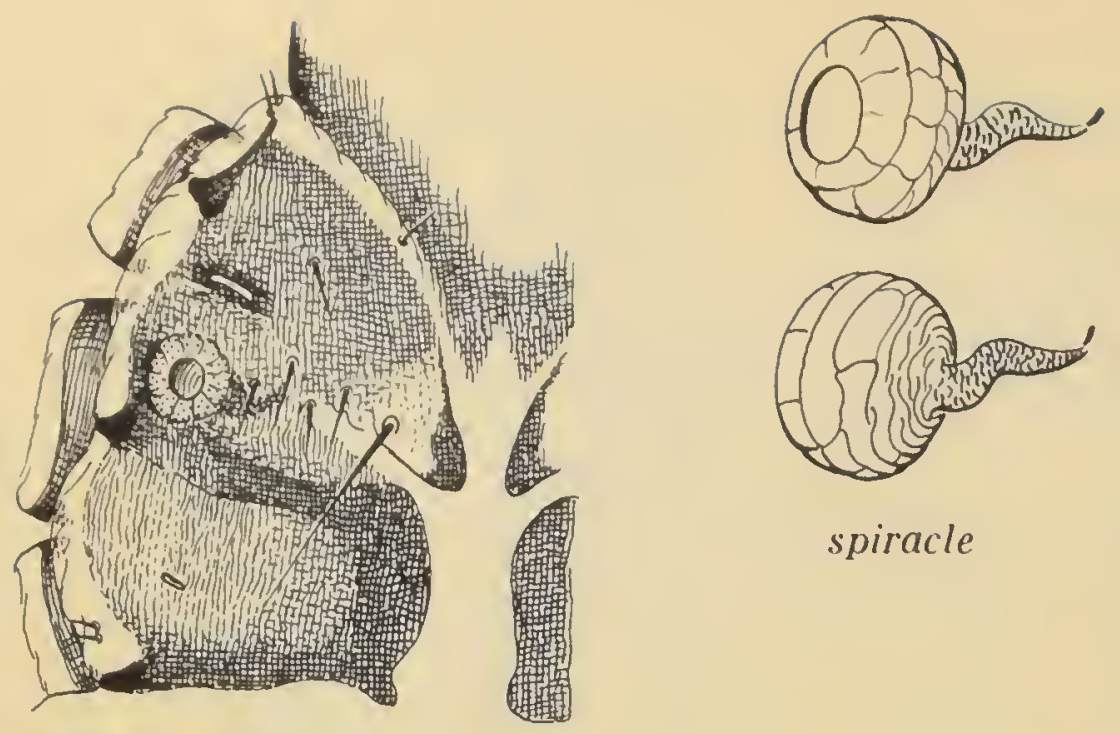

spiracle
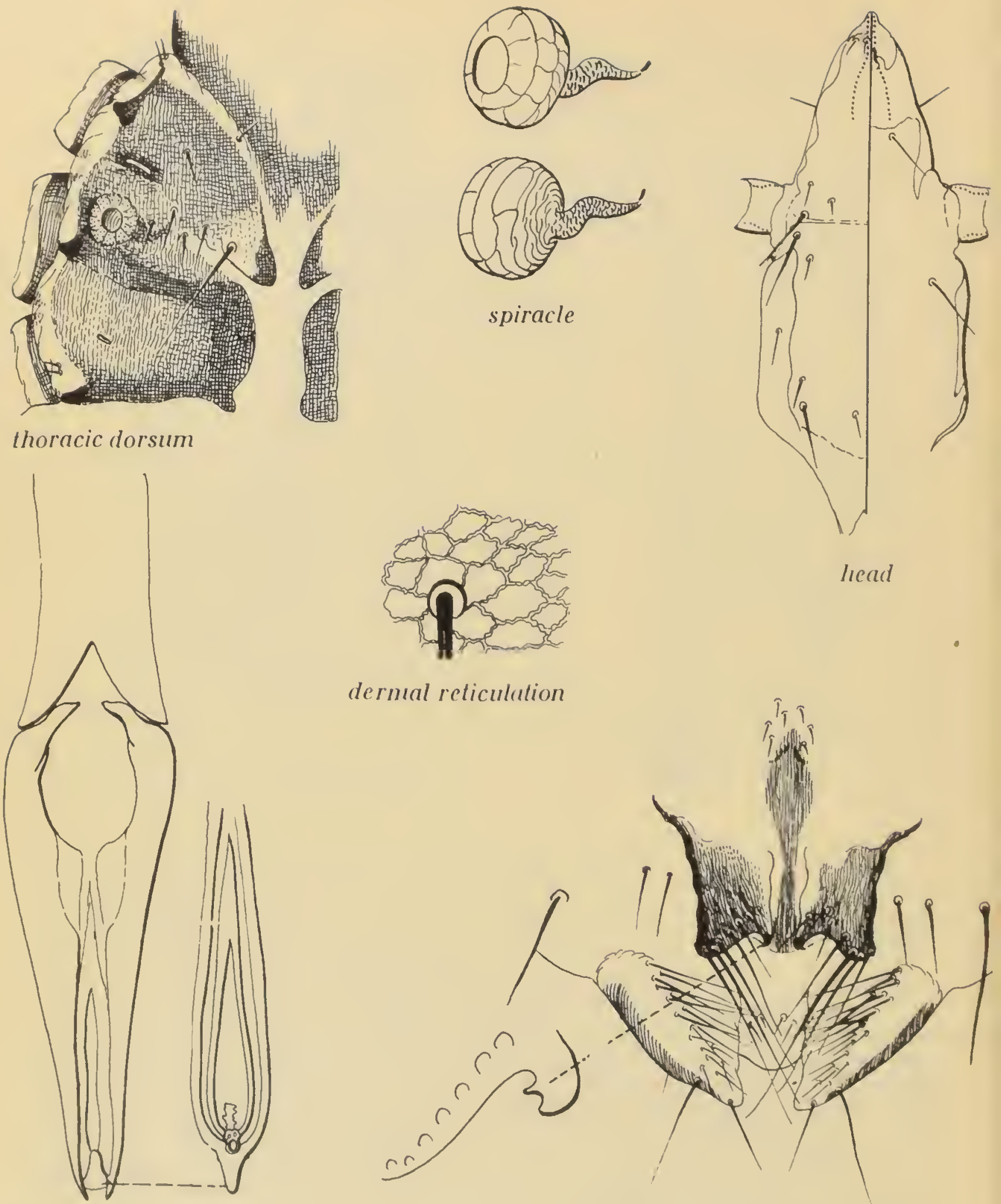

dermal reticulation

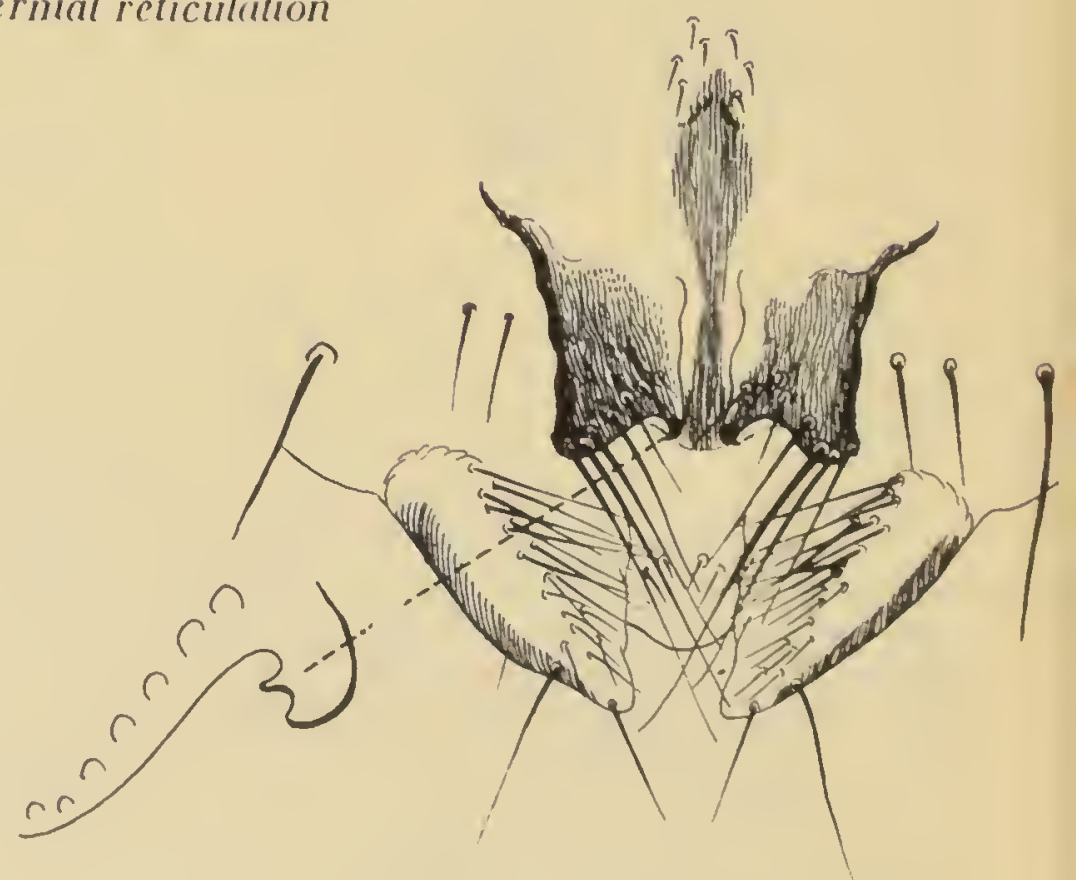

female genitalia

mule gemilalia

Figure 108

Linognathus vituli (Linnaeus), details 
1915. Nicrothoractus Filienholz, Archiv fur Naturgeschichle, Abteilung A, 81: 11: : :4).

1932. Nerothoractus, Ferris, Contributions Toward a Monogruph of the Sucking lice, Part 5:390.

1933. Microthoracius, Werneck, Memorias do Instituto 0swaldo Cru'z 27:21.

(iFNERIC IYPE. Hcrematoplnus (Linosnathus) praelonglceps Neumann.

CHARACTEKS. Linognuthidue in which clearly evident eyes are present, these heing represented by a lens just posterior to the base of each antenna. Head greatly elongated and more or less fusiform, at times heing alaost as long as the abdomen. 'Thorax very small, with no indication of a sterual plate but with the sternal apophyses present and with a delinite notal pit. Antennae five-segmented but with segments $4-5$ at times more or less fused. Spiracles beset internally with points. Derm of the abdomen tending to be minutely wrinkled.

NOTES. The assigrument of this genus to the Linonuthidue is open to question, for an argument can certainly be made supporting its assignnent rather to the llaematopinidae. The chief reason for the present assi innent is the absence of the paratergal plates, but the presence of the thoracic sternal apophyses, the delinite eyes, the thoracic notal pit, and possibly the spiracles, arirue for its placement with the Harmatopinidae.

Such understunding of this genus as we have we owe chief'ly to the work of Dr. Fabio We rneck.

The history of this genus and especially of its type species is of interest and is worth recital. In 1688 Redi, in his famous work on the seneration of insects, illustrated certain ectoparasites of birds and mammals, mong these being one which he designated merely as the louse of the camel. There was apparently no discussion of any of these species, identity being indicated merely by the legend on the illustration.

In his "Systema Naturae," Linnaeus gave this louse a binomial name, callin it Pediculus cameli, purely on the basis of the illustration iven by Redi. From the time of Redi until as recently as 1934 the insect was never again reported. In fact the illustration given by Redi seemed so fantastic that its faithfulness was doubted and the peculiarities of the species were ascribed merely to bad drawing of some other species, perhaps Haematopinus tuberculatus, which was the only sucking louse known from camels. However, in 1909, Neumann described a species from a llama which was sufficiently similar to cameli to indicate that the latter was not imaginary. In 1915 Fahrenholz assigned Neumann's species to the genus Microthoracius.

In 1932 Ferris discussed this genus. He had examined a female from the type material of praelonsiceps and had also at hand specimens from a llama from the zoological park at Washington. His conclusions concerning the species were thus based upon what seemed to be quite authentic material.

However, in 1932, Wernech described a new species, yicrothoraclus mazzat, and in 1933 he discussed these two species at length, the result of his work being to indicate that Neumann actually had two quite distinct species in his type lot of praelongiceps. Feumann had indeed indicated that one of his specimens differed from the others in the form of the head and it seems clear that this was the specimen examined by Ferris.

Then in 1934 Herneck reported the rediscovery of the long-lost Pedtculus camel $i$ on the basis of specimens laken in Algeria and he described another species, yicrothoracius minor, from another 11 ama. In 1935. Ferris discussed the genus again but his work had gone to press hefore Herneck's paper of 1934 had become available and full account had not been taken of Werneck's conclusions.

It is now evident that there are at least four species of this genus on nembers of the family Camelidae, a family that according to Irdekker's work 
of as late as 1915 contains but two genera, Camelus with one species and Lama with but two. Whether or not we even yet have the full complement of Anoplura occurring on this family remains to be determined.

\section{Key to Species of MICROTHORACIUS}

Werneck has discussed the problem of separating the species of this genus and has noted that it is difficult to do so upon the basis of any single character but that, in the totality of their characters, they seem to be readily recognizable. Unfortunately, specimens of minor are not available and this species must be included in the key solely upon the basis of Herneck's description, while available material of the other species is extremely scanty. Furthermore, differences in the treatment of the specimens may cause apparent differences in the form of the head and lead to confusion. Thus in mazzai, a species in which the head is extremely slender, a slight collapse of the specimen will exaggerate this slenderness. In the light of this the following key must be used with discretion.

1. Head very narrow throughout, but with a quite definite swelling on each side just posterior to the antenna, this swelling bearing the eyes; posterior to this swelling the head narrowing again............MAZZAI Head broader, definitely fusiform, expanding into a moderately sharp angle just posterior to each antenna, narrowing again immediately posterior to the swelling, the margins of the hindhead being smoothly

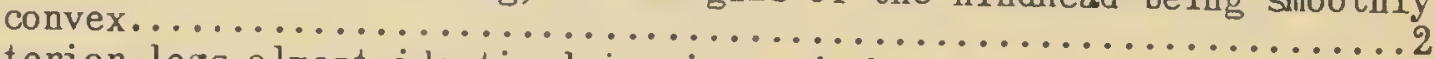

2. Anterior legs almost identical in size and shape with the others; alar ger form, attaining a length of $4 \mathrm{~mm}$. for the female and $2.5 \mathrm{~mm}$. for the male; 4 th and 5 th antennal segments quite closely fused....CAMELT Smaller forms, the adult female not exceeding $3 \mathrm{~mm}$. in length; first

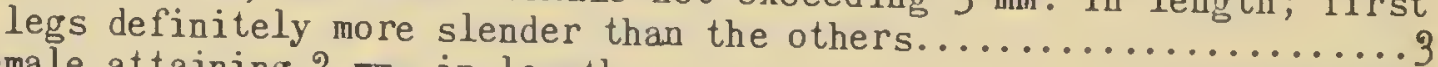

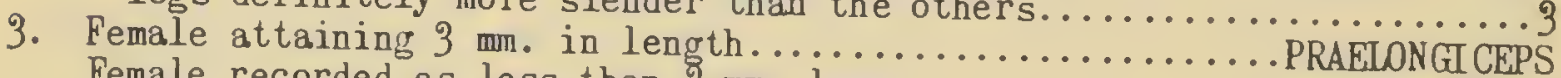

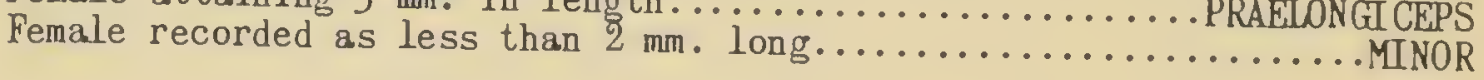

Microthoracius cameli (Linnaeus)

Figures 109, 110

1758. Pediculus cameli Linnaeus, Systema Naturae, Edition X, page 611.

1874. Haematoplnus cameli (Linnaeus), Giebel, Insecta Epizoa, page 47.

1909. Baematoplnus tuberculatus (Burmeister), Neumann, Archives de Parasitologie 13:499. (Misidentification)

1916. Mlcrothoracius cameli (Linnaeus), Fahrenholz, Archiv für Naturgeschichte, Abteilung A, 81:11:30.

1932. Mlcrothoracius cameli (Linnaeus), Ferris, Contributions Towarda Monograph of the Sucking lice, Part 5:394; figure 242.

1934. Mlcrothoracius camell (Linnaeus), Werneck, Memorias do Instituto Oswaldo Cruz 29:179; figures 1-5.

HOSTS AND DISTRIBUTION. The only actual record of the species is that given by Werneck, from Camelus dromedarius in Algeria.

\section{Microthoracius mazzai Herneck}

1909. Haematoplnus (Linoǵnathus) praelonglceps Neumann, Archives de Para-

1916. Mitologie 13:509. (In part; specimen recorded in a footnote)
tcrothactus praelonglceps (Neumann), Fahrenholz, Archiv für Naturgeschichte, Aliteilung A, 81:11:30. (In part)

1932. Mlcrothoracius praelonglceps (Neumann), Ferris, Contributions Toward a Monograph of the Sucking Lice, Part 5: 39; figures 240, 241.
(Misidentification) 


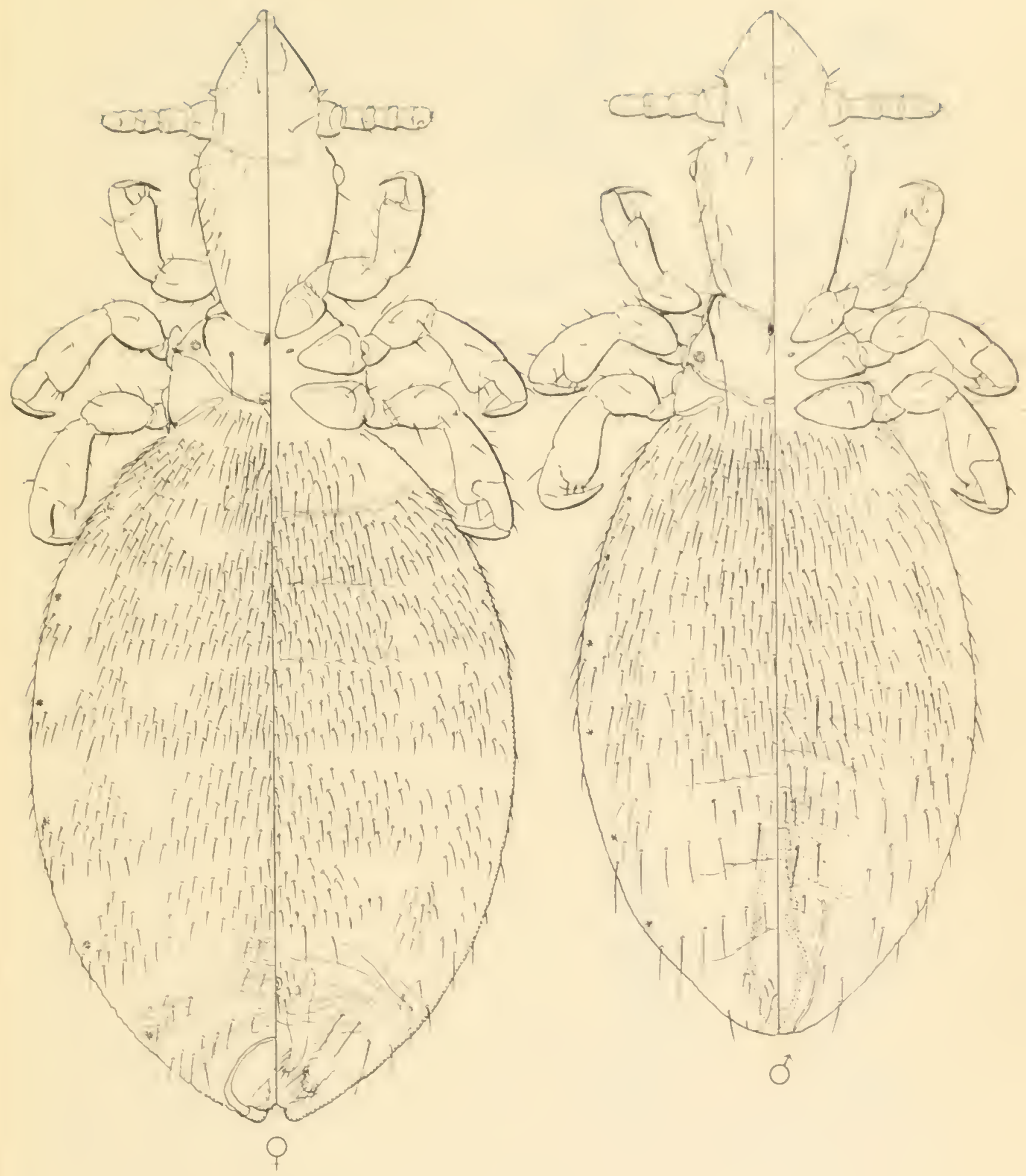

Microthoracius cameli (Linnaeus) 

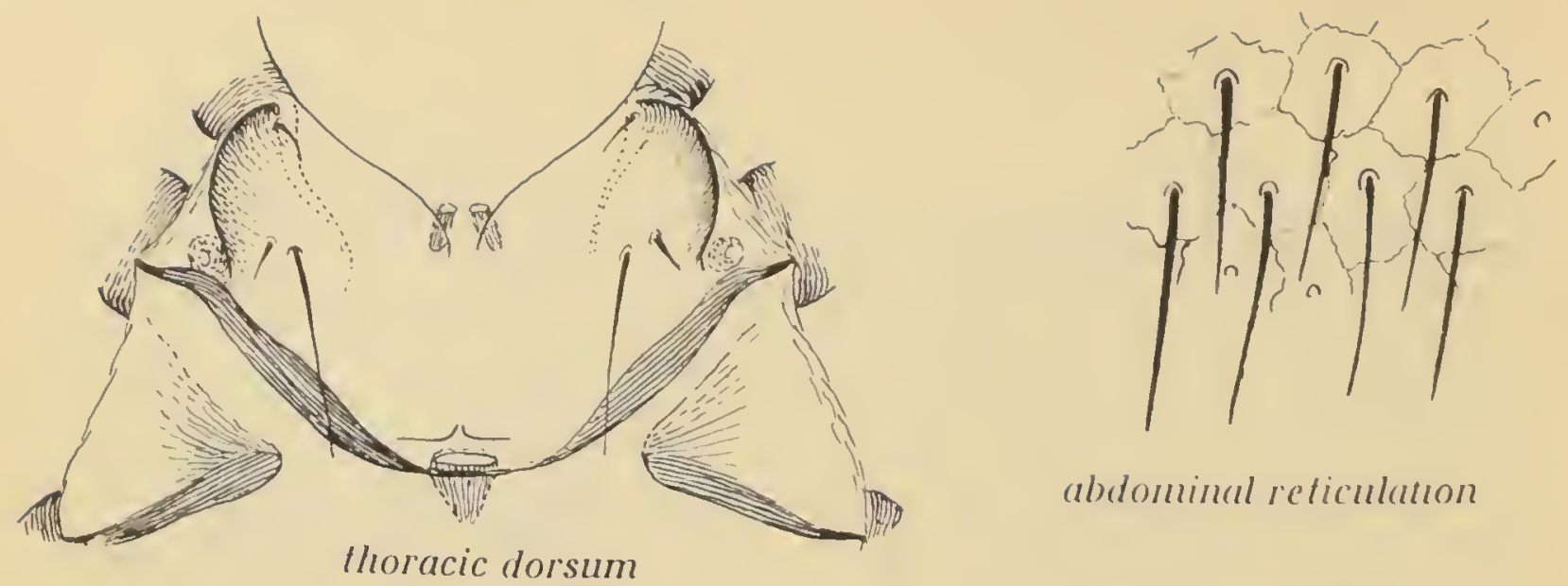

abdominal reticulatuon
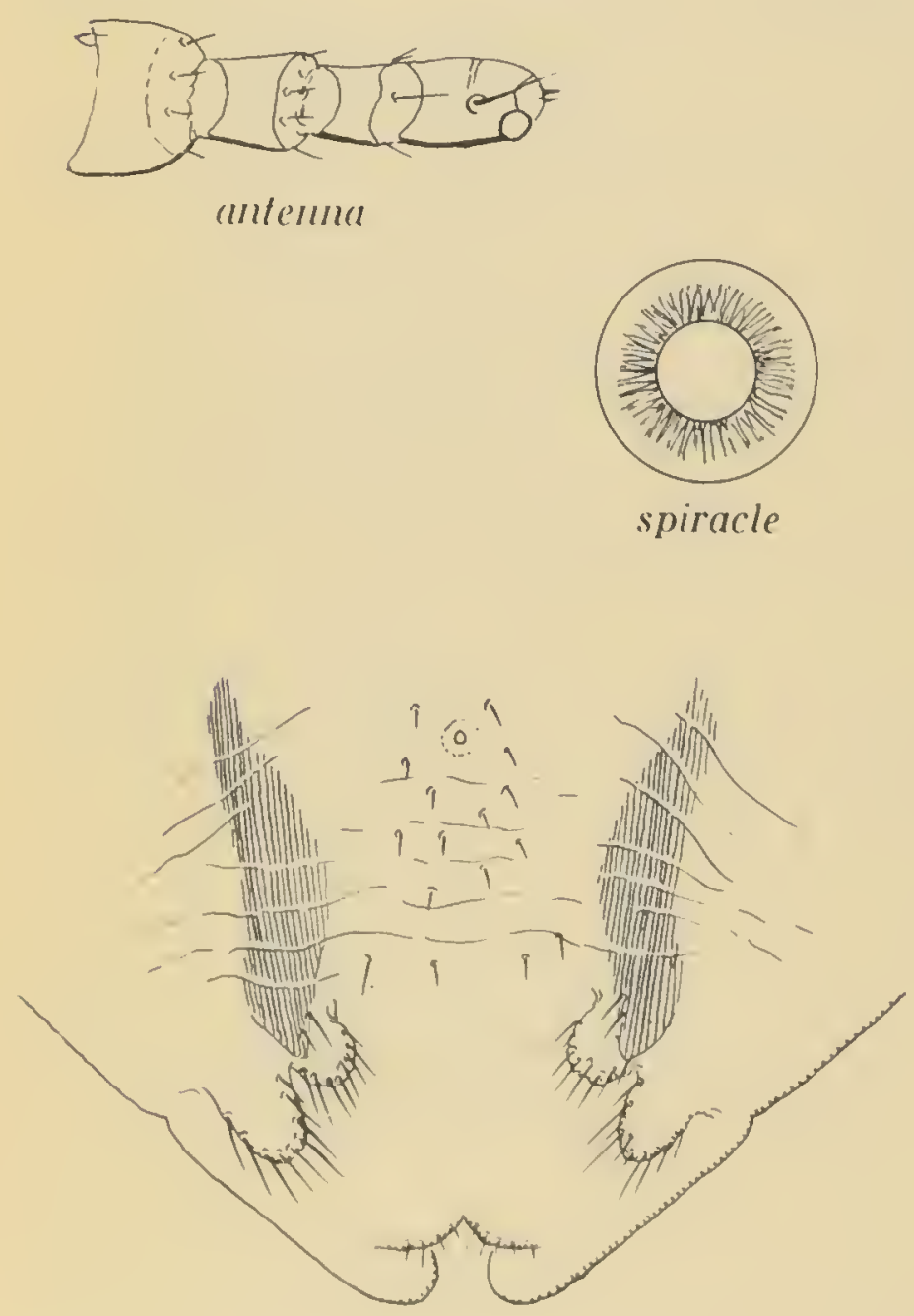

fomale genitalia

Microthoracius cameli (Linnaeus), details

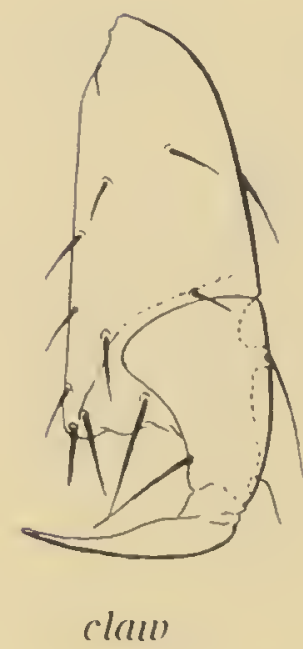

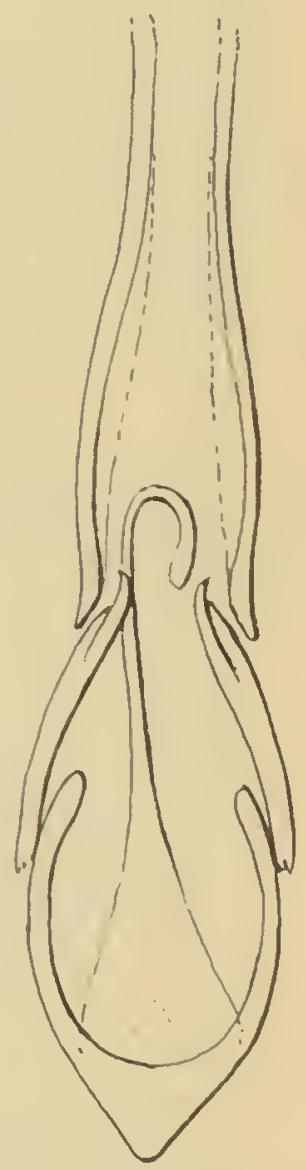

male genitalia

Figure 110 
1932. Hlcrothoraclus muzzal Werneck, Revista medico-cirurgica do lsrusil 40: 346 ; ligure.

1933. Mlerothoructus mazzut Werneck, Werneck, Memorius do Instituto Oswaldo Cruz $27: 26 ;$; inures 9-15.

1935. vicrothoractus mazzal Werneck, ferris, Contributions Toward a Monugraph of the Sucking Lice, Purt $9: 612$; f'igures 3981'-た.

HOSTS AND DISTRIBUTION. Types from Auchenla liama at Santa Calaliu, province de Jujuy in Argentiua. Presumably also the specimen recorded by Neumann in the tootnote to his description of praelongiceps, this from Auchenla llama t'ron Choqueconato, Bolivia, is this species, and the specimens recorded by Ferris from the sane host, fronall animal in the Zoological Purk of Washington, are the sane.

\section{Microthoracius minor Werneck}

1935. Nicrothoraclus minor Werueck, Revista medico-cirurgicu do Brasil 43: 112 .

1935. Microthoraclus minor Werneck, Werneck, Revista de Entomologia 5: 108; figures $1-4,5$.

HOSTS AND DISTRIUUTION. Types from Lama pacos, Aura Pampa, province de Jujuy, Argentina, and other specimens from Lama glama at the same place.

Microthoracius praelongiceps (Neumann)

1909. Haematopinus (Linognathus) praelonģiceps Neumann, Archives de Parasitologie 13:508; figures 10-12. (In part)

1916. Nicrothoracius praelonglceps (Neumann), Fahrenholz, Archiv für Naturge schichte, Abteilung A, 81:11:30. (In part)

1932. Vicrothoraclus praelongiceps (Neumann), Werneck, Revistamedicocirurgica do Brasil 40:346; figure.

1933. Nicrothoracius praelongiceps (Neumann), Werneck, Memorias do Instituto Oswaldo Cruz 27:21; figures 1-8.

1935. Nicrothoracius praelongiceps (Neumann), Ferris, Contributions Toward a. Monograph of the Sucking Lice, Part 8:610; figure 338A.

HOSTS AND DISTRIBUTION. Types recorded as from Auchenia huanaca, Choquecomato, Bolivia. Also recorded by Werneck from Auchenia llama. A specimen at hand from "llama" in the zoological garden at Onderstepoort, South Africa, received from the late Mr. G. A. H. Bedford, seems definitely to be this species.

\section{Genus PROLINOGNATHUS Ewing}

1929. Prol inognathus Ewing, Manual of External Parasites, payes 136, 201. 1932. Prol inognathus, Ferris, Contributions Toward a Monograph of the Sucking Lice, Part $5: 408$.

1939. Prolinognathus, Fahrenholz, Zeitschrift für Parasitenkunde 111:1:1.

GENERIC TYPE. Pediculus caviae-capensis Pallas.

CHARACTERS. Linognathidae in which there is no external indication of eyes. Antennae apparently four-segmented because of a close fusion of the Thorax without a sclerotized sternal plate and the ventral thoracic apophyses lacking. Spiracles of the abdomen extremely small. Abdominal setae much reduced in numbers, there being usually not more than tro setae in the median group on each sement, either dorsally or ventrally, and never any indication of more than one row of setae on any segment. Gonopods of the female well developed and produced apically.

NOTES. The members of this genus occur exclusively on members of the family Procaviidae of the Order Hyracoidea. 
The material at hand representing this genus is quite scanty and does not permit an extended treatment.

\section{Key to Species of PROLINOGNATHUS}

This key is based largely upon that given by Fahrenholz in the reference cited above, with some modifications suggested by such material as is available.

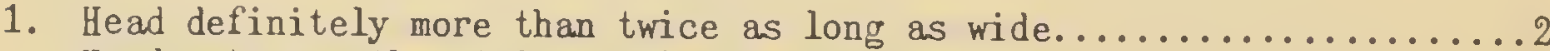

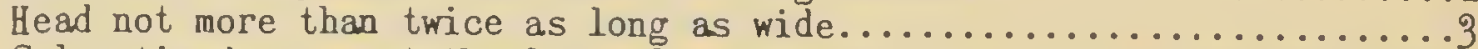

2. Sclerotized areas at the lateral margins of the forehead produced some what posteriorly on the dorsal side about the bases of the antennae..

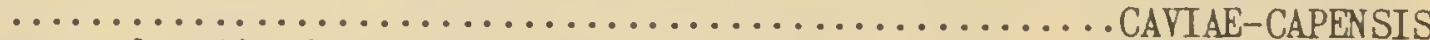

These sclerotized areas produced posteriorly on the dorsal side of the

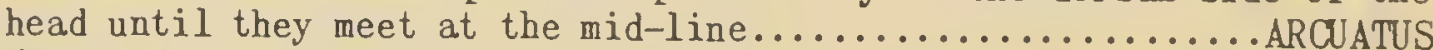

3. Abdomen with a single long seta on the lateral margin of each of the segments anterior to the seventh, in addition to the usual, long, paired setae at the margins of segments 7 and $8 \ldots \ldots \ldots$ LEPTOCEPHALUS Abdomen with such setae abernt only on segments 5 and $6 \ldots \ldots \ldots \ldots \ldots 4$

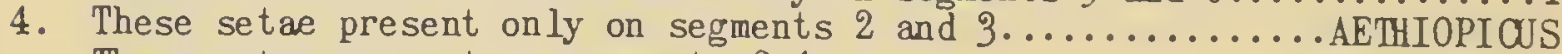
These setae present on segments $2-4 \ldots \ldots \ldots \ldots \ldots \ldots \ldots \ldots \ldots \ldots \ldots \ldots . \ldots \ldots$

5. Forehead rather short and the sclerotized transverse area so broad that it involves at least half its length...............................

Forehead with this transverse area involving at the most one-fourth of

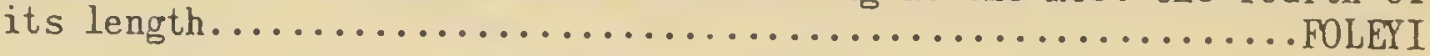

Prolinognathus aethiopicus Fahrenholz

1939. Prolinognathus aethiopicus Fahrenholz, Zeitschrift für Parasitenkunde 11:1:13; figures 8A, 9.

HOSTS AND DISTRIBUTION. Described as taken from Procavia shoana in the zoological garden at Copenhagen. According to Hopkins the proper name of this host is procavia habessinica sciona. A specimen that seems to be this species is at hand from a host identified merely as procavia capensis from Rooi Krans, Transvaal.

\section{Prolinognathus arcuatus Fahrenholz}

1939. Prolinognathus arcuatus Fahrenholz, Zeitschrift für Parasitenkunde 11: $1: 5$; figures $1 \mathrm{~b}, 2-4$.

HOSTS AND DISTRIBUTION. Described as from the same animal as recorded under aethiopicus. Certain specimens at hand from a host identified as Procavia coombsi at Onderstepoort, Pretoria, South Africa, seem to be this. This host seems to be regarded as a subspecies of procavia capensis.

\section{Prolinognathus caviae-capensis (Pallas)} Figures 111, 112

1767. Pediculus caviae-capensis Pallas, Spicilegia Zoologica 2:32; Plate 3, figure 12.

1816. Pediculus collaris von 0lfers, De vegetativis et animatis corporibus in corporibus animatis reperiundis commentarius, page 84.

1913. Linognathus caviae-capensis (Pallas), Gumings, Bulletin of EntomoIogical Research 4:37; figures 2, 3.

1932. Prolinognathus caviae-capensis (Cummings), Ferris, Contributions

Towird a Monograph of the Sucking Lice, Part 5:409; figures 250 A, $251 \mathrm{~A}, \mathrm{E}, \mathrm{F}, \mathrm{G}, \mathrm{H}, \mathrm{I}, \mathrm{J}$. 


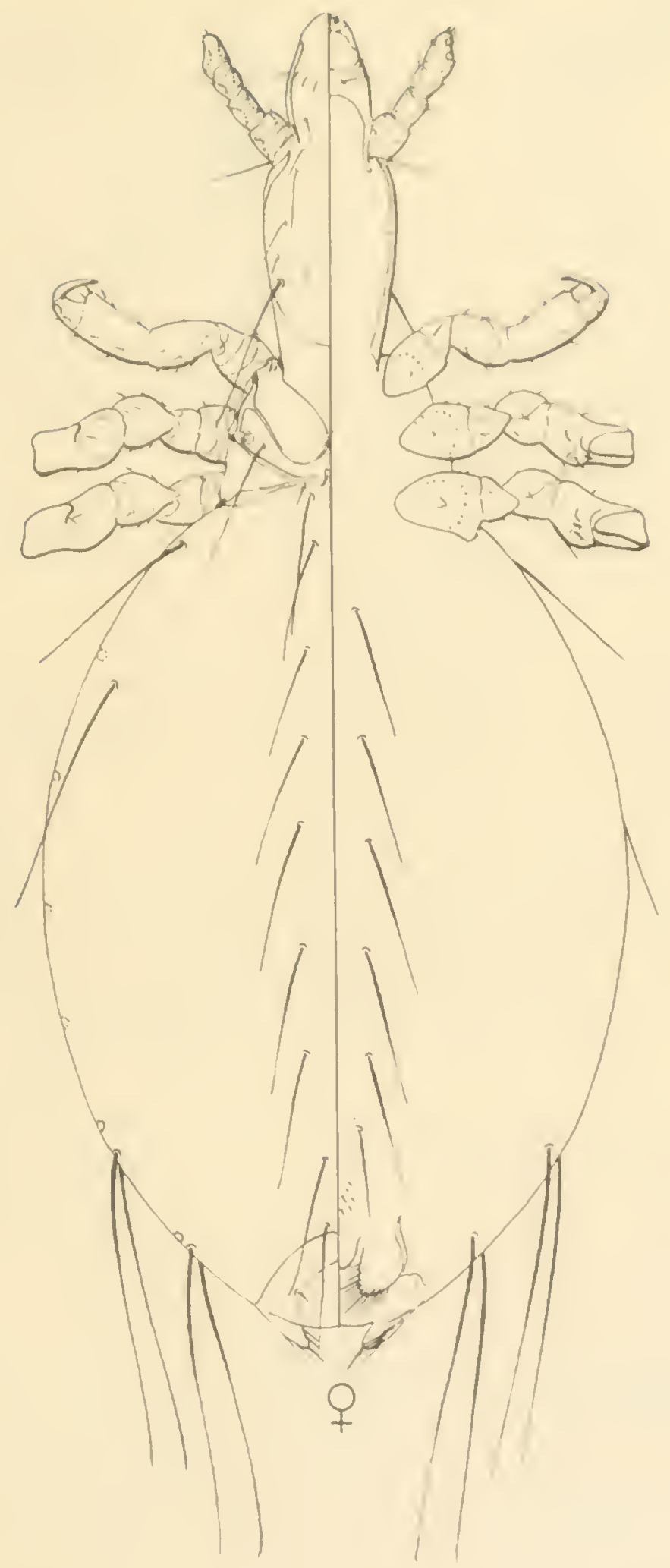

Prolinognathus caviae-capensis (Pallas)

Figure 111 


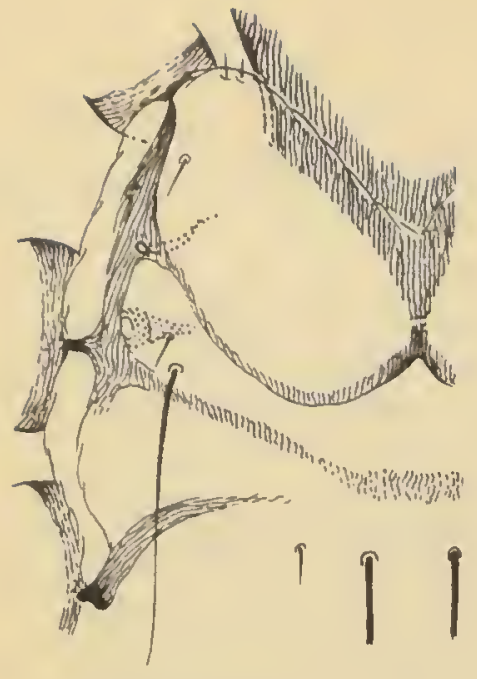

thoracic dorsum

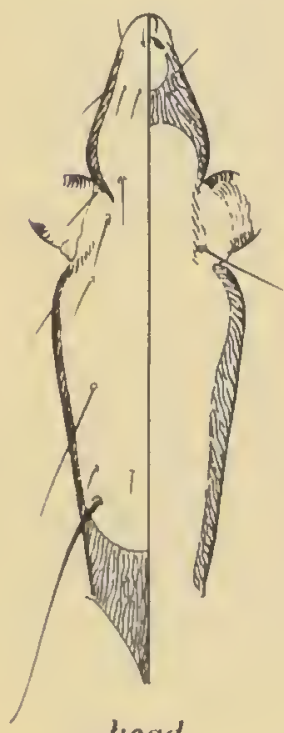

head

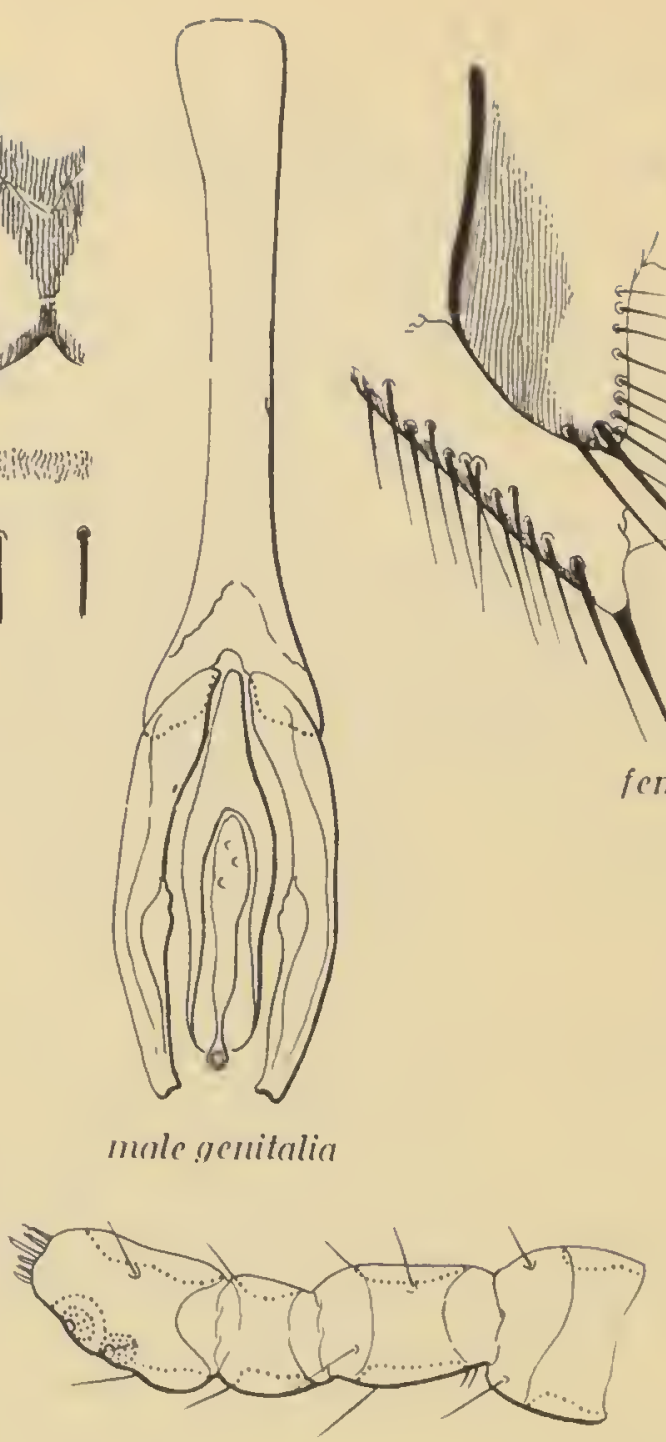

antermo

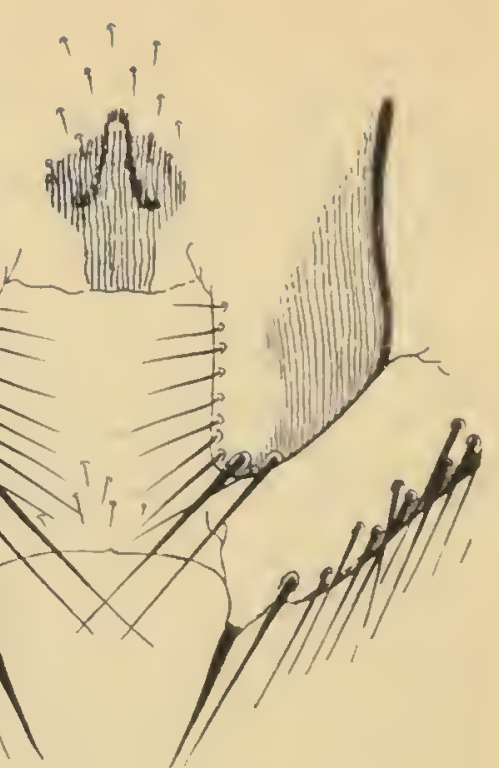

female genitalia

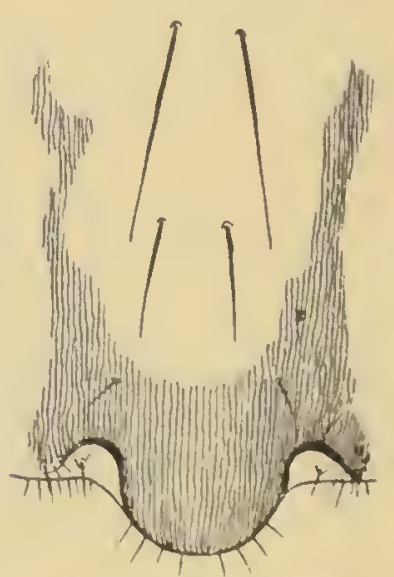

mole genital plute

Prolinognathus caviae-capensis (Pallas), details

Figure 112

1939. Prolinoßnathus caviae-capens is (Pallas), Fahrenholz, Zeitschrift für Parasitenkunde 11:1:2; fi rure 1a.

1949. Prolinognathus caviae-capensis (Pallas), llopkins, Proccedings of the Zoolorical Society of London 119:2:515, 516.

1 IOSTS AND DISTRIBUTION. Originally described as from Procau ia capens is from the Cipp of Good Hope. Recorded by Cummings from this host and from a host identif'ied under the same name in the zoolorical rarden at London. The species was redescribed by Ferris on the basis of Cummings' material and a record from a host identitied as Procavia coombsi t'rom Onderstepoort, Pretoria, South Alrici, was added. Hopkins records the species from a long list ol subspecies of Procau ia capensis, this including capensis, marlothi, klaverensis, griquae, albaniensts, natalensis, windihuki, reuningi, and waterbergensis, and from procauia johnstoni johnstoni from various localitics. 
NOTkS. The present writer has previously maintuined that the first gro uine validation of the mue coutae-capensis is to be ascribed to Cunnings. but fuhrenholz has given cornt reasons tor acceptin? Pallus as the author of the specil'ic nune.

Whe ther or not Cumings actually had the species described by Pallas is open to question, but there is no special point to inquiring too closely into this. The nccompanying illustrations are based upon his specinens.

Prolinognathus lerrisi Fahrenholz

1932. Prolinognathus leptocephalus (Ehrenberg), Ferris, Contributions 'loward a Monograph of the Sucking Lice, Part 5:142; 1igures 25013, 251C. (Misidentification)

1939. Prolinognathus ferrisi fahrenholz, Zeitschrilt für Palasitenkunde $11: 1: 12$.

HOSTS AND DISTKIBUTION. The mame given by fahrenholz seems to have been based entirely upon the illustration yiven by ferris and consequently the type of the species must be the specimen from which this illustration was made, this haviug been recorded as from procavia brucel rudolfi. Marsabit Road, British East Africa, which, accorling to Hopkins, is Heterohyrax syriacus rudolft. This type specimen should be in the United States National Museum. Hopkins has also recorded the species from the same host.

Prolinoynathus t'oleyi Fahrenholz

1939. Prolinosnathus foleyi Fahrenholz, Zeitschrift für Parasitenkunde 11: $1: 9$; i i gures $5-7,8 b$.

HOSTS AND DISTRIBUTION. Recorded as from Procavia rufescens bounhioli from Algeria. This is the only record.

\section{Prolinomathus leptocephalus (Ehrenberg)}

1828. Pediculus leptocephalus Ehrenberg, Symbolae Physicae, Decas Prima, page $f^{\prime}$.

1874. Hoematopinus leptocephalus (Ehrenberg), Giebel, Insecta Epizoa, page 47. (In part)

1932. Prolinosnathus leptocephalus (Ehrenberg), Ferris, Contributions Toward a Monograph of the Sucking Lice, Part 5:142. (In part; not as to figures)

1939. Prol inognathus leptocephalus (Ehrenberg), Fahrenholz, Zeitschrift für Parasitenkunde 11: 1:8.

HOSTS AND DISTRIBUTION. Described from Procavia syriacus, presumably from Syria. Ferris recorded a single immature specimen from this host from Srria and Fahrenholz has given additional notes on the species.

\section{Genus SOLEYOPOTES Enderlein}

1904. Solenopotes Enderlein, Zoologischer Anzeiger 28: 143.

1909. Haematopinus (Solenopotes) Veumann, Archives de Parasitologie 13: 530. 1915. Cervophthirius Mjöberg, Entomologisk Tijdskrift $36: 282$.

1916. Linognathus, Ferris, Entomolorical News 27:199.

1921. Solenopotes, Bishop, Journal of Asricultural Research 21:797.

1929. Cervophthirius, Ewing, A Manual of External Parasites, page 136.

1929. Solenopotes, Ewing, A Manual of External Parasites, pages 136, 139.

1932. Solenopotes, Ferris, Contributions Toward a Monograph of the Sucking Lice, Part 5:395.

GENERIC TYPE. Soleropotes capillatus Enderlein. Type of Cervophthirius: Cervophthirius tarandi Mjoberg. 
CHARACTERS. Linogmathidae without eyes. Antennae five-segnented. Head variously shaped but usually slightly elongate and broadened but little posterior to the antennae. Thorax with a sternal plate filling most of the space enclosed by the coxa but not marginally or apically free from the body. Abdomen membranous throughout except for the usual ninth tergite and the ventral genital areas; with not more than one row of setae on any segment either dorsally or ventrally. Spiracles, in the type species, more or less cylindrical, their apices projecting somewhat from the body on slightly sclerotized prominences. In other species they may be shorter, in some species being almost spherical, but some indication of the tubercle is present. Genitalia of female including a pair of quite large and prominent gonophyses. Ninth segment terminating in a pair of ventral, flattened lobes which may be quite long and slender. Genitalia of the male with the parameres well developed, elongate and enclosing the penis and pseudopenis.

NOTES. The type species of this genus was based upon a single male specimen which was rather poorly described and led Ferris to the belief that it was simply an immature specimen of Linognathus vituli. This was later shown to be quite erroneous when the species was rediscovered in North America. Mjoberg described the supposed new genus Cervophthirius in 1915, but this was placed as a synonym of Solenopotes by Ferris in 1932 .

Except for the one species, capillatus, all the members of this genus at present known are from Cervidae. It is probable that several more remain to be found.

\section{Key to Species of SOLENOPOTES}

Only a partial key can at present be given, and identifications must depend largely upon host associations until the genus has been completely reviewed by someone.

1. Head with the lateral margins posterior to the antennae tending to converge and presenting neither postantennal nor posterior lateral

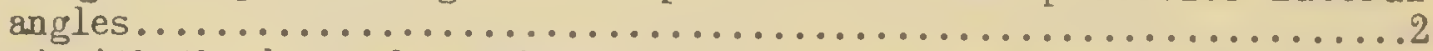

Head with the lateral margins posterior to the antennae tending to be nearly parallel, with definite postantennal and posterior lateral

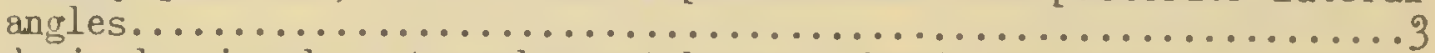

2. Abdominal spiracles strongly protuberant; female with apical lobes of the abdomen which are short and moderately broad and then are constricted sharply into a short, slender, terminal process; male with the parameres enclosing a broadly Y-shaped pseudopenis; as far as

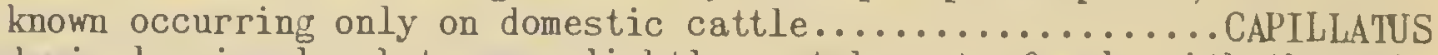

Abdominal spiracles but very slightly protuberant; female with the apical lobes of the abdomen constricted gradually into long, tapering processes; parameres of the male enclosing merely a very short aedeagus; occurring as far as known on New World deer of the genera Odo-

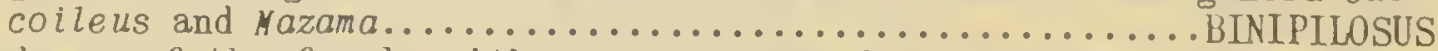

3. Abdomen of the female with not more than 2 long setae in the median group, either dorsally or ventrally, on any segment...........CAPREOLI

Abdomen of the female with 4-8 long setae in the median cluster, both dorsally and ventrally, on the abdominal segments; occurring as far as known on New World deer of the genus adocoileus..............ERRISI (The species tarand and burme istert will run in this key to the last couplet.)

Solenopotes linipilosus (Fahrenholz)

1910. Linognathus anğulatus (Piatret), Mjöberğ, Arkiv för Zoologi 2:157. (Misidentif'ication) 


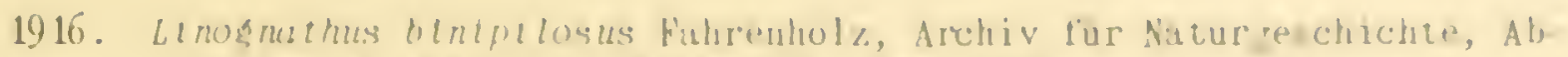
teilune 1, 81:11:11: Plate, riveres 11 13.

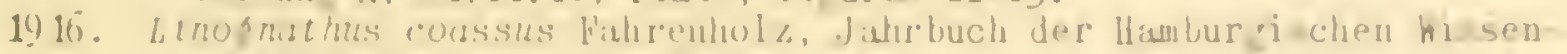

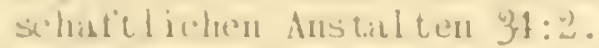

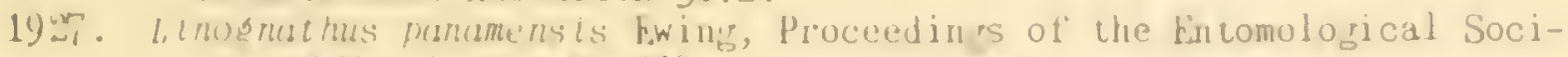
ety of Wishiligton 29:119.

1932. Solenopotes binipllesus (Fahenholz), Ferris, Contribuzions Tonurd a Yono rritph of the Sucking lice, Yart 5: 131; 1"i gures 245, 246.

HOSTS AYU DISTRIBUTLON. First described by fahrenholz l'rom "Miscama Il irsch" without indicition ot origin, lut this nune implies a host of the genus Vazana from South or Central America. Kecorded by f'athrentudz from "Cocssus" from the llantur"; zoological garden, this generic nume apparently

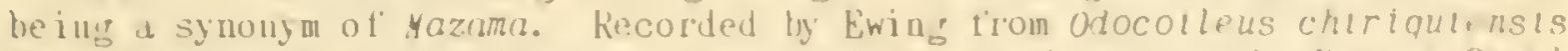

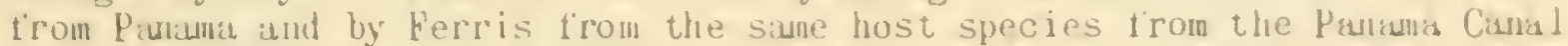
Zone. Specinens are at hand from tazuma simplicicornisat Jujuy, Arentina; Irom onocoileus conesi at Tucson, Mrizona; United States; and Irom "deer," at Sonora, l'exas, United States.

\section{Solenopotes burmeisteri (fahrenholz)}

1918. Pediculus crassicornis Nitusch, liermar's Magazin der Entomolo:ie 3: 305. (ihot Pediculus crassicornis Scopoli, and theretore preoccupied)

1916. Linosnothus crassicornis (Nitzsch), Fahrenholz, Archiv für Naturgeschichte, Abteilung A, 81:11:34.

1919. Linosnathus burmeisteri Fahrenholz, Juhresbericht des Niedersachsischen zoologischen Vereins zu Hannover 5-10:23.

1935. Solenopotes burmeisteri (Fahrenholz), Freund, Recueil de Travail dédié au 25me Anniversire scientifique du Professor Eugéné Pavlovsky, 1909. 1934, Leningrad et Yoscow, yage 278; 1igure A.

HOSTS IND DISTRIBUTION. Described from Cervus elaphus in Europe and known only trom a few records from that continent.

NOTES. European authors have considered that the species recorded from North Anerica by Ferris as this, under the name of Solenopotes crassicornis, is distinct, as is also the species illustrated by Ferris as burmeisteri in 1932. and which has been named as solenopotes capreoli. The name crassicornis, being preoccupied, wis replaced by the name burmeister $i$ in 1919. These three species are very closely similar and it remains to be determined just how they can be sepurated.

\section{Solenopotes cupillatus Enderlein Fi gures 113, 114}

1904. Solenonotes capillatus Enderlein, Zoolougischer Anzeiger 28:144; figures 14,15 .

1916. Linognathus vituli (Linnaeus), Ferris, Entomological News 27:199. (Misidentification)

1920. Solenopotes copillatus Enderlein, Freund, Zentralblatt für Bakteriologie und Parasitenkunde (1)84:142; finre.

1921. Solenopotes cnpillatus Enderlein, Bishop, Journal of Asicultural Research 21:797; 1'igures.

1932. Solenopotes canillatus Enderlein, Ferris, Contributions Toward a Yonopraph of the Suckin: Lice, Part 5:39\%: 1'i gures 243, 244.

HOSTS AND DISTRILUTION. First recorded trom domestic cattle in Germany. low known t'rom tomestic cittle trom various localities in Europe and North America.

lOTES. The opinion is held by the writer that this species has transferred to domestic cattle trom deer. althou it has never been taken from 


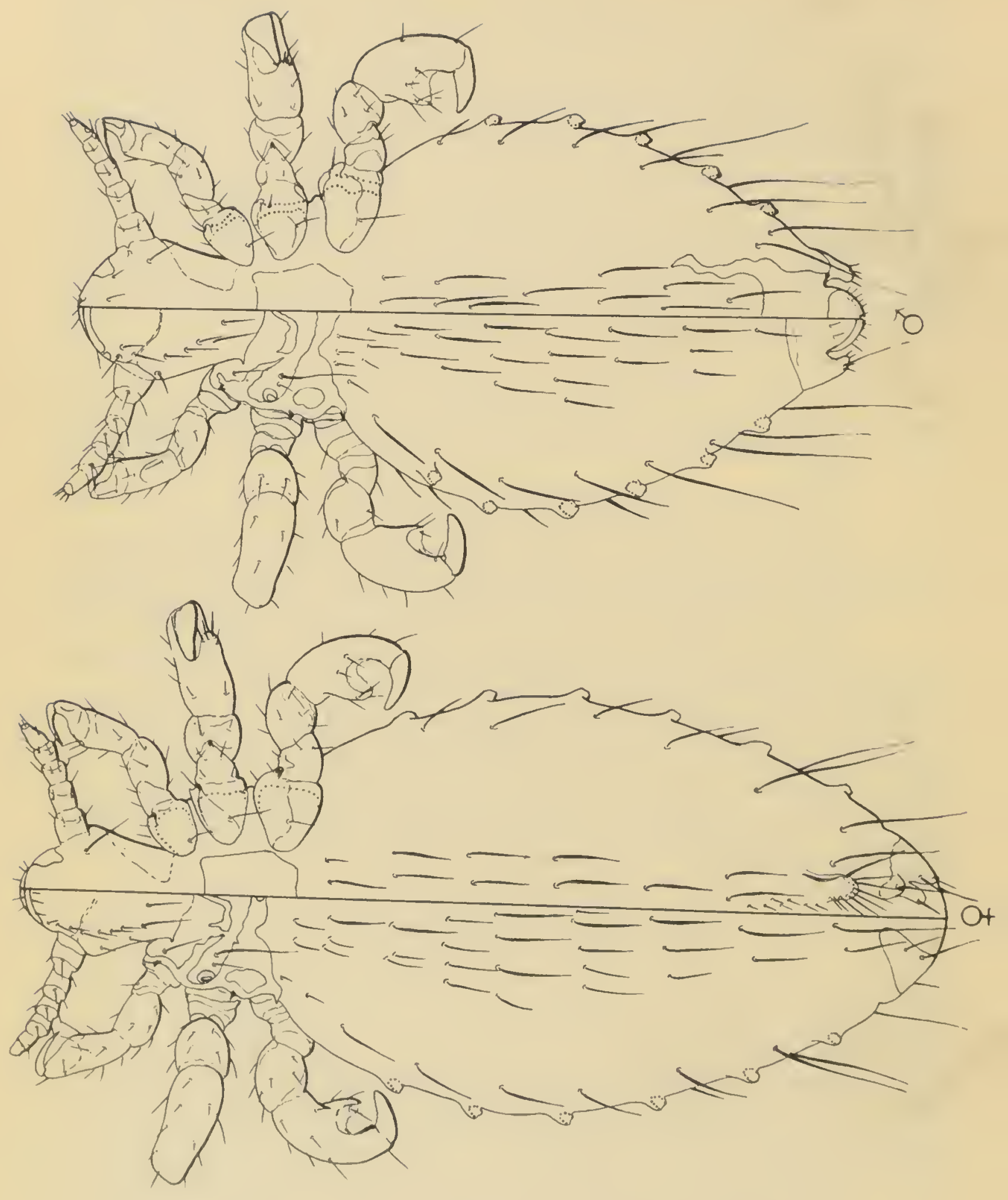

Solenopotes capillatus Enderlein

Figure 113 

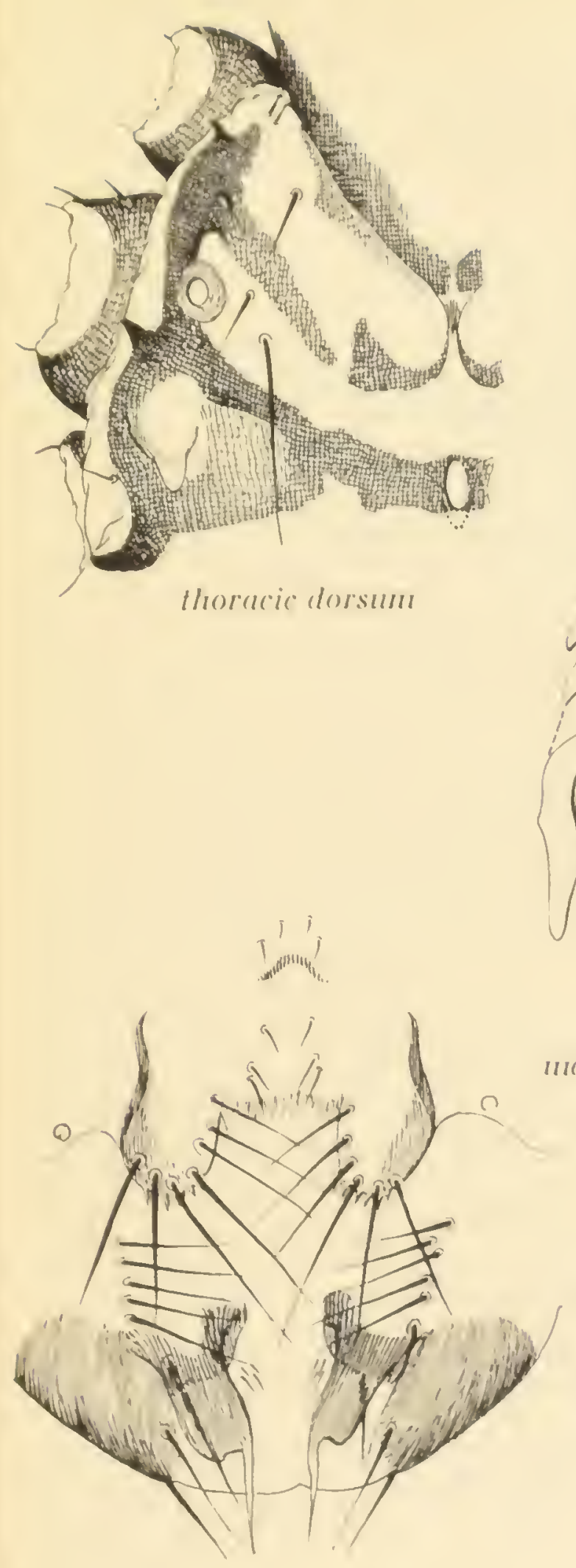

female yenitalia

Solenopotes capillatus Enderlein, details
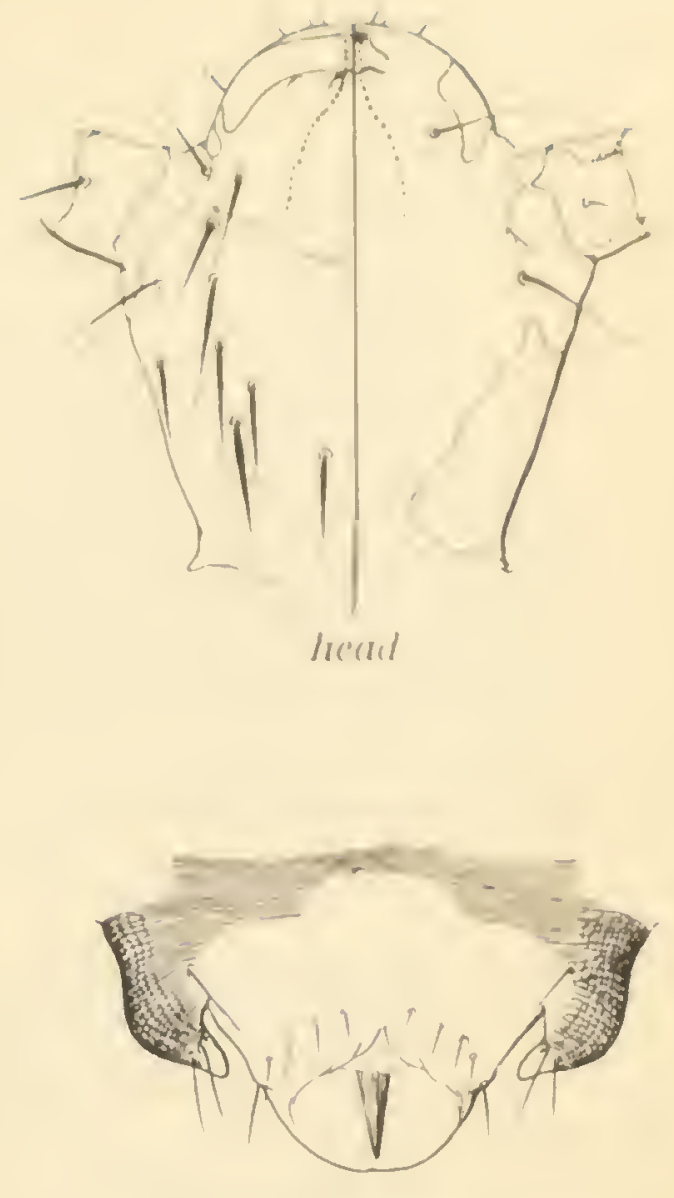

mule abdomen, dorsal

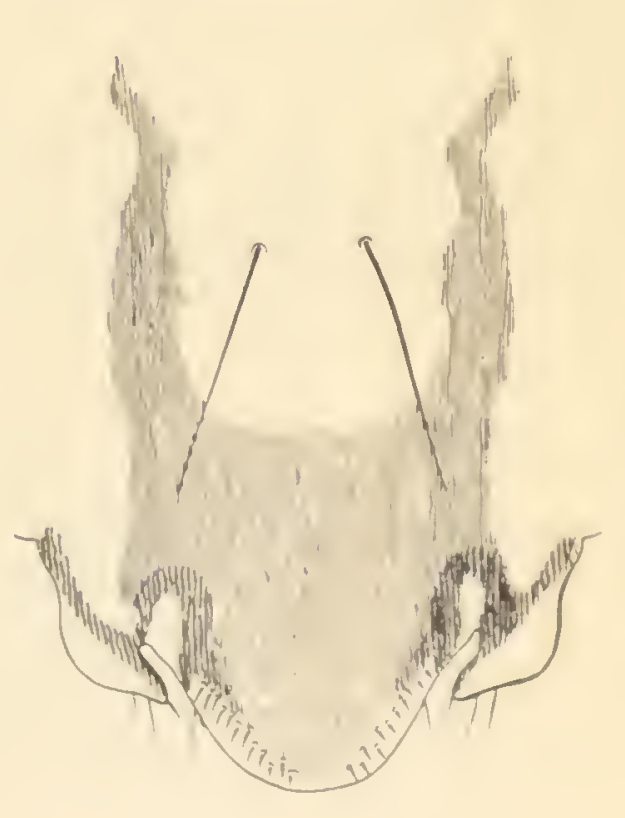

unule sernital plute

Figure 114 
any cervid and this opinion may be entirely erroneous. An extended discussion of the biology ot the species is yiven in the reference by Bishop cited above.

\section{Solenopotes capreoli Freund}

1932. Solenopotes burme isteri (Fahrenholz), Ferris, Contributions Toward a Monograph of the Sucking Lice, Part .5:404; figures 247, 248. (Misidentification)

1935. Solenopotes capreoli Freund, Recueil de Travail dédié au 25me Anniversaire, Scientifique du Professor Eứéné Pawlowsky, 1909, 1934, Leningrad and Moscow, page 278; figure B.

HOSTS AND DISTRIBUTION. The specimens upon which the record and illustrations biven by Ferris (reference cited above) were based were from Capreolus caprea trom Czechoslovakia. Freund described the species as new on the basis of specimens from the same host without indication of oririn.

NOTES. This species, as Freund remarked, is "In allen Details.....praktisch identisch mit solenopotes ferrisi...." differing only in the arrangement of the abdominal setae. Differences cited between this and burmeisteri are so slight as to offer no definite "key characters" for the separation of these two species.

\section{Solenopotes ferrisi (Fahrenholz)}

1916. Cervophthirius crassicornis (Nitzsch), Ferris, Entomological News 27: 197; figures. (Misidentification)

1919. Linognathus ferrisi Fahrenholz, Jahresbericht des Niedersächsischen zoologischen Vereins zu Hannover 5-10:24.

1932. Solenopotes ferrisi (Fahrenholz), Ferris, Contributions Toward a Monograph of the Sucking Lice, Part 5:134; f'igures 247, 248.

HOSTS AND DISTRIBUTION. Type from Odocoileus columbianus at Laytonville, Mendocino County, and recorded also from the same host at San Gregorio, San Mateo County, California, United States.

NOTES. This species was identified by Ferris as the European species which is now known as Solenopotes burme isteri, but Fahrenholz considered it to be distinct and named it as new on the basis of Ferris' description. For this reason it appears that the types of the species must be regarded as leing in the material recorded by Ferris. Freund has given a redescription of burme ister $i$, but it is still not clear wherein the two species differ, if they do so at all.

Solenopotes muntiacus Thompson

1938. Solenopotes munt iacus Thompson, Annals and Marazine of Natural History (Series 11) 1:634; figures.

HOSTS AND DISTRIBUTION. Known only from the original record from kunt iacus malabaricus at Mousakande, Gammaduwa, Ceylon. Accordin.r to Hopkins this is Muntiacus muntjak.

NOTES. Unfortunately the description and illustrations of this species are not adequate to permit any very clear concept of it or to afford any "key characters" for its identification. It is sid to be very similar to binipilosus.

\section{Solenopotes tarandi (Mjöherir)}

1915. Corvonhthirius tarandi Mjöberg, Entomologisk Tijdskrift 36:283; t'i $\mathbf{y}^{-}$ ures $1-4$.

1932. Solenonotes tarandi (Mjöhers), Ferris, Contributions Toward a Mono- 


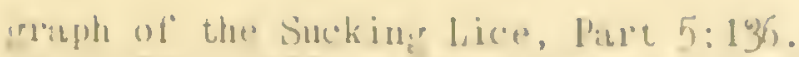

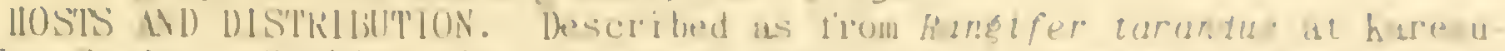
ando. Swerten. llophins, in his recent host list, indicates anothe lecourd, which hats not luen tracel in comection with the plosent work.

Nollis. 'lhe oripinal descriptiun and illustrations of this sprecies are intulequate and otler no bas is tor its separalion tlom such species as burmeisterl ind ferrist.

Family NEOLINOGNálll DAt; Fahrenhol'z

19:9. Neolino pnathidae, Ewing. Manual of Extenal l'alasites, fin;e 139.

1936. Neolinognithidite, Fuhnenholz, Ze itschritt tïn l'al'asitenkunde 9:1: 5r.

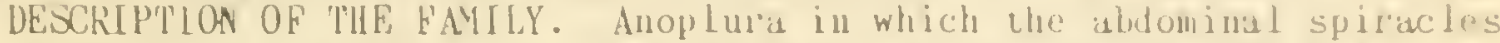

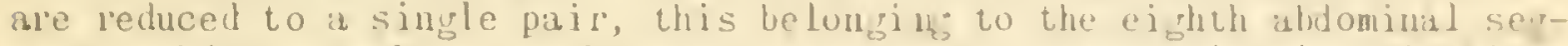
ment. Abdonen membranons throuphout "xcept tul the usum sclerotizations of' the renital region and the terminalia and except for the presence at times of minute sclerotized points; almost devoid of setae excep 2 for a pair at each lateral anirle of seiment eirht anl in the genital area. Legs with the t"ir'st pair small and slenter with slender claw; second and third pairs enlaliged and stoul, with stout claw. Antemule tive-se:mented, sexually dimorphic. Thoracic sternal plate present but not apically free, divided into two Lon ritudiual plates.

NOTES. This lamily was first recognized as an entity by Ewing who established it as the subfamily Neolinomathinae of the family Haematopinidae. It was elevated to tanily rank by Fahrenholz in 1936.

The single included renus with two species occurs on members of the family Macroscelididae of the Order Insectivora.

The members of this tanily are peculiar t'orms. The probabilities are that their actual relationships are with the family Hoplopleuridae hut they are so peculiar that even if' referred to this l'amily they would have to be maintained as a subfimily.

\section{Genus NEDLINOGNATHUS Bed ford}

1920. Neol inosnathus Bedtord. Entomolopist's Monthly Magazine (3)6:88.

1922. Neolinognathus, Ferris, Contributions Towarda Yonograph of the Sucking Lice, Part 3:166.

GENERIC TYPE. Veol inognathus elephantuli Bedford, by monotypy. One other species is included in the genus.

CHARACTERS. Without eyes. An tennae five-se,mented, not sexually dimorphic. Head fusitorm. Thorax with the sterual plate not apically or marcinally tree, divided lon riludinally into two small plates. Anterior legs small and with slender claw. Middle and posterior le rs enlarged, somewhat llattened. with stout claw. Abdomen membranous throughout except for the ninth tergite and the genital sternites beset with small, sclerotized points and entirely without setae except for a pair at each lateral maroin of segment ei ht. Abdominal spiracles present only on segment ei tht, these noticeably enlarped.

NOTES. The two species referred to this genus may he separated ty the followin key.

With a retrorse, tooth-like process on the dorsal (outer) distal an le of

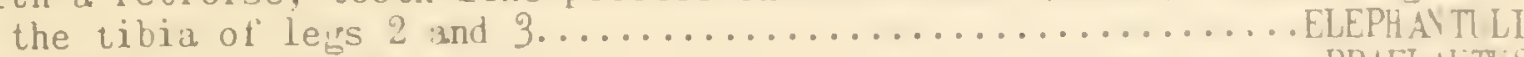
Without such a tooth.............................................. 
1920. Neol tnoßnathus elephantult Bedford, Entomologist's Monthly Magazine (3) $6: 89-90$; figure.

1922. Neol inoßnathus elephantuli bedford, Ferris, Contributions Toward a Monograph of the Sucking Lice, Part 3:166; figures 110-111.

HOSTS AND DISTRIBUTION. First described as from Elephantulus rupestris (myurus) jamesoni at Onderstepoort, Transvaal, South Africa. Later recorded by Ferris from Petrodromus tetradactylus and Nasilio brachyrhynchus delamert from British Central Africa and Loita Plains, British East Africa.

\section{Neolinognathus praelautus Ferris}

1922. Neolinoßnathus praelautus Ferris, Contributions Toward a Monograph of the Sucking Lice, Part 3:169; t'igure 111E and 112.

HOSTS AND DISTRIBUTION. Type from Elephantulus pulcher phaeus at lime Springs, British East Africa. Also from Elephantulus rufescens at Vor, British East Africa.

\section{Family PEDICULIDAE Leach}

1817. Leach, The Zoological Miscellany 3:64.

1842. Denny, Monographia Anoplurorum Britanniae, page 1.

1880. Piaget, les Pediculines, pare 615.

1904. Enderlein, Zoologischer Anzeiger 28:136.

1929. Ewing, A Manual of External Parasites, page 141.

DESCRIPTION OF THE FAMILY. Anoplura in which the eyes are very definitely present externally as a pair of distinct lenses which are accompanied each by a distinct spot of pigmentation that shows in uncleared specimens. Antennae five-segmented, not sexually dimorphic. Legs variable in form, either all practically the same or with the first pair small and slender and the second and third pairs large and stout. Paratergal plates represented on certain of the abdominal segments by a sclerotization which covers the apex of lateral lobes of the abdomen and which never has any part free from the body wall, although at times with lateral lobes. Abdomen otherwise membranous except for the usual terminal and genitalic plates and small tergal plates in the male. Female with well-developed gonopods on the eighth semment but with no definite indication of the sonopods of segment nine present. Genitalia of the male with the parameres fused hasally with the aedeagus.

NOTES. As here understood, this family - which at one time included all the Anoplura-is reduced to two genera that are here considered to involve not more than four unquestioned species. Ewing has held that the genus Phthirus should also be removed from it, leaving only the genus Pediculus in the family. While an argument can be made for this step it is not here accepted.

A step is taken, however, which undoubtedly will not meet with general approvil, but which is supported by the facts of morpholory. That is to remove the genus Pedicinus from the Pediculidae. Those who base their concept of the classification of the Anoplura upon the relationships of the hostsreal or supposed-will object to this procedure, but the fact remains that, considerinis the question from a morphological basis, the genus Pedicinus ippears to have very little to do with Pediculus, being apparently more closely related to the members of the family Hoplopleuridae as here understood. The question is discussed at length in connection with Pedicinus.

The two genera remaining in the Pediculidae can be separated from each other so readily that no key for their differentiation is here presented. 


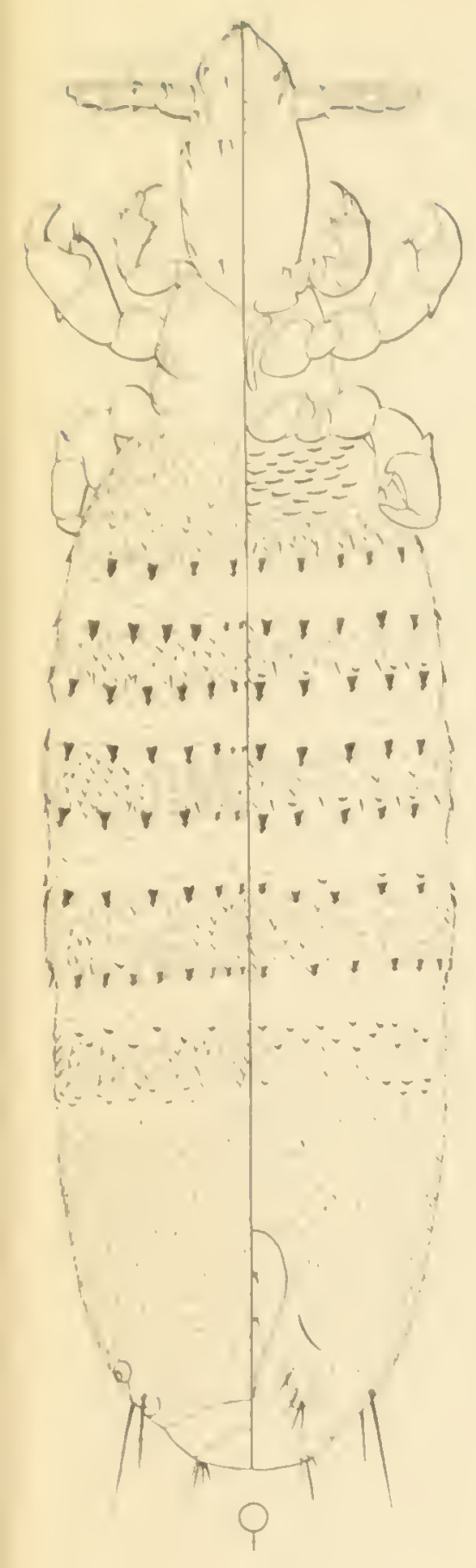

111

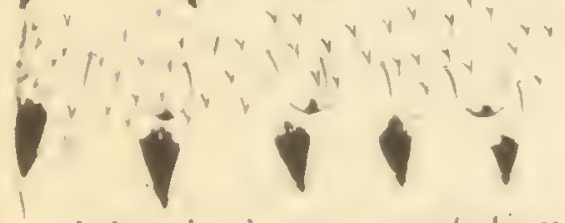

abdominal ornumbenlulion

Neolinognathus elephantuli Bedford

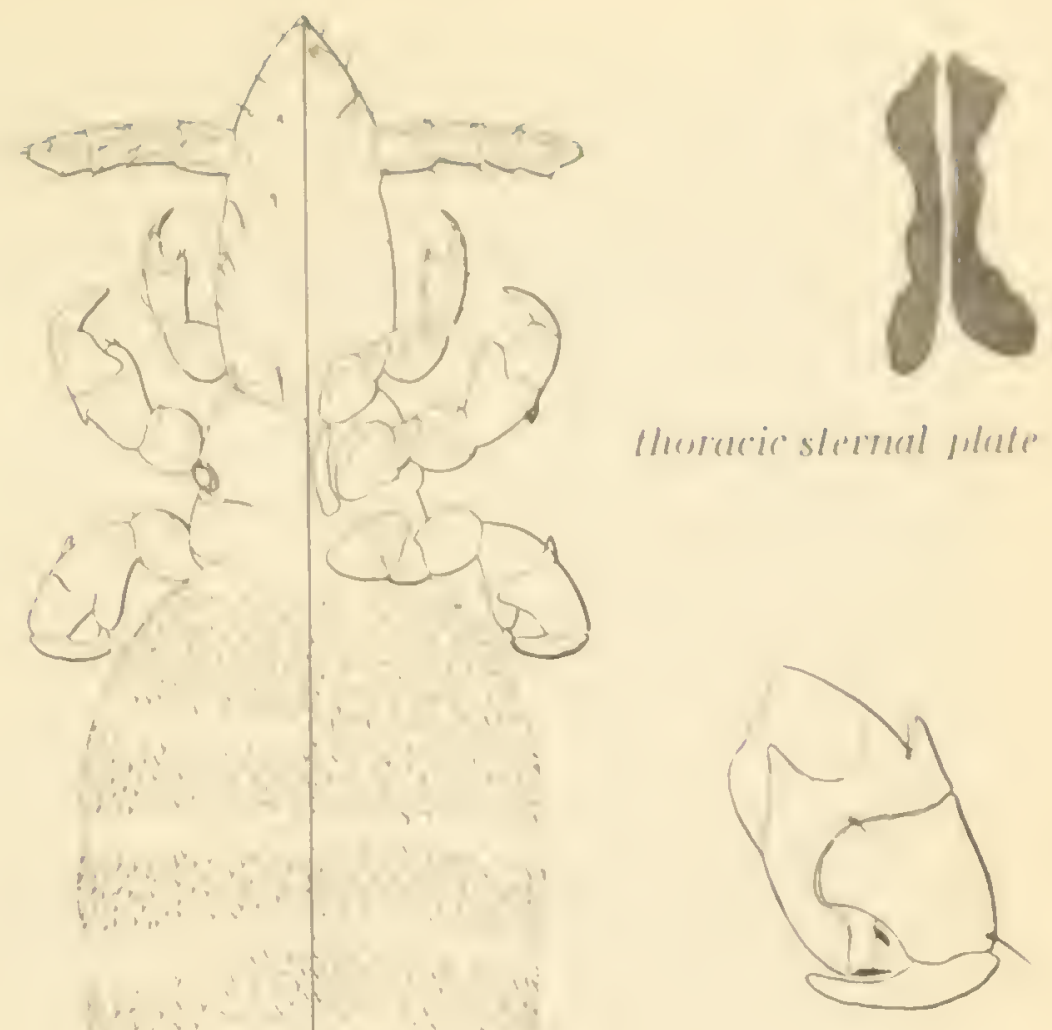

2ud or 3rd r laut)

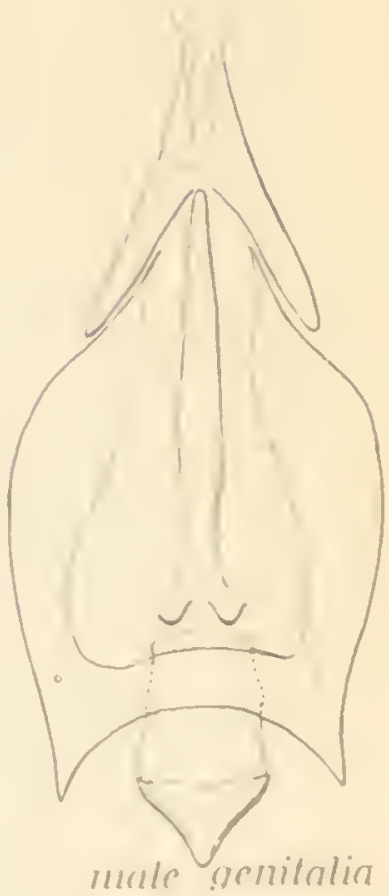

Figure 115 
It would be utterly impracticable here to present a complete bibliography of this genus. Consequently, only those references are given to which a specialized student of the group may refer for his purposes.

1758. Pediculus Linnaeus, Systema Naturae, Edition X, page 610.

1926. Pediculus, subgenus Parapediculus Ewing, Proceedings of the United States National Museum 68: Article 19:7.

1926. Pediculus, subgenus Paenipediculus Ewing, Proceedings of the Bioloirical Society of Washington 45:117.

1935. Pediculus, Ferris, Contributions Toward a Monograph of the Sucking Lice, Part 8:534.

1938. Pediculus, Ewinir, Journal of Parasitology 24:13.

GENERIC TYPE. The type of Pediculus is Pediculus humanus Linnaeus. The type of the proposed subgenus Parapediculus was stated by Ewing to be Pediculus consobrinus Piaget. The consequences of this latter type selection will be discussed in the notes which follow. The type of the proposed subgenus Paenipediculus was stated by Ewing to be Pediculus simiae Ewing, which is here considered to be a synonym of Pediculus schäffi Fahrenholz.

CHARACTERS. Anoplura in which eyes are very distinctly developed. Legs all of essentially the same size and shape, the tibiotarsal articulation distinct, the claws slender. Marjins of the abdomen more or less strongly lobed, the lobes covered by the sclerotized paratergal plates which are not at all or at the most but in part and then only slightly free from the body at any point on their margins. Thorax with a distinct notal pit. Thoracic sternal plate sclerotized, but with its margins not free from the body. Dorsum of the abdomen in the female membranous or at the most with slivhty developed, sclerotized plates; that of the male usually with small ter ral plates, the surrounding derm not minutely wrinkled. Spiracles present in normal position on the audomen, six pairs being present, these all enclosed within the borders of the paratergal plates. Male with the genitalia bearing very small parameres which are united basally with the pseudopenis.

HOSTS AND DISTRIBUTION. Occurring on members of the Order Primates, especially on man, the chimpanzee, and the New World monkeys of the family Cebidae. There are records of its occurience on gibbons.

It may be stated at the outset that the two supposed subgenera, parapediculus and Paenipediculus are here caterorically rejected. The author of these two subgenera, himself', indicated (1938) doubts as to the justification of the first of these but surgested that the second mirht well be raised to the ranl of a genus. That anything at all is to be gained by the recounition of either remains to be demonstrated. In the case of Parapediculus we have a question arising f'rom a misidentified generic type. The type of this proposed subigenus was definitely stated to be Pediculus consobrinus Piaget, a species that has been shown, on the basis of an examination of the sole remaining specimen in the Piaget collection at the British Museum, to be Pediculus humanus. Ewing, however, had before him when he named this subgenus specimens which were not this species and he had never seen this type specimen. If Parapediculus, as a name for the lice of the New World Cebidae, is ever reconized the question as to the status ot' its type species will need to be settled, but since it is here rejected no time will now be spent on the question.

\section{Key to Suecies of PEDICULUS}

Only those lorms are included in this key which in the writer's opinion have a reasonable claim to be recopnized as species. 


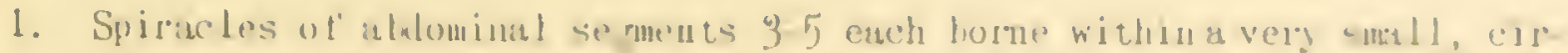

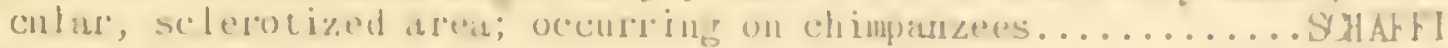

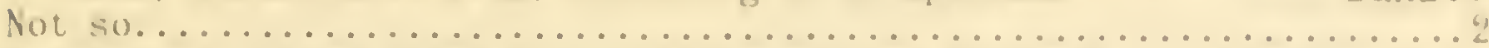

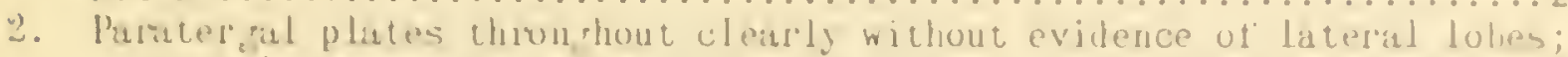

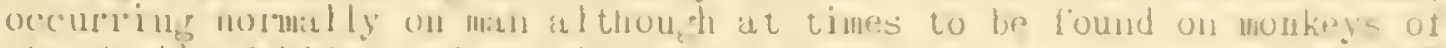

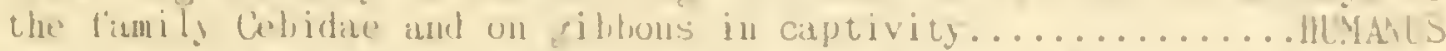

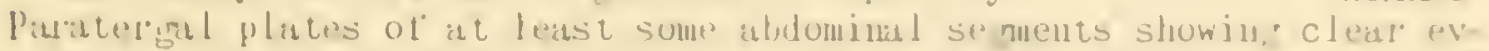
illence of luteral lobinp, both dorsally and ventrally...........

3. Palateroul plates of aldoninal segments $5-6$ bearing strong dateral lobes, hoth dorsilly and ventrally; occurrin on monkess of the lami-

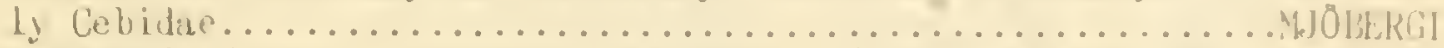

Paratergal plates of abdoninal segments $5-7$ with slisht, but distinct, evidence of laterul lobes, hoth dorsill! and ventrill!: occurrin on man and Celidie in the New World tropics and onl min in thes southmest-

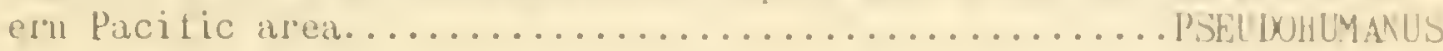

In presenting the following review it his seemed desidiale to considel the species by host irroup rather than ulphaletically.

Pediculus huminus Linnaeus

Figures $116,117,118,119$

The literature on this species is very extensive, but for the nost part is not pertinent in considering the taxonomy of the species. Only those references ale cited which are of importance in establishins stumy on or in presentin: evidence conceruing the status of the various forms that have been described.

1759. Pediculus humanus Linnaeus, Systema Naturae, Edition $\lambda$, pa: 610. (The original description of the species, containing no indication that the head and body lice were considered to represent varieties.)

1761. Pediculus humanus Linnaeus, Limaeus, Fauna Suecica, Edition 2, parge 475. (The be inning of the controversy concerning the two varieties. "Qui in vestimentis victitat ab eo, qui in capite vivit, non differt ut species, sed tantum varietas.")

1767. Periculus humanus linnaeus, Liunaels, Systema laturae, Edition XII, pare 1016 . (The two supposed varieties are designated as 1 and 2, respectively, for the head louse and the body louse and characterized thus: "Varietas Capitis durior, coloratior; Vestimentorum laxior, maris cinerea.")

17T8. Pediculus humanus Linnacus, de Geer, Mémoires pour servir á l'histoire des insectes $7: 67$; Plate 1, fi ures 6,7. (Here the terms "cabitis" and "corporis" are first employed. "Il y a donc une différence palpable entre ces deux sortes de poux, et qui semble indiquer qu'ils sont d'espèce differente, á moins qu'on ne veuille plutôt. conme a fait Y. de Linné, les remarder comme delx variétés. Quoiquil en soit, on pourroit les distinguer par les démoninations suivantes: (1) pediculus (humanus capitis) cinereus, thorace abdomineque lascia interrupta ni gra marginatus; (2) pediculus (humanus corporis) albidus, totus immaculatus.")

1803. Pediculus humanus Linnaeus, Latreille, In louveau dictionnaire d'histoire naturelle 18:403. (This reference not seen. According to Nutall, the name "humonus" is here definitely restricted to "le pou du corps," which would constitute the first type tixation.)

1803. Peficulus cervical is Latreille, In Youvean dictionnaire d'histoire naturelle 19:403. (This reterence accortin: to luttall. The name is indicated as applyin: to "le pou de téte.")

1805. Peículus niǵritarut Fabricius, Systema Antliatorum. pa. 


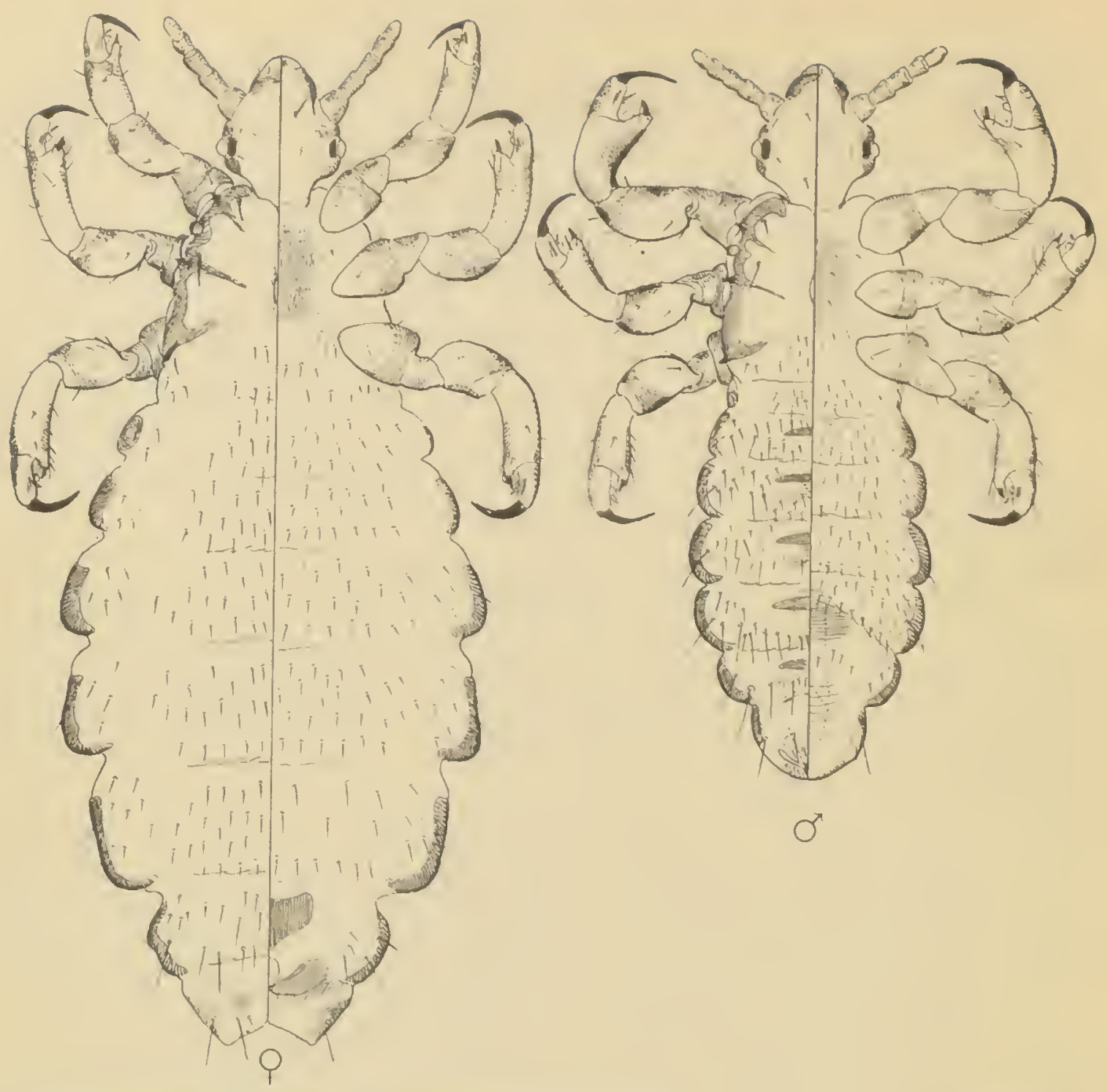

Pediculus humanus Linnaeus, the typical form called capitis

Figure 116

tablished for lice having their "habitat in nigritarum corpore.") 1816. Pediculus nigrescens von Oifers, De vergetativis et animatis corporibus in corporilus animatis reperiundis conmentarius, Part 1, pase
81.

1816. Pediculus albidior von 0lfers, De ve petativis et animatis corporibus in corporibus animatis reperiundis conmentarius, Pari 1, page 81. (Merely a new name for the lody louse.)

1816. Pediculus pubescens von 0lfers, De veretativis et animatis corporilus in corporihus animatis reperiundis commentarins, Part 1, pare 81. (Merely a new name for the head louse.)

1818. Pedlculus vestimenti Nitzsch, Germar's Miggain der Entomolorie 3: 305. (New name for the body louse.)

182A. Perliculus tabescentium Alt, De Phthiriasi, pare 7.

1834. Pediculus capitis de Geer, Burme ister, Generi Insectorum, Rhynchota, Order 1, Tribe 1, Family 1, Species 1.

1880. Pediculus consobrinus Piaget, les Pediculines, page 626 ; Plate 51 , "itgre 4. (Doubtlully described as new.) 


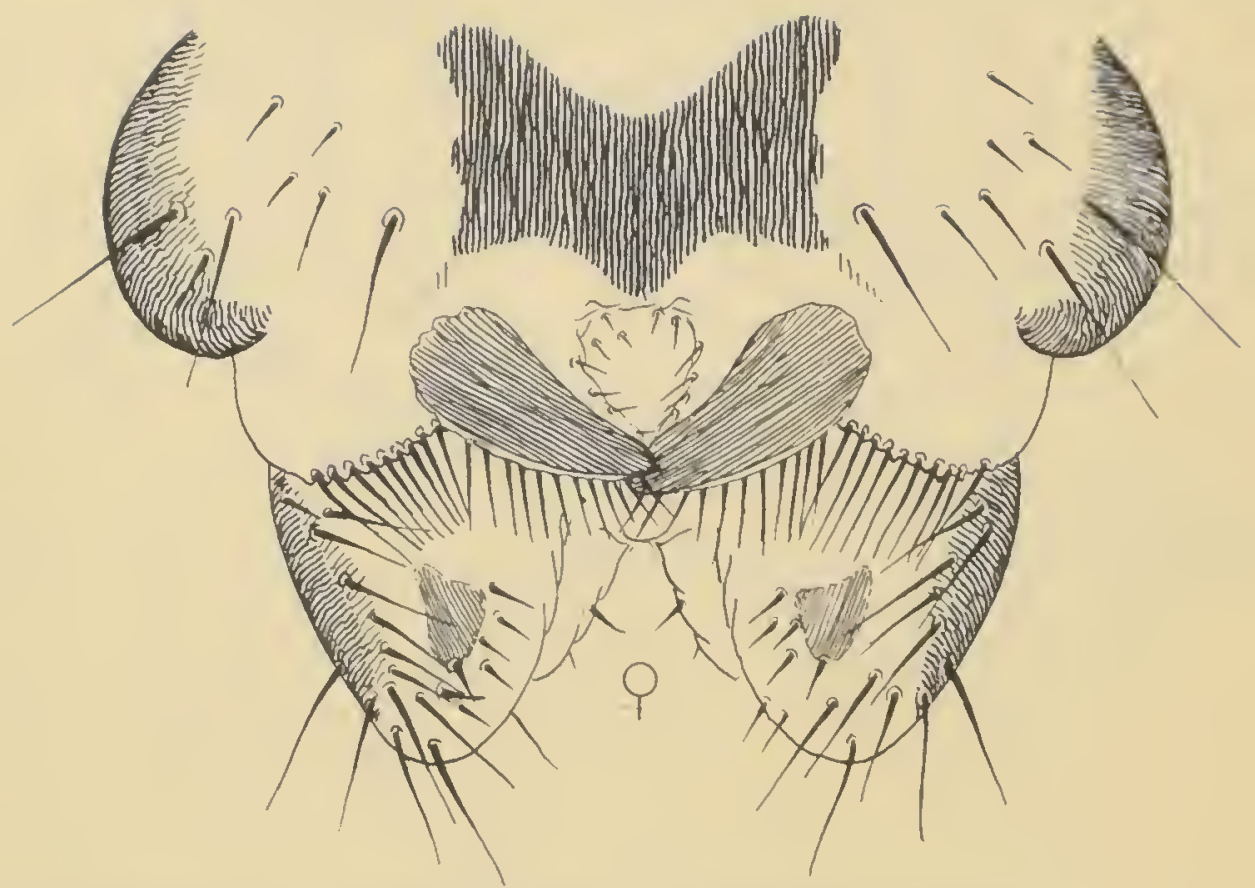

Pediculus mjöbergi Ferris, from Ateles dariensis, genitalia of female

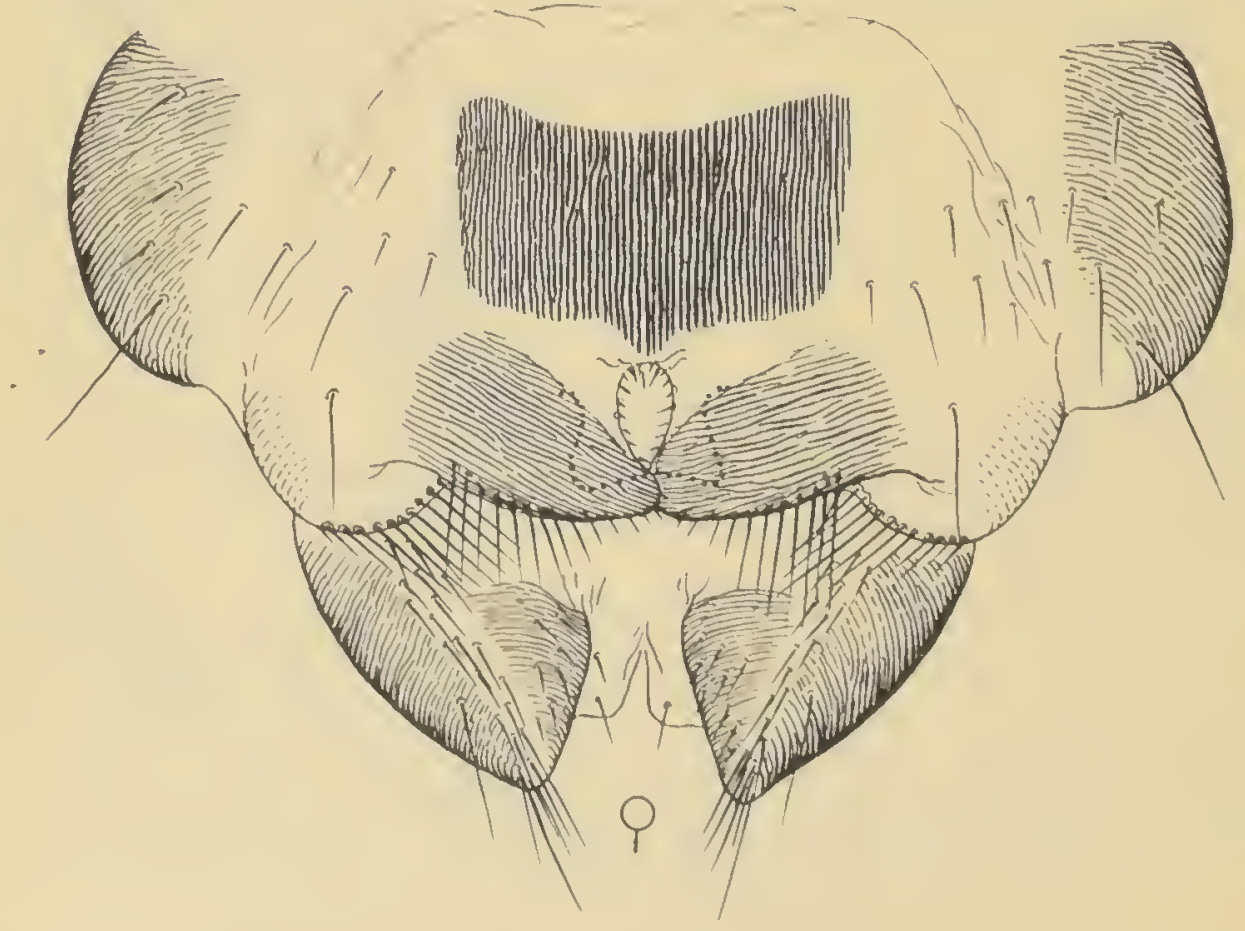

Pediculus humanus Linnaeus, genitalia of female 


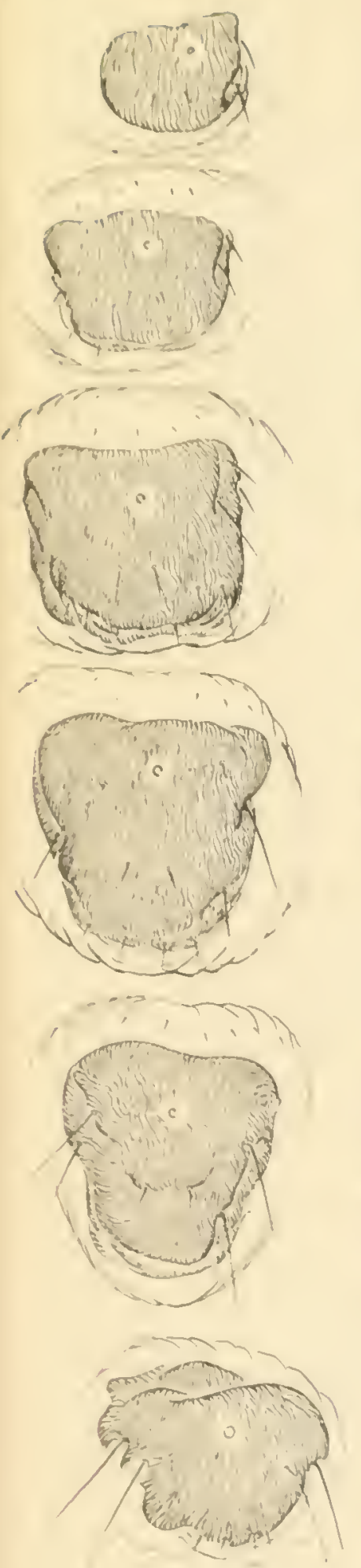

corporis
typical form

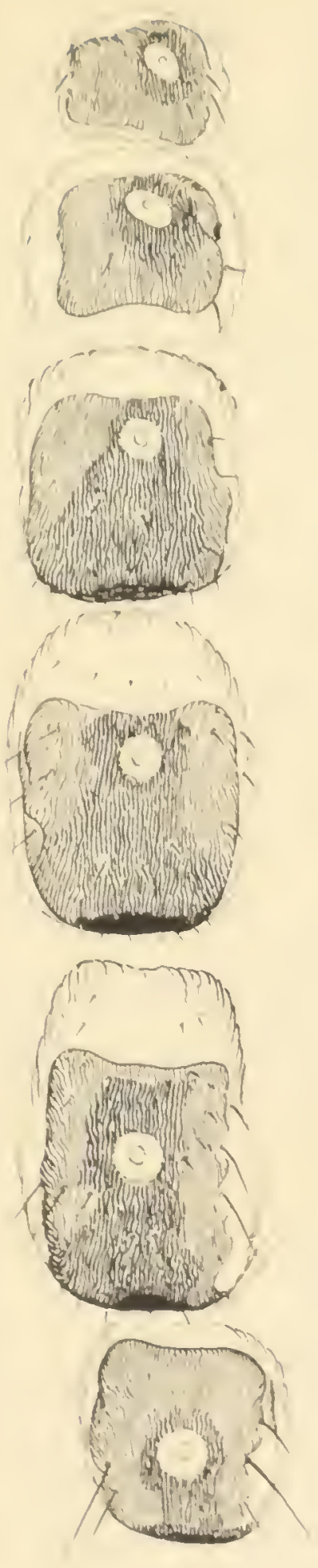

capitis
typical form
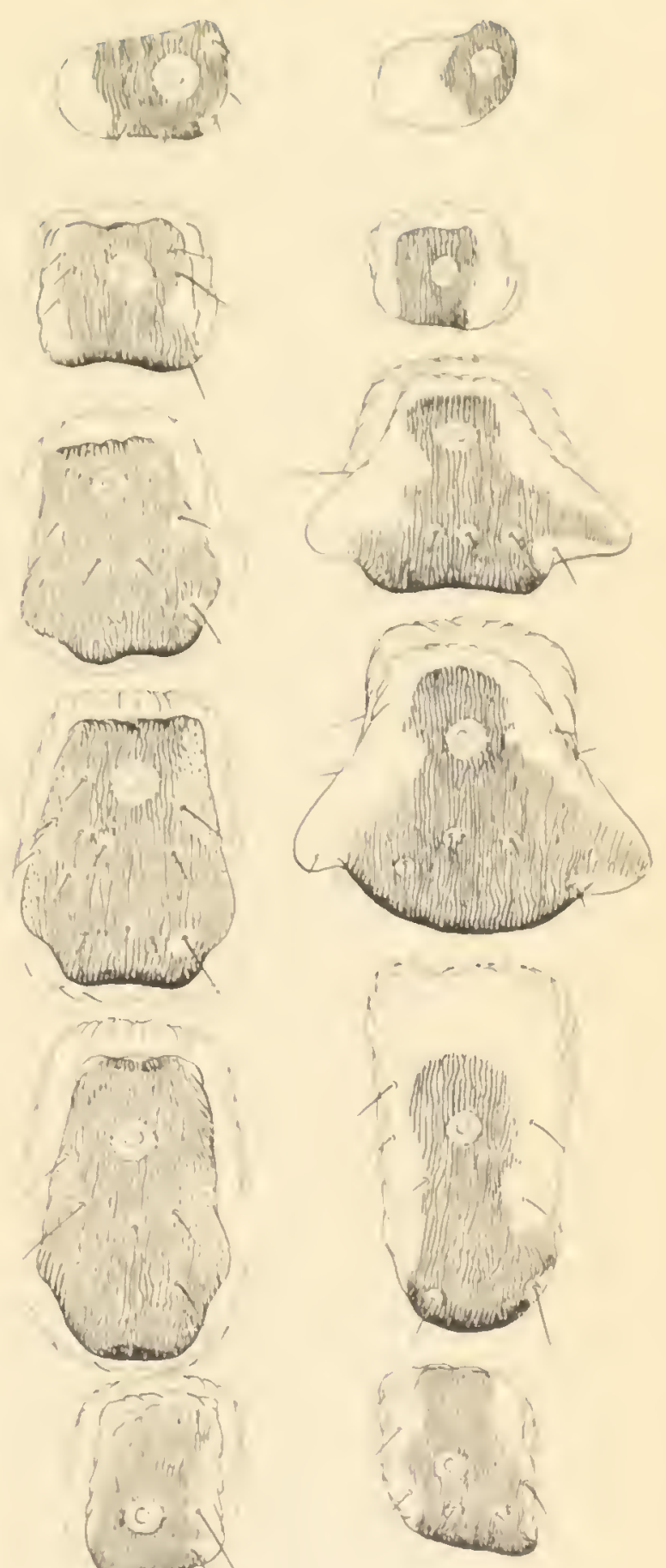

pseudohumanus

from man.

Marquesas Islands Ateles dariensis 
1911. Pediculus capitis de Geer and Pediculus capitis vestimenti Nitzsch, Neumann, Archives de Parasitoloyie 14:410-413. (Neumann concludes that the body louse is but a variety of the head louse and assigns to it, contrary to all rules of nomenclature, the name combination given above. He concludes also that Pediculus consobrinus Piaget is identical with Pediculus capitis.)

1912. Pediculus capitis de Geer and Pediculus corporis deGeer, Fahrenholz, Jahresbericht des Niedersächsischen zoologischen Vereins zu Hannover 2-4:2-12; text figures 1-7; Plate 2, figures 16-19; Plate 3, figures, 1-4. (Maintains the distinctness of head and body lice.)

1915. Pediculus corpor is niøritarum Fabricius, Fahrenholz, Zeitschrift für Morphologie und Anthropologie 17:596-597; text figure 1. (Assumes to recomize this form on the basis of a single specimen.)

1915. Pediculus capitis anģ tus Fahrenholz, Zeitschrift für Morphologie und Anthropologie 17:597; text figure 2; Plate 21, figure 1. (From Japanese.)

1915. Pediculus capitis maculatus Fahrenholz, Zeitschrift für Morphologie und Anthropologie 17:598; text figures 3, 4; Plate 21, figures 2, 3. (For the head louse of African negroes.)

1915. Pediculus corporis marøinatus Fahrenholz, Zeitschrift tür Morphologie und Anthropologie 17:599. (The body louse of Japanese.)

1916. Pediculus humanus Linnaeus, Fahrenholz, Zoologischer Anzeiger 47:269271. (Points out the proper application of the name "humanus," and rives data on literature.)

1916. Pediculus friedenthali Fahrenholz, Archiv für Naturgeschichte, Abteilung A, 81:11:2; text figures 1, 2; Plate, figure 1. (For a louse from Hylobates mülleri. Date of issue indicated as July.)

1916. Pediculus oblongus Fahrenholz, Archiv für Naturgeschichte, Abteilung A, 81:11:15; text firure 14. (For a louse from Hylobates syndactylus.) (Not Pediculus oblongus Geoff'roy)

1916. Pediculus humanus marginatus Fahrenholz, Zoologischer Anzeiger 48: 87. (This apparently was intended as a preliminary diaguosis to appear before the description in the reference cited above which, however, has priority. Date of issue indicated as 0ctober.) 1916. Pediculus corporis an£ustus Fahrenholz, Zoologischer Anzei.ger 48:88.
(The same note applies.)

1916. Pediculus capitis maculatus Fahrenholz, Zoologischer Anzei ger 48:88. (The same note applies.)

1916. Pediculus friedenthali Fahrenholz, ZoologischerAnzeiger 48:88. (The same note applies. The intended later description of this species appareutly has priority of three months.)

1916. Pediculus oblongus Fahrenholz, Zoologischer Anzeiger 48:88. (The same note as for the next preceding species applies.)

1916. Pediculus humanus chinensis Fahrenholz, Zooloyischer Anzeiger 48:87. (Preliminary description of the body louse of Chinese.)

1917. Pediculus humanus chinensis Fahrenholz, Fahrenholz, Mitteilungen aus dem zoologischen Museum zu Hamburg (Beiheft zum Jahrbuch der Hamburgischen Wissenschaftlichen Anstalten [2] ) 34:2, 6; text figure
1. (Definitive description.)

1917. Periculus capit is maculatus Fahrenholz, Fahrenholz, Mitteilungen aus dem zoologischen Museum zu Hamburg (Beihef't zum Jahrbuch der Hamburischen Wissenschatilichen Anstalten [2]) 34:2. (Records this form from Neproes in Dutch Gujana.)

1917. Pediculus humanus Linnaeus, Nuttall, Parasitology 10:1-79. (An extensive bililiom raphy is presented.)

1919. Pediculus assimilis Fahrenholz, Jahreslericht des Niedersächsischen 70olorischen Vereins zu Hannover 5-10:27. (New name for Pediculus oblongus, which was preoccupied.) 
1919. Pediculus mumanus limanus, Autull, Parisitulory 11:32y-315. (bye tematic position, symonym, and iconorraphy. All the speese ot

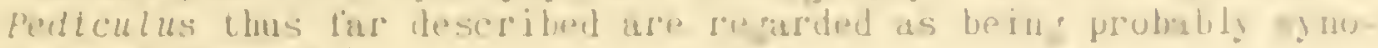
IIy us of tumaruss.)

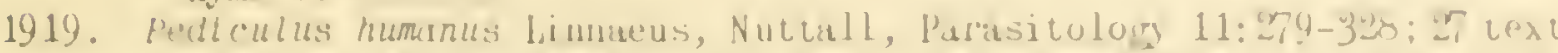
ligures; Plates 12-17. (kreoris of abrormalitios, to muter with consideration of hybridism between "car itis" ant "corforl " ant other evidence that they constitute hut races ot a sin le specifos.)

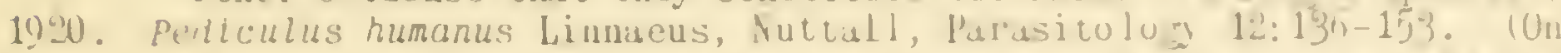
Fahrenhol ${ }^{\prime}$ purported new species, subspecies, and varielles of peticulus. A scuthing aml well-justitied criticism in which it is, huwever, erroneously concluded that all the nimed torms of pediculus belong to the sine species.)

19:-4. Pediculus capltis de Geer and pediculus lestimentl Nitusch, freund, Tierarztliches Archiv, Prat $4(A): 42$; text 1 i ruses 1-1. (Kसvives the idea of the specific listinctness ot head and hody lice and presents evidence intended to support this view.)

1936. Pediculus (periculus) humanus nieritarum fabricius, kwing, Proceedings of the United States Nationil Yuscum $6 x: 19: 16$; text 1igures $1 \mathrm{C}, 2,3 \mathrm{C}, 5,6$; Plate 2 , ligures 6, 7. (Revivell tor lice trom Neirroes.)

1996. Pediculus (Pediculus) hunanus angustus Fahrentoll, Ewing, Procedings of the United States National Yuseum 68:19:19. (hilile assunin: to identily this torm $\mathrm{Cn}$ the basis of two specinens, the author united with it periculus capitis marsinatus Fahrenholzand Pedirulus humanus chinensis Fiarentrolz.)

1926. Pediculus (Pediculus) humanus americanus Ewing, Proceedinis of the United States National Museum 68:19:20; text firures 1b, 2, 3B; Plate 3, figures 9, 10, 11. (Established for lice trom the heads ot' Peruvian mummies.)

1933. Pediculus humanus americanus Ewing, Beqraert, Carnerie Institution of Washington Publication Number 431, page 573 . (From Maya Indians, Yucatan and Guatemala.)

1936. Pediculus humanus anericanus Ewing, Proceedings of the Helminthological Society of Washington 3:36.

1939. Pediculus pseudohumanus Ewing, The Journal of Parasitolo 24:23; ii gures $5 i, 6 a$.

Review of the PEDICULl Ascribed to Man

The nomenclatorial history of Peticulus humanus begins with the tenth edition of Linnaeus" "Systema Naturae" in 1758. Here he named the species but save no indication of recornizing more than one form. In his "Fauna Suecica" of 1761 he indicated the head and hody infestin: forms as varieties and in the twelth edition of the "Sistema Naturae" they we re numbered as varieties 1 and 2 respectively.

In 1778, de Geer named these varieties as Pediculus humanus canitis and Pediculus humanus corporis. He need not go into the nomenclatorial problem as to which of these varicties should be called pediculus humanus humanus, in accordance with the present rules of nomenclature, other than to indicate that followin? the literature it appears that this name should le used for the head louse, while peficulus manans corporis should be used for the hody louse, if the distinction beiween them is to be recomized in nomenclature.

In 1S05. Fabricius naned a Feliculus nikritarum trom lesroes and it the form which seems actually to occur on leproes is to be recornized nomenclacorially it would appear that this name is availatile tor it.

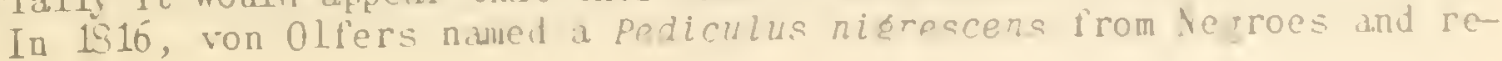


named the head and body lice as pubescens and albidior respectively.

In 1818, Nitzsch used the name capitis for the head louse and employed the name vestimenti for the body louse.

In 1824, Alt proposed the name Pediculus tabescentium for the body louse.

In 1880, Piaget named Pediculus consobrinus from a New Horld monkey of ghe tenus Ateles, this being, according to the evidence of the one specimen remaining in the Piaget collection, nothing more than Pediculus humanus.

Now the idea came to be generally accepted that the head louse and the body louse constitute two distinct species, these being referred to under various combinations of the names previously mentioned.

In 1911, Neumann concluded that these two forms can at the most be resarded as only subspecies and employed the names Pediculus capitis and Pediculus capitis vestimenti for them in complete disrerard of the accepted rules of nomenclature.

Fahrenholz, beginning in 1912, maintained the distinctness of the head louse and the body louse as species and began the process of supplying each presumed race of man with a subspecies or variety of each of them. He assumed to recognize Pediculus corporis nigritarum-on the basis of a single specimen-and named the varieties Pediculus capitis angustus and Pediculus corporis marginatus from Japanese. In 1916, he named Pediculus humanus chinensis from Chinese and added, also, the supposed species pediculus friedenthali and Pediculus oblongus, both from gibbons, and the species Pediculus lobatus from a New World monkey of the grenus Ateles. The name oblongus being preoccupied, he later altered it to assimilis.

During the first World War the recognition of the importance of the lice as the carriers of disease, most importantly typhus, led to a very large amount of study of them. Professor G. H. F. Nuttall rathered a large amount of material from various parts of the world and various races of man and came to the conclusion that the lice of man constitute at the most two unstable races of a single species. Work done by Bacot seemed to show that the head louse can be converted into the body louse experimentally, althourh he did not demonstrate the converse of this. His cxperiments are open to question in regard to the material that he employed, but he at least demonstrated that the two forms will interbreed successfully. Nuttall concluded that all records up to that time of supposedly distinct species of Pediculus on New World monkeys referred also to humanus, al though this conclusion can not now be supported. He vigorously-and from the point of vicw here held quite justifiably-criticized the work of Fahrenholz, although in some respects his conclusions were erroneous.

Freund, in a series of papers $(1924,1925,1927)$ maintained the distinctness of head and body lice as species.

In 1926, Ewing accepted the opinion that head and body lice of Europeans constitute a single species, but clung to the opinion that they represent subspecies. Although he was unable to accept Fahrenholz' assirament of three forms to Japanese and Chinese, he assumed to recognize one of these forms and also accepted the pediculus nigritarum of Fabricius for lice from Negroes. He then, for his own part, added a supposed subspecies, Pediculus humanus americanus, for lice from American Indians. In addition, he named two supposedly new species for lice from New World monkeys and accepted two

The result of all this naming stood at this time at about twelve names for the lice of man himself, two names for lice from gihhons, two names for lice of the chimpanzec-which are discussed elsewhere-and seven names for the lice of New World monkeys, which will be discussed elsewhere.

In 1935, Ferris reported upon his studies upon the larige collection of lice assombled by Professor Nuthill and material accumulated from other sources. He was able to exanine types or other authentic specimens of the forms named ly Fahrenhol\% and the type of Pediculus humanus americanus, 
namod by liwime, as well ats the sole reminniurs specimentrom the type lot ot

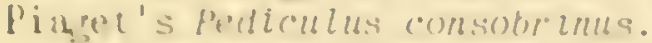

It mity as well he lrantly staled that his conclusions vere w a consid-

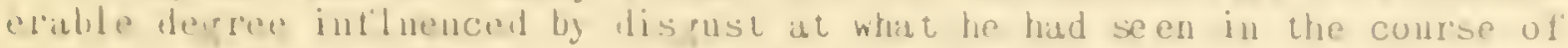
this worh and revoll inglinst the methuds that himb been empluyed in the syscematics of this group. It was clear that some forms had been aumed sulely npun diflionces in the method of preparation of specimens, upun supposed dillerences of the $n$ tinost triviality which had not been checked arainst a series of specimens to determine numal variation, and npon a philosophy of tixonomy which apparently alopted the concept that a species "is is specimen which looks difterent from other specimens." It is entirely possible that

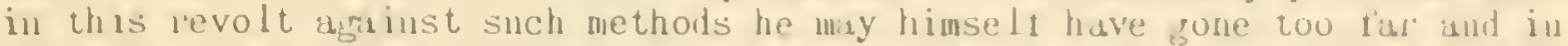
his turn made errors that arose trom too greal cunservatism, but he still holds that the revolt was sonnd in principle.

In 1936, Ening, in a paper dealing specifically with the dice of New horlat monkeys, exponnded the view that piaget must have had two species in his material of Pediculus consobrinus, one from monkeys and one from man. He recomized, however, that in selecting the sole remaining specimen from the Hich;et collection as type ferris had relegated this species to synonymy with pediculus humanus. In addition he named a nen species, pediculus pseudohumanus, which, while based upon lice from monkeys, also included specimens from American lndians. It will he discussed especially in connection wi th the lice of the Cebidae.

This, then, inbriet' is how the mitter of the lice of the genus Pediculus occurring on man stands at the present moment.

\section{The Problem of the PEDICULI of Man}

This problem has been recognized and argued about for nearly a hundred and lifty years, with still no satisfactory solntion. Ferris (1935) has presented the story in detail up to that date and it will here merely be abstructed.

As carly us 1761, Limnaeus, in his "Fauna Suecica, "recognized the existence of two torms of Periculus on man, these being the head louse and the hody louse. In 1878, de Geer applied names to these forms, calling then respectively pediculus humanus capitis and Pediculus humanus corporis. Under our now accepted rules of nomenclature one of these forms should have been called pediculus humanus humanus. Tracing the matter out it appears that the f'irst restriction, at least by implication, was by Latreille ahout 1805, in such a mamner that the name Pediculus humanus humanus should be applied to the body louse and humanus capitis he used tor the head louse, if the two f'orms are considered sufficiently distinct to be worthy of scientitic names.

Since our present rules of nomenclature were not well developed and not widely followed until almost 1900 , other names came to be applied to these lice. Thus, the names vestimenti, cervicalis, and tabescentium, as rell as both capitis and corporis were variously employed and the name vestimenti especially was much used for the hody louse. Also, the idea developed that the head louse and the body louse constitute tho distinct species and it was not until 1911 that this idea was challenged by Neumann. Since that time it has been both supported and attacked. Fahrenholz and Freund especially have supported the idea that two species are involved, while fiuttall and Ferris have maintained the opposing point ot view. It should here be emphasized that at the hottom ot this difference of opinion lies the fundamental question of "what do we mean by species?" So important is that question that a brief discussion of it and of 'the witer's point of view will be presented somewhat further alon:

Concurrently with the idea that two species are involved has gone also 
the idea that different forms occur on the different races of man. As early as 1805, Fabricius named a Pediculus nigritarum from Negroes and in 1816 von Olfers named a Pediculus nigrescens from the same source. In 1912, Fahrenholz not only maintained the distinctness of head and body lice as species, but apparently set out to provide every race of man with its own "variety" of" each of these species and this was added to by Ewing, who as Late as 1936 named Pediculus humanus americanus from American Indians.

Now, in the light of the evidence afforded by some other quite clear examples of the occurrence of two or more species of lice of the same venus on hosts of the same species, the possibility must be admitted that we may have to do with a similar situation in connection with the Pediculi of man. Thus, leaving out of consideration the extraordinary situation connected with the biting lice of the Order Hyracoidea, it appears that something of this sort occurs in the sucking lice of the Hyracoidea. Three clearly distinct species of the same genus of Anoplura occur on domestic sheep. Two clearly distinct species of the same renus occur on rodents of the genus Thryonomys. Apparently two quite distinct species of Haematopinus occur on zebras. So in the light of these considerations there is no a priori reason to assume that a parallel situation could not occur in the case of the lice of man. The question is merely as to whether or not it does.

It is a risky business for an entomolorist to become involved in anthropology without any personal basis of knowledge and in the face of the very considerable differences of opinion which exist among anthropologists. However, there are certain ideas which seem rather widely to be accepted. Thus it appears rather generally agreed that present-day Bomo sapiens falls into three broad groups which seem to be subspecies as that term is generally understood by mammaloyists. Furthermore, it is to be recalled that up to a relatively few thousand years ago there existed what is generally considered to have been a distinct specics of man, Homo neanderthalensis-if one can untanile the weird nomenclatorial practices of the anthropolorists-who must certainly have had contact with Bomo sapiens and whose females may very well have furnished sport and variety for the males of a conquering race. Some what parallel situations are not unknown today. It must also be recalled that there is evidence of other ancient forms of man regarded by some anthropologists as distinct species, which doubtless were to some degree contemporaneous with the ancestors of the living subspecies.

In fact, it appears that these three existing groups or subspecies, which display an apparently unlimited capacity for exchanging senes with unimpaired fertility to unnumbered generations, offer one of the best cxamples of the biological meaning of the word "species. "Relatively pure representatives of each of these groups exist and if considered by systematists working from a few preserved specimens would almost inevitably be regarded as belonging to distinct species. But there exist in the total population of man every conceivable degree of variation and evcry conceivable combination of the characters that mark these races as they presumably were constituted in their original state of nature.

Thus man, as he exists today, is a species within the formula which secms best to express the biological concept of that term as used in zoolo. That formula, as the writer has attempted to express it after a careful weishing of every word is this:

A species is a population, the members of which are parts of a continuously interlinked inenctic complex, which is scparated from other such complexes by barricrs or incompatibilitics of renctic oripin and which under natural conditions, that is, the conditions which have been concerned with cvolution, maintains itself' 'rom its own genetic resources.

An enormous experiment has been going on for many thousands of years, in which man has lieen the experimental animal. In the course of that experiment we may assume that certain mutants appeared from an original common 


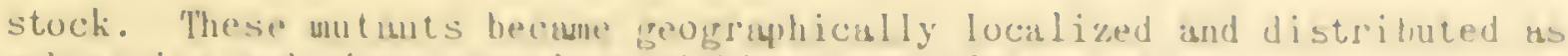
subspecies and minor fronpings within the population of mus.

Certain ol these minor ernetic groups, bein perhaps more ins ressive than others, spreat trom their original centers, and since no genetic barriers existed hetween them and the groups which they uverecume or with which they mingled, hybridization resulted and finally we have a world population in which all the mutations are mingled in every combination and to such in degree that the population as a whole is continuously genetically interLinked. Nor do the hybrid of tespring have to he renewed ly contiuued hybridiation in order to matutain themselves. In contrast to this we min cite the case of the domestic mule, which must continual! be re-estahlished hy renewed crossings and which otherwise camot maintinin itselt.

This would seem to he a reasonably objective stutement of the conditious which exist in the humin population of the earth ind of the basis tor considering man to coustitute a single species.

Now it would seem probable that something of this sort may ver'y well have happened in connection with the pediculi which have been the constiat companions of man and which have accompanied him in his original process ot diverying into sulspecies and his later reunification hy hybridization.

These Pediculi may very' well have begrun to develop into genetically differentiated forms upon the valious species of man, tor the past existence of which there is evidence, and the various subspecies that still exist. But as their hosts have intermingled with each other the opportunity for the intermingling of the parasites also has occurred. Thus we rould arrive at a condition anong the parasites which may rather closely parallel the condition found among their hosts. A population has resulted which conforms to the sune formula as does the host population. Here and there relatively pure populations of the parasites may exist. It is conceivable that certain forms may have inherited physiological as vell as morpholorical differences which would lead to some degree of segregation in the hybrids in accord with the degree of inheritance of these physiological characteristics. But the population as a whole presents a picture which closely parallels that presented by man himself.

It is the writer's belief, based upon an examination of many specimens of lice from different races of man and from various parts of the world, that the situation above described is that which actually exists in the population of Pediculus on man.

Material at hand from Negroes in Africa and South America would offer to a systematist working merely from a fen specimens a real basis for the beliet that a distinct species of Pediculus occurs on Negroes. Ten specimens of this torn compared with ten specimens of the characteristic "body lousc" of Europeans would almost inevitably lead to such a conclusion. These lice from Negroes are very darkly pigmented, their bodies are very compact, their length is scarcely more than one-half the length of the European body lice. However, other specimens present in a lot from Negroes in Africa show every degrce of gradation into normal head lice of Europeans.

And so with a comparison between normal "head lice" and normal "body lice" of Europeans. The body louse, in its most characteristic form, is much larger than the typical head louse, is paler in color and differs morphologically in the fact that the parateral plates ot the abdomen do not extend around the apex of their abdominal lobes into the intersegmental notch as is the case with the paratergal plates of typical head lice. But every deyree of variation amon: these forms exists.

There have heen available a wide range of specimens from Europeans, Eskimos, Hindus, Arabs, Negroes. American Indians, Chinese, and so on. From the point of view here adopted these constitute a single specics, within the detinition of the term explained above.

There remains the questions involved with the nomenclatorial procedure 
which should be followed in dealing with this material.

Within this material certain rather well-marked forms can be recognized and certainly some basis exists for the recognition of two or more groups that might be called subspecies, within the meaning of that term as employed by those who accept it on a biolouical basis. Actually, however, only a certain portion of this material will fall within these subspecies. The remainder consists of variants from the typical forms in such combinations that nothing more can be said of them than that they are Pediculus humanus.

Under these conditions and until the whole proulem can be submitted to examination by experimentation the opinion is here held that nothing whatsoever is to be gained by naming a series of "varieties" or subspecies. In fact, if this process is once started and carried to its lorical conclusion the number of named forms could be extended indefinitely. For example, a lot is at hand from natives of Rennell Island, one of the Solomon Is lands group, that could certainly be named as a new species if we were to employ criteria of the order of those used by Fahrenholz and Ewing. And when we have carried this process of naming to its ultimate limits, what have we gained? Nothing more than a series of names of' torms which can be recognized only if a perfectly typical example is at hand, which will be relatively seldom. When the needed experimental work has been done it may prove that some definite nomenclature can be supported, but there seems tc be no justification for complicating the nomenclatorial situation in advance of such work.

The employment of the name Pediculus humanus Linnaeus to cover this population as a whole, with the addition of the vernacular names head louse and body louse tor those forms when the occasion demands, would seem adequately to take care of the situation as it exists at present.

\section{Review of the Purported Species of PEDICULUS from Gibbons}

In the bibliography of Pediculus humanus there are included two names which have been wiven to lice reputed to have been taken from gibbons, which are Primates of the genus Hylobates. The two purported species are Pediculus assimilis Fahrenholz and Pediculus friedenthali Fahrenholz.

The writer has earlier seen specimens of the first-named of these, determined by Fahrenholz, which came from Bylobates syndactylus in the Zoological Garden at Berlin, but has not seen specimens of the second, which was described as from Bylobates mülleri without indication of locality.

The examination of specimens of assimilis and the description of friedenthal $i$ indicate no reason whatsoever for the recognition of these species as distinct from Pediculus humanus.

\section{Review of the Purported Species of PEDICULUS from New Horld Monkeys}

As will appear from the following discussion the question of the name to be used for the characteristic louse of the New World monkeys, which belong to the tamily Cebidae, is much confused. In the opinion here held there is but one species, apar from the at present very dulious question of Pediculus humanus Ewing, but if this be true what shall this species be cal led?

Actually, not until the matter has been subjected to an extended investigation involving an examination of a large mass of material, including the types-such as still exist-and an experimental genetic study of all the forns involved, will it he possible to arrive at a solution that may be generally sististinctory.

Leaving aside the name quadrumanus, for which no evidence of any sort is-or is likely to become-available, the first possible name is Pediculus 


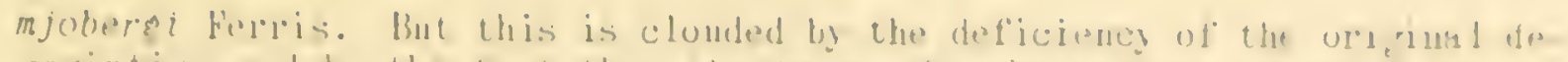
scription and hy the lase that the type-the wherrabere of which i un-

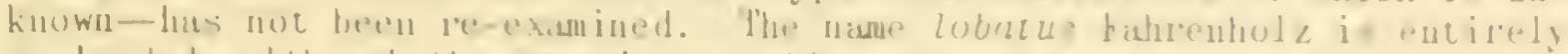

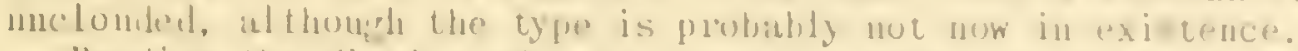

l'ending the linal sluely which must be made, the writer is inclinel to re-

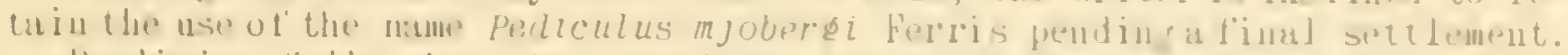

kenlizine loully that the questions concernin the species ol lice on the Now horlat monkeys involve minly dit'telenters of opinion and that tuture nor

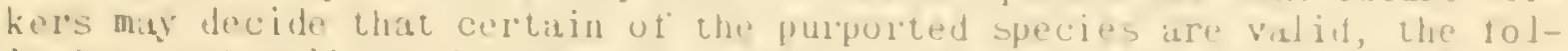
lowing review lists these numes and theil hiblion'iphies sepuntely in order to minimize tuture contusion as tal as mant be.

$$
\text { Peliculus atelophilus knin. }
$$

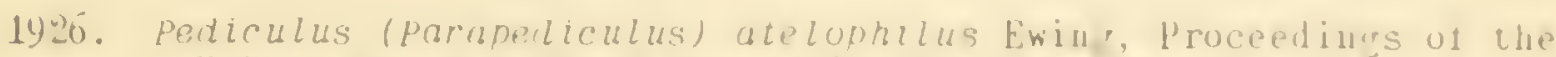
United States Nationil Yuseum 6r:19:9; $1 \mathrm{i}$ rures $4 \mathrm{~A}, 5$.

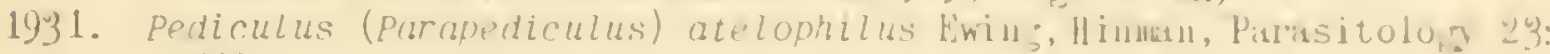
$48 \mathrm{~s}$.

1935. Pediculus mjöbergi ferris, ferris, Contributions Tuward a Monoraph

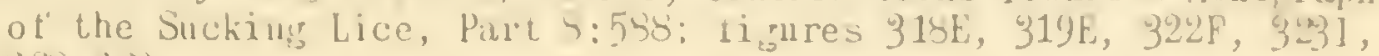
$3 x^{2}-3 x^{2}$.

1938. Perliculus atelophilus Ewing, Ewing, The Jourual of Piarusi lolory 24: 36 : 1'i rures 2, 50,66 .

HOSTS AND DISTRIBUTION. The type ot this species was recorded as from Ateles Eeoffroyi with unspeciflied type locality. Recorded at the same lime Irom stins of the sune host taken in Costa Rica. Recorded by Eking in 1939 trom Ateles pon from Guatemala; trom Ateles dariensis t'rom Panama; from Ateles hubridus from the National Zoological Park at hashington, D. C.

There is at hand a considerable amount of material undoultedly reterable to this name, including specimens trom the material recorded hy Hinman out ot a lot identitied by Ewing from Ateles Eeoffrolli in captivity and others trom this host in Panama: numerous specimens from Ateles dariensis, Cobus capuchinus, and Alouatto palliato, all from Panama f'rom monkeys in cuptivity; "ring-tailed monkey" trom the Bronx Zoological Park in New York.

NOTES. No basis appears in all this material for the recosnition of more than one species. It is here held that all these specimens are covered by pediculus lobatus Fahrenholz.

\section{Pediculus chapini Ewing}

1926. Pediculus (Paraneficulus) chanini Ewing, Proceedings of the linited States Vational Museum 68:19:13: 1'i:s. ¿, 4b, 万; Plate 1, figs. 3-4. 1935. Periculus mjöberह $i$ Ferris. Ferris, Contributions Toward a Monopraph of' the Sucking Lice, Part 8:588.

1935. Pediculus chapini Ewing, Ewiur, The Journal of Parasitolog 24:23; ii pures ta. $5 \mathrm{c}, 6 \mathrm{c}$.

HOSTS AND DISTRIBUTION. The types were recorded as from Ateles ater from the National Zoolopical Park at liashington. Specimens considered by Ewinis to be straplers were later recorded by him (1939) from Atfles geoffroyi trom the same place and from Cebus canuchinus irom Panama.

NOTES. Unfortunately the only specimens at hand trom the type host of this supposed species are immature. In the absence of authentic specimens it is not possible to assert that this species is identical with any other. although in the opinion here held it is the same as atelophilus.

\section{Pediculus lobatus Fahrenholz}

1916. Pediculus lobatus Fahrenholz. Archiv tûr laturgeschichte. Alteilun. 
A, 81:11: 16; Plate, figures 6, 7. (August)

1926. Pediculus (Parapediculus) lobatus Fahrenholz, Ewing, Proceedings of the United States National Museun 68:19:8; Plate 2, figure 5.

1935. Pediculus mjobergi Ferris, Ferris, Contributions Toward a Monosraph of the Sucking Lice, Part 8:588. 1938. Pediculus lobatus Fahrenholz, Ewing, The Journal of Parasitology 24:
29; Plate 2, figure 5.

HOSTS AND DISTRIBUTION. Recorded by Fahrenholz from Ateles rellerosus from the Berlin Zoological Gardens. Ewing (1938) identified with this specimens from Ateles paniscus from the National Zoological Park at Washington and recorded specimens which he considered to be straigulers from Leontocebus nigricollis at the same institution.

NOTES. The original description of this species is composed chiefly of useless detail which aids not at all in recognizing the species and the accompanying photomraphic illustrations do nothing more than indicate from the form that the species is probably of the type of those known from New World monkeys. Actually, comparing the illustration of the male given by Fahrenholz with that given by Mjöberg for his Pediculus affinis (=mjöbergi) there is no more basis for the identification of a species on the basis of one of these illustrations than of assuming it to represent some other species.

\section{Pediculus mjöberiri Ferris}

1910. Pediculus affinis Mjöberg, Arkiv för Zoologi 6:169, 258; text figures 85,151 ; Plate 5, figure 8. (Preoccupied)

1916. Pediculus mjöber $\$$ i Ferris, Proceedings of the California Academy of Sciences (Series 4) 6:136. (May)

1935. Pediculus mjöbergl Ferris, Ferris, Contributions Toward a Monograph of the Sucking Lice, Part 8:588.

HOSTS AND DISTRIBUTION. The types were recorded from Ateles sp. in a traveling menagerie. This constitutes the only positive record of the species.

NOTES. The name mjöbergi was proposed by Ferris to replace affinis of Mjoberg which was preoccupied by an earlier Pediculus affinis. A question might arise as to the priority of mjöbergi and lobatus, both of which were established in 1916. In 1913, Fahrenholz used the name lobatus without any accompanying description and the name was not nomenclatorially established until Aurust, 1916. Unfortunately, the name mjöber $i$ was established by publication in May, 1916, to replace the preoccupied name affinis of Mjoberg and therefore has priority in case any question arises in the future concerning these names.

If it be concluded that the lice of the New World monkeys represent but a single species it apparently should be called by the name mjöbergi.

Ewing (1936) has put forward the thesis that Mjöberg's description indicates his specimens to have been Pediculus humanus. Actually, Mjöberg's inconsequential description and the very poor accompanyini illustrations offer little or nothing to demonstrate anything, one way or another. The photograph of a male contains nothing more than a faint sugrestion, which can be magnified by a slight application of the imarination, into the characteristic louse of the New World monkeys. Ewing has maintained that Mjoberg's illustration of the egg indicates humanus, but in fact the drawing is erroneous even for that.

The writer will concede that until and muless Mjöberg's types are rediscovered the stitus of this nume will have to be held in abeyance, although on the hasis of a theory of probabilities it is used in this work to cover the nntire list of names employed for the lice of Cebidae except as is 


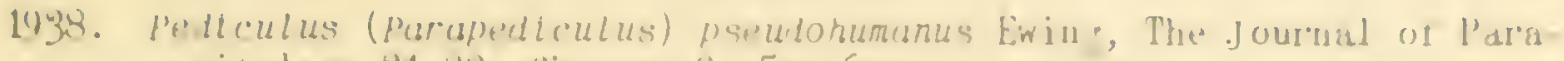
silolo:y 21:23); ri, rures 3, 5a, 6it.

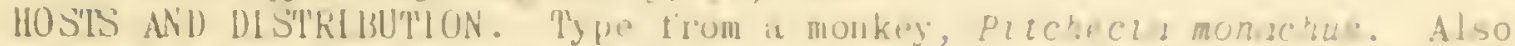

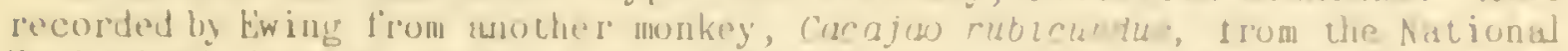
Loolorical Park at Washington. Also recorded by Ewing lroun an Indean at Coham, liututenalis.

NoTts. We have here a most extraordinary situatioll. The torm which Ewing described exists, without question, but its distrifution is extremely peculiar. Ferris (1935) mentioned the presence in his material of specimens trom Central dnerican lndians and trom nalives in the Yarquesas Istands in the south Pacilic which show a slight lateral lubin ol certain ul the paratergal plates. This is the torm that liwing ascribes to his prepurohumanus and the illustration here given, based upon a speeciment from the Marquesas Islands, almost duplicates that piven hy him. It may be nuted that the specimens from the south Pacilic all have a noticealily lar per mumber of setae on the dorsum of the abdomen than du those floun the vew horld.

The material at haud which appears to be covered by the name pseutohumonus is as follows: from natives at the villare of hakahitau, lapou, Marquesas 1slands; from natives at llitiad, Tuliti; tron Indian hut at Santa Emilia, Gualenala; from "dried head from Ecuador." specimens trom head of" Maya Indian, Xichel, Yucatan (f'rom a lot one time identified ly Exing as americanus), and others trom "natives," at Guayabilete, Panama, have the lobing of the paraterites of segments 5-6 even more strongly developed and approximating that to be seen in typical specimens of atelophilus.

Unfortunately, no specimens of this form are at hand from montieys, but since Ewing himself has recorded this supposed species from man, there should be no objections to the records given above.

The name pseurohumanus is here recognized to cover a torm which mas possibly le worthy of recognition.

\section{The Problem of the Lice of the Cebidac}

This problem has been reviewed by Ferris (1935) and by Ewing (1926, 1938 ), these authors coming to quite different conclusions. The general story is briefly this:

In 1577, Yurray ("Economic Entomolosy, Aptera," paye 3) described a Periculus quadrumanus which was suid to have been taken from a captive monkey of the genus Ateles. The species is entirely unrecognizable 1 rom the description and inquiry has led to the conclusion that if there ever were any types these are not now in existence. hhatever the possibilities may be there is certainly no justification for dispossessing any later name in tavor of quadrumanus.

In 1880, Piage ("Les Pediculines, "page 626: Plate 51. 1'i zure 4) described a Pediculus consobrinus taken trom ateles pentadcatmlus, Yuseum ot Leyden, whether trom a living or preserved animal not being indicated. No indication was given as to the number ot specimens examined, except for the statement that no male was observed. Ferris (1935) reported upon the single specimen from the Piaget Collection, which still exists at the British Yuseum, and illustrated this specimen. It is in his opinion definitely not separable from Periculus humanus. There is no reason to suppose that this specimen is not one of those which Piaret had betore him lut Exint. entirely on the basis of a comparison of the figures given by Piaget and ty Ferris, has offered the entirely gratilitous assumption that Piaget had two species in his material. Only some exercise of the imagination and a tirm will to believe in the results of that imagination could leat to such a 


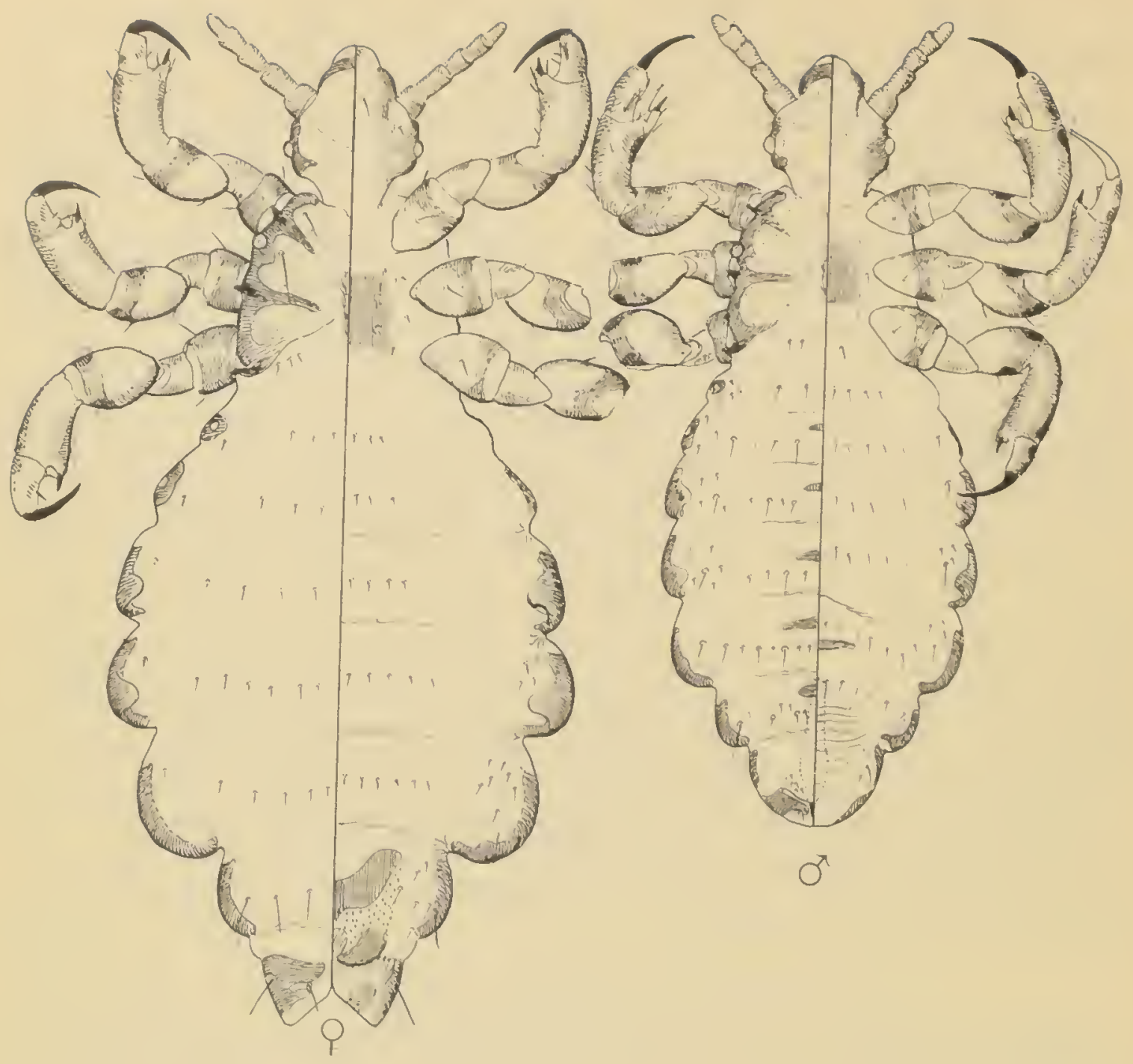

Pediculus mjöbergi Ferris, from Ateles dariensis

Figure 120

conclusion. The opinion is here maintained that we must accept the evidence from this one remaining specimen and place Pediculus consobrimus as a synonym of Periculus humanus. This is supported by the lact that other specimens of what scems undoubtedly to be humanus, ascribed to monkeys of this group, have been seen by the writer.

In 1910, Mjöhery described as Pediculus affinis a louse which was said to have been taken from some species of Ateles in a traveling menareric. The name affinis being preoccupicd it was later changed to mjöber $i$ by Ferris in 1916. Infortundely, the description viven hy Mjörer is useless and the illustration of the male given by him talls short of being actually decisive. Not until the types have been re-examined-it they exist-can the question of what this species actually is be definitely settled. Ferris (1935) was willing to accept the species, but Ewing (1939) considered the species to be humamus, partly on the lasis of an illustration of the egir
given by Mjober.

The next name availahle is pediculus lobatus fahe enholz (1916). The 


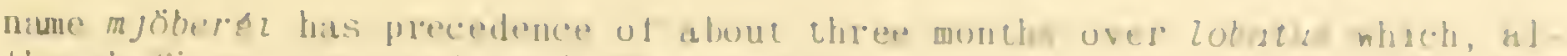

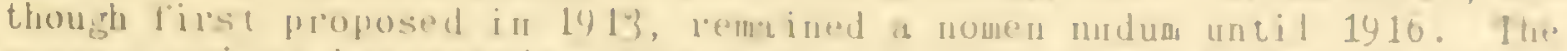
present writer has exumined the types of lobutus and illut trated them

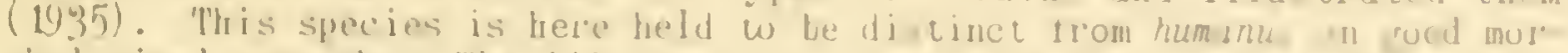
pholorical poumds. "lhe illustration eiven by ferris nas hased upon the moleated type specimen and represents that particulial specimen as well as possible.

II 19:6, freumd recorded specimens from ateles ater from the Leiphí Zoolorical (harden and employed tur them the nume peliculus capitis torma atelis. This is unreconizable troul the description.

In 1926, kwing presented an extensive paper on the New forld lice us the genus Pediculus (Proceedings of the United States Nationil Museun 6r, Article 19) in which he presumed to recornize Pedtrulua consolrinus piureq and Pediculus lobatus fahrenholz and ramed two new speeies, Pentlulus atelophilus and Pediculus chapinz trom New horld monkeys.

In 1935, Ferris (Contributious Toward a Monograph of the Sucking lice, Part 8) reviewed the whole question of the species of Ptilculus and cime to the conclusion that there is but one valid species on the family celidaeexclusive of occasional occurrences of what seems detinitely to be pedzculus humanus. For this species he employed the nume pediculus mjöber $i$ Ferris.

In 1938, Ewim (The Journal ot Parusitolog 24:13-33; Ijigures 1-6) presented another paper on the lice of the New Horld monkeys, maintinined the validity of the two species previously described by him and named another, pediculus pseurohumunus.

A considerable anount of material has been avalable in connection with the present work and on the basis of this material the writer still mintains the opinion that-apart from Pediculus humanus, which apparently can transter to and survive upon members of the Cebidae, and Pediculus pseudohumonus-there is but one actual species which seems to be normal to the New Horld monkeys of the family Cebidae. That species seems to be distinct from Periculus humonus.

\section{Pediculus schäl'ti Fahrenholz Figure 121}

1910. Pediculus schäfft Fahrenholz, Jahresbericht des Niedersächsischen zoologisclen Vereins zu Hannover 1:57: Plate 1, figres 1-3; Plate 3, figures 1. 2, 4, 5; Plate 4, figures 2, 6.

1915. Pediculus schïffi Fahrenholz, Fahrenholz, Archiv für Naturgeschichte, Abteilung A, S1:11:1.

1919. Pediculus humanus race schäffi Fahrenholz, Nuttall, Parasitolong 11: 336.

1932. Pediculus (Paenipediculus) simiae Ewing, Proceedings of the Biological Society of hashington 45:117.

1933. Pediculus (Paenipediculus) simiae Ewing, Ewing, Proceedings of the Biological Society of Hashington 46:168; 1"igure 2c.

1935. Periculus schäffi Fahrenholz, Ferris, Contributions Toward a Monograph of the Suckin: Lice, Part 8:599: 'tisures 3224, 333, 334.

HOSTS IND DISTRIBUTION. Recorded by Fahrenholz from chimpanzee, Pan (=Simia) troplodytes from the Zoological Gardens in Hamburg: and by Eving from the same host from the London Zoological Gardens.

N0TES. The accompanying illustrations, which are those given berris in 1035, were made from specimens which are apparently a part of the same lot on which Ewint hased his name simiae.

The upe ot achaffi was not seen by Ferris, but the description is suft'icient to indicate clearly that only one species is inrolved.

Ewing has based the subrenus Paenipeliculus upon this species. This is not here accepted. 


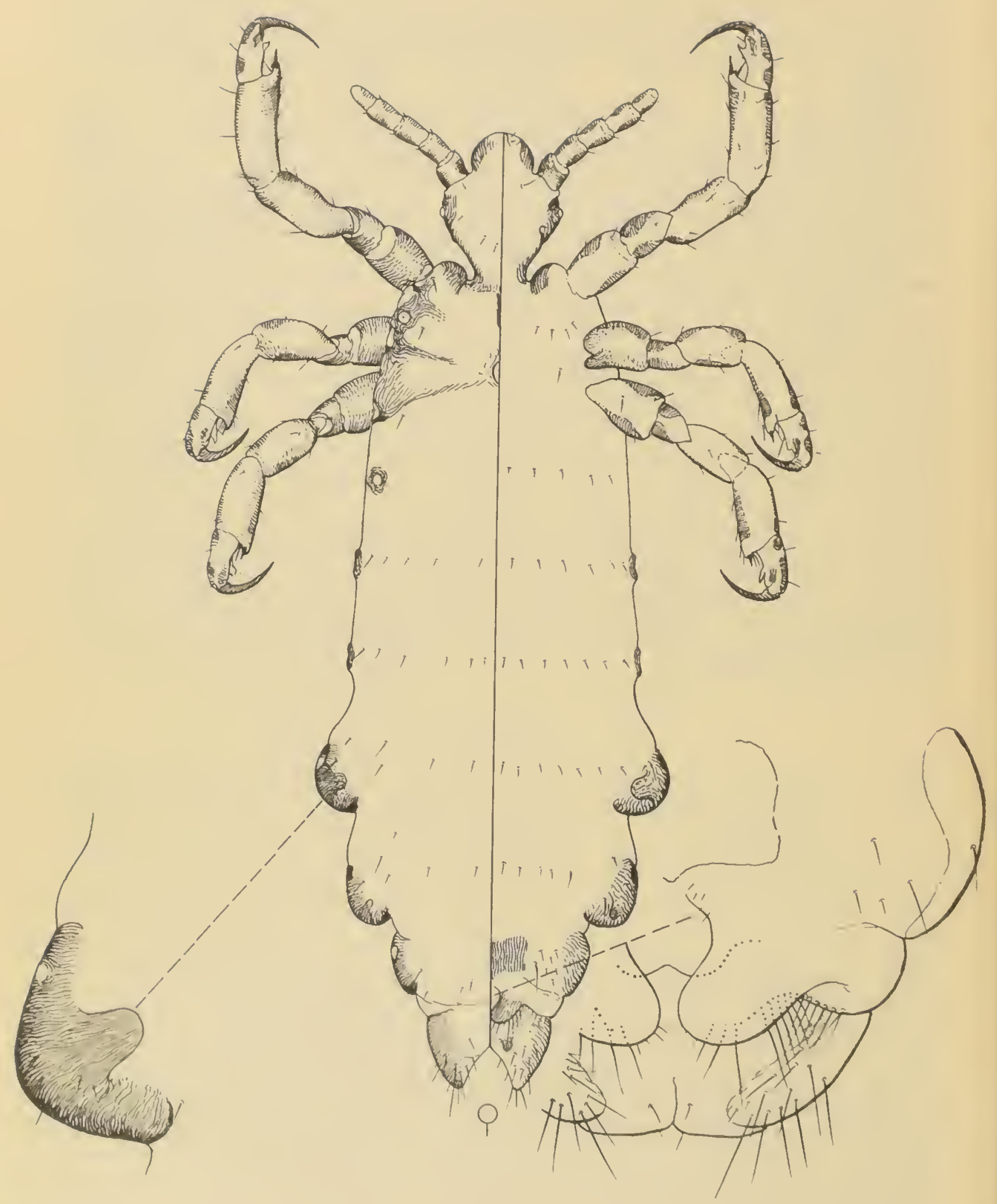

Pediculus schaffi Fahrenholz

Figure 121 
In the specesof perlculus occurring on man and on the hen horld monkeys of the tiunily Cobidae there appear a number of protlems which should be syproached l'rom a biological point of view and subritted to examination by the methods of experimental biolocy. It is evident that no sulution can be whieved merely hy the contemplution ot preserved specimens.

First of all there is the problem ot the lice of nan himselt. While this has been subnitted to a certain amount of experimental investigation those experiments are not entirely free from criticism and they are not sutliciently extensive to permit definite bioloricul conclusions. "Thus the experiunents of bacot seened to show that it is possible tu convert the head lice of man into torms havin' the appearance of lody lice, but the converse ol this experiment was not described. The experiments ut bacot shoned a complete hybridization of what he considered to be head lice with what he considered to be hody lice. But in the ot'spring ot these hyluridizations there appeared a large number of alnormalities that have been considered by Keilin and Nuttall (Parasitolouy 11:279-328; text tigrures 1-26; Plates 1217. 1919). Some occurrence of abmormalities seems to appear in "wild" populations, but that shown in this material is relatively large. Certaiu of the abnormalities are perhaps genetic. The suspicion occurs that these abnornalities nay have in part resulted t'rom the hybridization of genetically disharmonious individuals. Also, as the work wis done in Eupt there is a sugrestion that perhaps the supposed head louse employed represented a strain that is possibly farther removed from typical humanus than are typical head and hody lice from each other. Attention has been called to the existence on Atrican Negroes of a form which is so different from the typical head lice of' Europeans that if' specimens of both extremes were placed side by side the conclusion would almost inevitably be reached that we are dealin with difterent species. It is conceivable that Bacot had this extreme form actually in his possession and that the experiments on hybridization were in part based upon it. If so, these abnormalities might be explained on this basis.

Nuttall records experiments (Parasitolong 11:345. 1919) which led him to the conclusion that the two supposed subspecies, capitis and corporis, represent merely tro unstable races of a single species. He indicates that the head louse can be converted into the body louse by environmental conditions. But it remains to be shown that the changes of color and size recorded by him also extend to the apparent difterences in structure which are revealed by typical specimens of either race.

So it appears that this experimental work should be done argin, with proper precautions as to the status of all the material employed and proper attention to all changes that might be ascribed to changes in environment and proper consideration of all genetic factors that might be involved.

But this problem of the lice occurring normally on man is by no means all of the problem. There remains that of the lice of the Cebidae.

The Cebidae are supposed to be rather lar removed from the remainder of the Primates. Simpson (The Principles of Classification and a Classification of the Mammals, "Bulletin of the American Museum of Natural History," Volume 85, 1945) divides the Primates into three superfamilies-Ceboidea, Cercopithecoidea, and Hominoidea. There occurs on the Cercopithecoidea a yroup of lice, the genus pedicinus, which is far removed from the lice ot the Hominoidea. Why is it that the lice of the Ceboidea seem to be so closely related to those of the Hominoidea that they belong in the same genus? The Ceboidea are considered to be connected with the remainder of the Primates only at the base of the stem of the Order. Is it to le suggested that the members of the Ceboidea have retained the jenus fediculus from the time when the various stocks diverged, or is it to be supposed 
that they have received them from man in the time that man has been in the New World? How close are they grenetically to the lice of man?

And yet it is supposed that the lice of the Cebidae are sufficiently plastic in an evolutionary sense, to have formed at least four species, although at the best the characters assigned to those species are extremely unconvincing. What are the genetic relationships of these supposed species to each other? It certainly appears on morphological irrounds that the New World monkeys have upon them a species that can be easily distinguished from the lice of man, but even this is somewhat clouded.

And, to add the last bit to this tantalizing problem, what is the situation in regard to the supposed Pediculus subhumanus? Here is a form that is supposed to occur both on New World monkeys and upon man. More than that, it occurs not only upon man in the rerion where these monkeys occur naturally but what is apparently the same form occurs on man in the far distant South Sea Islands? What are the genetic relatiouships of the lice of this form in the New World to those on man in the New Horld and to those of the South Pacific?

These are problems for which the solution is to be obtained-if at allby experimental methods. Speculation on the basis of the present known specimens might easily lead the systematist to the endorsement of some idea that this form developed on man and monkeys after man appeared in the New World and then passed to the South Pacific following the mi ration of man from the New horld to that area, supporting the views of the author of KonTiki. It is futile to speculate upon such matters when all that is known of the lice is actually but a relatively few specimens.

The author holds that this is a problem which is eminently suited to an approach by experimental methods. Should some one gather together at one place representatives of typical head lice and body lice of Europeans, typical lice from African Negroes, lice of the type of Pediculus pseudohumanus from both man and monkeys from Central America and from the South Seas, and typical lice from a wide assortment of New Forld monkeys, subjecting them to careful genetic experiments, we might at last put an end to the otherwise endless ar pument concerning their relationships to each other. More than that, we might possibly have an answer that would apply to other cases involving parasitic insects and thus to a general biological problem.

Until that has been done the problems associated with the grenus Pediculus will remain for mere opinion and for speculation.

\section{Genus PTHIRUS Leach}

1815. Pthirus Leach, Edinburgh Encyclopaedia 9:77.

1817. Pthirus, Leach, Zoological Miscellany 3:36.5. 1935. Phthirus, Ferris, Contributions Toward a Monograph of the Sucking
Lice, Part $8: 602$.

GENERIC TYPE. Pediculus pubis Linnaeus.

CHARACTERS. Pediculidae with distinctly five-segmented antennae which are not sexually dimorphic. Anterior legs very slender, with slender claw; middle and posterior legs very large and stout, with stout claw; the coxae of all the leiss set at the extreme maring of the thorax and thus the members of corresponding pairs set far apart. Thorax very wide, forming the greater part of the body, without a sternal plate and without a notal pit, the sclerotization of the apparent notum confined to the lateral areas. Aldomen relatively small, as broad basally as the posterior part of the thorax and tapering somewhat posteriorly, membranous except for the projec-

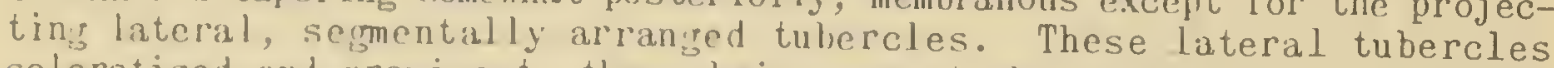
sclerotized and prominent, there heing one at the margin on each side of segments 6-8. Spiricles of these segments borne slightly removed from the base of tuhercles, those of segments 3-4 bein crowded close to those of 


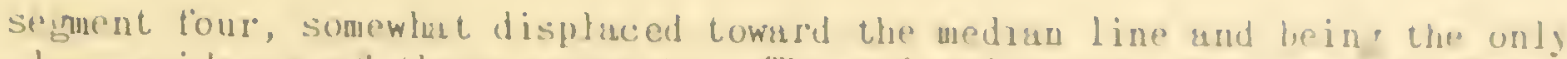
clear evidence of these segments. 'The spiracles are of' u peculiur lurm, the utrium being much enlanged, conical, with the base of the cone at the inmer end, the walls unirked by parallel, longitudinal ridges. Female with well-developed gonopods on segment eight and with a very latge spermatheca. Male with sumll, pointed parameres which articulate near their apices nith "L pair of small selerotized points; no endomeral plate present and no sclerotized penis, the gonopore being surrounded merely by a partiall! sclerotized ring.

NOTES. This genus was employed by Ewing (1929) as the type of the family Phthiridae, it being the only genus of this linily. Other workerstave recorrized it as the type of a subtiunily, Hhthirine, of the pediculidae. It is a peculiar torm, indeed, yet its relationship seems to he with pediculus and to place it in a separate tanily is to obscure this relationship. Its peculiar position is here recognized to the extent of accepting the sublamily Pthirinae of the Pediculidac.

\section{Pthirus pubis (Lintiseus) Figures 122, 123, 124}

1758. Pedlculus pubis Linnaeus, Systema Naturise, Edition X, pare 611.

1815. Pthirus ingulnalis Leach, Edintur th Encyclopaedia 9:77.

1816. Pediculus ferus von 0lfers, De vegetativis et animatis corporibus in corporibus animitis reperiundis commentarius, page 83. (Detinitely a synonym of Pthirus pubis (Linnaeus)

1904. Pthirus pubis (Linnaeus), Enderlein, Zoologischer Anzeiger 25:136; t'igures 10, 11.

19 18. Phthirus pubis (Linnaeus), Nuttall, Parasitolon 10:383: fipures 1, 3-5, 7-9.

1935. Phthirus pubis (Linnaeus), Ferris, Contributions Toward a Monograph of the Sucking Lice, Part 8:603; fi ures 335, 336, 337.

1935. Phthirus chaves $i$ Escomel and Velando, Cronicas de Medicina (Lima, Perı) 5: 335 .

1936. Phthirus pubis (Linnaeus), Bedford, Onderstepoort Journal of Veterinary Science and Animal Yedicine 7: 105.

1939. Phthirus pubis (Linniteus), Buxton, The Louse, page 93; figure 25.

HOSTS AND DISTRLBUTION. Occurring on man in many parts of the world. Bed tord (1935) has recorded it from a chimpanzee trom the French Congo. There have been occasional records of its occurrence on dogs, but no information exists that these are anything more than incidental.

NOTES. The original description of Phthirus chaves $i$ Escomel and Velando has not been scen in connection with this work, but the species was recorded as occurring in the evelorows of man and since this is well known for pubis there is no reason to suppose that any other species was involved.

The account by Buxton (1939) sums up what is known concerning the biology of the species.

\section{Pthirus gorillae Ewing}

1927. Phthirus sorillae Ewing, Proceedings of the Entomological Society of Washington $29: 120$.

1933. Phthirus gorillae Ewin: Ewing. Proceedings of the Biolopical Society of hashington $46: 170$; figures $1 \mathrm{c}, 2 \mathrm{~h}$.

1935. Phthirus gorillae Ening, Ferris, Contributions Toward a Monograph of the Sucking lice, Part 8:60s.

HOSTS AND DISTRIUUTION. Descrited from eass and first-stage nymphs taken from skins of Gorilla berengeri in the Belgian Congo.

NOTES. In the atsence of any intormation other than that siven try its 


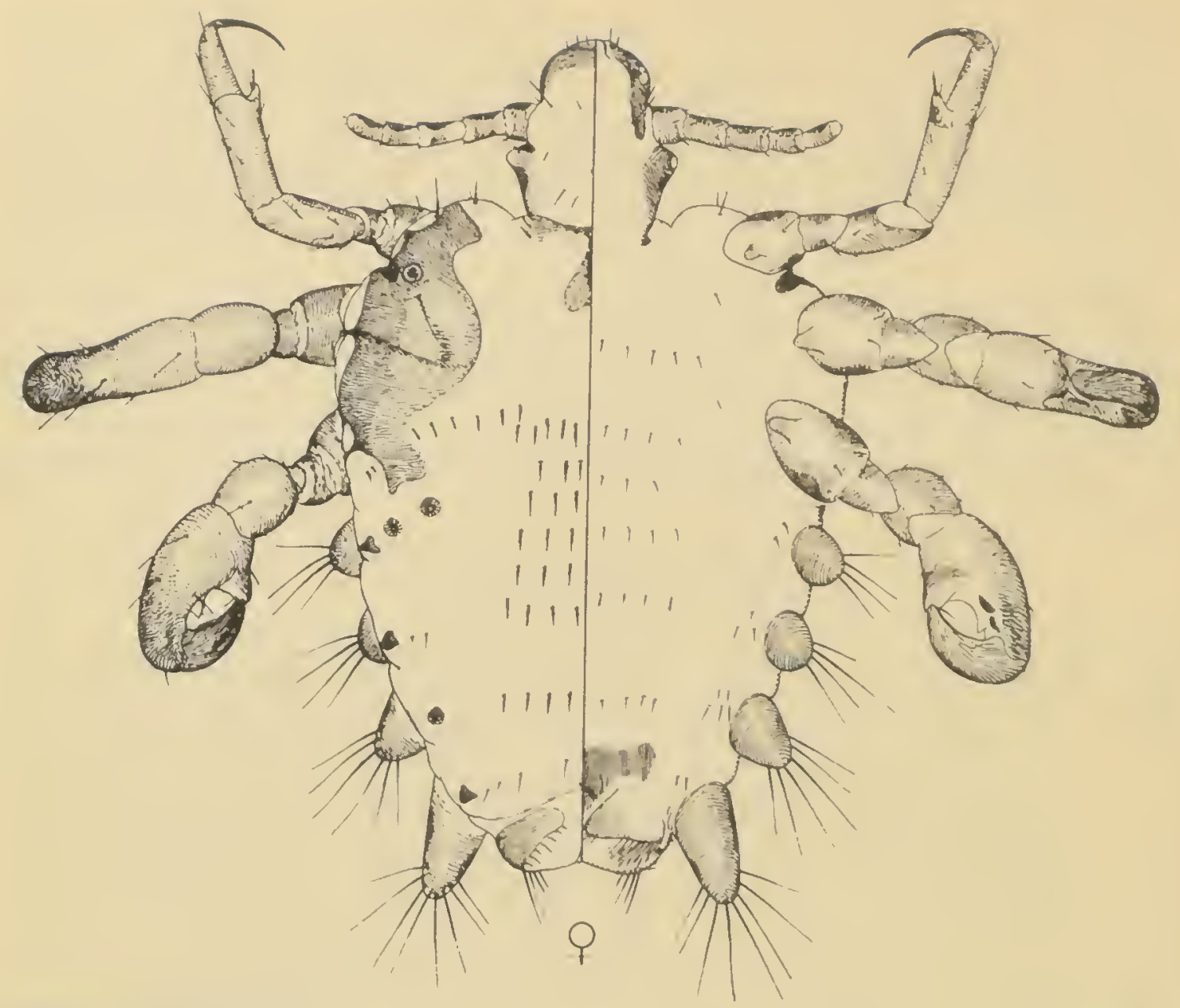

Pthirus pubis (Linnaeus)

Figure 122

descriler, nothing can be said concerning this species other than that it presumably demonstrates the occurrence of a species of Phthirus on a gorilla.

Unplaced Names

The following species names have been proposed, but the oripinal descriptions are unavilable or are so inadequate that the genera to which they belong cannot be determined. Perhaps future workers may be able to clarify them either through the rediscovery of their types or through circumstantial evidence.

\section{Pediculus aquaticus Pontoppidan}

1763. Periculus aquaticus Pontoppidan, Danske Atlas 1:699.

The original description of this species has not been available and I know nothing of it except a bibliographic reference by Fahrenholz.

\section{Pediculus clavicornis Nitzsch}

1864. Pediculus clavicornis Nitzsch, Zeitschrift f'úr die yesanten Naturwissenschaften 23:32.

1874. Haematopinus clavicornis (Nitzsch), fielel, Insecta Epizod, pare 37.

Perhips a species of Hoplopleura, it' we may judige by fiebel's redescription, which was tased upon a single temale from Meriones sp., trom Africa. 


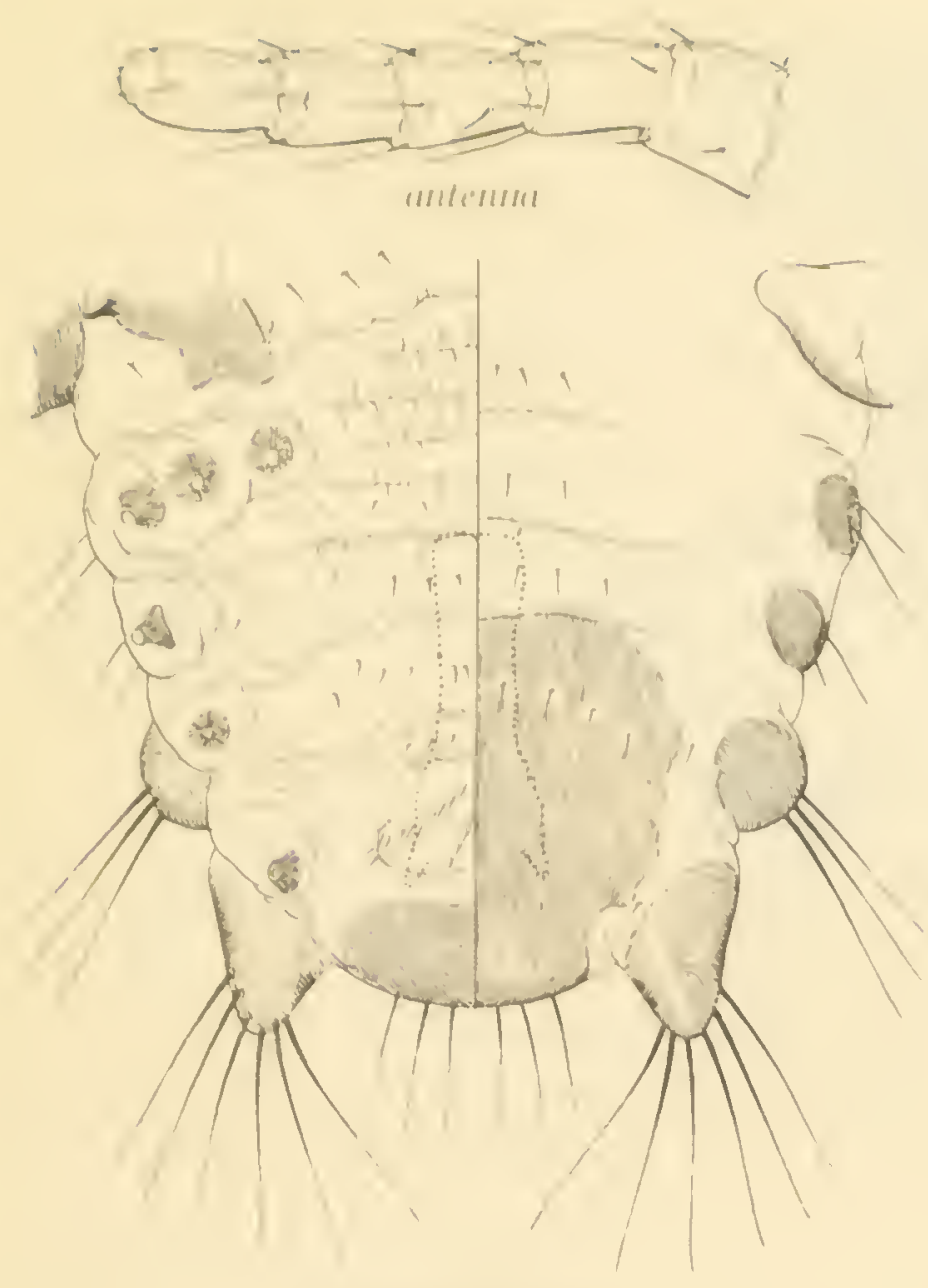

mule abdomen

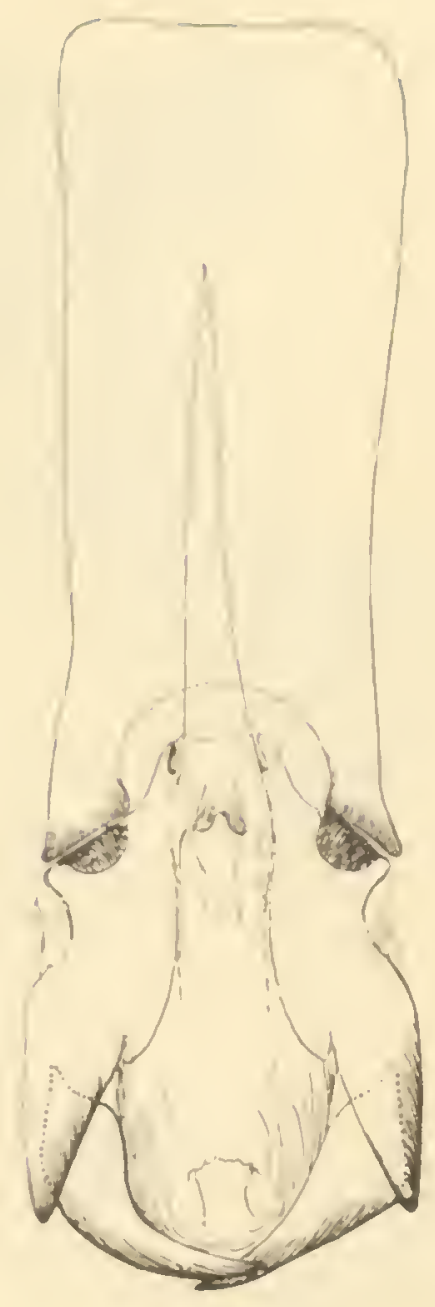

numle genilalia

Pthirus pubis (Linnaeus), details

Figure 123

Pediculus spiculiter Gervais

1544. Pediculus spiculifer Gervis, In halchenaer's Histoire naturelle des insectes apteres $3: 30 \%$.

This is apparently a species either of Polyplax or Hoplopleura. It was recurded as from "Yus barbarus" trom Algiers. This host is now called Lemilscomy burharus.

\section{Polyplax miacantha Speiser}

1905. Polypiax niacantha Speiser, Centralulatt tür Bateriolojie, Originale 3y:318. (The ficure does not helon: with this.)

1935. Polupiax mincantha speiser, Ferris, Contrilutions Toward a Monopraph of the sucking lice, Part 4: 237 .

Recordel as from a small rat with very thick, spine-like hair, from Silomona in llyssinia, in the collections of the Museum at honissher: in Prussia. The oritinal description is entirels inadequate for placin the species even gencrically, althou $\mathrm{g}$ it is probably either a Polyzax or a Hoplonleuri. 


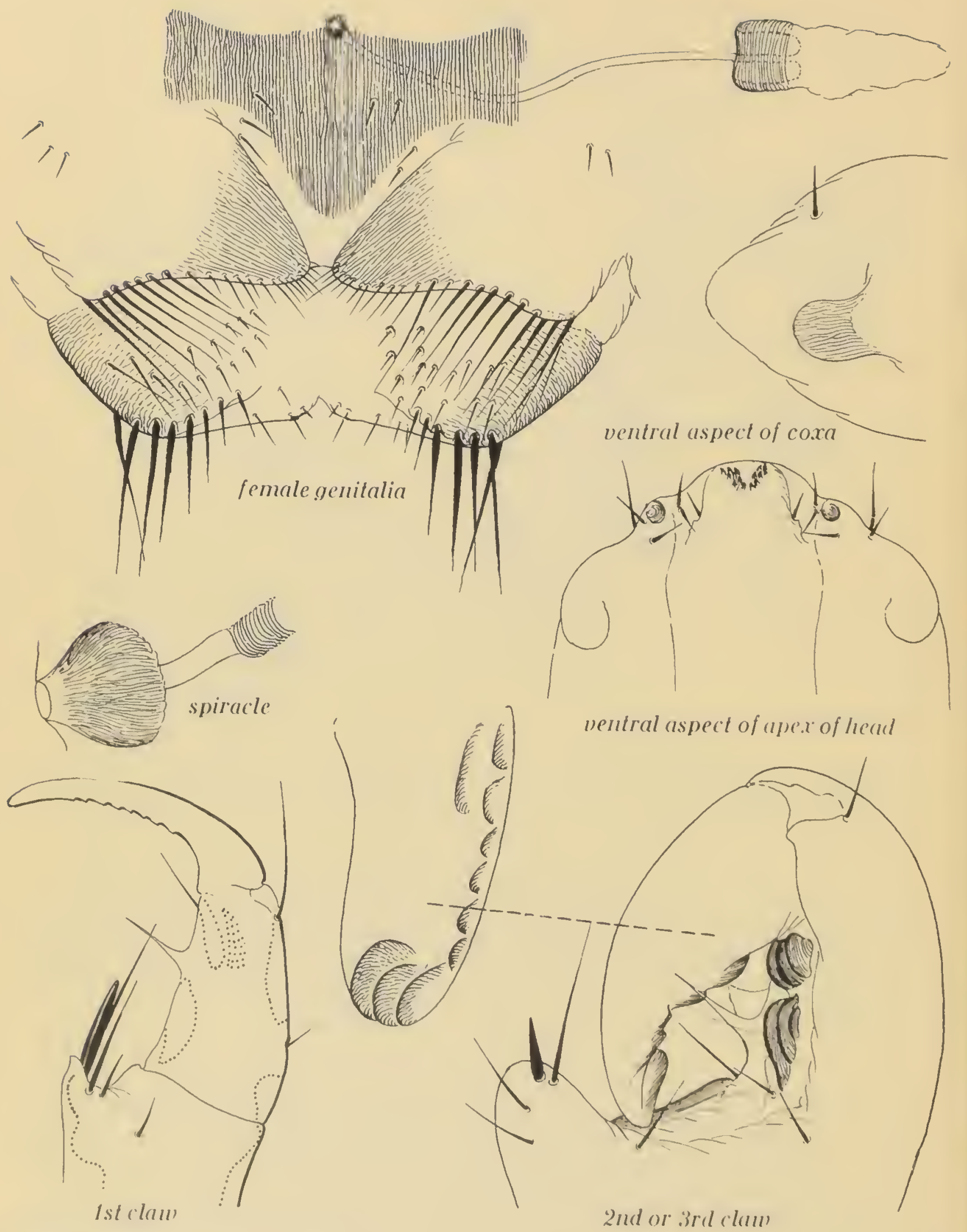

Pthirus pubis (Linnaeus), details

Figure 124 


\section{ERRATA}

The following references have been onitted from the preceding text:

$$
\text { Haematopinus asini (Linnaeus) }
$$

1865. Haematopinus equi Simnonds, Journal of the Koyal Agricultural Society of England (2) 1:60.

1880. Haematopinus astni, variety colorata Piagel, Les Pediculines, pare 654.

Schizophthirus pleurophaeus (Burmeister)

1874. Haematoplnus leucophaeus Giebel, Insecta Epizoa, page 37.

Haemodipsus lyriocephalus (Burme ister)

1864. Periculus lyriceps Nitzsch, Zeitschrift für den gesamten Naturwissenschaften 23:24. 


\section{CHAPTER VII}

\section{Host List}

The preparation of a dependable list of the mamal species from which Anoplura are known is not entirely a simple matter. In the first place, some of the hosts have been recorded merely by their vernacular names and these are not always sufficient to fix the record to a particular animal species. Then there have been a certain number of definite errors by the entomological recorders and there have been errors in the transcription of names from mammal specimens and also in regard to the identifications of mammals fron which Anoplura have been taken in zoological yardens where the mammals may have been misidentified. But the greatest source of difficulty arises from the fact that in many instances mammalogists themselves are not or have not been in agreement either as to the nomenclature or even the zoological status of the mammals.

Furthermore, there is no one master list of the mammals of the world which we may utilize as a source of reference. The catalogue of the mammals of the world, which was published many years ago by Trouessart, has lon been obsolete and nothing has been published that takes its place. He are therefore compelled to rely upon a series of lists, some regional, some applying only to the manmals of a limited proup, and where these lists overlap they are not always in ayreement either as to nomenclature or as to zoolorical status of some particular species. Under such circumstances an additional source of error is added, since the compiler of a host list, in pursuing names through these various lists of mamals, may himself go wrony and conmit errors of his own. All this should be understood by future students of the parasites.

In preparing the following list the following sources have especially been utilized.

First of all appreciation needs to be expressed of the work of Mr. G. H. E. Hopkins, who has published a host list of the Mallophaga and Anoplura of manmals. This was very carefully done and has aided rreatly in checking the records of the names which had already independently becn arranged in such a list for this work. Hopkins' paper is replete with notes, many of which are beyond the scope of the list here presented. The reference to his work is as follows.

HOPKINS, G. H. E. The host association of the lice of mammals. "Proceedings of the Zoological Society of London, "Volume 119, Part 2, pages $387-604,1949$.

Fortunately, a large percentage of the known species of the Anoplura occur on rodents and for this group we have available the great work of Ellerman which relatively simplifies the preparation of this portion of the host list.

ELLERMAY, J. R. "The Fanilies and Genera of Living Rodents." Three volumes. Published by the British Museum (Natural History). Volume 1, issued June, 1940; Volune 2, issued March, 1941; Volume 3, issued March, 1949.

For the so-called "Ungulates," the only work that the writer has been able to lind thit is at all comprehensive is that of Lydekter, in which, al though it is scarcely recent, one can at least find the names that have heen employed for most of the mammals of this serics, very lew havinis been described since its publication.

LYDEKKLK, R. "Catalogue of" the Ungulate Mammals in the British Museum (Natural II istory)." F'ive volumes. Published by the British Museum (Natural History). Volume 1, issued 1913; Volumes 2 and 3, issued 1914; Volumes 
4 und 5, issued 1915.

for the Primates the larige work of Elliot appears to he the only availahle generul relerence althongh the entire roup seems still to be in a contused comdition nomenclatorially. Thus, Simpson (1945, pare 181) remurks chat "most Primates have alternative names and hardy any two students use the sume numencluture tor them." Simpsou's work (cited below) has been employed tor the names of genera and larger groups and Elliot's tor the niunes of species.

Elli10'T, D. (i. A review of the Primates. "Monographs ot the Anerican Museum of Natural History," Volumes 1-3, 1913.

$0 t^{\circ}$ regional lists the most useful are the following. The first auned of these is 'specially important because of the lar'e number of mammal species involved.

ALLEN, (i. M. A checklist of Arricin uammals. "Bulletin of the Museum of Comparative Zoolougy at Harvard College, "Volume 83, 1939.

MILLER. G. S. "Catalogue ot" the Minumalsol" hestern Europe (Europe exclusive of Russia) in the Collections of the British Museum." Published by the British Museum. 1912.

MILLER, G. S. List of North American Land mamals in the United States National Muscum. "Bulletin of" the lnited States National Museum" 79, 1912.

For the ligher categories of the mamals the recent work lyy simpson is here relied upon.

SIMPSON, G. G. The principles of classitication and a classitication of the mamals. "Bulletin of the Anerican Museun of' Natural History" 85, (350 pauges) 1945.

For a ficw forms such as the Pinnipedia it has seemed necessary to accept all names as given by the recorders of the lice.

Since the hosts of all the comparatively few sucking lice known from South America are, with few exceptions, rodents, they are cared for in the work of Ellerman, as are also the rodents of Asia. The Carnivora, except for the Canidae and the Pinnipedia, have no sucking lice and the few names here needed cause no special difficulty. The Insectivora are cared for chiefly in the list of African mamals given by Allen and in various other regional lists.

Names of hosts are usually given in the review of species of lice in the text as given by the ori inal recorders of the lice, but the correct names - as far as they can be determined-will be found in the host list.

One other source of possible error in this list should be noted. This beyins with the collecting of the mammals. The wiriter has himself participated in such field collecting and is familiar with the problem involved. The collector of mamals is likely to obtain a considerable number of specimens and to pile them up on his work table before preparing the skins. As the animal becomes cold the parasites tend to come out to the ends of the hairs and from that position may cross over to other animals that may be in contact, thus leading to their ascription to the wrong host. Then the dried skins may be packed together in shipment, leading to the possibility that the dead lice may be shaken from one host to another and this may be followed by other possibilities of accident.

Many of the records of lice, especially from the rodents, have been based upon specimens secured by examination of museum skins. It is therefore probable that at least some of these records are erroneous. Not until repeated collections, or the finding of the parasites on freshly collected animals, have been made can this possibility be eliminated. On the other hand, merely to dismiss any peculiar record immediately as the result of such straplin; or contamination is probably also a mistake and is likely to produce a too great assurance that normal transfers never occur.

A small proportion of the records of lice from the larger nammals are based upon specimens tatien in zoolorical gardens. Some of these are espe- 
cially questionable, but they must be accepted until more positive information is available.

Considerable thought has been given to the question as to whether or not the host list should include subspecific mammalian names. The decision has been to ignore subspecific names and to present all mamnal names under the species names to which the subspecies are to be referred. The reasons for this action are as follows. In the first place, the writer knows of no instance where the subspecies make any difference in the distribution of the lice, except perhaps in the Hyracoidea. The whole subject of the lice of the Hyracoidea must be subjected to later review on the basis of much more extensive material of the lice than is available to anyone at present. In the second place, a listing of the mammalian subspecies would greatly extend the host list, to no special purpose. Mammalogists have been much enamored of the subspecies concept and have employed it to such a deyree that in the rodents, for example, most "full species" have at least five supposed subspecies, if not more. Peromyscus maniculatus is credited with forty-five subspecies. Since the Anoplura from Peromyscus seem not even to discriminate amon's species, it becomes, from the point of view here held, merely pretentious nonsense solemnly to list the parasites according to the subspecies of the host.

In the following list the arrangement of the higher categories of the mammals is in accord with that presented by Simpson, but the families, subfamilies, tribes, and genera are arranged alphabetically under the next higher category.

From the writer's point of view nothing is to be gained in such a list by attaching the names of the authors of mammalian names. They are therefore omitted.

\section{Class MAMALIA \\ Subclass THERIA \\ In traclass EUTHERTA \\ Order INSECTI VORA \\ Superfamily MACROSCELIDIDAE \\ Family Macroscelididae}

Elephantulus pulcher and rufescens

Neolinognathus praelautus Ferris

Elephantulus rupestris

Neolinognathus elephantuli Bedford

Nasilio brachyrhynchus

Neolinogmathus elephantuli Bedford

Petrodromus tetradactylus

Neolinognathus elephantuli Bedford

Superfamily SORICOIDEA

Family Soricidae

Subfamily Soricinae

Sorex araneus

Polyplax reclinata (Nitzsch)

Subfiamily Crocidurinac

Crocidura aranea (see Sorex)

Crocidura coerulea
Polyplax asiatica Ferris

Crocidura horsfieldi

Ancistroplax crocidurae Waterston

Crocidura leucodon

Polyplax reclinata (Nitzsch)

Pachyura luzonensis

Polyplax reclinata (Nitzsch)

Scutisorex congicus

Polyplax reclinata (Nitzsch)

Suncus coeruleus

Polyplax reclinata (Nitzsch)

Family Talpidae

Subtamily Scalopinae

Parascalops breweri

Haematopinoides squamosus (0shorn) Ṡcalopus aquaticus

Haematopinoides squamosus (0sborn)

Order DERMOPTERA Family Cynocepalidae

Cynocephalus sp. (=variegatus, according to Hopkins)

Hamophthirius paleopitheci Mjöber: Gialeopithecus $\mathrm{sp} \cdot=$ G.nocephalus 
Or.ler PRIMATES

subureler l'kUsigII

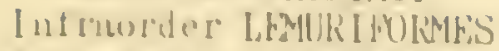

Supreliunily LRMIIRUIDHA

Finnily Indridite

Propithecus dialema

lhthipediculus plopitheci Ewing

propithecus edwards $\mathrm{i}=\mathrm{d} \mathrm{i}$ alema

Supertami ly TUPAIOIDEA

f'amily Tupatidae

Sultanily Tupaimae

Anathana ellioti

Docophthirus aciuetus Wilter'ston

\section{Intraorder LORISIFORMES \\ Fanily Lorisidae \\ Dulutanily Galarinae}

Che i romaleus sp.

Lemurphthirus verruculosus Ward

Galiugo demidovii

Lemurphthirus galitgus bedtord

Galaco moholi

Lemurphthirus galagnus Bediord

Galagusmisspelling of Galaso

Mouse lemur (=Cheirogaleus)

Suborder ANTHROPOIDEA

Sup e r fan i Iy CEBO IDEA

Fanily Cebidae

Subtauly Pi thecinae

Cacijo rubicundus

Pediculus subhunanus Ewing

Pithecis monacha

Pediculus pseudohumanus Ening

\section{Subfamily Alaouttinae}

Alouatta palliata

Pediculus mjöber

\section{Subtamily Cebinae}

Cebus capuchinus

Pediculus atelophilus Ewing

Pediculus chapini Ewin:

Subtamily A te linae

Ateles ater

Pediculus chapini Ewing

Ateles geoft royi

Pediculus atelophilus Ewing

Pediculus chapini Ewing
Aleles dirrieusis

Pediculus atelophilus kwin.

Ateles hybridus

Pediculus atelophilus kin'

Ateles pail

Pediculus a te lophilus Ehing

dieles paniscus

Pediculus lobatis Fabrentiolz.

Ateles vellerosus (recorded as rellerosus). This nume apparenty his been applied to ateles beelzebul and Ateles pron.

l'edicnlus lubatus f'alirenholiz lagothrix sp.

Pediculus pseudohumanus kwing

Sublimily Callithricidae

Leontocebus ni ricollis

l'ediculus loliatus Fahrenholz

\section{Superfamily CERCOPITHECOIDEA}

In speaking of this gronp Simpson (1945, page 185 and followinir) refers to the "confusion bequeathed to us by swarms of' students, of all de rrees of competence and shades of judgment," and further remarks "the macaques have been placed in at least twenty-five different yenera or subrenera, yet it is the present consensus that all belong to one genus with perhaps three subirenera, requiring a total of three names, only one of generic (and hence also subgeneric) rank." It is hopeless for an entomoloyist to try to untangle all of this. Consequently, records are cited as they were given, with such accompanying notes as are possible. There is always the possibility that in trying to do even this many new errors have been added. Also probauly many of the host names are misidentifications.

Cercopithecus aethiops (synonyms griseoviridis and pygerythraeus)

Pedicinus obtusus

Cercopi thecus albogularis=mitis

Cercopithecus cynomol ins-Macaca cynomolgus

Cercopithecus diana

Pedicinus obtusus

Cercopithecus griseoviridis=aethiops Cercopithecus kolbi=mitis

Cercopithecus martini=nictitans 
Cercopithecus mona

Pedicinus obtusus (Rudow)

Pedicinus euryaster (Burmeister)

Cercopi thecus mi tis

Pedicinus patas (Fahrenholz)

Cercopithecus patas=Ery throcebus patas

Cercopithecus pruinosus, apparently -Pyrathrix cristata

Cercopithecus pygerythraeus-aethiops

Comopithecus hamadryas

Pedicinus hamadryas Mjober

Cynocephalus=Papio

Cynomolinus=Macaca

Erythrocebus patas

Pedicinus patas (Fahrenholz)

Erythrocebus whitei

Pedicinus patas (Fahrenholz)

Guenon. Perhaps an Erythrocelus

Hamadryas, as a seneric name this appears to $=$ Comopi thecus

Innuus nemestrinus $=$ Macaca nemestrina

Innuus sinicus=Macaca sinica

Lasiopyga=Cercopithecus, under which grenus all names are listed.

Macaca. Frequently spelled Macacus. Includes Silenus and Rhesus.

Macaca adusta

Pedicinus eurysaster (Burmeister)

Pedicinus obtusus (Rudow)

Macaca albibarbata

Pedicinus eurygaster (Bumeister)

Macaca andamensis

Pedicinus obtusus (Rudow)

Macaca arctoides=speciosa

Macaca cynomoliga. Probably = Macaca fascicularis, although according to Elliot the name was long misapplied to Macaca ira.

Macaca ery thraea=rhesa

Macaca fascicularis, possibly, for records under the name Macacus cynomolisus.

Pedicinus eury yaster (Burmeister)

Macaca innuus, most probally Macaca sylvana.

Macaca ira, possibly for records under Macacus cynomolgus.

Pedicinus eury raster (Burmeister)

Macaca mindanensi=philippinensis

Macaca mindora

Pedicinus eurygaster (Burmeister)

Pedicinus ohtusus (kndow)

Macaca nemestrina, recorded as Innuus nemestrinus

Pedicinus obtusus (Kudow)

Macaca philippinensis

Pedicinus olitusus (Rndow)
Macaca rhesa

Pedicinus eury raster (Burmeister)

Pedicinus obtusus (Rudow)

Macaca silena. Apparently = Macaca albibarbata.

Macaca sinica

Pedicinus obtusus (Rudow)

Macaca speciosa

Pedicinus obtusus (Kudow)

Macaca sylvana

Pedicinus albidus (Rudow)

Papio. Includes Gyocephalus.

Papio sp.

Pedicinus obtusus (Rudow)

Papio griseipes

Pedicinus hamadryas Mjöber:

Pithecus=Macaca; all names attributed to it will be found under the latter, except as listed.

Pithecus patas. Is probably Erythrocelus patas.

Simia sylvanus=Yacaca sylvana

Subfamily Colotinae

Colobus caudatus=Colobus polykomos

Colobus polykomos

Pedicinus pictus Ferris

Pedicinus obtusus (Rudow)

Nasalis larvalis, error for larvatus.

Nasalis larvatus

Pedicinus obtusus (Rudow)

Presbytis. Includes all records under semnopithecus

Presbytis cristata

Pedicinus ancoratus Ferris

Presbytis entellus

Pedicinus obtusus (Rudow)

Presbytis germaini

Pedicinus ancoratus Ferris

Presbytis pullata. Rerarded by

Elliot as a subspecies of cristata

Presbytis rubicunda

Pedicinus ancoratus Ferris

Presbytis sanctorum

Pedicinus obtusus (Rudow)

Presbytis schistaceus

Pedicinus ancoratus Ferris

Pyrathrix aurata

Pedicimus obtusus (Rudow)

Pyrathrix priamus

Pedicinus ancoratus Ferris

Rhinopithecus concolor. Presumably is Simias concolor.

Simias concolor

Pedicinus curyguster (Burmeister)

Semnopithecus entellus. Here placed as =Preslytis entellus. 
S'mnopithecus manlus. Appiarently

- Presily tix ulliatis.

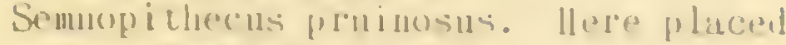

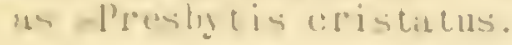

\section{Supereliamily HOMLNOLItA \\ finmily Ponsidae \\ subtumily Hylobutiuse}

Hy lubates syndicty lus

Pediculus humanus linnarms

Simpha langes symdic ty lus=lly lolates syoudacty'lus

\section{Subfamily Pontrince}

Gorilla bereniger i

Phthirus goril Lae Ewin:;

Pall sp.

Pediculus schiäti f'alrenhulz

Phthirus pulis (himueus)

fanily Hominidae

Hono sapiens

Pediculus hun:unns Linnaens

Pediculus sublumanus Eving

Phthirus pubis (Linnaeus)

Cohort GLIRES

Order LACOYORPHA

Family Leporidae

Lepus arcticus

Haemodipsus Lyriocephalus (Burmeister)

llacmodipsus setoni Ewing

Lepus californicus

Haemodipsus setoni Ewing

Lepus europaeus

Haemodipsus ly riocephalus (burmeister)

Lepus flacialis=arcticus

Lepus saxatilis Haemodipsus a tricanus Bedford

Lepus tomnsendi Haemodipsus setoni kwing

Lepus zuluensis=saratilis

Oryctola us cuniculus Haemod ipsus ventricosus (Denny)

Rabrit, domestic Haemodipsus ventricosus (Denñ)

Sylvilarus sp.

Haemodipsus setoni Ewing?

Family 0chotonidae

Ochotona cansus-thitutana

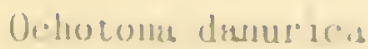

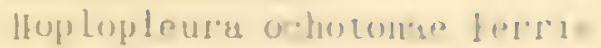

Ochutume ros lei

lloplopleura uclunguare ferre

U(h)tonis thile tintes

lioploplengis ocfotume ferros

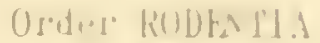

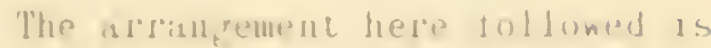
strictll accurdine Luthlemeth, except

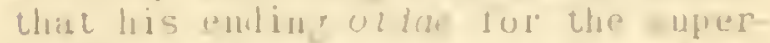

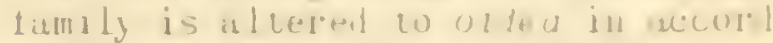
with more reserally accepted procticen

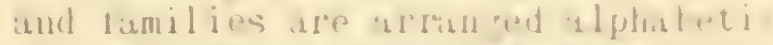
cally under supertamilios, subladuilies alplatretically maler latajlate, and renera alphabeticall! under sub Limilies.

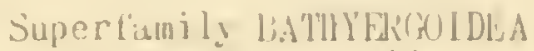
Fumily bialhy er riche

bithyer us miditimus

bulinomathus lawrensis (liedtiord)

Georhychus huttentotus=Crıptomys hottentotus

Cryptomys hottentotus

Eulinounathus hilli (bediord)

Supertamily HYSTKICOIDEA

Family Chinchill idae

Latgidium inca-pemanum

Lagidium peruanum!

Lagidiophthirus parvus (kello gir and Ferris)

Family Echimyidae

subtamily Abrocominae

Abrocoma cinearea

Neohaema topimus lon me herneck

Subfamily Echimyinae

Cercomys cunicularius

Ctenophthirus cercomidis Ferris

Cercomys sosteri=cunicularius

Procchimis cayennensis

Pterophthirus audax (Ferris)

Proechims oris=cayennens is

Proechimis semispinosus=carrennensis

\section{Subtamily 0ctodon inae}

Ctenomys brasiliensis

Eulinosnathus americanus trin; 
Ctenomys sericeus

Eulinomathus americanus Ewing

Octodontomys gliroides

Hoplopleura disgrega Ferris

0ctodontomys simousiogliroides

Subfamily Petromyinae

Petromus typicus

Scipio tripedata Ferris

Petromys=Petromus

Subfamily Thryonomyinae

Aulacodus-Thryonomys

Thryonomys aulacodus=swinderianus

Thryonomys gregor=gregorianus

Thryonomys gregorianus

Scipio longiceps Ewing

Proenderleinellus calva (Waterston)

Thryonomys swinderianus

Scipio aulacodi (Neumann)

Scipio breviceps Ferris

\section{Superfamily CAVIODEA \\ Family Caviidae}

Cavia apearea

Pterophthirus imitans Werneck

Caviella australis

Pterophthirus alatus (Ferris)

Galea leucoblephara=musteloides

Galea musteloides

Galeophthirus caviae (Werneck)

Kerodon australis apparently=

Caviella australis

\section{Superfamily SCIUROIDEA Family Sciuridae}

Ellerman recognizes no subfamilies in this family, but employs the terms "yroup" and "section." These are here arranired alphabetically.

\section{Pteromys group}

Glaucomys sabrinus

Hoplopleura trispinosa Kellogg and Ferris

Microphthir us uncinatus (Ferris)

Neohaematopinus sciurop teri

(Osborn)

Glaucomys volans

Hoplopleura trispinosa Kellorir and ferris

Neohiematopinus sciuropteri

(Osborn)
Petaurista batuana-petaurista

Petaurista inornata

Neohaematopinus petauristae Ferris

Petaurista petaurista

Neohaematopinus batuanae Ferris

Pteromys volans

Enderleinellus replicatus Redikorzey

Sciuropterus=Pteromys in part and Glaucomys in part.

\section{Sciurus group}

Lariscus section

Lariscus diversus=insignis

Lariscus insiynis Enderleinellus larisci Ferris Neohaematopinus sciurinus (Mjoberg)

Lariscus obscurus=insignis

Menetes berdmorei

Enderleinellus menetensis Ferris

Neohaematopinus sciurinus (Mjöberg)

Marmota section

Ammospermophilus sp.

Neohaematopinus patiki Kubin

Callospermophilus=Ci tellus

Citellus adocetus

Neohaematopinus traubi Rubin

Citellus barrowensis=parryi

Citellus beecheyi

Enderleinellus ostormi (Kellogip and Ferris)

Neohaematopinus laeviusculus (Grube)

Citellus beldingi

Enderleinellus suturalis (Osborn)

Neohaematopinus laeviusculus (Grube)

Citellus buckleyi=variegata

Citellus buxtoni=eversmanni

Citellus castanurus=lateralis

Citellus chrysodeirus=lateralis

Citellus columbianus

Neohaematopinus laeviusculi (Grube)

Citellus damricus

Enderleinellus suturalis (0sborn)

Citellus douglasii=beecheyi

Citellus elemans=richardsoni

Citellus eversmanni

Enderleinellus suturalis (Osborm)

Neohaematopinus laeviusculus (Grube) 
Citellus trumklinii

Finderleinellus sutural is (0shorn)

Neolnematopims laeviusculus (lilutie)

Citellus larrisi

Neohnematopinus citellinus ferris

Citellus manun mos=variegatus

Citellus lateralis

binderleinellus suturalis (0storn)

Aeohrematopinus lateviusculus (Grube)

Citellus leptodactylus, belongs to Spermophilopsis

Citellus madrensis

Enderleinellus occidental is Kellogg and Ferris

Citellus mexicanus

Enderleinellus suturalis (0sborn)

Citellus mollis=townsendi

Citellus mongolicus=dauricus

Enderle inellus sutural is (0storn)

Citellus nelsoni

Enderleinellus sutural is (0sborn)

Citellus oregonusabeldingi

Citellus os roodi

Enderleinellus suturalis (Osborn)

Neohrema topinus laeviusculus

(Grube)

Citellus parryi

Neohaema topinus laeviusculus (Grube)

Citellus plesius=parryi

Citellus richardsoni

Enderleinellus suturalis (Osborn)

Neohaema topinus Laeviusculus (Grube)

Citellus ruf'escens

Neohaematopinus Laeviusculus (Grube)

Citellus spilosoma

Enderleinellus suturalis (0storn)

Neohiematopinus citellinus Ferris

Neohaematopinus laeviusculus

(Grube)

Neohaematopinus marmotae Ferris

Citellus tereticaudus

Enderleinellus osborni kellog and Ferris

Vieohaematopinus citellinus Ferris

Citel lus townsend $i$

Enderleinellus suturalis (0sborn)

Citeilus tridecemlineatus

Enderleinellus suturalis (Osborn)

Neohaematop inus laeviusculus (Grube)

Citellus variegatus

Enderleinellus osborni kello and Ferris
Nevlatenat topinus mathesom Rubı

Q nomys gunnisoni

Enderleinellus sutural is (Ustrorn)

Ginomy's leucurus

Enderleinellus sucural is (Ostorm)

Aeohuematopinus laeviusculus

(Grube)

Qunomy's lucovicianus

Neohaenatopinus manotae Ferris

Marmotia aurea

?Neohaematopinus matulateris

Marmota thiviventer=flaviventris

Marmota thiviventris

Neohaematopinus misnotae f'erris

Marmota morrax

Finder-leinellus marmotize ferris

Paraxerus section

Indicated ly Ellerman merely as section D, without nume, lut for our purposes it may te listed as the paraxerus section.

Heliosciurus daucinus $=$ rambianus Heliosciurus gambiannc

Enderleinellus heliosciuri Ferris

Neohaematopinus keniae Ferris

Heliosciurus keniae= grambianus

Heliosciurus multicolor=irambianus

Heliosciurus palliatus = Paraxerus palliatus

Heliosciurus rufobrachiatus=yambianus Heliosciurus ruwenzorii

Enderleinellus heliosciuri (Ferris)

Neohaematopinus keniae Ferris

Heliosciurus undulatus=gambianus

Parasciurus=an error for Paraxerus

Parasciurus animosus Paraxerus

ochraceus

Paraxerus jacksoni=capitis

Paraxerus ochraceus

Werneckia minuta (Herneck)

Neohaematopinus heliosciuri

Cummings

Neohaematopinus suahelicus Ferris

Paraxerus palliatus

Neohaematopinus heliosciuri

Cummings

Neohaematopinus suahelicus Ferris

herneckia paraxeri (herneck)

Protoxerus stangeri

Enderleinellus heliosciuri Ferris

Sciurus section

Callosciurus henticanus=caniceps

Cillosciurus horneoensis=prevosti 
Callosciurus caniceps

Enderleinellus malaysianus Ferris Hoplopleura erismata Ferris Neohaematopinus sciurinus (Mjölerg) Callosciurus davison $i=$ caniceps

Callosciurus domelanus, misspelling tor domelicus caniceps

Callosciurus ferruyineus Hoplopleura erismata Ferris Neohaematopinus sciurinus (Mjöler ${ }^{\prime}$ )

Callosciurus tinlaysoni Neohaema topinus sciurinus (Mjölierug)

Callosciurus juvencus Neohaematopinus sciurinus (Mjöberir) Callosciurus lancavensis=caniceps

Callosciurus lucas=caniceps

Callosciurus maclellandi lioplopleura erismata Ferris

Callosciurus prevosti Enderleinellus malaysianus Ferris Neohaematopinus sciurinus (Mjöberip)

Callosciurus procerus Neohaematopinus sciurinus (Mjöberg)

Callosciurus vestitutus Hoplopleura distorta Ferris

Funambulus species (recorded as palmarum)

Hop Loplcura maniculata (Neumann) Neohaematopinus echinatus (Neumann)

Funambulus palmarum

Enderleinellus platyspicatus Ferris

Neohaenatopinus ceylonicus Ferris

Funambulus tristriatus (presumably= palmarum)

Hoplopleura maniculata (Neumann)

Microsciurus mimilus

Enderleinellus microsciuri Wemeck

Sciurus aberti

Enderleinellus longiceps Kellops and Ferris

Neohaematopinus sciurinus (Mjöberg)

Sciurus aes tuans

Neohaematopinus sciurinus (Mjóber

Sciurus alleni

Enderleinellus Loniceps Kellogrg and Ferris

Neohaematopinus sciurinus (Mjöber r্s)

Sciurus anomalus

Enderleinellus nitzschi (Burmeister)

Neohaematopinus syriacus Ferris

Sciurus apache.

Neohacmitopinus scimrinus (Mjöber

Sciums arizonensis

lloplopleura sciuricola Ferris

Scinrus aureopister

Enderleinellus extremus ferris

Neohaematolinus sciuriuus (Mjöber.r)

Sciurus bentincinus=Cialloscintus
Sciurus borneoensis=Callosciurus

Sciurus carolinensis

Enderleinellus longiceps Kellogg and Ferris

Hoplopleura sciuricola Ferris

Neohaematopinus sciurinus (Mjöberg)

Sciurus colliae

Enderleinellus mexicanus Werneck

Neohaematopinus sciurinus (Mjoberg)

Sciurus deppei

Enderleinellus extremus Ferris

Sciurus domelensis=Callosciurus

Sciurus dourlasi=Tamiasciurus

Sciurus fremonti=Tamiasciurus

Sciurus te rrugineus=Callosciurus

Sciurus gerrardi

Enderleinellus venezuelae Werneck

Hoplopleura sciuricola Ferris

Neohaematopinus sciurinus (Mjöberg)

Sci urus goldman $i=v a r i e g a$ toides

Sciurus griseoflavus

Enderleinellus extremus Ferris

Sciurus griseogena

Enderleinellus venezuelae Werneck

Hoplopleura sciuricola Ferris

Sciurus griseus

Enderleinellus kellogyi Ferris

Hoplopleura sciuricola Ferris

Neohaematopinus griseicolus Ferris

Sciurus ignitus

lloplopleura sciuricola Ferris

Sciurus kaibabensis

Enderleinellus longiceps Ferris

Sciurus lancavensis=Callosciurus

Sciurus lucas=Callosciurus

Sciurus melania=variegatoides

Sciurus meridensis=uriseogena

Sciurus nayaritensis

Enderleinellus longriceps Ferris

Sciurus negligens

Enderleincllus extremus Ferris

Sciurus nelsoni

Enderleinellus mexicanus Werneck

Sciurus nesaeus

Enderleinellus insularis Werneck

Hoplopleura sciuricola Ferris

Sciurus niger

Enderleincllus longiceps Kellogg and Ferris

Ncohaematopinus sciurinus (Mjöber.s)

Sciurus oculatus

Enderleincllus longiceps Kellogg and Ferris

Sciurus poliopus

Enderleinellus extremus Ferris

sciurus syriacus $\rightarrow$ anomalus

Sciurus truei

Enderleincllus mexicanus Werneck 
Seiulus variubilisimerratrili

ximps vill mutis

finderle inellus uitzschi

(lineme ister)

Neohumatopinus sciuri dincke

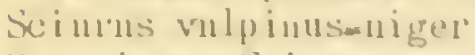

Urosciulusesciurus

Tim lits seclion
Teohnemiropinus sciurtus (Mjoter,

derus section

Atlintuxerus retulus

Aeohidatas copiuus pectiniter

( Ne(unn'inus)

Luxerus microrlon-derin er: thropus

lieosci urusalerus

Spermophilopis is leptoliacy lus

Neohumatopinus citelli (Cumnins)

Butanias is retinined by Éllerman solely for cerlain Asiatic species, while the North American formo common- Xerus ery thropus

ly refired to it are placed by him under the genus Tumias.

Scinrotiunias davidianus

Enclerleinellus sciurotiuniasis Ferris

Hoplopleura emarginata Ferris

Tamias alleni

Hoplopleura artoricola kellor and Ferris

Neohaematopinus pacil'icus Kellogig and Ferris

Tamias alpiutus

Neoharmatopinus pacificus Kellom and Ferris

Tan ias amoenus

Hoplopleura erratica (Osborn)

Tamias hindsi=townsendi

Tamias merriani

Hoplopleura arboricola kellors and Ferris

Tumias quidrivittatus

Hoplopleura arboricola kellog and Ferris

Veohaematopinus pacil'icus Kellorg and Ferris

Tamias speciosus=quadrivitutus

Tumias striatus

Enderleinellus tamiasis Fahrenholz Hoplopleura erratica (Osborn)

Tamias lownsendi

Hop Lopleura arhoricola kellog and Ferris

Veohaematopinus pacificus kelloger and Ferris

Tumiasciurus doujlasi

Enderleinellus nitzschi Fahrenholz Hoplopleura sciuricola Ferris

Neohaematopinus sciurinus (Yjöber ${ }_{b}$ )

Tamiasciurus íremonti

Enderleinellus nitzschi Fahrenholz

Tamiasciurus hudsonicus

Enderleinellus nitzschi Fahrenholz Hoplopleura sciuricola Ferris buderleinellus ruxeri Forris

Xerus illimr is

Neohacmatopinus faurei (liedtord)

Superfumily (iEOMIOLDEA

Fumily lle teromy idae

Dipodonys cal i lor.uicus-heermanni

Di podomys deserti

Fuhrenholzia piunista kellogg and Ferris

Dipodomys heermanui

Fahrenholzia pinnaza kellorg and Ferris

Vi podomys me rriami

Fahrenholzia pinnata Kellogir and Ferris

Dipodomys ordi

Fahrenholzia pinnata Kellogs and Ferris

Dipodomys ornatus

Fahrenholzia pinnata hellogs and Ferris

Dipodomys phillipsi

Fahrenholzia pinnata helloge and Ferris

Heteroms goldmanni

Fahrenholzia microcephala Ferris

Hete romys pictus-Liomys

Liomys irroratus

Fahrenholzia microcephala Ferris

Fahrenholzia microcephala Ferris

Liomys texensis irroratus

Yicrocipodops polionotus

Fahrenholzia pinnata kellos and Ferris

Pe rodipus-Dipodomys

Pero mathus californicus

Fahrenholzia tribulosa Ferris

Pero mathus lormosus

Fahrenholzia reducta Ferris

Peromiathus hispidus

Fahrenholzia zacatecae Ferris
Liomys pictus 
Perognathus parvus

Fahrenholzia pinnata Kellogrg and Ferris

Perognathus sp.

Fahrenholzia pinnata Ferris

\section{Superfamily PEDETOIDEA Family Pedetidae}

Pedetes cafer

Eulinognathus denticulatus Cummin Pedetes larvalis=surdaster

Pedetes surdaster

Eulinognathus denticulatus Cummings

\section{Superfamily DIPODOIDEA \\ Family Dipodoidea Subfamily Dipodinae}

Allactaga mongolica-sibirica

Allactaga sibirica

Eulinognathus aculeatus (Neurnann) Dipod ipus=Dipus

Dipus sp. Probably a species of Jaculus

Eulinognathus aculeatus (Neumann) Dipus sagitta

Eulinognathus biuncatus Ferris

\section{Superfamily MUROIDEA \\ Family Lophiomyidae}

Lophiomys ibeanus=imhausi

Lophiomys imhausi

Eulinognathus lophiomydis Ferris

Lophiomys thomasi=imhausi

Family Muridae

Subfamily Cricetinae

Ellerman remarks concerning this subfamily that the South American members are "an appalling chaos." Fortunately, from a nomenclatorial point of view, very few Anoplura are known from the South American species.

Akodon arenicola

Hoplopleura affinis (Burmeister)

Akodon arviculoides

Hoplopleura affinis (Burmeister)

Akodon aerosus

Hoplopleura aftinis (Burmeister)

Akodon aurosus=misspelling of aerosus

Akodon cursorarviculoides

Akodon mollis

Hoplopleura afl'in is (Burme ister)
Akodon pulcherrimus

Hoplopleura affinis (Burmeister)

Cricetulus andersoni=longicaudatus

Cricetulus incanus $=$ triton

Cricetulus lon ricaudatus

Polyplax dentaticornis Ewing

Cricetulus migratorius

Neohaematopinus citelli (Cuminis)

(Probably an error)

Eligmodontia collisae, misspelling of specific name=Hesperomys callosus

Euneomys pictus=Phyllotis pictus

Graomys priseoflavus

Hoplopleura affinis (Bumeister)

Hesperomys. In part=Peromyscus

Hesperomys callosus

Hoplopleura hesperomydis (Osborn)

Hesperomys venustus

Hoplopleura nesoryzomydis Ferris

Hodomys alleni

Neohaematopinus neotomae Ferris

Holochilus balnearum

Hoplopleura nesoryzomydis Ferris

Holochilus sciureus

Hop lopleura nesoryzomydis Ferris

Holochilus squamipes $=$ Nectomys squamipes

Holochilus vulpinus

Hoplopleura nesoryzomydis Ferris

Nectomys palmipes=Nectomy's squamipes

Nectomys squamipes

Hoplopleura quadridentata (Neumann)

Neotoma albigula

Neohaematopinus neotomae Ferris

Neotoma cinerea

Neohamatopinus inornatus Kellorig and Ferris

Neotoma fuscipes

Neohaematopinus neotomac Ferris

Neotoma micropus

Neohaematopinus neotomae Ferris

Neotoma streator $\mathrm{i}=$ fuscipes

Neotomodon allstoni

Polyplax auricularis Kellogig and Ferris

Nesory zomy s=0ryzomys

Nesoryzomys de fessus=0ry zomy s indefessus

Onychomys leucoyaster

Hoplopleura hesperomy dis (Osborn)

Polyplax auricularis Kellogg and Ferris

Onychomys torridus

Hoplopleura hesperomydis (Osborn)

Polyplax auricularis Kellogig and Ferris

Oryzomys angouya

lloplopleura nesoryzomydis Ferris 
Oryzoms s chupurensis

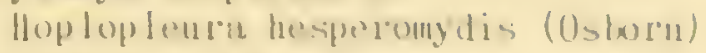

Oryzomy s of iturns

Hoploplentea atl in is (timme ister)

Oryzomys liturescens

Hoploplemar trilvissosi herenect

()1") Lomy s tulvesceus

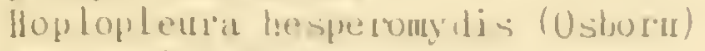

Ory zumys indel'essus

Hoploplentia nesuryzomydis fereris

0 lyzoms maborou hi

Hoplopleura nesoryzomydis ferris

0 ryzomys ratticeps

Hoploplenta quidridentuta (Neumirm)

Uryzomys rostratus

If oplop Leuria quadridentiata (Neumann)

0ryzomy's xantheolus

Hop lopleur'a nesoryzomydis terris

Peronyscus hoylei

lloplopleur'i hesperomydis (0sborm)

l'eromyscus calitornicus

Polyplax auricularis Kellogis and Ferris

Peromyscus leucopus

Hoplopleura hesperomydis (0sborn)

Peromyscus maniculatus

Hloplopleur'a hesperomy dis (Osborn)

Polyplax auricularis hellogg and Ferris

Peromyscus sitkensis

Polyplax auricularis Kellogy and Ferris

Pyyllotis arenarius Hoplopleura at'inis (Burmeister)

Phyllotis holiviensis Hoplopleura affinis (burme ister)

Phyllot is domo rum=Graomys riseot'lavis

Phyllotis micropus Hoplopleura aft'in is (Burmeister) Hop Lopleura reducta Ferris

Phyllotis pictus Hop lop leura affinis (Burmeister)

Phyllotis ricardulus Hoplopleura affin is (Burmeister)

Reithrodon cuniculoides lloploplenra at't'inis (Burmeister)

Reithrodon hatcheri=cuniculoides

Rei throdontonys mexicanus

Pólyplax auricularis hello: and Ferris

Rhi pidomy's leucodactylus Hop Lopleura an rulata Ferris

Rhipidomy's venezuelae Hoplopleura an rulata Ferris

Rhip idomys venustus Hoplopleura annlata Ferris Hoplopleura hirsuta Ferris
Simolon hispidu

lloplopleura hirsula ferris

si nomoidun ochro ruathus

Hop lopleuria hirsuta Ferris

si modon peruinns

Hop loplroug hirosuta fierris

Thuinisumys cillereus

nop lopleura an oulata herris

X'enomy's ne Loni

lloplopleurd hirsuta berris

Subfinily Dendromy inde

Dendromus mesome Las

Hoploplencis internedi hellog and ferlis

Subfiull! freplitlinae

Gerbillus indicatateris indica

Gerbillus pyramidun

Polyplux rerbilli Ferris

Meriones anceps=meridianus

Meriones meridianus

Polyplax chinensis ferris

lloplopleura merionidis Ferris

Meriones psammophilus=meridianus

Pachyuromys duprasi

Polyplax we rneri (Glinkiewicsz)

Tutera an rolae

Hoplopleura biseriata Ferris

Tatera boehmi

Hoplopleura veprecula Ferris

Tatera brantsi

Hoplopleura biseriata Ferris

lolyplax biseriata Ferris

Tatera indica

Polyplax stephensi (Christophers and Newstead)

Tatera joanae

Hop Lopleura biseriata Ferris

Tatera liodon

Polyplax taterae Bedford

Tatera lobengulae

Hoplopleuri biseriata Ferris

Polyplax biseriata Ferris

Tatera ni ricauda

Polyplax neumanni Fahrenholz

Tatera vicina

Polyplax taterae Ferris

Taterillus emini

Polyplax taterae Ferris

\section{Subfami ly Hydrom inae}

Chrotomys whitehead i

Hoplopleura chrotomydis Ferris

Hydromys chrysofister

Hop Lopleura bidentata (Neumann) 
Symoca brachyrrhynchus (Cummings)

Arvicola-Microtus in large part

Arvicola amphitius

Polyplax spinigger (Burmeister)

Clethrionomys rapperi

Hop lopleura acanthopus (Burmeister)

Clethrionomys nivarius Hoplopleura acanthopus (Burmeister)

Clethrionoris's rutocanus

Polyplax alaskensis Ewing

Clethrionomys rutilus

Hoplopleura edentulus Fahrenholz

Dicrostonyx torquatus

Hoplopleura acanthopus (Burmeister)

Larurus intermedius

Polyplax auscisa Fahrenholz

Lemmus alascensis

lloplopleura acanthopus (Burmeister)

Lemmus obensis

Hoplopleura hispida (Grube)

Microtus arrestis

Hoplopleura acanthopus (Burmeister)

Microtus arvalis

Hop lopleura acanthopus (Burmeister)

Microtus californicus

Polyplax abscisa Fahrenholz

Microtus constrictus $=$ californicus

Microtus mordax

Polyplax abscisa Fahrenholz

Microtus nival is

Hop lopleura acanthopus (Burmeister)

Microtus pennsylvanicus

Polyplax abscisa Fahrenholz

Microtus sp.

Polyplax alaskensis Ewing

Phaiomys blythei=leucurus

Phaiomys leucurus

Hoplopleura phaiomydis Ferris

Phenacomy's longicaudus

Polyplax spinulosa (Burmeister)

Pitymys pinetorum

Hoplopleura acan thopus (Burme ister)

Pitymy's savi $i$

Hoplop leura acanthopus (Burneister)

Pitymys subterraneus

Hop lopleura aequidentis Hahrenholz

\section{Subfamily Murinae}

Acomys cahirinus

Symoca brachyrrhyncha (Cummings)

Polyplax oxyrrhynchus Cummings

Aconty's hystrella

Polyplax oxyrrhycha Cummin's

Symoca brachyrrhyncha (Cummings)

Acomys percivali

Polyplax oxyrrhyncha Cumminirs

Acomys sp. (Probably)

Polyplax miacantha Speiser

Aethomys chrysophilus

Polyplax cummingsi Ferris

Apodemus arrarius

Polyplax affinis (Burmeister)

Apodemus insignis

Hoplopleura apomydis Ferris

Apodemus speciosus

Polyplax serrate (Burmeister)

Apodemus sylvaticus

Polyplax spinulosa (Burmeister) (questionable)

Polyplax serrate (Burmeister)

Hoplopleura affinis (Burmeister)

Apodemus bardus=insignis

Arvicanthis abyssinicus

Polyplax abyssinica Ferris

Arvicanthis niloticus

Polyplax abyssinica Ferris

Arvicanthis pumilio= Rhabdomys pumilio

Arvicanthis univittatusa Hybomys univittatus

Bandicota beniralensis

Polyplax spinulosa (Burmeister)

Bandicota malabarica

Polyplax asiatica Ferris

Cricetomys cosensi

Proenderleinellus calvus

(Waterston)

Cricetomy's emini

Proenderleinellus calvus

(Waterston)

Cricetomys gambianus

Proenderleinellus calvus (Waterston)

Dasymys incomtus

Hoplopleura oenomydis Ferris

Hoplopleura somereni Waterston

Polyplax cumminisi Ferris

Dasymys helukus $=i$ ncomtus

Epimysarat tus

Eropeplus canus

Polyplax eropepli Ewing

Grammiomys ibeanus

Polyplax phthisica Ferris

Grammomys surdaster

Hoplopleura oenomydis Ferris

Gunomy s=landicota

Hylomys univittatus

Hoplopleura laticeps Ferris

Lemniscomys barbarus

Hoplopleura enormis kellogg and Feris

Lemni scomys griselda

Hoplopleura enormis Kelloigr and 


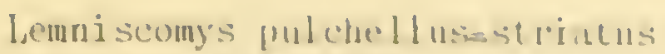

Lemuiscomys striatus Hoploplentra peloung lis fierer is

limmomy s me allus i

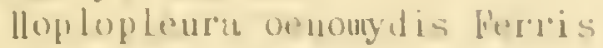

lophinromys sikapusi

Polyplat phthisica ferris

kphuromy's=squilus

Polyplax phthisica forris

Lophuromys zenta =aquilus

Mas tomy s=hiat tus

Micromys minutus

lloplopleura Longula fahrenholz

Polyplax yracilis Fuhienholz

Mus coucha=kattus coucha

Yus chry soph i Lus= de thomy's chrysophilus

Yus decumanus=Rattus decumaus

Mus gansus, errol for gansuensis= musculus

Mus minutusryicromy's inilutus

Mus musculus

Hoplopleura acarthopus (Burme ister)

Hoplopleura hespe romy is (Osborn)

Folyplax serrate (burme ister)

Hus spicilerus=musculus

Mus triton

llop Lopleura rukenyae Ferris

Yus wagneri=musculus

Mylony's cuninirhamei

Hoplopleura mylomydis Ferris

Mrlomys roosevelt $i=$ cuninghame $i$

Nesokia indica

Polyplax asiatica Ferris

Nesolia hardwickei=indica

Oenomys hypoxanthus

Hoplopleura oenomydis Ferris

Pelomys fallax

lloplopleura pelomydis Ferris

Praomys=Rat tus

Praomys namaquensis=Thallomys

Rattus calcis

Hop lopleura oenomydis Ferris

Polyplax spinulosa (Burmeister)

Rattus coucha

Hoplopleura intermedia Kellogs and Ferris

Polyplax praecisa (Neumann)

Eulinomathus denticulatus Cummings

Rattus culmorum

Polyplax spinulosa (Burmeister)

Rattus exulans

Hoplopleura oenomidis Ferris

Rattus hawi iensis

Hoplopleura oenomydis Ferris

Rattus migricaudus=Thallomys

Rat tus norvericus

Polyplax spinulosa (Burmeister) lloplopleuras oenom la remeis,

Eulinuertathus dentic-ulatu (Cinuni iu-s)

killus ratus

liat lus mbintus

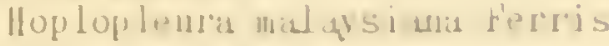

Polyplicx insulsid

Ratlus staideris

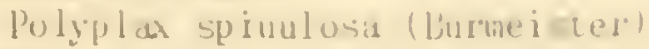

Kitlus sur ile!

hop Loplendia pectinatia (Cumminrs)

Rattus tull leer r

lloplopleura intermentia hellow and fierris

Polyplax naterstuni bedlord

killus voreilerins

lloplopleura ma lisy sinua fertis

lihubdoms pmuil io

Polyplax arviciuthis bedtord

Succostomus cumpestris

folyplax jonesi hellow and ferris

Thallomgs inoryi

Hoplopleura att'inis (Burmeister)

Polyplax spinulosa (Burme ister)

Thallomys namaquensis

Poliplax praomydis Bedford

Thallomys nipricauda

Hoplopleura at finis (Burmeister)

Thamnomy s=Grammomy's

Zelotomys hilde rardae

Hoplopleura intermedia kello ó and Ferris

Subfamily Otomy inac

Otomys angoniens is

Polyplax otomydis Cumnings

Otomys brantsi $i=$ Parotomys brants ii

Otomys irroratus

Polyplax otomydis Cumining

0tomys irroratus tropical is= tropicalis

Otomys tropicalis

Polyplax otomydis Cummints

Parotomys hrantsii

Polyplax otomydis Cummings

Family Muscardinidae

Subfamily Graphiurinae

Graphiurus alticola

Schizophthirus praphiuri Ferris

Graphiurus murinus

Schizophthirus raphiuri Ferris

Graphiurus nanus

Schizophthirus graphiuri Ferris

Graphiurus raptor=murinus 
Subfamily Muscardininae

Dryomys nitedula

Schizophthirus pleurophaeus

(Burmei ster)

Dryomys pallidus=nitedula

Eliomys pallidus=Dryomys nitedula

Eliomys quercinus

Schizoph thi rus pleurophaeus

(Burmeister)

Muscardinus avellanarius

Schizophthirus pleurophaeus

(Burmeister)

Cohort FERUNGULATA

Superorder FERAE

Order CARNI VORA

Suborder FISSIPEDA

Superfamily CANOIDEA

Family Canidae

Subfamily Caninae

Alopex lagopus

Linognathus setosus (von 0lfers)

(blue fox and arctic fox $=$ presumably Alopex lagopus)

Canis aureus

Linognathus setosus (von 0lfers)

Canis brasiliensi $s=$ Dusicyon

Linognathus taeniotrichus Werneck

Canis cupus, misprint for lupus

Canis lupus

Lino mathus setosus (von 0lfers)

Canis mesomelas

Linognathus setosus (von 01 fers)

Domestic dog

Linognathus setosus (von 01 fers)

Dusicyon fulvipes

Linognathus taeniotrichus Werneck

Dusicyon thous

Linogmathus taeniotrichus Werneck

Vulpes fulva

Linognathus setosus (von 0lfers)

Vulpes vulpes

Linognathus setosus (von 0lfers)

Suborder PINNIPEDIA

Family Odobenidae

0 dobenus obesus

Antarctophthirus trichechi

(Bohemann)

Odobenus rosmarus

Antarctophthirus trichechi

(Bohemann)

Family 0tariidae

Callorhinus alascanus
Antarctophthirus callorhini

(0sborm)

Proechinophthirius fluctus

(Ferris)

Eumetopias jubata

Antarctophthirus microchir

(Trouessart and Neumann)

Otaria hookeri

Antarctophthirus microchir

(Trouessart and Neumann)

Phocarctos $=0$ taria

Zalophus californianus

Antarctophthirus microchir

(Trouessart and Neumann)

Family Phocidae

Subfamily Phocinae

Greenland seal

Echinophthirius horridus (von 01 fers)

Halichoerus grypus

Echinophthirius horridus (von 0lfers)

Phoca foetidachispida

Phoca groenlandica

Echinophthirius horridus (von 0lfers)

Phoca hispida

Echinophthirius horridus (von 0lfers)

Phoca richardii

Echinophthirius horridus (von 0lfers)

Phoca sibirica

Echinophthirius horridus (von 0lfers)

Phoca variegata

Echinophthirius horridus (von 01 fers)

Phoca vitulina

Echinophthirius horridus (von 0lfers)

Subfamily Lobodontinae

Hydrurga leptonyx

Antarctophthirus ogmorhini

Enderlein

Leptonychotes weddelli

Antarctophthirus omorhini

Enderlein

Lobodon carcinophayus

Antarctoph thi rus lobodontis Enderlein

Ogmorhinus-Hy drurira

Ommatophoca rossi

Antarctophthirus mawsoni Harrison

Sublamily Cystophorinae

Cystophorus cristata

Ech inophthirius horridus (von 01 fers)

Macrorhinus-Mi rounga

Yi rounga leonina

Lepidophthirus macrorhini Enderlein 


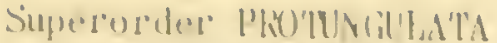

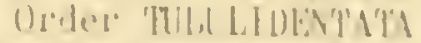

l'iunily Orycteropudilias

Oreceropus alem

ily hophthitor notophad lus (Neunume)

Ulycteropus cinpersis

ily hophthirus notophallus (Aeunkmu)

Orier HYRACOIDEA

family Procavi idae

There seems to be considerable disarreement concerming the species of this roup. They are listed here accordin: to hyducher, 1916, merely as a standard point of refereuce.

Procavia hounhioli=rut'iceps

Procavia lince $i=$ ruticens

Procavia capens is

Prolinornathus aethiopicus fahrenholz

Prolino thathus caviac-capensis (Pallas)

Procavia coomusi=capensis

Procavia natalensis=capensis

Procavia rutescens=misspelling for ruticeps

Procavia ruliceps

Prolino nathus toleyi Fahrenholz

Procavia shoana (properly sciona) $=$ hathessinica

Procavia habessinica

Prolinomathus aethiopicus Fahienholz

Prolinothathus arcuatus Fihrenholz

Heterohyrax syriacus

Prolinomathus leptocephalus (Ehrenter:s)

SuperordeI" YESATONIA Order PERISSODACTYLA Suborder HIPPOMORPHA Family Equidae

Equus asinus

Haematopinus asini (Lirnaeus)

Ratemia squamulata ( (leumann)

Equus burchelli

Haeratopinus acuticeps Ferris

laematopinus asini (Linnaens)

Ratenia squanulata (Jeumann)

Equus cahallus

Haemianinus as in (Linnaeus
Superomiler PALACNOTA

Oriker Alíl]OB)AC' H, A

Sulurder slifUR'Mt

Intraorier S I.A A

fiunils suidare

subtumily Suillae

Koiropotinus chueroprotanus app arent1y-Pucomochoerus choeropotamus

Phacochorrus ael iallimathiopicus

Phicochoerus atechiopicus

Huematopinus phrocochoeri Enderlein

Phacochuerus sundevali iarethiopicus

Potanochoerus allinis (unable to trace)

llaenktopinus Litus Teuman

p'o tamochoerus ntricallus-larvitus

Potiunochoerus choeropotanus

Haema topinus latus Neumann

Sus cristilus

liaema topinus suis (Linnaeus)

Sus scrotu

liaematopinus apri foureau

Sus vittatus

Haematopinus suis (Linnacus)

Domestic swine

Hacma topinus suis (Linnaeus)

Fanily Tayassuidae

Subtamily Tayassuinae

Dicotyles-Tayassu

Pecari=Tayassu

Pecari javalii=Tayassu an rulatus

Tajassu javalii

Pecaroecus javalii babock and Ewin:

\section{Infraorder OREODONTA Suborder TILOPODA Family Camelidae}

Auchenia-Lama

Auchenia lama=Lama slama

Camelus dromedarius

Haematopinus tuherculatus

(Burmeister)

Yicrothoracius cameli (Linnaens)

Lama lama

Yicrothoracius mazzai hemech

Yicrothoracius minor hernech

'licrothoracius praelon-iceps

(Veuminn)

Lima huinaca $=$ lama

Lama pacos $=$ liama 
Suborder RUMINANTIA

Infraorder PECORA

Superfamily CERVOIDEA

Fanily Cervidae

Subtamily Cervinae

Cervus elaphus

Solenopotes burneisteri Fahrenholz

Cervus nippon

unnamed species of Solenopotes

Cervus unicolor

Haematopinus longus Neumann

Subfamily Muntiacinae

Muntiacus muntjak

Solenopotes muntiacus Thompson

Subfamily odocoileinae

Capreolus capreolus

Solenopotes capreoli Freund

Coassus-Mazana

Mazama rondoni

Solenopotes binipilosus

(Fahrenholz)

Mazama simplicicornis

Solenopotes binipilosus

(Fahrenholz)

Odocoileus chiriquiensis=rothschildi

Odocoileus columbianus

Solenopotes f'errisi (Fahrenholz)

Odocoileus couesi

Solenopotes binipilosus

(Fahrenholz)

Odocoileus hemionis

jolenopotes ferrisi (Fahrenholz)

Rangifer tarandus

Solenopotes tarandi (Mjölerg)

Superfamily GIRAFFOIDEA

Family Giratfidae

Giraffa camelopardalis

Linognathus brevicornis (Giebel)

Superfamily BOVOIDEA

Family Bovidae

Subtamily Antilopinae

Tribe Antilopini

Acpyceros melampus

Lino mathus aepyceros Bedford

Antidorcas marsupialis

Linogmathus bedfordi Ferris

Linormathus tibialis (Piaret)

Antilope cervicapri.

Linornathus cervicuprue (lucas)

linoinathus pitholes Cummings
Antilope euchore-Antidorcas marsupialis

Antilope maori (as recorded by Piaret. The name does not appear in available lists).

Linognathus tibialis (Piaget)

Antilope subgutturosa

Linognathus tibialis (Piaget)

"Antilope"

Linogmathus tilialis (Piaget)

"Antilope, North African"

Linognathus petasata Ferris

Gazella (possibly either a misidenti-

fication or owing to straggling)

Linoirnathus gazella Mjöberg

Gazella thomsoni

Linognathus lewisi Bedford

Oreotragus saltator-oreotraigus

Oreotragus oreotragus

Linornathus africanus Kellogg and Paine

Raphicerus campestris

Linognathus tibilais (Piaget)

\section{Tribe Bovini}

Bison americanus=bison

Bison bison

Haematopinus tuberculatus

(Burmeister)

Bos grunniens

Haematopinus tuberculatus

(Burmeister)

Bos indicus

Haematopinus eurysternus (Nitzsch)

Bos taurus

Haematopinus eurysternus (Nitzsch)

Linognathus vituli (Linnaeus)

Solenopotes capillatus Enderlein

Bubalus bubalis

Haematopinus tuberculatus

(Burmeister)

Syncerus cafer

Haematopinus bufali (de Geer)

Tribe Strepsicerotini

According to Simpson the generic nane strepsiceros antedates Tragelaphus and Limnotragus should be reparded as a subienus of the former. There seens to le some question here, however, and the latter names are retained tor this list.

Also, there seems to be confusion concerninir Boselaphus. The name has lieen used tor Taurotraşus, but seems to apply to an entirely different animil. 


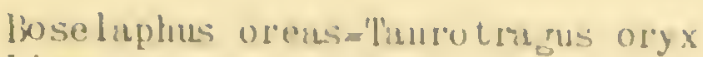

li imuotragus grat tus

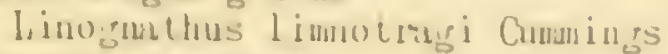

Ristrotritgus oryx

Hnematopinns tisurotrigi Chmmings

Lino grathus titurotmergs bed tored

Trifireluphrs scriptus

Lino mathus l'uctus Ferris

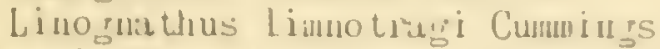

Tratgelaphus sylvalicusmseriptus

Subtanily Capr inate

Tribe Capriui

Capra hircus

Linogmathus atricunus kellow and Paine

I, inognithus stenops is (Burme ister)

Capra ibex

Lino prathus stenopsis (Burneister)

Capra manificus (no such name in any list)

Linomathus ovifor'mis (Kudow)

Caprella rupicapra=Rupicapra

Domestic roat $=$ Capra hircus

0 vis aries

Linomathus africanus hellog and Paine

Linoynathus ovillus (veunann)

Linoruathus pedalis (Osborn)

Ovis longipes

Linoynathus ovillus (Neumann)

Rupicapra rupicapre

Lino ma thus stenopsis (Burmeister)

Subtumily Cepha lophinac

Tribe Cephalophini

Cephalophus grimni=Sylviacapra primmi

Cepha lophus incurwelli

Lino,gathus breviceps (Piaget)

Cephalophus natalensis

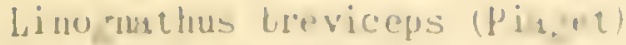

Cephalophus ui "lillous

Lino riathus anculatis (Pis req)

Philintomba. At times ure 1 lor ome species renerall! galerved tu cevhalophus.

Sj I viacapta riuni

lino abthus Ireviceps (Piapet)

Sultanily hippotra rinac

Tribe alcelaphini

Connochisetes grnu

Limormathus rou bediurd

Damaliscus all ifrous

Lino inathus danaliscus bedlord

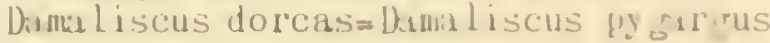

Dianaliscus horri rum

Lillo pllathus dintial iscus bedlord

Damka liscus py gar ous

Linognathus damaliscus Bedtord borgon taurinus

Linognathus pruu bedtord

Lino. Hathus holorastrus herneck

Lino mathus spiciatus Ferris

Tribe Hippotindini

Hippotragus nigger

Lino mathus hippotra ji Ferris

Tribe lieduncini

Cervicapra-Reduncia

Pelea capreolus

Linorgathus peleus bediord

Redunca arundinum.

Linornathus fishrenholzi Paine

Redunca fulvorufula

Linosnathus fahrenholzi Paine Redunca redunca

Linornathus fahrenholzi Paine 


\section{CHAPTER VIII}

\section{The Distribution of the Anoplura}

The problems associated with the spatial distribution of plants and animals have attracted a vast amount of attention and have cone to represent a field by themselves which is athered under the seneral title of biogeo:raphy. This field impinges upon other f'ields of inquiry in relation to which there may we a high degree of reciprocal arreement and support, or conversely, an equal degree of entertainin: disagreement. Thus, the seological concept of continental drift may on the one hand be supported by conclusions drawn from biogeopraphy or on the other hand be exposed to most vigorous criticism from the same source. The strictly practical field of economic entomolo:y may find a utilitarian aid since it may employ the seographical distribution of insect pests for which the discovery of their natural enemies is desirable. The purely philosophical aspects of biology and geouraphy may be concerned with the problems of the spread of natural populations and the light that present-day distribution of plants and animals may throw upon the distribution of ancient land masses.

The distribution of parasitic forms is a specialized aspect of biogeoraphy and is one of special philosophical interest. It is a matter of conimon biolojical knowledge that in the evolution of their parasitic habit many organisms - whether plant or animal-are very closely adjusted, both physically and physiologically, to the environment of a single host or host group. Thus, in the Anoplura there is a general adjustment to the environment afforded by the hair of the hosts. This involves the loss of the wings, the reduction or loss of the eyes, the modification of the le:p for clasping the hairs, and the alteration of the ovipositor for the laying of egiss attached to the hairs of the host. Obviously, this physical adjustment has been carried still farther into an adjustment to a particular host, for an Anopluran which can grasp the delicate hairs of a mouse would be completely helpless among the huge bristles of a pig. But beyond such obvious adjustments as these, there seems also to be an adjustment to the physiolovy of the host. There are indications that a suckin' louse transferred from its normal host to one of a very different kind may find the blood of the new host physiologically unsuited. One may surmise that we have here something analagous to the allergies which at least make life miserable for many people. These factors seem to apply rather renerally anong many kinds of parasites and they appear very stron ly to influence the distribution of the parasites.

Nor is this all. The adjustment of the parasite may be so delicate that it cannot pass from one host to another of the same species except under a limited set of conditions. Thus, in the Anoplura the modilications of the leigs for clasping the hairs of the host have proceeded so far that the louse is unable to move about effectively when detached from its host. Consequently, such an animal can pass readily from one host to another only when the hosts are in contact and a bridge of hair is available.

The outcome of all these factors is that one micht expect to find a particular louse species confined to a particular species of host. At times this is true, but usually the distrilution of the louse species is broader. The louse species may, ind very frequently does, occur on various closely related losts. It seems to be a quite tenable assumption that the louse species has been inherited from the common ancestor of the various host species and that the lice have evolved somewhat more slowly than have the 
It this hyputhesis he pursued turther in t ts inplications, it mas very well he utilized $t$ a weonnt for the occurrence of reluted specie of lice upon related hosts, sinch as the occurrence ol species of the louse renus

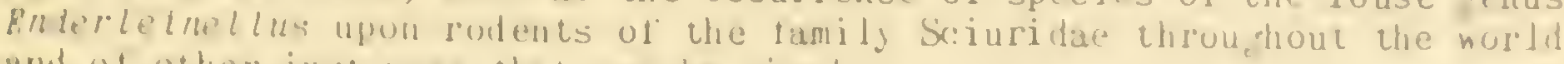
and ol other instances thit call be cited.

How, the puestion arises as to how tar this hypothesis ma te pursued.

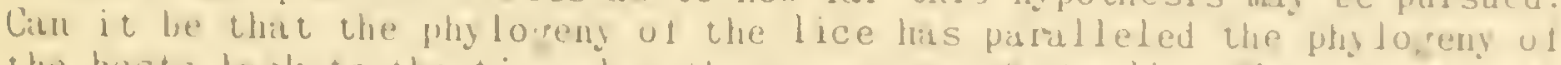
the hosts lack to the time nhen the ancestors ut the lice tirst hecume estublisted on the ancestors of the mamils? It is must templin: zu subrest that the clissilication ul the lice, which are a sall and compact stoup, might he ntilized to throw lisht upon the phy logeng of the much lar reg and more diverse group of the mammals. These are most intriguing speculations for the expression of hypotheses. But before ne conver speculations into hypotheses and hy potheses into expressions ol opinion we need co inqujre into all the avialiabe lacts and to take intu consideration all the rarious pitlalls that ma be encountered. betore the student ol lice presumes to oller advice to the mamnlogist concerning moot points in manual classisication he should lirst be sure that the classitication ot the lice is placed upon a sound bas is and that he genuinely huows whereol he speahs.

In consillerin: such mutters, it should be enphasized at the outset that at the present lime we know probably only abuut hall the species of Anoplura that may be expected to occur in the world and that until we know substantially the whole launa we are scarcely justified in devising in classification of the Anoplura that may be regarded as approachinis linality. At the moment, as is empliasized elsewhere, we do not have a satisfactory classification of the Anoplura as a whole. Most of the genera are relatively clear, lut the way in which these genera may be assembled into genuinely significant higher categories is not yet so. Tribes, sublanilies, lanilies, superfamilies, these elements in iny classificatory systen that will be biologically sound, remain sill to be clucidated.

A lew things, however, appear to be reasonably clear.

First, it appears that the Anoplura are confined to the manmals.

Next, it appears that they are confined to the kutheria, althourh it is still possible that they may be l'ound upon the Yonotremata which have not yet been adequately examined. No evidence exists that they occur on the Metatheria (the Yarsupials) although biting lice are known f'rom this group.

Then it appears that they do not occur on certain large "roups of the Eutheria. They seem detinitely not to be included among the weird assortment of parasites that occur on the bats. Amon: the Ferungulata, which includes the Livinit Orders Carnivora and Pinnipedia, the Carnivora seem to have no Anoplura-with the exception of two species-although they are well supplied with liallophara. The Pinnipedia, on the other hand, seem to possess only inoplura.

Further it appears that there are groups of Anoplura which are definitely restricted to roups of related hosts, so much so that if any Anopluran specimen of one of these groups came to hand with no host data it would be possible to predict with a hish degree of probability the family of mammals Irom which it came. But not always! There are enou discrepancies to introduce the possibility ot error into such a prediction. Some of these discrepancies are very strange and at the moment admit of no logical solution on the hasis oi present evidence.

Thus, we have the Anopluran renus Linosnothus, with about 30 included and apparently evidently related species, which is restricted absolute to hosts of the Order Artiodactyla, with two strange exceptions. One species occurs on the domestic do: and the arctic fox and another species occurs on a wild do: of South america. These are all the Anoplura that are known from the terrestrial Carnivora.

There is also the jenus polyplax, with about 30 included species, wnich 
occurs on rodents of the family Muridae, except that two species-clearly belonging to this genus-occur on shrews of the family Soricidae.

But apart from such glaring exceptions, the species of the various renera of Anoplura are as far as known rather generally restricted to host groups anon which some degree of relationship is commonly recounized.

Thus the genus Enderleinellus with about 28 species is, as at present known, restricted to rodents of the tamily Sciuridae. The genus Neohaematopinus with 25 known species is restricted to the same tamily, except for two species which occur on members of the family Muridae. The genus Mtcrothoracius, with four known species, is restricted to the family Camelidae, occurring in both South America and the 0ld Horld. The peculiar renus Neolinognathus, with two known species, is confined to the elephant shrews of the family Macroscelididae. The irenus Prolinognathus, with at least five apparently distinct species, is confined to the Hyracoidea. The renera Antarctophthirius and Echinophthirius are confined to the Pinnipedia. The genus Schizophthirus, with two included species, is confined to the rodent family Muscardinidae. The genus Fahrenholzia, with about five known species, is confined to the rodent family Heteromidae. The genus Pedicinus with seven included species is confined to the monkey irroup Cercopithecoidea.

These instances are clear enough. It matters not at all if there be ditferences of opinion concerning whether these Anopluran roups be called genera or are broken each into more than one genus. The group-subgenus, genus, superyenus, tribe, or whatever it may be called-as a whole is associated with a particular yroup of mammals.

Up to this point everything works out nicely. The hypothesis that the phylogeny of the lice and the phylogeny of the Anoplura are correlated is entirely tenable. But beginning with these instances we must proceed in two directions. On the one hand, how much farther does the correlation go in associating these groups of lice with larger groups? On the other hand, how much farther does it go in associating closely related species of Anoplura with closely related hosts?

Here arain we have some beautiful instances of correlation and equally we have some discrepancies.

Enderleinellus nitzschi occurs in North America on squirrels that according to the most recent classification by mamalogists are placed in the genus Sciurotamias. But what is apparently the same species occurs also on the European Sciurus vulgaris, while other species of Enderleinellus occur on other North American species of Scturus. He have here a partial arreement and a larger area of disagreement. It would certainly be presumptious for a student of the Anoplura to advise the marmaloists that Tamiasciurus should be made to include a species which they utilize as the type of the genus sciurus and that other species should be removed trom Sciurus!

However, within one section of the cenus Enderleinellus we have a very interesting condition. There is a certain group of squirrels that has been recognized by mammalogists as a caterory, although the status of this categrory seems not jenerally to be arreed upon. By some the igroup has been called the subfamily Marmotinae, bui Ellerinan places it simply as a "Section" of the Sciuridae. 'The basic genera are Marmota, Citellus, and Cynomys. 'The indications at present concernin the members ot the genus Ender-
leinellus occurring upon them are as t'ollows.

The section of the genus Ender leinellus involved has been elevated to a irenus, Cyclophthirus, by Ewing and whatever opinion he held concerning this genus it exists as a group. Much more collecting needs to be done betore any final conclusions are possible, but the evidence at present indicates that the members of this group of lice wre restricted to what we may call the Marmotinae. 'The genus Marmota seems to have a distinct species. The genus Cynomlys has upon it a species that seems possibly to be distinct. but otherwise the problem ot the possible species of Enderleinellus is much 
confused, und recornt stadies concerming the delationshiph of the squrrets of this sroup seen to he equally so. he cismot here o into the mater in detuil, fut the sitmution in the classitication ol the squirrets seem- very much to parallel that tound amon? the lice. hlien is study of the lice has been carried to completion it may show a very interestin. paralled with the conclusions of mumalo ists.

Other illustrations are even more contusing. Thus, the species of the gerus Hoplopleura range over a wide variely of rodents ot the various sulfanilies ot' what Ellerman calls the tamily Mnridae and the Sciuridue. A louse of very similar type occurs on the lajomorph genus or potona. hithin the genus Hoplopleura various minor groups carr te reco enized, witich seem to be associated with minor proups of rodents, there leing a fairly well defined group on the Sciuridae. But one species, or at least a series of very closely similar forms, rantes from burope and Asia into suuth imerica on various genera ot both Murinac and Cricetinte.

A rather striking instance of an anomilous distribution is that of the species Hoplopleura oenomyitis, which was described trom a rodent ul the Murine renus Oenomys in Africa and recorded troll other genera ot this group in Africa and Asia, hut which has apparently transferred to domestic rats and is now common in southern United states. The ideutitication is on available evidence correct.

At the other end of the scale are such senera as Anc istroplax and Haematopinotdes which on the totality ot their structure seem merely to te somewhat modifiel relatives of Hoplopleurs, but occur on Insectivora.

A very peculiur jerus is Lemurphthirus, with one species, which occurs on a lemuroid. In the characters of head and thorax it seems evidently related to Neohaematoplnus, which is a senus that occurs on squirrels, lut in the characters of its atdomen it is very much a thing ly itself althou it is here placed iu company with Neohaematopinus in the Polyplacinae. Other species from lemuroids show no seneral apreement among thenselves and are placed in this subtamily, which mosty occurs on rodents.

A very illumiuating instance is furnished by the one known species of Phthirpediculus. In describing this renus Ewing remarked that it stands "intermediate between Pediculus Limnaeus and Phthirus Leach." This seems reasonable enough, since Phthirpericulus is t'rom a lemur and the lemurs are supposed to stand somewhere near the bottom of the phyloreny of the Primates. But the renus Phthirpediculus, considered on morphological brounds, has nothing to do with either of these other two senera. In fact, none of the few lice known from lemuroids seems to have anything especially to do with the lice of the Primates.

he may here once more call attention to the genus pericinus. In all previous classifications this has been placed in the Pediculidae as a relative ot Pediculus. This has seemed eminently reasonalle, since the hosts of Pedicinus and Periculus are Prinites. But it is here questioned that these two generd of lice have anvthing to do with each other und poficinus is here removed to the Hoplopleuridae, where it is placed as constitutin; a subfamily by itselt. The morphological evidence does not indicate any close relationship with peticulus.

liebb has been much impressed ly considerations ot host relationship and the phylogeny of the Anoplura and has used host relationships to intluence his opinions concerning louse classitication to a degree thit seems to the writer not to be supported by the evidence ol morpholng other than his somewhat questionable evidence derived trom the spiracles.

Hopkins (1949) has considered this matter at considerable length in connection with his list of host-associations ot the lice ol mamals and rointed out factors concerned with the presence-or, of equal interest. the atr sence-of certain groups of lice on various host groups. He sugesis that where Anoplura and Yallophaga occur on the same host there is perhaps a 
competition between the members of the two groups of lice which may result unfavorably for the sucking forms and lead to their disappearance. It may be pointed out that the rodent family Heteromyidae supports only sucking lice of the peculiar genus Fahrenholzia, while the Geomyidae support only biting lice of the family Trichodectidae. Yet while in most lists of mammals these two groups of rodents are placed as separate families there are mammaloyists who have maintained that they are nothing more than subfamilies of the same family. Again, the rodents of the family Erethizontidae, the porcupines, seem to possess only biting lice, although in reneral sucking lice are much developed on the rodents. However, there are groups of mammals, such as many of the Ungulates, on which both biting and sucking lice are well represented. The idea that the absence of the sucking lice may be due to competition with biting lice must be considered, but there are other causes that can be envisioned and the present writer is not convinced that this can have been a tremendously important factor in the present host distribution of the Anoplura.

With such matters as these in mind we may approach the problem of the correlation of a classification of the higher groups of the Anoplura with their distribution.

From the writer's point of view the matter of classification should be developed first and then the problem of distribution should be considered after the morphological evidence has been developed.

From the point of view here adopted the distribution of the lice in reneral is on the whole rather consistent with the idea of a correlation of the phylogeny of the lice with the phylogeny of their hosts. But above that point it becomes increasingly inconsistent, and finally tades away into the realm of pure speculation. If it were pushed to its extreme limits one would assume that the original ancestor of the sucking lice boarded the original ancestor of the mammals and the descendants of the one have divided and followed the various successors of the original ancestor of the manmals-with the interposition of various accidents-ever since. But it seems probable that the lice could not have joined the mamals until the latter had already reached some measure of differentiation into groups. Under this speculation it may be assumed that some of the ancestral mammals never achieved the company of any sucking lice. Also, it may be speculated that the oritinals of the lice were not specifically adapted to a limited host group and therefore may have passed rather freely from host to host, even lon: after the hosts were quite widely separated phylogenetically, thus placing the members of a single phylogenetic line of the parasites upon many phylogenetic lines of hosts. Even after the lice had differentiated to a considerable deyree this possibility of transfer may have remained. Then there may have leen a certain number of what may be considered to be accidental transfers having nothing to do with phylo reny.

Out of all this the correlation of the phylogeny of the parasites with the phy'logeny of the hosts may have begun a process of obscuration early in the period of differentiation of both groups. This being possible, it therefore becomes improbable that the phylogeny of the two sroups would follow parallel paths back to the points of origin of both.

The problem then centers merely upon the question of how far these parallel paths extend before they become entangled in the criss-crossing of roads that may have occurred before a system of parallel paths had developed.

From the writer's point of view it is upon this question that future interest in the reneral problem should he concentrated.

The conclusions here adopted are as follows:

1. The distribution of the smaller sroups-such as venera-is in gencral reasonably consistent with the idea that they have followed the phylogeny of the hosts in their development. 


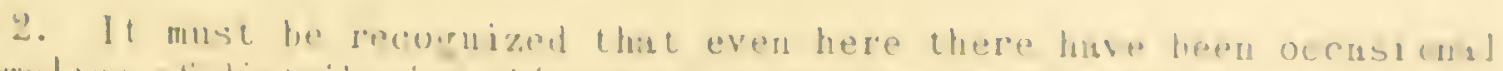
momalies of distribution which mist be accepted as they are.

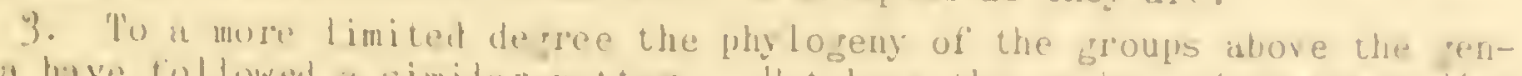
ara have followed a similar pattern. Lut here the number of apprent discrepalle ies increaser.

4. When we come to the larerer groups of peneria, which we may call fimilies, this parallelism of phylopentes is but taintl! shown.

5. Spreculation in refard to the problem should remain bimly within the bounds of ascertitined lact.

6. Discrepancies which cannot be accounted tor on a bas is of knowll fact should be accepted us they exist and not forced into some frumework ot' ideas as to how thes ought to be accounted tor by the system of classirication.

7. Future work should be directed in larpe part toward the completion of our knowledge of the species of troplura that still remain to be found and the "itting ol" these into a system of classitication that is based on the Anoplunir themselves.

8. Then and then on $y_{y}$ will we be in a position to theorize conceming the relation of the phy logeny of the lice to the phyloseng of their hosts. 



\section{INDEXES}

Index to Anopluria

Acanthopinus, in synonymy, 185

anternatus, 195

sciurinus, 195

Achimella, in synonymy, 72

callorhini, 72

Ahuematopiums, in synonymy, 185 inornatus, 142

insulsus, "Wo

ANCISTKOPLAX, 120 crocidurie, 120

ANOPLURA, 58, 61

AYTARCTOPHITHIRUS, 71, 72

Antarctophthiriimae, 63

cal i fornianus, 73

callorhini, 7?

lotodontis, 73

mawsoni, 72,73

microchir, 72,73

monachus, 72

onmorhini, 72,73

trichechi, 72, 75

Arctophtirius, 72

lat thyer ricola, in synonymy, 169 hilli, 172

lawrensis, 173

lophiomydis, 173

Bedtordia, in symonymy, 151

tripedata, 156

Cervophthirius, 251

crassicornis, 256

taranti, 256

CTENOPHTHIRUS, 163

cercomydis, 164

Ctenopleura, in symonymy, 125

Ctenura, in synonymy, 125

cryptica, 135

pectinata, 142

Crclophthirus, in synonymy, 102 suturalis, 113

DOOOPHTHIRUS, 163, 164

ac ine tus, 165

ECHIYOPITHIRIDAE, 63, 68, 71, 72, 75

ECH LYOPH THIRIUSIIYAE，63, 71

ECHINOPHTHIRUS, 75

baiknlensis, 76

fluctus, 81

groenlandicus, 76,78

horridus, 75

microchir, 79

sericans, 76

setosus, 79
Ellipoptera, iy

ENDKRLEIMEL,MAK, $64,69,101$

EM DERLEIAELLLS, $101,102,103$

arriemens is, $105,106,104$

brasiliensis, 105, 145

dremomydis, 104, 10k

euxeri, 104,108

extremus, 106, 108

lreliosciuri, 103, 108

honduremsis, 105, 106, 10k

insularis, $105,106,109$

kellos i, 165, 106, 109

Iarisci, 103, 109

longiceps, 101, 105, 106, 109

lon riceps group, 104

malaysianus, 104, 105, 110

marmolae, 103,110

menetensis, 104, 110

mexicanns, $105,106,110$

microsciuri, 106, 110

minutus, 115, 118

nannosciuri , 104, 110

nitzschi, 104, 110

occidentalis, 113

ostorni, 103, 113

paraxeri, 115

platyspicatus, 103, 113

replicatus, 113

sciurotamiasis, 104, 113

sphaerocephalus, 110

suturalis, 103, 113

tamiasis, 104, 113

uncinatus, 115

"rosciuri, 105, 114

venezuelae, 106, 114

zonatus, 103, 114

Eremophthirius, in synonymy, 199

biseriatus, 207

gerbilli, 208

praecisa, 209

stephensi, 214

subtaterae, 214

tarsomydis, 214

toterae, 214

werneri, 215

Euenderleinellus, in stnonymy, 102 larisci, 109

Euhaematopininae, 63

Euhuematopinus, in synonymy, 120 abrormis, 120

Euhoplopleura, 125 
Euhoplopleura-

trispinosa, 144

EULINOGNATHUS, 169

aculeatus, 169, 170

americanus, 170

biuncatus, 170

caviae, 177

denticulatus, 169, 170

hilli, 170,172

lawrensis, 170, 173

lophiomydis, 170, 173

parvus, 184

surdasteri, 170

FAHRENHOLZIA, 163, 173

microcephala, 174

pinnata, 174

reducta, 174

tribulosa, 174

tribulosa, 175

zacatecae, 174,175

Ferrisella, in synonymy, 125

ochotonae, 125

GALEOPHTHIRUS, 163, 177 caviae, 177

Haemat omyzus, 59, 60

HAELATOPINIDAE, 63, 64, 68, 81, 199

Haematopininae, 63, 64

HAEMATOPINOIDES, 64, 119, 120 squanosus, 120

Haenatopinoidinae, 64

HAEMATOPINUS, 83, 84

acanthopus, 130

aculeatus, 170

acuticeps, 83, 84

adventicius, 91

affinis, 130

albidus, 158

annulatus, 75

antennatus, 195

aperis, 84

appenticulatus, 240

apri, 84

asini, 84,85

aulacodi, 153

bicolor, 236

bidentatus, 133

breuiceps, 228

brevicornts, 229

breviculus, 87

bufiali, 84,88

bufali-capensts, 88

bufalt-eliropaet, 95

burchellts, 85

crumeli, 244

cervicaprae, 2xy

chinensts, 91, 94

clavicornis, 282

coloratus, 285
HAEMATOPINUS-

columbianus, 193

crassicornis, 253

echinatus, 191

elegans, 85

equit, 285

erraticus, 136

eurysternus, 84,88

forficulus, 238

germanicus, 94

germanus, 94

hesperomydis, 136

incisus, 90

irritans, 91

laeviusculus, 193

latissimus, 90

latus, 84, 90

leptocephalus, 251

longulus, 137

longus, 83, 91

lyriocephalus, 179

macrocephalus, 85

maniculatus, 139

microcephalus, 231

minor, 85

montanus, 193

notophallus, 151

obtusus, 159

ovi formis, 231

outllus, 231

pectintfer, 194

pedalis, 231

peristictus, 90, 91

phachochoeri, 84, 91

piliferus, 236

pleurophaeus, 285

praecisus, 139, 209

praecitus, 138, 209

praelongtceps, 247

praviprocursus, 88

punctatus, 95

quadridentatus, 142

quadripertusus, 38

reclinatus, 210

rupicaproe, 238

saccatus, 235

sardiniensis, 94

sciuropteri, 196

serratus, 210

setosus, 194

sphaerocephalus, 110

spiculi fer, 283

spiniker, 211

spinulosus, 211

squamulatus, 217

stephensi, 214

suis, 84, 91

suturalis, 113 
HAt'MTYMPINIS-

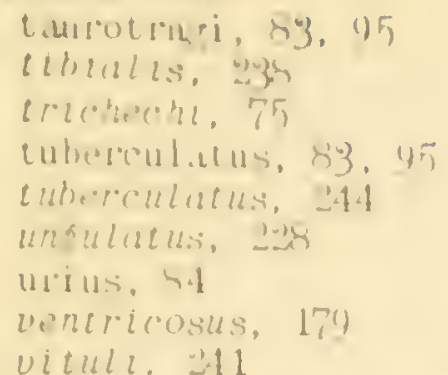

Haemalopinus, in synomygn, 199, 251

HAFYOLLPIS, 16\%, 17\%

at'ricillus, 179

lyriocephalus, 17?

parvus, 18's

setolli, 179

ventricosus, 179

Hamophthiriinae, 64

HAYOPTHIRUS, 163,183

saleopitheci, 183

Hasel lus, in synonymy, 147 pleurophaeus, 147

Haus telleta, 59

Hemintera, 59

Hoplophthirus, in synonymy, 102 euxeri, 108

HOPLOPLFURA, 119, 125

acanthopus, 128,130

acanthopus, 135

atfinis, 127,130

affinis, 133, 134

alata, 144

arrolata, 129, 133

a

arboricola, 129, 133

argentina, 129, 133

audax, 147

bidentata, 126, 133

biseriata, 128,134

brasiliensis, 125.134

chilensis, 125,134

chrotony dis, 129, 134

cricetuli, 12r, 134

cryptica, 126,135

disyresa, 125, 135

tisereca, 131

distorta, 139. 135

edentula, 135

emar inata, 125, 135

enormis, $12 \%, 135$

e rismata, 128,136

erratica, 128.136

erraticn, 133

fonsecai, 125,136

hesperomydis, 127.136

hirsuta, 129. 136

hispida, 137

intermedia, 126, 137
HOP'WH't.t. $\mathrm{kI}=$

laticeps, 126, 15

lintalte, 13h

lon rula, 1:h, 19x

malaty sialla, 1:2y, 138

miniculihi, 1'y, 13b

meriontis, 12y, 13s

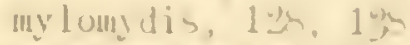

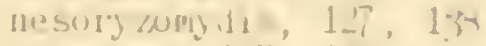

neunsuni, 1:7, 193

ochutunir, 1:6, 139

venchuldis, 129, 134

oryzamydis, 12, 134

uximycteri, 13y, 1-39)

pulciflect), $13 y)$

pectin'tis, 1.6, 11:

pelomy dis. 121), 112

phatomydis, 120. 142

quinlridentiatis, 15, 1.12

reductir, 124, 142

reichrodontonydis, 14h, 143

rukenyue, 146, 143

sciuricola, 129, 143

somereni, 127,143

sukenyne, 143

travassosi, 127,143

trispinosa, 126, 143

veprecula, $1: 6,144$

HOPLOPLEURT DAE, 69,98

Hoplopleurinac, 68, 101, 119

HY 1DOPH THIRI LIAE, 64, 68, 101, 148

HYIOPHTH IRILS, 148, 151

notophallus, 151

I IIrostrata, 60

LASI DIOPHTHIRUS, 163,183 parvus, 189

LEMIRH'THIRUS, 163, 185

ralacus. 195

verruculosus, 185

LEPI DOPH TH I RI INAE, 64

LEPI DUPIITHIRUS, 78

macrorhini, is

LIYOGIATHI D.LE, 69,220

Lino mathinae, $63,64,220$

Lino mathoides, in synonymy, 185 citelli, 191

faure $i, 191$

inornatis, 192

pectinifer, 194

spermodhlil, 191

LIOFITHU. 222, 223

aepycenis. 295

africanus, 225

an jula tus, 225,23

angूulatus, 252

antennatus, i3s

appenticulatus, 240

bedtordi. 233, 239 


\section{LINOGNATHUS-}

binipilosus, 253

breviceps, 225,228

brevicornis, 225, 229

burme isteri, 253

caviae-capensis, 248

cervicaprae, 225, 229

coassus, 253

crassicornis, 253

damaliscus, 229

euchore, 240

fahrenholzi, 224, 229

ferrisi, 230

ferrisi, 256

forficulus, 229

fractus, 225, 230

Sazella, 228

giluus, 228

gor छonus, 230

mu, 230

hippotrarri, 224, 230

holojastrus, 224, 230

lewisi, 223, 231

limnotrairi, 225, 231

oviform is, 231

ovillus, 224, 231

panamensis, 253

pedalis, 224, 231

peleus, 225, 231

petasmatus, 224, 233

pithodes, 223, 234

praelongiceps, 244

saccatus, 235

setosus, 224, 235

squamulatus, 217

spicatus, 223, 237

stenopsis, 224,238

stenopsis, 225, 227

taeniotrichus, 224, 238

taurotragus, 224,238

tibialis, 225, 238

vituli, 223,241

vituli, 253

ungula lus, 228

Linognathus, in synonymy, 251

Lutegus, in synonymy, 185 pectinifer, 194

Mallophaga, 59

Mandi bulata, 56

MICROPHTHIRUS, 102, 115

unc inatus, 115

MICROTHORACIUS, 222, 243

cime li , 244

mrzzai, 244

minor, 244, 247

prie lonericeps, 244, 247

praeloneicens, 244

NEOHAEYATOPINUS, 164,185
NEOHAELATOPINUS-

batuanae, 190

ceylonicus, 189, 190

citelli, 188, 191

citellinus, 189, 191

echinatus, 189, 191

echinatus, 190

faurei, 190, 191

griseicolus, 189, 192

heliosciuri, 190, 192

inornatus, 189, 192

kenyae, 190, 192

laeviusculus, 190, 193

longus, 189, 193

macrospinosus, 195

marmotae, 190,193

mathesoni, 190, 194

neotomae, 189,194

pacificus, 189, 194

patiki, 194

pectinifer, 189, 194

petauristae, 190, 195

sciuri, 189, 195

sciurinus, 189, 195

sciurinus, 192

sciuropteri, 189, 196

semifasciatus, 195

suahelicus, 190, 196

syriacus, 189,196

traubi , 190, 196

NEOLINOGNATHIDAE, 257

NEDLINOGNATHINAE, 64

NEOLINOGNATHUS, 257

elephantuli, 257,258

praclautus, 257,258

Neopedicinus, in synonymy, 157 patas, 162

Neumannellus, in synonymy, 151 aulacodi, 151

Paenipediculus, in synonyny, 260 schäffi, 277

simiae, 277

Parapediculus, 260, 273

atelophilus, 260

chapini, 273

lobatus, 274

pseudohumanus, 275

Parasita, 59

Parasiti, 61

PECAROECUS, 83, 98 javali i, 98

PEDICININAE, 63, 64, 69, 101, 156, 258

PEDICINIS, 157

albidus, 157,158

ancoratus, 15 , 158

breviceps, 158, 159

colobi, 159

eurgaster, 157,158 


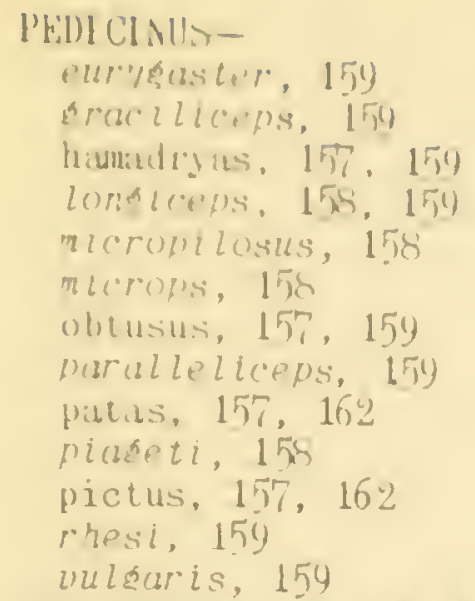

PEDI CULID.LE, 59, 63, 258

Pediculina, 59

Pediculinae, $63,64,156$

PEIDICLLLS, 260

aconthopus, 130

affinis, $130,274,276$

albidior, 262

(smericanus, 267

angुustus, 266

annulatus, 75

aquaticus, 28.3

$a s \ln i, 84$

assimilis, 2006

atelis, 277

atelophilus, 273

bufali, S8

bufali-capensis, 88

bufali-europaei, 95

cameli, 244

cospitis, 262

c(u)iae-capensis, 248

cervicalis, 261

chapini, 273

chinensis, 266

clavicornis, 282

collaris, "4s

consobrinus, 262, 275

corporis, 266

crassicornis, 253

denticulatus, 211

puryśaster, 158

eurysternus, 98

ferus, 281

flovidus, 236

friedenthall, 266

hispirius, 137

horridus, 75

humanus, 261

i sopus, 236

loeviusculus, 193

leptocephalus, 251

lobatus, 273.276

lyriocephalus, 179

macrocephalus. 85
PEDICULS-

misculatus, $=206$

marglmatus, Lub

Hijober ri, , $261, \quad \frac{17}{4} 4$

mirrops, $15 x$

negrescens, 262

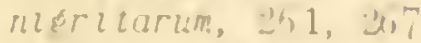

oblonklus, "t)

oxirrhynchus, :-11

pupplllosus, es

phocese, 7!!

piliferus, 236

whltirlopsis, on

pleurophaeus, 14

pseudohumunus, 261.275

pseludohumanus, "ú?

pubescens, 262

Tubis, ast

qualrumanus, 275

reclinatus, 210

schätti, 261, 277

schistopysus, 23y

serratus, 210

setosus, 75

simlae, 277

spermophili, 193

sphaerocephalus, 102, 110

spiculiter, 283

spinieer, 211

spinulosus, 193, 211

stenopsis, 230

suis, 91

tabescentium, 262

tenuirostris, 241

tuberculatus, 95

urius, 91

vestimenti, 262

vitull, 211

Petallistophthirus, in synonymy, 185 petauristze, 195

Phihiraptera, 60

Phthiriidae, 64

Phthirius, 144, 280

Phthirpedicinus, in synonymy 157 micronilosus, 158

microps, $15 s$

PHTHIRPEDI QULLS. 163. 199 propitheci. 199

Phthirus, in synonymy. 350 Eorillae, 281

shavesi. 281

POLYPLACTAAE, 69, 101, 16?

POLIPLAX, 163, 199. 209

abscisa, 205

abyssinica, 204, 205

acanthopus, 130

affinis, 130

alaskensis. 205 
POLYPLAX-

arvicanthis, 204, 206

asiatica, 203, 206

auricularis, 203, 206

bidentata, 133

biseriata, 203, 207

borealis, 205

brachyrrhyncha, 220

californiae, 206

calva, 216

campylopter $i, 211$

chinensis, 203, 207

cummingsi, 208

del toides, 204, 207

dentaticornis, 202, 207

echinata, 191

eminata, 214

eriopepli, 203, 207

gerbilli, 203, 208

gracilis, 208

Eracilis, 208

insulsa, 203, 208

jonesi, 204, 208

laeviuscula, 193

longula, 137

maniculata, 138

miacantha, 283

otomydis, 203, 208

oxyrrhynchus, 209

painei, 206

pectinifer, 194

phthisica, 204, 209

praecisa, 203, 209

praomydis, 211

quadridentata, 142

reclinata, 204, 210

reclinata, 207

serrata, 204, 210

spinigera, 202, 211

spinulosa, 205, 211

spinulosa, 205

stephensi, 203, 214

subtaterae, 214

tarsomydis, 204, 214

taterae, 203, 214

waterstoni, 204, 214

werneri, 203, 215

PROECHINOPHTHIRIUS, 81

fluctus, 81

PROFNDERLEINELJUS, 163， 215

africanus, 216

calva, 216

hillt, 172

lourensis, 173

PKOIINOGNATIIUS, 222, 247

nethiopicus, 248
PROLINOGNATHUS-

arcuatus, 248

caviae-capensis, 248

ferrisi, 248, 251

foleyi, 248, 251

leptocephalus, 248, 251

Pseudorhynchota, 59

PTHIRUS, 280

gorillae, 281

inguinalis, 281

pubis, 281

PTEROPHTHIRUS, 119, 144

alata, 144

audax, 144, 147

imitans, 144, 147

we riecki , 144, 147

RATEYIA, 163, 216

squamulata, 217

Rhinapterd, 59

Rhinophthi rus, 102 heliosciuri, 196

Rhynchota, 59

Rhynchophthirina, 59, 60

SCHIZOPHTHIRUS, 119, 147, 148 raphiuri, 148

leucophaeus, 285

pleurophaeus, 148

SCIPI0, 148, 151

aulacodi, 152, 153

breviceps, 152, 154

loniceps, 154

tripedatus, 152, 156

Siphunculata, 59, 60

SOLENOPOTES, 222, 251

vinipilosus, 252

burmeisteri, 253

capillatus, 252, 253

capreoli, 252, 256

ferrisi, 252, 256

muntiacus, 256

panamensis, 253

tarandi, 256

Stobbella, in synonymy, 223 pithodes, 235

SYMOCA, 164, 220

brachyrrhyncha, 220

Symy sadus, in synonymy, 215 crlua, 216

Trichaulinae, in synonymy, 220

Trichaulus, in sinonymy, 223

Waterstonia, in synonymy, 215 calva, 216

zanzibariensis, 216

HERNECKIA, 102,115

minuta, 115, 119

maraxeri, 115, 118 


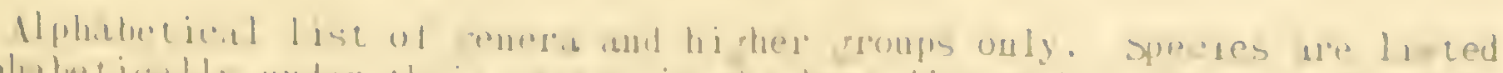

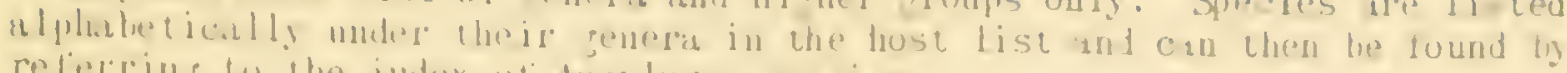
relerline lis the index of hopluran species.

Mlineromit, in) 1

Alrocomintere, Subtimily, g) 1

Acoms s, als

meprevos, 30z

de thomes, gas

.livilon, 2x)6

Alcoliuhiui. Tribe, 303

Allitclitil, 296

Alopex, 300

Alollitlia, 2sig

Mourtimae, subtimily, xy9

Amosp ermophilus, 29)

dnathana, 289

Anthropoidea, Suborder, 284

Antidorcas, 302

Antilope. $30^{\circ}$

Antilopinac. Subtamily, 302

Antilopini, Tribe, 302

Apodemus, 298

Artiodactyla, Order, 301

Arvicanthis, 298

Arvicola, 295

Ateles, wa

Atelinae, Subtiamily, 289

Atl.untoxerus, 295

Auchenia, 301

dulacodus, 29"

Linndicota, 298

lathyeridae, Fumily. 291

Bathyer poidea, Supertumily, 291

bathy er rus, 91

Bison, 302

Bos, 302

Bose laphus, 303

linvidae. Family, 303

Boviui, Tribe, 30:

lovoidea. Supertauily, 302

Cicajo, as9

Callithricidae. Subfamily. Sas

Callorhinus, 300

Callosciurus. 243

Callospermoph ilus. 29?

Camelidae, Family. 301

Camelus, 301

Canidae, Family. 300

Caninae. Sultamily, 300

Canis, 300

Canoidea, Supertamily, 3(0)

Capra. 303

Caprella, 303

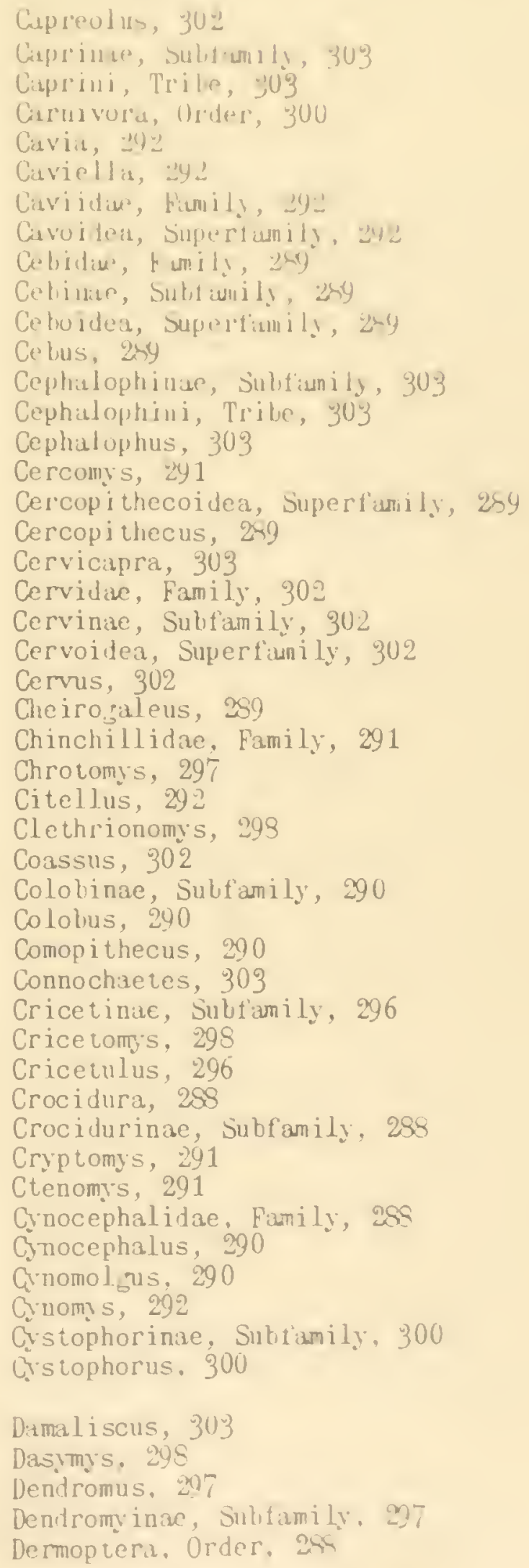


Dicotyles, 301

Dicrostonyx, 298

Dipodidae, Family, 296

Dipodinae, Subfamily, 296

Dipodipus, 296

Dipodoidea, Superfamily, 296

Dipodomys, 295

Dipus, 296

Dryomys, 300

Drusicyon, 300

Echimyidae, Family, 291

Echimy inae, Subfamily, 291

Elephantulus, 288

Eli mmodontia, 296

Eliomys, 300

Epimys, 298

Equidae, Family, 301

Equus, 301

Eropeplus, 298

Ery throcelus, 290

Eume topias, 300

Euneomys, 296

Eutheria, Infraclass, 288

Euxerus, 295

Ferae, Superorder, 300

Ferun ulata, Cohort, 300

Fissipeda, Suborder, 300

Funambulus, 294

Galarinae, Subtamily, 289

Galaro, 289

Galea, 292

Galeopithecus, 288

Gazella, 302

Geonyoidea, Superfamily, 295

Georhychus, 291

Geosciurus, 295

Gerbillinae, Subfanily, 297

Gerbillus, 297

Giraffa, 302

Giraftidae, Family, 302

Giraftoidea, Superfamily, 302

Glaucomys, 292

Glires, Cohort, 291

Gor:son, 303

Gorilla, 291

Grammoniss, 298

Graomys, 296

Graphinrinie, Subfamily, 299

Graphiurus, 299

Fuenton, 290

Gunouny's, 2y8

Hal ichoerus, 300

Hamul ryas, ixy 0

Heliosciurus, 293
Hesperomys, 296

Heterohyrax, 301

Heteromyidae, Family, 29.5

Heteromy's, 295

Hippomorpha, Suborder, 301

llippotraginae, Subfamily, 303

Hippotrafini, Tribe, 303

hippotrasus, 303

tiodonitys, 296

Holochilus, 296

Hominidae, Family, 291

Hominoidea, Supertamily, 291

Homo, 291

Hybomys, 298

Hydromyinae, Subfamily, 297

Hydromys, 297

Hydrurita, 300

Hylobates, 291

Hylobatinae, Subfanily, 291

Hyracoidea, Superfamily, 301

Hystricoidea, Superfamily, 291

Indridae, Family, 289

Innuus, 290

Insectivora, 0rder, 288

Kerodon, 292

koiropotamus, 301

Lagidium, 291

Largomorpha, Order, 291

Lago thrix, 289

La gurus, 289

Launa, 301

Lariscus, 292

Lariscus section, 292

Lasiopyga, 290

Lemmus, 298

Lemniscomys, 298

Lemuriformes, Intraorder, 289

Lemuroidea, Superfamily, 289

Leontocebus, 289

Leporidae, Family, 291

Leptonychotes, 300

Lepus, 291

Limnomys, 299

Limnotra us, 303

Lionys, 295

Lobodon, 300

Lobodontinae, Subfiamily, 300

Lophiony idae, Fauily, 296

Loph i onys, 296

Lophuromy's, 299

Lorisidie, f'umily, 289

Lorisiformes, Int'raorder, 289

Yacaca, 290

Macacus, 290 
Marc rorthinus, 300

Mineroscelididae. F'unily, gxx

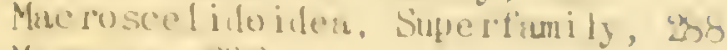

Marno\{

Munotat section, 光)

Mrstoms. in)"

Mazirma, 300

Menetes, $292^{2}$

Heriones, w)?

Mestuxonia, Superorder, 301

Micrudipodops, 295

Microny's, 299

Yicrosciumus, 294

Microtime, Subtanily, 294

Microtus, 298

Mi rounira, 300

Muntiacinae, Subfanily, 302

Muridue, Family, 296

Murinae, Subtanily, 298

Muroided, Superfamily, 296

Mus, 299

Muscardinidue, Fumily, 299

Muscardininae, Subtamily, 30

Muscardinus, 300

Mylomys, 299

Nasalis, 290

Nasilio, 288

Nectomys, 296

Nesokia, 2yg

Nesoryzomys, 296

Neotoma, 296

Neotomodon, 296

Ochotona, 291

Ochotonidae, Family, 291

Octodontinae, Subiamily, 291

Octodoutomys, 292

Odobenidae, Family, 300

Odobenus, 300

Odocoile inas, Subfamily, 302

Odocoileus, 302

Denomy's, 299

0ymorhinus, 300

Oumatophoca, 300

Onychomys, 296

Oreodonta, Infraorder, 301

Orycteropodidae. Family, 301

Orycteropus, 301

Oryctolagus, 291

Oryzomys, 296

0 taria, 300

Otariidae, Family, 300

Otominae, Subtamily, 299

Otoms, 299

Ovis, 303

Pachyura, 288
P'icholisuromy's, 297

Pan, 291

Yapio, 290

Parizonia, Superorder, 301

Parascislops, 24s

Parusciurus, 293

Paraxerus, gy 3

Parcuxerus section, 293

Purutomys, igl

Pecari, 301

Pecoris, In1raorder, 30:

Pedetes, $2 y 0$

Pedetidie, family, arg,

Pedetoidea, Superitunily, 296

Peleis, 303

Pelomys, ixyy

Perissodictyla, Order, 301

Perodipus, 295

Pero mathus, 295

Peromyscus, 295

Pelaurista, 292

Petrodromus, 288

Petromus, 292

Petromyinae, Subfanily, 242

Petromys, 292

Phachochoerus, 301

Phaiomy's, 298

Phenacomy's, 298

Philantomba, 303

Phoca, 300

Phocarctos, 300

Phocidae, Family, 300

Phocinae, Subramily, 300

Phrllotis, 297

Pinnipedia, Sutorder, 300

Pithecis, 289

Pithecinae, Subfamily, 289

Pithecus, 290

Pitymys, 298

Pongidae, Family, 291

Ponginae, Subfamily, 291

Potamochoerus, 301

Praomys, 299

Presbytis. 290

Primates, Order, 299

Procavia, 301

Procaviidae, Family, 301

Proechimys, 291

Propithecus, 289

Prosimii, Suborder, 289

Protoxerus, 993

Protun rulata, Superorder, 301

Pteromys, 292

Pteromys group, 292

Pyinathrix. 290

Ran-iler, 302

Rat tus. 299 
Redunca, 303

Reduncini, Tribe, 303

Reithrodon, 297

Reithrodontomys, 297

Rhaldomys, 299

Rhinopi thecus, 290

Rhividomy's, 297

Rodentia, Order, 290

Ruminantia, Suborder, 302

Rupicapra, 303

Siaccostomus, 299

Scalopinae, Sulfamily, 288

Scalopus, 288

Sciuridae, Family, 292

Sciuroidea, Superfamily, 292

Sciuropterus, 292

Sciurotamias, 295

Sciurus, 294

Sciurus group, 292

Sciurus section, 293

Scutisorex, 288

Semnop i the cus, 290

Si mnodon, 297

Simia, 290

Simias, 290

Sorex, 288

Soricidae, Family, 288

Soricinae, Sulfamily, 288

Soricoidea, Superfamily, 288

Spermop hi lus, 29.5

Strepsiceros, 302

Strepsicerotini, Tribe, 302

Suidae, Family, 301

Suiformes, Suborder, 301

Suina, Infraorder, 301

Suinae, Subfamily, 301

Suncas, 288
Sus, 301

Sy I viacap ra, 302

Sylvilarus, 291

Synup ha lian ${ }_{i j}$, 291

Syncerus, 302

Talpidae, Family, 288

Tamias, 299

Tamias section, 295

Tamiasciurus, 295

Tatera, 297

Taterillus, 297

Taurotrasus, 303

Tayassu, 301

Tayassuidae, Family, 301

Tayassuinae, Subfamily; 301

Thallomys, 299

Thamnoinys, 299

Theria, Subclass, 288

Thomasomys, 297

Thryonomyinae, Subramily, 292

Thryonomys, 292

Tutulidentata, 0rder, 301

Tupaiidae, Family, 289

Tupaiinae, Subtamily, 289

Tupaioidea, Superfamily, 289

Tylopoda, Suborder, 301

Urosciurus, 295

Vulpes, 300

Xenomys, 297

Xerus, 295

Xerus section, 295

Zalophus, 300

Zelotoinys, 299 





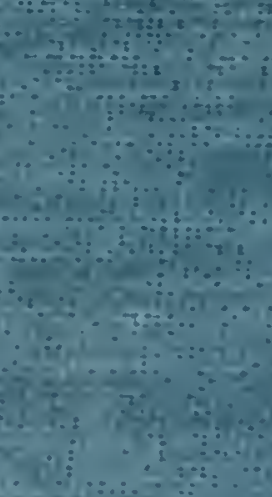

